\title{
Archaeological and Geological Test Excavations at Site 41HM61, Hamilton County, Texas
}

Richard A. Weinstein

Coastal Environments, Inc.

Follow this and additional works at: https://scholarworks.sfasu.edu/ita

Part of the American Material Culture Commons, Archaeological Anthropology Commons, Environmental Studies Commons, Other American Studies Commons, Other Arts and Humanities Commons, Other History of Art, Architecture, and Archaeology Commons, and the United States History Commons

Tell us how this article helped you.

This Article is brought to you for free and open access by the Center for Regional Heritage Research at SFA ScholarWorks. It has been accepted for inclusion in Index of Texas Archaeology: Open Access Gray Literature from the Lone Star State by an authorized editor of SFA ScholarWorks. For more information, please contact cdsscholarworks@sfasu.edu. 


\section{Archaeological and Geological Test Excavations at Site 41HM61, Hamilton County, Texas}

\section{Licensing Statement}

This is a work for hire produced for the Texas Department of Transportation (TxDOT), which owns all rights, title, and interest in and to all data and other information developed for this project under its contract with the report producer. The report may be cited and brief passages from this publication may be reproduced without permission provided that credit is given to TxDOT and the firm that produced it. Permission to reprint an entire chapter, section, figures or tables must be obtained in advance from the Supervisor of the Archeological Studies Branch, Environmental Affairs Division, Texas Department of Transportation, 125 East 11th Street, Austin, Texas, 78701 


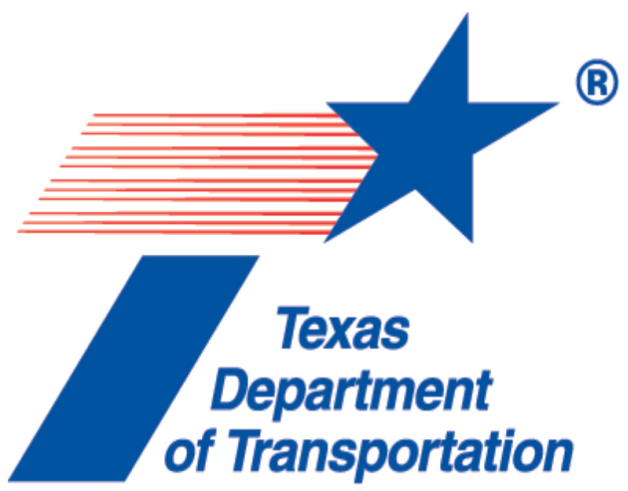

\section{Archaeological and Geological Test Excavations at Site 41HM61, Hamilton County, Texas}

\section{Middle Archaic Through Late Prehistoric Occupation in the Leon River Valley of Central Texas}

CSJ: 0251-01-058, Waco District

Texas Antiquities Permit No. 6023

Coastal Environments, Inc.

525 S. Carancahua Street

Corpus Christi, Texas 78401 
This report was written

on behalf of the Texas

Department of Transportation

by

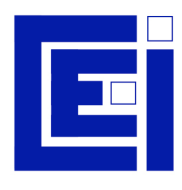

Coastal Environments, Inc.

525 S. Carancahua Street

Corpus Christi, TX

78401

www.coastalenv.com 


\title{
Archaeological and Geological Test Excavations at Site 41HM61, Hamilton County, Texas:
}

\section{Middle Archaic Through Late Prehistoric Occupation in the Leon River Valley of Central Texas}

\author{
edited by: \\ Richard A. Weinstein \\ with contributions by: \\ James T. Abbott \\ Leslie L. Bush \\ Charles D. Frederick \\ Sarah K. Gilleland \\ Brittney Gregory \\ Jennifer A. Kelly \\ Jon C. Lohse \\ Mary Madden \\ Sean R. Nash \\ Evan Peacock \\ Timothy K. Perttula \\ Traci Popejoy \\ Charles R. Randklev \\ Susan L. Scott \\ Robert Z. Seldon, Jr. \\ Steve Wolverton
}

Richard A. Weinstein

Principal Investigator

CSJ 0251-01-058

Waco District

Texas Antiquities Permit No. 6023

Contract No. 57-1XXSA004, Work Authorization No. 57-102SA004

Contract No. 57-3XXSA001, Work Authorization No. 57-302SA001

FinAl REPORT

NOVEMber 2015

Prepared for:

Environmental Affairs Division Texas Department of Tansportation Archeological Studies Branch

Report No. 169

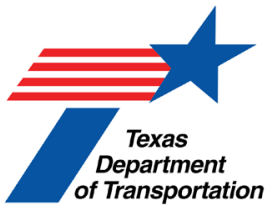

Prepared by: 


\title{
Archaeological and Geological Test Excavations at Site 41HM61, Hamilton County, Texas:
}

\section{Middle Archaic Through Late Prehistoric Occupation in the Leon River Valley of Central Texas}

\author{
Copyright(@) 2015 \\ Texas Department of Transportation (TxDOT) \\ CSJ 0251-01-058 \\ Waco District
}

Texas Antiquities Permit No. 6023

All rights reserved.

This is a work for hire produced for the Texas Department of Transportation (TXDOT), which owns the rights, title, and interest in and to all data and other information developed for this project under Contract Nos. 57-1XXSA004 and 57-3XXSA001. Brief passages from this publication may be reproduced without permission provided that credit is given to TxDOT and Coastal Environments, Inc. Permission to reprint an entire chapter, section, figures or tables must be obtained in advance from the Supervisor of the Archeological Studies Program, Environmental Affairs Division, Texas Department of Transportation, 125 East $11^{\text {th }}$ Street, Austin, Texas, 78701. Copies of this publication have been deposited with the Texas State Library in compliance with the State Depository Requirement.

\author{
printed by: \\ Connelly Press \& Copy, Inc. \\ 9864 Professional Blvd. \\ Baton Rouge, Louisiana 70809 \\ published by: \\ Texas Department of Transportation \\ Environmental Affairs Division \\ Archeological Studies Program \\ Scott Pletka, Ph.D., Supervisor \\ and \\ Coastal Environments, Inc.
}

ISBN 978-1-935545-36-1 


\section{Abstract}

Coastal Environments, Inc., (CEI) conducted archaeological testing at 41HM61 to determine if that site is eligible for inclusion in the National Register of Historic Places (NRHP). The site, which is located in northern Hamilton County, Texas, would be affected by replacement of the current U.S. Highway 281 bridge over the Leon River. TxDOT archaeologists had previously examined the bridge location through a series of 14 backhoe trenches in the search for buried cultural remains. Although such remains were found, it was uncertain at the time whether they were in situ or had been eroded out of several known sites located just upstream and then transported downriver to the bridge location. CEI was contracted by TxDOT to revisit the site and conduct the NRHP testing. Work was conducted under the direction of Mr. Richard A. Weinstein, Principal Investigator. Ms. Jennifer A. Kelly served as Project Archaeologist for the fieldwork, while Dr. Jon C. Lohse served as Project Archeologist throughout the analysis and writing phases. Dr. Charles D. Frederick served as Geoarchaeologist.

CEI reopened and expanded three of the earlier TxDOT trenches (equaling ca. 14 linear meters), excavated eight new trenches (for a total of 98 additional linear meters), and then dug six 50-by-50-cm or 1-by-1-m witness columns and five block excava- tions, the latter each of varying size and consisting of a series of contiguous 1-by-1-m units. The witness columns and block excavations were hand-dug using a combination of shovels and trowels and resulted in the removal of 14.05 cubic meters of soil. Over 30 features were identified and several were examined in detail by the hand excavations, including concentrations of ash and charcoal and clusters of firecracked rocks and mussel shells.

Twenty-six samples of charcoal, organic sediment, mussel shell, bone, and floral remains were radiocarbon dated, resulting in a remarkably concise understanding of the different site occupations which span from the latter part of the Middle Archaic period through the Late Prehistoric and/or Protohistoric periods (ca. 2460 B.C. to A.D. 1600). Through analysis of the remains associated with each recognized occupation, particularly the lithic tools and vertebrate faunal material, plus selected samples of floral material, freshwater mussel shells, and snails, it is possible to piece together a fine-grained picture of hunter-gatherer subsistence through time, along with changes in the local environment that would have affected subsistence strategies and living conditions. Overall, site 41HM61 is considered eligible for inclusion in the NRHP. It also is considered eligible for status as a State Antiquities Landmark. 



\section{TABLE OF CONTENTS}

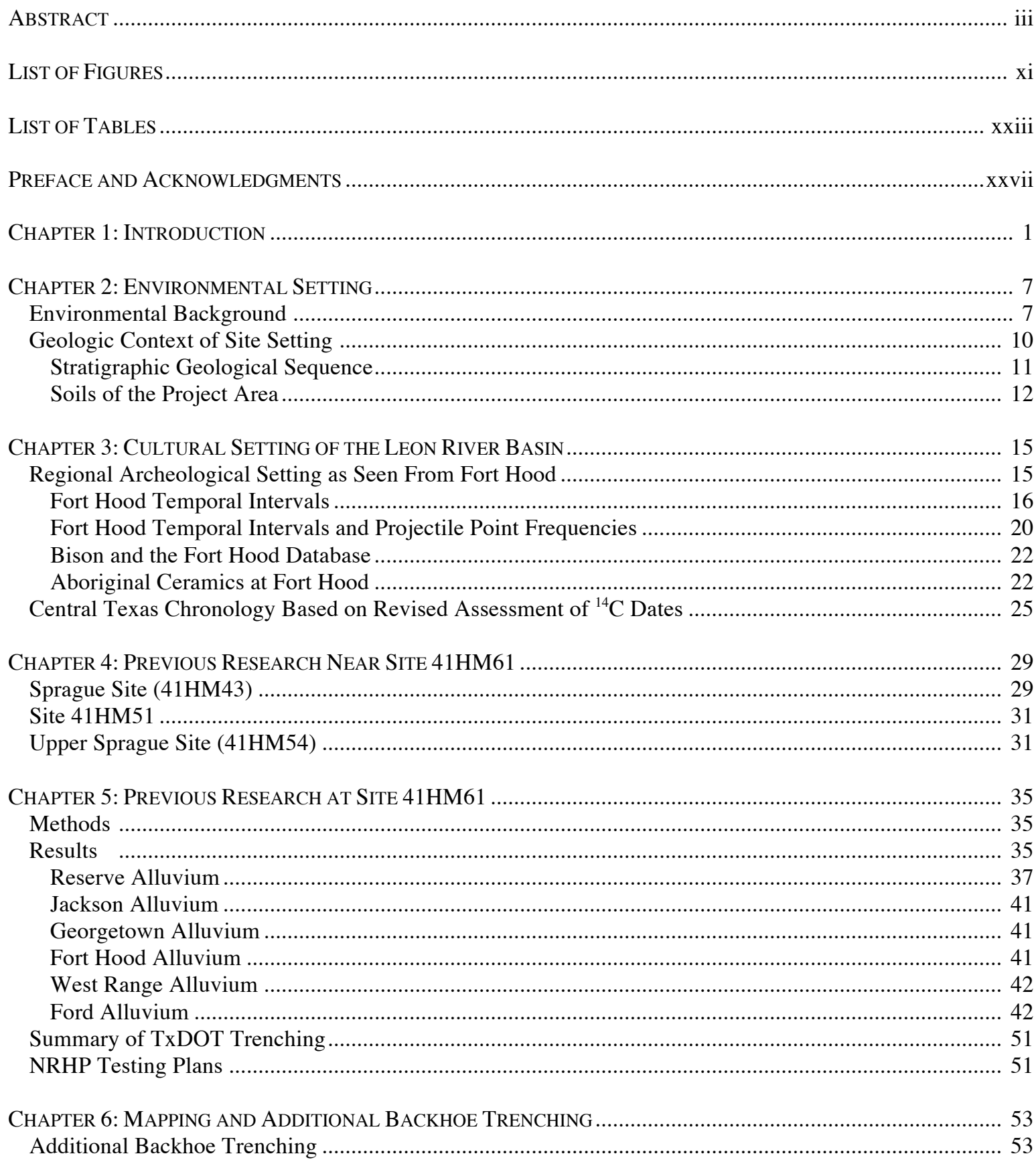




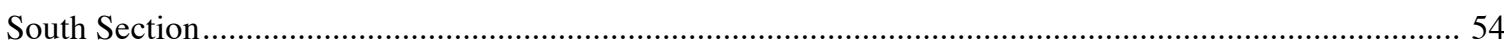

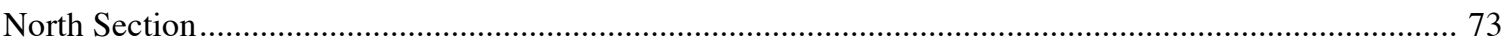

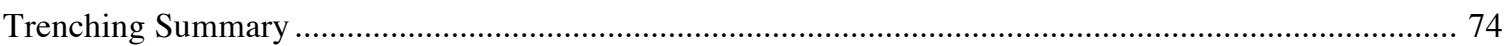

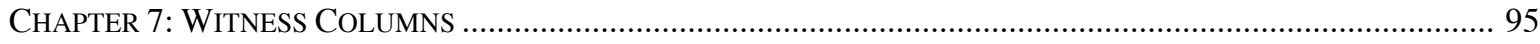

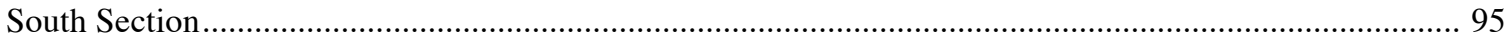

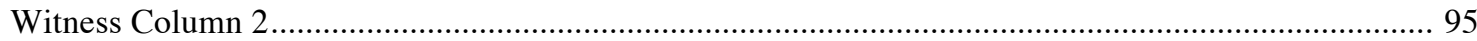

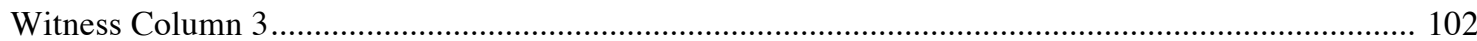

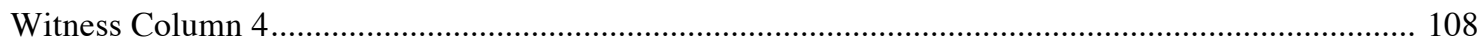

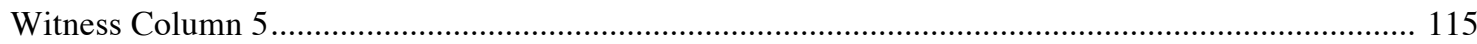

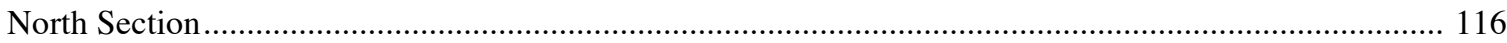

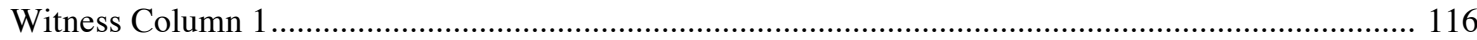

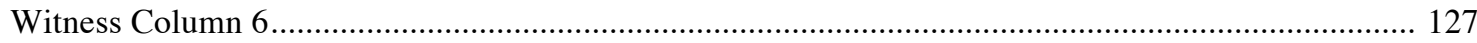

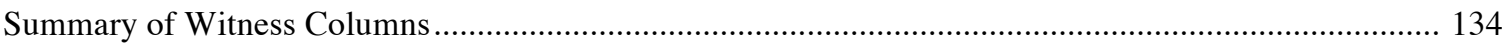

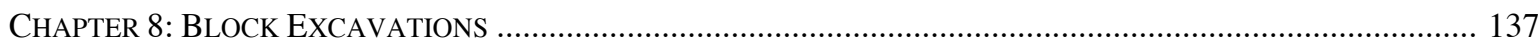

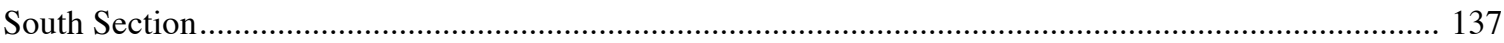

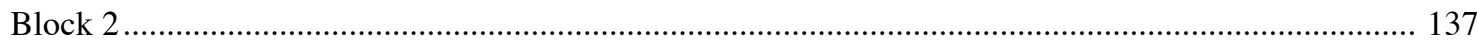

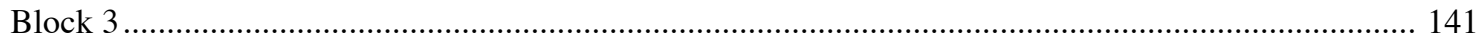

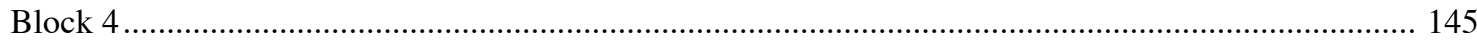

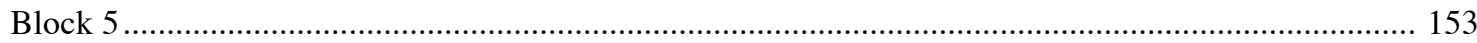

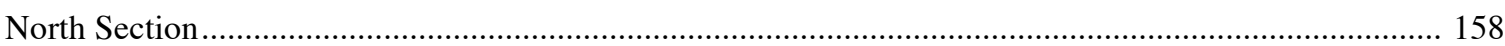

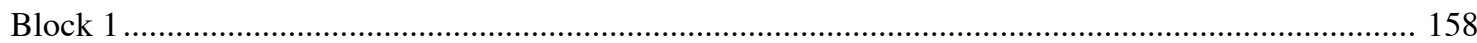

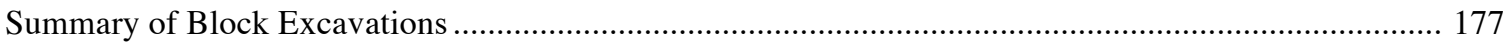

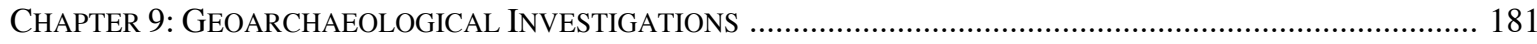

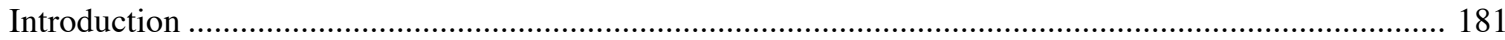

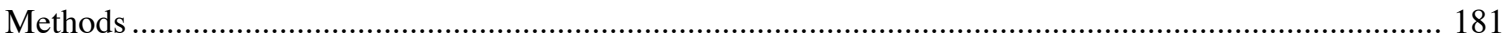

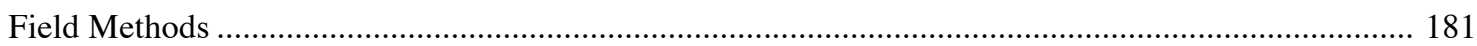

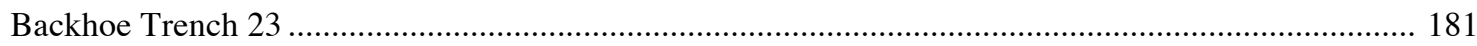

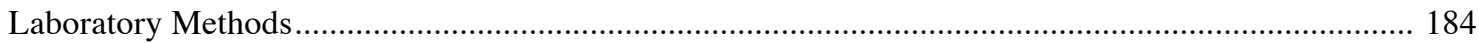

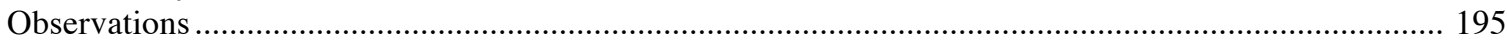

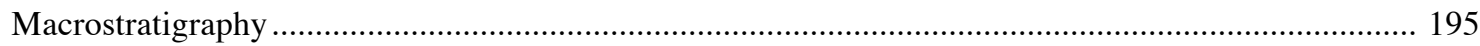

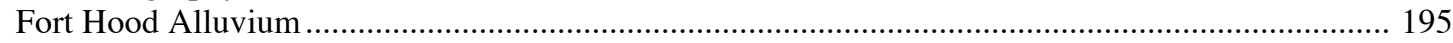

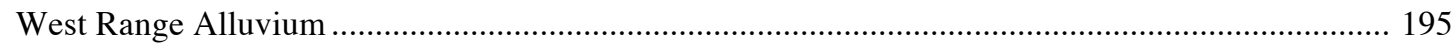

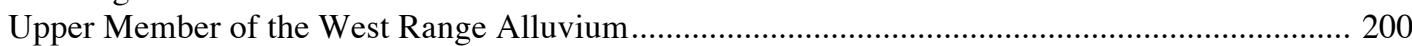

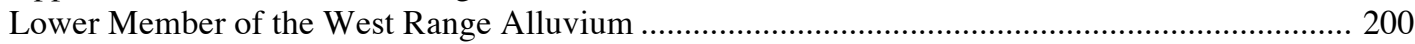

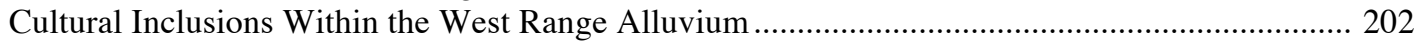

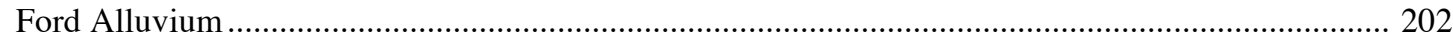

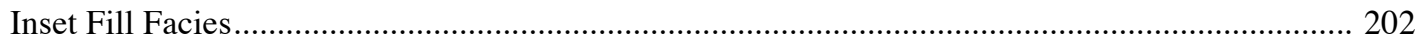

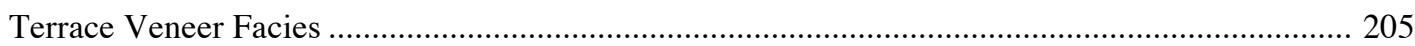

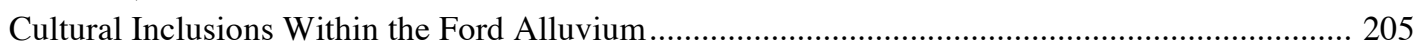

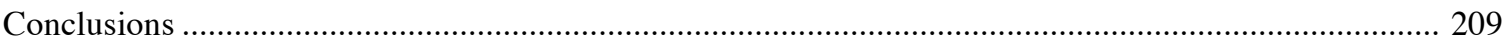

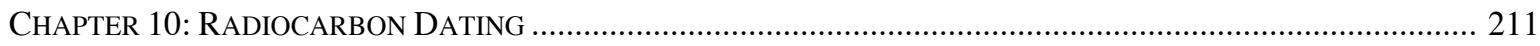

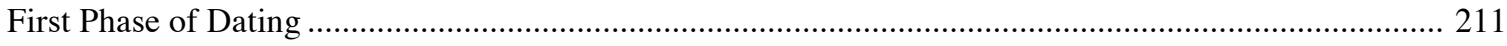

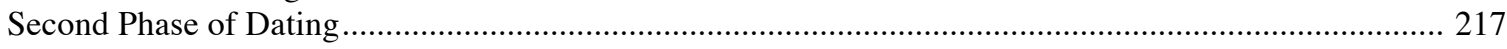

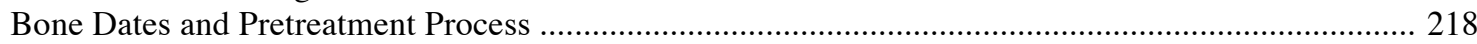

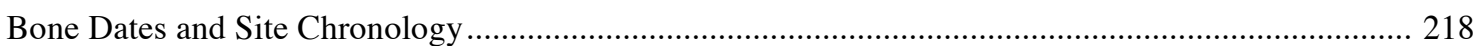

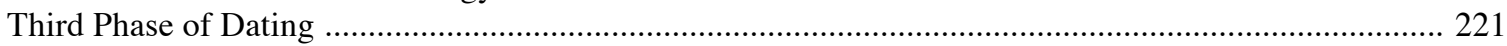

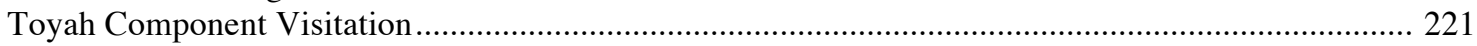

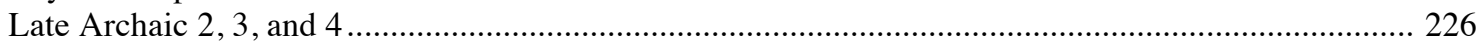

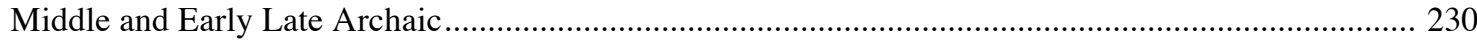

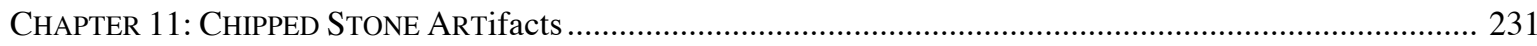

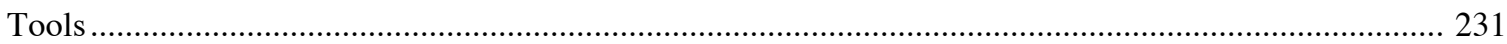




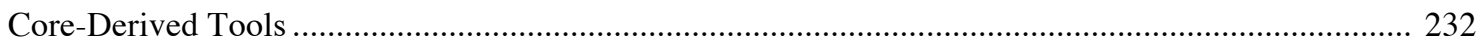

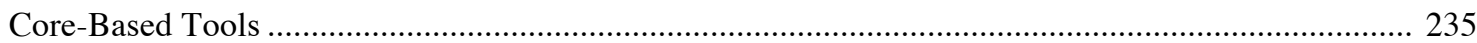

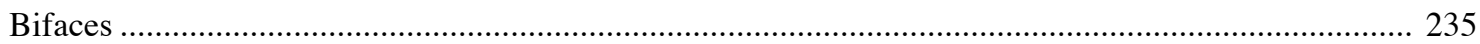

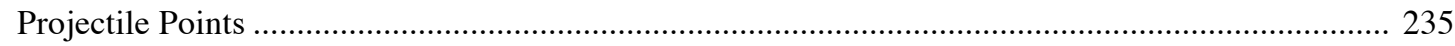

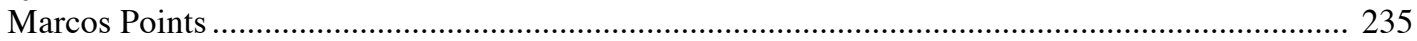

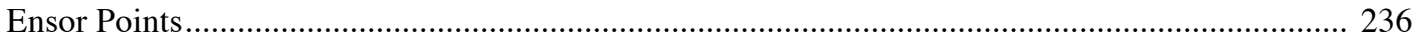

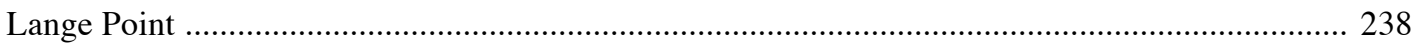

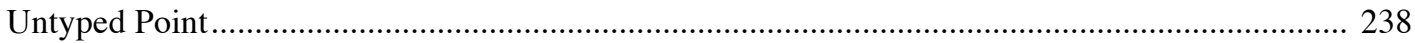

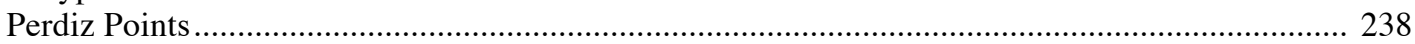

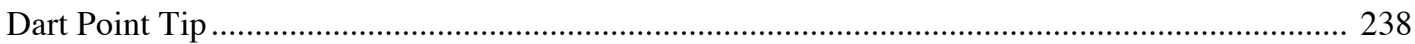

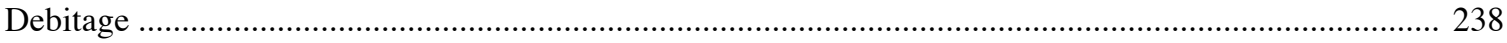

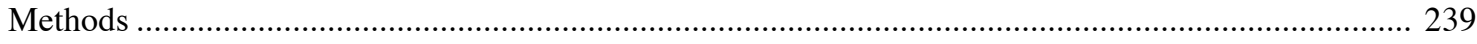

Minimum Number of Nodules and Size Grading ……................................................................. 239

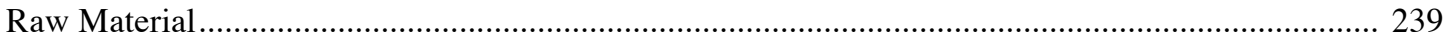

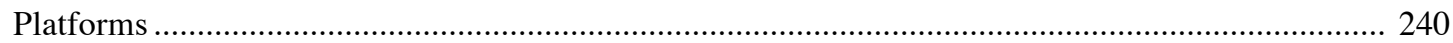

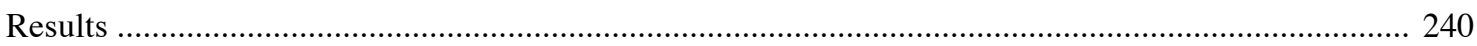

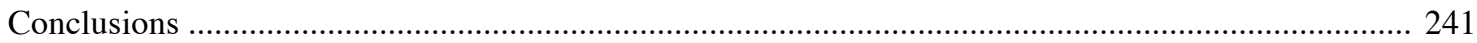

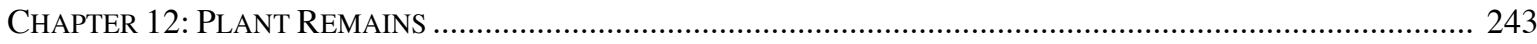

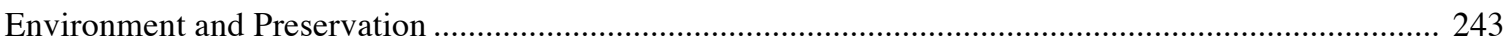

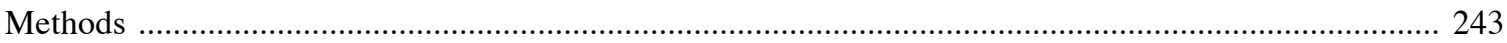

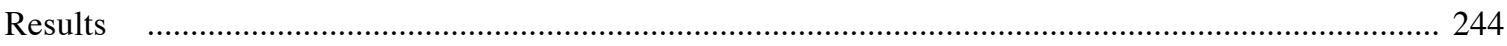

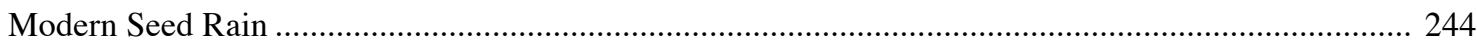

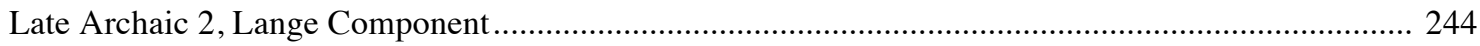

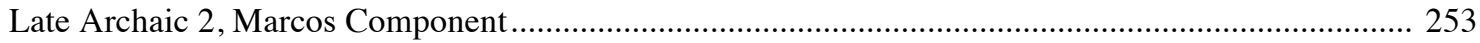

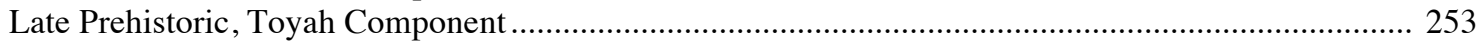

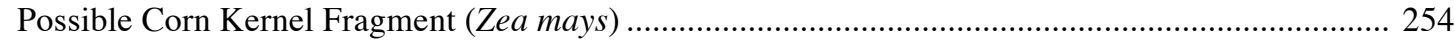

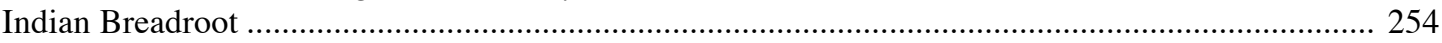

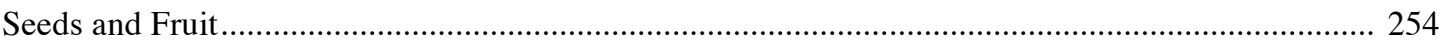

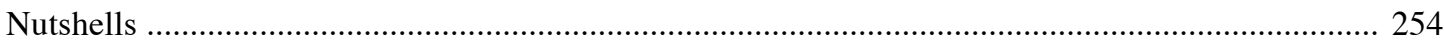

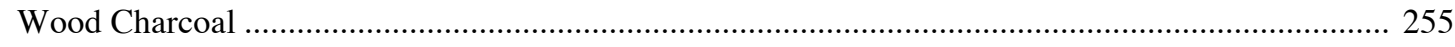

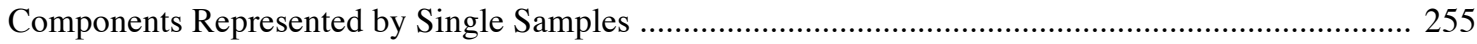

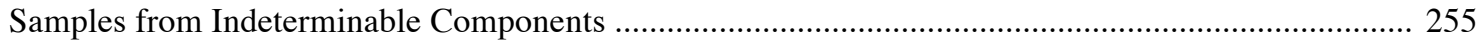

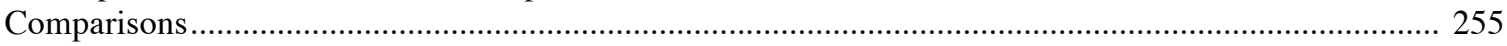

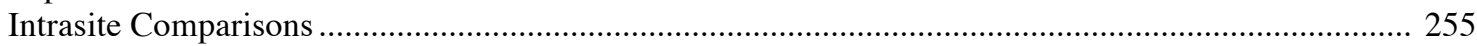

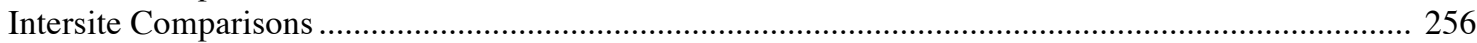

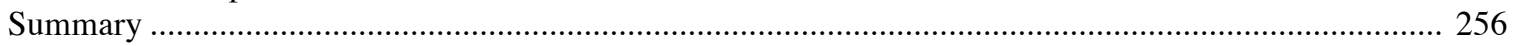

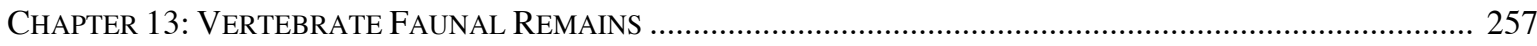

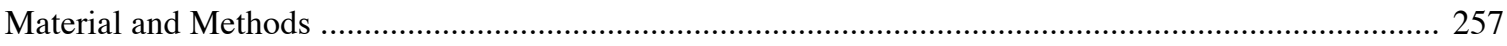

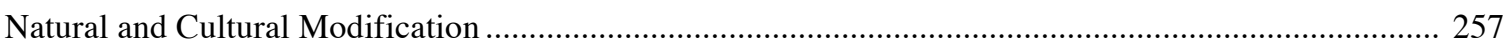

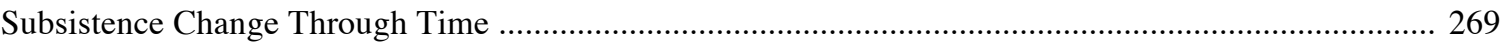

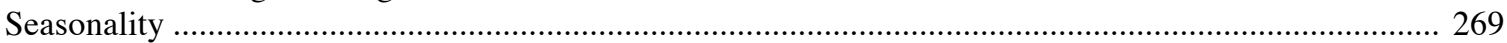

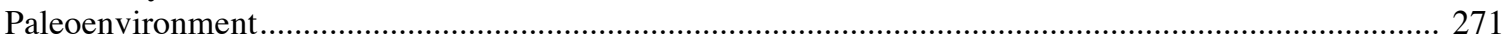

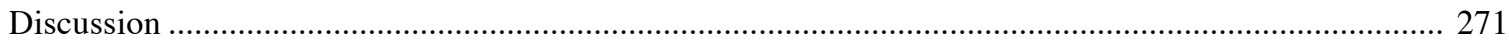

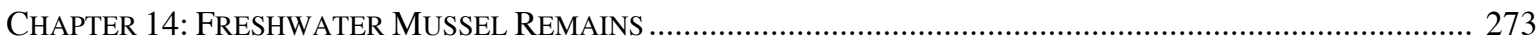

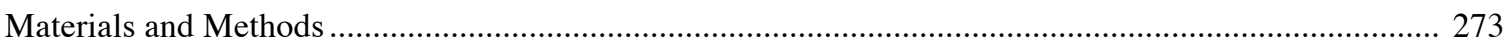

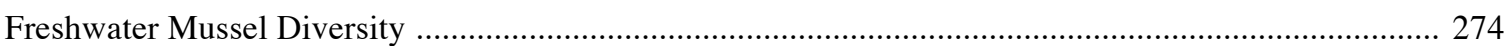

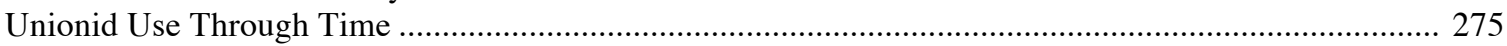

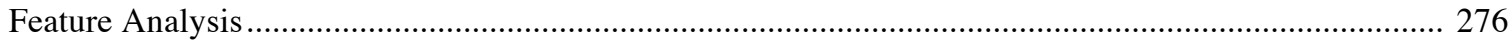

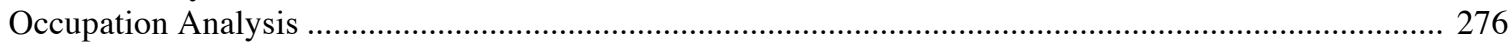

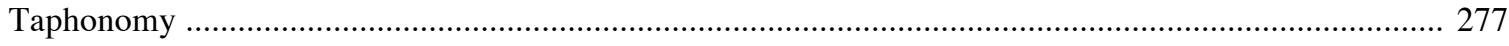

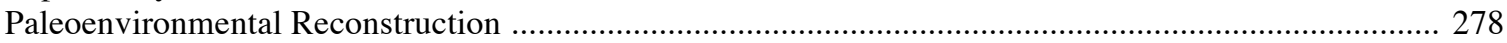

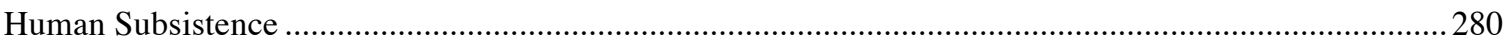

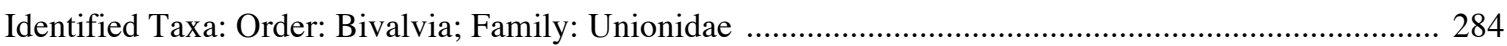




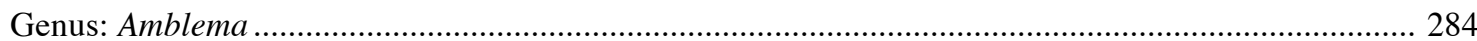

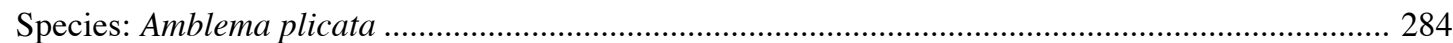

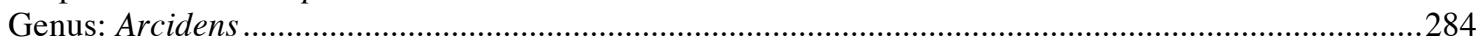

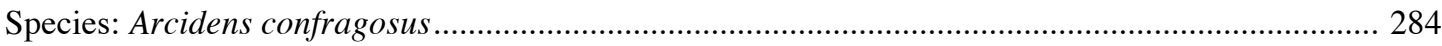

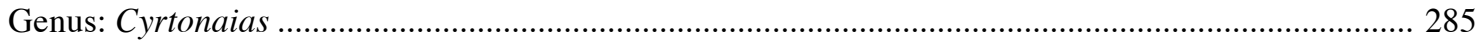

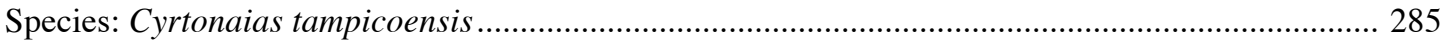

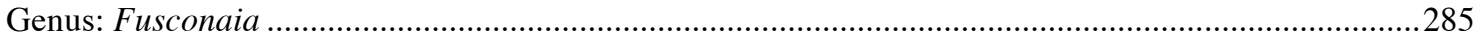

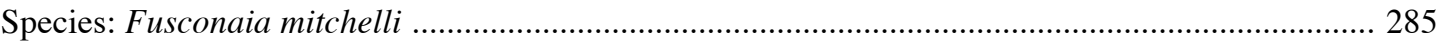

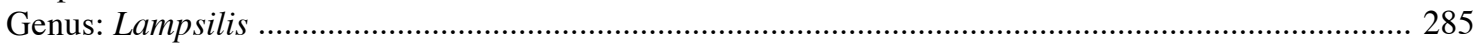

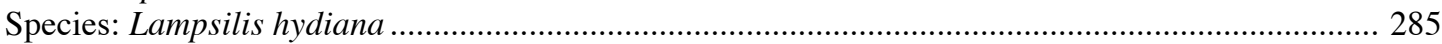

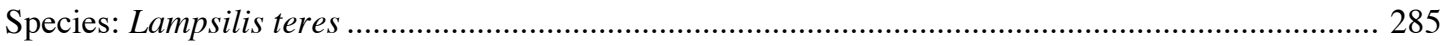

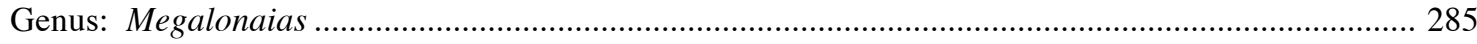

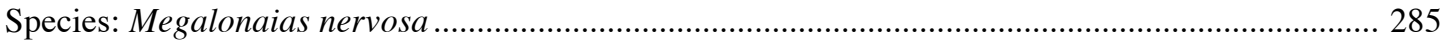

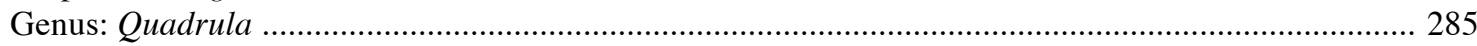

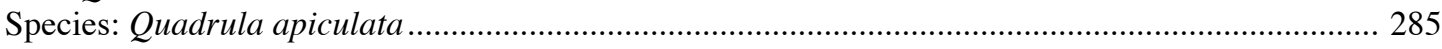

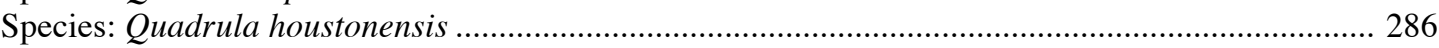

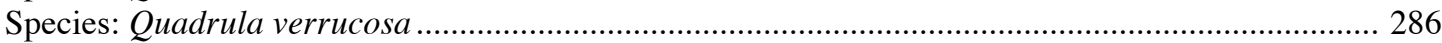

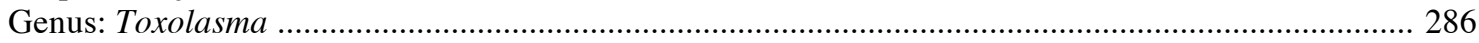

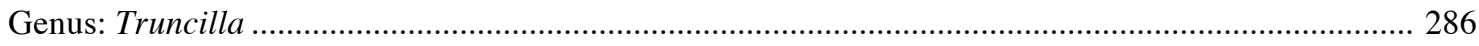

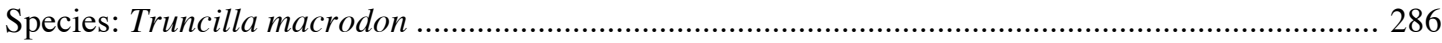

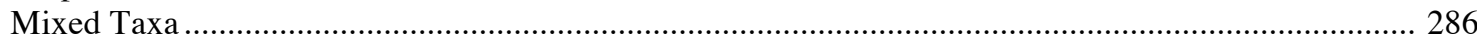

Species: Amblema plicata or Megalonaias nervosa ..................................................................... 286

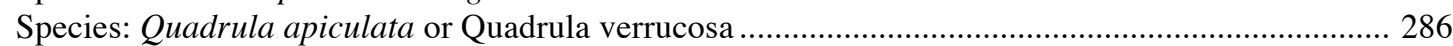

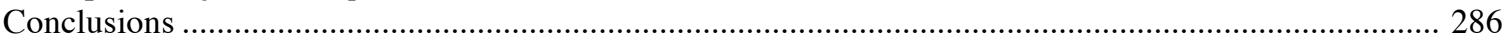

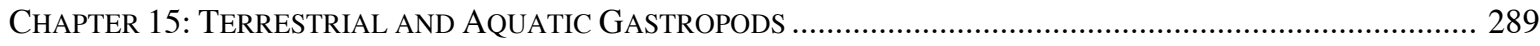

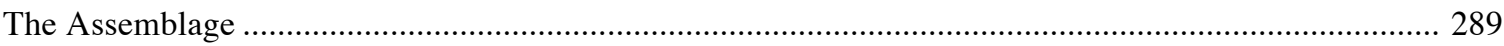

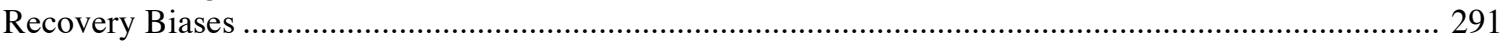

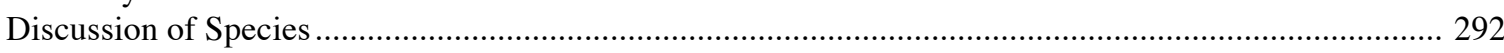

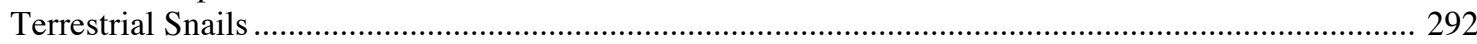

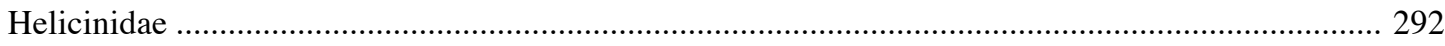

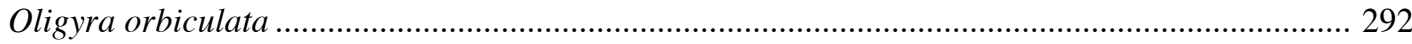

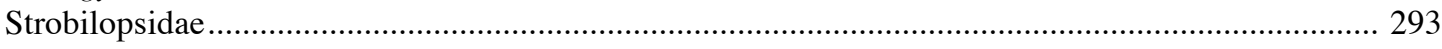

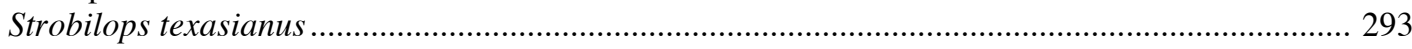

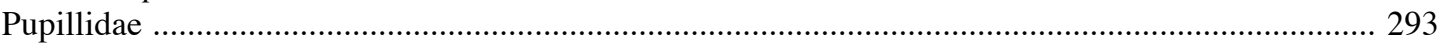

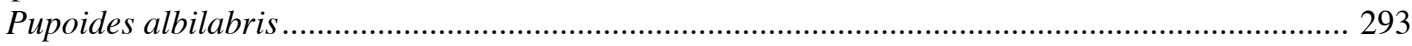

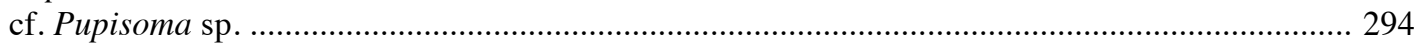

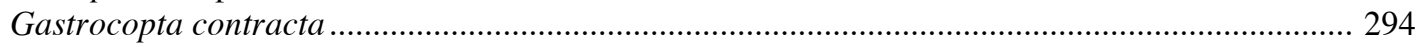

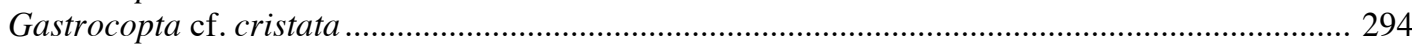

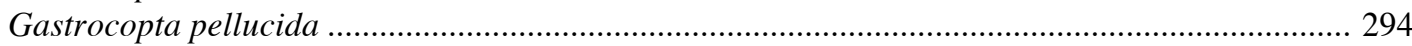

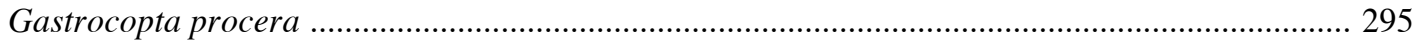

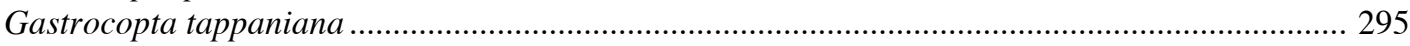

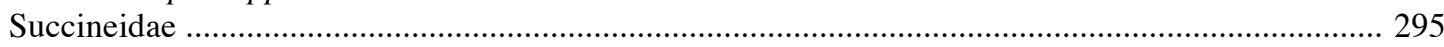

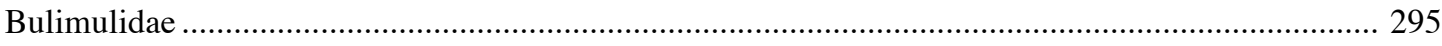

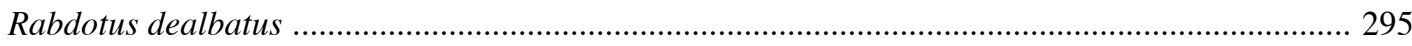

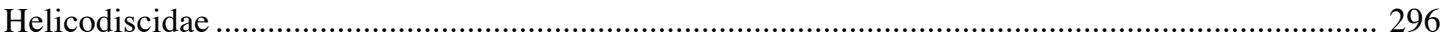

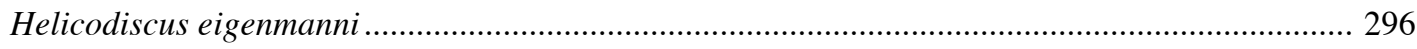

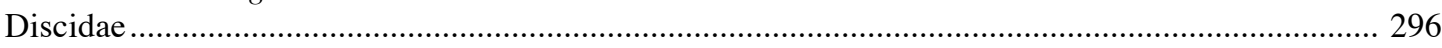

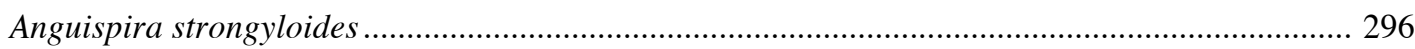

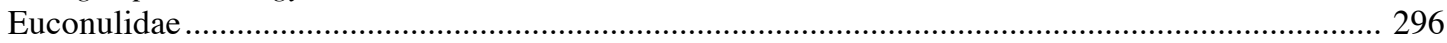

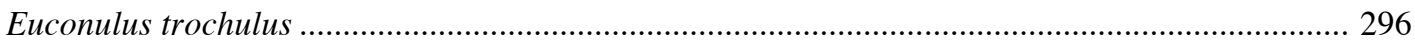

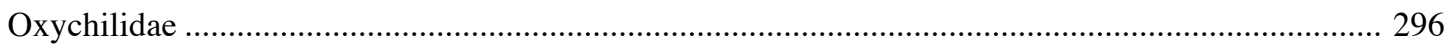

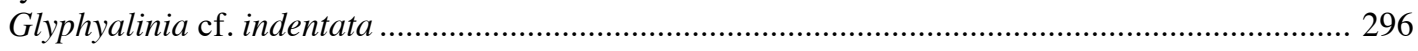

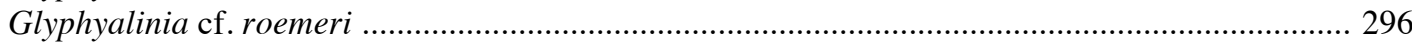

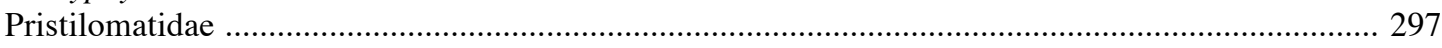

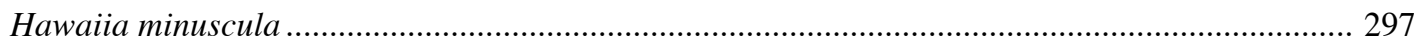




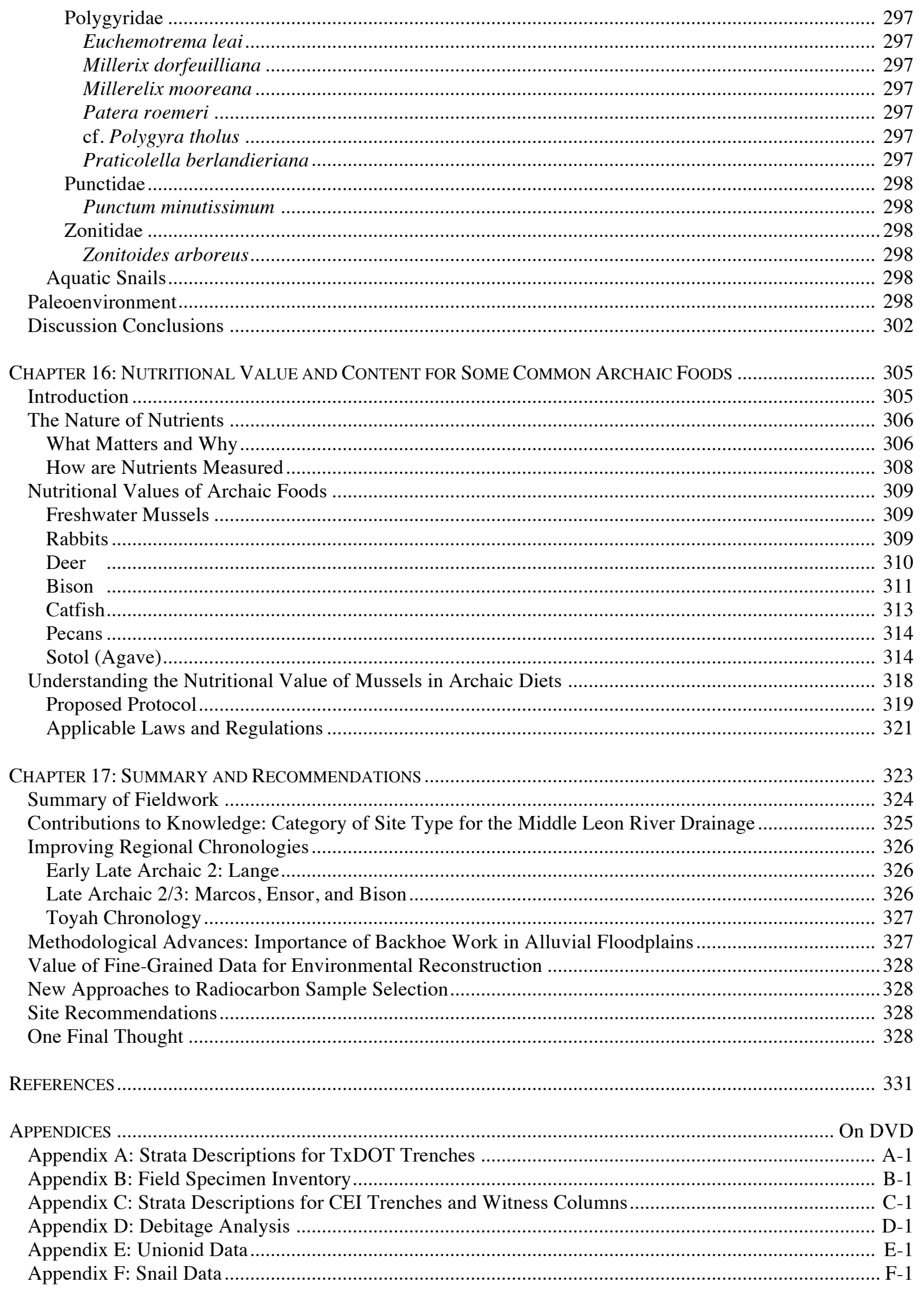





\section{LIST OF FIGURES}

1-1. Current project area shown on 1956 7.5-minute topographic quadrangle maps 2

1-2. Detailed aerial photograph of the current project area showing the TxDOT ROW along U.S. Highway 281 ..... 3

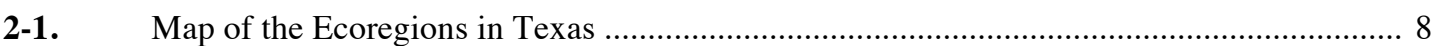

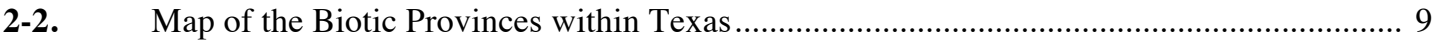

2-3. Location of the project area shown in relation to Geological Atlas of Texas

2-4. Stratigraphy of the Leon River at Fort Hood

2-5. Soil map of the study area, adapted from the USDA web soil survey, with TxDOT trench locations superimposed

3-1. Central Texas temporal intervals and age ranges as defined by Collins et al. (2011) and number of dates per century within each interval based on the Ft. Hood radiocarbon database

3-2. $\quad$ Summed radiocarbon probability distribution of the calibrated radiocarbon dates ascribed to Temporal Intervals $\mathrm{J}$ through $\mathrm{K}$ from the Fort Hood radiocarbon database

3-3. Point frequencies per century by the temporal intervals defined for the study area based on the Ft. Hood projectile point database.

3-4. Points and dates per century at Ft. Hood combined for comparative purposes

3-5. Comparing regional chronologies for the purpose of contextualizing archaeological investigations at 41HM61

4-1. Aerial view of the project area showing the locations of the Sprague (41HM43) and Upper Sprague (41HM54) sites just upriver from the U.S. Highway 281 bridge over the Leon River 
5-1. Digital ortho quarter-quadrangle image of the study area showing the location of the abandoned natural channel, the approximate boundary between terraces, and the location of positive and negative backhoe trenches

5-2. DEM-based profile along the U.S. Highway 281 alignment as it crosses the Leon River valley

5-3. Photograph of the northwestern bridge quadrant. Backhoe is

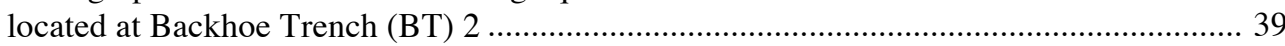

5-4. Photograph of the low terraces on the north side of the Leon River................................... 39

5-5. Photograph of the terraces on the south side of the artificial channel

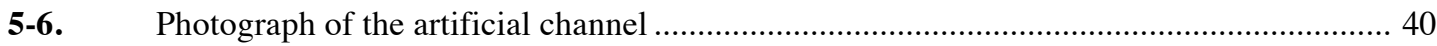

5-7. Photograph of the abandoned natural channel of the Leon River ........................................ 41

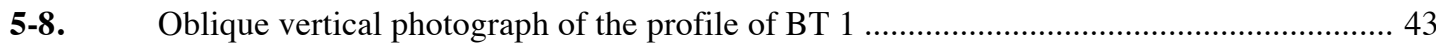

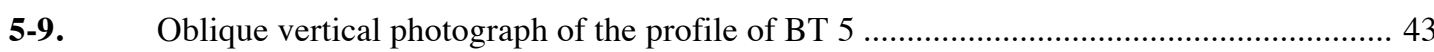

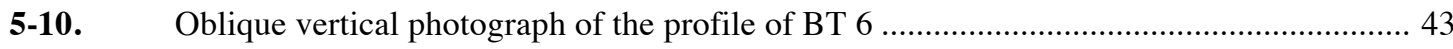

5-11. Oblique vertical photograph of the profile of BT 4 showing the stratigraphic context of cultural material

5-12. Photograph of the profile of BT 8 showing stratigraphic context of the West Range alluvium cultural zone and onlap of Ford-age alluvium

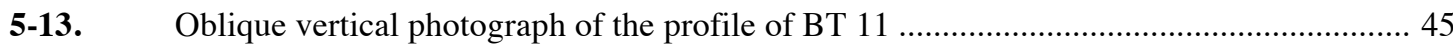

5-14. Oblique vertical photograph of the profile of BT 12 ......................................................... 45

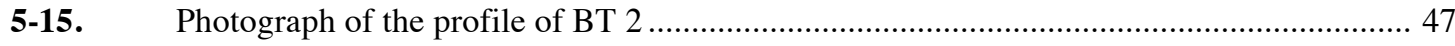

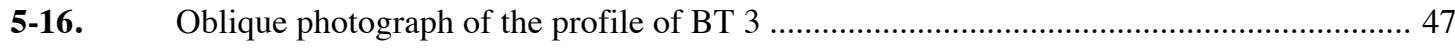

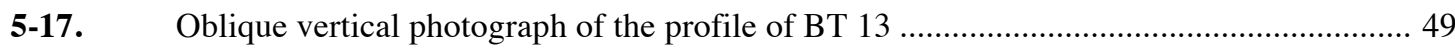

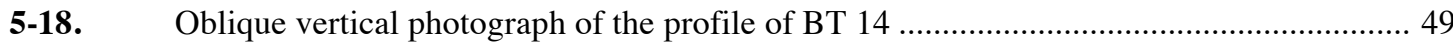

5-19. Photograph of the profile of the end wall of BT 7 showing a section through the artificial levee

6-1. Photograph of a crew member recording site topography with a

Total Data System

6-2. Contour map of site 41HM61 showing the locations of 12 of

TxDOT's 14 previous backhoe trenches

6-3. Photograph of the backhoe beginning to reopen TxDOT BT 9 
6-4. Contour map of site 41HM61 showing the locations of various backhoe trenches excavated (and re-excavated) during the current project

6-5. Blow-up of the southern portion of site contour map showing the locations of reopened TxDOT BTs 9 and 11; previously excavated TxDOT BTs 10,12, and 13; and newly excavated BTs 15,16 , and 17

6-6. Photograph of the excavation of BT 15 with Charles Frederick observing..

6-7. Photograph of the reopened TxDOT BT 11 and newly opened BTs 15 and 16 from atop the U.S. Highway 281 bridge

6-8. Photograph of the reopened TxDOT BT 11 and newly opened BTs 15 and 16 .

6-9. $\quad$ Another photograph of the reopened TxDOT BT 11 and newly opened BTs 15 and 16 from atop the U.S. Highway 281 bridge

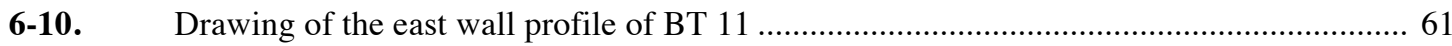

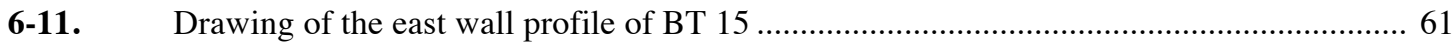

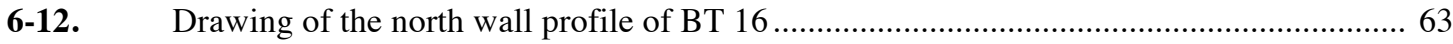

6-13. Map showing the locations of features uncovered in BTs 11,15 , and 16 in the southeastern quadrant of the site.

6-14. Map showing the locations of features uncovered in BTs 9 and 17

in the southwestern quadrant of the site

6-15. Photograph of crew member collecting field specimens from the east wall of BT 15

6-16. $\quad$ Photograph of Rich Weinstein pointing to a Lange dart point exposed within the West Range alluvium near the base of BT 15

6-17. Close-up photograph of the Lange dart point in situ near the base of the east wall of BT 15

6-18. Drawing of the east wall profile of BT 9 showing the relatively deeply buried A horizons associated with the West Range alluvium 75

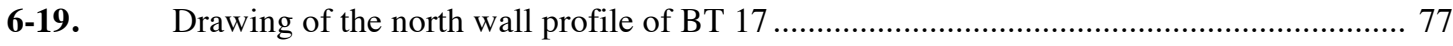

6-20. Photograph of reopened TxDOT BT 9 and newly excavated BT 17 as seen from atop the U.S. Highway 281 bridge

6-21. Photograph of BT 21 and TxDOT BT 9 with the natural channel of

Leon River in trees in distance.

6-22. Photograph taken from atop the U.S. Highway 281 bridge of BT

17 showing the easily recognizable A horizon at the top of the

West Range alluvium .... 
6-23. Map showing the southern portion of site 41HM61, backhoe trenches, and the estimated extent of intact cultural deposits

6-24. Map showing the locations of those BTs situated within the southern part of the northern portion of the project area

6-25. Photograph of the backhoe excavating BT 18 in the northern part

of the site with reopened TxDOT BT 4 in the background

6-26. Photograph of the excavation of BT 22 under the U.S. Highway 281 bridge with the central portion of BT 20 visible in the foreground

6-27. Drawing of the profile of a section of the east wall of BT 18

6-28. Drawing of the west wall profile of combined BT 4/19 83

6-29. Photograph of Charles Frederick spraying the west wall of combined BT 4/19 prior to recording FSs and the wall's profile

6-30. Photograph of Charles Frederick and Sally Morehead recording stratigraphy along the west wall of combined BT 4/19

6-31. Photograph of continuing profiling of the west wall of BT $4 / 19$...... 85

6-32. Another photograph of combined BT 4/19 with Frederick and Morehead identifying FSs and recording the trench's west wall profile

6-33. Drawing of the strata exposed on the north wall of BT 20 showing the major deposits present and some of the internal stratification of the inset fill facies of the Ford alluvium

6-34. Drawing of the profile of a section of the north wall of BT 21

6-35. Photograph of Rich Weinstein monitoring the beginning excavation of BT 22

6-36. Photomosaic of the inset fill facies of the Ford alluvium exposed on the north wall of Backhoe Trench 22 and interpretive line drawing derived from the photo in the upper panel

6-37. Map showing features exposed during trenching within the southern part of the northern area of the site

6-38. Map of the northern portion of site 41HM61 showing backhoe trenches and the estimated extent of intact deposits related to the site's Late Prehistoric, "Toyah" occupation.

7-1. Enlargement of the southern part of the site contour map showing trenches and witness columns excavated in that area 96

7-2. Photograph of Richard Walter beginning the excavation of WC 2 adjacent to north wall of BT 17 
7-3. Photograph of the Excavation of WC 2 adjacent to the north wall of BT 17

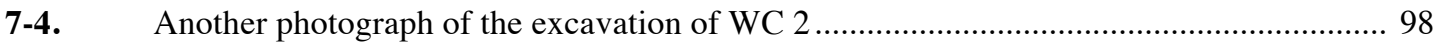

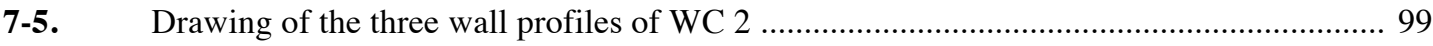

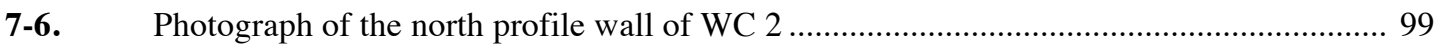

7-7. Plan view drawing of the Feature 16 mussel shell concentration within WC 2

7-8. Photograph of the exposed top of Feature 16 mussel shell concentration within WC 2

7-9. Photograph of Bo Nelson excavating WC 3 adjacent to the east wall of the southern part of BT 15

7-10. Photograph of Bo Nelson continuing to excavate WC 3 adjacent to the east wall of BT 15

7-11. Drawing of the three wall profiles of WC 3

7-12. Photograph of east wall profile of WC 3

7-13. Plan view drawing of the Feature 19 shell concentration within the lower A horizon of WC 3.

7-14. Photograph of the exposed top of the Feature 19 mussel shell concentration near the base of WC 3 within the lower West Range alluvium

7-15. Plan view drawing of the distribution of the fire-cracked rock associated with Feature 20 in WC 3

7-16. Photograph of the initial exposure of the Feature 20 fire-cracked rock concentration as exposed near the bottom of WC 3

7-17. Additional photograph of the fire-cracked rock concentration of Feature 20 following the removal of the upper layer of rock

7-18. Photograph of Richard Walter excavating WC 4 adjacent to the north wall of BT 16

7-19. Another photograph of Richard Walter excavating WC 4 adjacent to the north wall of BT 16

7-20. Profile drawing of the three walls of WC 4

7-21. Photograph of the north wall profile of WC 4

7-22. Plan view drawing of the Feature 21 burned-rock cluster within

WC 4

7-23. Photograph of the exposed top of the Feature 21 fire-cracked rock concentration within the West Range A horizon in WC 4 
7-24. Profile drawing of the three walls in WC 5

7-25. Photograph of the east wall profile of WC 5 showing the sharp contrast between the overlying Ford alluvium and the Upper West

Range A horizon

7-26. Plan view drawing of the top of the so-called "living surface" within WC 5

7-27. Photograph of the top of the concentration of fire-cracked rock and other artifacts found within the 70-to-80-cm level of WC 5

7-28. Map of a portion of the northern part of site 41HM61 showing backhoe trenches and witness columns....

7-29. Photograph of Bo Nelson excavating WC 1 adjacent to the west wall of BT4/19

7-30. Photograph of Bo Nelson shovel skimming the Ford alluvium during the excavation of WC 1 along the west wall of BT 4/19

7-31. Profile drawing of the three walls of WC 1

7-32. Photograph of the west wall profile of completed WC 1

7-33. Photograph of Patrick Brogan beginning the excavation of WC 6

adjacent to the south wall of BT 20

7-34. Photograph of Patrick Brogan continuing to excavate WC 6

7-35. Profile drawing of the three walls of WC 6

7-36. Photograph of the south wall profile of completed WC 6

7-37. Plan view drawing of the area of ash, charcoal, and fired earth identified as Feature 30 within Stratum 9 of WC 6

7-38. Plan view drawing of the area of concentrated ash, charcoal, and fired earth recognized as Feature 31 in WC 6

7-39. Photograph of the top of Feature 31 within Stratum 10 of the "Toyah" zone in WC 6 .

8-1. Contour map of the southern portion of site 41HM61 showing

locations of backhoe trenches, witness columns, and block excavations

8-2. Photograph of the commencement of careful excavation of Block 2 following removal by shovel of the upper $20 \mathrm{~cm}$ or so

8-3. Profile drawings of the east and west walls of Block 2

8-4. Profile drawings of the north and south walls of Block 2 
8-5. Photograph of the south wall profile of Block 2 with BT 17 and

WC 2 in background

8-6. Plan view drawing of the Feature 16 shell uncovered in Block 2

along with those previously recorded in WC 2 .

8-7. Photograph of the surface of the Feature 16 shell concentration

within the southwestern quadrant of Unit N477E561 in Block 2

8-8. Photograph of the excavation of Blocks 3 (background) and 5

(foreground) along the east wall of BT 15

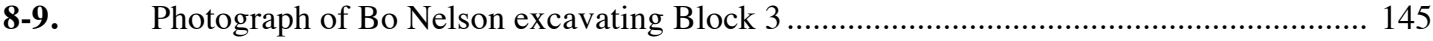

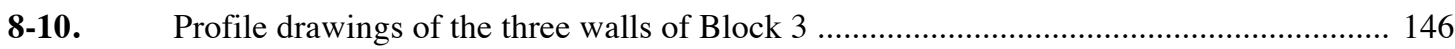

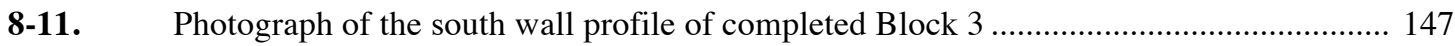

8-12. Plan view drawing of Block 3 showing the extent of mussel shells

associated with Feature 19

8-13. Plan view drawing of Feature 20 within Block 3

8-14. Photograph of the extent of the Feature 20 shell concentration

following the removal of the overlying soil....

8-15. Photograph of Feature 20 and scattered fire-cracked rock near the base of Block 3

8-16. Photograph of Stephanie McKernan and Sally Morehead beginning

the excavation of Block 4 adjacent to WC 4 and BT 16

8-17. Photograph of the continuing excavation of Block 4 adjacent to the north wall of BT 16

8-18. Profile drawings of the four walls of Block 4

8-19. Photograph of the west wall profile of completed Block 4 ........................................... 156

8-20. Plan view drawing of the Feature 26 cluster of fire-cracked rock in

Block 4

8-21. Photograph of the small concentration of fire-cracked rock

identified as Feature 26 within the upper portion of the Upper West

Range A horizon in Unit N474E602 of Block 4

8-22. Plan view drawing of the fire-cracked rock within Block 4 thought

to possibly be an extension of Feature 21 in WC 4

8-23. Photograph of Sally Morehead and Stephanie McKernan working

in Block 5

8-24. Photograph of the continuing excavation of Block 5 ...................................................... 161

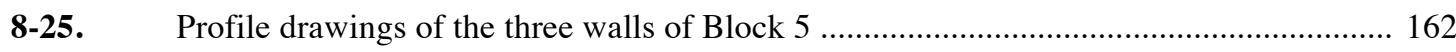


8-26. Photograph of the south wall profile of completed Block 5

8-27. Plan view drawing of the mussel shell associated with Features 18 and 28 in Block 5

8-28. Photograph of the extent of Features 18 and 28 following the removal of overlying Stratum 6 soil

8-29. Contour map of a portion of the northern part of site 41HM61 showing locations of backhoe trenches, witness columns, and block excavations

8-30. Photograph of Block 1 and WC 6 from the U.S. Highway 281 bridge

8-31. Photograph of crew members shoveling out the upper 50 to $60 \mathrm{~cm}$ of overburden in Block 1 to reach the top of the West Range A horizon containing the Toyah occupation.....

8-32. Photograph of crew members continuing to shovel out the upper 50

to $70 \mathrm{~cm}$ of overburden in Block 1

8-33. Profile drawings of the three walls of Block 1

8-34. Photograph of the south wall profile of Block 1

8-35. Photograph of the commencement of controlled excavations in

Block 1 by shovel skimming and the use of trowels

8-36. Plan view drawing of the top of the A horizon in Block 1

8-37. Photograph of the top of the Stratum 7 A horizon in Block 1

following the complete removal of the overlying Ford alluvium in the western two-thirds of the block

8-38. Photograph of crew members removing the first $10-\mathrm{cm}$ cut into the Stratum 7 A horizon in the three partial 1-by-1-m units adjacent to BT $4 / 19$

8-39. Photograph of crew members continuing to excavate the A horizon within Block 1

8-40. Photograph of Block 1 following the removal of the initial 10-cmthick cut into the Stratum 7 A horizon .....

8-41. Photograph of the southern part of Block 1 after the removal of the upper ca. $20 \mathrm{~cm}$ of the Stratum 7 A horizon

8-42. Plan view drawing showing the distribution of all field specimens related to the Stratum 7 Toyah occupation in Block 1

9-1. Map of a portion of the southeastern quadrant of site 41HM61 showing the location of Backhoe Trench (BT) 23 in relation to previously excavated BT 15 and Blocks 3 and 5 
9-2. Photograph of Charles Frederick recording the stratigraphy of the cleared profile along the west wall of BT 23 with Brittney Gregory holding the TDS prism

9-3. Close-up photograph of the cleared and picked profile along the west wall of BT 23

9-4. $\quad$ Plot of the stratigraphy and results of texture and magnetic susceptibility analysis of samples collected from Witness Column 1 adjacent to Trench 19

9-5. Chart showing the stratigraphy of WC 6 , which is situated on the sloping margin of the inset fill facies of the Ford alluvium

9-6. Plot of texture and magnetic susceptibility analysis of samples collected from strata exposed at the base of BT 20

9-7. Expressions of the West Range alluvium in the southern part of 41HM61

9-8. Plots of texture, magnetic susceptibility, calcium carbonate, organic carbon, and stable carbon isotopes within the Ford and West Range alluvia exposed in the west wall of BT 23

9-9. Scale drawing of the stratigraphic relationship observed between the West Range alluvium and Ford alluvium in the north side of site 41HM61

9-10. $\quad$ Photomosaic of the Inset Fill facies of the Ford alluvium exposed on the north wall of BT 22 and interpretive line drawing derived from the photo in the upper panel.....

9-11. Scatterplot of the relationship between the magnetic susceptibility and mean particle size for the Ford and West Range alluvial deposits and Scatterplot depicting the relationship between the coefficient of frequency dependence (\%) and mean particle size (in phi units) for the Ford alluvium and West Range alluvium.

9-12. Photograph of the soil formed in the inset fill facies of the Ford alluvium in BT 20 and photograph of the west wall of WC 1 adjacent to BT 19 showing the soil formed in the terrace veneer facies of the Ford alluvium

9-13. Plot of the mean particle size versus the sorting for the Ford alluvium and the West Range alluvium

10-1. Comparisons of calibrated bone dates from 41HM61 showing $2 \sigma$ calibrated distributions and means.

10-2. Calibrated (2б) Toyah dates from 41HM61 223

10-3. All Toyah dates (calibrated 2 $\sigma$ ) from site 41HM61 plotted on the latest calibration curve 
10-4. Proposed three-part Toyah chronology based on a total of 27

XAD-purified AMS dates on bison bone, including three from this study, as well as short-lived botanical taxa from 41HM61.

10-5. Late Archaic 2 through 4 radiocarbon data from 41HM61 with

$\mathrm{LA}_{\mathrm{B}} 1$ and $\mathrm{LA}_{\mathrm{B}} 2$ events shown for context

11-1. Analytic taxonomy for chipped stone tools as outlined in the

TxDOT LP

11-2. Core-derived and core-based tools from site 41HM61 ..................................................... 234

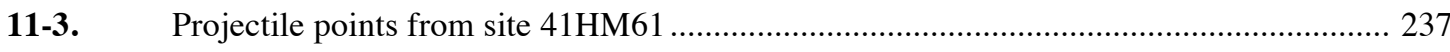

12-1. Photograph of the possible corn kernel fragment from Feature 31 at 41HM61

12-2. Drawing showing the location of the possible corn kernel fragment on the kernel from Feature 31 at 41HM61

13-1. Bar graph depicting relative bone weight by time period at 41HM61

13-2. Bar graph depicting number of identified specimens by time period from 41HM61 270

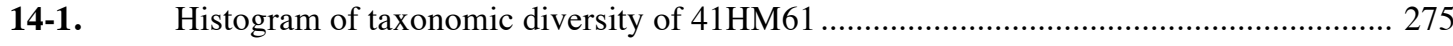

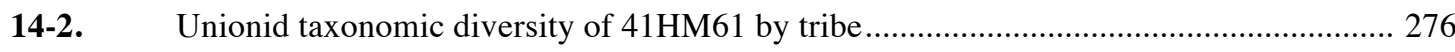

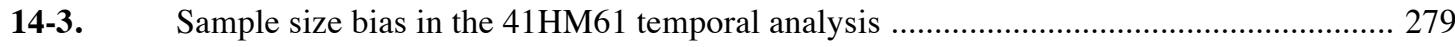

14-4. Taphonomic conceptual model for freshwater mussel shell ............................................ 281

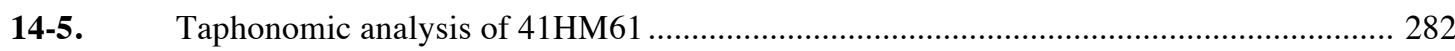

14-6. Paleoenvironmental reconstruction based on UNIO calculations ................................... 283

15-1. Line graph of snail shell recovery in flotation (heavy fraction) vs. non-flotation samples from 41HM61.

15-2. Line graph of snail shell recovery in flotation (heavy fraction) samples by size-grade vs. non-flotation samples from 41HM61

15-3. Line graph of snail shell recovery in flotation (light fraction) samples vs. flotation (heavy fraction) samples and non-flotation samples from 41HM61

15-4. Bar graph of proportions of taxa by general habitat type for the total identified assemblage at site 41HM61

15-5. Bar graph of proportions of Woodland/Floodplain species to Grassland/Open Woodland/Open species by time period 
15-6. Ordination diagram of snail lots from Berger Bluff, the Southern Plains Gastropod Survey, the Mississippi Black Prairie, and site 41HM61

15-7. Ordination diagram of snail lots from Berger Bluff, the Southern

Plains Gastropod Survey, and site 41HM61

17-1. Aerial image showing the potential extent of intact cultural deposits south of the channelized Leon River at the U.S. Highway 281 bridge 



\section{LIST OF TABLES}

3-1. Radiocarbon Dates Per Century (from Fort Hood Database) by Cultural Intervals as Defined by Collins et al. (2011) ............................................ 17

3-2. $\quad$ Projectile Point Types by Interval and Frequency From Fort Hood............................. 21

3-3. Sites at Fort Hood with Very Large Mammalian (cf. Bison)

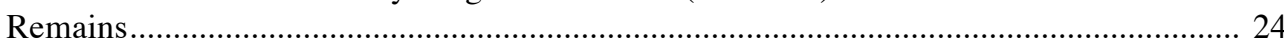

3-4. Fort Hood Sites with Aboriginal Ceramic Sherds ............................................. 24

4-1. Radiocarbon Dates from the Test Excavations at Site 41HM51 ................................. 32

4-2. Radiocarbon Dates from the Upper Sprague Site (41HM54) ..................................... 32

5-1. UTM Coordinates for TxDOT Backhoe Trenches .............................................. 37

5-2. Zones of Cultural Material Identified in the Six Positive Backhoe Trenches Excavated by TxDOT Personnel.............................................................. 47

6-1. Features Recorded During Trench Excavations at Site 41HM61 ................................65

6-2. $\quad$ Material Recovered from Backhoe Trenches at Site 41HM61 .....................................69

7-1. Witness Column 2: Excavated Strata and Levels and Corresponding Natural Strata as Identified on Wall Profiles

7-2. $\quad$ Material Recovered from Witness Column 2 Excavations .......................................... 101

7-3. Material Recovered from Witness Column 3 Excavations ...................................... 106

7-4. Witness Column 3: Excavated Strata and Levels and Corresponding Natural Strata as Identified on Wall Profiles

7-5. Material Recovered from Witness Column 4 Excavations 113

7-6. Witness Column 4: Excavated Strata and Levels and Corresponding Natural Strata as Identified on Wall Profiles 114

7-7. Material Recovered from Witness Column 5 Excavations 119 
7-8. Witness Column 5: Excavated Strata and Levels and Corresponding Natural Strata as Identified on Wall Profiles

7-9. Material Recovered from Witness Column 1 Excavations

7-10. Witness Column 1: Excavated Strata and Levels and Corresponding Natural Strata as Identified on Wall Profiles

7-11. Material Recovered from Witness Column 6 Excavations

7-12. Witness Column 6: Excavated Strata and Levels and

Corresponding Natural Strata as Identified on Wall Profiles

7-13. Witness Columns Excavated at Site 41HM61, Including Column

Size, Quantity of Hand-Excavated Soil, and Features and Principal

Components Present

8-1. Material Recovered from the Block 2 Excavations

8-2. Block 2: Excavated Strata and Levels and Corresponding Natural

Strata as Identified on Wall Profiles

8-3. Material Recovered from the Block 3 Excavations 148

8-4. Block 3: Excavated Strata and Levels and Corresponding Natural

Strata as Identified on Wall Profiles

8-5. Material Recovered from the Block 4 Excavations

8-6. Block 4: Excavated Strata and Levels and Corresponding Natural Strata as Identified on Wall Profiles

8-7. Material Recovered from the Block 5 Excavations

8-8. Block 5: Excavated Strata and Levels and Corresponding Natural Strata as Identified on Wall Profiles

8-9. Material Recovered from the Block 1 Excavations

8-10. Block 1: Excavated Strata and Levels and Corresponding Natural Strata as Identified on Wall Profiles

8-11. Blocks Excavated at Site 41HM61, Including Block Size, Quantity of Hand-Excavated Soil, Features, and Principal Components

Present

9-1. Particle Size Analysis for Witness Column (WC) 1 and Backhoe

Trench (BT) 19

9-2. Particle Size Analysis for WC 6 and BT 20.

9-3. Particle Size Analysis for the Base of BT 20

9-4. Particle Size, Magnetic Susceptibility, Calcium Carbonate

Equivalent, Organic Carbon, and Stable Carbon Isotope Analysis

of Backhoe Trench 23 
10-1. Samples Selected for AMS Radiocarbon Dating from 41 HM61

10-2. Measured and Comparative Data for Bone Dates Processed by

Different Methods

10-3. Radiocarbon Dates from the Toyah Component and Their Contexts

or Comparative Criteria

10-4. Radiocarbon Dates with Contexts and Comparative Criteria

Relevant for Understanding the Late Archaic 2 Through 4 Periods at $41 \mathrm{HM} 61$

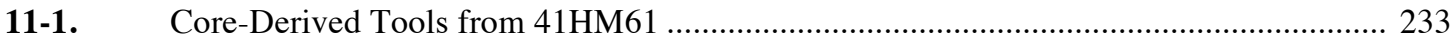

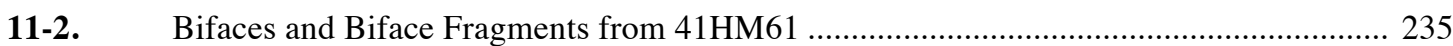

11-3. Projectile Points and Point Fragments from 41HM61 ............................................ 236

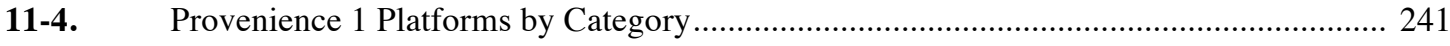

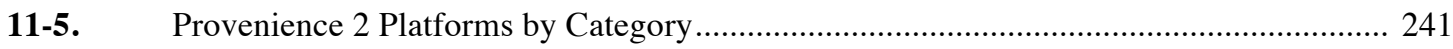

12-1. Index of Tables of Archaeological Plant Remains from Site 41HM61 by Component

12-2. Archaeological Plant Remains from the Lange Component at 41HM61 by Number of Fragments

12-3. Archaeological Plant Remains from the Lange Component at 41HM61 by Weight

12-4. Archaeological Plant Remains from the Marcos Component at 41HM61 by Number of Fragments

12-5. Archaeological Plant Remains from the Marcos Component at 41HM61 by Weight

12-6. Archaeological Plant Remains from the Toyah Component at 41HM61 by Number of Fragments

12-7. Archaeological Plant Remains from the Toyah Component at 41HM61 by Weight

12-8. Archaeological Plant Remains from Single-Sample and Samples of Indeterminable Components at 41HM61 by Number of Fragments

12-9. Archaeological Plant Remains from Single-Sample and Samples of Indeterminable Components at 41HM61 by Number of Fragments

12-10. Uncarbonized Plant Remains from All Components at 41HM61 by Number with Weights in Grams in Parentheses

12-11. Bone and Lithics from Flotation and Botanical Samples, All Components at Site 41HM61 by Number with Weights in Grams in Parentheses 
12-12. Proximate Analysis of Four Edible Tree Nuts and Cornmeal per 100 g Dry Weight.

12-13. Total Plant Weight per Cubic Decimeter of Processed Fill at Site 41HM61 by Component.

13-1. $\quad$ Count (NISP) and Weight (g) for All Analyzed Vertebrate Fauna at 41HM61

13-2. $\quad$ NISP, Weight (g), and MNI of Vertebrate Faunal Remains, by Time Period, from Site 41HM61

14-1. Freshwater Mussel Taxa Present at 41HM61 ................................................................. 271

14-2. Feature Analysis of Taxonomic Richness for 41HM61 ….................................................. 277

14-3. Occupation Analysis of Taxonomic Richness for 41HM61 ………………………........ 278

14-4. Samples Aggregated by Occupation for the Analysis of Unionid Use by Occupation 280

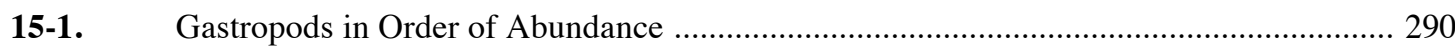

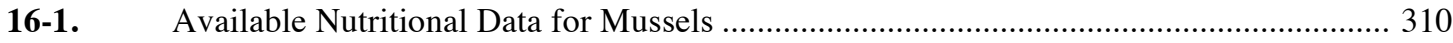

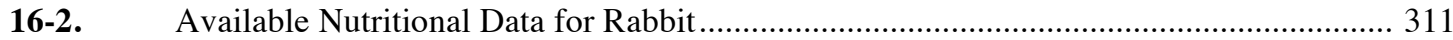

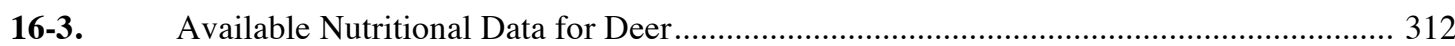

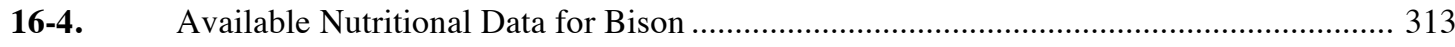

16-5. Available Nutritional Data for Catfish ........................................................................... 315

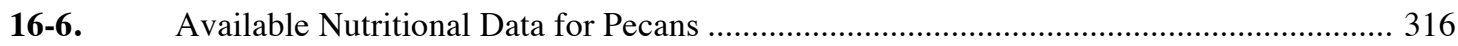

16-7. Available Nutritional Data for Agave as a Proxy for Sotol ............................................. 317 


\section{Preface and ACKNOWLEDGMENTS}

This report presents the results of archaeological testing at site 41HM61 to determine if that site is eligible for inclusion in the National Register of Historic Places (NRHP). The site, situated about six miles north of the City of Hamilton in northern Hamilton County, Texas, would be affected by replacement of the current U.S. Highway 281 bridge over the Leon River. As noted in the Abstract, personnel from the Texas Department of Transportation (TxDOT) had previously examined the bridge location and discovered prehistoric cultural material in several of their backhoe trenches (Abbott 2011). They were unable, however, to determine at that time if those remains were in situ or if they had been eroded out of several known sites located just upstream and then transported downriver to the bridge location. Accordingly, Coastal Environments, Inc., (CEI) was contracted by TxDOT to revisit the site and conduct the NRHP testing. That research, along with the production of an Interim Report (Weinstein et al. 2012), was carried out under Work Authorization (WA) No. 57-102SA004 of Contract No. 57-1XXSA004. Subsequent analyses and report writing, conducted in preparation of the current report, were carried out under WA No. 57-302SA001 of Contract No. 57-3XXSA001. Both phases of work occurred under Texas Antiquities Permit No. 6023.

Fieldwork for the project was divided into two phases. The first phase, which consisted of the vast majority of the work, occurred between September 12 and November 19, 2011, and included mapping of the area to be examined, additional backhoe trenching, and the excavation of a series of hand-dug witness columns and block excavations. The second phase of fieldwork took place almost two years later, on September 10, 11, and 12, 2013, and included excavation of one more backhoe trench in an attempt to reach potential deeply buried cultural remains.

Fieldwork was a multi-team effort involving personnel from CEI, Archeological \& Environmental Consultants, LLC (A\&E), Austin, Texas, the Center for Big Bend Studies (CBBS) at Sul Ross State University, Alpine, Texas, and Dr. Charles D. Frederick and his assistant, Brittney Gregory, of Dublin and Denton, Texas, respectively. Richard A. Weinstein, Vice President and Senior Archaeologist at CEI's main office in Baton Rouge, Louisiana, served as Principal Investigator for the project and directed the first phase of fieldwork. He also served as a coordinator between CEI and several of the subcontractors hired to conduct special analyses. Mr. Weinstein also served as editor of the present report and authored or co-authored several of its chapters. Ms. Jennifer A. Kelly, of CEI's office in Corpus Christi, Texas, served as Project Archaeologist for the fieldwork and doubled as operator of the total station. She later returned to the site in September 2013 to aid in excavation and mapping of the final backhoe trench. Ms. Kelly also coauthored part of Chapter 2 of the current study and helped format and prepare the draft final report for printing. Ms. Sally A. Morehead, also of CEI's Corpus Christi office, Mr. Patrick Brogan of CEI's Baton Rouge office, and Ms. Stephanie McKernan of Houston, Texas, served as CEI's Archaeological Field Technicians. Ms. Morehead subsequently served as Laboratory Director at CEI's archaeological laboratory in Cor- 
pus Christi. As such, she oversaw and aided in the initial phases of artifact and material processing. Ms. Morehead also drafted many of the plan views and wall profiles of the witness columns and block excavations, and photographed most of the artifacts illustrated in Chapter 11.

Two individuals from A\&E were instrumental in helping with the fieldwork. Rodney "Bo" Nelson of Pittsburg, Texas, served a Crew Chief for the duration of the work, while Dr. Shawn Marceau of Austin, Texas, joined the field team as another Crew Chief during the latter part of the work. Richard Walter of CBBS served as a Crew Chief during much of the first phase of fieldwork. As noted, Dr. Charles D. Frederick served as the project's Geoarchaeologist, while Brittney Gregory acted as Dr. Frederick's assistant throughout the fieldwork and later in Dr. Frederick's laboratory in Dublin. Dr. Frederick and Ms. Gregory subsequently returned to the site in September 2013 to oversee excavation of the final backhoe trench. Dr. Frederick also authored Chapter 9 and drafted all of the trench profiles shown in Chapter 6 along with all of the profiles and figures in Chapter 9.

In addition to the field crews, numerous individuals contributed both their time and expertise to the completion of this research, and the editor would like to acknowledge them at this point. Dr. James T. Abbott of TxDOT's Environmental Affairs Division, Austin, oversaw the project for that agency and provided CEI with all previous information related to the site, including his 2011 report on TxDOT's trenching. Dr. Abbott's report has since been employed in the present study as part of Chapter 2 and all of Chapter 5. Dr. John W. Arnn, also with the Environmental Affairs Division, Austin, offered helpful suggestions and guidance during the course of the project. Both Drs. Abbott and Arnn visited the field crew on numerous occasions and subsequently provided comments to the Interim Report. Dr. Abbott also provided comments to the draft final.

The editor would be remiss if he didn't thank Mr. Frank Sprague, owner of the Sprague and Upper Sprague sites situated just upstream form 41HM61. Mr. Sprague not only gave the editor and Drs. Abbott, Arnn, and Frederick a tour of those sites, but he also graciously allowed CEI to store much of its equipment in a storage shed on his property. Mr. Sprague also visited the field crew on several occasions during the fieldwork and provided information on other sites in the area.
As noted, several subcontractors were engaged in conducting special studies following completion of the fieldwork. Principal among these was Dr. Timothy K. Perttula, owner of A\&E, Austin. Dr. Perttula served as a Project Archaeologist during the first WA and preparation of the Interim Report, and subsequently served as Lithic Specialist during analysis and preparation of the present report. Dr. Perttula initially analyzed the patterned tools recovered as part of the lithic assemblage from the site and later co-authored Chapter 11. Dr. Perttula also conduced a considerable amount of research in order to prepare all of Chapter 4 and most of Chapter 3, regarding previous archaeological investigations in the vicinity of site 41HM61 and the prehistoric cultural setting of central Texas, respectively. Dr. Robert Z. "Zac" Seldon of Stephen F. Austin University, Nacogdoches, Texas, joined Dr. Perttula in preparing much of Chapter 3.

Dr. Evan Peacock, of the Cobb Institute of Archaeology at Mississippi State University (MSU), Starkville, Mississippi, oversaw analysis of selected samples of terrestrial and aquatic snails recovered from features and occupation levels at the site. Dr. Peacock, along with MSU students Ms. Sarah K. Gilleland and Ms. Mary Madden, co-authored Chapter 15 on the results of the snail analysis and created Appendix F. Ms. Tracy Glyn Popejoy, of the University of North Texas in Denton, Texas, conducted the analysis of selected samples of freshwater mussel shells also collected from features and occupation levels at the site. Along with Dr. Charles R. Randklev of the Institute of Renewable Natural Resources, Texas A\&M University, College Station, Texas, and Dr. Steve Wolverton of the University of North Texas, Ms. Popejoy authored Chapter 14 and produced Appendix E.

Ms. Susan L. Scott of Jackson, Scott and Associates, LLC, Hattiesburg, Mississippi, conducted analysis of the vertebrate faunal remains recovered from the site. Ms. Scott authored Chapter 13 on the results of that analysis. Dr. Leslie L. Bush of Macrobotanical Analysis, Manchaca, Texas, analyzed samples of floral material obtained from selected features and occupation levels at the site. Ms. Bush authored Chapter 12 on the results of such analysis.

Drs. Douglas Kennett and Brendan Culleton performed the collagen extraction and XAD purification on select bone samples included among the radiocarbon data discussed in Chapter 10. Once prepared at the Human Paleoecology and Isotope Geochemistry Laboratory at Pennsylvania State University, these samples were processed at the Keck Carbon Cycle 
Accelerator Mass Spectrometer Laboratory at the University of California, Irvine. Other samples were processed at Beta Analytic, Inc., Miami, Florida, under TxDOT's service agreement with that facility.

Lastly, this project could not have been completed without the aid of several other members of CEI's professional staff. Foremost among these individuals is Dr. Jon C. Lohse, of CEI's office in Houston, Texas. Dr. Lohse served as Project Archaeologist during the analysis and report-preparation phases of the current study. As such, he reanalyzed the patterned lithic tools and also analyzed all of the other core-derived tools found at the site, and subsequently served as a co-author of Chapter 11. Dr. Lohse also took on the added tasks of co-authoring Chapter 3 on the overview of the region's culture history and overseeing most of the radiocarbon analyses conducted by Beta Analytic, Inc., Pennsylvania State University, and the University of California, Irvine. As such, Dr. Lohse authored Chapter 10 on the results of the radiocarbon dating. $\mathrm{He}$ also co-authored the final chapter that summarizes the potential importance of site 41HM61 in the archaeology of central Texas and provides avenues for future research at the locale.

Other members of CEI's staff contributed to the successful completion of the current project. Mr. Sean R. Nash, Project Archaeologist at CEI's office in Corpus Christi, analyzed the debitage from the site and co-authored Chapter 11. Mr. Nash also drew the profiles of the lithic artifacts illustrated in that chap- ter. Ms. Kelly M. Ervin, GIS Specialist in Corpus Christi, created all of the GIS-based figures used in the report, particularly the contour map of the site and all subsequent figures utilizing that map as a base. Ms. Heather Perez initially worked as a Laboratory Technician at CEI's office in Corpus Christi, but later took over the role of Laboratory Director at that office. She either directed or helped conduct all of the flotation processing, plus all of the washing, sorting, and cataloging of the material recovered from the site. Ms. Perez also was instrumental in preparing the draft final report by correcting and/or modifying several of the figures, formatting most of the tables, and generally preparing the report for printing. Several individuals served as Archaeological Laboratory Technicians at CEI's Corpus Christi office during the course of the project. Included were Ms. Kaitlyn Frederick, Ms. Veronica Garcia, Mr. Jared Pringle, Mr. Alejandro "Alex" Lopez, and Mr. Antonio "Tony" Lichtenberger. Mr. Donald G. Hunter of CEI's Baton Rouge office was responsible for layout and final report production.

Finally, the editor would like to express his gratitude to Mr. Paul D. Bundy, Director of Operations and Principal Investigator at the Shreveport, Louisiana, office of Cultural Resource Analysts, Inc., for providing a copy of the report detailing excavations at the Keller site in Dearborn County, Indiana. That site contained a pit feature very similar to the potential mussel-steaming pit (represented by Features 19 and 20) found at site 41HM61. 


\title{
Chapter 1
}

\section{INTRODUCTION}

\author{
Richard A. Weinstein \\ Jon C. Lohse
}

This study presents the results of test excavations conducted to evaluate the potential of site 41HM61 for inclusion in the National Register of Historic Places (NRHP). The site is located on both the north and south sides of the current channel of the Leon River about $10 \mathrm{~km}$ north of Hamilton, Texas, at the crossing of the U.S. Highway 281 bridge over the river (Figures 1-1 and 1-2). Research at site 41HM61 was driven by the need to replace the existing bridge, which originally had been constructed in the early 1950s, with a newer, improved structure (CSJ 0251-01-058). At the time of the fieldwork, replacement of the bridge was to occur within a few years. However, that schedule has since been changed and construction of the new bridge has been delayed until 2060 .

The site initially was discovered by personnel from the Texas Department of Transportation (TxDOT) during the excavation of 14 backhoe trenches at the bridge crossing to determine if any potentially significant cultural remains were present within the U.S. 281 right-of-way (ROW) (Abbott 2011). Although evidence of prehistoric cultural activity was uncovered within six of the TxDOT backhoe trenches, it was unknown at the time whether such material was in situ within the ROW or whether it had eroded out of two nearby archeological sites situated just upriver and washed downstream to the bridge crossing. Accordingly, archaeologists from Coastal Environments, Inc., (CEI) were asked to conduct additional testing to determine if the cultural remains were in situ, and, if they were in situ, to investigate the site's potential NRHP eligibility. As noted in the Preface and Acknowledgments, fieldwork for the project took place in two phases, with the bulk of the investigations occurring between September 12 and November 19, 2011. A limited amount of additional backhoe trenching followed almost two years later, between September 10 and 12, 2013.

Importantly, although the length of the bridge structure itself measures ca. $250 \mathrm{~m}$ in a roughly northsouth direction, the TxDOT investigators chose to extend their search area within the highway ROW beyond both the north and south ends of the bridge for additional distances of ca. 90 and $190 \mathrm{~m}$, respectively. ${ }^{1}$ This brought the overall length of investigated highway ROW to ca. $525 \mathrm{~m}$. Since the southern portion of the ROW (between TxDOT BT 14 and the south bridge abutment) averaged about $47 \mathrm{~m}$ in width, while the northern portion of the ROW (from the south bridge abutment north to TxDOT BT 5) averaged about $70 \mathrm{~m}$ in width, the total area examined by the TxDOT investigations covered ca. 32,170 square meters. Nevertheless, much of that ROW north and south of the actual bridge included the highway and its raised embankment, thus limiting TxDOT's search in those areas to the terrain between the bottom of the road embankment and the east and west edges of the ROW. Under the bridge, however, there was no impediment to trenching, save for the bridge's bents, so trenches in that area could be placed across the entire width of the ROW. Regardless of the overall TxDOT search area, no formal "Area of Potential Effect"

TxDOT's BT 1 was positioned so far to the north of BT 5 (ca. $450 \mathrm{~m}$ ) that it was not included in identification of the horizontal APE. 


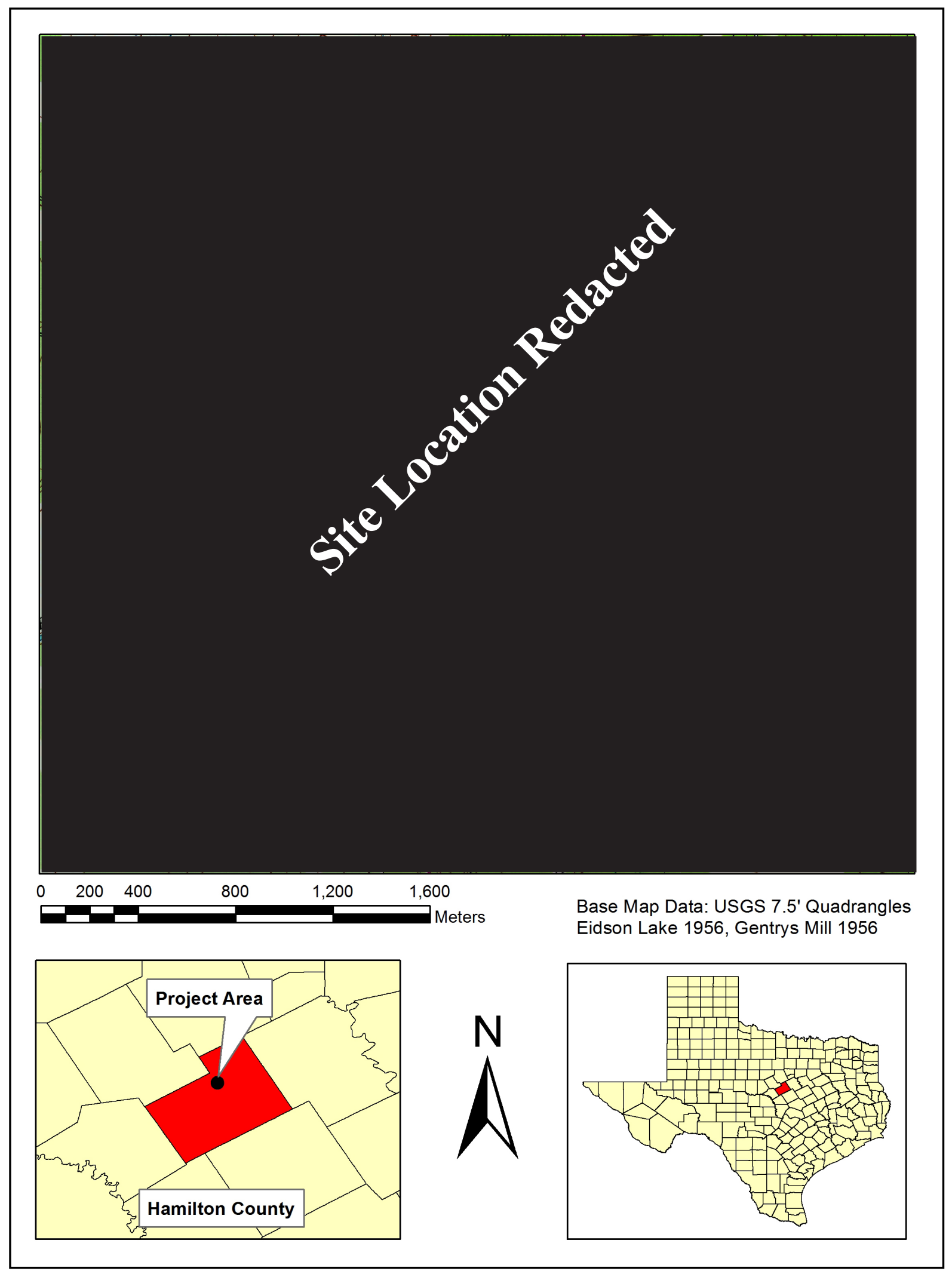

Figure 1-1. Current project area shown on 1956 7.5-minute topographic quadrangle maps. Note that the maps were created prior to the channelization of the Leon River, such that the river is shown within its former course. This may provide a good indication of the site setting during the latest prehistoric occupation. 


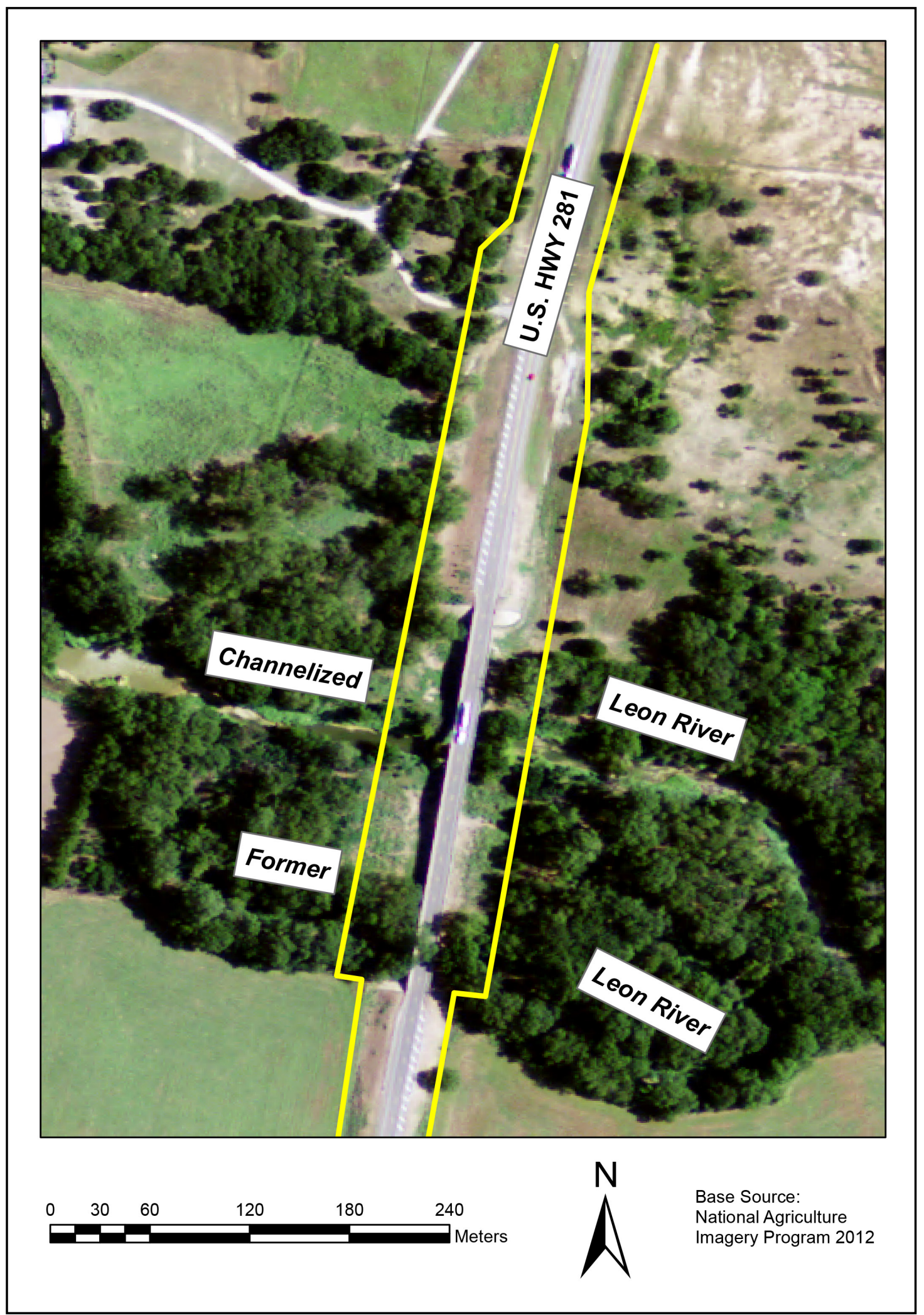

Figure 1-2. Detailed aerial photograph of the current project area showing the TxDOT ROW along U.S. Highway 281. Both the existing (channelized) and former (natural) channels of the Leon River are visible. 
(APE) had been defined prior to CEI's investigations Thus, the area examined by TxDOT served as the horizontal extent of the APE for the CEI testing project. As such, information derived from the 14 TxDOT trenches was employed by CEI to determine where to conduct its investigations in order to help delineate the overall size and integrity of site 41HM61. Vertically, the APE was considered to extend from the ground surface to a depth equivalent to the deepest holes that would be dug for the new bridge bents, roughly $-25 \mathrm{~m}$. Since current investigations were limited to the depth to which a backhoe could reach, CEI's excavations occurred only within the extreme upper portion of the vertical APE.

The current testing project was sponsored by the Environmental Affairs Division of TxDOT under Contract Nos. 57-1XXSA004 (Work Authorization [WA] No. 57-102SA004) and 57-3XXXSA001 (Work Authorization [WA] No. 57-302SA001) and Antiquities Permit No. 6023 (Richard A. Weinstein, Principal Investigator) from the Texas Historical Commission (THC). It was conducted in compliance with the National Environmental Policy Act (NEPA) of 1969, the National Historic Preservation Act, as amended (USC §470), as well as with other federal laws pertaining to standards and regulations associated with the protection and study of historic properties that may be affected by federal undertakings. These laws include, but are not limited to: Procedures of the Advisory Council on Historic Preservation (36 CFR 800); the National Historic Preservation Act of 1966, as amended (PL 89-665); the Archaeological Resource Protection Act of 1979 (16 USC $\$ 470$, aa-mm); and regulations governing the eligibility of properties for inclusion in the National Register of Historic Places (36 CFR 60.4). The study also was conducted in compliance with those Texas standards and guidelines related to the protection, landmark designation, and study of historic properties on state-owned lands, specifically the Antiquities Code of Texas (Texas Natural Resource Code, Title 9, Chapter 191), and Title 13, Chapter 26, of the Texas Administrative Code, plus those guidelines set forth by the Council of Texas Archeologists that have been adopted by the THC.

Exhibit A of the WA provided specific requirements for the testing project. These requirements included two main tasks: (1) Field Investigations and (2) Preparation of an Interim Report. Included in the first task was preparation of documents needed to obtain the Antiquities Permit (Task 1, Deliverable 1). Other aspects of Task 1 concerned the actual field investigations and encompassed three subtasks:
[Subtask 1.] Conduct mechanical trenching totaling at least 70 linear meters, placed to maximize exposure and reveal buried features (if present). Placement of trenches shall be according to [CEI's] professional judgment; however, trenching shall be concentrated in the general vicinity of the State's positive trenches (BT $4,8,910,11 \& 12)$, the general locations of which have been previously provided to $[\mathrm{CEI}]$. Trenches shall be at least $1.5 \mathrm{~m}$ and no more than $2.5 \mathrm{~m}$ deep, and shall be benched as necessary for OSHA compliance. Excavation shall be monitored by at least two archeologists and utilize a wide (at least 30 inch), smooth-bladed bucket. [CEI] shall clean the walls as necessary to identify zones of stratified cultural material, document and sample as warranted to document the stratigraphy, and map the trench locations [Texas Department of Transportation 2011].

[Subtask 2.] [CEI] shall excavate a minimum of eight $50 \times 50 \mathrm{~cm}$ witness columns down the walls of the exposed trenches. Individual witness columns may be offset as needed to accommodate benching, and shall be placed to optimally document natural and cultural stratigraphy. All hand-excavated sediments shall be dry screened through 1/4" hardware mesh [Texas Department of Transportation 2011].

[Subtask 3.] Based on the results of trenching, geoarcheological investigations, and the witness columns, [CEI] shall target identified cultural zones and features for additional hand investigation with small groups of $1 \times 1$ hand units (typically $1 \times 2$ or $2 \times 2 \mathrm{~m}$ ). Hand units shall be allocated according to [CEI's] professional judgment to acquire an adequate sample of recognized cultural strata. Total hand excavated volume, excluding the witness columns, shall be between $12 \mathrm{~m}^{3}$ and $16 \mathrm{~m}^{3}$. [CEI] shall mechanically strip the overburden from each hand unit in order to limit the thickness of individual test units and target occupational zones and features. If [CEI] comes to believe that the allocated volume is either excessive due to low initial return, or is not sufficient to adequately evaluate the site, they shall notify the State immediately 
so that changes to the level of effort can be made (if the State agrees) while [CEI's] crew is in the field. The locations of all trenches and hand excavation units shall be mapped with a total data station, and documentation shall be sufficient to satisfy THC standards [Texas Department of Transportation 2011].

As noted, Task 2 included preparation of an Interim Report: "[CEI] shall complete preliminary analysis of the recovered artifact assemblage and prepare an interim report in accord with the provisions of Attachment B, Section 2 of the contract. The level of analysis conducted shall be sufficient to document the work performed, make an informed recommendation regarding the NRHP eligibility and SAL status, and (if appropriate) provide sufficient data to plan effectively for data recovery." (Texas Department of Transportation 2011). The Interim Report (Weinstein et al. 2012) was submitted to TxDOT several months following completion of fieldwork and it provided the basis of the current, more detailed report.

The current report describes the field methods utilized during CEI's investigations at site 41HM61, and also the results of those investigations. These discussions are contextualized by a brief overview of the regional environment and geology (Chapter 2) and cultural sequences (Chapter 3), as well as a summary of previous investigations conducted at several nearby sites (41HM43, 41HM51, and 41HM54) (Chapter 4). Results of TxDOT's previous trenching and other prior work at the site are presented in Chapter 5. Chapters 6 through 9 present different phases of investigation at 41HM61, including mapping and additional trenching (Chapter 6), excavation of witness columns located on the edges of the trenches (Chapter 7), expanded block excavations at or near certain witness columns (Chapter 8), and additional geological investigations, including one deep trench (Chapter 9). Following chapters present the results of different analyses of recovered remains. Chapter 10 presents the results of the radiocarbon dating, while Chapter 11 reviews and discusses the results of analyses of the small assemblage of chipped stone tools from the site. Chapters $12,13,14$, and 15 present the analytical results for charred plant remains, vertebrate fauna, freshwater mussels, and terrestrial and aquatic gastropods, respectively. Chapter 16 offers an overview discussion of the nutritional value of certain archaic foodstuffs commonly found in open alluvial sites in Texas. Lastly, Chapter 17 presents a summary of the findings of this project as well as recommendations for any future work.

Based on the results of the fieldwork and the subsequent analyses conducted relative to site 41HM61, CEI concludes that the locale contains information capable of making important contributions to our understanding of local, regional, and statewide prehistory. Deposits in this alluvial floodplain context demonstrate exceptional stratigraphic integrity, thereby making possible highly resolved interpretations of past cultural activities that were carried out there. Although none of the cultural components identified at the site is extensive in terms of volume of material it contains, the geomorphic integrity is such that most time periods can be distinguished from other periods with high degrees of confidence and analytical precision. Additionally, the presence of well-preserved subsistence remains and other organics means not only that dietary and environmental information are available at 41HM61, and presumably at other similar sites, but also that these sequences can be precisely and accurately dated by radiocarbon means given the proper protocols for selecting and interpreting samples. Occupations documented at the site include components of the Late Prehistoric through late Middle Archaic periods. Furthermore, since CEI's excavations did not reach the demonstrated bottom of alluvial deposits at the site, it is possible that cultural material from yet earlier periods remains to be documented. 


\title{
Chapter 2
}

\section{Environmental Setting}

\author{
James T. Abbott \\ Jennifer A. Kelley
}

This chapter provides brief background information on the environment and geology of the central Texas region in which site 41HM61 is located, with specific attention paid to the Leon River valley and Hamilton County. The geology section is a slightly revised version of the initial portion of the "Introduction" prepared by Abbott as part of his 2011 report detailing TxDOT's backhoe trenching at the site.

\section{Environmental Background}

Hamilton County is located in central Texas about 114 miles north of Austin. Comanche, Erath, and Johnson counties border the county to the north, while Mills County is located to the west, and Lampasas and Coryell counties are situated to the south. The center of Hamilton County lies at $31^{\circ} 47^{\prime}$ north latitude, $98^{\circ} 13^{\prime}$ west longitude. The county covers 844 square miles, and has elevations that range between 900 and 1,600 ft above sea level (Leffler 2012). The average annual rainfall is 29.61 inches. While the average daily temperature in winter is $47^{\circ} \mathrm{F}$, in summer, daily temperatures average $82^{\circ} \mathrm{F}$ (USDA et al. 2007).

Hamilton County is located west of the Balcones Fault on lower Cretaceous carbonate rocks. The surface expression of the fault is the Balcones Escarpment, which forms the eastern boundary of the Texas Hill Country and the western boundary of the Texas Coastal Plain. The Leon, Lampasas, and Bosque rivers are the principal waterways draining Hamilton County, with many of their valleys bordered by limestone cliffs that abut the intervening flat divides (Goetz and Nelson 2009).
The project area is within the natural region that Gould et al. (1960) refer to as the Western Cross Timbers. Griffith et al. (2004, 2010) delineated the project area, as well as all of Hamilton County, as within the Limestone Cut Plain (Figure 2-1). Those authors refer to this as the Level VI Ecoregion, which is within the Level III Ecoregion identified as the Cross Timbers. The Limestone Cut Plain is characterized by "stair-step" topography due to the differential erosion of the underlying layers of limestone from the Lower Cretaceous Glen Rose and Walnut Clay formations. The resulting landscape is a series of broad mesas separated by stair-stepped valleys holding streams. The project area is located along the Leon River with an elevation in the immediate area ranging between 982 and 1,048 ft above sea level (Griffith et al. 2004).

According to Blair (1950), Hamilton County lies on the border between the Balconian and Texan biotic provinces (see Figure 2-2). Because of that, the flora and fauna in the county are typical of both the Balconian and Texan biotic zones. Many ecological niches exist in this area of intersecting zones, as does a mix of species from the Blackland Prairie to the east and the Edwards Plateau to the south. Grasslands are common on the upland surfaces, but oak scrub and juniper tend to cover the high upland surfaces. A variety of hardwoods exist along riparian zones. Tall grass dominates in the eastern part of Hamilton County and shorter grasses to the west. Before the days of fire suppression and agricultural development, little bluestem (Schizachyrium scoparium), big bluestem (Andropogon gerardii), Indian- 


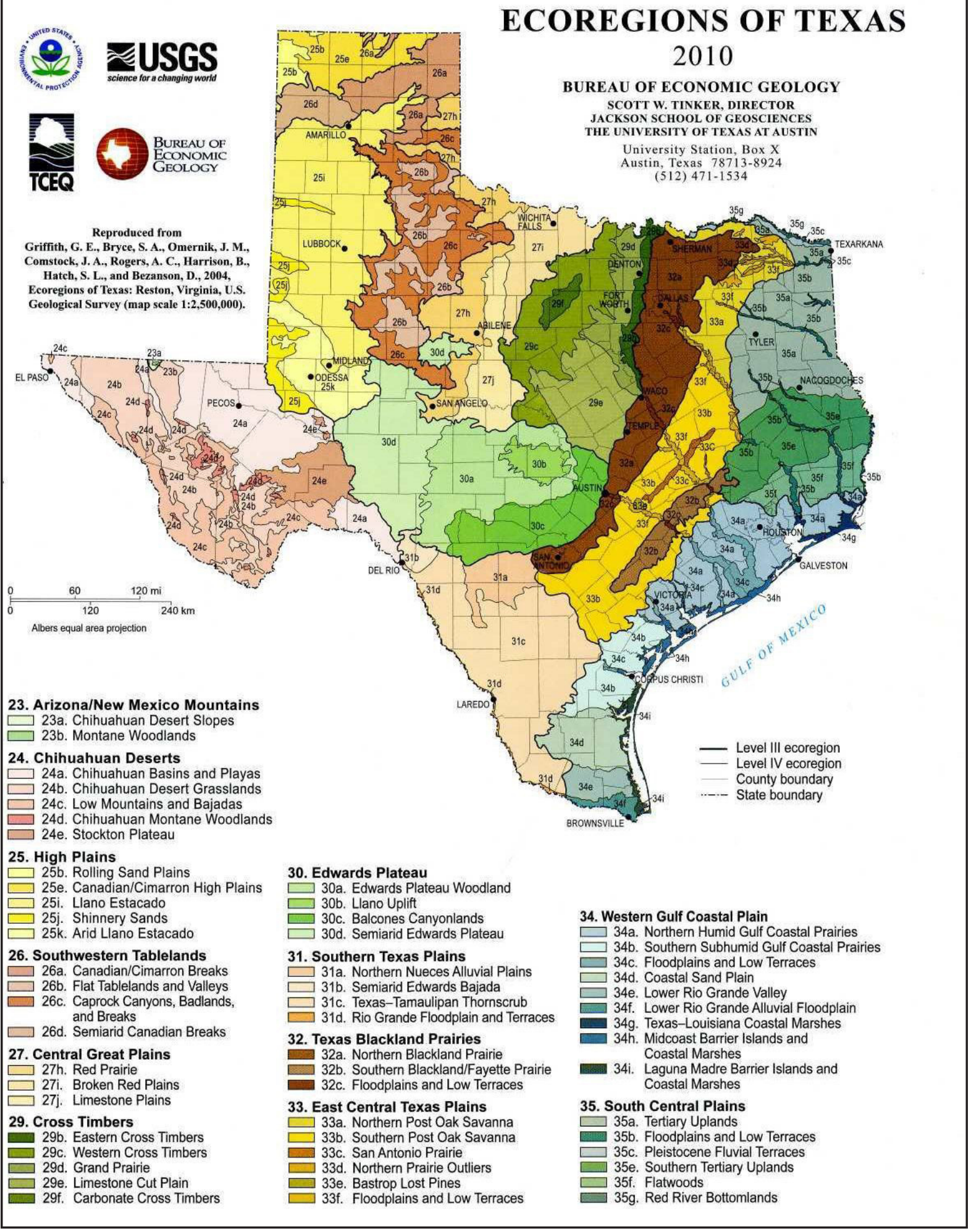

Figure 2-1. Map of the Ecoregions in Texas (after Griffith et al. 2010). Hamilton County is located in the Lampasas (Limestone) Cut Plain (29e) of the Cross Timbers Eco Region. 


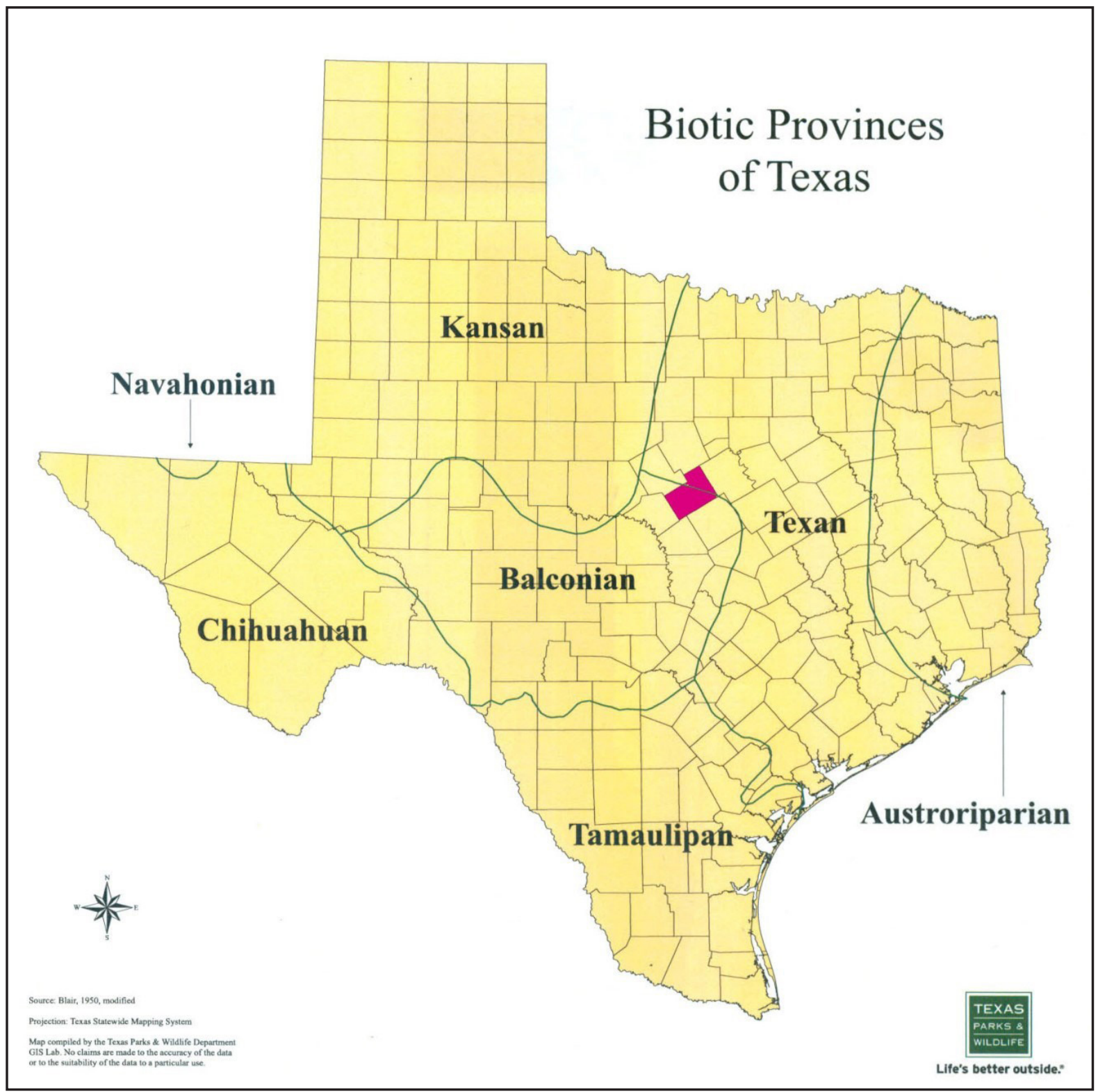

Figure 2-2. Map of the Biotic Provinces within Texas (after Blair 1950). Hamilton County (shown in red) is on the line between the Balconian and Texan provinces.

grass (Sorghastrum nutans), and tall dropseed (Sporobolus asper) dominated the uplands (Blair 1950).

Forested areas were mostly limited to draws and drainage areas, stream banks, and river valleys. Mapped vegetation (McMahan et al. 1984) consists of Oak-Mesquite-Juniper Parks and Woods in the lowlands and silver bluestem and Texas wintergrass grassland in the uplands. The actual distribution is somewhat more complex, with juniper-dominated woodlands and cleared agricultural fields and pastures common at all elevations. Today, invasive woody vegetation, such as honey mesquite (Prosopis glandulosa) and ash juniper (Juniperus ashei) is spreading rapidly throughout the uplands in the area. The bottomlands include pecan (Carya illinoinensis), black walnut (Juglans nigra), cottonwood (Populus deltoids), black willow (Salix nigra), American sycamore (Platanus occidentalis), and bur oak (Quercus macrocarpa) tree species. A large part of the region has been converted to cropland or improved pasture; however, this area still supports the largest area of native grass in Texas (Texas Forest Service 2008a, 2008b) (also see Chapter 12 for further discussion of the vegetation in the region). 


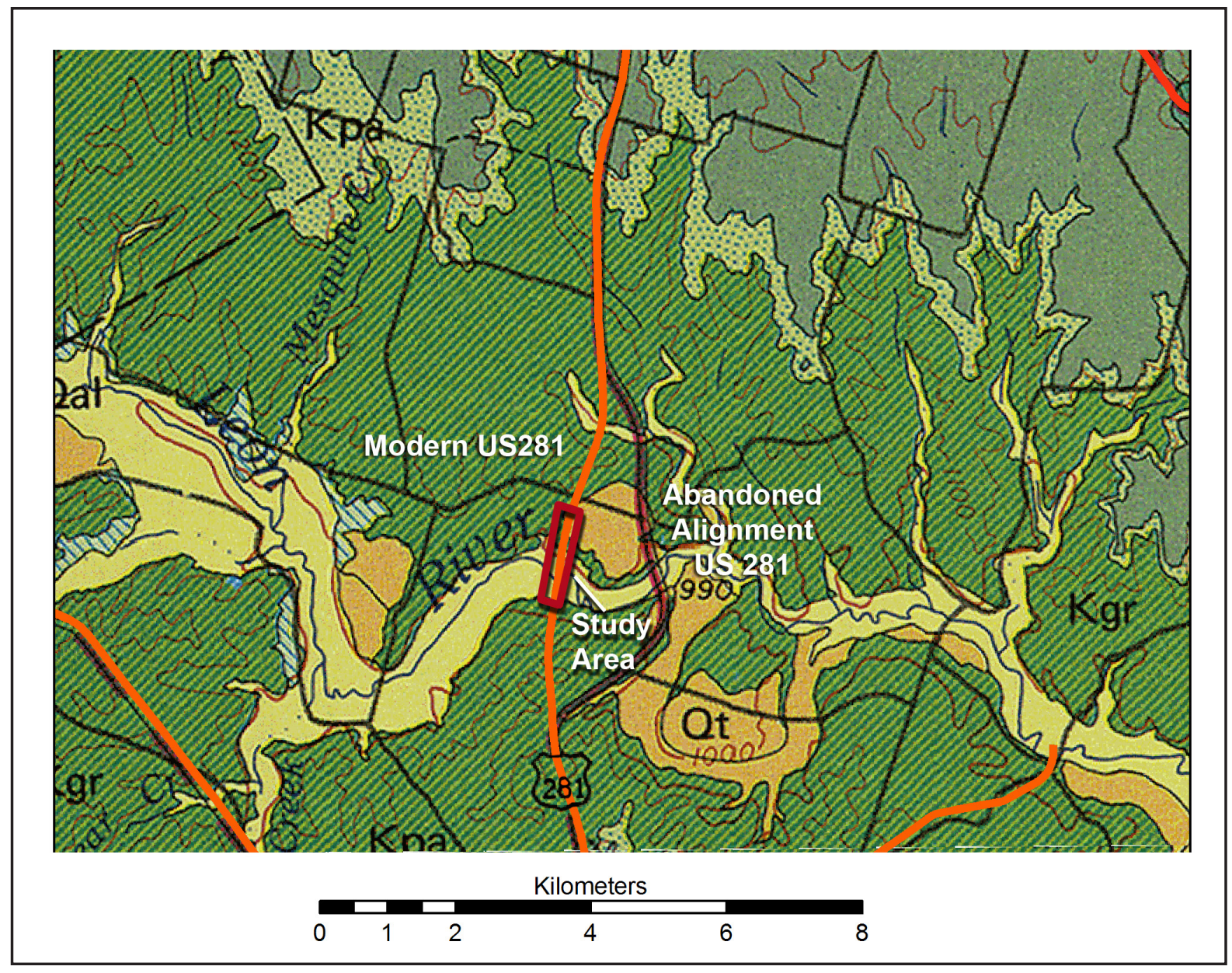

Figure 2-3. Location of the project area shown in relation to Geological Atlas of Texas (Brownwood Sheet). The modern highway alignment is superimposed for reference.

The Balconian faunal assemblage includes 57 species of mammals. Eight of these inhabit the Texan province to the east and the interconnecting riparian areas. Other native fauna include 36 species of snakes, 15 species of frogs, and 16 species of lizards. Prehistoric species once common to the area included bison (Bison bison) and pronghorn antelope (Antilocapra americana), most of which were killed off during historic times (Blair 1950:101).

\section{Geologic Context of Site Setting}

Northern Hamilton County, including the area surrounding site 41HM61, consists mainly of a two-tiered landscape that includes deflated upland plains and rich alluvial valleys, both underlain by Lower Cretaceous rocks (Figure 2-3). These rocks include, from oldest to youngest, the Glen Rose Formation (map unit Kgr); Paluxy Formation (map unit Kpa); Walnut Formation (map unit Kwa); Comanche Peak Limestone (map unit $\mathrm{Kc}$ ); and Edwards Limestone (map unit Kked). The valley is incised into the alternating limestones and marls of the Glen Rose Formation, and is ringed around the upper slopes by a thin band of the Paluxy sands. Limestones and clays of the Walnut Formation underlie the upland cut plain. Remnants of a higher upland surface are preserved as isolated high mesas underlain by the Comanche Peak and Edwards Limestones. Pleistocene fluviatile terrace deposits (map unit Qt) and recent alluvium (map unit Qal) are inset into the Glen Rose exposure (Barnes 1976).

The Leon River valley is one of the larger river valleys encountered along this stretch of U.S. Highway 281. At the highway crossing of the river, the Holocene-aged surface is approximately $725 \mathrm{~m}$ wide, and an associated high terrace of almost equal width is present on the north side of the valley. The valley exceeds $2 \mathrm{~km}$ in width where high terraces are well developed. These high terraces are part of a network 
of very large meanders entrenched into the bedrock (for example, note the large abandoned valley shown southeast of the study area in Figure 2-3) that appear related to the path of the ancestral Brazos River (Lewand 1969). This ancient river cut a broad, looping path across the Lampasas Cut Plain, strewing High Plains gravels ultimately derived from the Rocky Mountains. When the Brazos avulsed to the north some time in the middle-late Pleistocene, the much smaller drainage area of the Leon River limited discharge considerably, the stream became underfit, and the supply of siliciclastic rocks from the High Plains was cut off. As the stream continued to incise through the Late Pleistocene and Holocene, perched fill terraces lying from approximately 7-10 $\mathrm{m}$ to more than 20 $\mathrm{m}$ above the current stream were formed.

\section{Stratigraphic Geological Sequence}

The stratigraphic sequence of the Leon River was studied in detail by Nordt (1992) at Fort Hood, which lies approximately 30 miles to the southeast of the U.S. 281 river crossing. Nordt described four alluvial terraces in the Leon River valley, which he designated $\mathrm{T} 0, \mathrm{~T} 1, \mathrm{~T} 2$, and T3. One or more alluvial fills (allostratigraphic units) underlie these terraces and are termed (from oldest to youngest) the Reserve, Jackson, Georgetown, Fort Hood, West Range, and Ford alluvia (Figure 2-4). The oldest of these fills, and the only one that does not have equivalents on the smaller Fort Hood streams, is the Reserve alluvium, which underlies the T3 terrace at an elevation of approximately $21 \mathrm{~m}$ above the modern stream. Nordt (1992) notes that the Leon differs from the local streams in that it carries a mixed to siliceous load, and weathers "rather easily" into well-developed Alfisols. This is particularly true of the higher terraces, where Paleustalfs such as the Minwells series are developed. Nordt (1992:56, 60) describes the Reserve fill as "less than 2 $\mathrm{m}$ of soil-weathered sediments displaying A-E-Bt profiles with clay loam to sand clay loam subsoils" and notes that it rests on a bedrock strath. The Reserve fill occurs only in the Leon drainage, and is associated with the high terraces that Lewand (1969) interprets as remnants of the ancestral Brazos drainage. Nordt makes no interpretation of the age of the fill, other than that it is older than the subsequent Jackson fill.

Nordt's T2 terrace is situated approximately $16 \mathrm{~m}$ above the Leon River. It is underlain by the Jackson alluvium, a mixed siliceous/calcareous fill that has a rubified and substantially decalcified A-Bt or A-EBt soil with an occasional discontinuous petrocalcic horizon. Sediments making up the unit are relatively equally divided between channel and overbank facies, and Nordt speculates that they may represent more than one phase of activity. On the basis of one radiocarbon age, Nordt estimates the age of the Jackson alluvium at approximately 15 thousand years ago (ka).

Nordt's T1 terrace on the Leon River lies approximately $1.5 \mathrm{~m}$ above the existing floodplain (T0) and 8.5 to $9 \mathrm{~m}$ above the modern stream. It is underlain by sandy alluvium that either represents the Georgetown fill (which does not crop out at the surface in any of the other streams) or an alluvial strath cut into the margin of the Jackson fill. Regionally, the Georgetown is capped by a buried soil, termed the Royalty Paleosol, but this buried soil does not occur in the Leon River valley in Nordt's study area. Stratigraphic position and radiocarbon ages bracket the deposition of the Georgetown unit between the end of a widespread incision event that abandoned the T2 surface around 15 ka-11 ka, and renewed downcutting that abandoned the Royalty Paleosol around 8.2 ka.

The T0 terrace is the most complex of Nordt's surfaces in the Leon River valley, and is underlain by three distinct alluvial fills composed primarily of loam, clay loam, clay, and gravel. The oldest of these, the Fort Hood fill, is a relatively fine-grained sequence characterized by sediments that are brown (typically 7.5YR hues) and exhibit soils with A-Bk profiles. It is dated to between approximately 8200 and 5000 B.P. The next younger unit, the West Range unit, is often somewhat more gravelly, and exhibits generally darker grayish brown colors (typically $10 \mathrm{YR}$ to $2.5 \mathrm{Y}$ hues) with A-Bk profiles. It is subdivided into older and younger members dated to between approximately 4300 and 2400 B.P. and 2800 and 600 B.P., respectively (note the overlap). Although both units aggraded to approximately the same elevation in the Leon River valley (and are therefore laterally inset beneath the T0 surface), on other streams the equivalent units form one or more terraces (typically termed $\mathrm{T} 1$ and $\mathrm{T} 1 \mathrm{~A} / \mathrm{T} 1 \mathrm{~B}$, respectively). The difference in color between the Fort Hood and West Range fills is attributed primarily to the contribution of rubified sediments as upland soils were eroded during the early-middle Holocene (Nordt 1993).

The final unit that underlies the T0 terrace is termed the Ford alluvium, and dates to the period more recent than approximately 600-800 B.P. On the Leon River, Nordt (1992) suggests that this unit overlaps and buries both the Fort Hood and West Range units (see Figure 2-4), while in other contexts on Fort Hood it underlies a lower inset floodplain. Soil development 


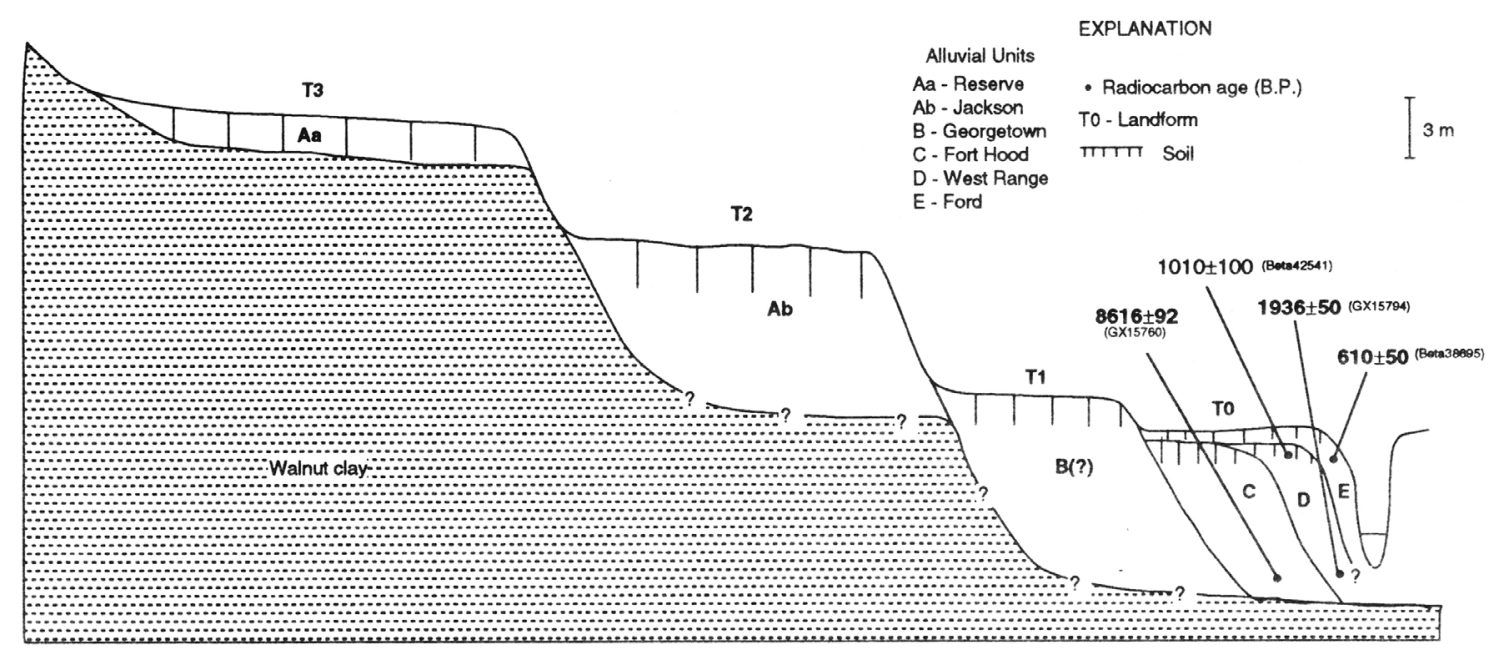

Figure 2-4. Stratigraphy of the Leon River at Fort Hood (adapted from Nordt 1992).

in the unit is relatively limited; although A-Bk profiles are common, preserved primary stratification is also frequently observable. Sediments are typically yellowish brown to grayish brown (10YR hues).

\section{Soils of the Project Area}

Figure 2-5 illustrates the soils mapped in the vicinity of the project area based on an earlier assessment by TxDOT staff. Important soils include Bosque clay loam, which is rarely flooded (map unit Bo) and mapped on the $\mathrm{T}_{0}$ and $\mathrm{T}_{1}$ terraces; Bastsil loamy fine sand with 1- to 3-percent slopes (map unit $\mathrm{BaB}$ ) and which developed on poorly expressed $T_{2}$ terraces northeast and southwest of the ROW corridor; Rumley clay loam with 1- to 3-percent slopes (map unit RuB); Krum silty clay with 1- to 5-percent slopes (map unit $\mathrm{KrB}$ ); Riesel gravelly fine sandy loam (map unit RsC) on the upper $\left(\mathrm{T}_{3}\right)$ terraces; and Brackett gravelly clay loam (map unit BtE) and Real-Doss complex on the valley side slopes.

Bosque soils are Cumulic Haplustolls (Mollisols) exhibiting a typical Ap-A1-A2-Bw-Akb profile formed in loam, clay loam, and clay. They do not always exhibit the buried soil, but carbonate filaments are common through the section. Nordt identifies the Bosque series as typical of the Ford alluvium, West Range alluvium, and sometimes the Fort Hood alluvium.
Bastsil soils are Udic Paleustalfs (Alfisols) and exhibit a typical A-E-Bt1-Bt2-Bt3-Bt/E profile formed in siliceous or mixed alluvium. The degree of soil development expressed by Bastsil soils is greater than would be expected for early Holocene sediments, so it is likely that the soil represents weathering of Jackson alluvium. Nordt notes that the Jackson fill on Fort Hood is typically mapped as Lewisville, but that equivalent terraces on the Leon are characterized by Minwells series. Both Bastsil and Minwells soils are characterized by strongly developed, thick, dark red argillic horizons reflecting weathering of siliceous load; however, Minwells soils also have secondary carbonate horizons at depth, possibly reflecting more pervasive input of calcareous sediment.

The soils mapped on the high $\left(\mathrm{T}_{3}\right)$ terrace include the Krum, Riesel, and Rumley series. Krum and Rumley soils are Mollisols (Udertic Haplustolls and Udic Calciustolls, respectively), while Riesel soils are Udic Paleustalfs (Alfisols). Krum soils exhibit a typical A-Bw-Bk1-Bk2 profile developed silty clay that grades from grayish brown (10YR hues) to reddish yellow (7.5YR hues) with depth. Carbonate morphology is late Stage II (Machette 1985), with common hard concretions and soft powdery masses. Rumley soils are typified by an Ap-A-Bk1-Bk2-Bk3Bk4 profile developed in silty clay loam and silty clay. Like Krum soils, color grades from grayish 


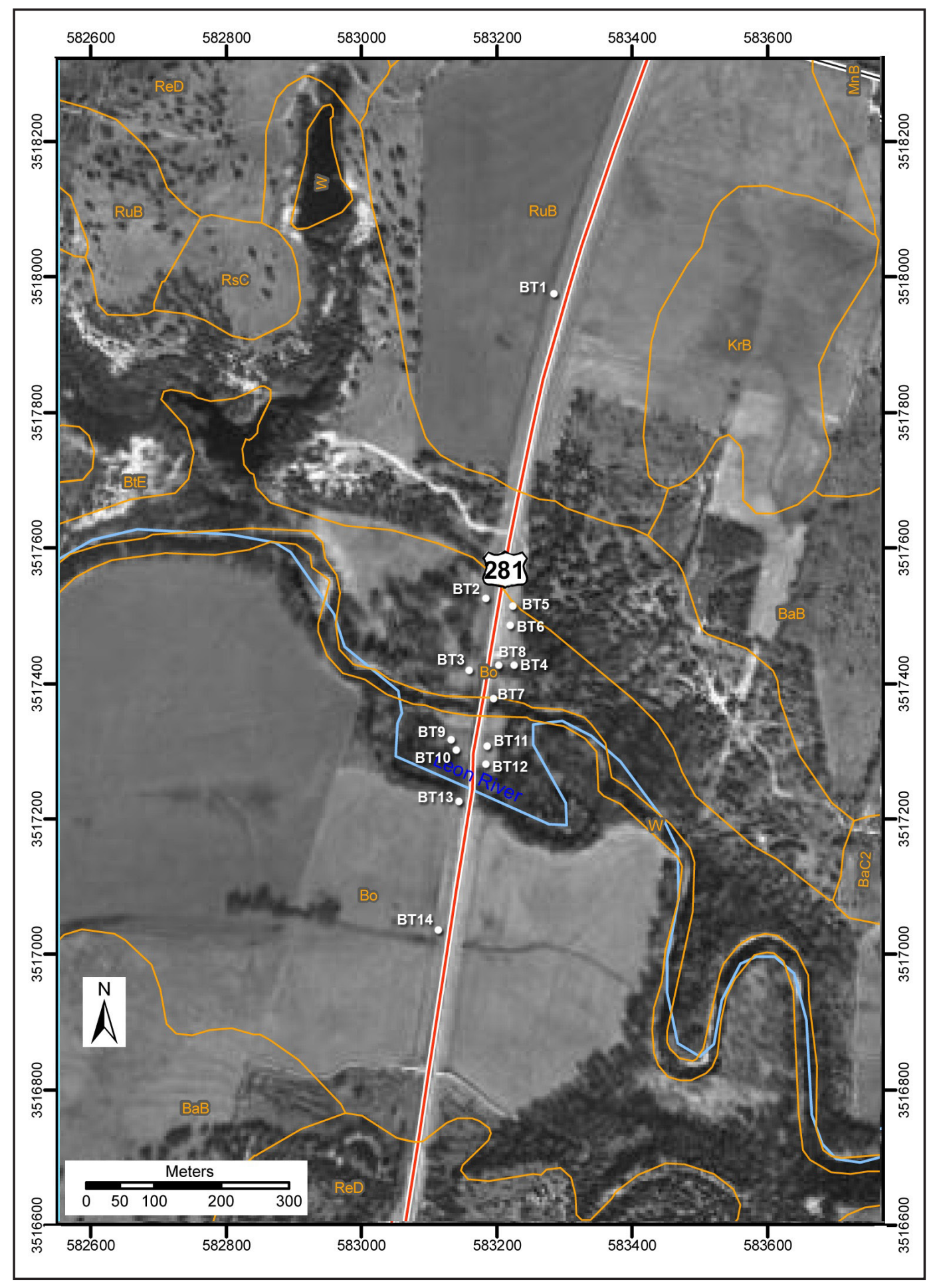

Figure 2-5. Soil map of the study area, adapted from the USDA web soil survey, with TxDOT trench locations (see Chapter 5) superimposed. Key: BaB-Bastsil loamy fine sand, 1- to 3-percent slopes; $\mathrm{BaC} 2$-Bastsil fine sandy loam, 2- to 5-percent slopes, eroded; $\mathrm{Bo}-$ Bosque clay loam, rarely flooded; $\mathrm{BtE}-$ Brackett gravelly clay loam, 8- to 30-percent slopes; DnB -Denton silty clay, 1- to 3-percent slopes; $\mathrm{KrB}$-Krum silty clay, 1-to 5-percent slopes; $\mathrm{MnB}$ - Minwells fine sandy loam, 1- to 3-percent slopes; ReD-Real-Doss complex, 1- to 8-percent slopes; RsCRiesel gravelly fine sandy loam, 1- to 5-percent slopes; RuB - Rumley clay loam, 1- to 3-percent slopes. 
brown to reddish yellow with depth, but carbonate is even more common (concretions make up as much as 30 percent of the volume of the lower Bk horizons).
Reisel soils exhibit a typical A-E-Bt1-Bt2-2C profile that grades from sandy loam to red gravelly clay, then into gravelly sand. 


\section{Chapter 3}

\section{Cultural Setting of THE LEON River BASIN

\author{
Timothy K. Perttula \\ Robert Z. Selden, Jr. \\ Jon C. Lohse
}

This chapter discusses the prehistoric cultural setting of the Leon River basin generally, and the Hamilton County area specifically, within the Lampasas Cut Plain of the central Texas archeological region (Collins 2004:Figure 3.4a). This is accomplished primarily through an examination of certain facets of the archeological record obtained over more than 35 years of investigations at Fort Hood in Bell and Coryell counties in the Leon River basin (see Barrett et al. 2007). Fort Hood is about $50 \mathrm{~km}$ to the southeast of site 41HM61 and serves as a convenient source of information for modeling and understanding regional culture prehistory. Additionally, however, and in order to overcome some of the limitations of the Ft. Hood data, the regional record is reconciled with new models for understanding Middle Archaic to Late Prehistoric culture and chronology in central Texas based, on an analysis and review of select radiocarbon data from the region (Lohse et al. 2014a) and also on a directly dated record of bison exploitation in central Texas (Lohse et al. 2014b, 2014c).

The purpose of combining these datasets is to help enhance the resolution of the regional sequence through the application of newer, somewhat improved sample-selection and dating-consideration protocols than have typically been applied in the study area. From CEI's perspective based on the testing at site 41HM61 and similar sites located in active alluvial floodplains, such locales have the significant potential to help improve the accuracy and precision of existing regional cultural models. Indeed, this kind of potential may presently be among the most significant research opportunities afforded by such sites, since their artifact and cultural feature content tends to be moderate to low. However, this potential can best be realized by recognizing certain limitations inherent in working with extant radiocarbon data and also by clearly understanding how newly derived radiocarbon data can be improved upon.

\section{Regional Archeological Setting as Seen from Fort Hood}

More than 1,110 prehistoric sites have been recorded at Fort Hood since the 1970s (Richard S. Jones, personal communication 2011), which is a very large site database for the central Texas archeological region. Beyond the extensive archeological surveys that have occurred in the region, there have been a number of more expansive investigations that include: (1) site assessments (Trierweiler 1994); (2) test excavations (Carlson 1993a, 1993b); (3) test excavations and geoarcheological investigations (Abbott and Trierweiler 1995; Arnn et al. 2000; Carlson 1997; Mehalchick and Kibler 2005; Mehalchick et al. 2000, 2002, 2003a, 2003b, 2004; Trierweiler 1996); (4) test excavations in conjunction with geophysical investigations at a variety of sites, including rockshelters (Simpson 2008, 2011; Simpson and Peterson 2004); and (5) data recovery at a few sites (Carpenter et al. 2010; Mehalchick et al. 2004; Zeidler 2004). Campbell and Johnson (2004) have also developed a temporal predictive model for archeological sites in the Cowhouse Creek drainage at Fort Hood.

There are a number of existing documents for Fort Hood projects that provide basic archeological backgrounds as well as research contexts concerning the prehistoric and early historic hunter-gatherer groups 
that foraged across the Leon River landscape (e.g., Mehalchick et al. 2004; Simpson 2011). In addition to these published archeological investigations, the Fort Hood Cultural Resource Management Program has compiled a series of databases regarding certain characteristics of the archeological record on the fort; in this chapter we use some of the information in these databases to discuss the archeological setting in the Leon River basin, a setting episodically occupied by hunter-gatherers.

\section{Fort Hood Temporal Intervals}

The temporal context for this consideration of the Fort Hood archeological record is derived from Collins et al. (2011:Figures 3-13), who explore the temporal and geographic distribution ("realms") of projectile points across Texas. ${ }^{1}$ Collins et al. (2011) divide the prehistoric and early historic record into 11 temporal intervals, which we have labeled A through $\mathrm{K}$ (Table 3-1). Age ranges assigned to these intervals by Collins et al. (2011) follow generally from earlier chronology syntheses (e.g., Collins 1995, 2004), and are presented in calibrated years B.P. We correlate these realms with the database of almost 400 radiocarbon dates from Ft. Hood in order to use the Ft. Hood radiocarbon database to understand the regional expression of culture historical sequences outlined by Collins et al. (2011) (at the request of the Ft. Hood cultural resources staff, none of their databases are reproduced here). To do this, Ft. Hood assays were first calibrated using the IntCal13 curve (Reimer et al. 2013) and then were assigned to these temporal intervals based on the median age of the calibrated radiocarbon date B.P. Working with massive databases of radiocarbon data in this manner can be a useful way of reconstructing, in general terms, regional demographic trends and temporally patterned adaptations (e.g., Kelly et al. 2013; Miller 1996). Caution should be taken, however, because several factors potential-

1 The temporal periods employed by Collins et al. (2011) include a series of archeological style intervals of projectile points keyed to "radiocarbon years before present (B.P.)," extending from 13,300 to 250 years B.P. In actuality, based on the ages shown in various figures in Collins et al. (2011: Figures 3-13), the projectile point style intervals are in calibrated radiocarbon years B.P., not intervals in conventional radiocarbon ages B.P. This can be readily seen by comparing the age provided by Collins et al. (2011:Figure 3) for Clovis - roughly 13,000 years agowith the conventional radiocarbon age of Clovis offered by Waters and Stafford (2007) - 11,050 to 10,800 years B.P. The calibrated age range for Clovis suggested by Waters and Stafford (2007) is 13,100 to 12,800 years B.P., virtually identical to the temporal range in Collins et al. (2011). ly undermine the usefulness of this approach, including taphonomic loss of dates as a function of time and accessibility to archaeological investigation (e.g., more younger dates typically appear in such records than older dates). Loss of sites themselves is also a critical factor, as sediments that contain older sites are likely to have been progressively affected by erosion. This "geomorphic bias" results in the removal of many older sites, leading to a decrease in the number of such locales when compared to younger sites that are better preserved and more visible across the landscape. Additionally, it may be difficult to know whether radiocarbon ages in such records have been correctly reported or have been corrected for isotopic fractionation. Nonetheless, based on the assumption that radiocarbon dates represent, generally, human occupation and presence on the landscape, these kinds of records may offer opportunities to reconstruct large-scale, deep-time patterns and shifts in the prehistoric record.

During these intervals, hunter-gatherer groups used the Leon River basin at varying intensities and at different times, which likely relates to (1) the short and long-term availability and productivity of plants and animals that could be exploited by prehistoric peoples (i.e., bison abundance varied widely across time in central Texas), (2) group mobility and size, and (3) paleoclimatic conditions over the long prehistoric and early historic eras. Collins et al. (2011:6) note that, "climatic conditions exerted a strong influence on the distribution and movements of the people or peoples using the form of projectile points we find archeologically." In turn, the varying distribution and movements of peoples across the landscape-everything else being equal (which of course it never is) - would affect the number of radiocarbon dates and age ranges that would be obtained archeologically. Thus, as noted above and with appropriate caveats, the absolute number of radiocarbon dates (and the number of radiocarbon dates per century) may serve here as a proxy of aboriginal use over the long term.

The radiocarbon database for the Fort Hood archeological record includes 429 radiocarbon dates (some of which come from geoarcheological contexts) that are older than about 283 calibrated years B.P. (A.D. 1667). A careful review of the database indicates some duplicate entries and other samples with incompletely reported data; the total number of samples usable for the present purpose is 373 . This record indicates that the period between 13,300 and 5800 calibrated years B.P. was not one where dated sites are extensive (Figure 3-1). The number of dates (based on the median of the calibrated age range) per 
Table 3-1. Radiocarbon Dates Per Century (from Fort Hood Database) by Cultural Intervals as Defined by Collins et al. (2011).

\begin{tabular}{|l|c|c|}
\hline \multicolumn{1}{|c|}{ Temporal Interval and Associated Point Types ${ }^{1}$} & $\begin{array}{c}\text { Calibrated Age Range } \\
\text { (Years B.P.) }\end{array}$ & $\begin{array}{c}\text { No. of Ft. Hood } \\
\text { Dates per Century }\end{array}$ \\
\hline A: Clovis & $12,300-13,300$ & 0.2 \\
\hline B: Folsom, Midland & $11,200-12,300$ & 0.09 \\
\hline C: Golondrina, Plainview, Wilson, Angostura, Barber, Merserve & $9000-11,200$ & 0.27 \\
\hline D: Hoxie, Gower & $8000-9000$ & 0.6 \\
\hline E: Martindale, Uvaled & $6900-8000$ & 0.47 \\
\hline F: Andice, Bell & $5800-6900$ & 0.63 \\
\hline G: Bulverde, Travis, Nolan, Tayloe, Dawson, Morrill & $3300-5800$ & 2.44 \\
\hline H: Pedernales, Kinney & $2700-3300$ & 3.16 \\
\hline I: Ensor, Castroville, Montell, Lange, Marshall, Marcos, Darl & $1200-2700$ & 8.2 \\
\hline J: Scallorn, Alba, Bonham & $750-1200$ & 17.55 \\
\hline K: Perdiz, Fresno, Young, Cuney & $250-750$ & 11.8 \\
\hline
\end{tabular}

${ }^{1}$ After Collins et al. (2011).

century among these temporal intervals (A-F) ranges between 0.09 and 0.63 , with only a very gradual increase of use intensity over this long span of time. After 5800 calibrated years B.P., the Fort Hood area was more widely used by hunter-gatherer groups, especially after 2700 years B.P. As Collins et al. (2011) note, the period of time beginning around $2700 \mathrm{cal}-$ ibrated years B.P. was mesic and bison were abundant (especially between 2100 and 2700 calibrated years B.P., see Lohse et al. [2014a]); conditions were favorable for the wide dispersion of hunter-gatherer groups across many areas of the state of Texas.

The number of dates per century ranges from 2.44 for the period between 5800 and 3300 calibrated years B.P. (Temporal Interval G), to 3.16 dates per century for Temporal Interval H (3300 to 2700 calibrated years B.P.), and then to 8.20 for Temporal Interval I (2700 to 1200 calibrated years B.P.). The number of dates then increases rapidly, peaking at 17.55 dates per century for Temporal Interval J (1200 to 750 calibrated years B.P.), followed by 11.80 per century for Temporal Interval K (750 to 250 calibrated years B.P. (see Figure 3-1). Overall, then, the most intensive use of the Leon River region based on the radiocarbon record from Fort Hood seems to have been between ca. 2700 and 250 calibrated years ago, or an approximate 2,500-year-long era between 750 B.C. and A.D. 1700.

An examination of the summed radiocarbon probability distributions (SPD; see Williams 2012) of the Fort Hood calibrated dates for Intervals J through K provides a slightly different perspective (Figure 3-2). This method of evaluating large bodies of radiocarbon data is subject to the same kinds of cautionary caveats as discussed above. Additionally, the irregular shape of the calibration curve potentially affects the distribution of calibrated age probabilities by causing, or contributing to, peaks or declines in age probabilities. This method, however, allows researchers to evaluate age probabilities with far greater precision than simply counting the number of dates in a given period or interval. Considering possible issues concerning the reliability of these kinds of datasets for accurately representing cultural behavior, in many cases it may be appropriate to view these simply as heuristic models for the purposes of general illustration of larger trends. 


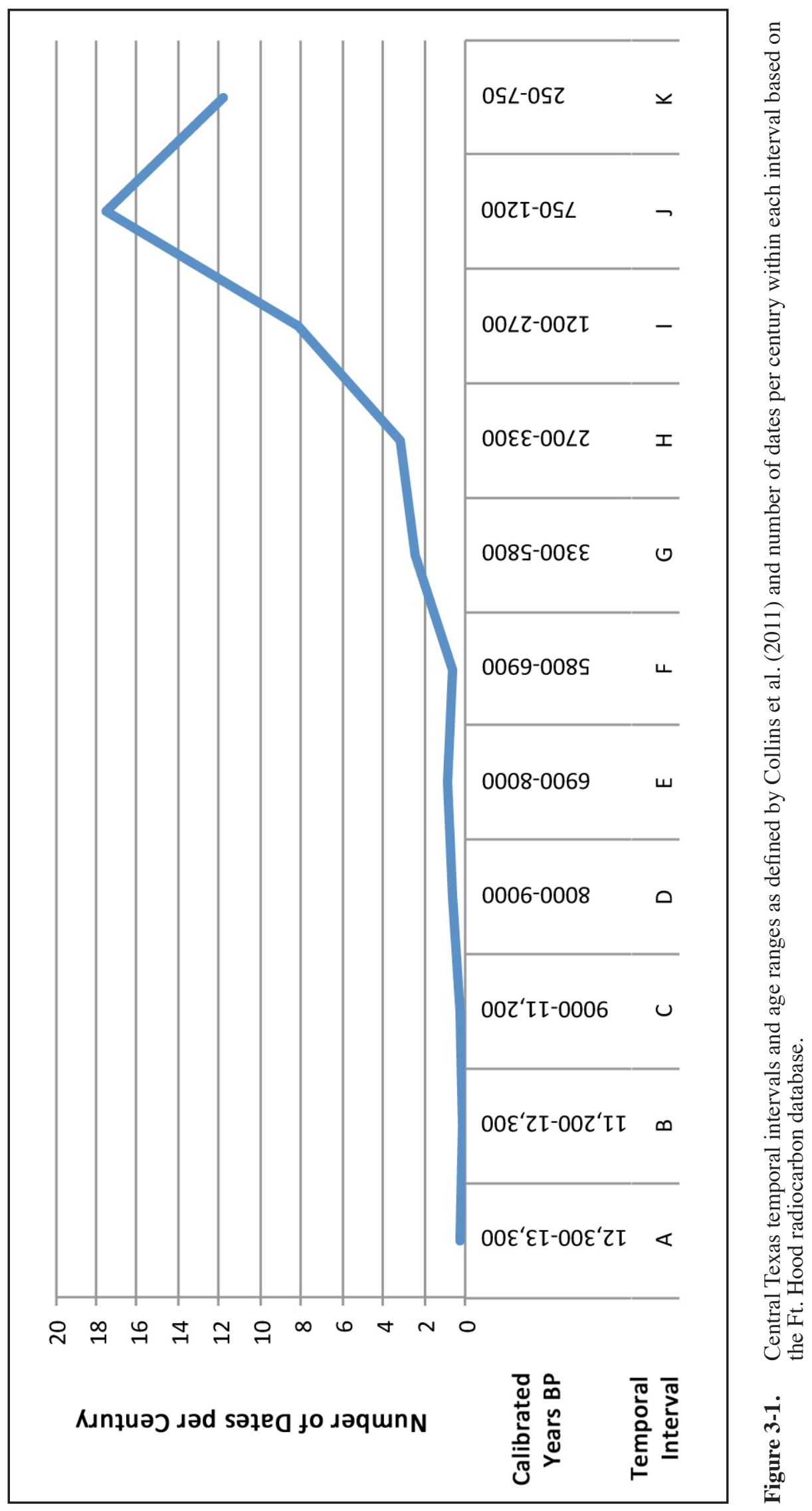




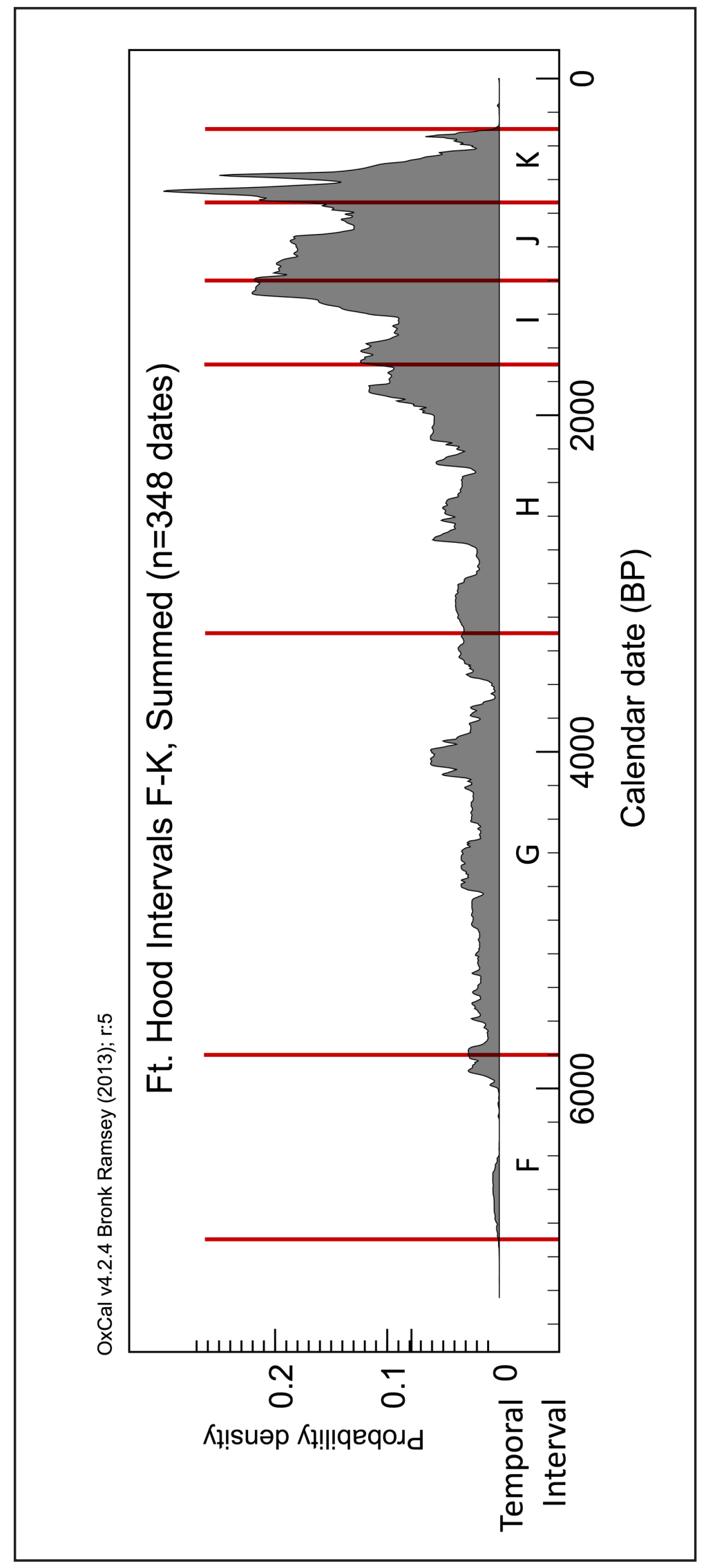

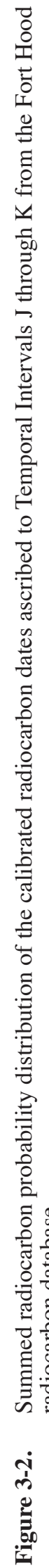


Summed probability distributions indicate little dated use of the Fort Hood area before about 6900 calibrated years B.P. (the beginning of Temporal Interval F), but with a first noticeable peak in probability density about 5900 calibrated years B.P., the beginning of the Calf Creek horizon at the end of the Early Archaic (Lohse et al. 2014a). However, the largest peaks in probability densities in the Fort Hood calibrated radiocarbon dates begin after 2000 calibrated years B.P., in Temporal Interval I, and most notably after 1500 calibrated years B.P. Minimally, this means that far more late dates have been analyzed from Ft. Hood than earlier ones. Greater analytic value may come from examining the magnitude of change within the overall summed record, including, for instance, clear declines in probabilities just before $6000 \mathrm{cal}$ B.P., and again at $3600 \mathrm{cal}$ B.P., at about 2900 cal B.P., at about 2300 and again at 2200 cal B.P., at about 1500 to 1400 cal B.P., at about 1000 to $800 \mathrm{cal}$ B.P., and the precipitous decline that culminates at about $400 \mathrm{cal}$ B.P. It may be informative to compare each of these intervals with reliable, similarly highly resolved environmental or climate records to see whether these dips correspond with regional arid periods that may have rendered the region less suitable for habitation than during other periods. Nevertheless, the precision implied by SPD models indicates that cultural periods or intervals spanning a millennia or more clearly encompass an enormous amount of behavioral variation that would be important for any understanding of local or regional cultural adaptations.

\section{Fort Hood Temporal Intervals and Projectile Point Frequencies}

Since Collins et al. (2011) have identified the representative projectile point types that are found in each of the 11 defined temporal intervals, the Fort Hood archeology database was next examined to determine which temporal intervals are marked by notable increases (in total number of points and especially in projectile points per century) in the quantity of certain types of dart points and arrow points across this part of the Leon River region. There are a total of 2,094 projectile points identified to type and Temporal Intervals A-K at Fort Hood (Table 3-2). This is a mean of 16.4 points per century over the long span of the Paleoindian, Archaic, and Late Prehistoric periods. However, almost half of all the typologically identified projectile points in the database were made and used between 2700 and 1200 calibrated years B.P., in Temporal Interval I.

With respect to the variation in projectile point frequency per century and per Temporal Intervals $\mathrm{A}-\mathrm{K}$, there are notable peaks and valleys in the projec- tile point database (Figure 3-3), which, through time, suggest differences in local and regional landscape use by prehistoric hunter-gatherers (at least as marked by the discard and loss of projectile points across that landscape). There was minimal use of the area prior to 11,200 calibrated years B.P. (in Temporal Intervals A-B), followed by a slow but increasing use between 11,200 and 6900 calibrated years B.P. (Temporal Intervals C-E). The period between 6900 and 5800 calibrated years B.P. (Temporal Interval F, and a period marked by bison abundance) is characterized by a substantial decrease in projectile point frequency per century that seemingly corresponds with a similar decline in radiocarbon data. This is followed by a rapid increase in use from 5800 to 3300 calibrated years B.P. (Temporal Interval G).

That increase is masked, however, by a nearly eight-fold increase in projectile points per century that occurred at 3300 calibrated years B.P. and lasted until 1200 years B.P. (Temporal Intervals $\mathrm{H}$ and I). This 2100-year period marks an extensive and wide-ranging use of both lowland and upland settings by hunter-gatherer groups in the Fort Hood area and Leon River basin, as Carpenter and Hartnett (2011:240) have pointed out. Carpenter and Hartnett have also suggested that there was a peak in regional site use, based on the number of sites per 100-year period, between 1400 and 1200 calibrated years B.P. (Carpenter and Hartnett 2011:Figure 3). This peak is corroborated by the Fort Hood projectile point frequencies per century.

Although the frequencies of projectile points per century in the Fort Hood region decreased after 1200 calibrated years B.P., dropping to 36.7 in Temporal Interval $\mathrm{J}$ and 13.4 in Temporal Interval $\mathrm{K}$, the use of the region by hunter-gatherer groups still remained substantial (especially when examined in conjunction with the radiocarbon database; see Tables 3-1 and 3-2 and Figures 3-1 and 3-2). In fact, the period between 3300 and 250 calibrated years B.P. represents one of the principal eras during which mobile hunter-gatherers exploited Fort Hood and the Leon River region. It should be noted that both Temporal Intervals $\mathbf{J}$ and $\mathrm{K}$ are marked by the presence of arrow points, as opposed to all previous intervals that are represented by dart points. Most arrows are much smaller in size than darts, making them more difficult to see during visual surveys. Thus, it is possible that the decrease in points during the last two intervals is the result of survey bias. Without comparing the numbers of darts and arrows found during surveys against those found during controlled excavations, it is impossible to know 
Table 3-2. Projectile Point Types by Interval and Frequency From Fort Hood.

\begin{tabular}{|c|c|c|c|}
\hline $\begin{array}{l}\text { Temporal Interval } \\
\text { (Cal Years B.P.) }\end{array}$ & Associated Point Types & No. of Points & $\begin{array}{c}\text { Points per } \\
\text { Century }\end{array}$ \\
\hline $\mathbf{A}(13,300-12,300)$ & Clovis & 0 & 0.00 \\
\hline B $(12,300-11,200)$ & Folsom, Midland & 2 & 0.18 \\
\hline $\mathbf{C}(11,200-9000)$ & $\begin{array}{l}\text { Golondrina, Plainview, Wilson, Angostura, } \\
\text { Barber, Meserve }\end{array}$ & 89 & 4.05 \\
\hline D $(9000-8000)$ & Hoxie, Gower & 58 & 5.8 \\
\hline E $(8000-6900)$ & Martindale, Uvalde & 77 & 7.0 \\
\hline F $(6900-5800)$ & Andice, Bell & 12 & 1.09 \\
\hline $\mathbf{G}(5800-3300)$ & Bulverde, Travis, Nolan, Dawson, Morrill & 211 & 8.44 \\
\hline $\mathbf{H}(3300-2700)$ & Pedernales, Kinney & 395 & 65.8 \\
\hline I (2700-1200) & $\begin{array}{l}\text { Ensor, Castroville, Montell, Lange, Marshall, } \\
\text { Marcos, Darl, Edgewood, Fairland, Ellis, Gary, } \\
\text { Godley, Kent }\end{array}$ & 1,018 & 67.9 \\
\hline $\mathbf{J}(1200-750)$ & Scallorn, Alba, Bonham & 165 & 36.7 \\
\hline $\mathbf{K}(750-250)$ & Perdiz, Fresno, Young, Cuney & 67 & 13.4 \\
\hline
\end{tabular}

at present exactly how much bias is involved. This may be an interesting study for the future.

How do these peaks and valleys in projectile point frequency through time correspond to the peaks and valleys in the radiocarbon database from Fort Hood? The highest projectile point per-century values occur between 3300 and 250 calibrated years B.P., in Temporal Intervals H-K, as does the number of radiocarbon dates per temporal interval (Figure 3-4). Both data categories indicate that the use of Fort Hood and the Leon River region by hunter-gatherer groups increased substantially around 3300 calibrated years B.P. (during the Late Archaic), and this extensive foraging use remained relatively unabated through the Late Prehistoric period. However, these two lines of data peak at distinctly different times within this period; points per century peaks in 


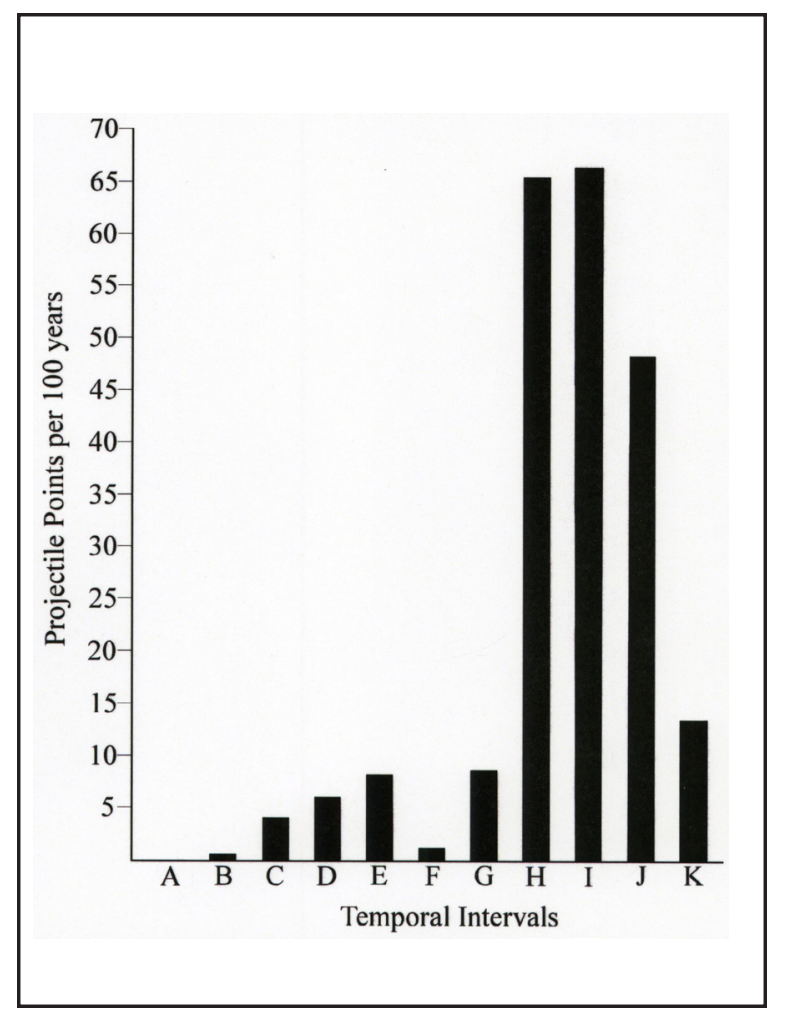

Figure 3-3. Point frequencies per century by the temporal intervals defined for the study area based on the Ft. Hood projectile point database.

Intervals $\mathrm{H}$ and $\mathrm{I}$ before declining in $\mathrm{J}$ and $\mathrm{K}$, while dates per century continue to increase until Interval $\mathrm{J}$ before declining in K. Seemingly the two datasets indicate slightly different aspects of prehistoric land use at Ft. Hood and the Leon River basin. Regardless of these differences, only at the beginning and end of this ca. 3,000-year-long period was foraging use associated with periods of bison abundance, at least in the Fort Hood area. This suggests that the foraging patterns of the hunter-gatherer groups were based primarily on a highly generalized subsistence/mobility pattern wherein a wide range of plant and animal resources were exploited (including bison when available) in conjunction with the bulk processing of certain resources (i.e., geophytes such as wild onion and eastern camas, among others; see Thoms 2008).

\section{Bison and the \\ Fort Hood Database}

The direct evidence of bison use is relatively meager at Fort Hood (Table 3-3). This record suggesting low frequency may reflect preservation biases; however, bison ought to have been exploited when present on the landscape. According to the Fort Hood database, there are 24 sites with very large mammalia (cf. bison) remains, but only at 13 of those sites can a temporal context be assigned to the archeological deposits that contained the remains. In each case, the number of specimens is small, ranging from only 1 to 35 specimens per site.

The available temporal information associated with the very large mammalia remains include three sites with Middle Archaic components, two sites with Late Archaic components, and eight sites with Late Prehistoric components. The Middle Archaic components at sites 41CV48, 41CV137, and 41CV389 have calibrated radiocarbon dates that range from 4971 to 3770 calibrated years B.P. (Temporal Interval G). The two Late Archaic components have calibrated radiocarbon dates that fall in both Temporal Intervals $\mathrm{H}$ and I (3210 to 2106 calibrated years B.P.). The Late Prehistoric sites with very large mammalia remains at Fort Hood likely all fall in Temporal Interval K, which dates from 750 to 250 calibrated years B.P. Although this review of bison presence is consistent with traditional approaches to this topic, recent studies involving the direct dating of bison remains using reliable pretreatment procedures indicates that considerably more precision is to be found in the bison record than these generalized reconstructions suggest. The current understanding of regional bison chronology will be discussed in detail, below.

\section{Aboriginal Ceramics at Fort Hood}

Another facet of archeological research conducted at Fort Hood included the geochemical analysis of aboriginal ceramic sherds from the fort and its vicinity (Perttula et al. 2003; see also Creel et al. 2013). Based on petrographic analysis, instrumental neutron activation analysis (INAA), and considerations of pottery style, Caddo ceramics from east Texas manufacturing locales are present on sites in the Fort Hood area as early as 1050 calibrated years B.P. Stylistically distinct local ceramic traditions developed in this part of central Texas only after ca. 750 to 650 calibrated years B.P., are subsumed under the Toyah phase/interval rubric (Arnn et al. 2010:64-66), and are recognized by two principal bone-tempered ceramic types: Leon Plain and Doss Red ware. "Why and precisely how ceramics were adopted by broad spectrum foragers" (Arnn et al. 2010:66) in central Texas are questions that remain to be answered, but one possibility is that their adoption and use was related to food-processing needs and bone-grease production efforts that arose 


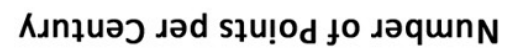

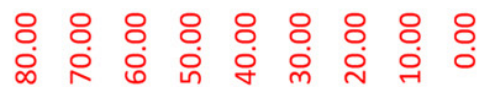

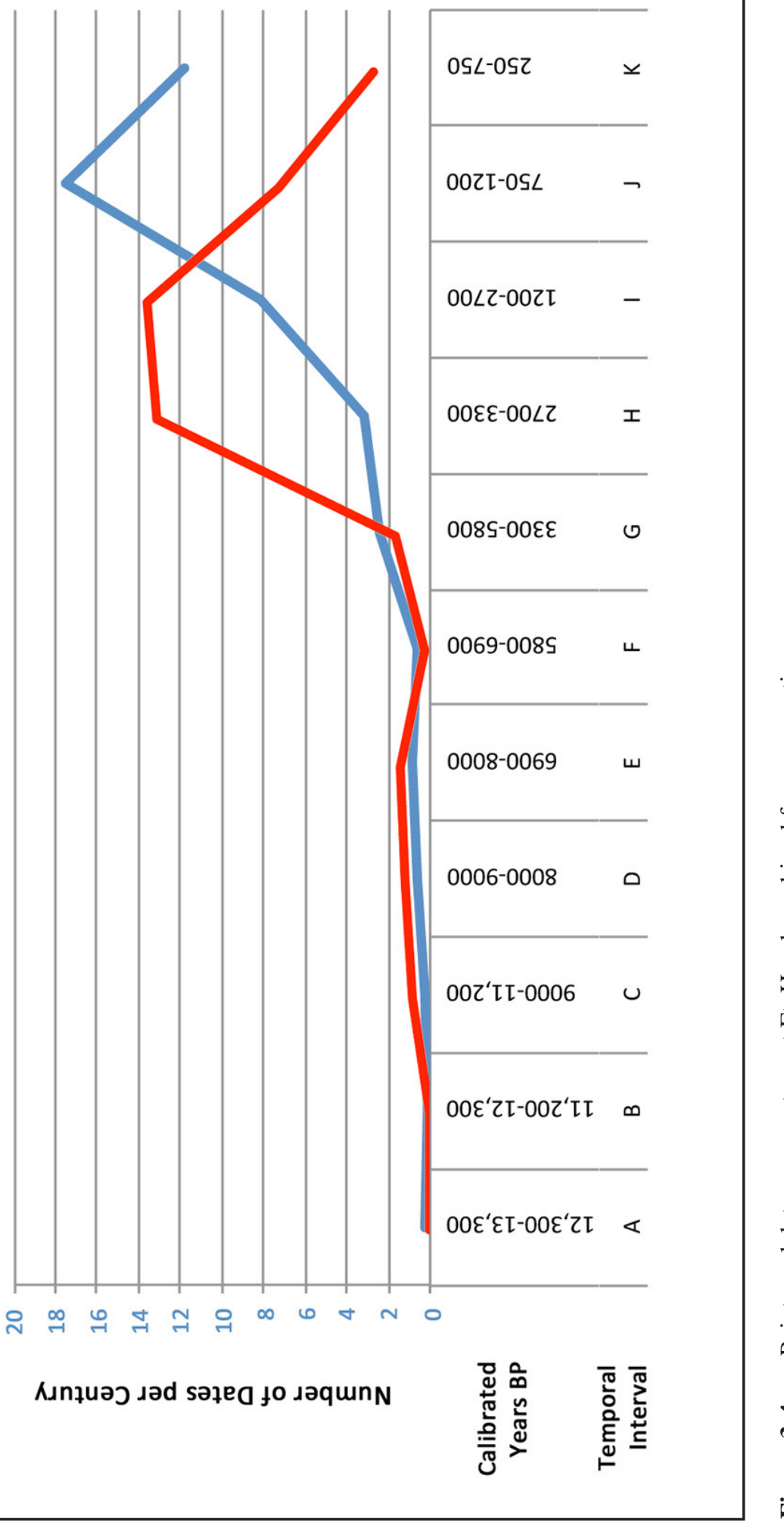

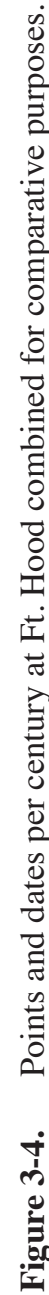


Table 3-3. Sites at Fort Hood with Very Large Mammalian (cf. Bison) Remains.

\begin{tabular}{|c|l|}
\hline Temporal Unit & \multicolumn{1}{|c|}{ Site Trinomials (No. of Specimens) } \\
\hline Late Prehistoric & $\begin{array}{l}\text { 41BL844 (1), 41CV97 (2), 41CV115 (1), 41CV174 (35), 41CV935 (1), 41CV1007 (1), } \\
\text { 41CV1038 (5),41CV1080 (4) }\end{array}$ \\
\hline Late Archaic & 41CV117 (1),41CV1038 (12) \\
\hline Middle Archaic & 41CV48 (1), 41CV137 (1), 41CV389 (2) \\
\hline
\end{tabular}

with the more intensive exploitation of bison around 700 to 600 years ago. However, given their rarity in Toyah phase sites in general, and more specifically in the Fort Hood site artifact assemblages (see below), it seems more likely that ceramics were used by aboriginal peoples after ca. A.D. 1200 for non-subsistence-related activities and practices (cf. Arnn 2012:78-79).

Aboriginal ceramics in general are not at all abundant on Fort Hood sites, as only about 1 percent of the prehistoric and early historic sites recorded on the fort have evidence of ceramic manufacture and/or use (Table 3-4), and these sherds likely represent the broken fragments of, at most, only a few vessels. Most of the sites have bone-tempered Leon Plan sherds from jars and bowls, as well as sherds from jars with brushed marks; grog-tempered brushed sherds from site $41 \mathrm{CV} 48$ may be from a Caddo vessel made in East Texas that was traded/exchanged with a group foraging in this part of central Texas. Several sites, including 41BL3, 41CV41a, 41CV92, and 41CV344, have engraved Caddo wares that were made between ca. 1050 and 350 calibrated years B.P., and these are either the only ceramics found on a Fort Hood site, or, in the case of site 41CV344, are found co-associated with Leon Plain wares. Applicable radiocarbon dates on sites at Fort Hood with Leon Plain ceramics postdate 530 calibrated years B.P.

In sum, the Fort Hood archeology database of projectile points, radiocarbon dates, occurrence of bison bones on sites, and the presence of aboriginal ceramic sherds, provides a context for examining 13,000 years of hunter-gatherer use in the Leon River region of central Texas. These data have indicated that the
Table 3-4. Fort Hood Sites with Aboriginal Ceramic Sherds.

\begin{tabular}{|c|c|}
\hline Site Trinomial & No. of Sherds \\
\hline $41 \mathrm{BL} 181$ & 40 \\
\hline $41 \mathrm{BL} 183$ & 1 \\
\hline $41 \mathrm{BL} 821$ & 5 \\
\hline $41 \mathrm{CV} 41 \mathrm{a}$ & 7 \\
\hline $41 \mathrm{CV} 48$ & 4 \\
\hline $41 \mathrm{CV} 92$ & 1 \\
\hline $41 \mathrm{CV} 111$ & 3 \\
\hline $41 \mathrm{CV} 174$ & 14 \\
\hline $41 \mathrm{CV} 240$ & 67 \\
\hline $41 \mathrm{CV} 344$ & 1 \\
\hline $41 \mathrm{CV} 495$ & 1 \\
\hline $41 \mathrm{CV} 570$ & 1 \\
\hline Isolated Find & \\
\hline
\end{tabular}

region has been episodically occupied by broad-spectrum hunter gatherers for the length and breadth of the prehistoric and early historic (ca. A.D. 1700) periods, but with marked differences through time in foraging intensity and, presumably, the establishment of encampments and other kinds of sites. The peri- 
od after about 5800 calibrated years B.P. (3850 B.C.) saw the most use across the region by hunter-gatherer groups - at least as determined by the absolute frequencies and frequencies per century for projectile point and radiocarbon dates. However, the most extensive and wide-ranging use of the region occurred between 3300 and 250 calibrated years B.P. (1350 B.C. to A.D. 1700). The exploitation of bison may well have been important to these groups at several times during this era (in Temporal Intervals H, I, and $\mathrm{K})$. Consequently, a broad-spectrum resource exploitation of a wide range of plants and animals across a broad and expansive landscape is a dominant feature of the archeological record at Fort Hood and in the Leon River region of central Texas.

While databases, such as those relied upon here from Ft. Hood, are significant sources of information regarding regional developments and cultural trends, certain limitations exist that remain to be overcome. Specifically, many of these limitations involve the general lack of temporal precision associated with traditionally excavated contexts. Summed probability distributions of the radiocarbon database may help indicate the kinds of precision that can be achieved under certain circumstances, albeit with appropriate caution. Indeed, enhanced temporal precision may be the single most important topic or issue that could be improved upon in archaeological investigations, regional syntheses, and programs of site assessment in the region.

\section{Central Texas Chronology Based on Revised Assessment of ${ }^{14} \mathrm{C}$ Dates}

With the objective in mind of increasing the reliable precision associated with some key temporally diagnostic point types, Lohse et al. (2014a) recently presented a revised cultural chronology for central Texas starting around $6000 \mathrm{cal}$ B.P. This sequence is based on a review of published radiocarbon data that were filtered through a series of considerations intended to help separate culturally mixed or conflated contexts from stratigraphically pristine, unmixed ones. The resulting sequence consists of a Middle Archaic that remains poorly resolved (lasting ca. 5800-4200/4100 cal B.P.); four Late Archaic periods-Late Archaic 1 (4200/4100-3100 cal B.P.), Late Archaic 2 (ca. 31002150 cal B.P.), Late Archaic 3 (ca. 2150-1270 cal B.P.) and Late Archaic 4 (ca. 1270-650 cal B.P.). The Calf Creek horizon (ca. 5950-5800 cal B.P.) defines the end of the Early Archaic in this model, although subsequent dating of Calf Creek remains suggests that this period may extend as late as about $5700 \mathrm{cal}$ B.P.
(Lohse et al. 2014c). One significant aspect of this revised sequence is that it redefines the Late Prehistoric period as consisting solely of the Toyah interval. The introduction of arrow points is seen as an adaptation that took place over a moderately long period of time that otherwise was not associated with particularly notable or dramatic changes in terms of technology, subsistence practices, or site-use patterns.

Another, perhaps more significant, aspect of this revised sequence is that it relies heavily on the directly dated record of bison presence and exploitation from Calf Creek times onward (Lohse et al. 2014c). The presence of bison is largely in response to environmental conditions, specifically including the occurrence of cold climatic intervals that were severe enough to influence the available forage suitable to bison in this far southern reach of the Plains environmental province (Lohse et al. 2014b). However, because this top-ranked resource theoretically would have been pursued and exploited whenever it was found on the landscape, the presence of bison in archaeological assemblages can be used to provide temporal precision in cases where such remains are directly dated by reliable procedures. This record of bison exploitation, which is examined in additional detail in Chapter 10 in this report, defines five specific intervals of bison presence occurring in three general time periods: Calf Creek (ca. 5950-5800 cal B.P.), Late Archaic (including Late Archaic Bison 1 [LA 1 1, 3295-3130 cal B.P.] and Late Archaic Bison 2 [ $\mathrm{LA}_{\mathrm{B}} 2,2700-2150 \mathrm{cal}$ B.P.]), and Toyah (including Early Toyah [ca. 650-530 cal B.P.] and Late Toyah [about 385-200 cal B.P.]) (Lohse et al. 2014b, 2014c; Weinstein et al.2014). This record will continue to be adjusted as bison dating continues, and it is expected that modifications will occur, in particular, at the beginning and ending dates of bison periods.

Comparing the different cultural records discussed to this point is somewhat difficult because of the varying degrees of chronological precision inherent to each. For example, the broad Fort Hood temporal intervals encompass as little as 450 years (Interval $\mathrm{J}$ ) and as much as 2,500 years (Interval G). The radiocarbon-based chronologies, however, can be evaluated in a comparative manner using calibrated years for purposes of scaling (Figure 3-5). This comparative record suggests that some larger patterns, indicated by correspondences in radiocarbon probabilities, can be addressed in future research.

Starting with the part of the record where radiocarbon data appear in abundance, ca. 6000 cal B.P., the regional record suggests that evidence of the Calf Creek 
OxCal v4.1.7 Bronk Ramsey (2010); r:5 Atmospheric data from Reimer et al (2009);
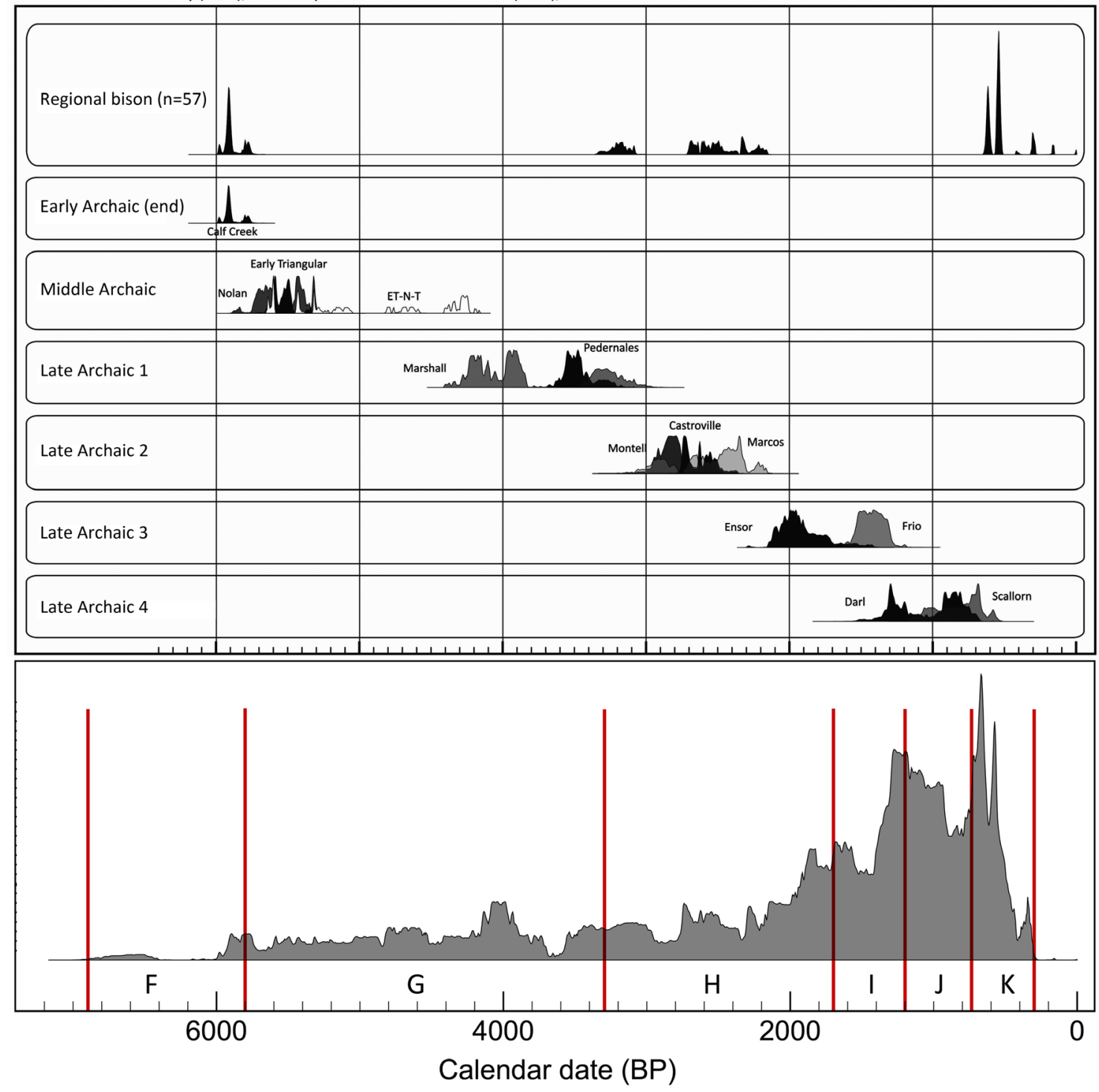

Figure 3-5. Comparing regional chronologies for the purpose of contextualizing archaeological investigations at 41HM61. Upper sequence (from Lohse et al. 2014a:Figure 5). Lower element is summed probability distributions from the Ft. Hood radiocarbon database (see Figure 3-2 above). Temporal Intervals F-K are indicated.

horizon ought to be moderately abundant in the region. Dates ascribed to this interval by Collins et al. (2011) are likely to be too broad, and we rely instead on the more concise age range of $\sim 5950-5800$ cal B.P. presented by Lohse et al. (2014a). Immediately following this brief period, the Ft. Hood radiocarbon record indicates a brief reduction in dated contexts before a generally long and consistent period of probability distribution begins around $\sim 5700 \mathrm{cal}$ B.P. This period corresponds almost perfectly with the Middle Archaic as defined by
Lohse et al. (2014a), even extending to the increase in probability distributions at about $4200 \mathrm{cal}$ B.P. In the absence of more detailed data, this sequence suggests that Middle Archaic contexts are present and should be expected in alluvial settings in the Leon River Basin, even if hunter-gatherer use of the region was light compared with later periods.

The combined regional sequences suggest that the transition from Middle Archaic to Late Archaic 1 
should also be well represented in the region, and is characterized by a distinct increase in dated contexts. Projectile points per century (see Figure 3-3) begin to increase sharply around this time, although without better temporal precision this trend requires additional clarification. The poorly dated interval immediately prior to the regional occurrence of Pedernales point types, ca. 3750-3600 cal B.P., is also defined by a nearly complete absence of radiocarbon dates from Ft. Hood. Future research should consider whether some brief but significant climatic event, such as an intense dry interval, occurred at or around this time.

After about 3600 cal B.P. the regional radiocarbon record again increases, consistent with the dated regional occurrence of Pedernales points as well as the first Late Archaic bison event $\left(\mathrm{LA}_{\mathrm{B}} 1\right)$. Indeed, at this point the Ft. Hood regional chronology seems to match especially well with the Late Archaic bison record for central Texas; the next distinct reduction in probability distributions occurs at about 3000-2800 cal B.P., the age of the hiatus between $\mathrm{LA}_{\mathrm{B}} 1$ and $\mathrm{LA}_{\mathrm{B}} 2$ (Lohse et al. 2014c:109). Because of where this interval falls on the radiocarbon calibration curve, it may actually have lasted as long as about 400 years. Nevertheless, with the return of bison to the region starting about $2700 \mathrm{cal}$ B.P., the occurrence of calibrated probabilities begins to increase again and continues relatively unabated until about $1600 \mathrm{cal} \mathrm{B.P.} \mathrm{This} \mathrm{trend} \mathrm{is} \mathrm{significant,} \mathrm{as}$ it covers the end of $\mathrm{LA}_{\mathrm{B}} 2$ and its reported association with the Marcos point type. One very important implication of this pattern is that the Leon River basin appears to hold great potential to add significant clarification to the Late Archaic 2-3 record, characterized by the transition away from bison hunting around $2100 \mathrm{cal}$ B.P. and the transition from Marcos to Ensor point styles. This issue, in particular, is addressed by the data at 41HM61.

Based at least on the Ft. Hood radiocarbon record, the period of about $1600-1500$ cal B.P. appears as a clear interruption or break of some kind in the record, defined by a 100-200-year-long reduction in probabilities. This period corresponds with the Frio point type, which is not represented at 41HM61. This period is immediately followed by a sharp increase in calibrated probabilities starting at about $1300 \mathrm{cal}$. B.P. This increase corresponds with the beginning of the Darl point type and the Late Archaic 4 cultural interval (Lohse et al. 2014a). Future environmental studies may target this interval specifically to better understand what climatic conditions may have prevailed at this time that may have supported increasing regional populations (as also indicated by regional point frequencies; see Table 3-2). What Lohse et al. (2014a) identify as Late Archaic 4 appears to be divided into at least two periods based on the Ft. Hood radiocarbon record as seen by a sharp decrease in probability distributions at about 1000-800 cal B.P. This period generally corresponds with the Medieval Climate Anomaly (MCA, e.g., Mann et al. 2009), a period of notably warmer temperatures recorded across the northern hemisphere. This decline is sharply reversed almost immediately starting with Temporal Interval K, the Toyah interval. Climatically, this period corresponds with the Little Ice Age, a sharp reversal of MCA warming and, additionally, the return of bison to the project area for the first time in about 1,500 years (Lohse et al. 2014c). 


\title{
Chapter 4
}

\section{Previous Research Near Site 41HM61}

\author{
Timothy K. Perttula
}

This chapter reviews previous archeological research in the vicinity of site 41HM61, specifically concentrating on three prehistoric sites along the Leon River where significant archeological excavations have taken place or currently are ongoing. The three sites are: Sprague (41HM43), site 41HM51, and Upper Sprague (41HM54). All three sites primarily were occupied in Temporal Interval I (2700 to 1200 calibrated years B.P.) and Temporal Interval K (750 to 250 calibrated years B.P.) (see Chapter 3), with important Toyah phase components at 41HM51 and Upper Sprague. Other occupations at the sites fall in Temporal Interval G (at Sprague, 5800 to 3300 calibrated years B.P.) and Temporal Interval J (at Upper Sprague, 1200 to 750 calibrated years B.P.). The fact that each site was occupied in the period after 5800 calibrated years B.P. (3850 B.C.) is consistent with the notion that this appears to have been the time of principal use of the region by hunter-gatherer groups, at least as preserved in the regional radiocarbon record. Furthermore, the most extensive and wide-ranging use of these sites after 2700 calibrated years B.P. is also in concordance with regional archeological findings (see Chapter 3 ). ${ }^{1}$

\section{Sprague Site (41HM43)}

The Sprague site is located on a Late Holocene alluvial terrace (T1) along the north bank of the

1 The reader should again be aware, however, of the potential for "geomorphic bias" that can affect the preservation of older archaeological sites and result in an apparent greater number of younger locales.
Leon River, approximately $300 \mathrm{~m}$ northwest of site 41HM61 (Figure 4-1). When the site was initially recorded in 1997 there were several stratified layers of fire-cracked rock visible in the cut bank of the river at depths ranging between 1 and $4 \mathrm{~m}$ below the surface. The investigations reported by Jameson and Potter (1999) concentrated on the uppermost of the buried archeological deposits, where three small block excavations were completed. These deposits contained lithic debris and core fragments, dart points, bifaces, flake tools, animal bone (pronghorn antelope, coyote, deer, rabbit, and raccoon), mussel shell, and an abundance of fire-cracked rock from hot-rock cooking activities. Several rock hearth or oven features were excavated that lay between 135 and $214 \mathrm{~cm}$ below the surface.

Feature 1, an earth oven, was a 2-by-1.5-m cluster of fire-cracked limestone rocks exposed at -135 cm (Jameson and Potter 1999:Figures 3 and 4). Two Marcos dart points were found in association with this feature (Bryan Jameson, personal communication, 2011). Charcoal from within the feature yielded a conventional radiocarbon date of $2570 \pm 40$ B.P. This offered a two-sigma calibrated age range of 810 to 760 B.C. (2760 to $2710 \mathrm{cal}$ B.P.). This date is somewhat older, by a couple of centuries, than the age range most closely associated with Marcos points, about 2400 to 2150 cal B.P. (Lohse et al. 2014a; also see below). Although intensive excavations have not been conducted in the lower portion of the buried archeological deposits, charcoal from a feature located between 3.6 and $4.6 \mathrm{~m}$ below the surface of the cut bank was dated to $3550 \pm 90$ B.P. This provided a two-sigma calibrated age range of 2140 to 1670 B.C. (4090 to 3620 cal B.P.). 


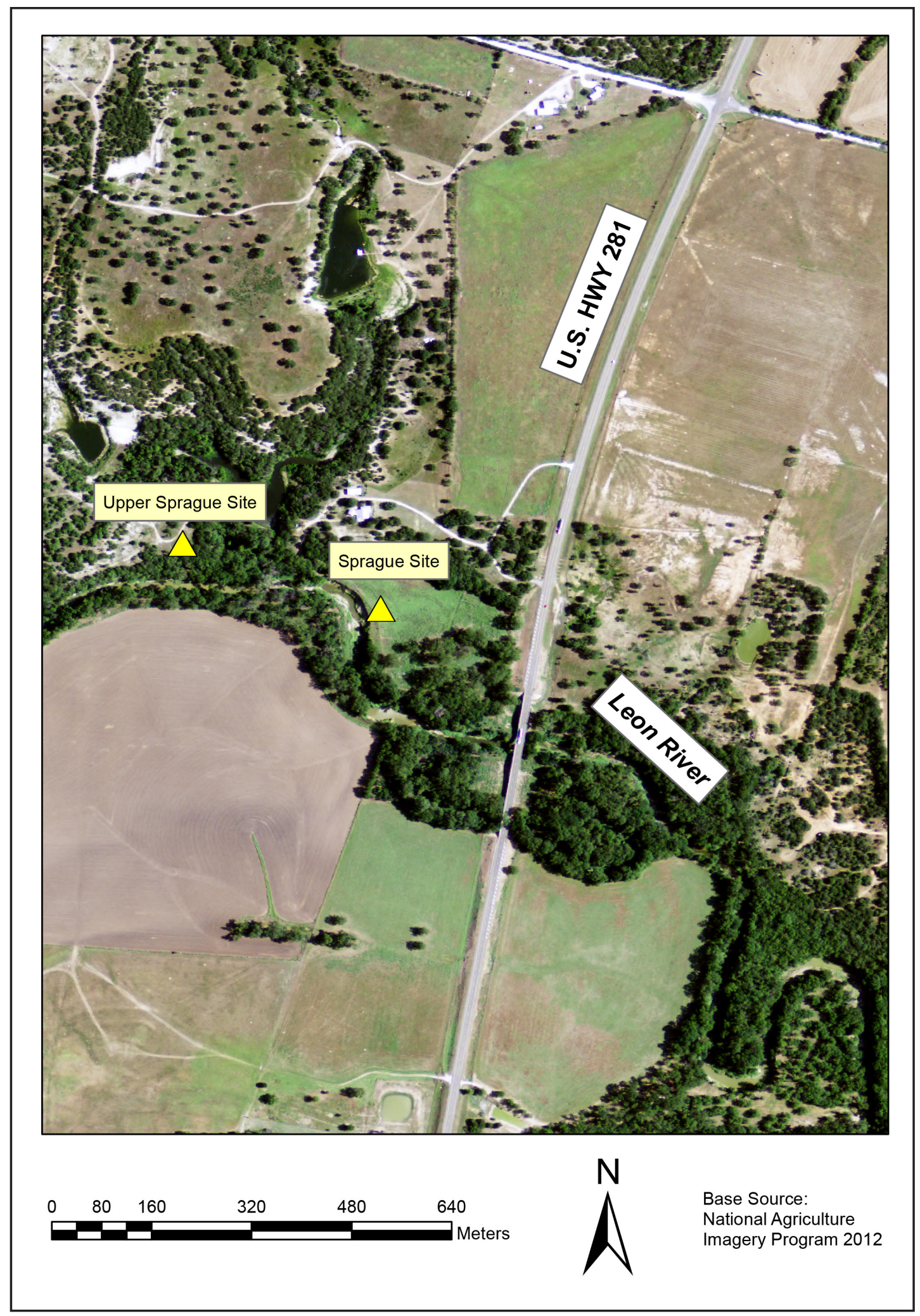

Figure 4-1. Aerial view of the project area showing the locations of the Sprague (41HM43) and Upper Sprague (41HM54) sites just upriver from the U.S. Highway 281 bridge over the Leon River. 


\section{Site $41 \mathrm{HM} 51$}

Site 41HM51 is located ca. 15 river kilometers upstream from the Sprague site, and 8.3 aerial kilometers west-northwest of site 41HM61. The site is buried in a paleosol in a T1 alluvial terrace of the Leon River. Prewitt \& Associates, Inc., (P\&A) conducted test excavations and data-recovery investigations in 2003 and 2004, but a full report on that work has not yet been completed (Broehm and Kibler 2004; Broehm et al. 2004; Kibler and Broehm 2005). Nine backhoe trenches and 18 1-by-1-m units were excavated at the site during the testing phase. This was followed during data recovery by the mechanical stripping of an area covering $256 \mathrm{~m}^{2}$ and the hand excavation of 155 additional 1-by-1-m units (Broehm and Kibler 2004).

The principal occupation at 41HM51 is a Toyah phase component that accumulated at the top of the paleosol; this component was the focus of the data-recovery work. Some 70 to $90 \mathrm{~cm}$ below the top of the paleosol was a terminal Late Archaic occupational deposit with Ensor dart points, a cluster of mussel shells, fire-cracked rock, and a few animal bones. Kibler and Broehm (2005:20) also suggest that there may be a third component buried 10 to $23 \mathrm{~cm}$ below the surface of the paleosol, although its temporal and cultural affiliation has not been established.

The Toyah phase component has a number of different kinds of features clustered in two different parts of the block excavation, including: shallow basins with burned rock and charcoal; an ash pit; a cluster of boiling stones dumped from a hearth; and clusters of broken tools, mussel shells, burned rock, and/or animal bones (one solely with bison bones and another with deer elements). Material culture remains associated with this component include Perdiz arrow points, bifaces, unifaces, and edge-modified flakes, five flakes of obsidian, lithic debitage, ground stone tools, modified animal bones, 44 sherds from at least two Late Caddo style ceramic vessels (including a Bullard Brushed jar), animal bones (primarily bison), freshwater mussel shells, and carbonized wood (Broehm and Kibler 2004:23-26).

Five radiocarbon dates were initially obtained from testing work at site 41HM51, all from features excavated during the test excavations (Table 4-1). All fall clearly in the temporal interval represented by the Toyah phase, with two-sigma calibrated age ranges extending from A.D. 1300 to 1660 . An additional 13 radiocarbon dates from 41HM51 were subsequently obtained from features excavated during the data-recovery work, and the conventional ages range from $680 \pm 50$ to $210 \pm 50{ }^{14} \mathrm{C}$ B.P. (Karl Kibler, personal communication 2011). Taken together with the dates from the test excavations, they indicate that the Toyah component at the site spanned-perhaps episodically - the fourteenth century to the late seventeenth century A.D.

As mentioned, four small obsidian flakes were recovered in the Toyah component. Geochemical analyses of these flakes indicate that they are from two different Jemez Mountains (Valles Caldera) sources in northern New Mexico (see Arakawa et al. 2011:Figure 4): the Cerro Toledo Rhyolite and Valles Rhyolite (Cerro del Medio) (Karl Kibler, personal communication 2011).

The unaffiliated component shallowly buried in the paleosol contained primarily animal bones (bison mostly), "bits of oxidized soil, and mussel shells. Lithics of any type are largely absent from this component" (Broehm and Kibler 2004:29).

\section{Upper Sprague Site (41HM54)}

Baylor University's Field School (under the direction of Carol Macaulay Jameson) and the Tarrant County Archeological Society have been investigating in recent years a second locale on Mr. Sprague's property, the Upper Sprague site (41HM54). This site is situated adjacent to the Leon River only a few hundred meters upstream from the Sprague site, along the western side of a small tributary that flows south into the river. Archaeological deposits range from Middle Archaic to the latter part of the Late Prehistoric periods.

Only the upper deposits at the Upper Sprague site have received intensive archaeological investigations to date, although the results of these investigations have been presented only as papers and posters at several annual meetings of the Texas Archeological Society (Adcock and Hanks 2008; Aran and Estep 2007; Arrington et al. 2009; Byrd 2010; Casiano 2010; DiPietro 2008; Durham 2010; Everett and Kocian 2007; Grassbaugh 2010; Haley and Macaulay 2008; Jameson 2007; Mann and Kemp 2007; Millard and Macaulay 2008; Millard et al. 2008; Rangel and Witt 2010; Reed and Beach 2009; Saenz and Shallenberger 2009; Sneed and Macaulay 2008; Truitt 2010; Tryon 2010; Tuttle 2010; Wasson and Windham 2010). The very uppermost part of the archaeological deposits consists of a Toyah phase component with Perdiz arrow 
Table 4-1. Radiocarbon Dates from the Test Excavations at Site 41HM51 (from Broehm and Kibler 2004: Table 1).

\begin{tabular}{|c|c|c|c|}
\hline Context & Laboratory Number & Conventional Age ${ }^{14}$ C B.P. & 2-Sigma Calibrated Age (A.D.) \\
\hline Feature 6 & UGA-13209 & $540 \pm 40$ & $1300-1370,1380-1450$ \\
\hline Feature 8 & UGA-13211 & $460 \pm 40$ & $1320-1350,1390-1530,1550-1640$ \\
\hline Feature 9 & UGA-13212 & $440 \pm 40$ & $1400-1530,1560-1630$ \\
\hline Feature 4 & UGA-13208 & $390 \pm 40$ & $1430-1530,1540-1640$ \\
\hline Feature 8 & UGA-13210 & $310 \pm 40$ & $1480-1660$ \\
\hline
\end{tabular}

Table 4-2. Radiocarbon Dates From the Upper Sprague Site (41HM54).

\begin{tabular}{|c|c|c|c|}
\hline Laboratory Number & $\begin{array}{c}\text { Conventional } \\
\text { Radiocarbon Age B.P. }\end{array}$ & ${ }^{13} \mathbf{C} /{ }^{12} \mathbf{C}$ Ratio & 2-Sgima Calibrated Age (A.D.) \\
\hline Beta-260964 & $940 \pm 40$ & $-25.6 \%$ & $1020-1200$ \\
\hline Beta-260960 & $800 \pm 40$ & $-25.7 \%$ 1170-1280 \\
\hline Beta-260963** & $770 \pm 40$ & $-20.5 \%$ o & $1210-1290$ \\
\hline Beta-260959* & $710 \pm 40$ & $-7.8 \%$ & $1260-1310,1360-1380$ \\
\hline Beta-260965 & $360 \pm 40$ & $-23.0 \%$ & $1440-1640$ \\
\hline Beta-260962* & $310 \pm 40$ & $-10.1 \% 0$ & $1460-1660$ \\
\hline Beta-260961* & $290 \pm 40$ & $-10.4 \%$ & $1480-1660$ \\
\hline
\end{tabular}

* bison bone

** deer bone

points and bison bone. Stratified below that occupation is an Austin phase component with Scallorn arrow points, and below that is reported to be a Late to Transitional Archaic component (Bryan Jameson, personal communication 2011).
The excavations in one area of the site (Area D) have exposed portions of Late Prehistoric encampments with various features and concentrations of artifacts, animal bones, and mussel shell from both Austin and Toyah phase occupations. Features identified in these 
deposits include a bison bone cluster, a freshwater mussel midden concentration, a Rabdotus snail cluster, an arc-shaped daub concentration that may represent the remnants of a burned structure, a burned-clay concentration (possibly a surface hearth), a basin-shaped hearth, two shallow basin-shaped pits, a possible storage pit, a flat stone cluster, a concentrated lithic-reduction area, and a trash midden in the northern part of the area's block excavations. The trash midden contained fire-cracked rock, mussel shell, animal bone, lithic debris, and broken and expended chipped-stone tools.

The various habitation features and recovered artifacts from the Upper Sprague site suggest that the Late Prehistoric inhabitants of the site used it for food preparation/processing activities. They apparently discarded fragmented and fractured faunal remains into a nearby trash midden, likely extracting bone grease from the broken bison bones and the remains of medium-sized mammals. Small mammals, turtles, and fish were also consumed at Upper Sprague. Lithic tools were made, refurbished, and discarded at the site, as well. The absence of ceramics from this component suggests that the technology of fat rendering used at the site did not rely on this newly adopted form of material culture.
Seven charred plant and animal bone samples were submitted for radiocarbon dating from the Upper Sprague site (Table 4-2). These seven samples were collected from both Toyah and Austin phase contexts in Area D. The calibrated dates suggest the Austin phase component dated from A.D. 1130 to 1290 at one sigma, and A.D. 1020 to 1380 at two sigma. The calibrated intercepts range from A.D. 1040 to 1280 . One of these samples is from a deer bone (A.D. 1210 to 1290) and another is from a bison bone (A.D. 1260 to 1380 ), and two others are from charred materials found in hearths.

At one sigma, the calibrated Toyah phase dates from the Upper Sprague site range from A.D. 1460 to 1650 , while the two-sigma calibrated dates have an almost identical range from A.D. 1440 to 1660 (see Table 4-2). Calibrated intercepts for the three Toyah phase dates range from A.D. 1490 to 1640. The two dates on bison bone from this component have a two-sigma calibrated age range of A.D. 1460 to 1660 , although these samples were not pretreated in any way to ensure full removal of all contaminants and exogenous carbon prior to their having been dated. 


\title{
Chapter 5
}

\section{Previous Research at Site 41HM61}

\author{
James T. Abbott
}

As discussed previously, the recent study by Abbott (2011) provided a summary of the earlier field investigations conducted by TxDOT personnel (himself and John Arnn) at the location of the U.S. Hwy. 281 bridge over the Leon River, plus a review of the geological setting of the project area. Since the latter already has been provided in Chapter 2, only the actual TxDOT field investigations will be addressed at this time. Those investigations consisted mainly of backhoe trenching designed to locate any potential cultural remains that might lie buried beneath the present ground surface. In all, Abbott and Arnn excavated 14 backhoe trenches (BTs) within the highway's ROW at the bridge (Figure 5-1; see also Figure 2-5). These trenches were positioned both north and south of the artificial channel that had been dug in the early 1950s to redirect the flow of the Leon River when the modern bridge was built. Prior to that time, the natural channel of the river flowed to the south of the artificial channel, such that 12 of TxDOT's 14 trenches actually were situated to the north of the former river course (see Figure 5-1).

The following sections are derived directly from Abbott's (2011) report. They are presented here, not only to provide information on the TxDOT trenching at 41HM61, but also to allow that information to be distributed on a much wider basis. When the TxDOT data are coupled with the subsequent geoarchaeological investigations conducted by Charles Frederick (presented later in Chapter 9), it becomes possible to offer an exceedingly detailed picture of the geology and associated cultural components at site 41HM61.

\begin{abstract}
Methods
As noted, 14 trenches were excavated in the project area (see Figure 5-1). Additionally, the UTM coordinates for all trenches are provided in Table 5-1. Excavation was conducted with a backhoe equipped with a three-foot, smooth-bladed bucket. Two archeologists actively monitored excavation of the trenches; one scanned the excavation while the other monitored back dirt released from the bucket for artifacts and other anomalies. Trenches were entered and scraped when the depth reached approximately $150 \mathrm{~cm}$, then continued if considered necessary to expose underlying deposits. If deeper parts of the trench were judged to merit close examination, then a safety bench up to a meter deep was cut parallel to the trench on the more southerly (sunward) side to facilitate photography. Although no trench profiles were prepared in an archeological sense, each trench was examined, photographed, and a schematic profile was prepared using criteria outlined by Olson (1976). All trenches were backfilled immediately after recording.
\end{abstract}

\section{Results}

Interpretation of the stratigraphic sequence was made with considerable reference to Nordt's (1992, 1993) work on the Leon River at Fort Hood, summarized previously in Chapter 2, with the results of the trenching organized by allostratigraphic unit. Although at least four of Nordt's units were identified, a single allostratigraphic unit dominated each trench, although thin veneers of more recent material capped several of the older units on the lower terraces. 


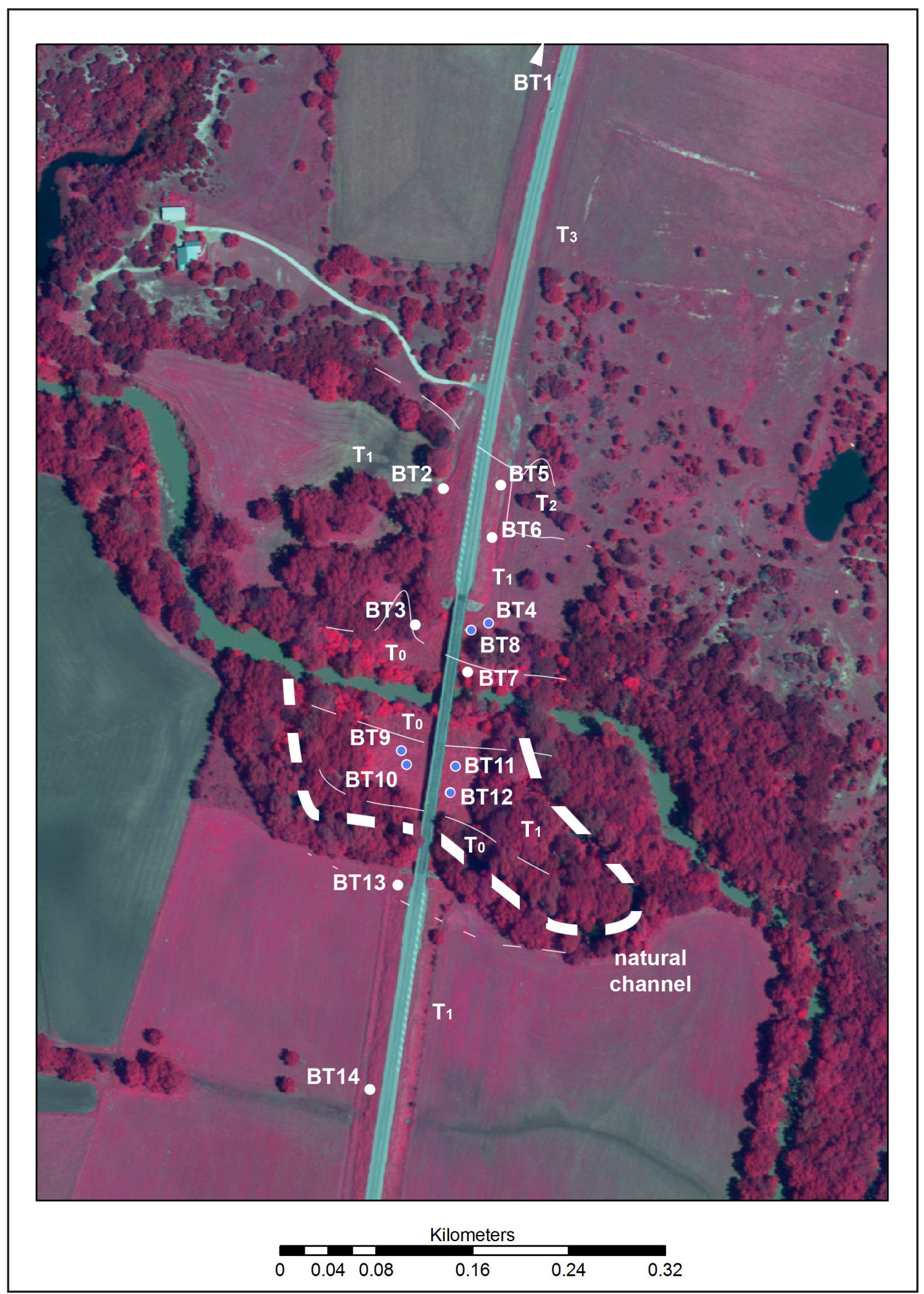

Figure 5-1. Digital ortho quarter-quadrangle (DOQQ) image of the study area showing the location of the abandoned natural channel (heavy dotted line), the approximate boundary between terraces (faint white lines), and the location of positive (blue dot) and negative (white dot) backhoe trenches. 
Table 5-1. UTM Coordinates for TxDOT Backhoe Trenches (NAD 83).

\begin{tabular}{|c|c|c|c|c|}
\hline Unit & Zone & Easting & Northing & Error ( $( \pm)$ \\
\hline BT 1 & 14 & 583275 & 3517946 & 4 \\
\hline BT 2 & 14 & 583178 & 3517540 & 5 \\
\hline BT 3 & 14 & 583160 & 3517432 & 6 \\
\hline BT 4 & 14 & 583217 & 3517424 & 6 \\
\hline BT 5 & 14 & 583230 & 3517512 & 4 \\
\hline BT 6 & 14 & 583226 & 3517472 & 5 \\
\hline BT 7 & 14 & 583189 & 3517386 & 7 \\
\hline BT 8 & 14 & 583201 & 3517420 & 6 \\
\hline BT 9 & 14 & 583143 & 3517298 & 8 \\
\hline BT 10 & 14 & 583149 & 3517290 & 8 \\
\hline BT 11 & 14 & 583186 & 3517296 & 5 \\
\hline BT 12 & 14 & 583177 & 3517272 & 6 \\
\hline BT 13 & 14 & 583134 & 3517227 & 8 \\
\hline BT 14 & 14 & 583111 & 3517034 & 7 \\
\hline
\end{tabular}

Three (possibly four) constructional alluvial surfaces were recognized in the study area (Figure 5-2; see also Figure 5-1). The two principal terraces are a low $\left(\mathrm{T}_{1}\right)$ terrace at an elevation of approximately 5 to 8 $\mathrm{m}$ above the river (300 to $303 \mathrm{~m}$ above mean sea level [amsl]) and a high $\left(\mathrm{T}_{3}\right)$ terrace at approximately 17 to $25 \mathrm{~m}$ above the stream ( 312 to $320 \mathrm{~m}$ amsl). There is also a low $\left(\mathrm{T}_{0}\right)$ floodplain that lies 1 to $1.5 \mathrm{~m}$ below the $\mathrm{T}_{1}$, and a remnant of a probable degraded $\mathrm{T}_{2}$ terrace outside the ROW fence in the northeastern quadrant of the project area (this terrace is indistinct outside the fenceline and was heavily impacted inside the ROW during construction). Further complicating the issue, as noted, the natural channel of the river was shortened by excavating an artificial channel through a $\mathrm{T}_{0}$ swale, and infilling the ends of the natural channel. Artificial levee deposits approximately $1.5 \mathrm{~m}$ thick flank this artificial channel on both sides of the stream.

Figures 5-3 through 5-7 illustrate the character of the landscape in the project area. Figure 5-3 shows a view looking north along the western ROW from the northern bridge abutment toward the $\mathrm{T}_{3}$ terrace. The backhoe is at the location of BT 2 . Note the height of the $\mathrm{T}_{3}$ surface and the way the ROW has been cut down below the elevation of the $T_{1}$ surface. Figure 5-4 shows a view looking towards the channel from approximately the same spot. It illustrates the relief between the $\mathrm{T}_{0}$ and $\mathrm{T}_{1}$, and the height of the artificial levee flanking the mechanically excavated channel. TxDOT district personnel reported that this levee has been modified several times as part of routine maintenance activity. Figure 5-5 illustrates the $\mathrm{T}_{1}$ and $\mathrm{T}_{0}$ terraces on the south side of the artificial channel, and Figure 5-6 illustrates the appearance of the artificial channel. Figure 5-7 illustrates the remains of the natural channel.

\section{Reserve Alluvium}

One trench (BT 1) was excavated on the $\mathrm{T}_{3}$ terrace, and revealed a profile equivalent to Nordt's Reserve alluvium (Figure 5-8; Appendix A). The soil was less than $2 \mathrm{~m}$ thick and consisted of reddish brown clay loam to clay with common fine, rounded siliceous gravels. Although the profile is composed primarily of 


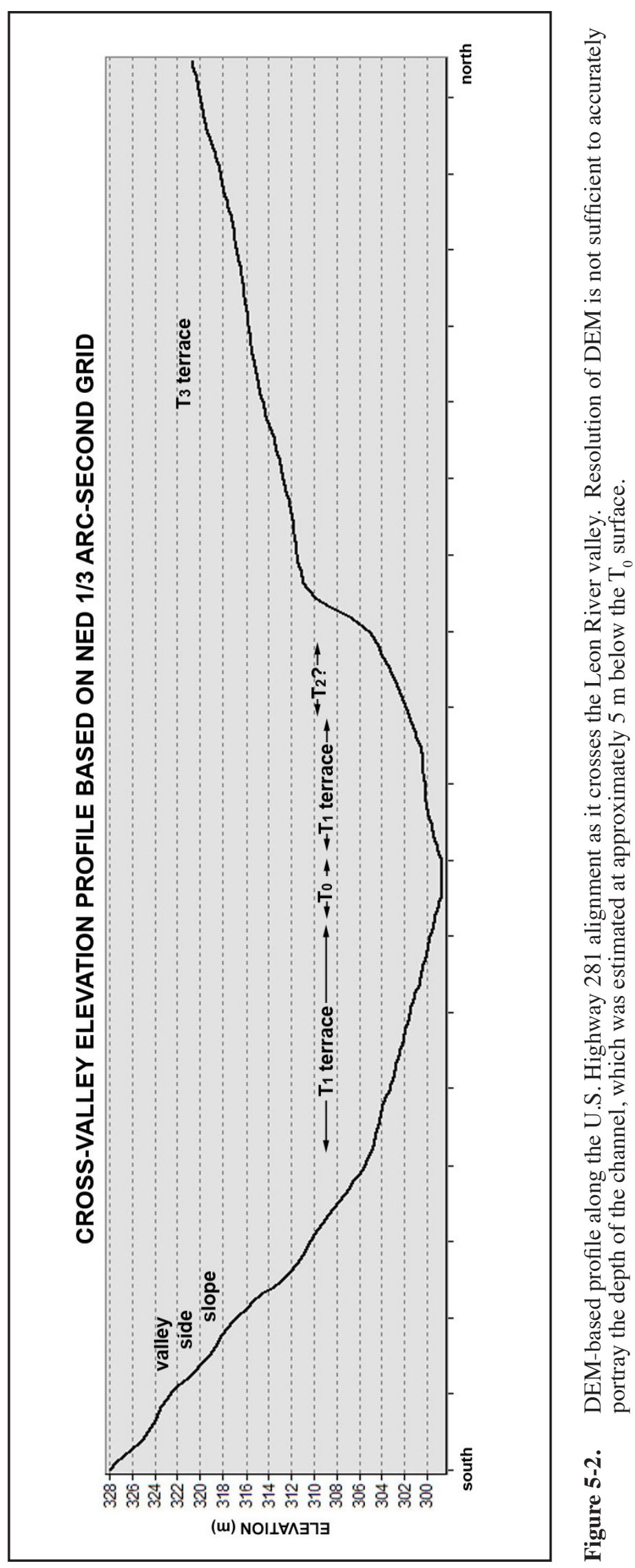




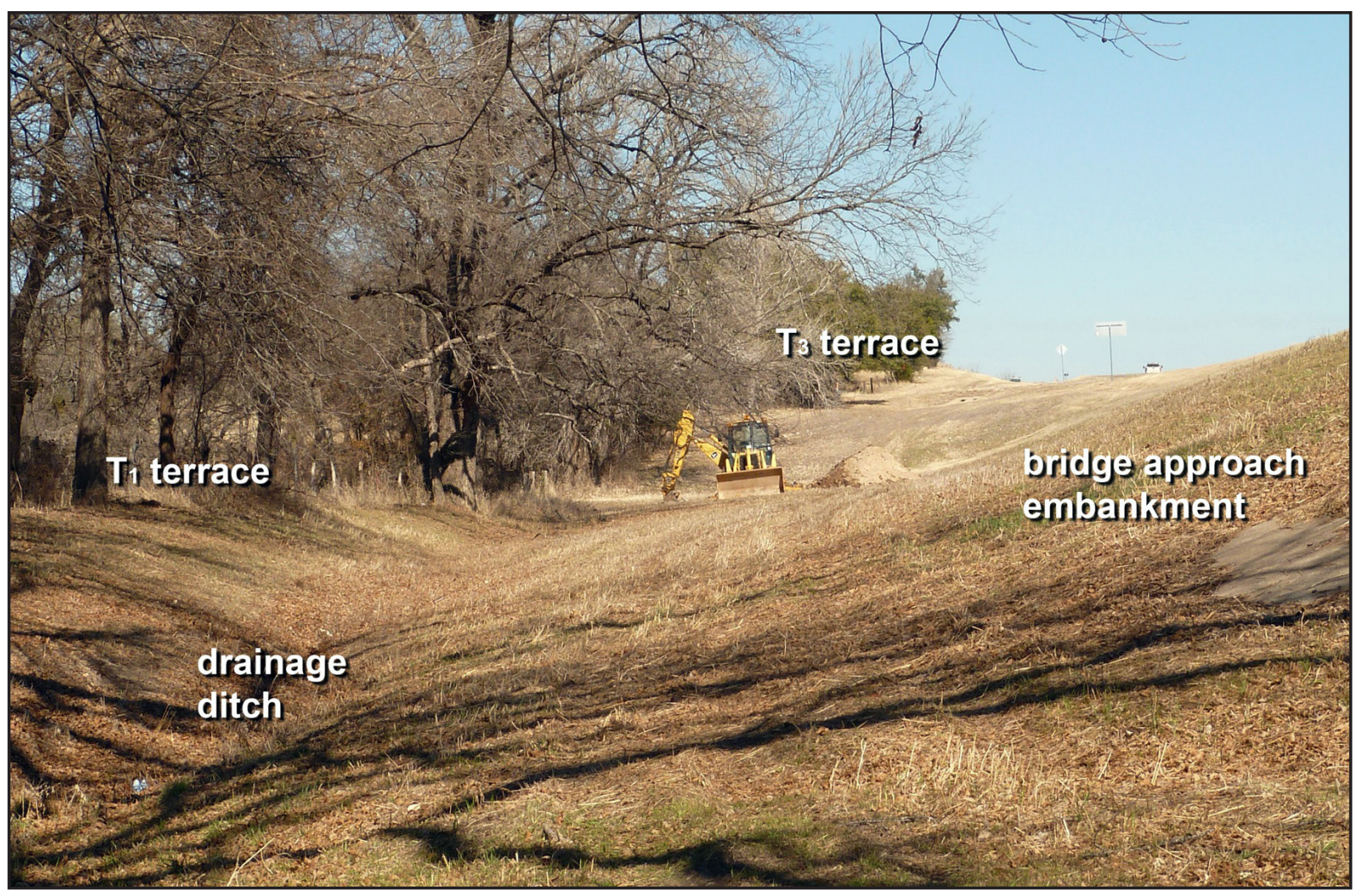

Figure 5-3. Photograph of the northwestern bridge quadrant. Backhoe is located at Backhoe Trench (BT) 2. View to the north.

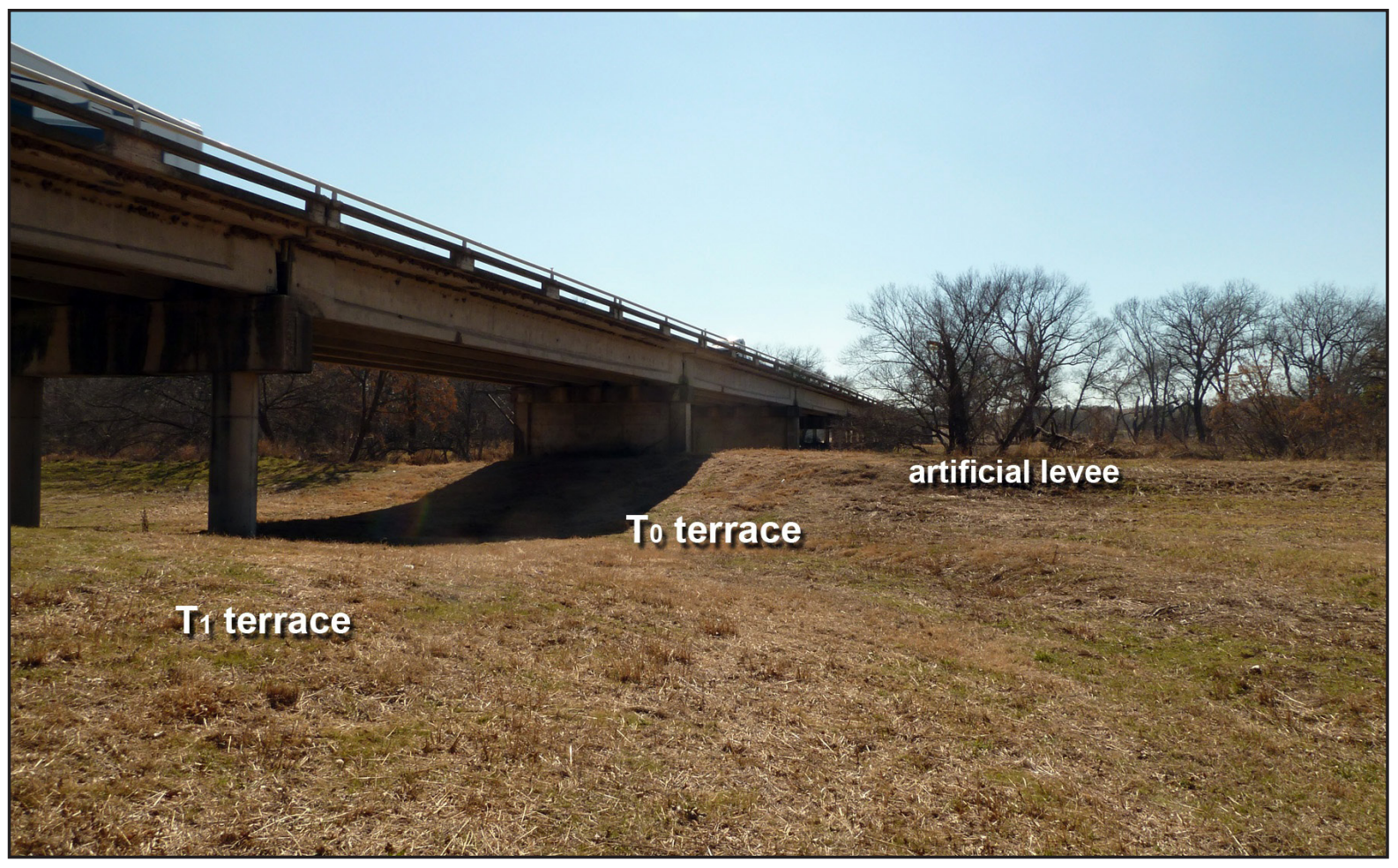

Figure 5-4. Photograph of the low terraces on the north side of the Leon River. Swale at the lower left is the terminus of the drainage ditch shown in Figure 5-3. View to the south-southeast. 


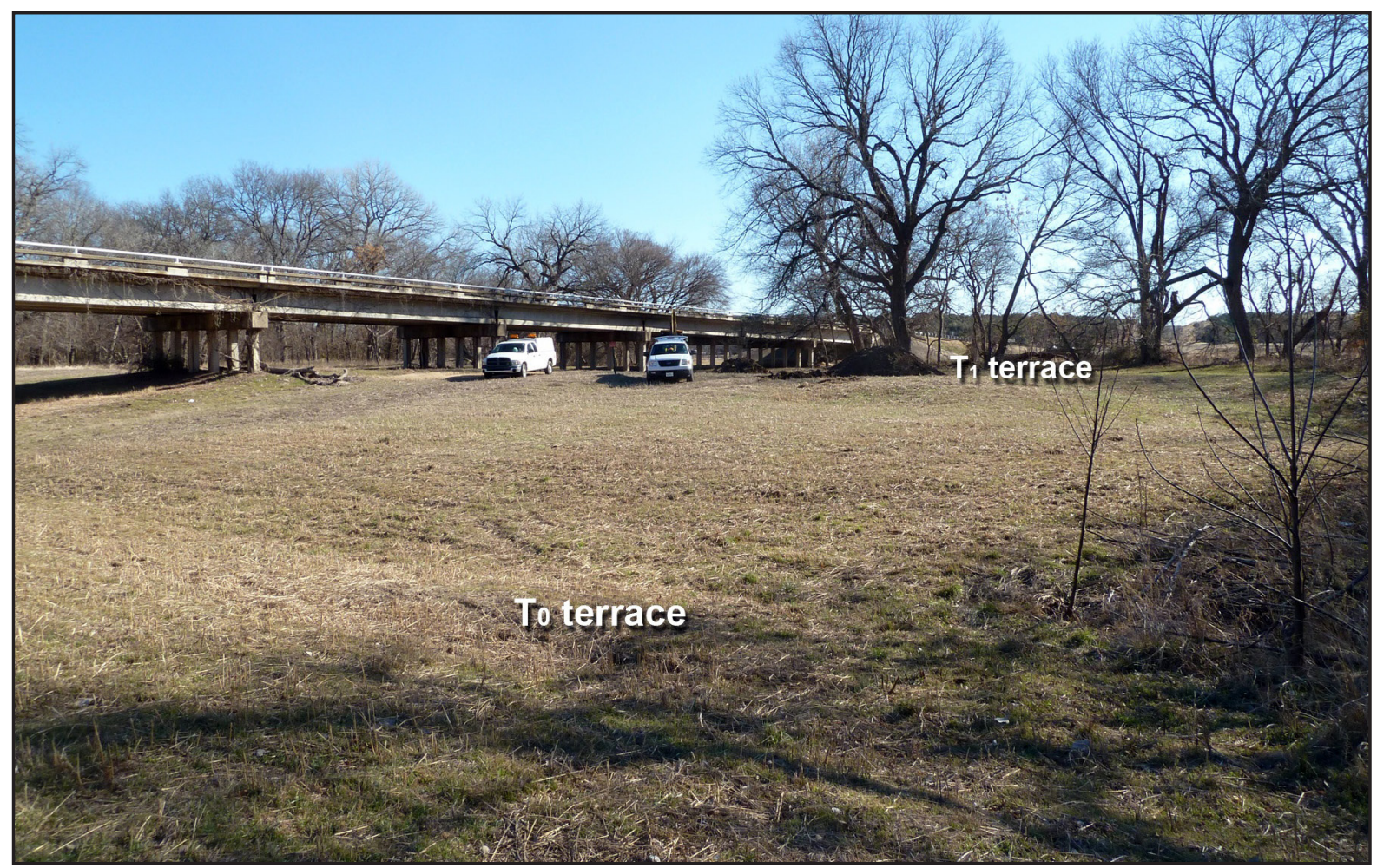

Figure 5-5. Photograph of the terraces on the south side of the artificial channel. View to the southeast.

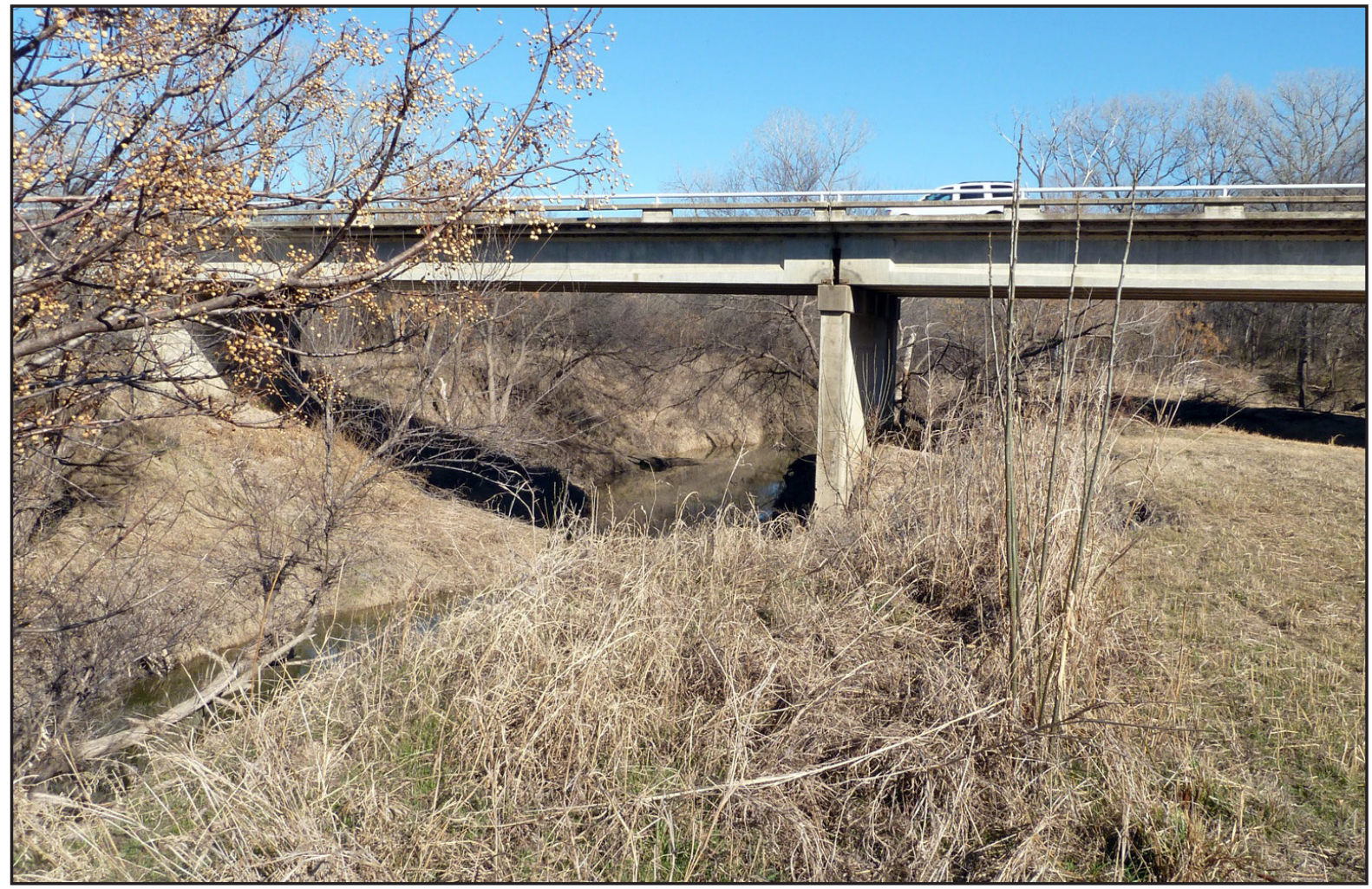

Figure 5-6. Photograph of the artificial channel. Note the slope of the artificial levee. View to the east-noretheast from its southern bank. 


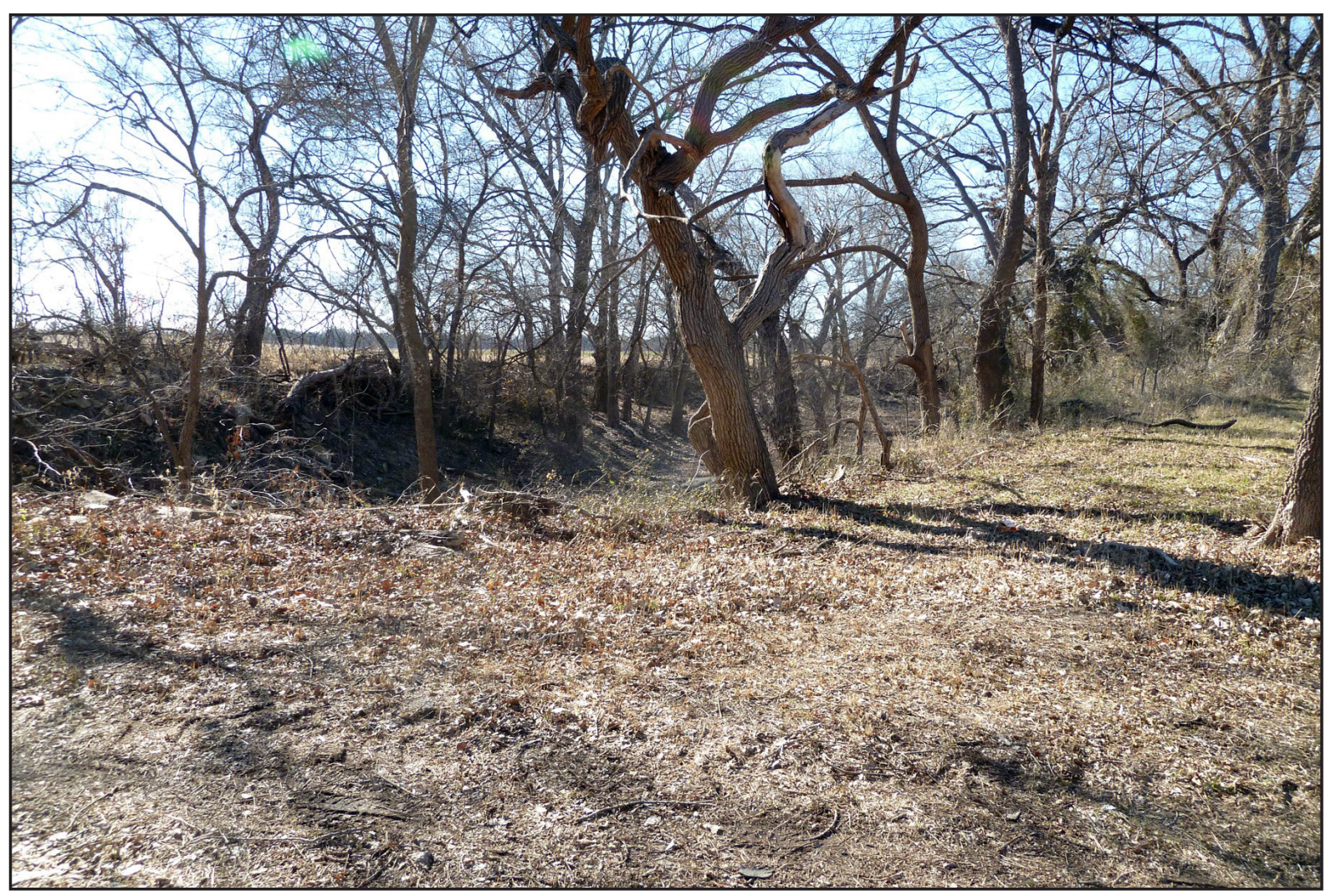

Figure 5-7. Photograph of the abandoned natural channel of the Leon River. View to west-southwest.

sandy clay and exhibited moderate structure, the material did not readily separate into peds. Short slickenside planes were noted throughout the profile, but no conclusive evidence of argillic horizon formation was observed. A few small carbonate masses were also present in the lower profile, which rested on decomposing bedrock. It is worth noting that this rubified, largely decalcified profile bears little resemblance to the heavily calcified profile of the mapped soil series (Rumley). Nordt's work suggests that the deposits on the $\mathrm{T}_{3}$ surface are substantially older than Clovis culture of the Early Paleo-Indian period. The elevation of the surface above the river and the character of the soil profile support this interpretation.

\section{Jackson Alluvium}

No deposits interpreted as Jackson alluvium were encountered in the study corridor, although it is considered possible that the mechanically truncated deposits found in BT 5 (see Appendix A) may actually represent truncated Jackson-age alluvium. Jackson alluvium is also pre-Clovis in age.

\section{Georgetown Alluvium}

Georgetown alluvium essentially spans the PaleoIndian period. No deposits interpreted as Georgetown alluvium were encountered in the study corridor.

\section{Fort Hood Alluvium}

Fort Hood alluvium, deposited during early to middle Holocene, is typified by loamy deposits that support thick, moderately developed soils with A-Bw-Bk profiles and colors that are predominantly in the 7.5YR hues. Two trenches (BTs 5 and 6), containing material tentatively interpreted as Fort Hood alluvium, were encountered at the rear of the $\mathrm{T}_{1}$ terrace east of the highway. BT 5 (Figure 5-9) was the more distal of these two units, and was only exposed at the base of a trench dominated by layered alluvial fill. This truncated unit is tentatively correlated with Nordt's (1992) Fort Hood fill on the basis of its color (7.5YR 3/4), degree of carbonate development (strong filaments), and stratigraphic location (distal low terrace). The ROW edge adjacent to BT 5 exhibited a rounded scarp about a half a meter 
high, suggesting that the natural soil had been truncated to a depth of almost two meters during the original construction of the roadway. This slightly higher surface is what is interpreted as the possible degraded $\mathrm{T}_{2}$ terrace. If this is actually the case, the unit may represent a highly truncated profile of the Jackson alluvium, but it is similar in character to the profile in BT 6. The other trench that exposed probable Fort Hood alluvium was BT 6 (Figure 5-10). This profile was essentially intact, exhibiting an A-ABk-Bk profile, but no cultural material was observed in association with the fill.

\section{West Range Alluvium}

Alluvium interpreted as Nordt's Late Holoceneage, West Range unit was encountered beneath the $\mathrm{T}_{1}$ surface in BTs 4, 8, 9, 10, 11, and 12 (Figures 5-11 through 5-14). In every case, the West Range alluvium was capped with a veneer of grayish brown, weakly weathered alluvium interpreted as Ford alluvium. The West Range fill was preserved on both sides of the artificial channel, but was not ubiquitous under the $\mathrm{T}_{1}$ terrace. Where present, it consisted of a moderately structured, very dark gray to black clayey paleosol that graded down into dense clay loam alluvium (in one case adjacent to the former channel-BT 12-the A horizon exhibits a distinct downslope catena, with the A horizon grading laterally into a very strongly structured Assb soil formed in a floodplain depression). This soil typically exhibits an A (or Ak, or in the case of BT 12, Akss)-[ABk]-Bk profile with colors in the 10YR hues. Cultural material in the form of sparse mussel shell clusters; isolated small burned limestone and sandstone fragments; occasional small, amorphous clusters of burned rock; and occasional fragments of charcoal were noted in all of these trenches. Additional materials noted in a few of the trenches (BTs 4, 11, and 12) include limited burned earth, minor amounts of bone, and very sparse lithic debitage (the latter in BT 11 only). Table 5-2 lists the cultural material associated with each alluvial deposit in those trenches yielding such remains. No tools or prehistoric features were recovered from, or noted in, any of the trenches.

Although the material associated with the West Range unit is clearly of cultural origin, the character of this debris is somewhat troubling. Cultural material is typically distributed haphazardly through up to 60 to $70 \mathrm{~cm}$ of the profile, with few obvious zones of stratigraphic concentration. Given the low concentration of material, its geographic ubiquity in the West Range paleosol, the generally small size of recovered clasts (most burned rocks were fist-sized or smaller), the lack of observed features, and the dispersion of material through more than half a meter of slowly accumulating floodplain soil, there is a strong possibility that some or all of this material represents artifacts reworked from the nearby Sprague (41HM43) and/ or Upper Sprague (41HM54) sites (see Figure 4-1) and washed downstream to the present project area. However, this is far from certain, and NRHP eligibility testing of the unit is recommended.

\section{Ford Alluvium}

Ford alluvium is the most recent alluvial fill described in the Leon River valley. Deposits correlated with the Ford alluvium made up the entirety of BTs 2, 3,13 , and probably 14 (Figures 5-15 through 5-18). In BTs 4, 8, 9, 10, 11, and 12, Ford-age alluvium overrides and buries the preceding West Range alluvium. Finally, in BT 7, Ford alluvium is itself capped with approximately $1.5 \mathrm{~m}$ of artificial levee deposits (Figure 5-19).

The Ford alluvium varies considerably in appearance, but consists of loamy, clayey, and occasional sandy deposits that retain subtle to prominent color stratification and limited pedogenic overprinting. Colors are generally in the 10YR range, varying through grayish brown, brown, and dark gray, with sandy deposits at depth tending to pale brown and light brownish gray. In general, the color of the sediment correlates with its texture, with finer-grained sediments tending to be darker. Although there is limited melanization of the upper deposit (A horizon development), most sediment color appears to be inherited from the parent material. The main exception to this generalization is BT 14, which was excavated adjacent to a former channel or overflow chute swale on the $\mathrm{T}_{1}$ terrace south of the former river channel (see Figures 2-3 and 5-1). There, a relatively strong, vertic A horizon has developed in a dense overbank clay, and primary stratification is not apparent. This deposit is tentatively interpreted as a distal overbank facies of the Ford alluvium based on sediment color, pedogenic character, and the absence of a recognizable drape, although it could represent a facies of either of the older Holocene units.

The distribution of Ford alluvium in the backhoe trenches suggests that it underlies both the $T_{1}$ and $\mathrm{T}_{0}$ surfaces. The $\mathrm{T}_{0}$ surfaces appear to represent swales and chute channels carved into the $\mathrm{T}_{1}$ surface by scouring flow. Where older (i.e., West Range and possibly Fort Hood) units are preserved, 


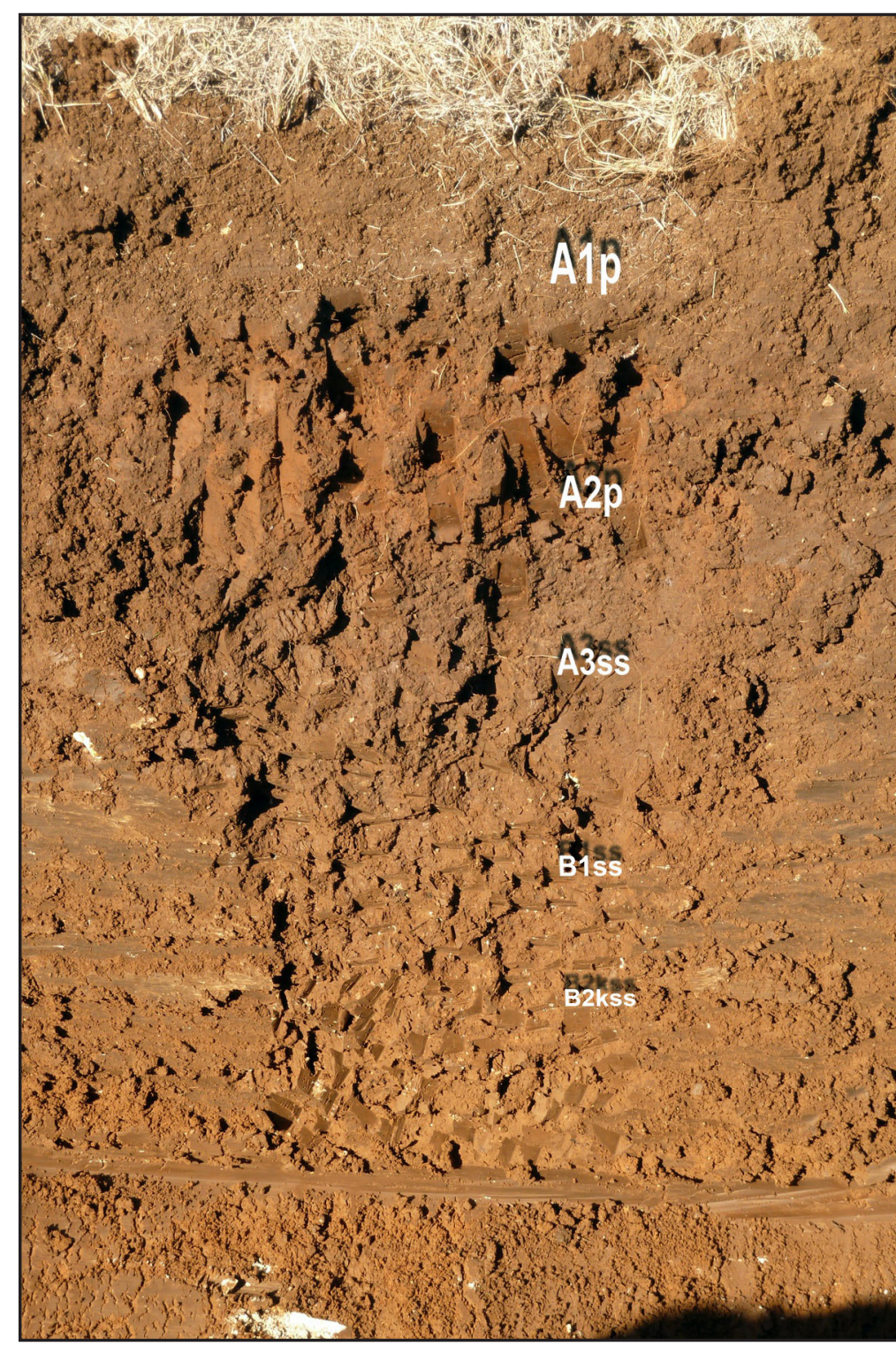

Figure 5-8. Oblique vertical photograph of the profile of $\mathrm{BT} 1$ (ReOblique vertica)
serve alluvium)

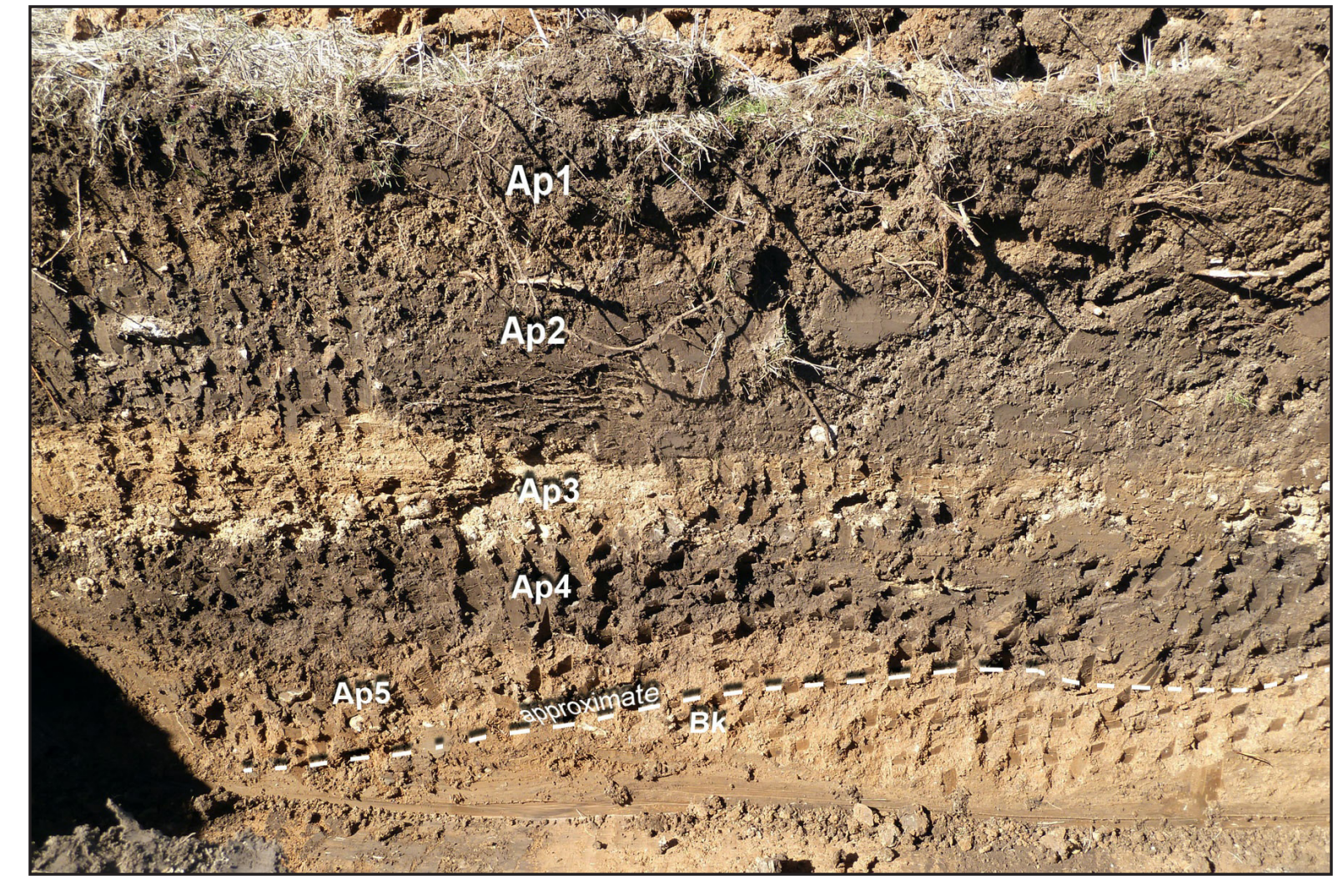

Figure 5-9. Oblique vertical photograph of the profile of BT 5, which consisted of approximately $1.25 \mathrm{~m}$ of layered artificial fill over a truncated brown alluvial unit tentatively correlated with Nordt's Fort

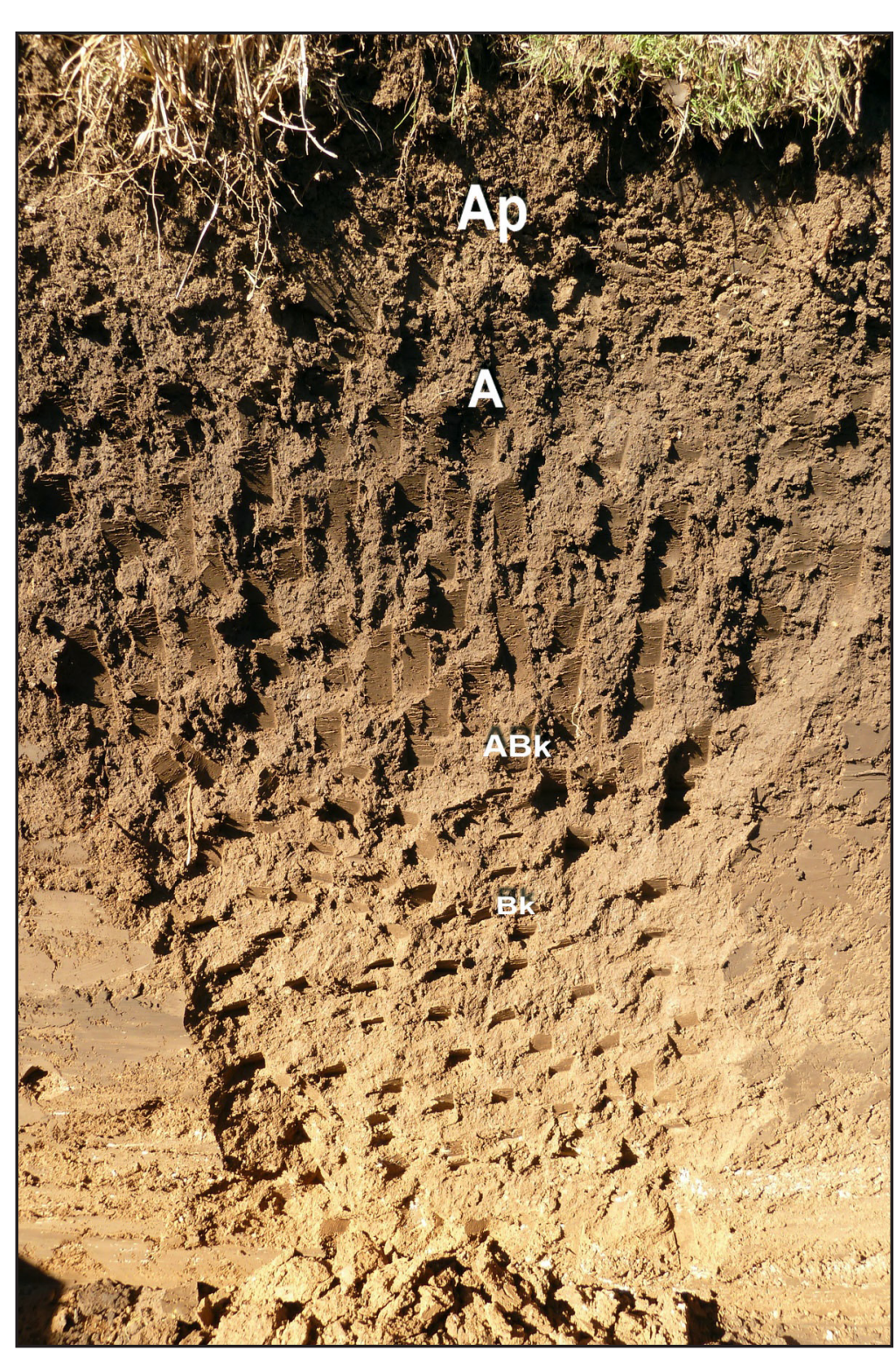
Figure 5-10. Oblique vertical photograph of the profile of BT 6 (Fort 



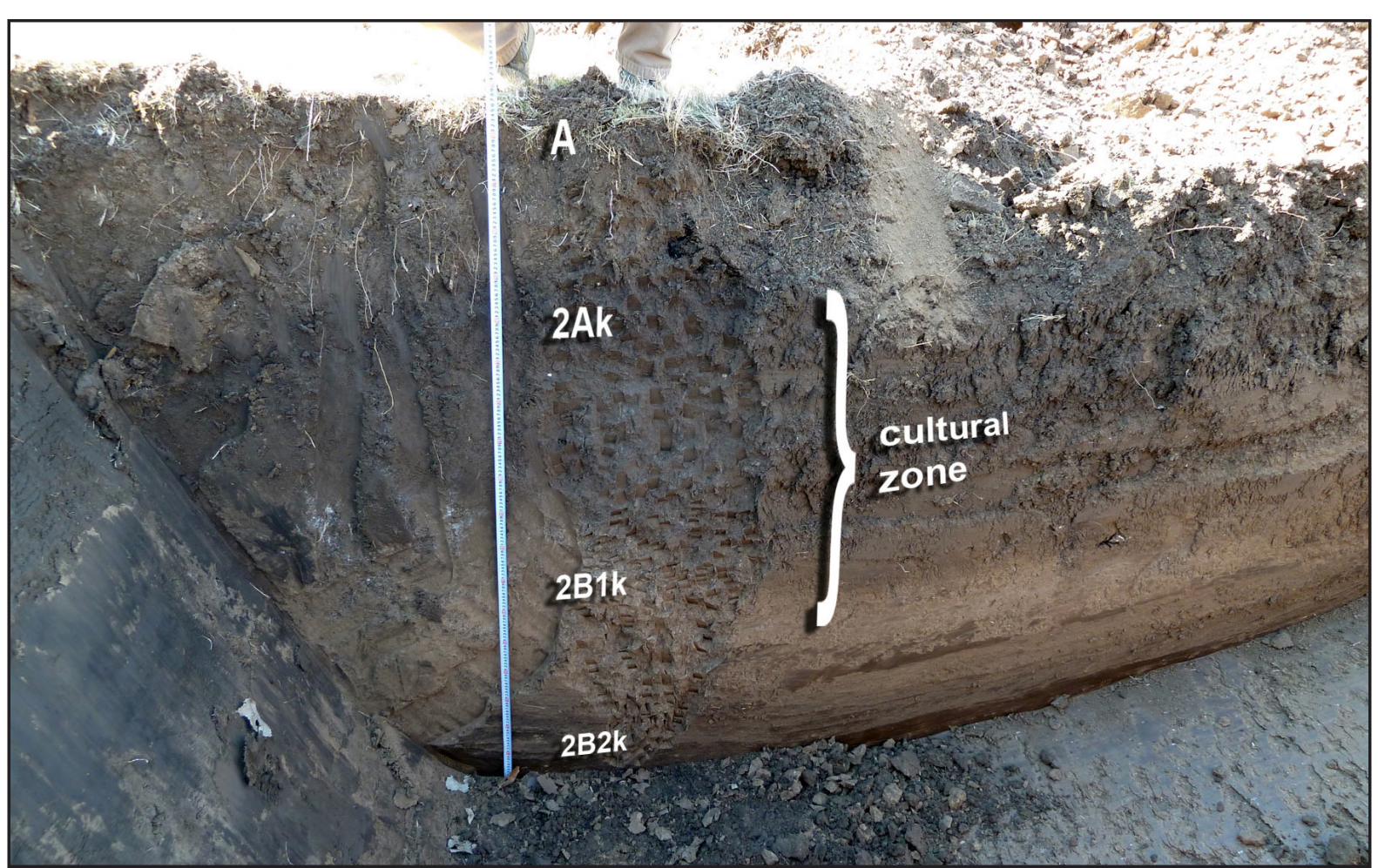
Figure 5-11. Oblique vertical photograph of the profile of BT 4 (West Range alluvium with veneer of Ford
alluvium) showing the stratigraphic context of cultural material.
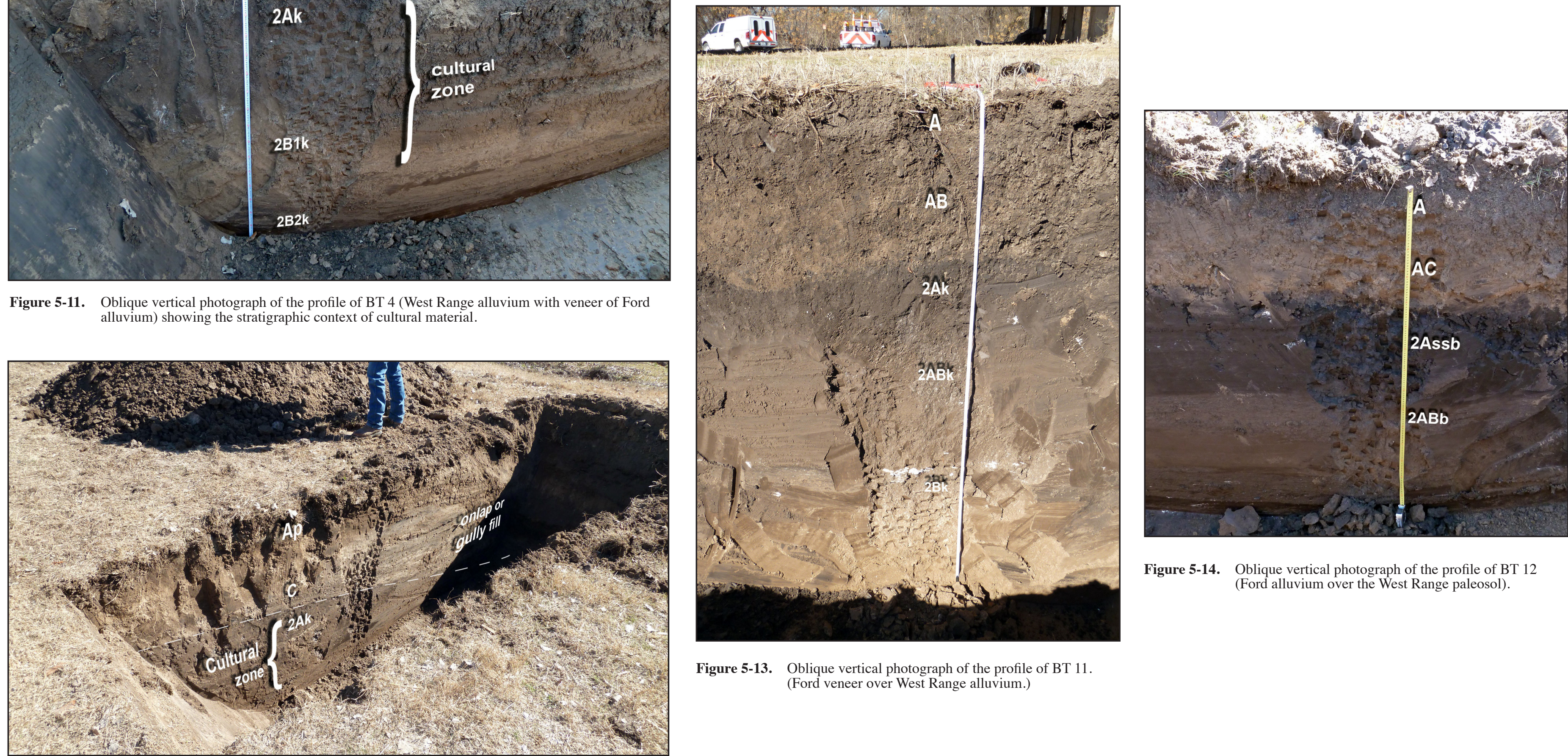

Figure 5-14. Oblique vertical photograph of the profile of BT 12

Figure 5-13. Oblique vertical photograph of the profile of BT 11.
(Ford veneer over West Range alluvium.) Figure 5-12. Photograph of the profile of BT 8 showing stratigraphic context of the West Range alluvium
cultural zone and onlap of Ford-age alluvium. 



\begin{tabular}{|c|c|c|c|c|}
\hline \multirow[t]{2}{*}{ Table 5-2. } & \multicolumn{4}{|c|}{$\begin{array}{l}\text { Zones of Cultural Material Identified in the Six Positive Backhoe Trenches Excavated by TxDOT } \\
\text { Personnel. }\end{array}$} \\
\hline & Depth (cm) & Horizon & Alluvium & Cultural Material \\
\hline \multicolumn{5}{|l|}{ BT 4} \\
\hline Zone 1 & $0-70$ & A & Ford & None \\
\hline Zone 2 & $70-110$ & $2 \mathrm{Ak}$ & West Range & mussel shell, burned rock, bone \\
\hline Zone 3 & $110-150$ & $2 \mathrm{~B} 1 \mathrm{k}$ & West Range & mussel shell, burned rock, bone \\
\hline Zone 3 & $150-185$ & $2 \mathrm{~B} 1 \mathrm{k} / 2 \mathrm{~B} 2 \mathrm{k}$ & West Range & None \\
\hline \multicolumn{5}{|l|}{ BT 8} \\
\hline Zone 1 & $0-80$ & $\mathrm{Ap} / \mathrm{AC}$ & Ford & None \\
\hline Zone 2 & $80-180$ & $2 \mathrm{Ak}$ & West Range & mussel shell, burned rock, charcoal, bone \\
\hline Zone 2 & $180-200$ & $2 \mathrm{Ak}$ & West Range & None \\
\hline \multicolumn{5}{|l|}{ BT 9} \\
\hline Zone 1 & $0-70$ & A & Ford & None \\
\hline Zone 2 & $70-105$ & $\mathrm{C}$ & Ford & None \\
\hline Zone 3 & $105-130$ & $2 \mathrm{~A} / \mathrm{C}$ & Ford & None \\
\hline Zone 4 & $130-220$ & $2 \mathrm{Ak}$ & West Range & mussel shell, burned rock, charcoal \\
\hline Zone 5 & $220-300$ & $2 \mathrm{ABk}$ & West Range & None \\
\hline \multicolumn{5}{|l|}{ BT 10} \\
\hline \multicolumn{5}{|c|}{ Same as BT 9} \\
\hline \multicolumn{5}{|l|}{ BT 11} \\
\hline Zone 1 & $0-30$ & $A(p)$ & Ford & None \\
\hline Zone 2 & $30-60$ & $A(p) B$ & Ford & None \\
\hline Zone 3 & $60-100$ & $2 \mathrm{Ak}$ & West Range & mussel shell, burned rock, lithics \\
\hline Zone 4 & $100-150$ & $2 \mathrm{ABk}$ & West Range & mussel shell, burned rock, lithics \\
\hline Zone 5 & $150-160$ & $2 \mathrm{Bk}$ & West Range & mussel shell, burned rock \\
\hline Zone 5 & $160-210$ & $2 \mathrm{Bk}$ & West Range & None \\
\hline \multicolumn{5}{|l|}{ BT 12} \\
\hline Zone 1 & $0-20$ & A & Ford & None \\
\hline Zone 2 & $20-50$ & $\mathrm{AC}$ & Ford & None \\
\hline Zone 3 & $50-90$ & 2Assb & West Range & mussel shell, burned rock, charcoal \\
\hline Zone 4 & $90-150$ & $2 \mathrm{ABb}$ & West Range & mussel shell, burned rock, charcoal \\
\hline Note: & $\begin{array}{l}\text { ndicates zonese that } \\
\text { at depths ranging }\end{array}$ & $\begin{array}{l}\text { ed cultura } \\
150 \text { and } 2\end{array}$ & 1. All of th & ural material came from the West Range \\
\hline
\end{tabular}

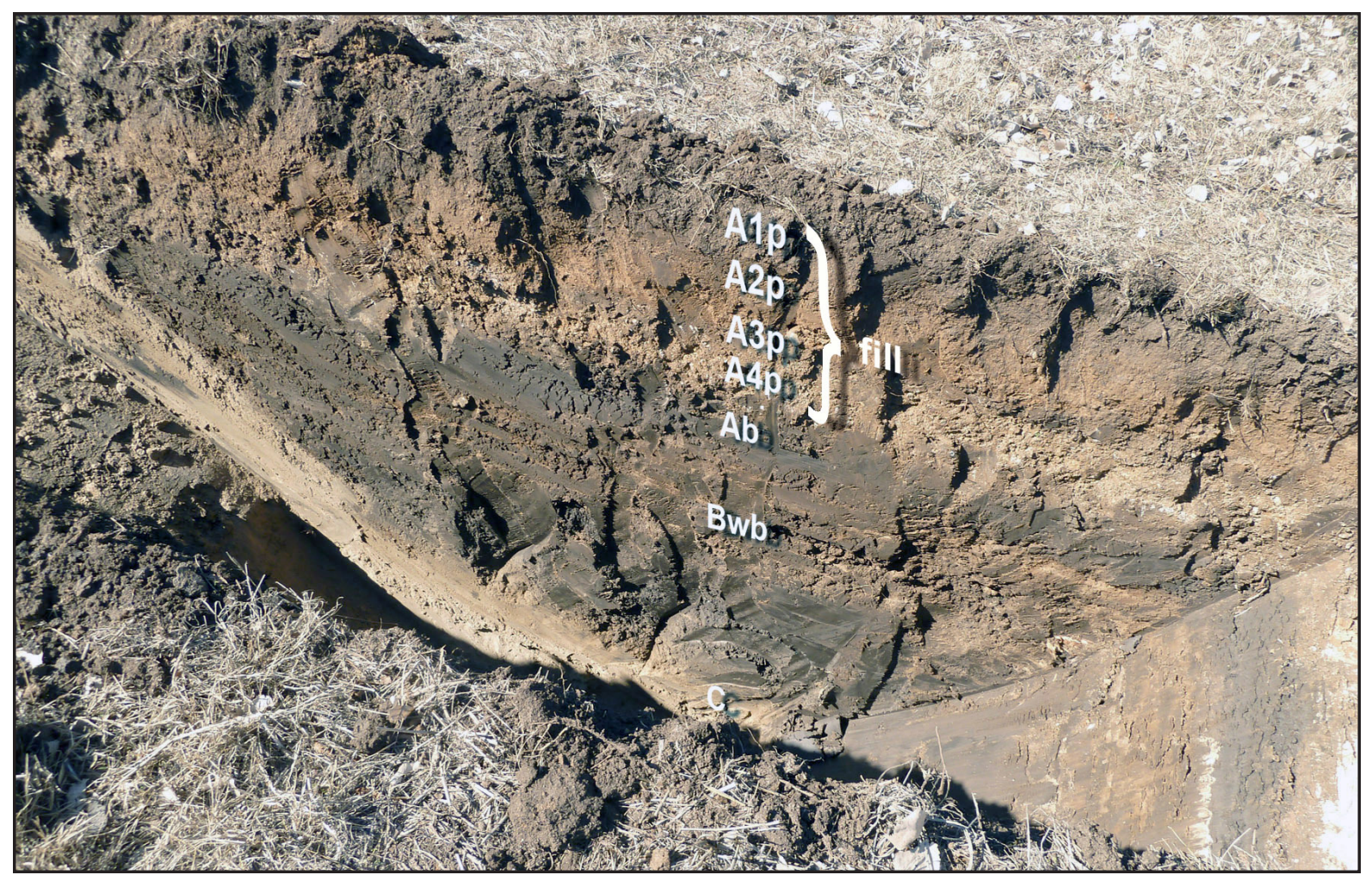

Figure 5-15. Photograph of the profile of BT 2 (Ford alluvium).

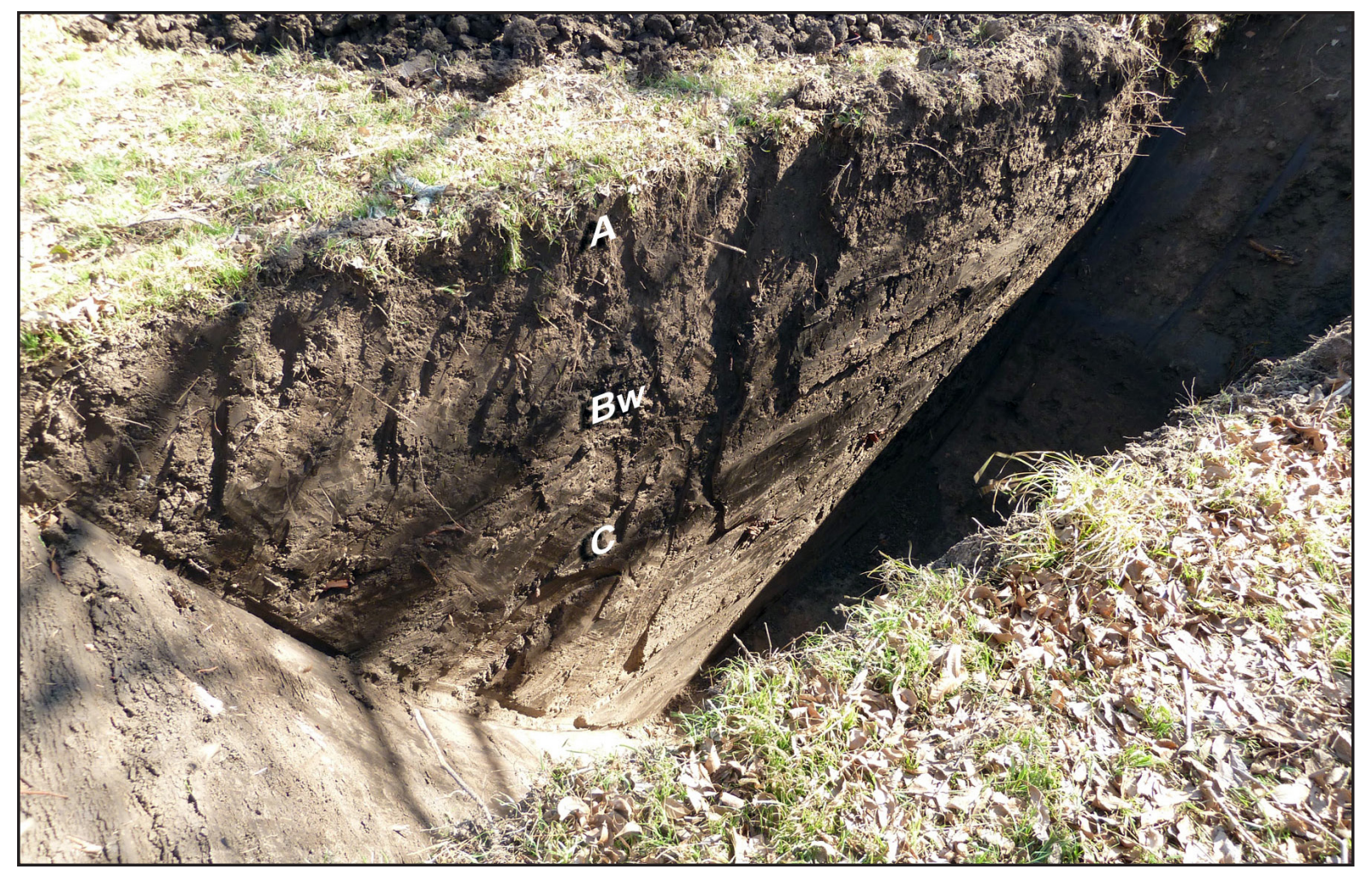

Figure 5-16. Oblique photograph of the profile of BT 3 (Ford alluvium) 



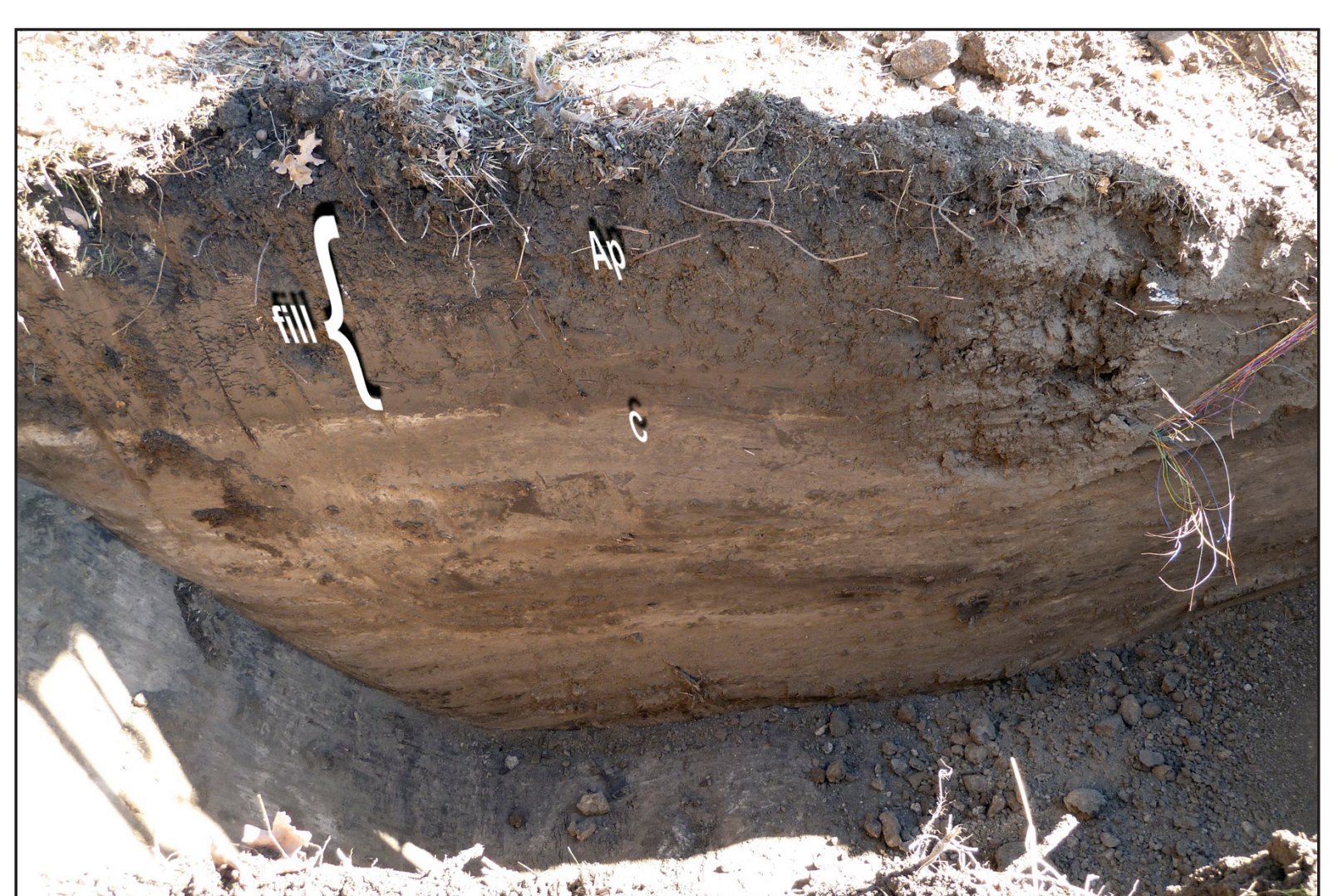

Figure 5-17. Oblique vertical photograph of the profile of BT 13 (Ford alluvium).

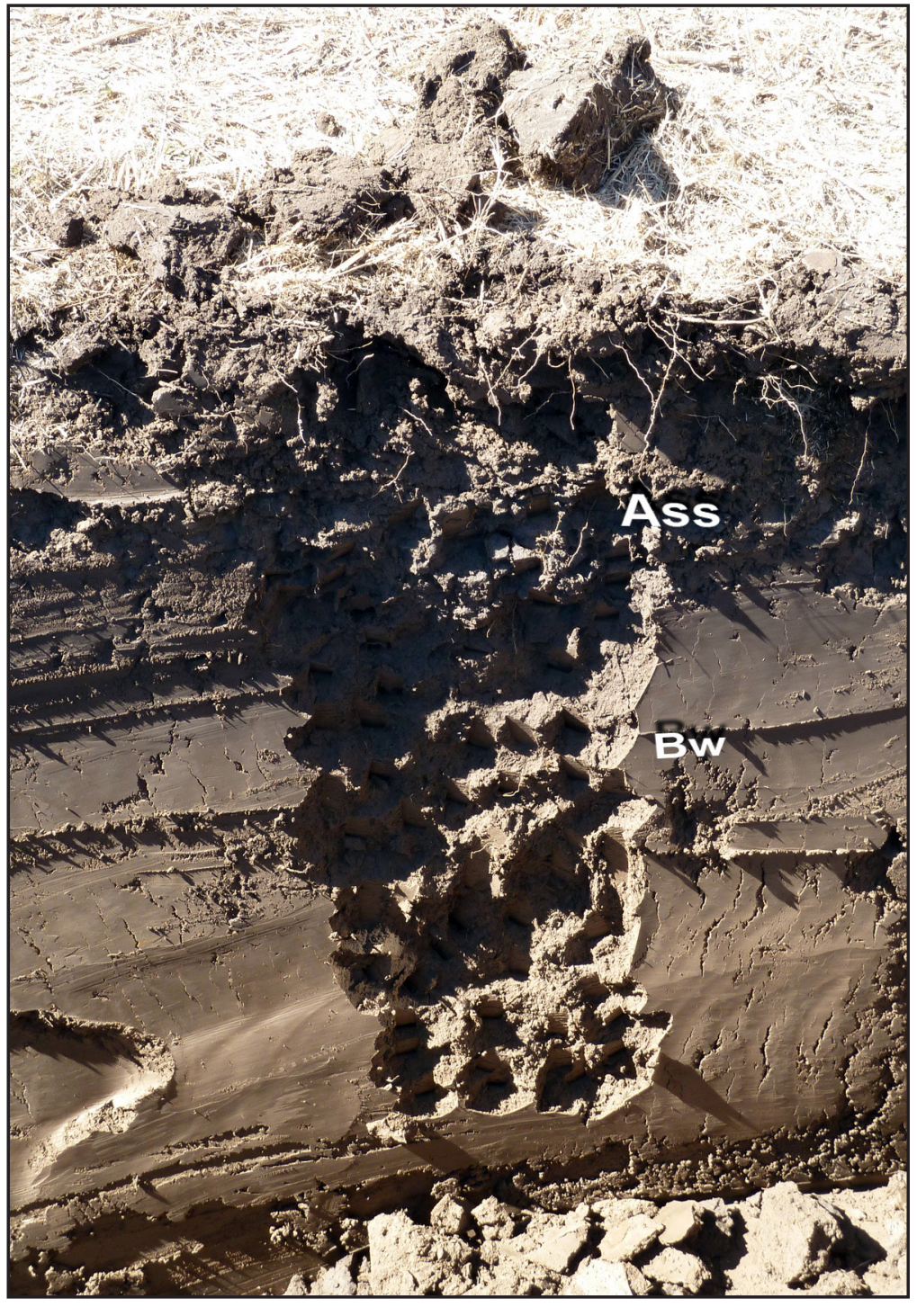
Figure 5-18. Oblique vertical photograph of the profile of BT 14
(probable Ford alluvium).

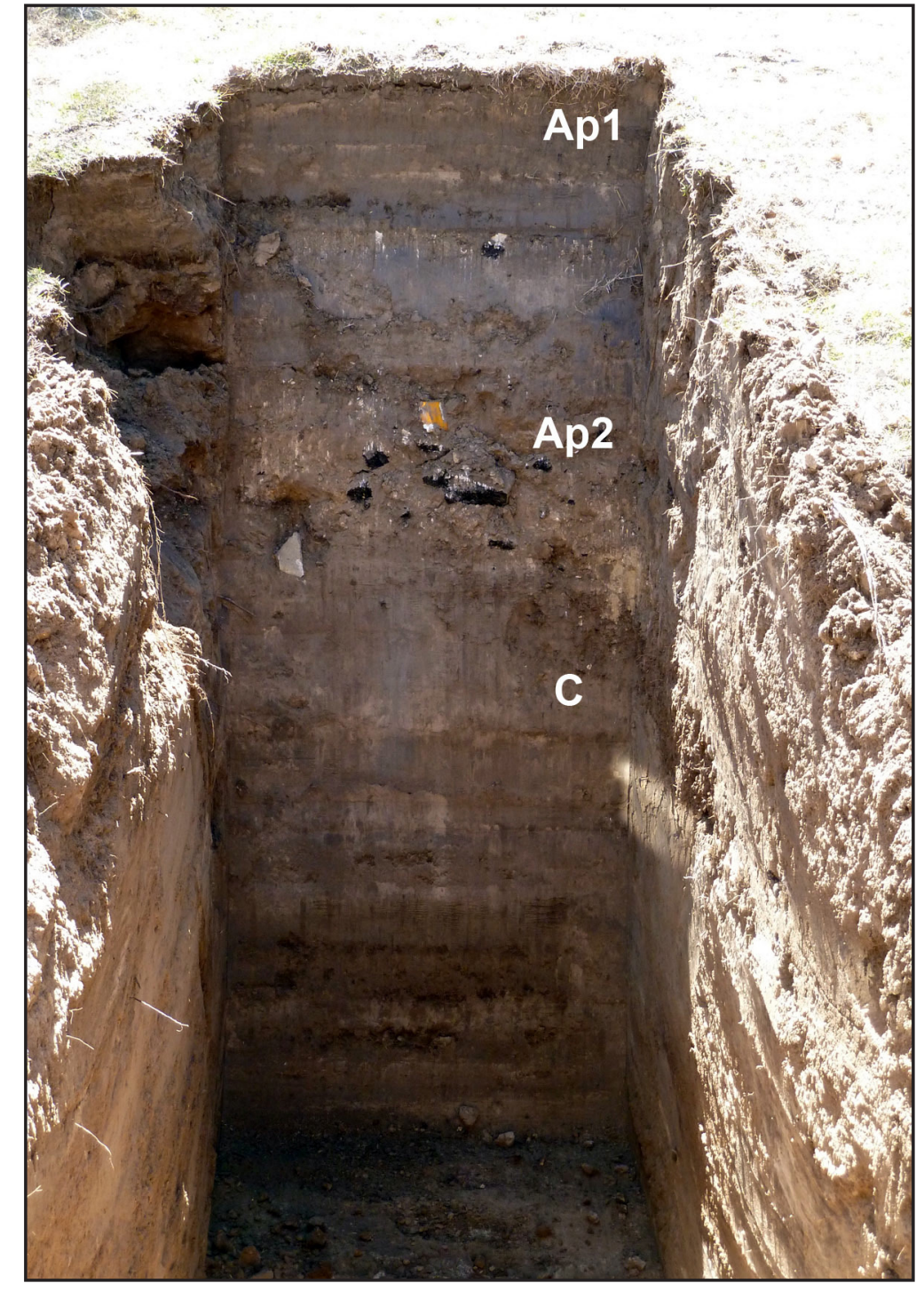

Figure 5-19. Photograph of the profile of the end wall of BT 7 showing a section through the artificial levee. Note construc-
tion debris with artificial fill over the Ford alluvium. 

the Ford alluvium is present as a surficial veneer. In other places, however, lateral erosion has removed these older units and the Ford is the only unit preserved. A buried scarp marking the margin of one of these fill boundaries is present somewhere beneath the northern approach embankment of U.S. Hwy. 281, and separates the thick deposits of Ford alluvium in the northwestern bridge quadrant from the older profiles east of the road and south of the artificial channel. No cultural material was noted anywhere in the Ford alluvium.

\section{Summary of TxDOT Trenching}

Trenching investigations at U.S. Hwy. 281 and the Leon River revealed deposits representing at least four distinct allostratigraphic units, which are correlated with units defined by Nordt (1992) on the Leon River at Fort Hood. Trench investigations suggest that archeological materials in the study area are restricted to the late Holocene, West Range fill. Although traces of cultural material are common in the buried soil associated with this fill, it is relatively sparse and limited in character, and it is not clear whether the material is in primary or secondary context. NRHP eligibility testing is recommended, but investigators should pay particular attention to contextual indications in evaluating the results.

\section{NRHP Testing Plans}

Regardless of the questionable nature of the cultural material uncovered in the trenches, it was decided that the area where cultural material had been found should be accorded site status. Thus, TxDOT filed the necessary paperwork to record the site with the Texas Archeological Research Laboratory. The area at the U.S. Hwy. 281 bridge over the Leon River was assigned trinomial 41HM61.

In accordance with the TxDOT findings just summarized, CEI then proposed to reopen at least one of the trenches in each of the three segments of the project area where cultural remains had been found, i.e., either BT 4 or 8 in the northeast portion of the project area, either BT 11 or 12 in the southeast segment of the project area, and either BT 9 or 10 in the southwest part of the project area. Once the walls of these trenches had been profiled and photographed, then an additional $70 \mathrm{~m}$ of trenches would be excavated to better define and delimit the cultural remains. After that, the eight witness columns would be excavated, followed by at least $12 \mathrm{~m}^{3}$ of hand-excavated 1-by-1-m units that collectively would form several block excavations positioned over distinct cultural zones and/or recognizable features, should any be encountered. The following three chapters review the results of the additional backhoe trenches, the witness columns, and the block excavations. 


\title{
Chapter 6
}

\section{Mapping ANd AdDitional Backhoe Trenching}

\author{
Charles D. Frederick \\ Richard A. Weinstein
}

As with most archaeological testing projects, the first order of business at site 41HM61 was the establishment of a permanent site datum and the creation of a contour map of the project area. Since the area north of the artificial channel and east of the highway offered a relatively clear area within which to begin work, it was decided to place the main site datum near the eastern edge of the highway ROW fence, immediately adjacent to a gate leading from the ROW to a pasture owned by local resident Rodney Cozby. A 2-ft-long iron rebar was pounded into the ground at that location, with about an inch or two of the rebar sticking out of the soil to aid in identification should it be necessary to relocate the datum at a later date. The datum was assigned grid coordinates N600E600, and an arbitrary elevation of $100 \mathrm{~m}$. A secondary permanent datum then was placed $40 \mathrm{~m}$ to the north, at N640E600 and also marked by an iron rebar pounded into the ground.

Once the data points were established on the northern part of the site, a Sokkia SET 2110 total station then was employed to obtain elevation readings in order to create a contour map of the site area within the TxDOT ROW. Again, the arbitrary datum of $100 \mathrm{~m}$ was used to create the contour map. The north part of the site was mapped first and then the total station was moved to the south side of the artificial channel to continue mapping in that area (Figure 6-1). Overall, 796 elevation readings were taken to produce the contour map illustrated in Figure 6-2.
In addition, two more permanent data points were positioned on the south side of the site for ease in reestablishing the site grid in that area should only the south portion be selected for future archaeological investigations. These also consisted of 2-ft-long rebars positioned just inside the wooded area at the eastern edge of the ROW. Again, an inch or two of each rebar was left exposed above the ground surface to aid in relocation. The two rebars were placed at grid coordinates N460E620 and N480E620.

\section{Additional Backhoe Trenching}

As noted in the "Introduction," CEI was to excavate a minimum of $70 \mathrm{~m}$ of backhoe trenches in an effort to better understand the geology at the site and to locate intact midden and/or cultural features. These trenches were to be placed in the general vicinity of TxDOT's earlier BTs 4, 8, 9 10, 11 and 12 . Before the CEI trenches were excavated, however, it was decided to reopen and record the stratigraphy in TxDOT's BTs 4, 9, and 11 (Figure 6-3). These were the trenches that had produced the most cultural material and appeared to offer the best opportunity for gaining initial insight into the site's stratigraphy. It also was thought that these trenches could aid in the identification of those locations where additional trenching would be most productive.

Once BTs 4, 9, and 11 had been reopened and examined, eight additional trenches (BTs 15 through 22) 
were excavated (Figure 6-4). ${ }^{1}$ Since the site is basically divided into two main sections (that area north of the channelized Leon River and that area south of the channelized river), the following discussion will be divided in like a manner. Not only does this division make sense from a topographic point of view, it also makes sense from a cultural perspective as the two site areas primarily produced different cultural components. Since backhoe trenching began in the southern section, and since the majority of the trenching occurred there, that area of the site will be reviewed first.

\section{South Section}

TxDOT's BTs 9 and 11 were reopened and three additional trenches (BTs 15, 16, and 17) were excavated in the site area south of the channelized Leon River (Figure 6-5). East of the bridge, BT 11 was reopened and BTs 15 and 16 were added (Figures 6-6 through 6-9).

Owing to difficulty in precisely locating TxDOT's original BT 11, re-excavation of that trench expanded the width of the original trench towards the east, forming a trench that was about $2 \mathrm{~m}$ wide by $4 \mathrm{~m}$ long. BT 16 then was dug from the southern end of expanded BT 11 towards the east for $8 \mathrm{~m}$. BT 15 was placed down about a meter west of the west wall of BT 11 and extended in a north-south line for $39 \mathrm{~m}$, eventually extending south of the location of previously excavated BT 12 (see Figure 6-5).

All three of these trenches revealed the same stratigraphy plus a relatively large quantity of cultural remains (Figures 6-10 to 6-12). Basically, a very prominent A horizon, ca. 30 to $50 \mathrm{~cm}$ thick, was present in the upper portion of the West Range alluvium across all of the area, with a lower, less pronounced A horizon situated about 20 to $60 \mathrm{~cm}$ beneath the upper A horizon, depending on the trench in which it occurred. The upper A horizon usually was located beneath 20 to $30 \mathrm{~cm}$ of a disturbed zone resulting from highway and bridge construction. Importantly, there appeared to be at least two distinct occupation levels associated with the upper A horizon, one near the top and one near the horizon's base. Both were marked by scattered burned rocks, several concentrated areas of burned rocks which were assigned feature numbers, scattered mussel shells, and lithic debris. One Marcos dart point

1 All CEI backhoe trenches were assigned numerical designations beginning where the TxDOT designations had ended. Since TxDOT had excavated BTs 1 through 14, the first CEI trench simply was identified as BT 15 .
(FS 371) was found in the east wall of the middle portion of BT 15 near the base of the upper A horizon.

A list of all features identified during the backhoe trenching, including the location of each feature within its respective trench, is provided in Table 6-1. Likewise, the locations of those features uncovered by the southern trenches can be seen in Figures 6-13 and 6-14. In some instances, a feature was exposed in the floor of a trench while the trench was being dug. At that point, rather than cutting through the feature, excavation of that part of the trench was halted and the feature left in place on a raised pedestal within the trench. One pedestal is particularly noticeable on the east wall profile of BT 15 (see Figure 6-11). There, a concentration of fire-cracked rocks and a few mussel shells was encountered and identified as Feature 1. Excavation of the trench continued to the north and south of the Feature 1 pedestal, but that pedestal and the feature never were removed. In other instances, features were encountered only after a trench had sliced through part of them, leaving the remaining portion exposed in the trench's wall. Such a feature is shown on Figures 6-13 and 6-14 by a solid green line positioned on the trench wall for the distance of the exposed shell or fire-cracked rock that served to define it. Feature 18, a linear deposit of mussel shells, also exposed in the east wall of BT 15, is a good example of such a situation (see Figures 6-11 and 6-13). Witness columns and/or block excavations subsequently examined several of these trench-wall features.

Besides the features uncovered by the BTs, it should be noted that every piece of cultural material (artifacts, bones, shells, burned rocks, etc.) identified in the walls of the trenches was given a Field Specimen (FS) number in a sequence of FS numbers assigned specifically to the trenches. Each item was piece plotted by means of the total station and then placed in its own collection bag along with a tag listing its FS number (Figure 6-15). The locations of many of these FSs also were included on the various profile drawings of the trench walls. It was hoped that plotting these items would both confirm the presence of those occupation surfaces seen in the trench walls plus reveal similar surfaces not recognized during the fieldwork. Table 6-2 provides a tally of all items recorded as an FS during the backhoe trenching, while Appendix B lists the material collected as an individual trench-related FS.

As noted above, below the A horizon was additional evidence of occupation in the form of concentrations of burned rocks, mussel shells, and combina- 


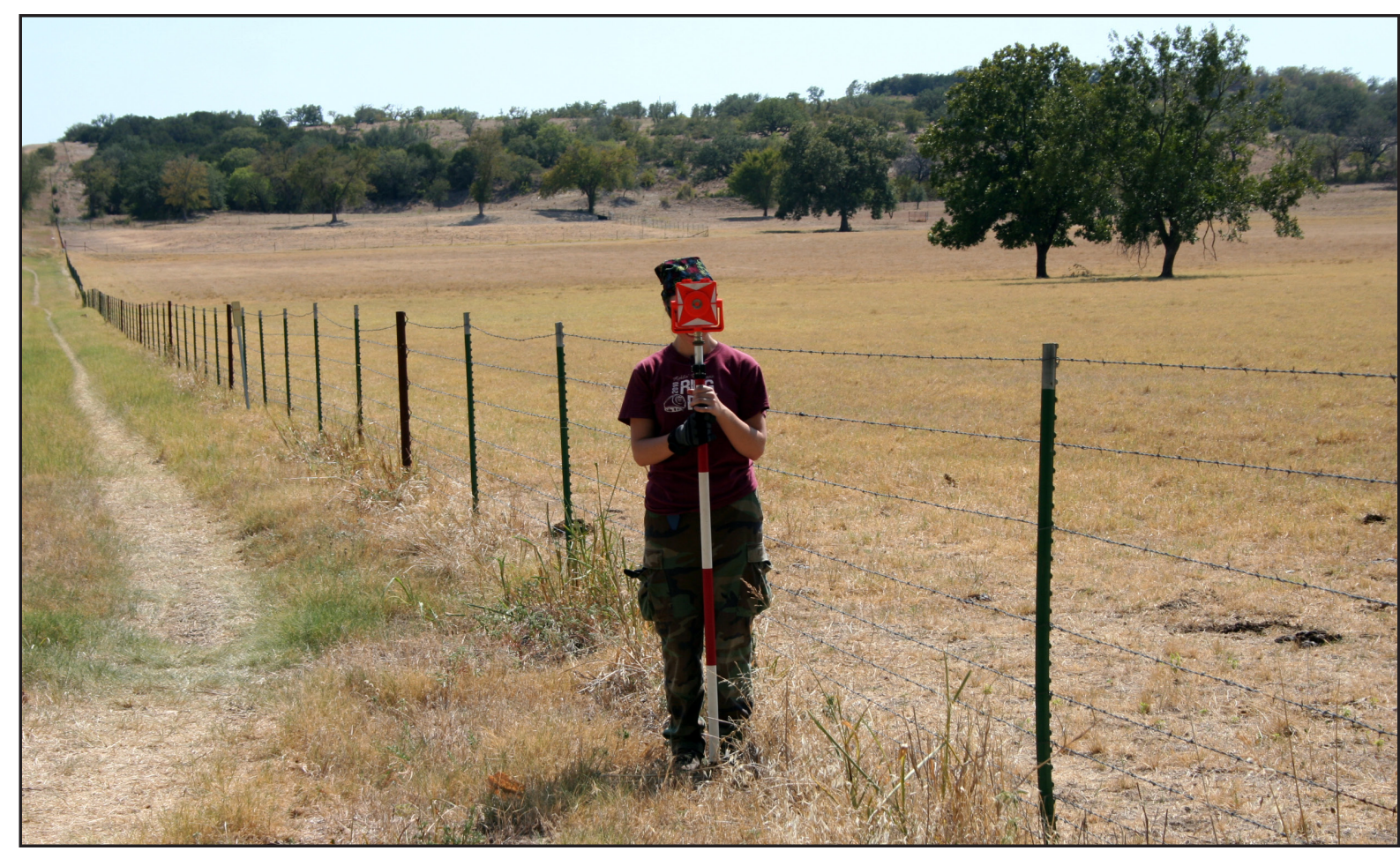

Figure 6-1. Photograph of a crew member recording site topography with a Total Data System (TDS) . View to the south-southwest along the ROW fence leading south from the site across the Leon River floodplain. 9/14/11.

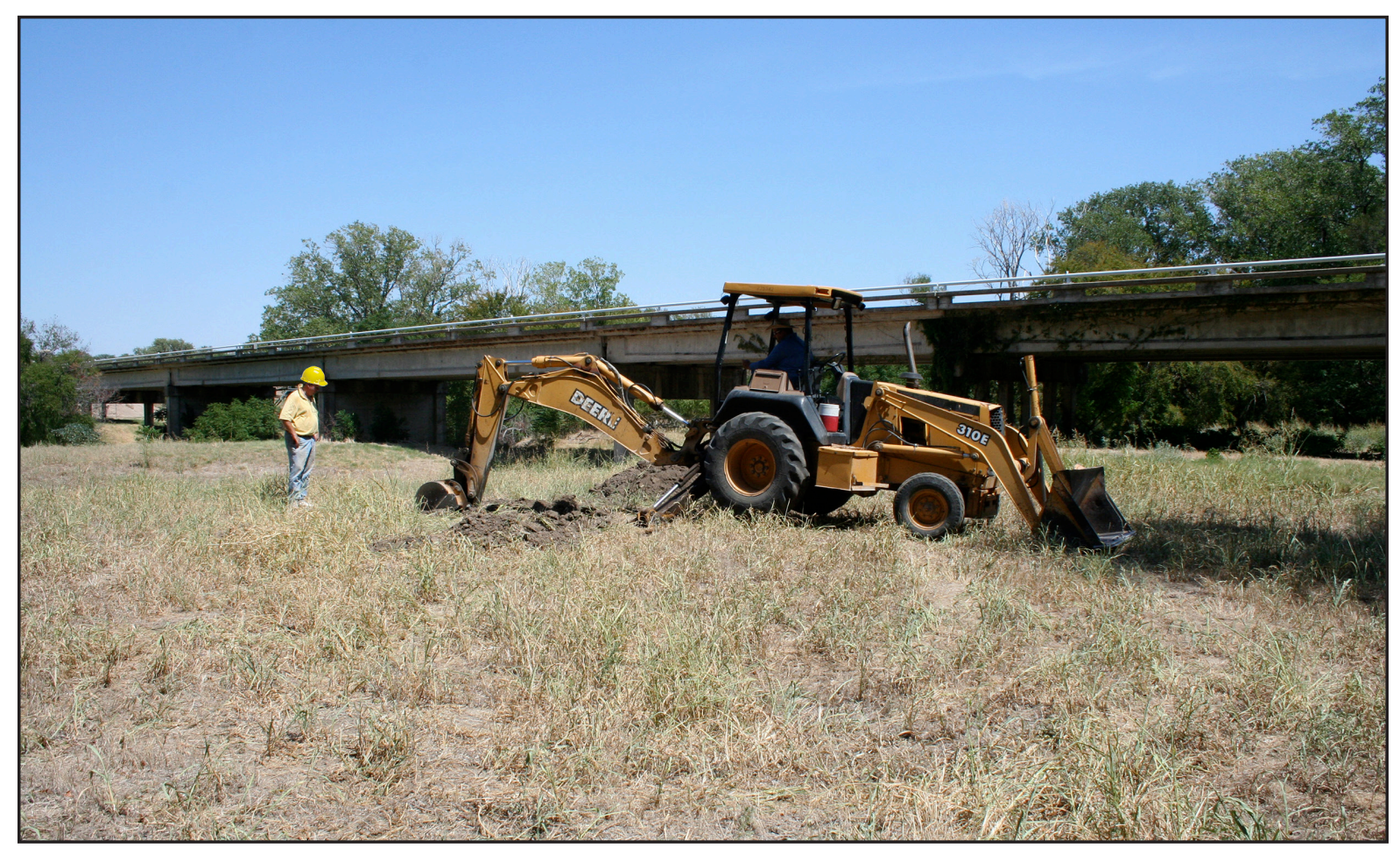
Figure 6-3. Photograph of the backhoe beginning to reopen TxDOT BT 9. View to the northeast with the

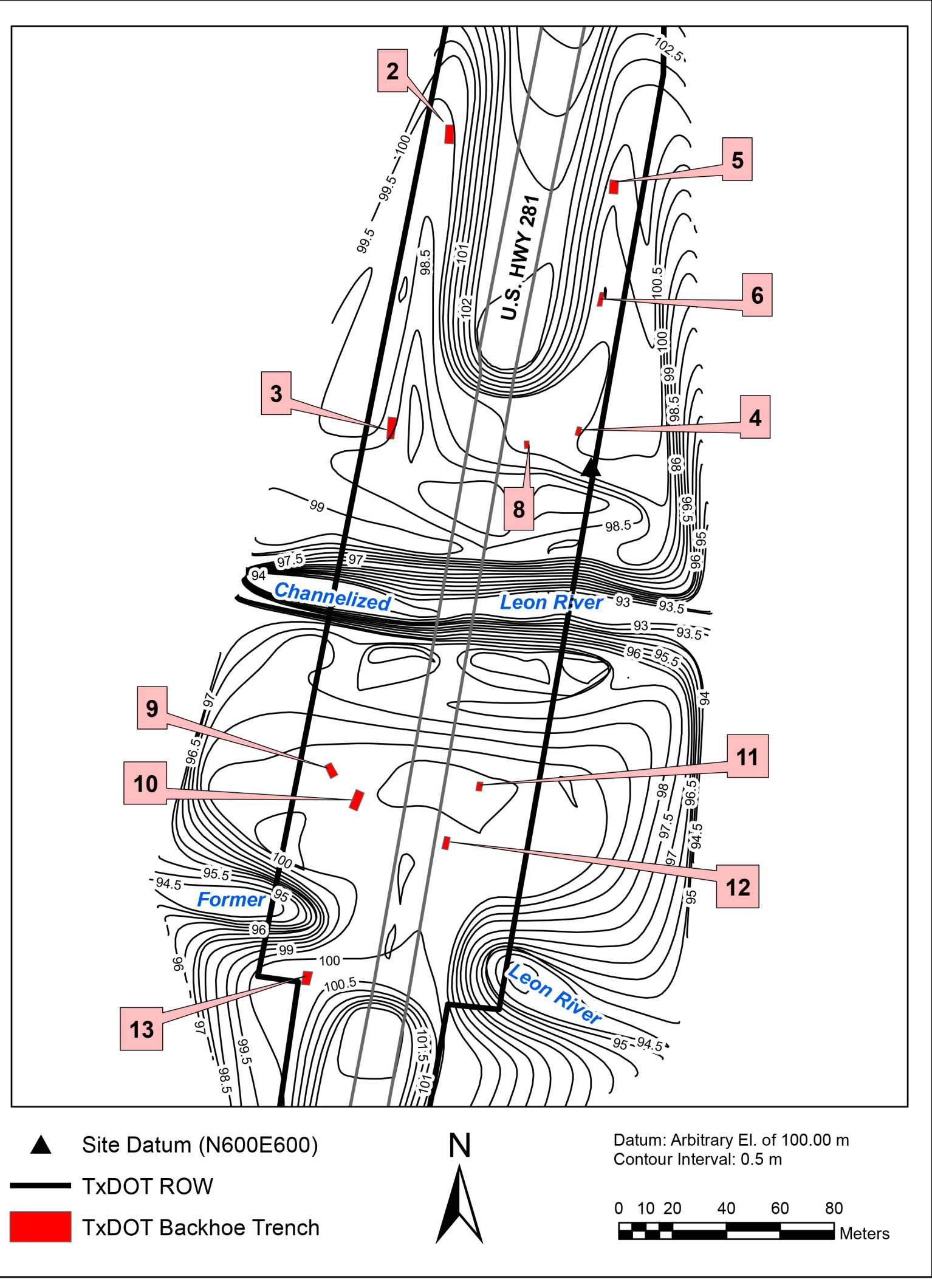

Figure 6-2. Contour map of site 41HM61 showing the locations of 12 of TxDOT's 14 previous backhoe trenches (BT). Note that TxDOT BTs 1 and 14 are too far to the north and south, respectively, to
be shown on this map. 



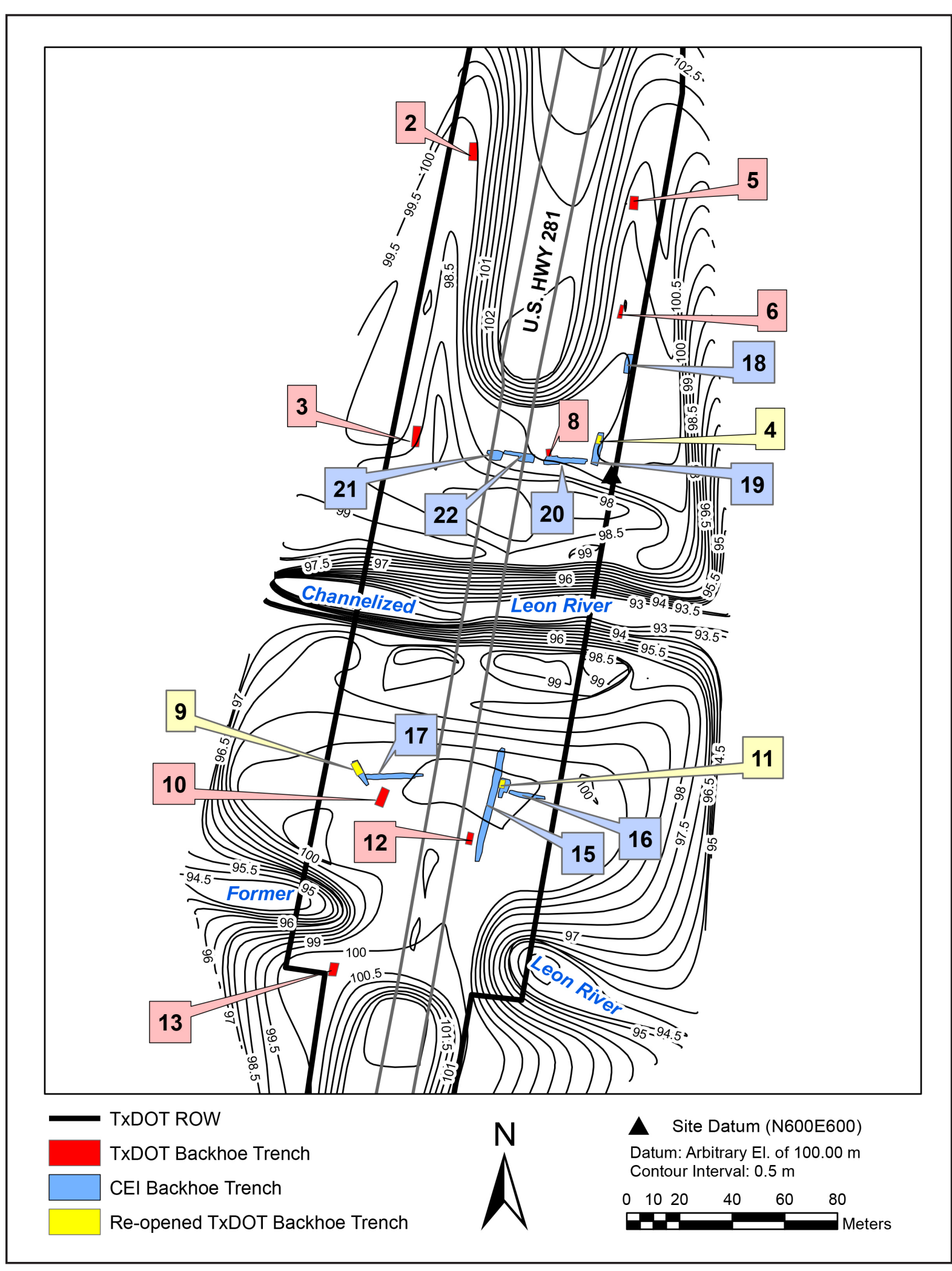

Figure 6-4. Contour map of site 41HM61 showing the locations of various backhoe trenches excavated (and re-excavated) during the current project.

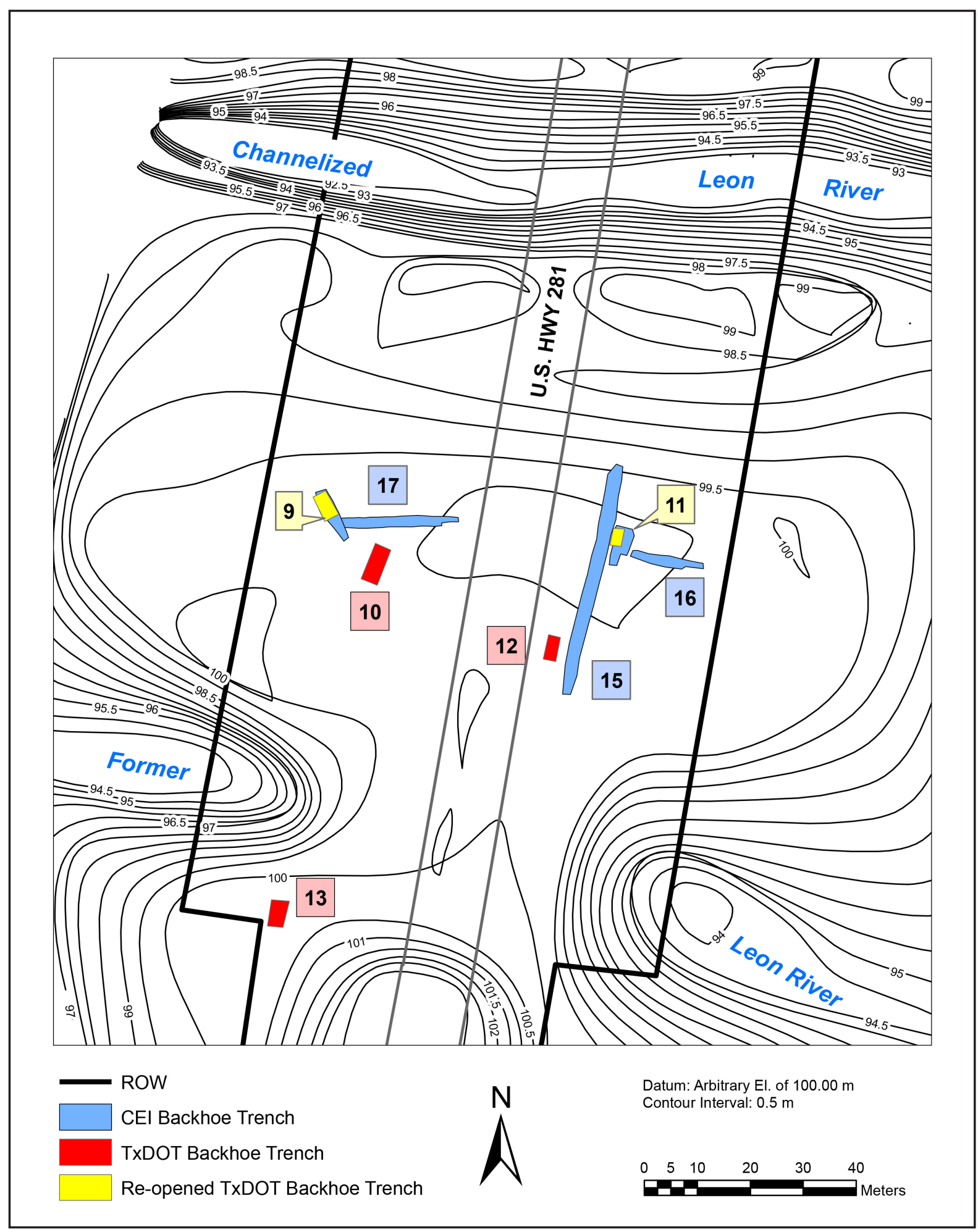

Figure 6-5. Blow-up of the southern portion of site contour map showing the locations of reopened TxDOT
BTs 9 and 11; previously excavated TxDOT BTs 10, 12, and 13; and newly excavated BTs 15, BTs 9 and 11; previously excavated TxDOT BTs 10,12 , and 13; and newly excavated BTs 15 ,
16, and 17. 



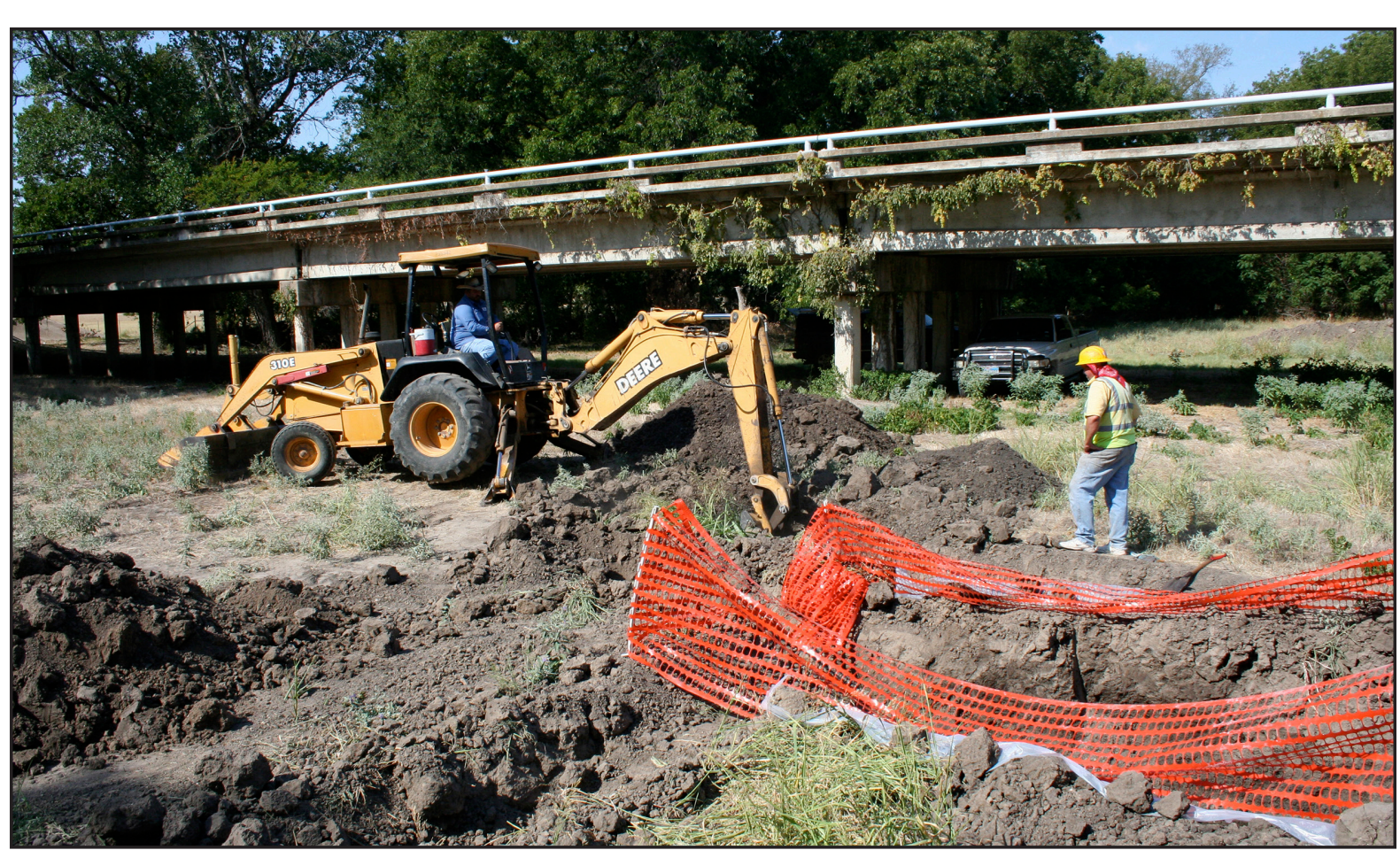

Figure 6-6. Photograph of the excavation of BT 15 with Charles Frederick observing. TxDOT BT 11 has been reopened already and is surrounded by orange safety fencing. View to the southwest.

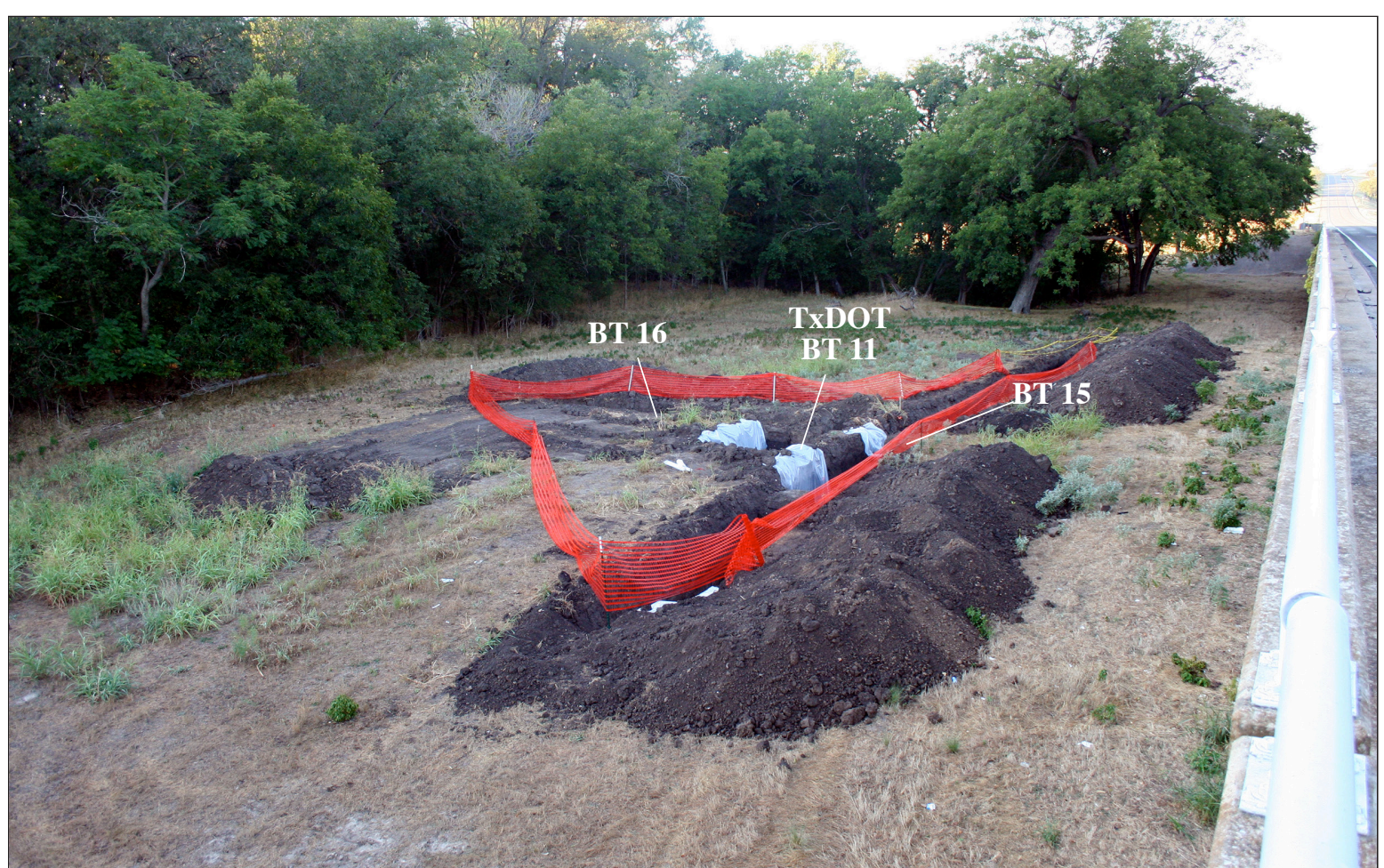

Figure 6-7. Photograph of the reopened TxDOT BT 11 and newly opened BTs 15 and 16 from atop the U.S.
Highway 281 bridge. View to the south-southeast. $9 / 14 / 11$.

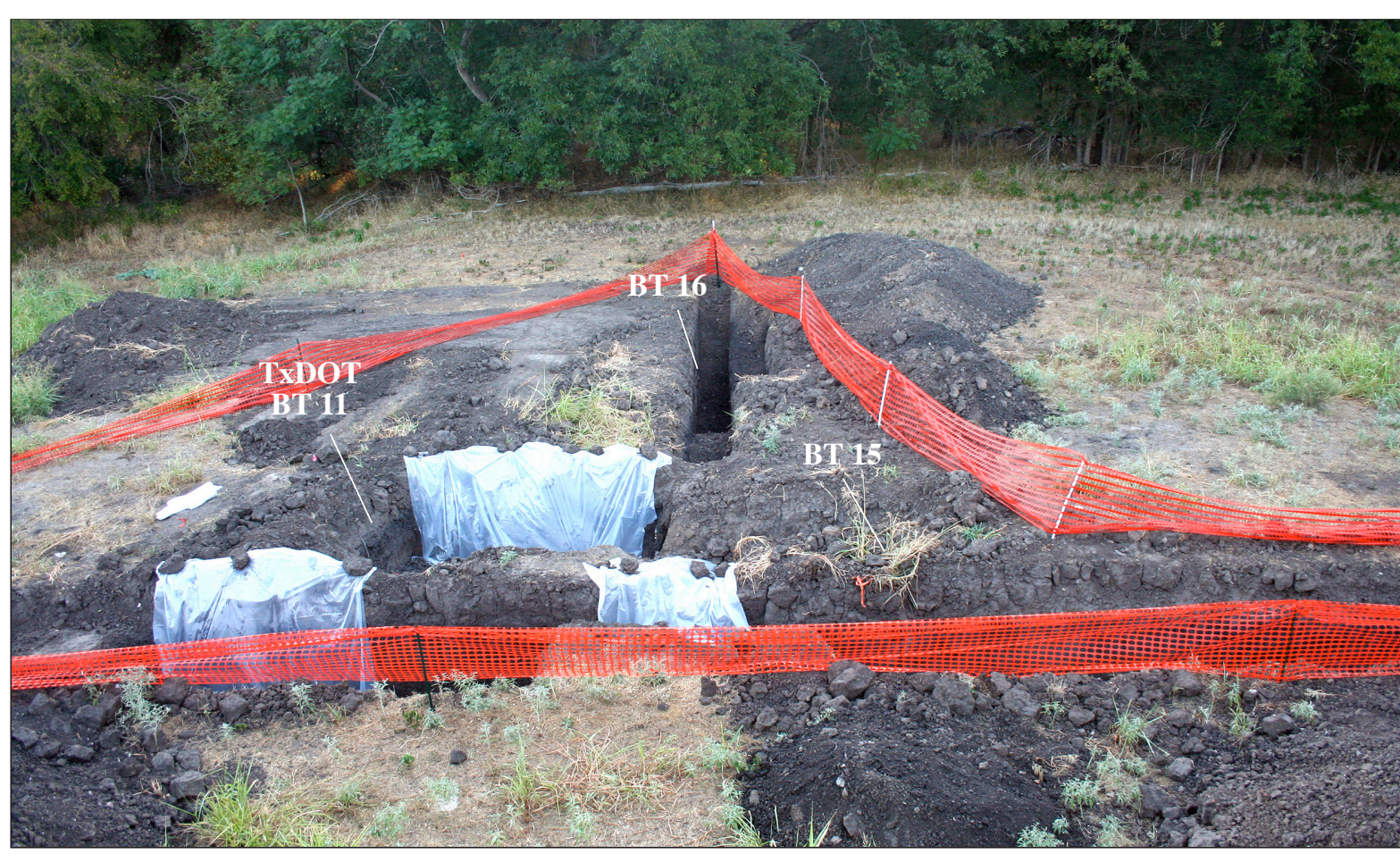

Figure 6-8. Photograph of the reopened TxDOT BT 11 and newly opened BTs 15 and 16. Two pieces of plastic sheeting have been draped over potential features exposed in the east wall of BT 15, while a larger sheet covers the entire east wall of TxDOT BT
of cultural material were exposed. View to the east. 9/14/11.

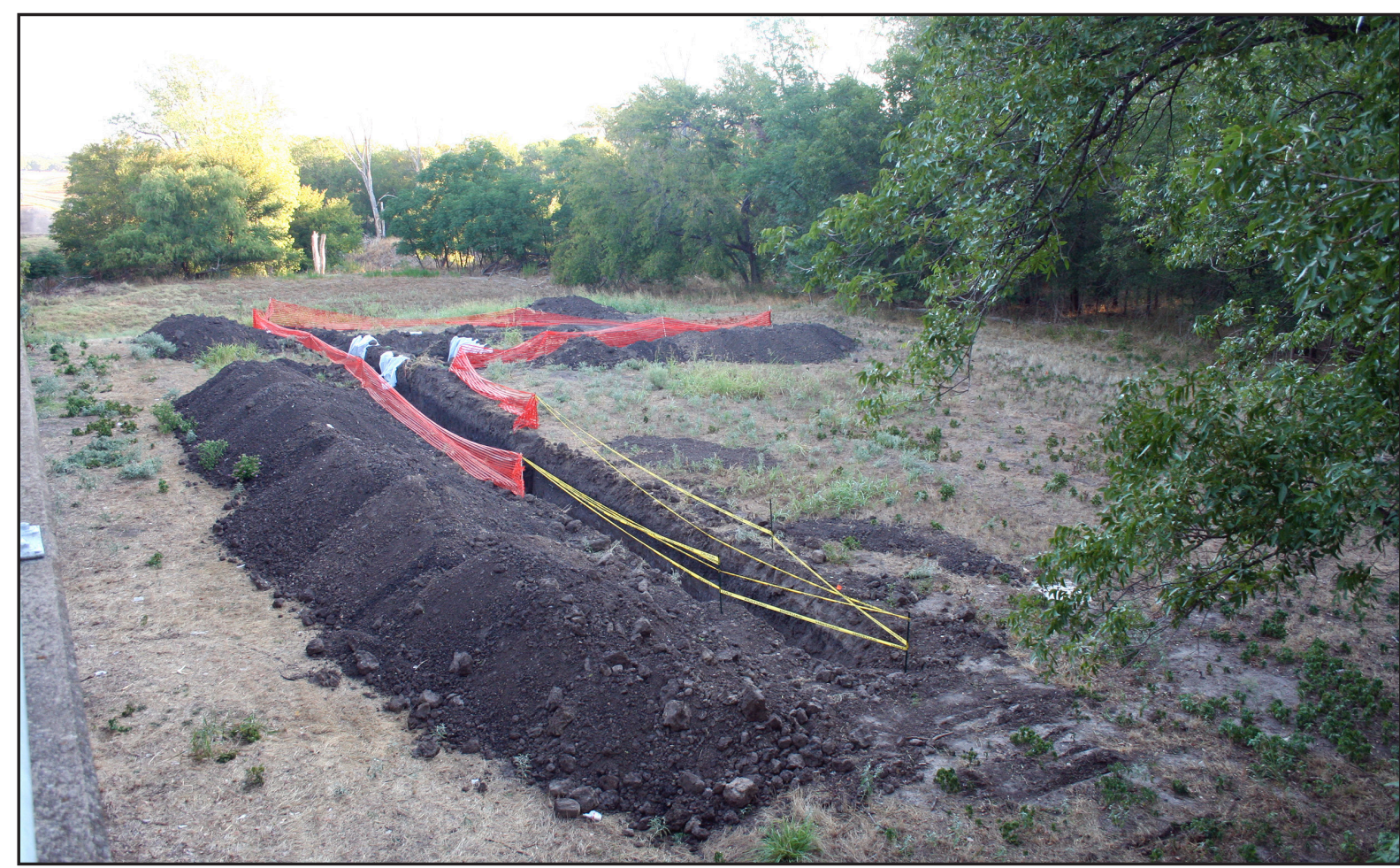

Figure 6-9. Another photograph of the reopened TxDOT BT 11 and newly opened BTs 15 and 16 from atop
the U.S. Highway 281 bridge. View to the north-northeast. $9 / 14 / 11$. 



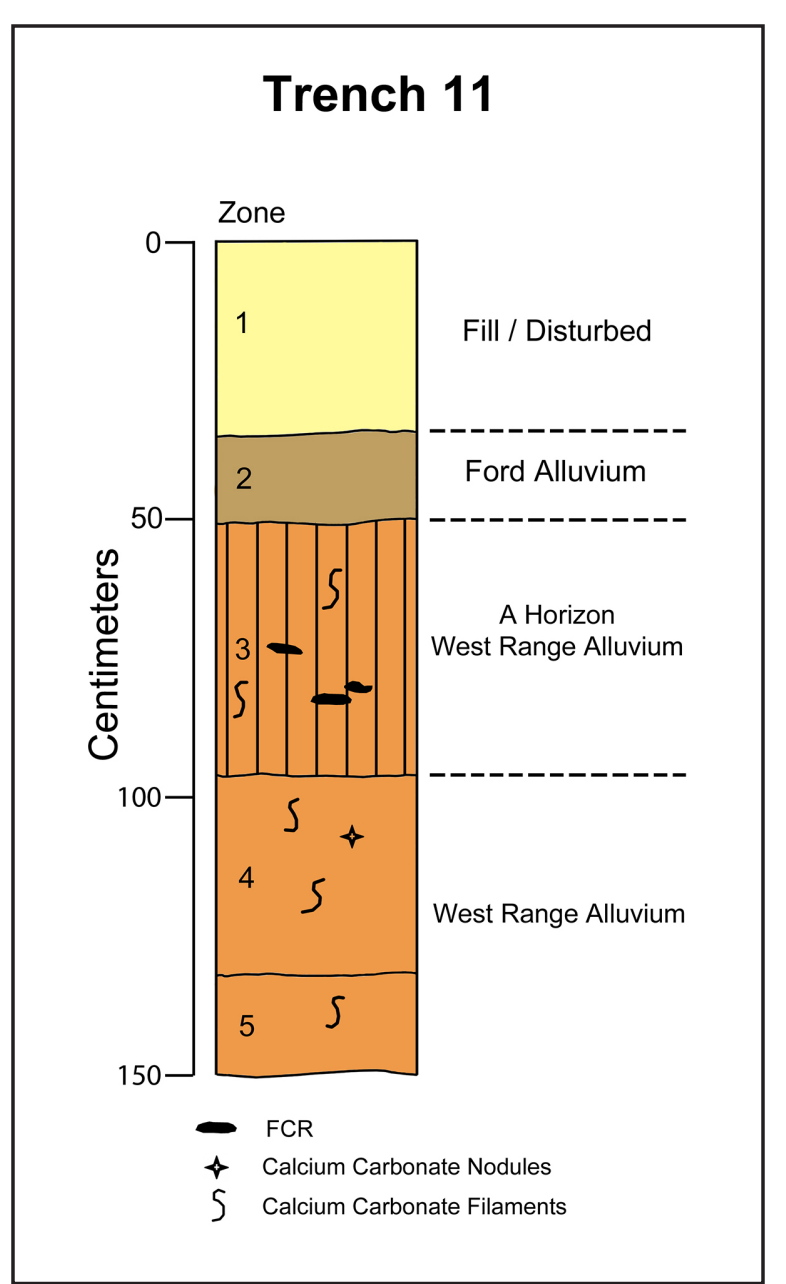
Figure 6-10. Drawing of the east wall profile of

\section{Trench 15, East Wall}
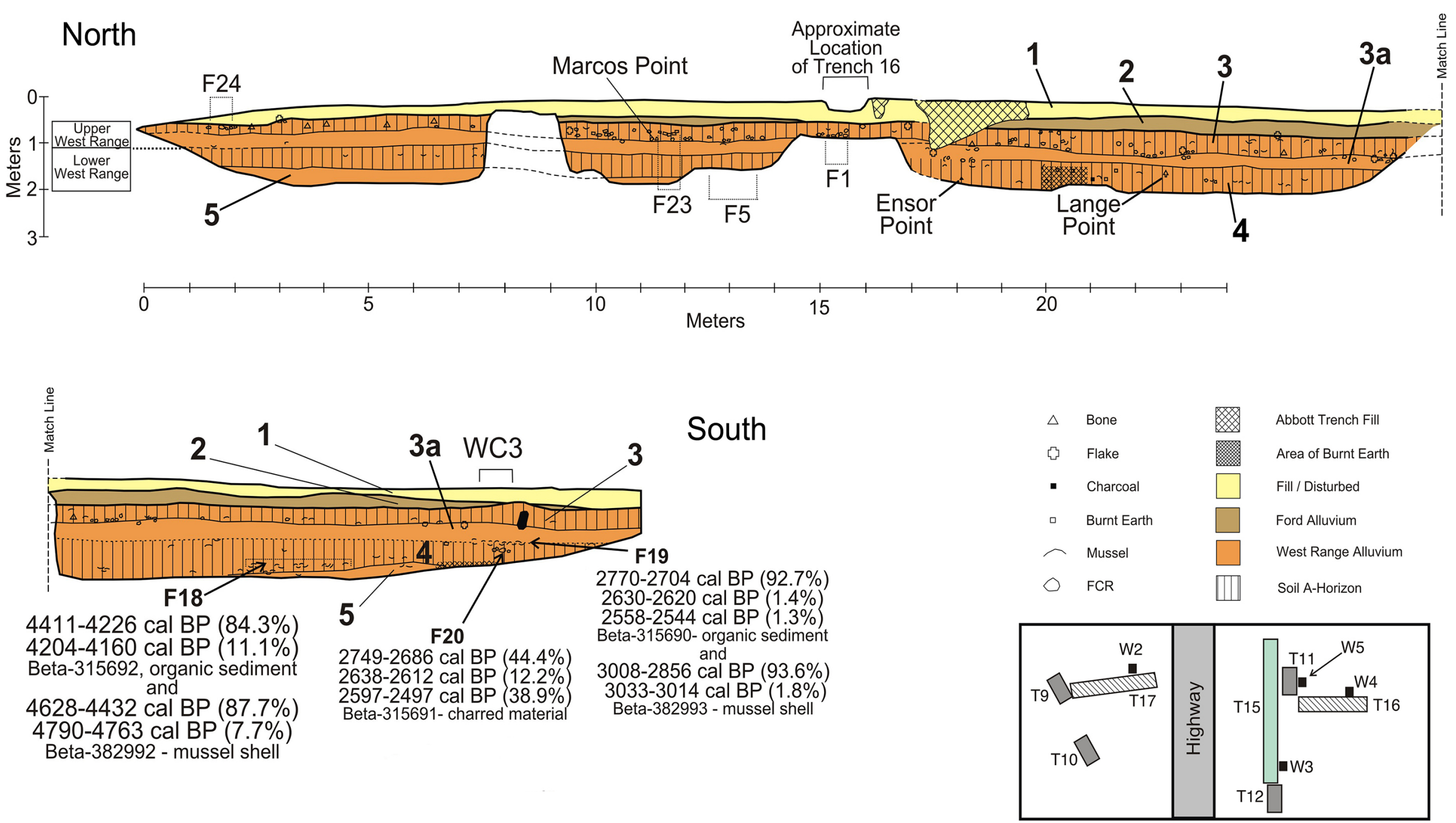

Figure 6-11. Drawings of the east wall profile of BT 15. Note the locations of Features 18,19, and 20, plus the diagnostic dart points. The two A horizons associated with the Upper and location of Witness Column (WC) 3 , discussed in detail in the following chapter, plus several radiocarbon dates obtained from Features 18, 19, and 20. The latter will be discussed more fully in Chapters 9 and 10 . 



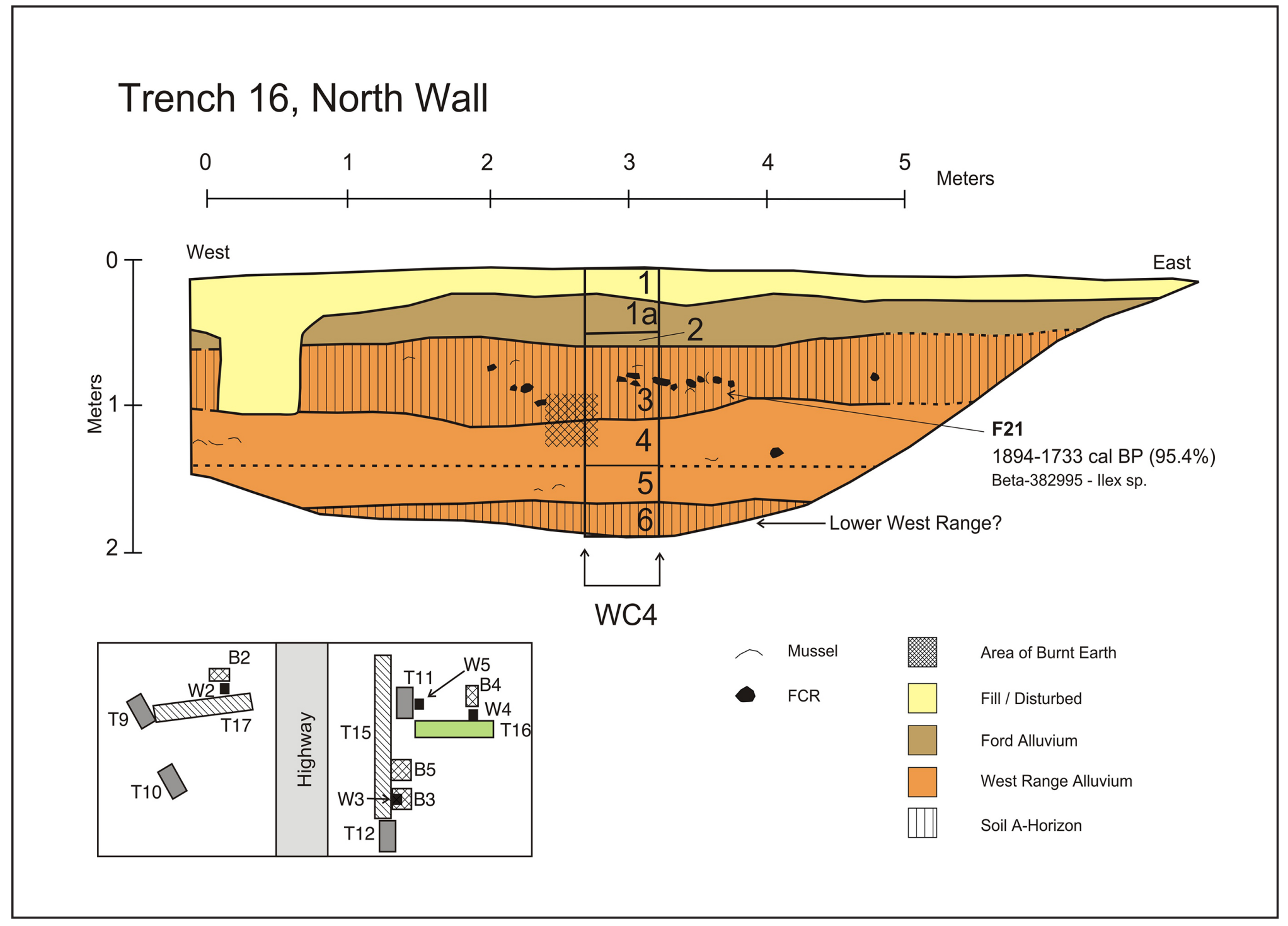

Figure 6-12. Drawing of the north wall profile of BT 16. The location of WC 4 is also shown, along with a radiocarbon date obtained from

column will be presented in the next chapter, while the radiocarbon date is reviewed in detail in Chapter 10 .

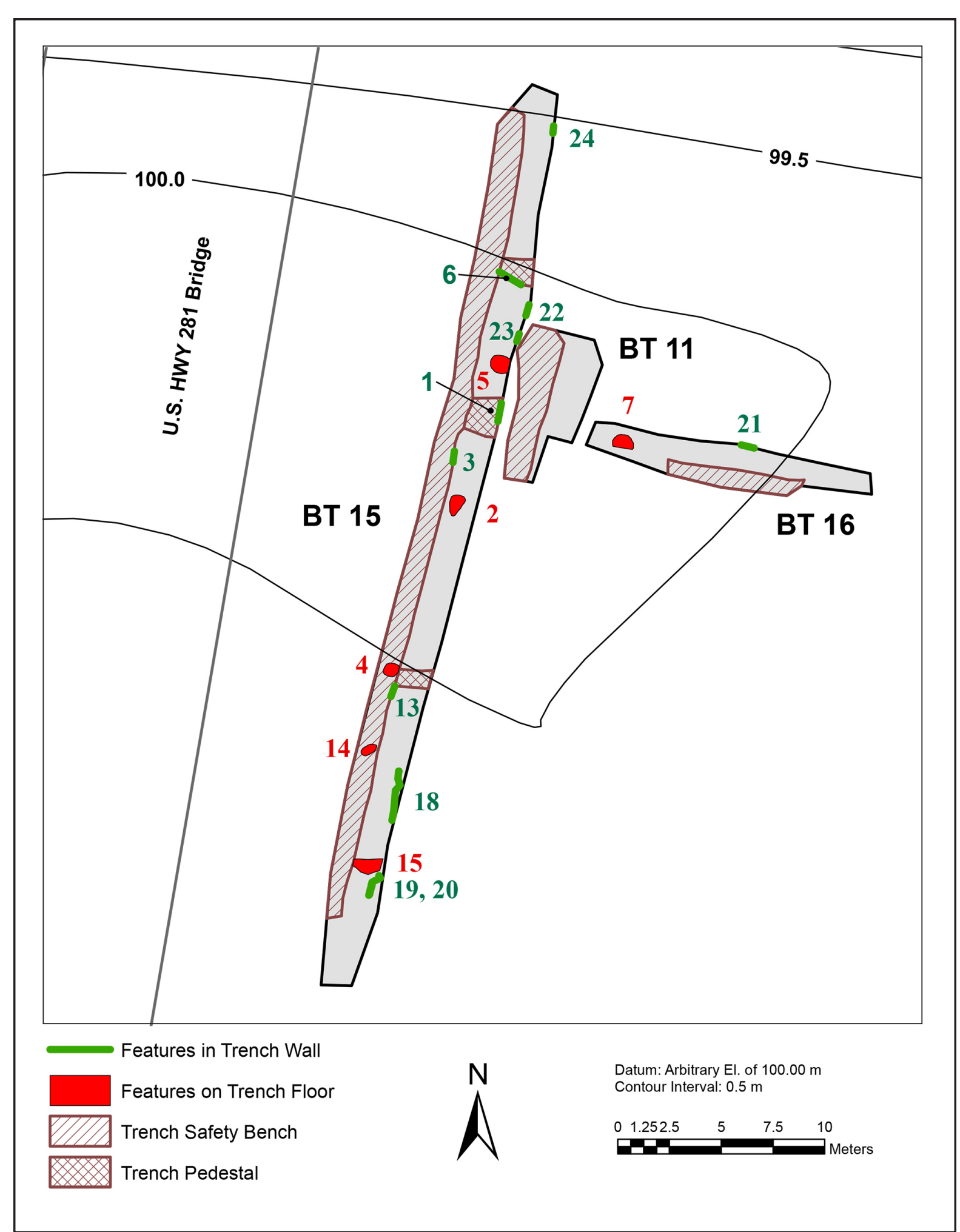

Figure 6-13. Map showing the locations of features uncovered in BTs 11,15 , and 16 in the southeastern quadrant of the site. Some of the features were discovered on the floors of the trenches while the trenches were being excavated, wille ohter fectures were identified on the trench walls are shown, as are three "pedestals" of non-excavated soil in BT 15. These pedestals were left in place when features were discovered either on or adjacent to them. Note that Features 4 and 14 



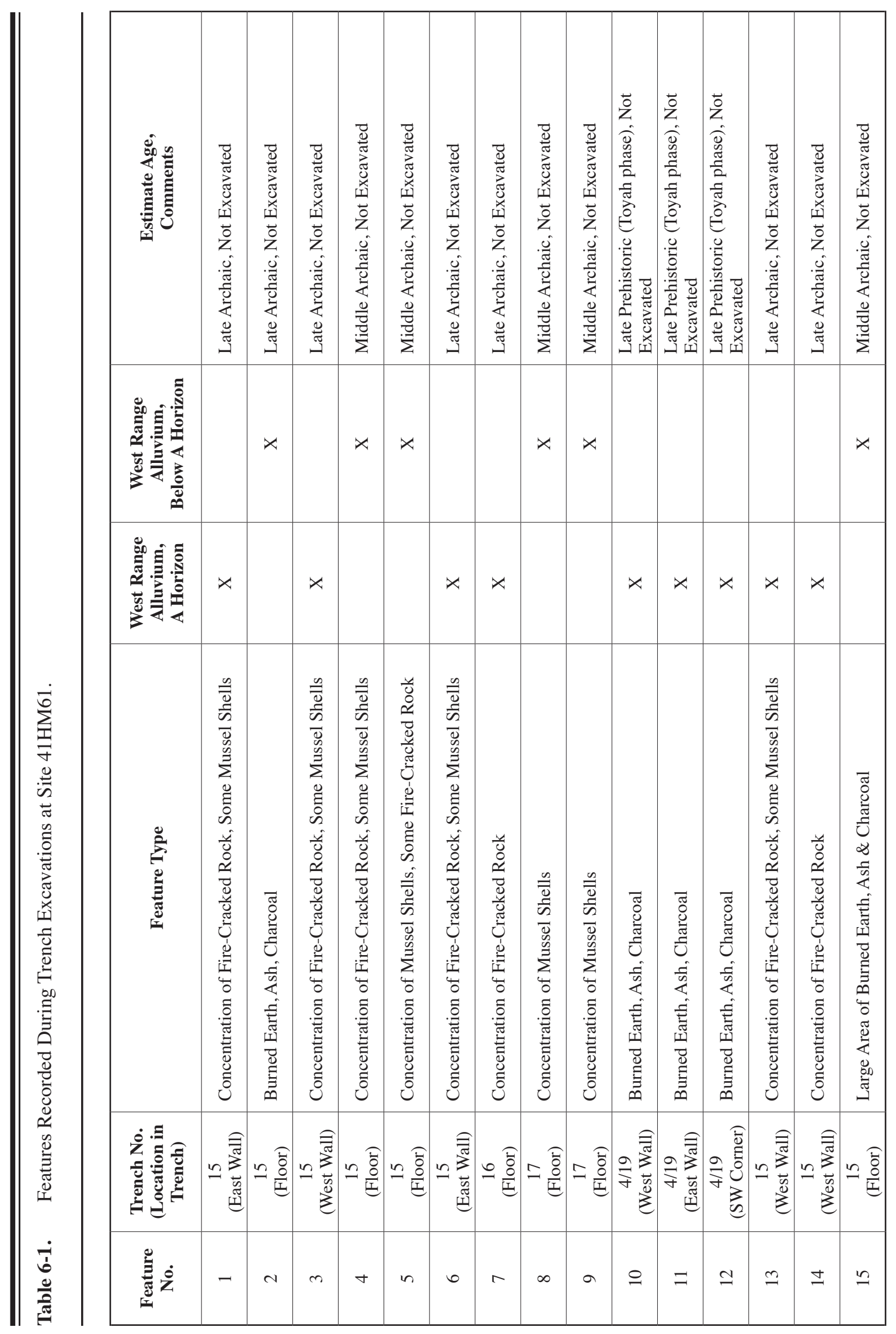




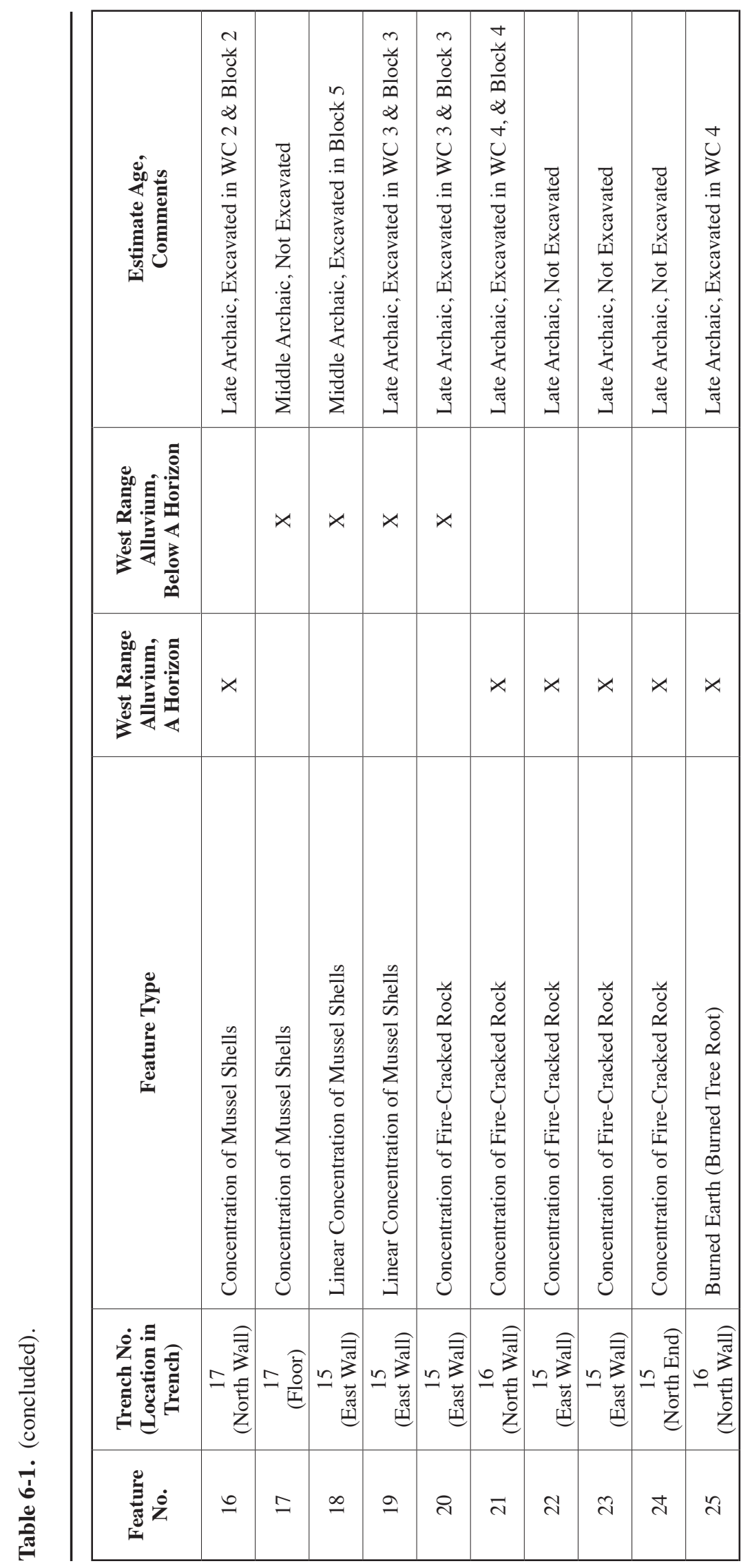




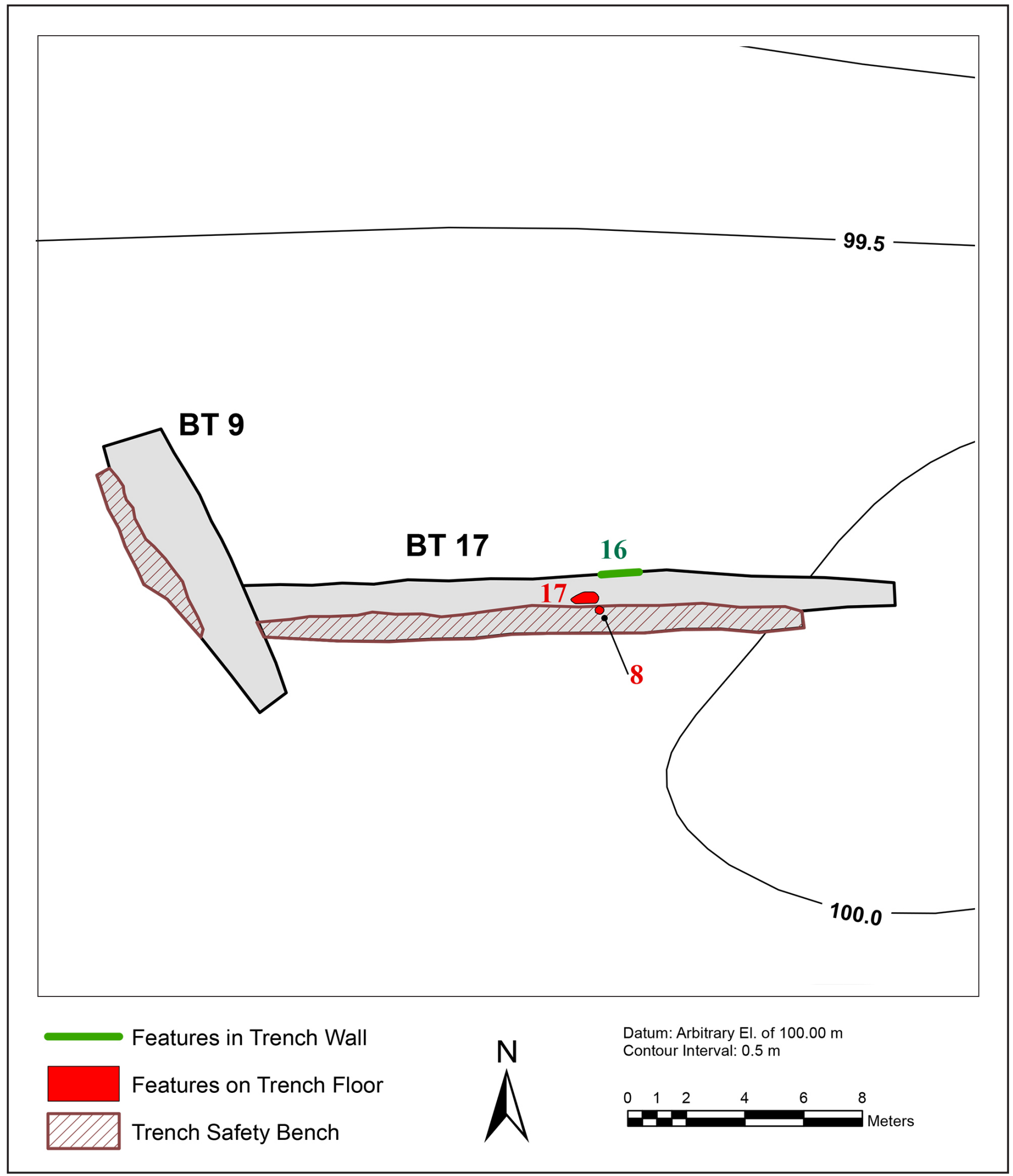

Figure 6-14. Map showing the locations of features uncovered in BTs 9 and 17 in the southwestern quadrant of the site. Map showing the locations of features uncovered in BTs 9 and 17 in the southwestern quadrant of the site.
Again, the locations of the safety benches in each trench are shown. Note that Feature 8 is located atop the safety bench in BT 17 .

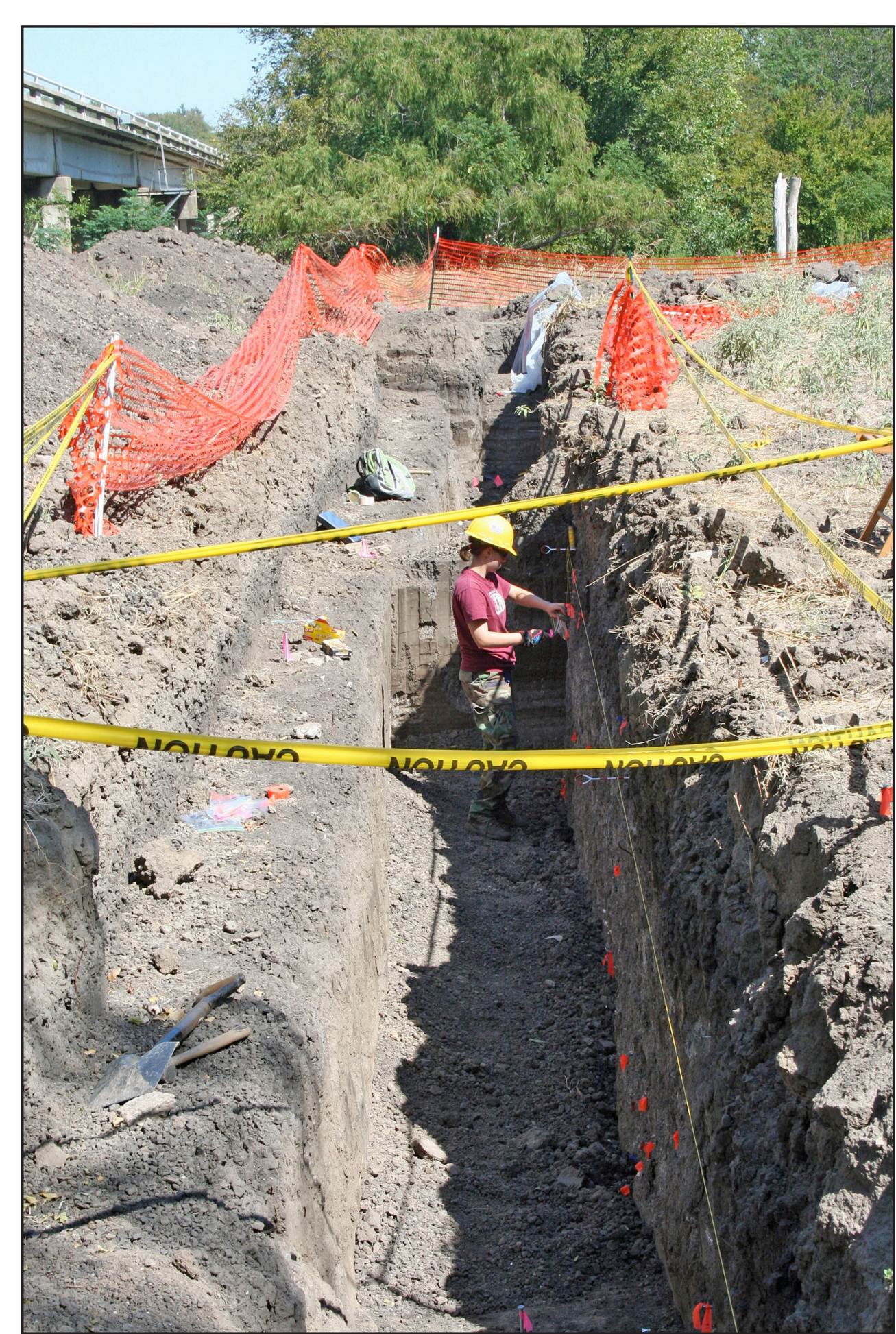

Figure 6-15. Photograph of crew member collecting field specimens from the east wall of BT 15. Each FS was assigned a unique number, which was written on a piece of flagging tape and inserted into the trench wall adjacent to the speci-
men. That piece of tape was collected with the FS and served as its identifying label from the field to the laboratory. 



\section{Table 6-2. Material Recovered from Backhoe Trenches at Site 41HM61}

\begin{tabular}{|c|c|c|c|c|c|c|c|c|c|c|c|c|c|c|c|c|c|c|c|c|c|c|c|c|}
\hline \multirow{3}{*}{ Material Recovered } & \multicolumn{6}{|c|}{ Trench 4/19 } & \multicolumn{4}{|c|}{ Trench 9} & \multicolumn{4}{|c|}{ Trench 11} & \multicolumn{8}{|c|}{ Trench 15} & \multirow{2}{*}{\multicolumn{2}{|c|}{$\begin{array}{l}\text { Trench } 18 \\
\text { Backdirt }\end{array}$}} \\
\hline & \multicolumn{2}{|c|}{ East Wall } & \multicolumn{2}{|c|}{ West Wall } & \multicolumn{2}{|c|}{ Backdirt } & \multicolumn{2}{|c|}{ East Wall } & \multicolumn{2}{|c|}{ North Wall } & \multicolumn{2}{|c|}{ East Wall } & \multicolumn{2}{|c|}{ Backdirt } & \multicolumn{2}{|c|}{ East Wall } & \multicolumn{2}{|c|}{ West Wall } & \multicolumn{2}{|c|}{ Pedestal 1} & \multicolumn{2}{|c|}{ Backdirt } & & \\
\hline & No. & Wt. & No. & Wt. & No. & Wt. & No. & Wt. & No. & Wt. & No. & Wt. & No. & Wt. & No. & Wt. & No. & Wt. & No. & Wt. & No. & Wt. & No. & Wt. \\
\hline Dart Points & & & & & & & & & & & & & & & & & & & & & & & & \\
\hline Ensor & & & & & & & & & & & & & & & 1 & 0.7 & - & & & & 1 & 4.5 & & \\
\hline Lange & & - & - & & - & - & - & - & & & & & & & 1 & 10.6 & - & & & & & & & - \\
\hline Marcos & & & - & & - & - & - & - & & & & & & - & 1 & 5.1 & - & - & & & & & & \\
\hline Unknown & & & & & & & & & & & & & & & & & & & & & & & & \\
\hline (Distal End) & & & & & - & - & - & - & & & & & & & - & - & - & & & & & & & \\
\hline Arrow Points & & & & & & & & & & & & & & & & & & & & & & & & \\
\hline Perdiz & & - & - & - & 1 & 1.1 & - & - & - & - & - & - & - & - & - & - & & - & - & - & - & - & - & - \\
\hline Proximal End & & & 1 & 1.3 & - & - & - & - & - & & & & & & - & - & - & - & - & & & & & \\
\hline Grinding Stone & & & - & - & - & - & - & - & - & & & & & & & & & & & & & & & \\
\hline Unifacial Scraper & - & - & - & - & & & & & - & - & - & - & 1 & 29.5 & - & - & - & - & - & & & & & \\
\hline Large Biface & & & & - & - & - & - & - & - & - & - & - & 1 & 40.0 & & & - & - & - & - & - & & - & - \\
\hline Hammerstone & 1 & 185.3 & & & & & & & & & & & & & 1 & 65.0 & - & & & & & & & - \\
\hline Debitage & & & & & & & & & & & & & & & & & & & & & & & & \\
\hline Blocky Debitage & & & - & & 1 & 27.6 & - & - & - & & & & 1 & 21.6 & - & - & - & - & & & & & & \\
\hline Flakes & 1 & 0.1 & - & - & 1 & 4.4 & - & - & - & - & - & - & - & - & 8 & 12.2 & 2 & 2.7 & 1 & 2.5 & 5 & 17.5 & 2 & 0.5 \\
\hline Fire-Cracked Rock & 1 & 9.8 & 3 & 73.4 & - & - & 9 & 71.0 & 3 & 154.0 & 60 & $5,563.6$ & & & 211 & $5,533.0$ & 163 & $3,842.2$ & - & - & & & & \\
\hline Vertebrate Remains & & & & & & & & & & & & & & & & & & & & & & & & \\
\hline Unburned Bone & 4 & 2.4 & 40 & 198.6 & 1 & 9.9 & - & - & - & - & 4 & 0.9 & - & - & 27 & 41.3 & 14 & 109.2 & & & 3 & 8.3 & 40 & 253.0 \\
\hline Invertebrate Remains & & & & & & & & & & & & & & & & & & & & & & & & \\
\hline Mussel Shell & & 1.6 & & 23.3 & - & - & - & 19.3 & & & & 118.1 & & & - & 361.2 & - & 254.1 & & 0.4 & & & - & - \\
\hline Snail Shell & - & - & - & - & - & - & - & - & - & - & - & - & - & - & - & 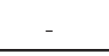 & 1 & 0.2 & - & - & - & - & - & - \\
\hline Totals & 7 & 199.2 & 44 & 296.6 & 4 & 43.0 & 9 & 90.3 & 3 & 154.0 & 64 & $5,682.6$ & 3 & 91.1 & 250 & $6,029.1$ & 180 & $4,208.4$ & 1 & 2.9 & 9 & 30.3 & 42 & 253.5 \\
\hline
\end{tabular}

Note: Most of the items were collected as field specimens, although several came from trench backdirt piles. Weights are in grams. 

Table 6-2. (concluded).

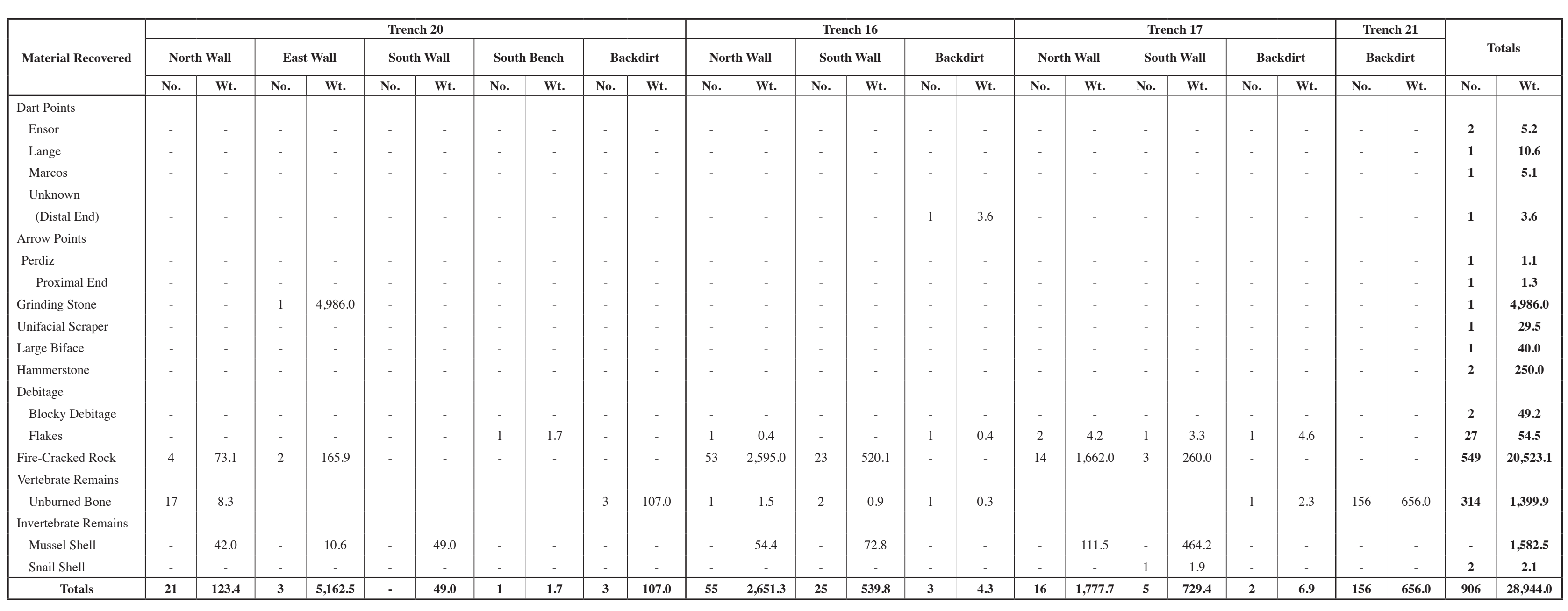

Note: Most of the items were collected as field specimens, although several came from trench backdirt piles. Weights are in grams. 

tions of the two, within the lower West Range A horizon. Cultural material within this deeper A horizon also seemed to occur in at least two distinct layers that ranged anywhere from 70 to $80 \mathrm{~cm}$ below the upper $\mathrm{A}$ horizon to roughly a meter or so below the upper A. As with similar concentrations in the A horizon, these deeper clusters of rocks and shells also were assigned feature numbers. Interestingly, an Ensor dart point was found within the lower A horizon at an elevation of $98.53 \mathrm{~m}$, roughly $90 \mathrm{~cm}$ beneath the Marcos point found in the upper A horizon. Since Ensors are known to postdate Marcos points, the point's position within the lower A horizon would appear to be somewhat problematic. A review of this apparent stratigraphic discrepancy, plus a more detailed discussion of other patterned tools found at the site, will be presented later in Chapter 11. For now, it can be assumed that the Ensor's position near the bottom of BT 15 is related to disturbances caused by the excavation and backfilling of adjacent TxDOT BT 11. Indeed, such disturbances were clearly visible near the top of the trench immediately above the Ensor and are shown by crosshatching on Figure 6-11. Also found within the lower A horizon was a broad-bladed dart point that closely matches the Lange type. It was at an elevation of $98.46 \mathrm{~m}$, which was slightly higher than several shells and clusters of shells, including the relatively prominent shell lens of Feature 18 (Figures 6-16 and 6-17).

West of the highway, BT 9 (6 m long) was reopened and then BT 17 was extended roughly eastward from the southern end of BT 9 for about $14 \mathrm{~m}$ (see Figures 6-5 and 6-14). The east wall of BT 9 was recorded and profiled along with the north wall of BT 17 (Figures 6-18 through 6-21). Both showed the same stratigraphy, which generally matched the stratigraphy recorded in the trenches east of the bridge. Once again, a prominent A horizon was present in the upper portion of the West Range alluvium. It included scattered burned rocks, some lithic debris, minor bits of bone, and at least one deposit of mussel shell identified as Feature 16 (see Figure 6-19). Interestingly, the A horizion could be seen dipping downward to the west (and slightly to the north), so that it occurred only 30 to $50 \mathrm{~cm}$ below the ground surface in the eastern part of BT 17 but over a meter deep in the western part of BT 17 and all of BT 9 (Figure 6-22). A few burned rocks and scattered mussel shells appeared below the A horizon within the West Range alluvium, with some a meter or more beneath the A horizon. Unlike the mussel shells in the A horizon, however, none of the rocks and shells in the deeper alluvium were concentrated into possible features.
Based on the trenching in the southern part of the site, an area within the ROW measuring ca. 76 m eastwest by $61 \mathrm{~m}$ north-south, and covering ca. 4,200 $\mathrm{m}^{2}$, could be identified as the main locus of both the Late Archaic occupations associated with the West Range A horizon and the deeper clusters of burned rocks and shells present in the lower portion of the A horizon (Figure 6-23). Interestingly, the occupation area east of the bridge occurred on a slight topographic rise that likely was a favorable place to camp while residing adjacent to the Leon River during Archaic times.

\section{North Section}

The northern portion of the site included the reopening of BT 4 (ca. $4 \mathrm{~m}$ long) and the excavation of five new BTs (Figure 6-24). The latter included BT 18 (7 m long; located about $20 \mathrm{~m}$ north of BT 4), BT 19 (8 m long; actually a southward extension of BT 4), BT 20 (13 m long; ran westward from the south end of BT 19), and BTs 21 and 22 (4 and $5 \mathrm{~m}$ long, respectively; both dug to the west of BT 20) (Figures 6-25 and 6-26). BT 18 measured about 7 $\mathrm{m}$ in length, mainly exposed Fort Hood alluvium, and was culturally sterile. ${ }^{2}$ After recording a profile along a small section of its eastern wall (Figure 6-27), the trench was backfilled.

The other trenches all had cultural remains. Principally, this included a prominent Late Prehistoric occupation present within the A horizon atop the West Range alluvium. Included were deer and bison bones, lithic debris, a small non-rock hearth, and one Perdiz arrow point. Given the association of the bison bones and the Perdiz point, the investigators referred to this occupation as a Toyah or Toyah-like component. While only one of classic Toyah culture's diagnostic artifacts (the Perdiz point) is present within this occupation, there are several recognizable Toyah components at sites in the vicinity (see Chapter 3), so it seems that the Late Prehistoric occupation at 41HM61 is likely similar. Thus, the term "Toyah" will be used for this occupation throughout the remainder of the report, with the caveat that it may not be Toyah in the true sense of the culture as recognized by Johnson (1994) and Arnn (2012).

\footnotetext{
2 A few flakes were found on the back-dirt pile of BT 18 , suggesting that there either may have been some extremely ephemeral occupation in the area or that disturbances from highway construction had moved such cultural material from its original location farther to the south. Since no cultural items or evidence of any midden was seen in the trench's wall profiles, for all intents and purposes the trench location can be considered culturally sterile.
} 
This "Toyah" occupation zone occurred at a depth of roughly 30 to $60 \mathrm{~cm}$ below the modern ground surface in the extreme southern end of BT 4 and for most of the length of BT 19 (Figures 6-28 through 6-32), and within the eastern portion of BT 20 (Figure 6-33). However, as can be seen in Figure 6-33, the Toyah zone dipped dramatically downward in the western part of BT 20 where it occurred as a distinct band of dark sediment, charcoal, and bone within a deposit of laminated alluvial fill. Originally, this "deep Toyah" zone was thought to be within a gully that had cut into the margin of the West Range alluvial fill, but it now is considered to be the onlap of the Ford alluvium. At its maximum depth in BT 20, the Toyah zone occurred at ca. $2.3 \mathrm{~m}$ below ground surface. Large bone fragments, sizable pieces of charcoal, and scattered thermal refuse (burnt earth and ash) were present within the zone at that depth.

Below the A horizon Toyah zone in BT 4/19, a few scattered pieces of burned rock and mussel shells were present to a depth of ca. $1.5 \mathrm{~m}$. These all were within the West Range alluvium, indicating that there was some evidence for very sparse, Late Archaic usage of the area. However, unlike the southern part of the site (as discussed above), no cultural features or definite occupation surfaces related to the Late Archaic were found in the area around BTs 4, 19, and 20.

Regardless of the sparse Late Archaic remains, BT 20 was not long enough to determine the full westward extent of the "deep Toyah" zone. Since it was necessary to determine if the zone occurred west of the U.S. Hwy. 281 bridge, two additional trenches, BTs 21 and 22, were excavated under the bridge and partially to the west of the bridge (see Figure 6-24). Although BT 21 produced some scattered bison bone and charcoal fragments, there was no evidence of the distinct dark Toyah band seen at the west end of BT 20 (Figure 6-34). Thus, BT 22 was placed down about midway between BTs 20 and 21 (Figure 6-35). Again, the trench mostly produced only scattered charcoal fragments within nicely laminated Ford alluvium (Figure 6-36). However, at the extreme eastern end, at a depth of almost $4 \mathrm{~m}$, a displaced block of alluvium was present at the base of the trench. This block contained the same dark Toyah zone as present in BT 20. Apparently, the block had fallen down the bank of the Leon River after the river had cut towards the north and into earlier alluvium containing the Toyah zone. The slump block had slipped down the river's bank and subsequently been covered by more Ford alluvium. Given this scenario, it became clear that there was no deep Toyah zone west of the area where BTs
20 and 22 intersect. Thus, only the western end of BT 20 contained such a zone.

Features identified during the trenching within the northern part of the site are shown on Figure 6-37. As can be seen, only combined BT 4/19 produced any features, with two of them exposed in the trench's walls. Information on these features can be found in Table 6-1.

It is interesting to note that TxDOT's excavation of BT 4 had stopped right at the northern edge of the intact Toyah occupation zone. North of the junction of BTs 4 and 19, the zone had been truncated by activities related to construction of U.S. 281 when the current highway bridge was built in the early 1950s. This would explain why TxDOT personnel did not see any evidence of the so-called Toyah occupation in BT 4. If BT 4 had been extended for only two or three meters to the south (where CEI's BT 19 eventually was dug), then the Toyah occupation would have been uncovered within the West Range alluvium's A horizon.

Overall, based on the various backhoe trenches excavated in the northern part of the site, plus the topography of that location, it would appear that the Toyah occupation is confined to a relatively small area that extends for about $12 \mathrm{~m}$ in an east-west line between the eastern ROW fence and the eastern end of BT 20, and for about $11 \mathrm{~m}$ in a north-south direction between the junction of BTs 4 and 19 and the edge of the bank where it drops down into the channelized Leon River (Figure 6-38). Overall, the intact deposits cover about $127 \mathrm{~m}^{2}$ within the ROW.

\section{Trenching Summary}

Re-excavation of several of TxDOT's backhoe trenches (BTs 4, 9, and 11), along with the additional excavation of BTs 15 through 22, revealed the presence of intact cultural deposits related to several distinct cultural components. Overall, the combined length of the reopened TxDOT trenches equaled about $14 \mathrm{~m}$, while the total length of the additional eight trenches equaled approximately $98 \mathrm{~m}$. This latter total significantly exceeded the original minimum of $70 \mathrm{~m}$ specified in the work authorization. To compensate for this discrepancy, Supplement No. 2 to the work authorization increased the total length of additional trenching to a minimum of $90 \mathrm{~m}$. Furthermore, since it also was deemed necessary to identify the extent and depth of the "deep Toyah" zone in the northern part of the site, permission was obtained to excavate several of the trenches (BTs 20,21, and 22) 


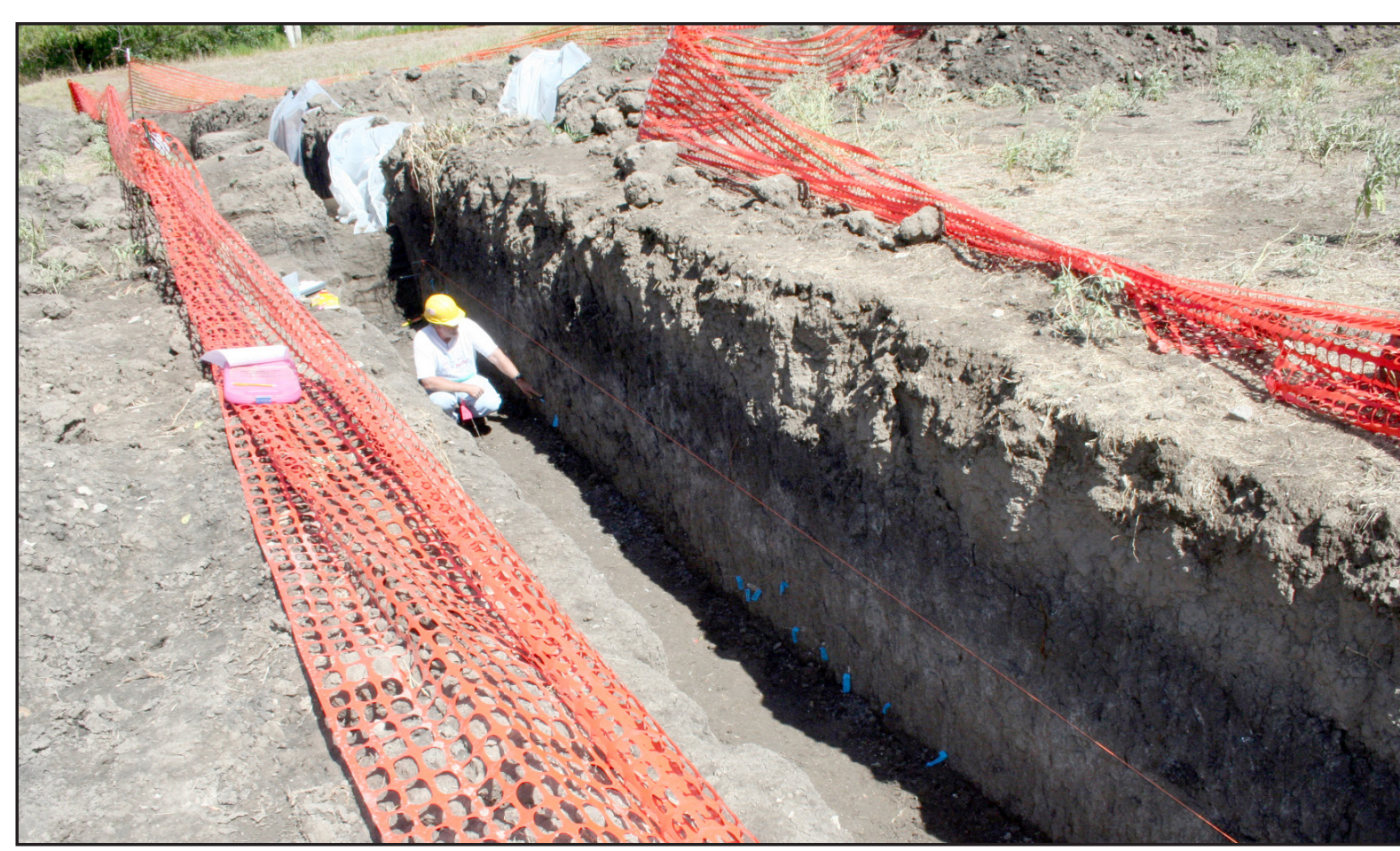

Figure 6-16. Photograph of Rich Weinstein pointing to a Lange dart point exposed within the West Range alluvium near the base of BT 15. Note the prominent dark-colored West Range A horizon about individual mussel shells, many of which eventually became elements within Feature 18 . View to the northeast. $9 / 30 / 11$.

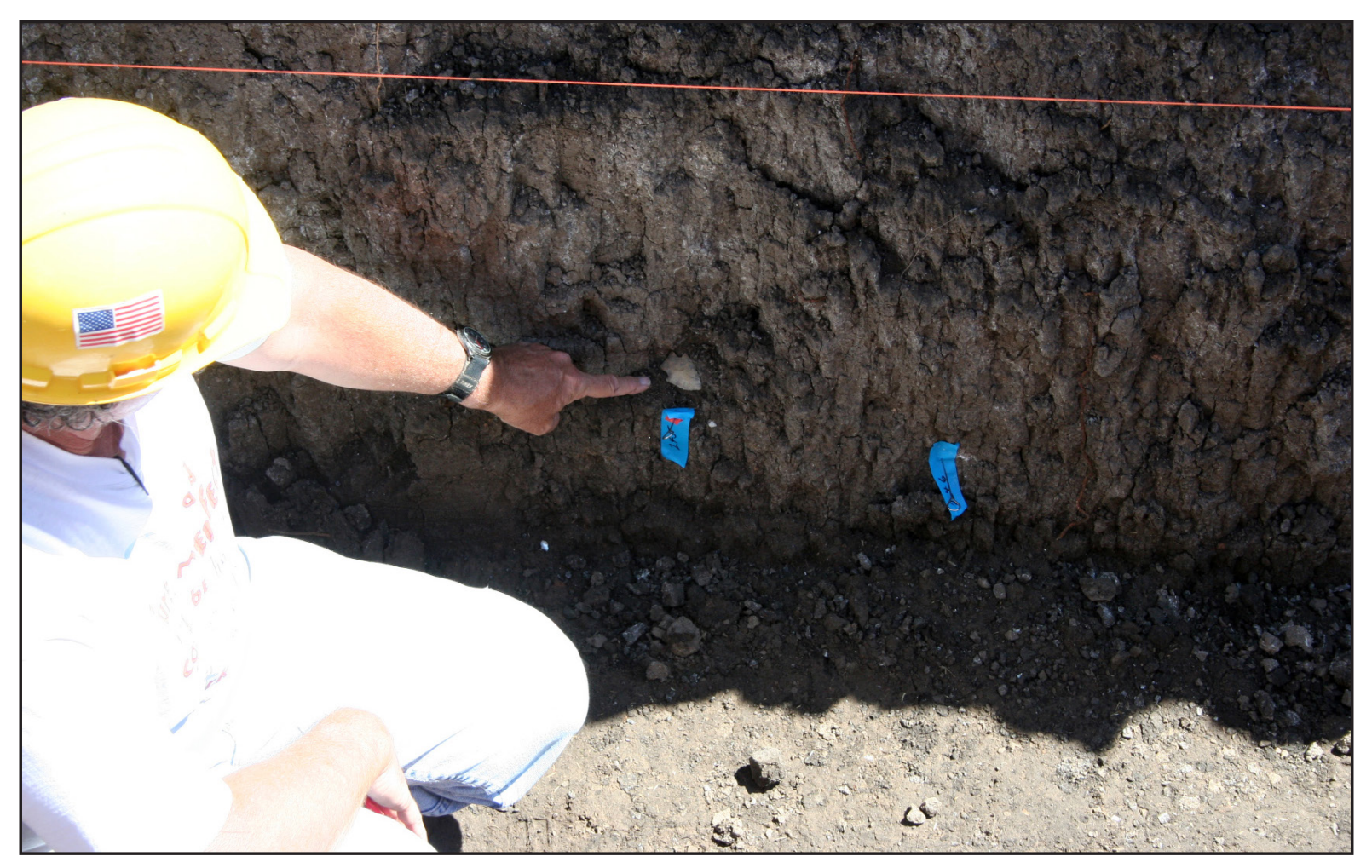

Figure 6-17. Close-up photograph of the Lange dart point in situ near the base of the east wall of BT 15 .

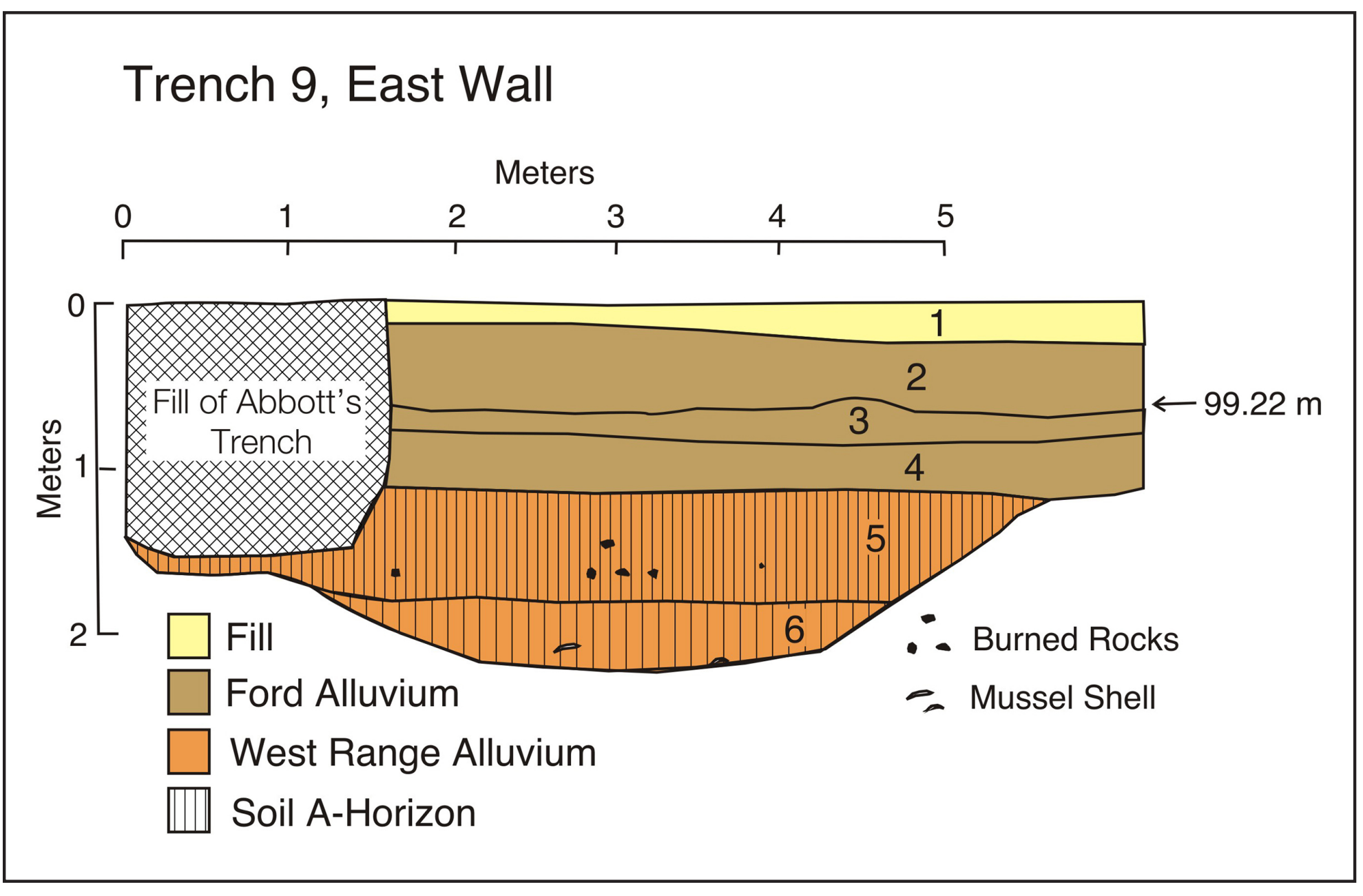

Figure 6-18. Drawing of the east wall profile of BT 9 showing the relatively deeply buried A horizons associated with the West Range alluvium. Also note the location of TxDOT's previously backfilled portion
of BT 9 . 



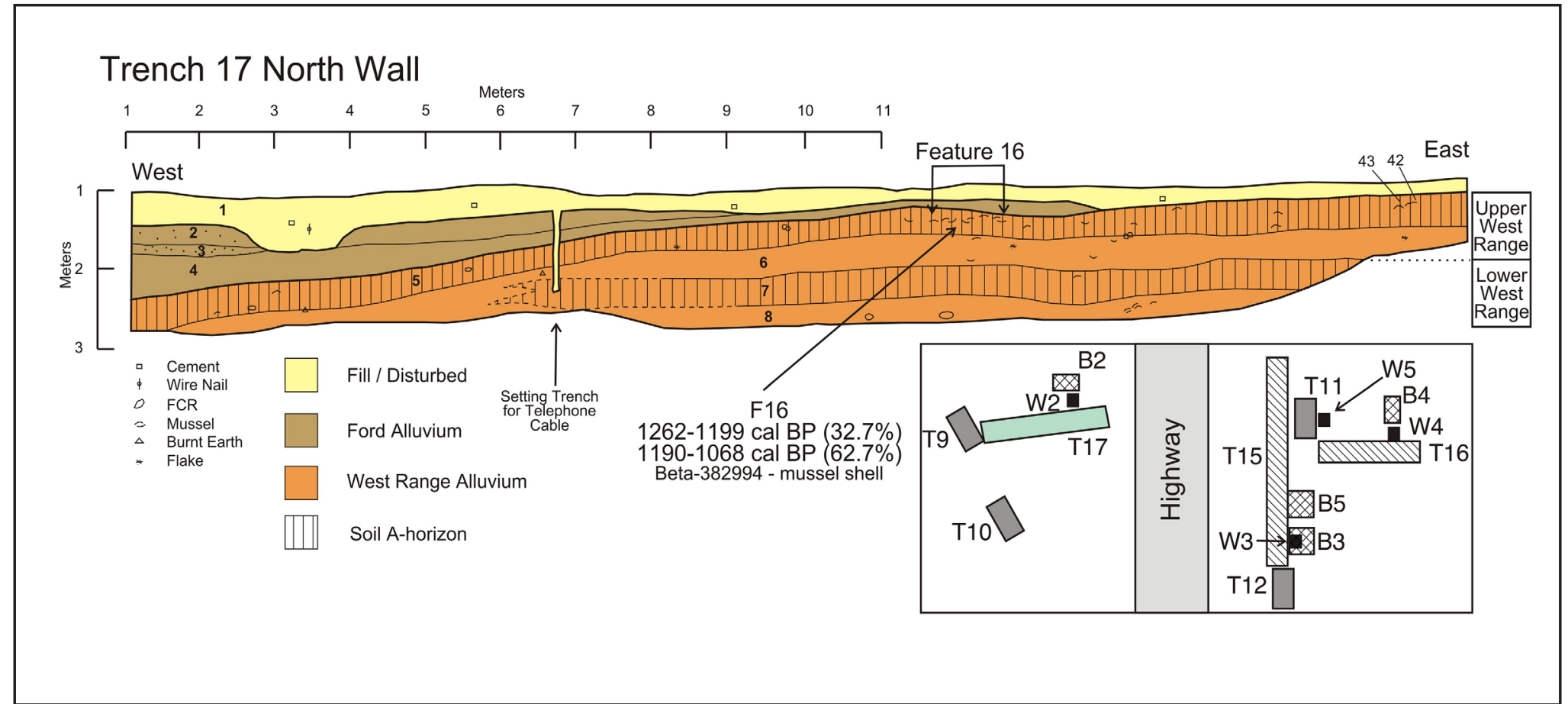
Figure 6-19. Drawing of the north wall profile of BT 17. Note the location of Feature 16 and its associated radiocarbon date. The feature was
excavated in WC 2 and is described in Chapter 7 . Likewise, the radiocarbon date is discussed in Chapter 10 .

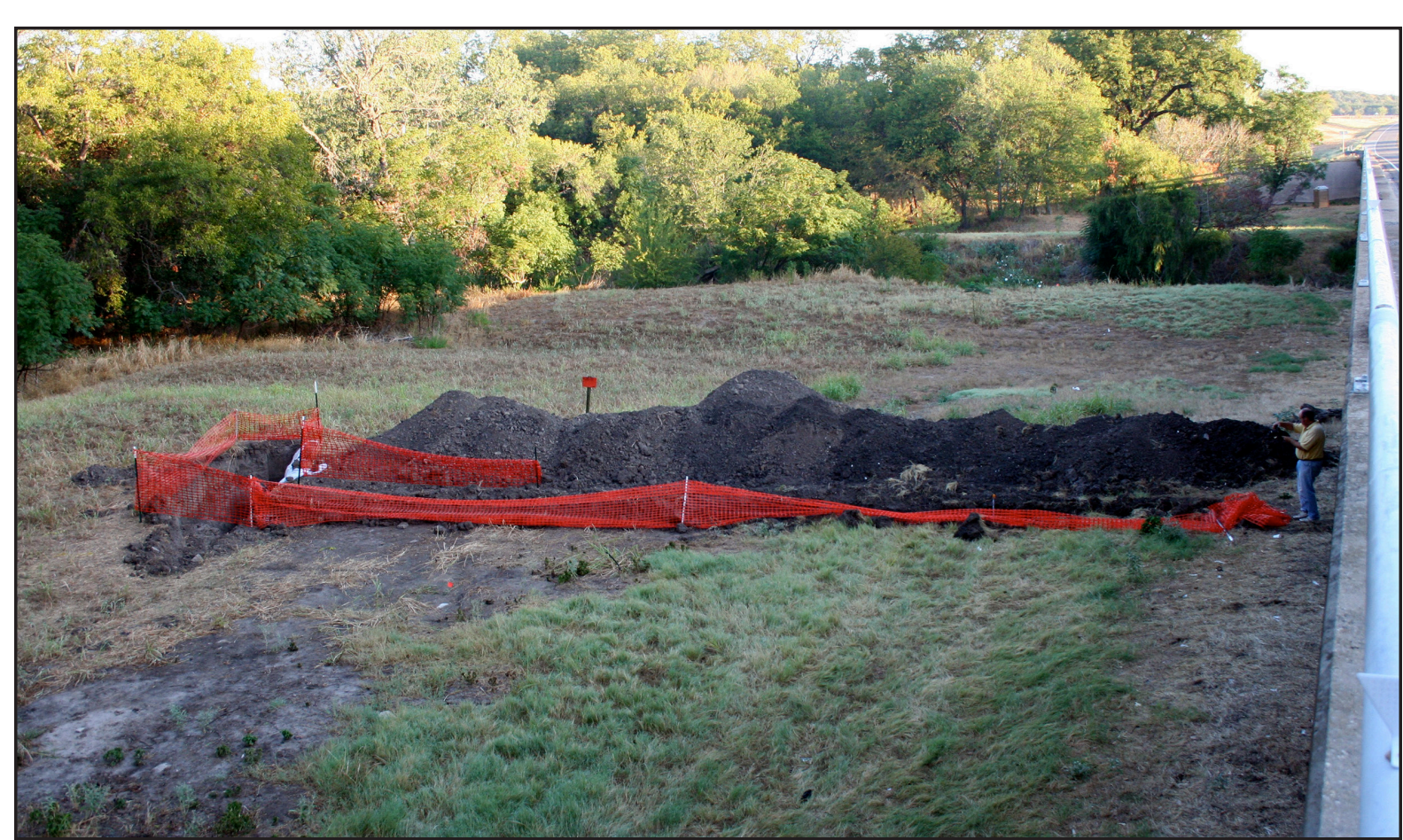

Figure 6-20. Photograph of reopened TxDOT BT 9 and newly excavated BT 17 as seen from atop the U.S. Highway 281 bridge. The channelized sech
View to the north-northwest. 9/14/11.

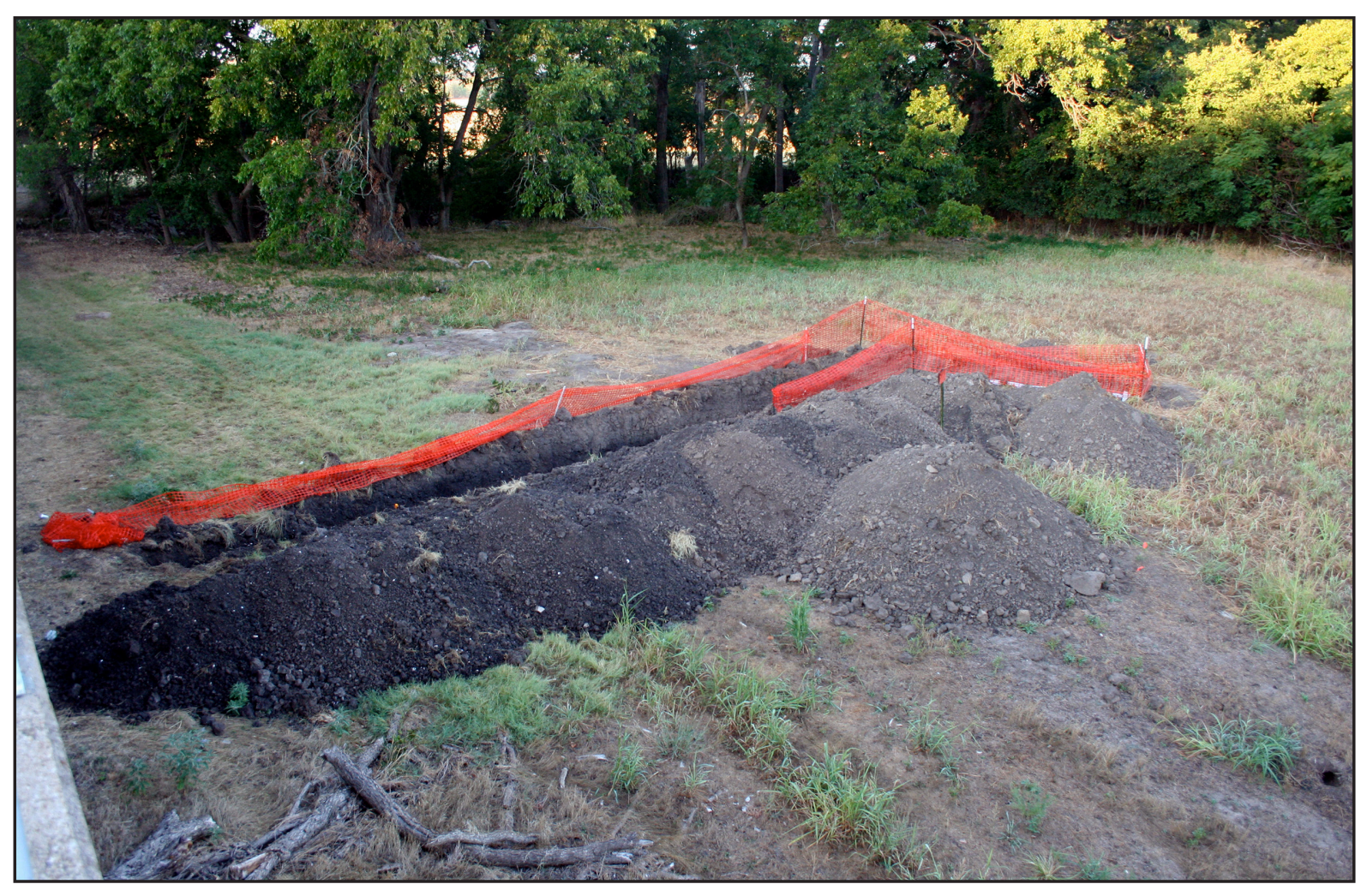

Figure 6-21. Photograph of BT 17 and TxDOT BT 9 with the natural (now relict) channel of Leon River in trees in distance. View to the southwest. 9/14/11. 



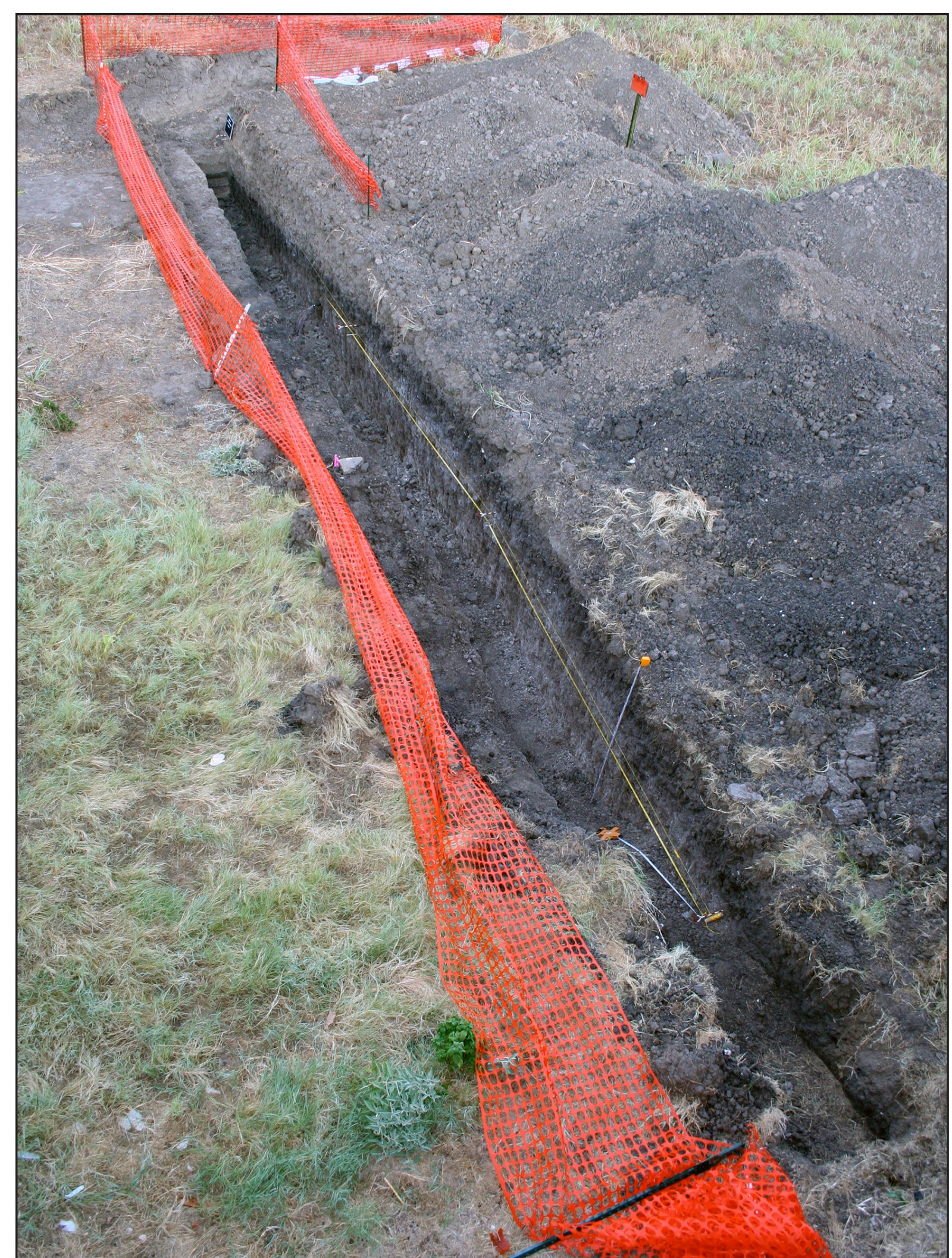

Figure 6-22. Photograph taken from atop the U.S. Highway 281 bridge of BT 17 showing the easily recognizthe western part of the trench. View to the west-northwest. 9/14/1 .

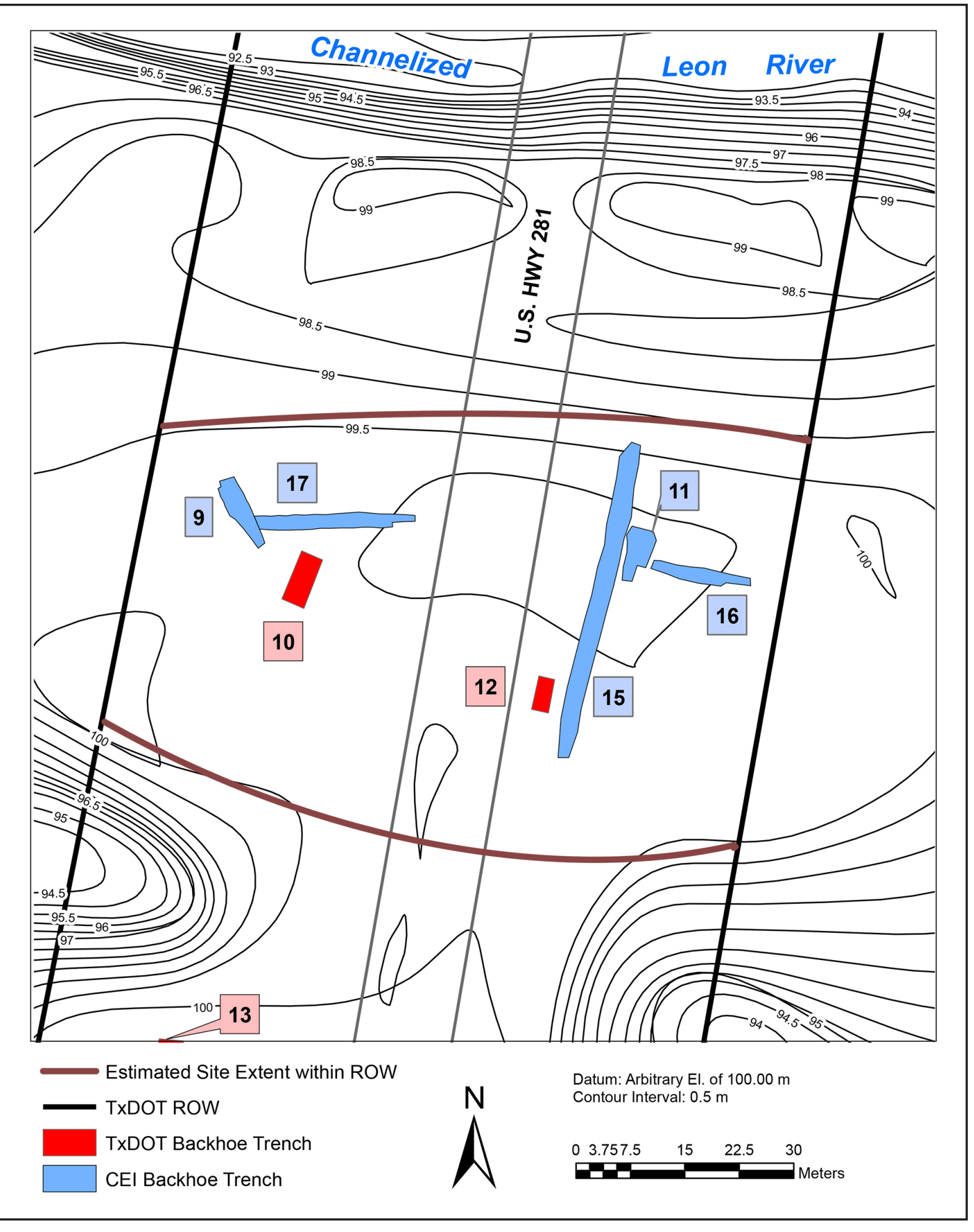

Figure 6-23. Map showing the southern portion of site 41HM61, backhoe trenches, and the estimated extent of intact cultural deposits. 



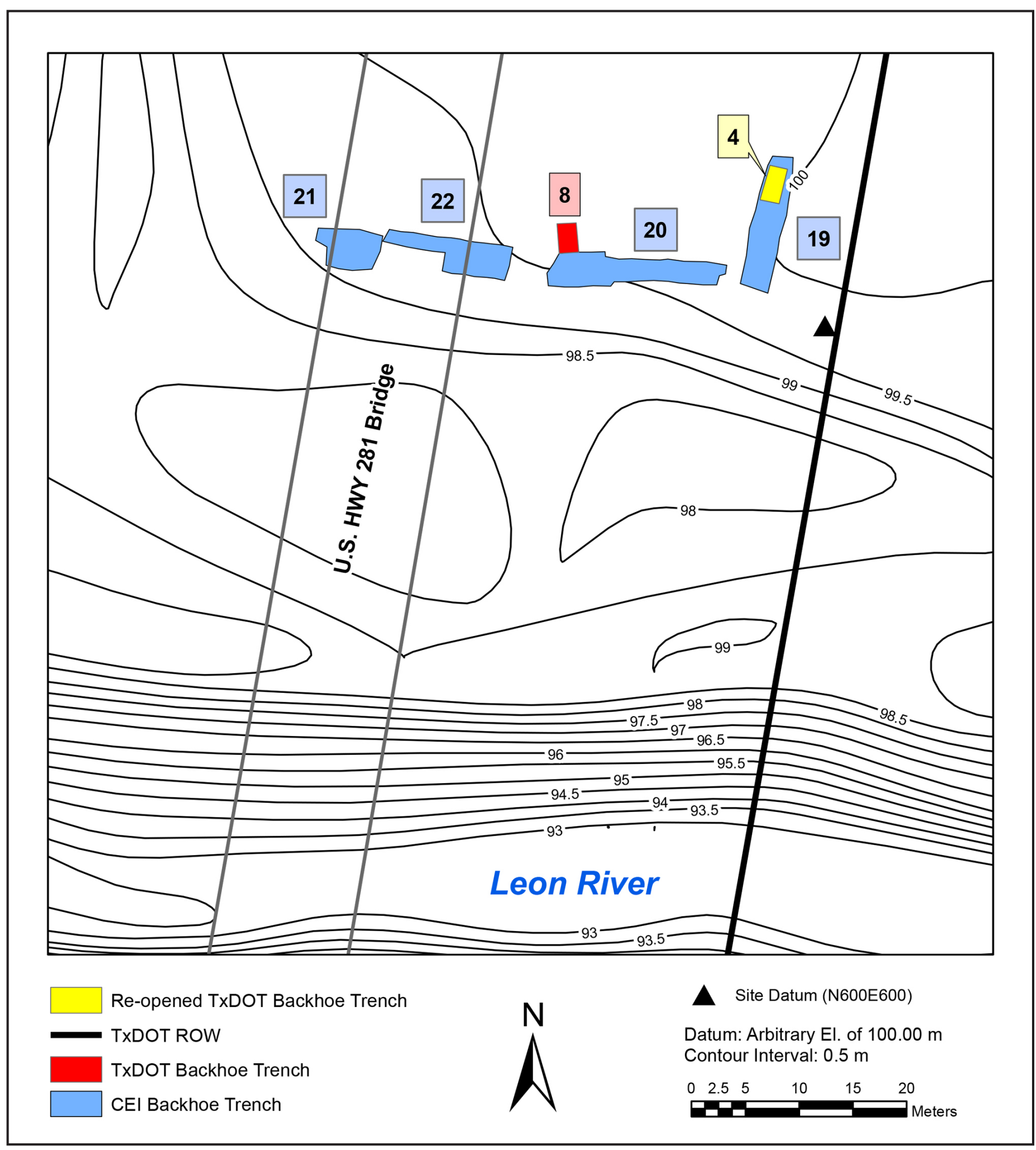

Figure 6-24. Map showing the locations of those BTs situated within the southern part of the northern portion of the project area. Shown are reopened TxDOT BT 4, newly opened BTs 19, 21 , and 22 , and former TxD
opened BT 18 is situated to the north of the figure. Its location can be seen in Figure 6-4.

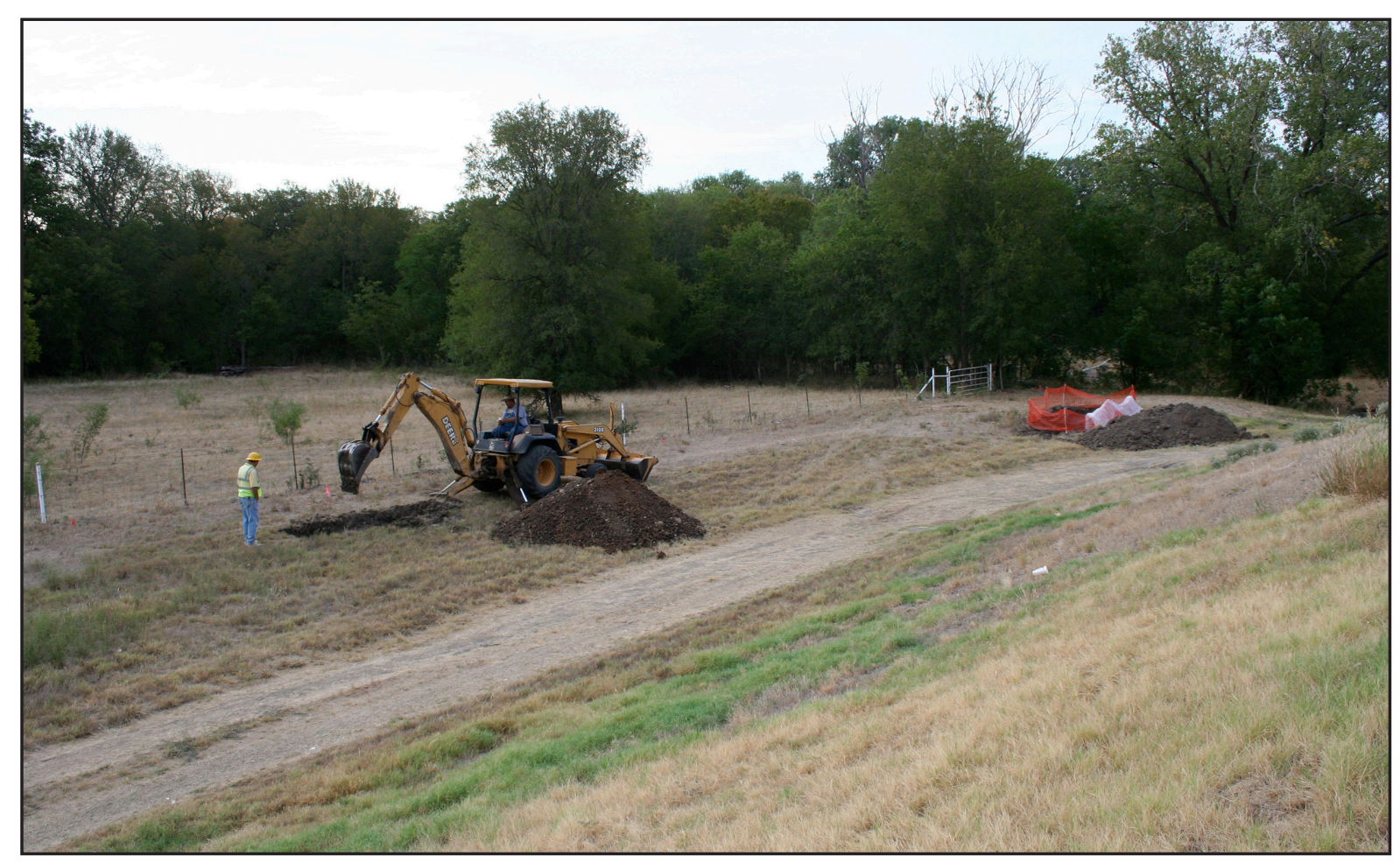

Figure 6-25. Photograph of the backhoe excavating BT 18 in the northern part of the site with reopened TxDOT BT 4 in the background. The highway ROW fence can be seen immediately to the left of
both trenches. View to the southeast from atop the U.S. Highway 281 embankment. 9/15/11.

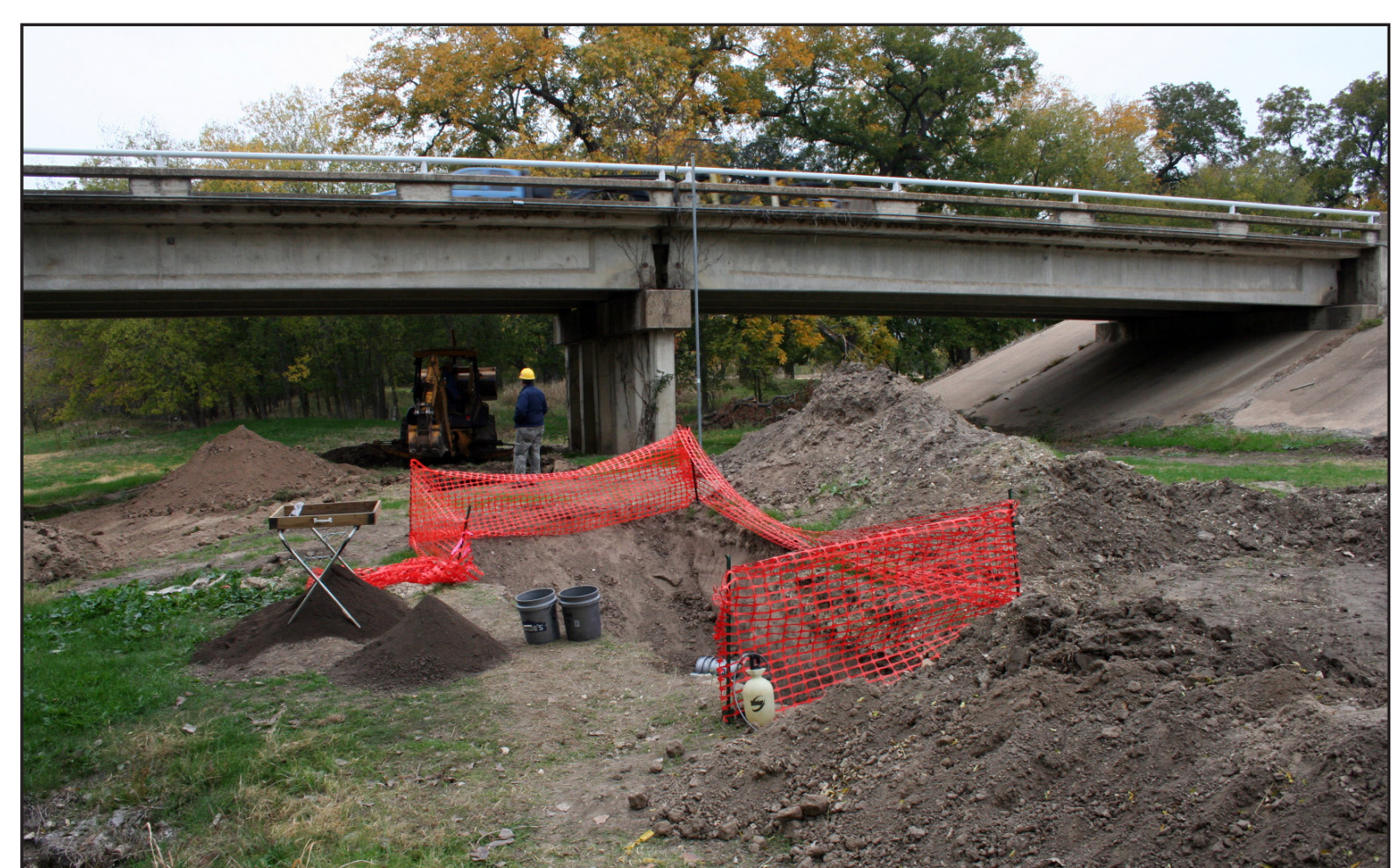

Figure 6-26. Photograph of the excavation of BT 22 under the U.S. Highway 281 bridge with the central portion of BT 20 visible in the foreground. At this point in the project, all of BT 21 and most of
BT 20 had been backfilled, leaving open only that portion of BT 20 in which WC 6 was located. View to the west-northwest. 11/16/11. 



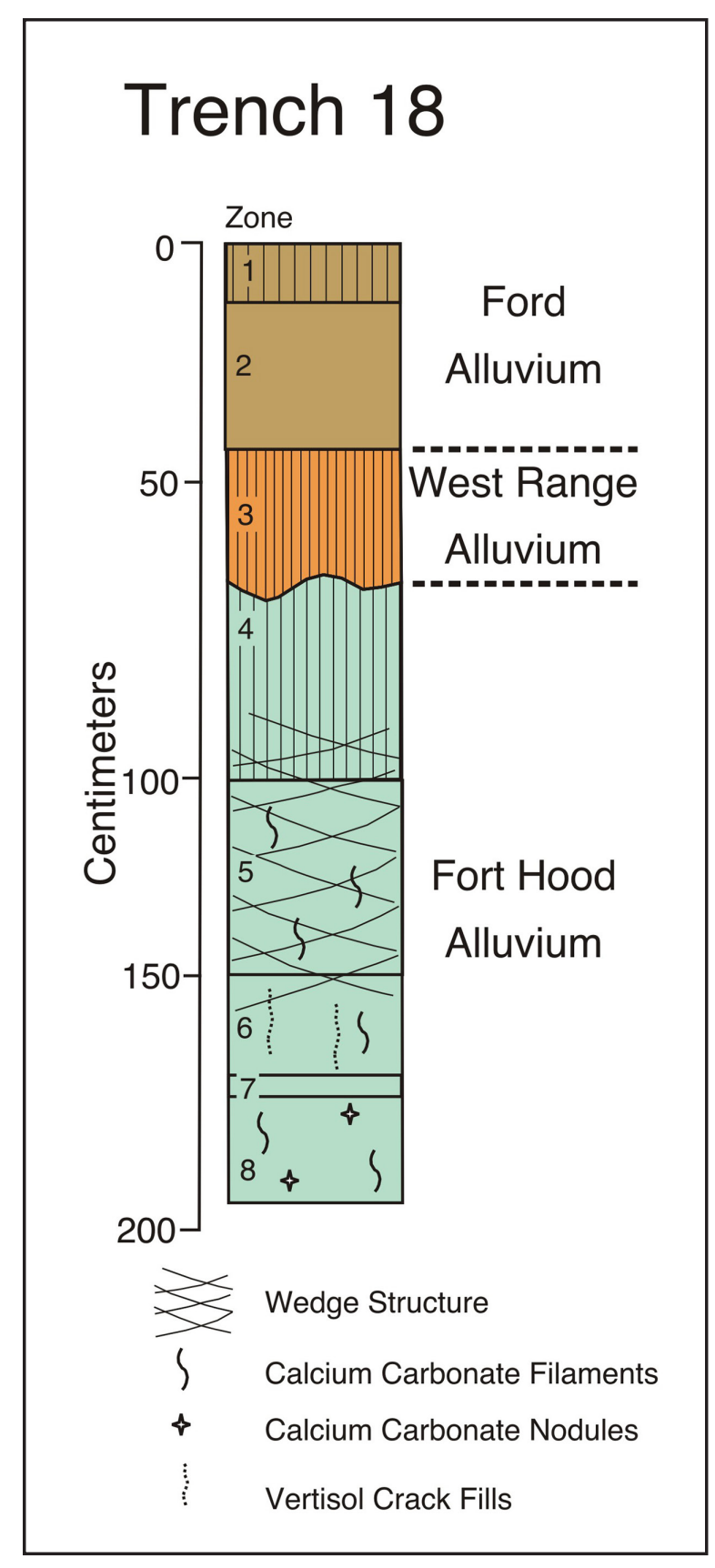

Figure 6-27. Drawing of the profile of a section of the east wall of BT 18. This was the only CEI trench to uncover evidence the West Range alluvium was presen near the top of the trench, no cultural remains were found within either it or the overlying Ford alluvium.

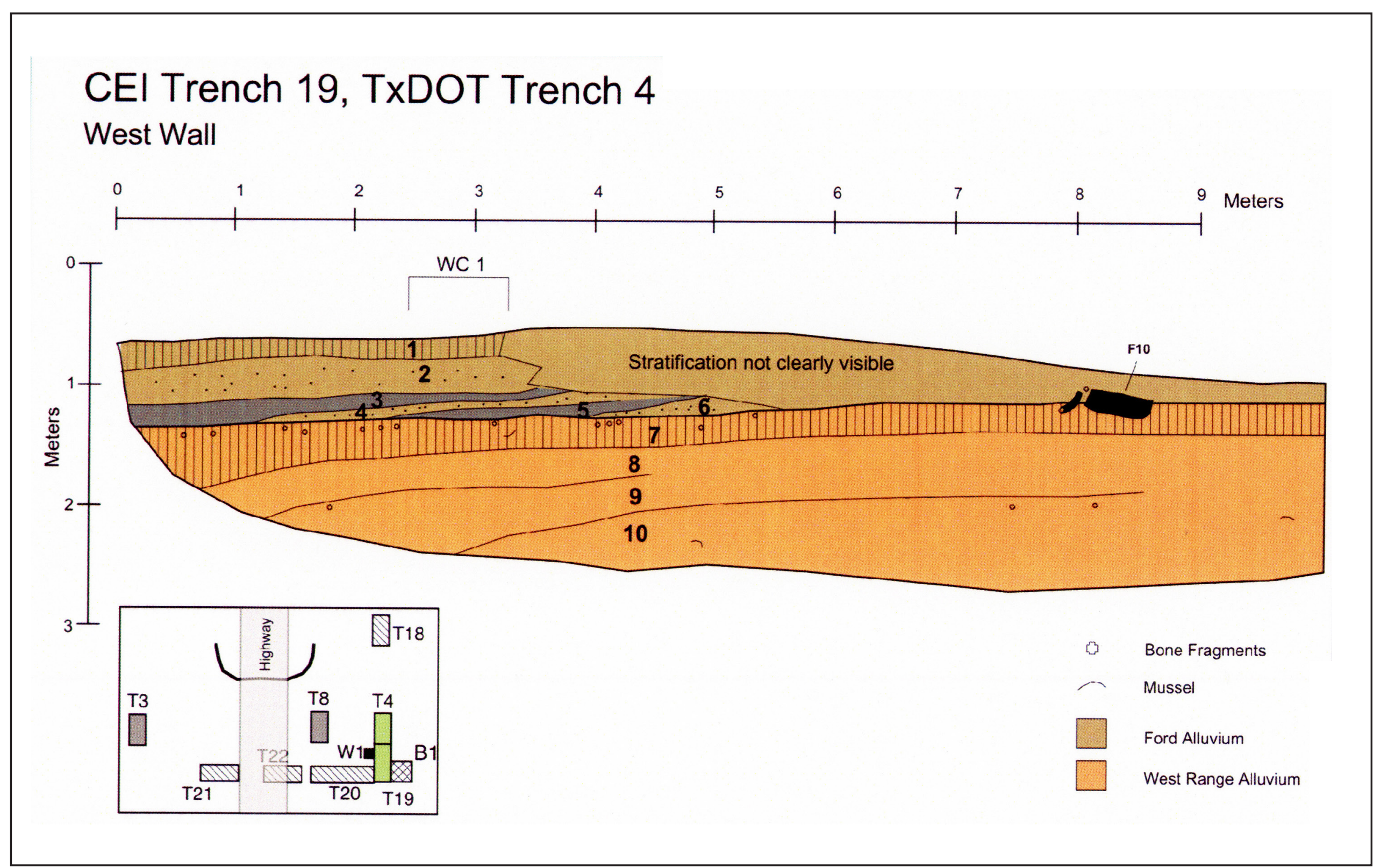
Figure 6-28. Drawing of the west wall profile of combined BT 4/19. Note the bone fragments within Zone 7 and the location of WC 1 , the latter
described in detail in Chapter 7 . 



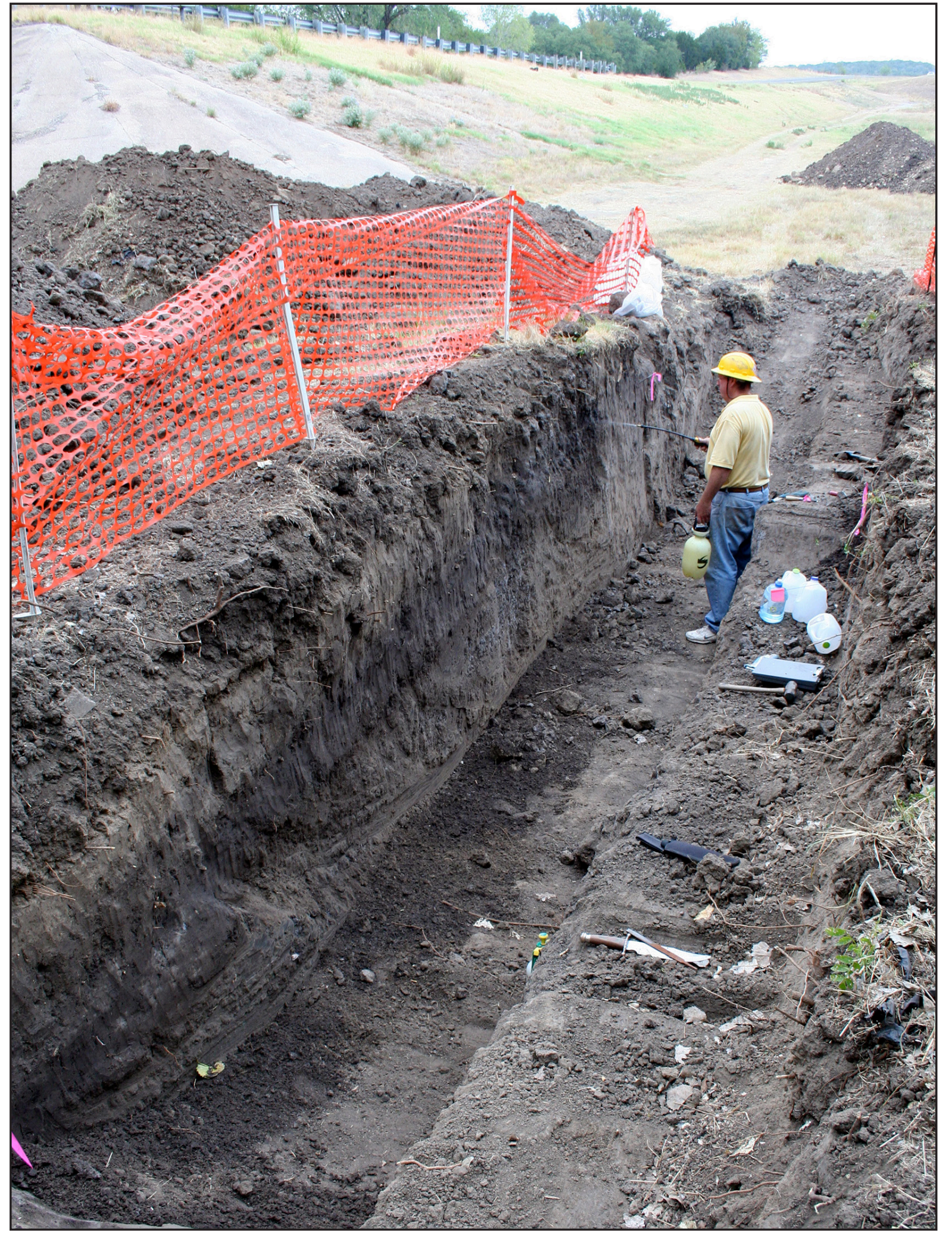

Figure 6-29. Photograph of Charles Frederick spraying the west wall of combined BT 4/19 prior to recording noticeable along the wall. View to the north-northwest, with the backdirt from BT 18 visible in noticeable along the

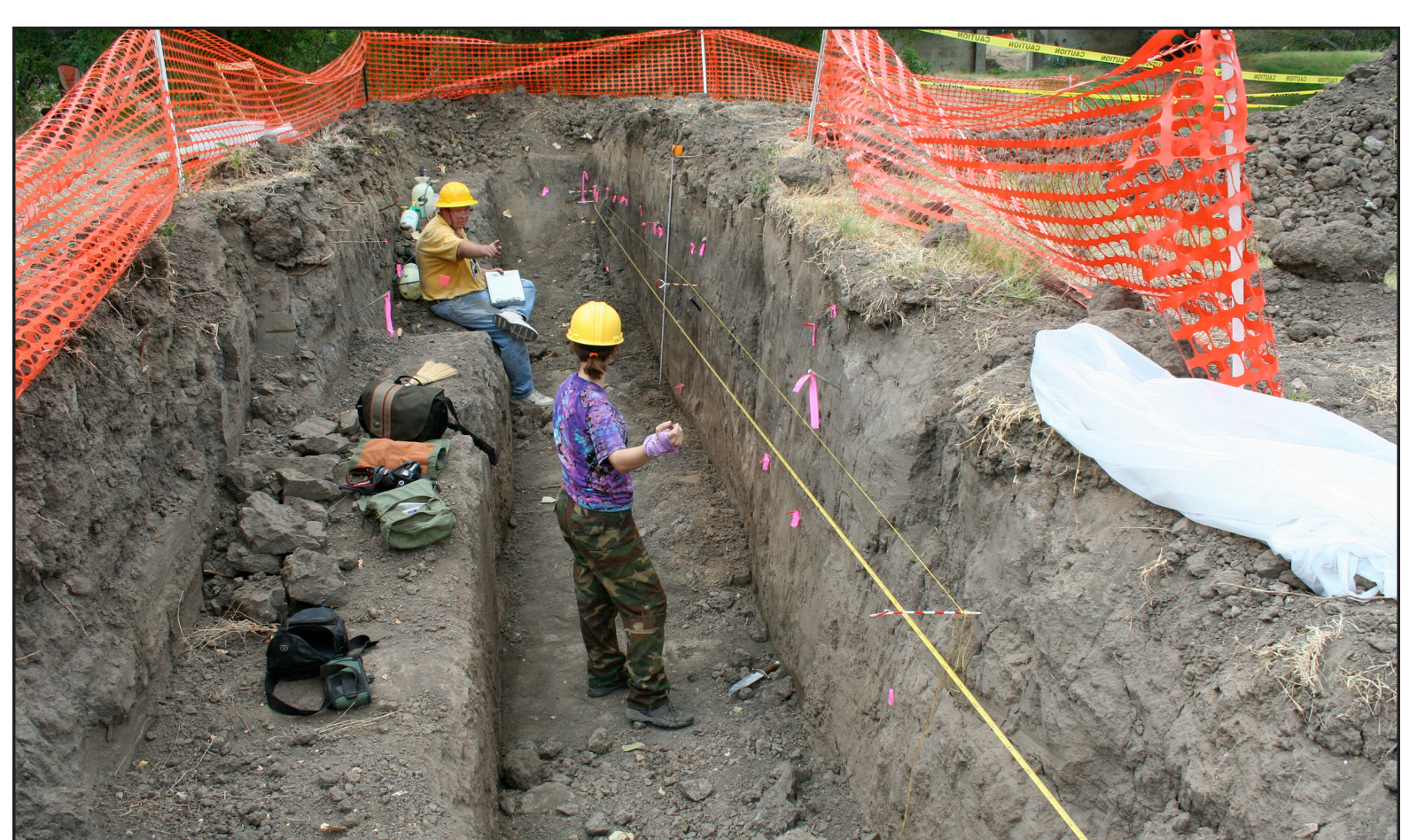

Figure 6-30. Photograph of Charles Frederick and Sally Morehead recording stratigraphy along the west wall of combined BT 4/19. Pink pieces of flagging tape mark the location of FSs identified in the
wall. Note the line of FSs near the top of the A horizon at the far end of the trench. View to the
south. $9 / 17 / 11$.

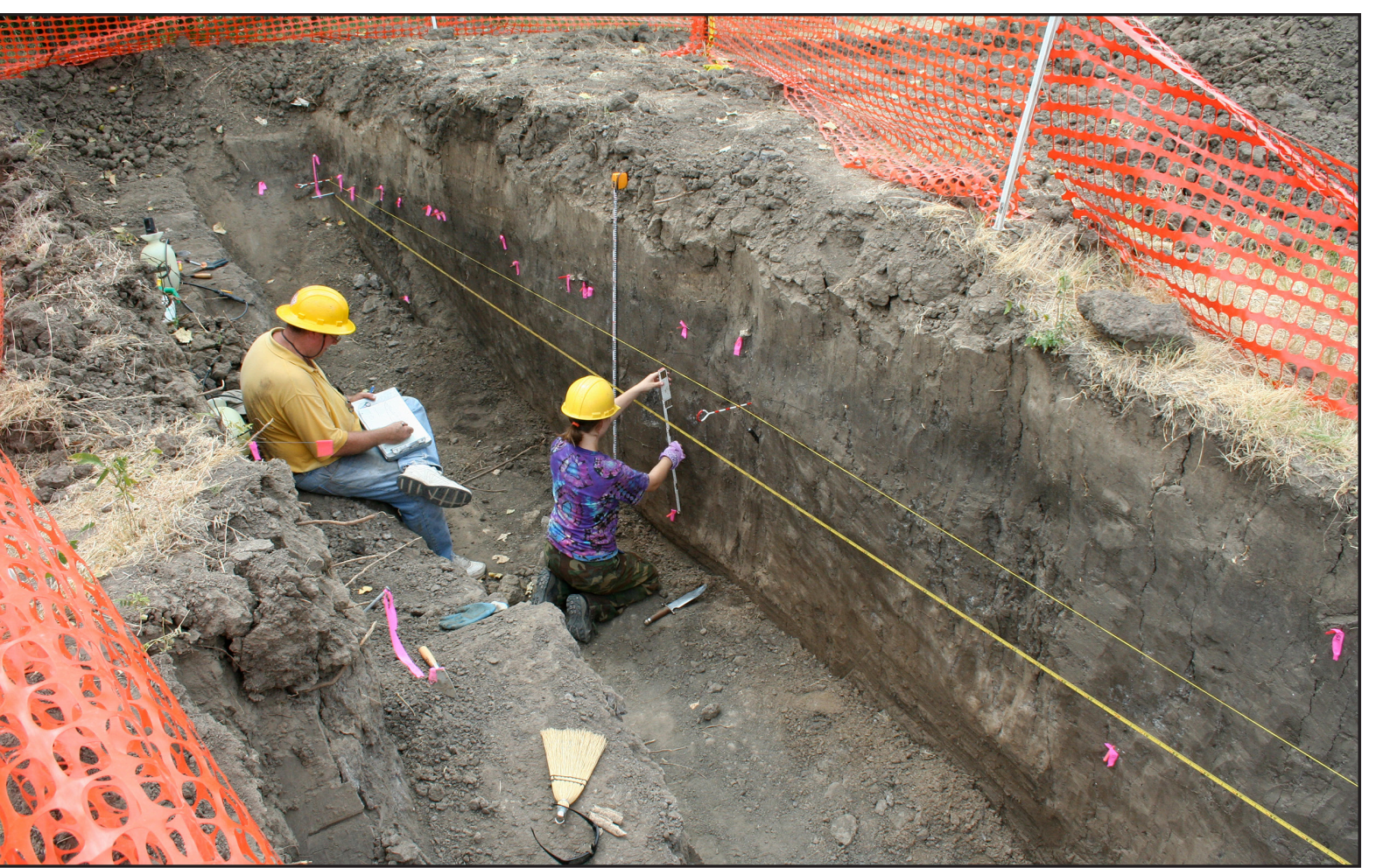

Figure 6-31. Photograph of continuing profiling of the west wall of BT 4/19. The line of FSs marking a probsouthwest. 9/17/11. 



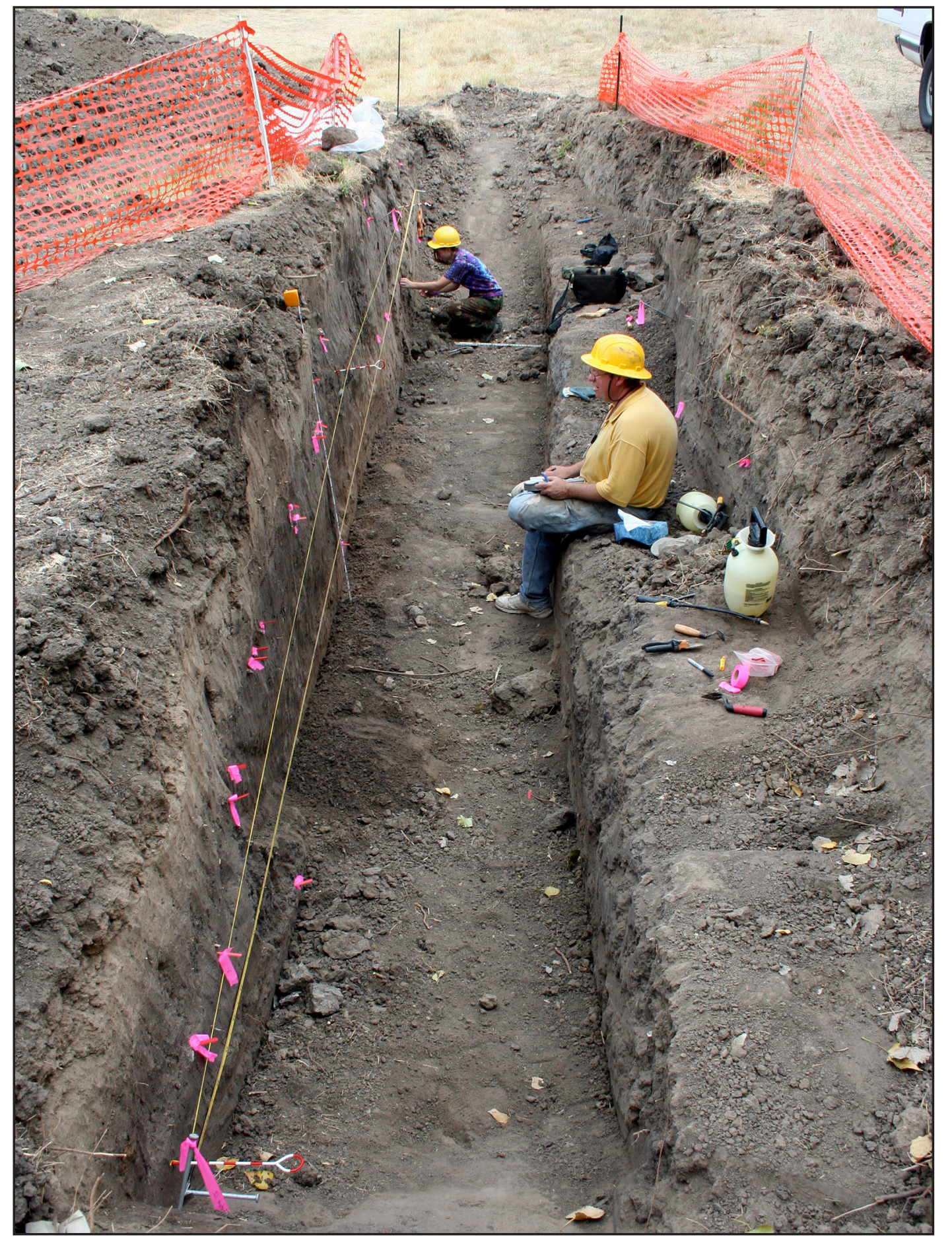

Figure 6-32. Another photograph of combined BT $4 / 19$ with Frederick and Morehead identifying
FSs and recording the trench's west wall profile. View to the north. $9 / 17 / 11$.

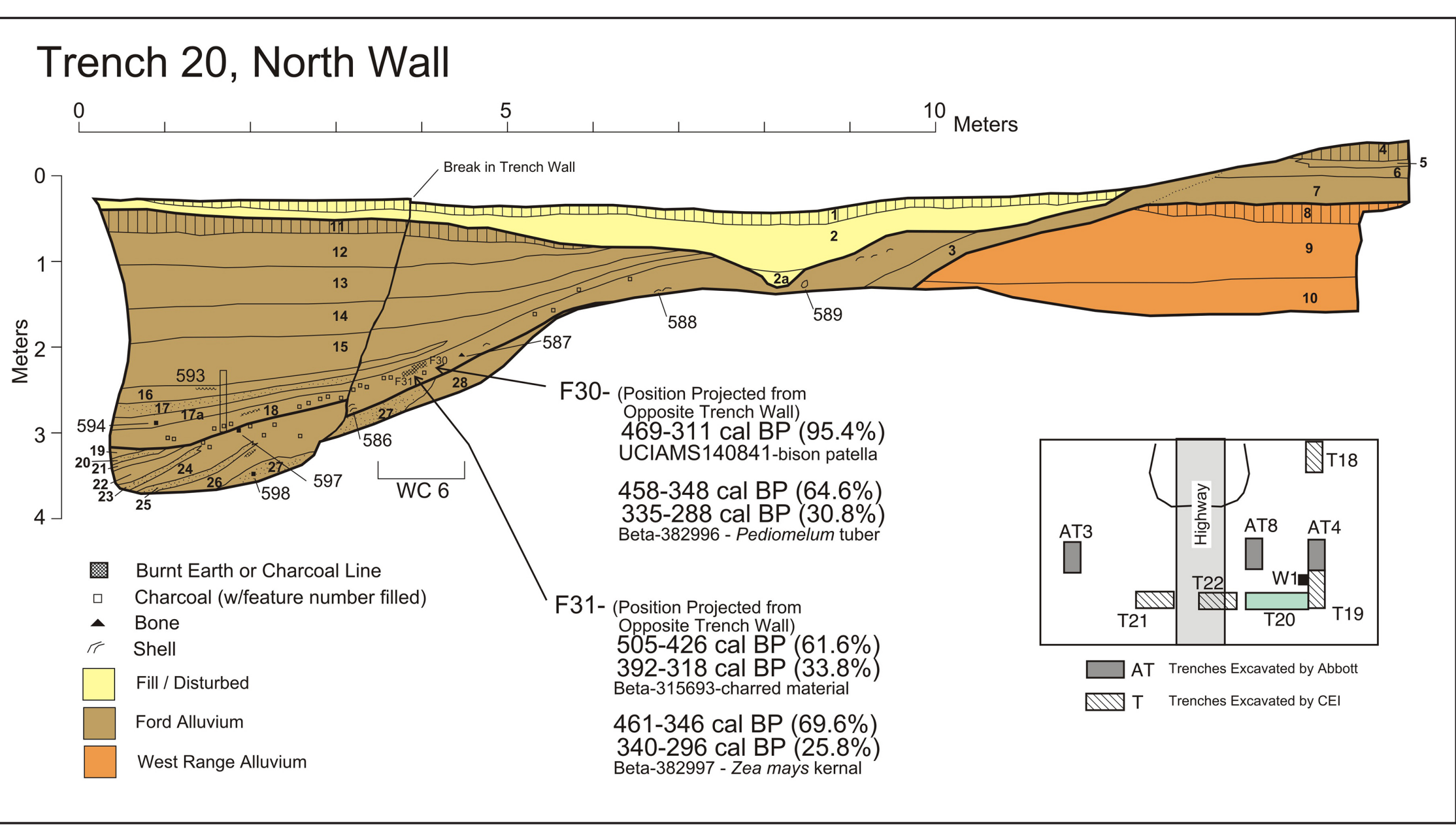

Figure 6-33. Drawing of the strata exposed on the north wall of BT 20 showing the major deposits present (i.e.,, Ford alluvium, West Range alluvium, and disturbed fill) and some of the internal stratification of the inset fill facies of the Ford alluvium. Also shown are radiocarbon dates obtained on Features 30 and 31 , which were excavated in WC 6 positioned on the south side of the trench. Their projected positions are shown here to provide
dates for Zone 18. The actual stratification is much more complex than depicted. (See Chapter 9 and Appendix C for descriptions of the alluvia and inset fill facies. See Chapter 7 for a description of WC 6 , and see Chapter 10 for a summary of the relevant radiocarbon dates.) 



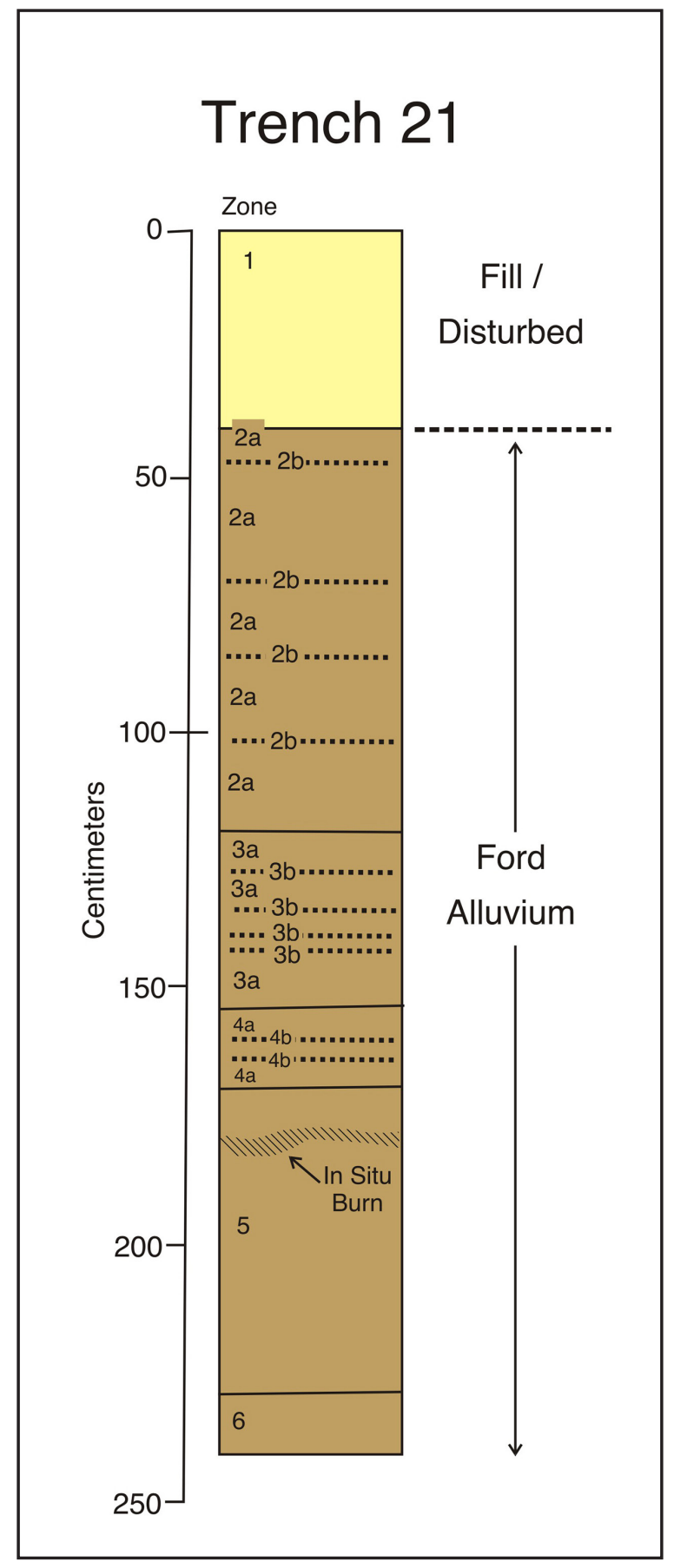

Figure 6-34. Drawing of the profile of a section of the north wall of BT 21 . Note the numerous strata associated with the
inset fill facies of the Ford alluvium plus the burned layer within Zone 5 . at the base of the trench at a depth of ca. $2.5 \mathrm{~m}$. No cultural remains were found in the trench. (See Chapter 9 stratigraphy of BT 21.)

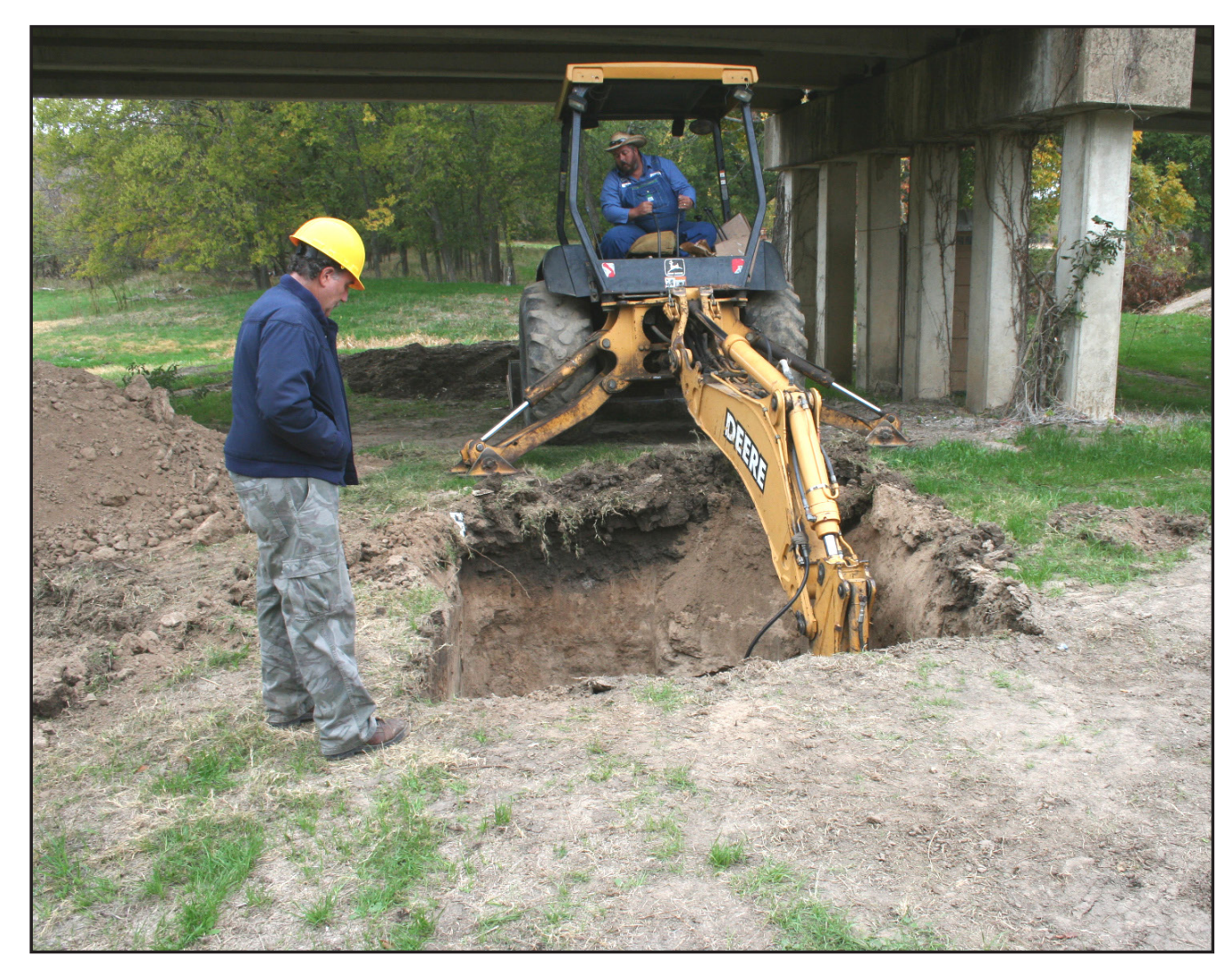

Figure 6-35. Photograph of Rich Weinstein monitoring the beginning excavation of BT 22 . The low pile of dirt visible under the bridge and behind the
location of backfilled BT 21. View to the west. 11/16/11.

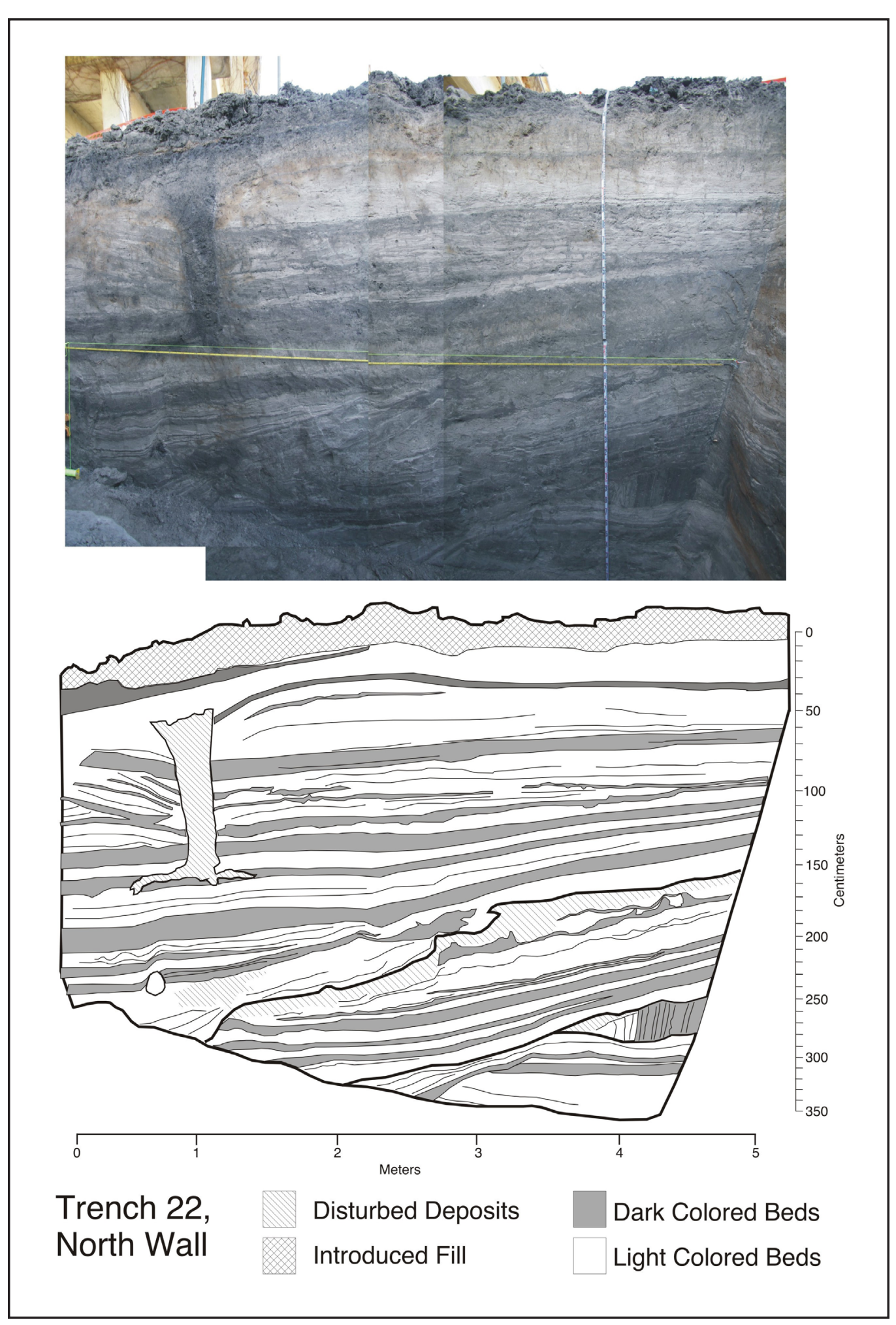

Figure 6-36. (Upper Panel) Photomosaic of the inset fill facies of the Ford Alluvium exposed on the north wall of Backhoe Trench 22. (Lower Panel) Interpretive line drawing 政 denote disturbed deposits and fill, respectively. Major bounding surfaces denoted by heavy lines. (See Chapter 9 and Appendix $\mathrm{C}$ for more detailed description.) 



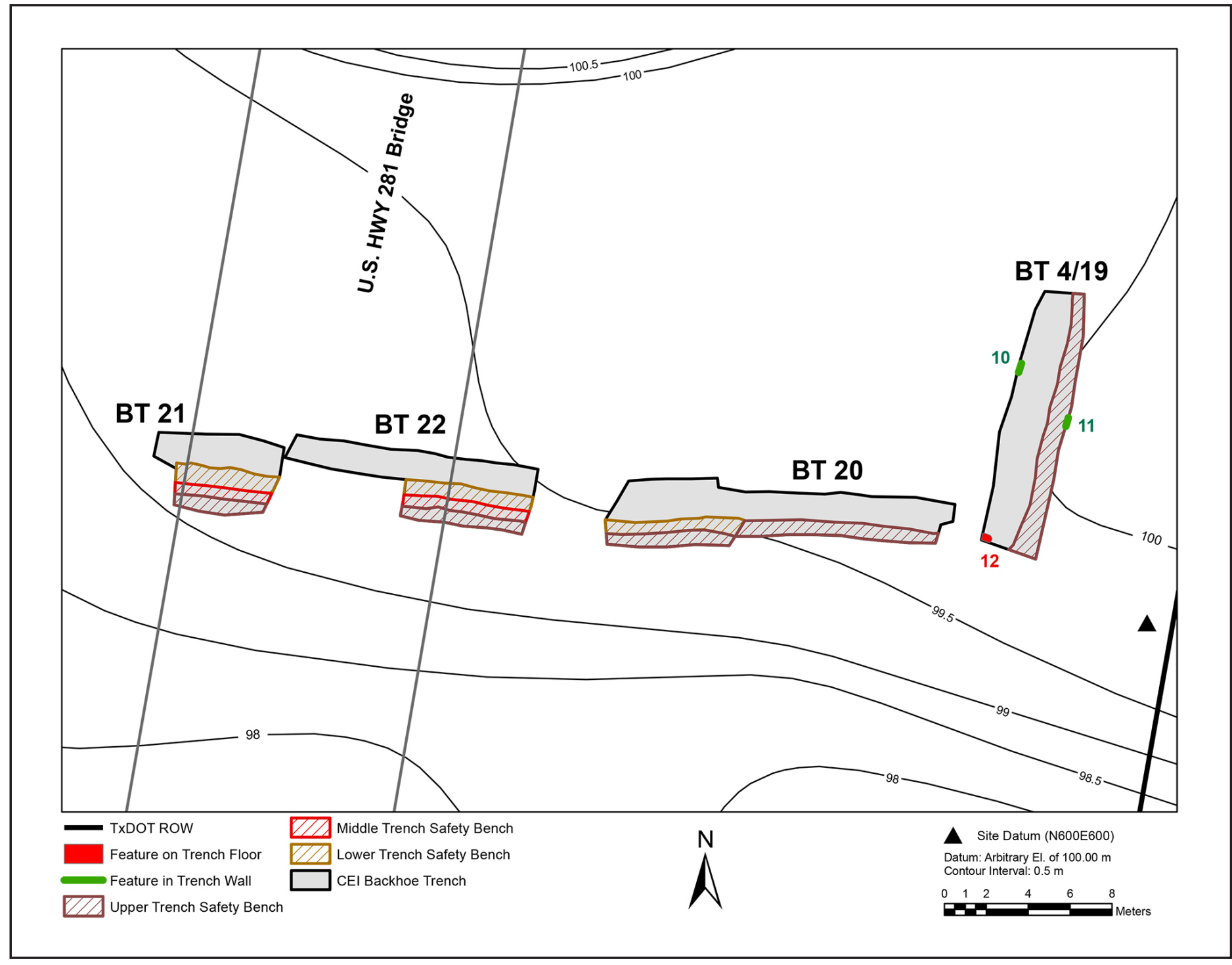

Figure 6-37. Map showing features exposed during trenching within the southern part of the northern area of the site. Note that depths of BTs 21 and 22, a series of three stepped safety benches were employed in each trench.

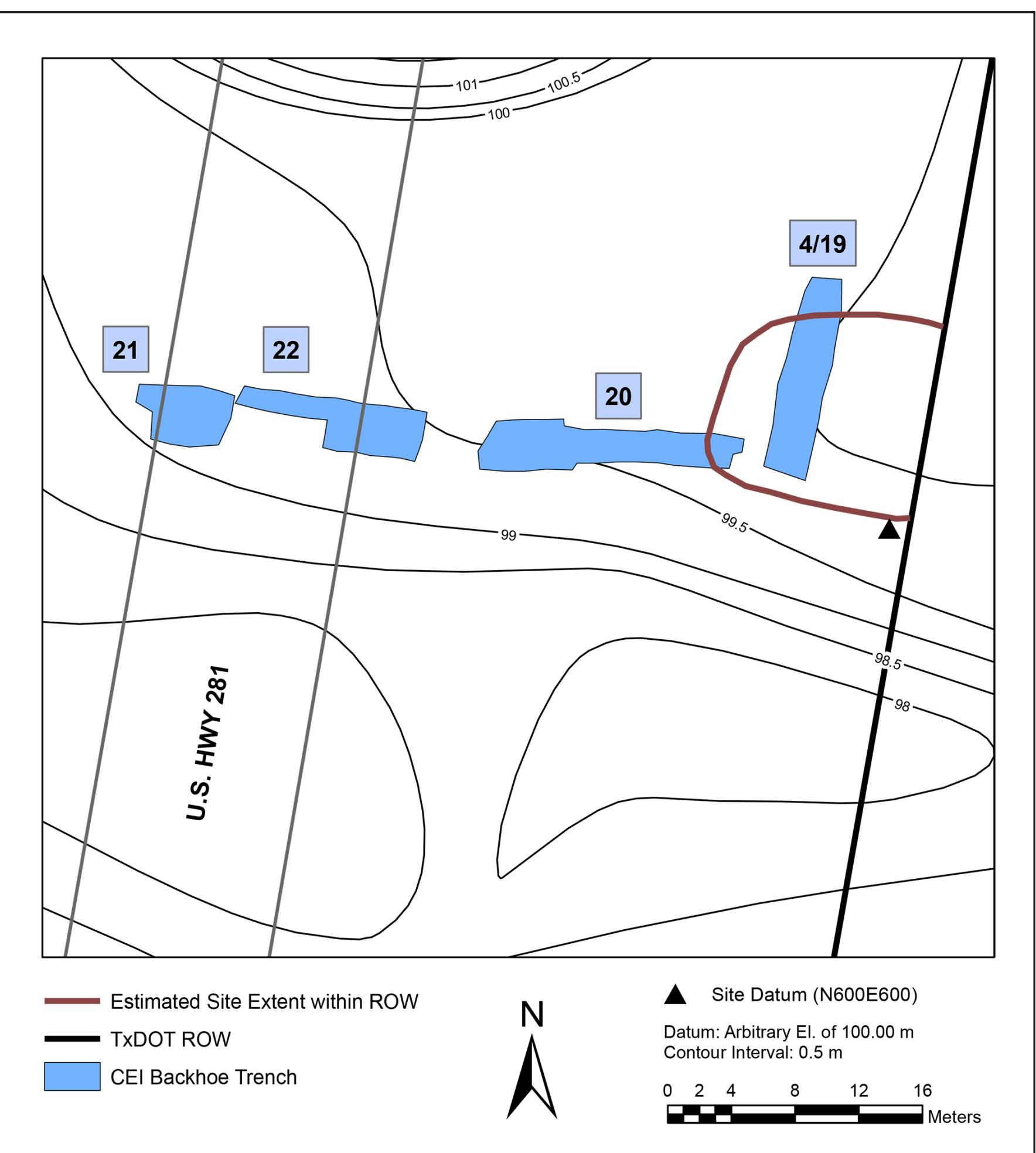

Figure 6-38. Map of the northern portion of site 41HM61 showing backhoe trenches and the estimated extent of intact deposits related to the site's Late Prehistoric "Toyah" occupation. 

to depths greater than the 2-m limit originally noted in the work authorization.

In any case, north of the channelized Leon River a small area related to a Toyah occupation was found east of the highway. This area mainly was marked by the presence of artifacts and bison and deer bone within a 20 - to $30-\mathrm{cm}$ thick A horizon that rested atop the West Range alluvium. Below the A horizon were found scattered mussel shells and pieces of firecracked rock that likely represent sparse usage of the area during earlier Archaic times.

Interestingly, a portion of the Toyah zone dipped dramatically downward to the west where it occurred within laminated deposits of Ford alluvium. This "deep Toyah" zone presumably had been deposited atop the sloping edge of the former bank of the river, but almost all of it had been truncated and removed by subsequent river migration. Thus, only a small segment of the deep Toyah still was present at the western end of BT 20. Included within it were additional bison bones, charcoal, ash, and fired earth, the latter presumably indicative of a hearth or hearth-like debris.

Given that two somewhat distinct Toyah zones were present in the northern part of the site, it was decided to excavate two witness columns (WCs) in the area. Accordingly, WC 1 was positioned along the western side of BT 19 in order to acquire data on the main Toyah occupation visible in the A horizon exposed in the walls of that trench. WC 6, on the other hand, was positioned along the south wall of the western portion of BT 20. This WC was designed to investigate the deep Toyah zone present at a minimum depth of -1.45 $\mathrm{m}$ in that area. Results of the excavations of these WCs will be presented in the next chapter.

The site area south of the channelized Leon River produced several distinct occupation levels within basically the same alluvial stratigraphy. A $30-$ to $50-\mathrm{cm}-$ thick A horizon was present in the upper levels of the West Range alluvium across almost the entire area examined. Within it were at least two recognizable occupation levels that were marked by artifacts (including a Marcos dart point), fire-cracked rocks, and/or mussel shells. Several concentrated areas of fire-cracked rocks and mussel shells were assigned feature numbers. Additional mussel shells, artifacts, and fire-cracked rocks also were present in a lower A horizon within the West Range alluvium. Again, several concentrated areas of mussel shells and fire-cracked rocks were assigned feature numbers. One probable Lange dart point was found in the east wall of BT 15 with the lower A horizon, while an Ensor dart point that had likely been displaced by previous TxDOT trenching also was uncovered within the lower A horizon of BT 15.

In order to sample both the occupations within the Upper West Range A horizon and the deeper cultural material within the lower West Range A horizon, four more WCs were laid out. WC 2 was positioned adjacent to the north wall of BT 17, directly over the mussel shell concentration present within the upper A horizon and identified as Feature 16. WC 3 was positioned along the east wall of BT 15 near its southern end where the trench had exposed two deep features, a mussel shell concentration (Feature 19) near the top of the lower A horizon and a burned rock concentration (Feature 20) within the lower A horizon. The mussel shells were located about 10 to $20 \mathrm{~cm}$ above the burned rock, with apparent culturally sterile alluvium separating the two features. WC 4 was positioned adjacent to the north wall of BT 16, above a layer of burned rock (Feature 21) present at the base of the A horizion. Lastly, WC 5 was placed along the east wall of expanded BT 11, above several layers of burned rock visible within the A horizon. These layers were not as concentrated as those in WCs 3 and 4, so they were not assigned feature numbers. As with the backhoe trenches excavated at the site, the four WCs situated south of the channelized river will be discussed first in the following chapter. 


\title{
Chapter 7
}

\section{Witness Columns}

\author{
Richard A. Weinstein
}

As just mentioned in the previous chapter, six witness columns were excavated at site 41HM61 following completion of the backhoe trenching. Although the original work authorization called for the excavation of a minimum of eight 50-by-50-cm witness columns, it was agreed that the number of columns could be reduced to six, given that the stratigraphy was relatively consistent across most of the southern portion of the site and since there was only a small area worthy of controlled excavations in the northern section. Accordingly, Supplement No. 2 to the work authorization for the fieldwork officially reduced the number of WCs from eight to six. Each of these six columns will be reviewed separately below, with those located on the south side of the channelized river presented first.

\section{South Section}

\section{Witness Column 2}

WC 2 was set up along the north wall of BT 17 directly above the Feature 16 mussel shell concentration exposed within the A horizon at the top of the Upper West Range alluvium (Figures 7-1 to 7-4). Although projected to measure 50 by $50 \mathrm{~cm}$ in size, the column actually measured $50 \mathrm{~cm}$ east-west by $65 \mathrm{~cm}$ northsouth due to the need to place it slightly farther away from the edge of BT 17. The WC's northwest corner (located at N475.7E560) served as the column's specific datum, and it was from this point that a line level was attached to measure depth during excavation. The WC was dug to $-1.68 \mathrm{~m}$ below ground surface.
Since it was obvious from the examination of the north wall of BT 17 that the upper few centimeters consisted of a zone disturbed by bridge and highway construction, the excavators simply removed that zone by shovel and discarded the soil. Once below the disturbed zone, however, excavation proceeded through the use of trowels and/or careful scraping with a flatblade shovel. At this point, a few words concerning excavation methods seem appropriate.

Excavation of all WCs was by natural strata, with separate $10-\mathrm{cm}$-thick levels removed from those strata greater than $10 \mathrm{~cm}$ in thickness (unless, as just noted, it was obvious that the strata in question had been disturbed by past construction, in which case they simply were removed and discarded). Numbers were used to identify individual strata, while levels within a stratum were assigned letter designations. For instance, if the third recognizable stratum was $46 \mathrm{~cm}$ thick, then the first 10 -cm cut into that stratum would have been identified as Stratum 3, Level A. The second 10-cm cut would then be recognized as Stratum 3, Level B, and so forth. In addition, the beginning and ending depths of each level were recorded, based on an elevation of 0.00 for that corner of the column deemed the most appropriate to serve as the column's specific datum. Thus, for each excavated level, the beginning and ending depths also were recorded. Using the example above, the fourth and final cut into Stratum 3 would have begun at $-76 \mathrm{~cm}$ and ended at $-82 \mathrm{~cm}$ since it was only $6 \mathrm{~cm}$ thick. Accordingly, it would be listed as Stratum 3, Level C (76-82 cm). 


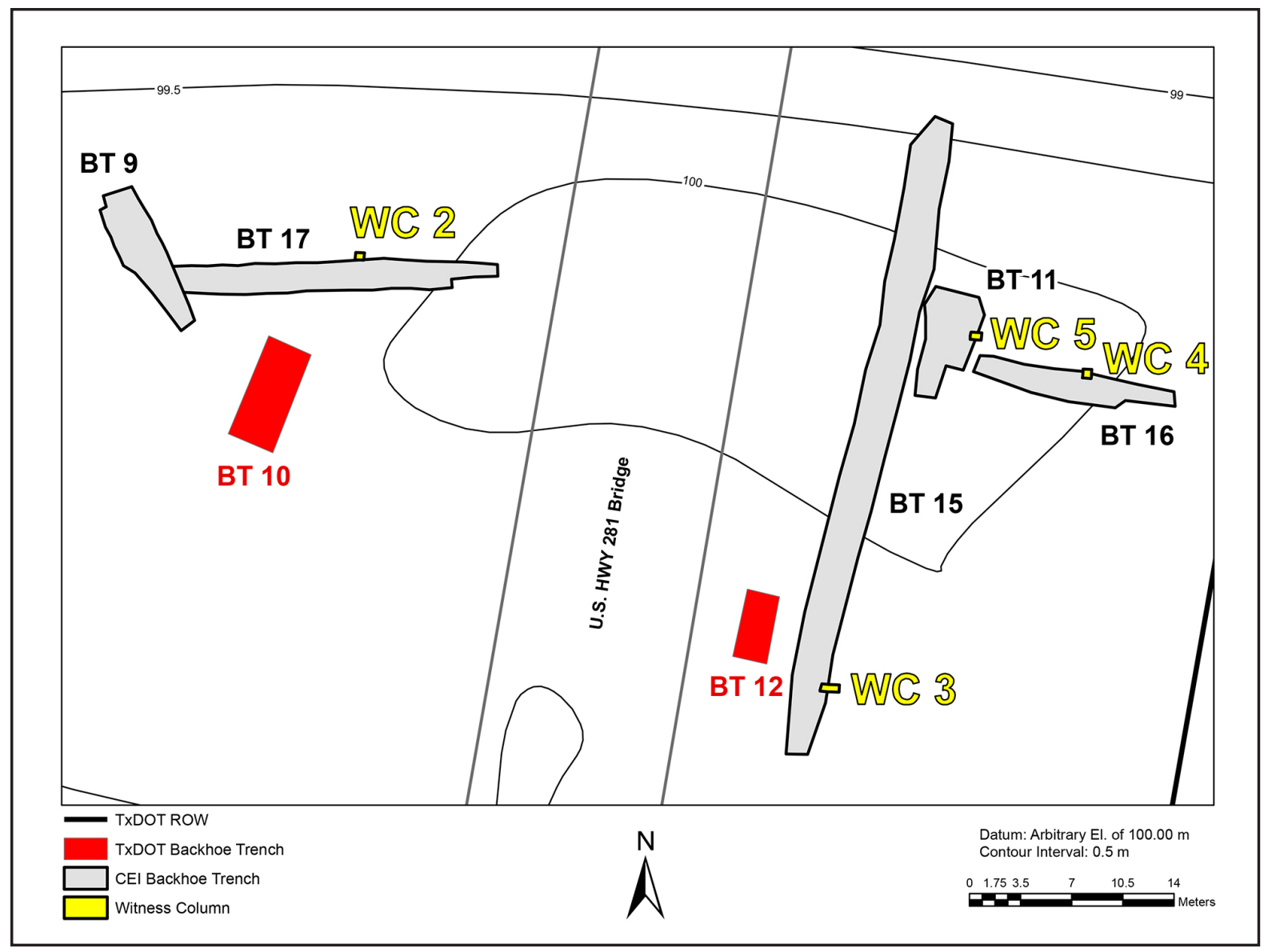

Figure 7-1. Enlargement of the southern part of the site contour map showing trenches and witness columns excavated in that area. Witness Column (WC) 2 was placed adjacent to the north wall of Backhoe Trench (BT 17) to sample the Feature 17 shell deposit, while WC 3 was placed adjacent to the east wall of BT 15 to sample the Feature 19 shell deposit and underlying Feature 20 burnedrock layer. Similarly, WC 4 was placed adjacent to the north wall of BT 16 to sample the Feature 21 burned-rock deposit, and WC 5 was positioned along the east wall of expanded BT 11 to sample the potential "living surface" exposed in that trench.

If artifacts or other cultural items (bone, shells, fire-cracked rocks, etc.) were recognized during excavation, they were assigned individual FS numbers and piece plotted using the total station. So as not to confuse the WC FSs with those obtained from the trench walls, a separate series of FS numbers was assigned to each WC. For WC 2, for example, individual FSs would have been recorded as WC 2-FS 1, WC 2-FS 2 , etc. All soil matrices removed from an excavated level were dry screened through a 1/4-inch wire mesh. Prior to such screening, the soil from a specific level was placed in a plastic bucket, a piece of flagging tape identifying the site, WC, stratum, level, date, and excavator then was placed in the bucket. This flagging tape remained with the screened material from the field to the laboratory. In addition, a one-liter sample of soil from each excavated level was saved for future processing through a flotation system back at CEI's laboratory in Corpus Christi. This system also served as a method for fine screening the coarse fraction of the one-liter sample, as it contained a 1/16-in cloth mesh designed to trap tiny artifacts.

The excavator maintained a standard "Level Record" for each 10-cm-thick cut. Included on the form was information pertaining to the beginning and ending depths of the level, the color and consistency of the soil matrix, the presence of any recognizable artifacts, and the presence of any additional cultural material. Floor plans were drawn and photographs taken of each excavation level. Once the WC was finished, its three walls were photographed and their profiles drawn.

Figures 7-5 and 7-6 illustrate the three walls of WC 2. As can be seen, the mussel shells of Feature 16 


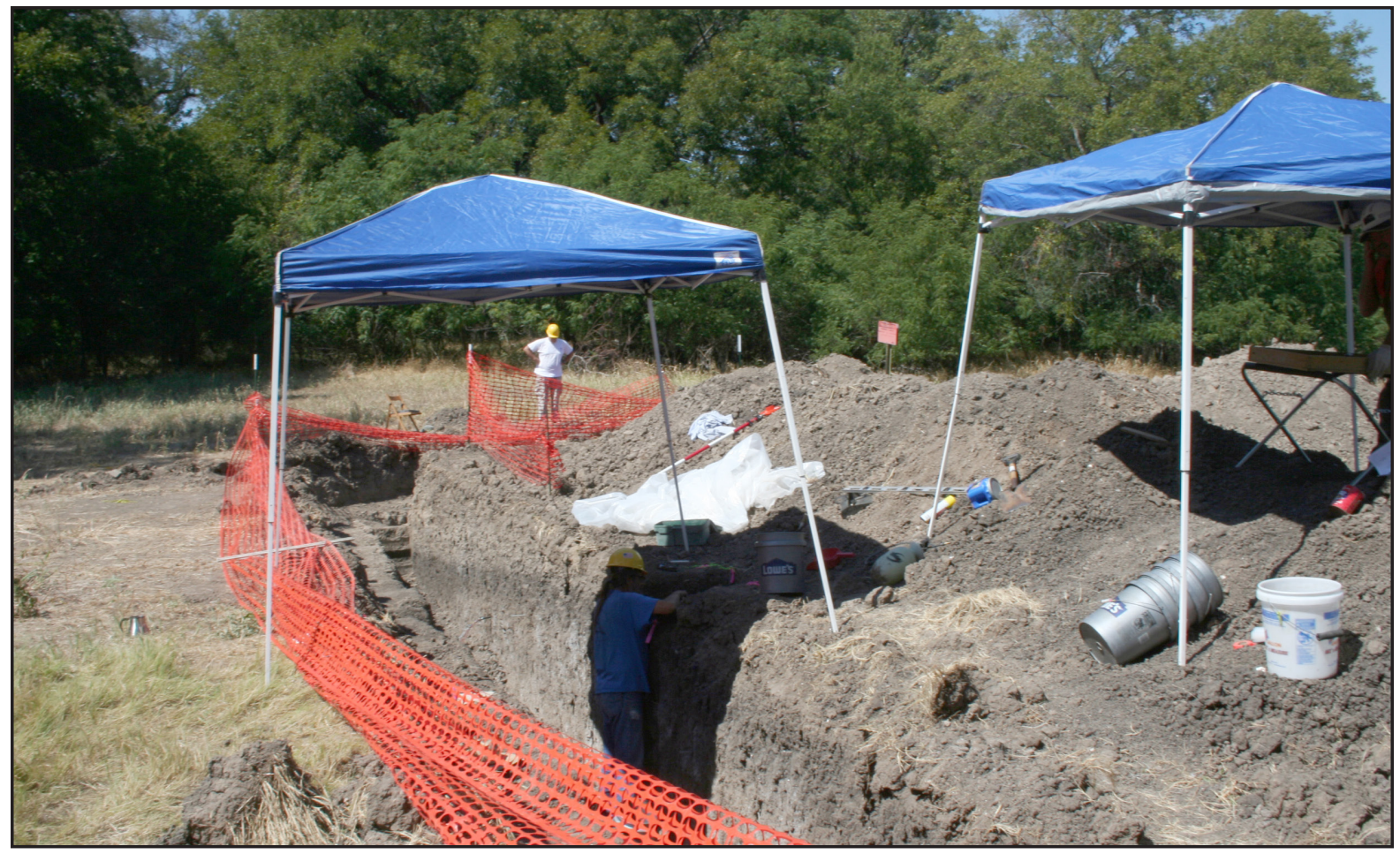

Figure 7-2. Photograph of Richard Walter (in shade) beginning the excavation of WC 2 adjacent to north wall of BT 17. Again, note the dramatic downward dip of the West Range A horizon in the western part of the trench. View to the west-northwest. 9/26/11.

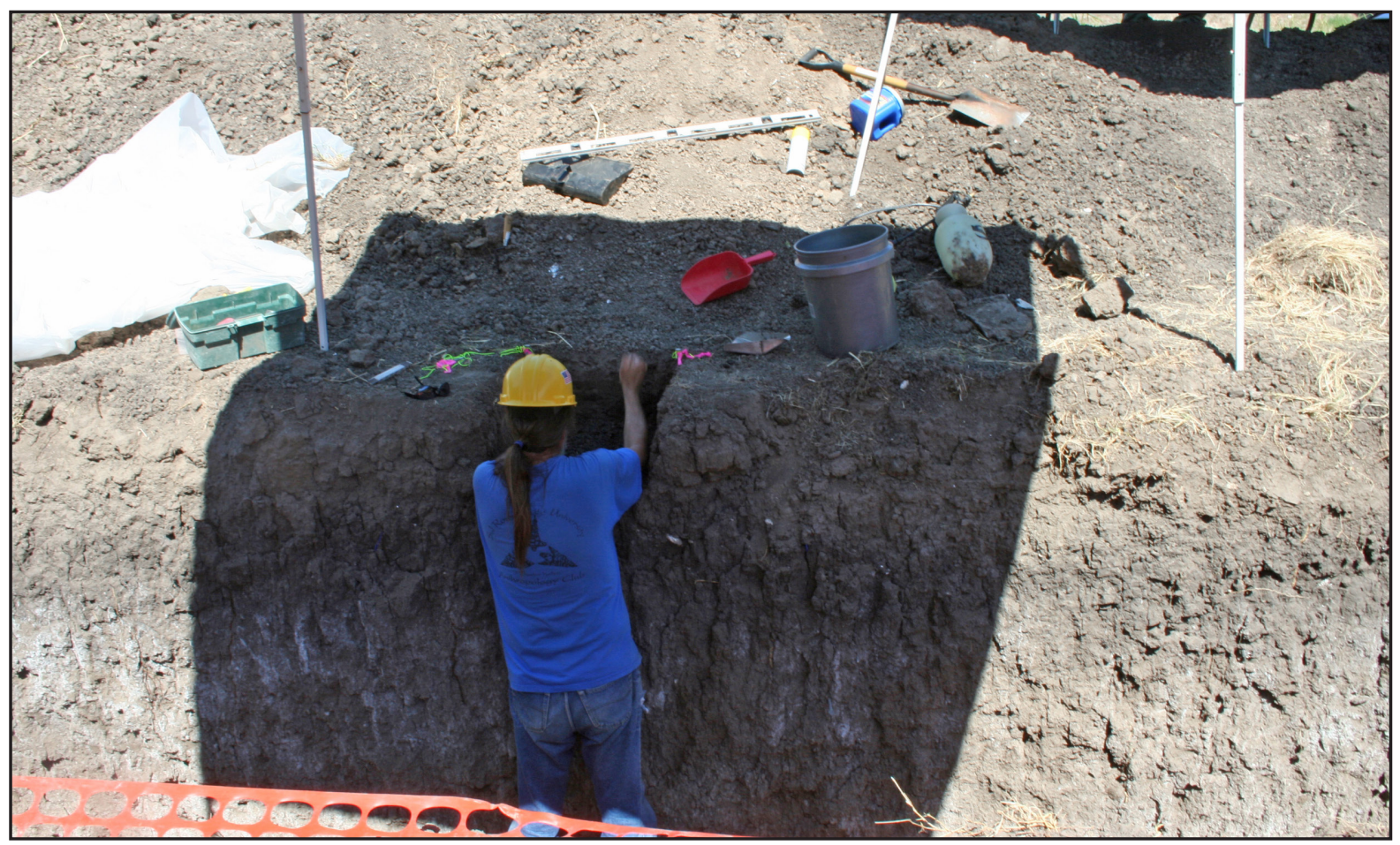

Figure 7-3. Photograph of the Excavation of WC 2 adjacent to the north wall of BT 17. Note the presence of at least one mussel shell near the top of the A horizon immediately to the right of the WC. That shell represents part of Feature 16 located beyond the limits of the witness column. View to the north. $9 / 26 / 11$. 


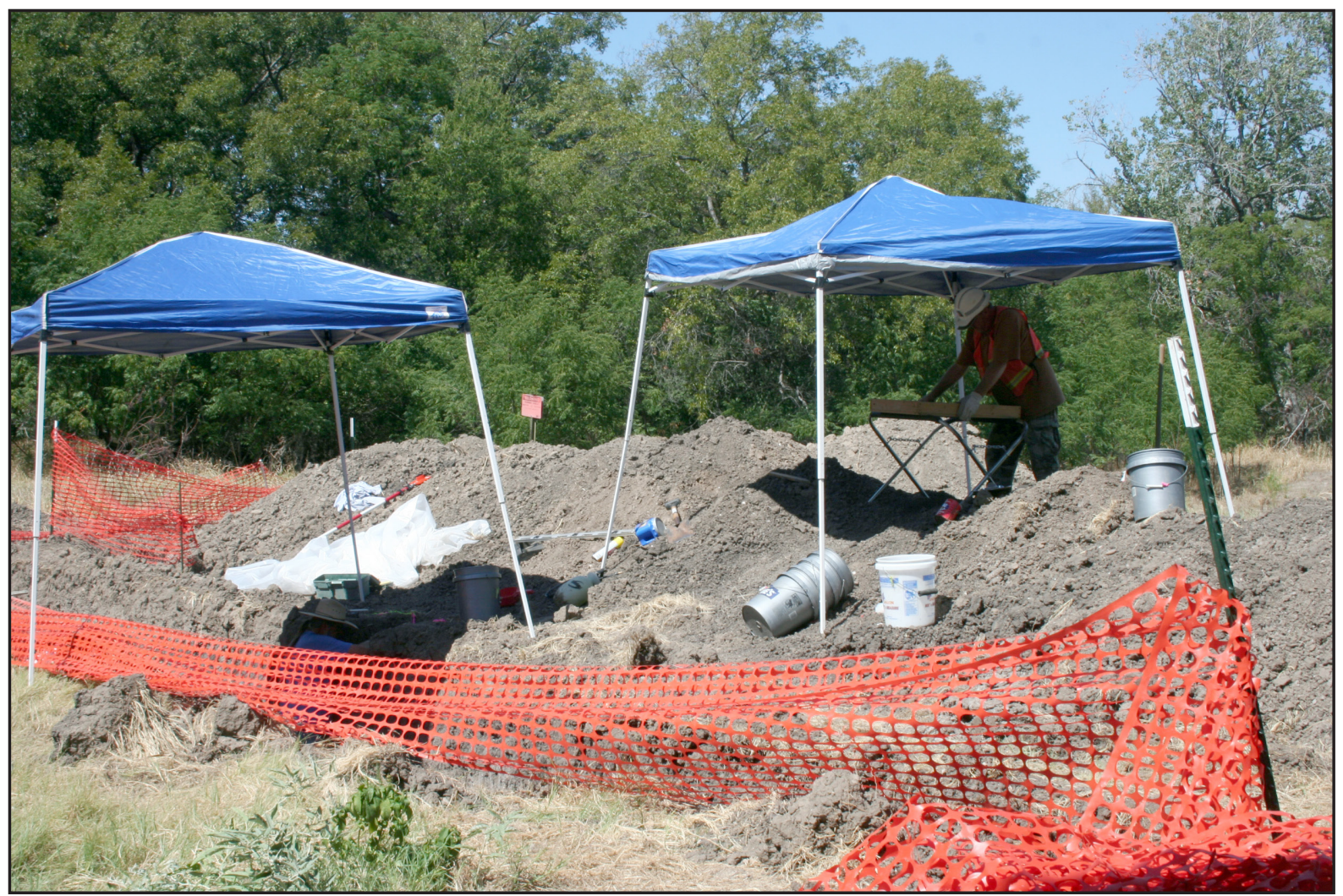

Figure 7-4. Another photograph of the excavation of WC 2. One crew member is working on the WC, while the other is screening atop the adjacent backdirt pile. View to the northwest. 9/26/11.

are visible within the upper $10 \mathrm{~cm}$ of the Upper West Range's A horizon, particularly on the east and north walls of the column. Also shown are the six separate strata that were recognized when the profiles were drawn, and these match the same six strata recorded along the eastern part of the north wall of BT 17 (see Figure 6-19). However, the excavators only identified five strata during the course of digging, as Stratum 4 was not recognized as a deposit distinct from Stratum 1. Table 7-1 provides data on the beginning and ending depths of the five recognized strata, their inclusive 10-cm-thick levels, and the corresponding natural strata as revealed by the wall profiles of BT 17 and WC 2. Similarly, Table 7-2 lists all artifacts recovered from the WC, either as an FS or captured by the 1/4inch screen.

As can be seen in the above figures and tables, the first carefully excavated level $(6-16 \mathrm{~cm})$ took out the middle portion of the disturbed Ford alluvium (Stratum 1), while the next level $(16-26 \mathrm{~cm})$ removed the remainder of the disturbed Ford alluvium plus the upper portion of the underlying, undisturbed Ford alluvium (Stratum 4). Since WC 2 was the first witness column to be excavated in the southern part of the site, it was unknown at the time if any cultural material was associated with the Ford alluvium. Accordingly, save for the upper $6 \mathrm{~cm}$ of obviously disturbed soil, the remainder of the Ford alluvium was removed by trowel and/or shovel scraping and screened through the 1/4-inch mesh. As it turned out, the only items to be captured on the screen from the levels noted above (aside from concrete chunks and some rusted metal fragments) were a few tiny pieces of mussel shell and one snail shell. Given similar results from the other witness columns located in the southern part of the site, it eventually became clear that the Ford alluvium south of the channelized river was devoid of cultural remains.

The next cut $(26-36 \mathrm{~cm})$ was intended to remove the upper part of the underlying Upper West Range's A horizon (Stratum 5), although a comparison of its depth readings with the wall profiles shows that it actually took out the very bottom part of the Ford alluvium along with the upper 5 to $8 \mathrm{~cm}$ of the West Range's upper A horizon. Also included in the latter level were the majority of the shells associated with 


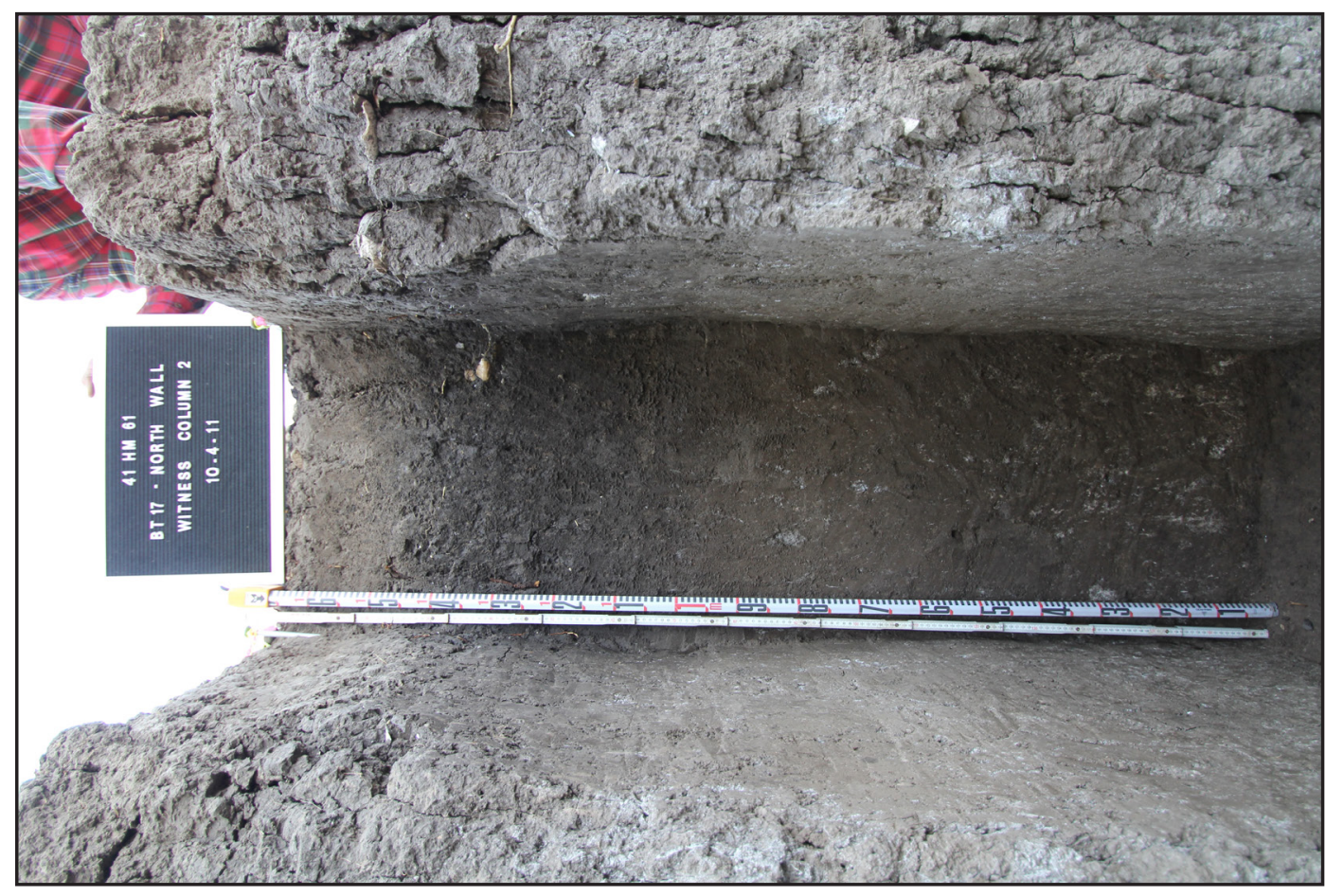

i莺吾突

U芒要

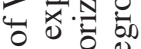

큰ำ

$3 \stackrel{0}{0.0}$

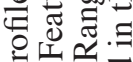

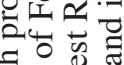

뉼 तै

항

的

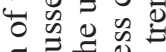

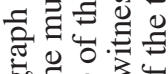



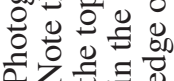

它

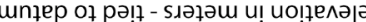

응
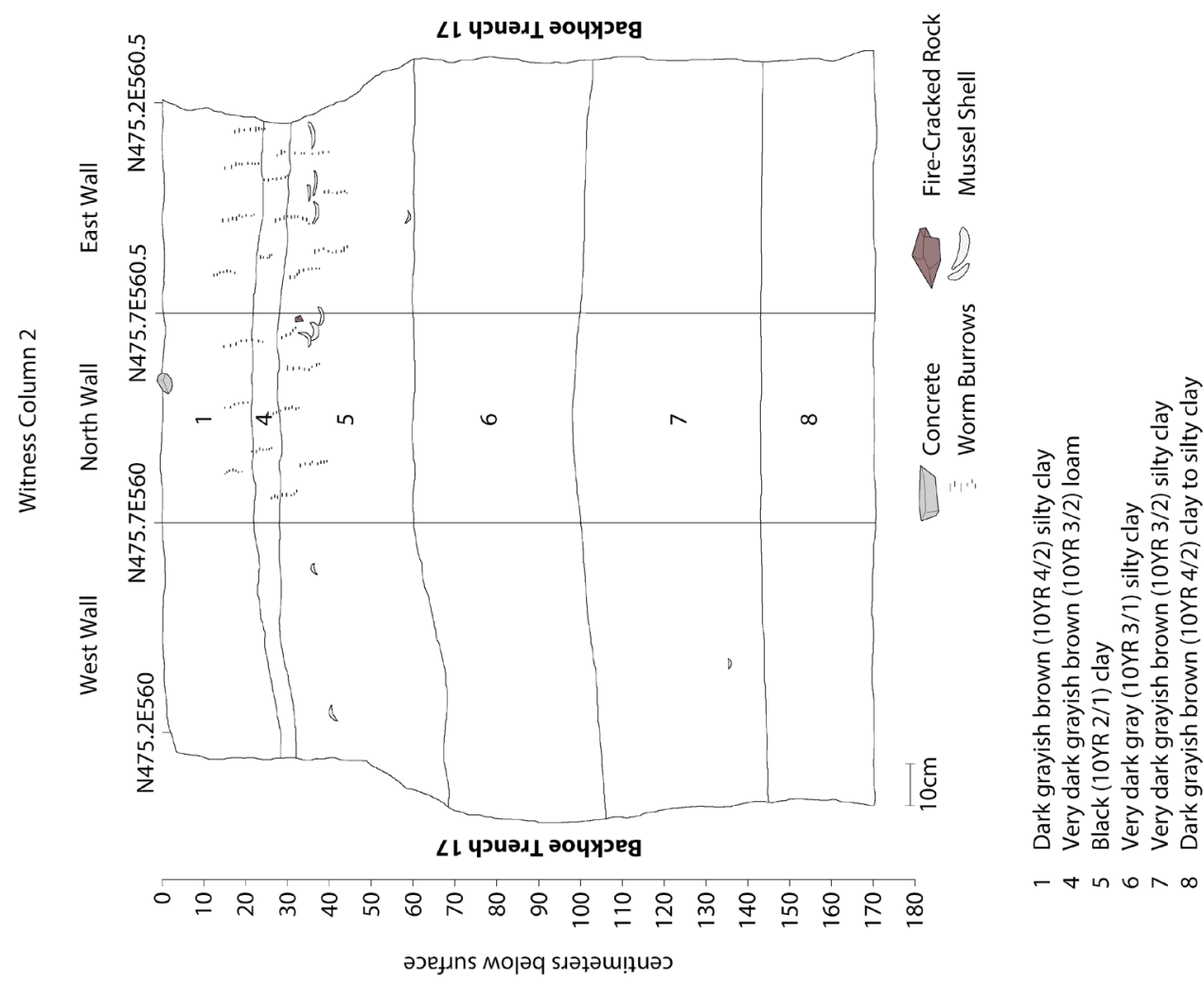

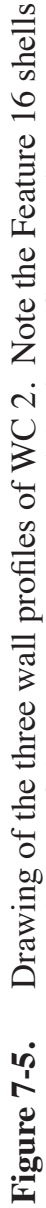


Table 7-1. Witness Column 2: Excavated Strata and Levels and Corresponding Natural Strata as Identified on Wall Profiles.

\begin{tabular}{|c|c|}
\hline $\begin{array}{c}\text { Excavated Strata } \\
\text { and Levels } \\
\text { (Depth Below WC Datum) }\end{array}$ & $\begin{array}{c}\text { Natural Strata on } \\
\text { Wall Profiles } \\
\text { (Elevation Based on Site Datum) }\end{array}$ \\
\hline $\begin{array}{c}\text { Stratum } 1, \text { Level A } \\
(0-6 \mathrm{~cm}) \\
\text { (Shoveled out }- \text { no material } \\
\text { saved or screened) }\end{array}$ & $\begin{array}{c}\text { Stratum 1 } \\
\text { (Disturbed Ford Alluvium } \\
(99.95 \text { to } 98.89 \mathrm{~m})\end{array}$ \\
\hline $\begin{array}{l}\text { Stratum 1, Level B } \\
\quad(6-16 \mathrm{~cm})\end{array}$ & $\begin{array}{c}\text { Stratum 1 } \\
\text { (Disturbed Ford Alluvium) } \\
(99.89 \text { to } 99.79 \mathrm{~m})\end{array}$ \\
\hline $\begin{array}{l}\text { Stratum 1, Level C } \\
\quad(16-26 \mathrm{~cm})\end{array}$ & $\begin{array}{c}\text { Strata } 1 \& 4 \\
\text { (Disturbed Ford Alluvium, } \\
\text { Ford Alluvium) } \\
(99.79 \text { to } 99.69 \mathrm{~m})\end{array}$ \\
\hline $\begin{array}{c}\text { Stratum 2, Level A } \\
\text { (Includes most of F. 16) } \\
\text { (26-36 cm) }\end{array}$ & $\begin{array}{c}\text { Strata } 4 \& 5 \\
\text { (Includes most of F. 16) } \\
\text { (Ford Alluvium, A Horizon, } \\
\text { West Range Alluvium) } \\
(99.69 \text { to } 99.59 \mathrm{~m})\end{array}$ \\
\hline $\begin{array}{l}\text { Stratum 2, Level C } \\
\quad(46-53 \mathrm{~cm})\end{array}$ & $\begin{array}{c}\text { Stratum } 5 \\
\text { (A Horizon, West Range Alluvium) } \\
\text { (99.49 to 99.42) }\end{array}$ \\
\hline $\begin{array}{l}\text { Stratum 3, Level A } \\
\quad(53-63 \mathrm{~cm})\end{array}$ & $\begin{array}{c}\text { Strata } 5 \text { \& } 6 \\
\text { (A Horizon, West Range Alluvium, } \\
\text { West Range Alluvium) } \\
(99.42 \text { to } 99.32 \mathrm{~m})\end{array}$ \\
\hline $\begin{array}{l}\text { Stratum 3, Level B } \\
\quad(63-73 \mathrm{~cm})\end{array}$ & $\begin{array}{c}\text { Strata } 5 \text { \& } 6 \\
\text { (A Horizon, West Range Alluvium, } \\
\text { West Range Alluvium) } \\
(99.32 \text { to } 99.22 \mathrm{~m})\end{array}$ \\
\hline $\begin{array}{l}\text { Stratum 3, Level C } \\
\quad(73-83 \mathrm{~cm})\end{array}$ & $\begin{array}{c}\text { Stratum } 6 \\
\text { (West Range Alluvium) } \\
(99.22 \text { to } 99.12 \mathrm{~m})\end{array}$ \\
\hline $\begin{array}{l}\text { Stratum 3, Level D } \\
\quad(83-93 \mathrm{~cm})\end{array}$ & $\begin{array}{c}\text { Stratum } 6 \\
\text { (West Range Alluvium) } \\
(99.12 \text { to } 99.02 \mathrm{~m})\end{array}$ \\
\hline $\begin{array}{l}\text { Stratum 3, Level E } \\
\quad(93-103 \mathrm{~cm})\end{array}$ & $\begin{array}{c}\text { Strata } 6 \& 7 \\
\text { (West Range Alluvium) } \\
(99.02 \text { to } 98.92 \mathrm{~m})\end{array}$ \\
\hline $\begin{array}{l}\text { Stratum 4, Level A } \\
\quad(103-113 \mathrm{~cm})\end{array}$ & $\begin{array}{c}\text { Stratum } 7 \\
\text { (West Range Alluvium) } \\
(98.92 \text { to } 98.82 \mathrm{~m})\end{array}$ \\
\hline $\begin{array}{l}\text { Stratum 4, Level B } \\
\quad(113-123 \mathrm{~cm})\end{array}$ & $\begin{array}{c}\text { Stratum } 7 \\
\text { (West Range Alluvium) } \\
(98.82 \text { to } 98.72 \mathrm{~m})\end{array}$ \\
\hline $\begin{array}{l}\text { Stratum 4, Level C } \\
\quad(123-133 \mathrm{~cm})\end{array}$ & $\begin{array}{c}\text { Stratum } 7 \\
\text { (West Range Alluvium) } \\
(98.72 \text { to } 98.62 \mathrm{~m}) \\
\end{array}$ \\
\hline $\begin{array}{l}\text { Stratum 4, Level D } \\
\quad(133-143 \mathrm{~cm})\end{array}$ & $\begin{array}{c}\text { Stratum } 7 \\
\text { (West Range Alluvium) } \\
(98.62 \text { to } 98.52 \mathrm{~m})\end{array}$ \\
\hline $\begin{array}{l}\text { Stratum 5, Level A } \\
\quad(143-153 \mathrm{~cm})\end{array}$ & $\begin{array}{c}\text { Stratum } 8 \\
\text { (West Range Alluvium) } \\
(98.52 \text { to } 98.42 \mathrm{~m})\end{array}$ \\
\hline $\begin{array}{l}\text { Stratum 5, Level B } \\
\quad(153-168 \mathrm{~cm})\end{array}$ & $\begin{array}{c}\text { Stratum } 8 \\
\text { (West Range Alluvium) } \\
(98.42 \text { to } 98.27 \mathrm{~m})\end{array}$ \\
\hline
\end{tabular}

Note: Depths based on elevations of the NW corner of the witness column, which served as the column's datum during excavation. 


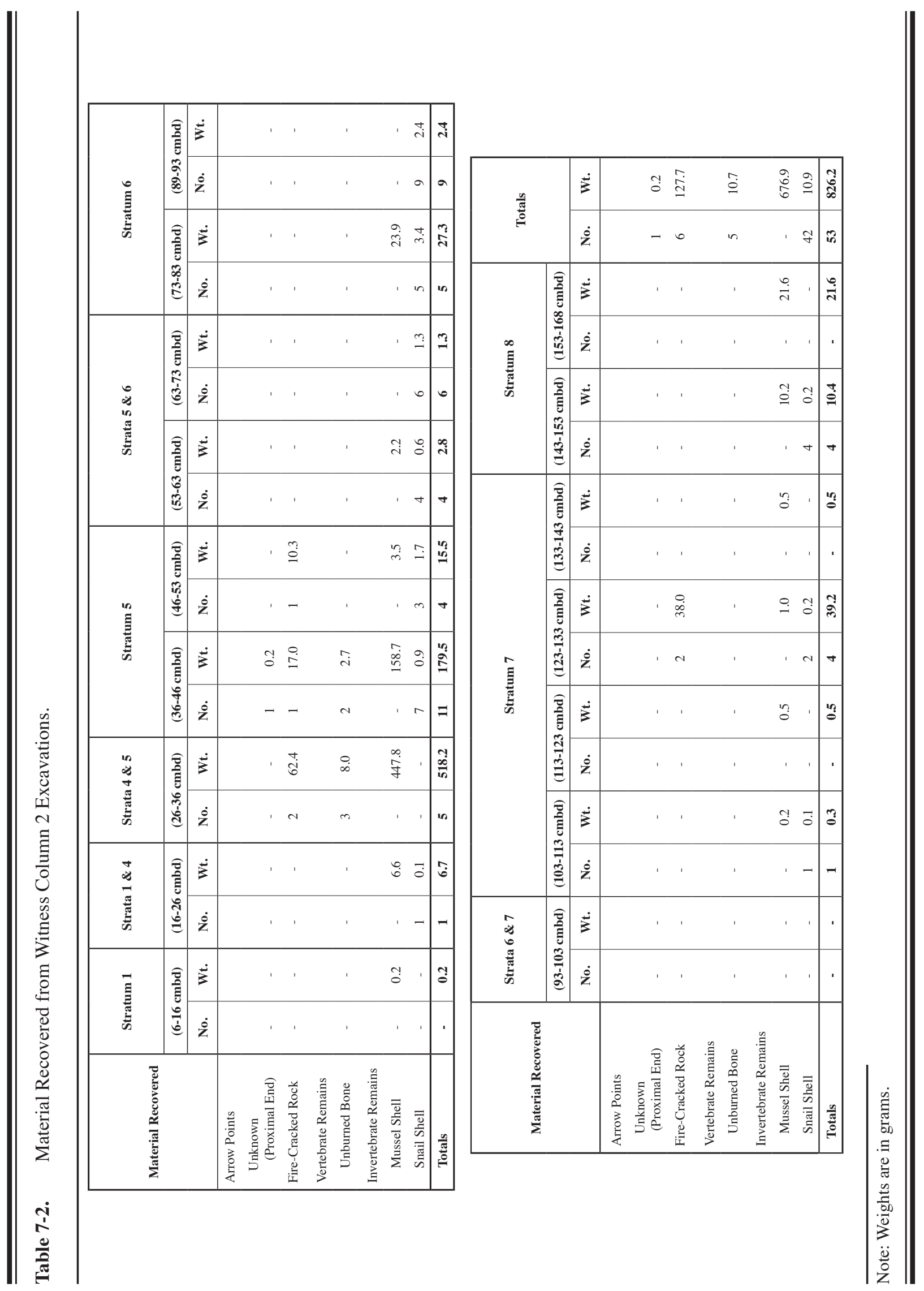


the Feature 16 shell deposit (within the Upper West Range A horizon). Figures 7-7 and 7-8 show the distribution of freshwater mussel shells and other faunal remains associated with the feature, as exposed within the 26-to-36-cm level.

Most of the remaining Upper West Range A horizon was taken out in the next three cuts that were confined only to Stratum 5 (26-36, 36-46, and 46-53 $\mathrm{cm}$ ) (see Table 7-1). Interestingly, the distal end of a dart point came from the $36-46-\mathrm{cm}$ level. Although the point fragment could not be typed, it is likely that it represents the tip of a chronologically late type, as subsequent radiocarbon dating of the mussel shell from F. 16 indicated an age equivalent to the Late Archaic 4 period (see below, and Chapter 10).

Unfortunately, no charcoal for possible ${ }^{14} \mathrm{C}$ dating was found associated with the F. 16 shell deposit during excavation, nor was any seen during a quick visual inspection of soil from the feature that had been saved for flotation. Similarly, a careful search of each mussel valve collected as an individually piece-plotted FS failed to locate any charcoal adhering to a valve. Instead, one of the mussel shells from F. 16 was submitted to Beta Analytic, Inc., for dating. Although all radiocarbon dates are discussed in detail in Chapter 10, it is worth noting here that the shell returned a ${ }^{14} \mathrm{C}$ age of $1230 \pm 30$ cal B.P., with a calibrated 2-sigma date range of between 1260 and 1070 cal B.P. (ca.A.D. 690 to 880) (Beta-382994). This date range may be a few hundred years earlier than the true age of the feature due to the likely need to apply a so-called "reservoir correction" to compensate for "dead" carbon absorbed by the mussel from the Leon River during formation of its valves. Based on the results of paired shell and either charcoal or organic sediment dates from two other features at the site, a correction on the order of ca. 200 years could be needed. Thus, the actual age of Feature 16 may be more in line with a date range of between ca. A.D. 890 and 1080. Either way, the date points to a time during the Late Archaic 4 period, as noted above.

Below the upper A horizon, the WC encountered three additional strata related to the West Range alluvium. As mentioned above, only two of these were recognized during the excavation of the column, although that really is not a problem given the minor amount of cultural remains encountered (see Table 7-2). Overall, only a few scattered pieces of fire-cracked rock and mussel shell were found. No definite living surface could be seen, nor were any lithic items or vertebrate faunal remains recovered. For all intents and purposes, the West Range alluvium beneath the upper A horizon can be considered culturally nonproductive, at least in the area of WC 2.

\section{Witness Column 3}

WC 3 was positioned along the east wall of the southern portion of BT 15 directly above Features 19 and 20, the deeply buried concentrations of mussel shell and fire-cracked rock within the lower part of the West Range alluvium (Figures 7-9 and 7-10; see Figure $7-1)$. Although projected to be 50 by $50 \mathrm{~cm}$ in size, the column actually measured between 85 and $90 \mathrm{~cm}$ eastwest by $50 \mathrm{~cm}$ north-south due to the need to place it slightly farther away from the slumping edge of BT 15 . The WC's northeast corner (located at N448.5E589.3) served as the column's specific datum, and it was from this point that a line level was attached to measure depth during excavation. The WC was dug to $-1.43 \mathrm{~m}$.

Figures 7-11 and 7-12 illustrate the three walls of WC 3, while Table 7-3 provides a list of artifacts and other cultural items recovered from the $\mathrm{WC}$ as either field specimens or material captured in the 1/4inch screen. As can be seen, four separate strata were recognized on the wall profiles, and these match the same four strata seen along the east wall of BT 15 (see Figure 6-11). The folks excavating WC 3 were fairly successful in identifying natural strata breaks and recognized most strata changes correctly (Table 7-4). Only the 40-to-50-cm level crosscut the boundary between Strata 3 and 4.

Basically, the first $30 \mathrm{~cm}$ of the column removed a zone of disturbed Ford alluvium similar to that encountered in WC 2. Soil from this zone was shoveled out and discarded without screening. Strata 2 and 3 represent undisturbed segments of the Ford alluvium. The next stratum encountered during the excavation was the West Range alluvium's A horizon (Stratum 4 on the wall profiles). This was a relatively thick deposit that required five individual levels to remove (30-40, 40-50, 50-60, 60-70, and 70-78 cm). No features were present within the A horizon, although a moderate quantity of mussel shell, fire-cracked rock, snails, and burned bone was present (see Table 7-3). Importantly, a Marcos dart point was recovered (on the screen) from the very bottom of the upper A horizon within the 70-to-78-cm level. As mentioned in Chapter 6 and shown on Figure 6-11, at least one other Marcos point was found at the bottom of the Upper West Range A horizon in the southern part of the site.

Below the A horizon, the excavators encountered a lighter-colored deposit of West Range alluvium that 


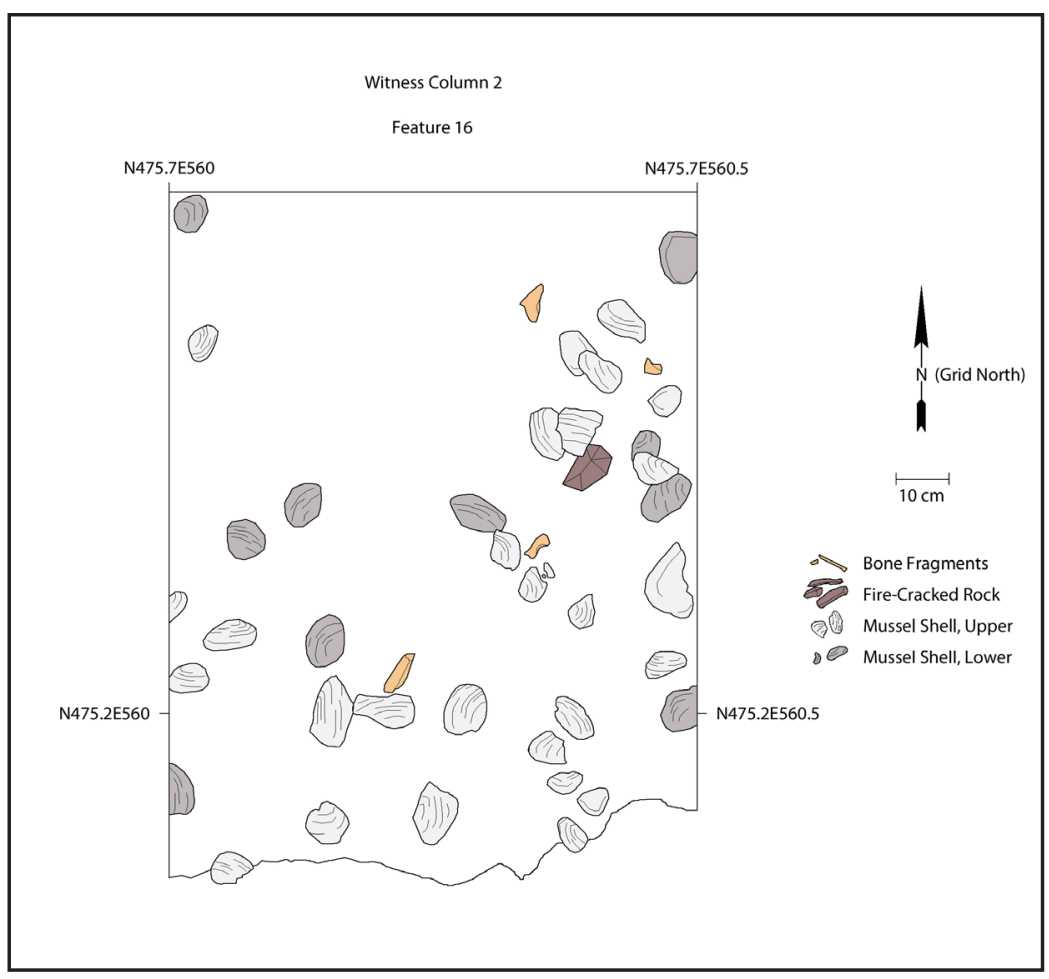

Figures 7-7. (Left) Plan view drawing of the Feature 16 mussel shell concentration within WC 2 .

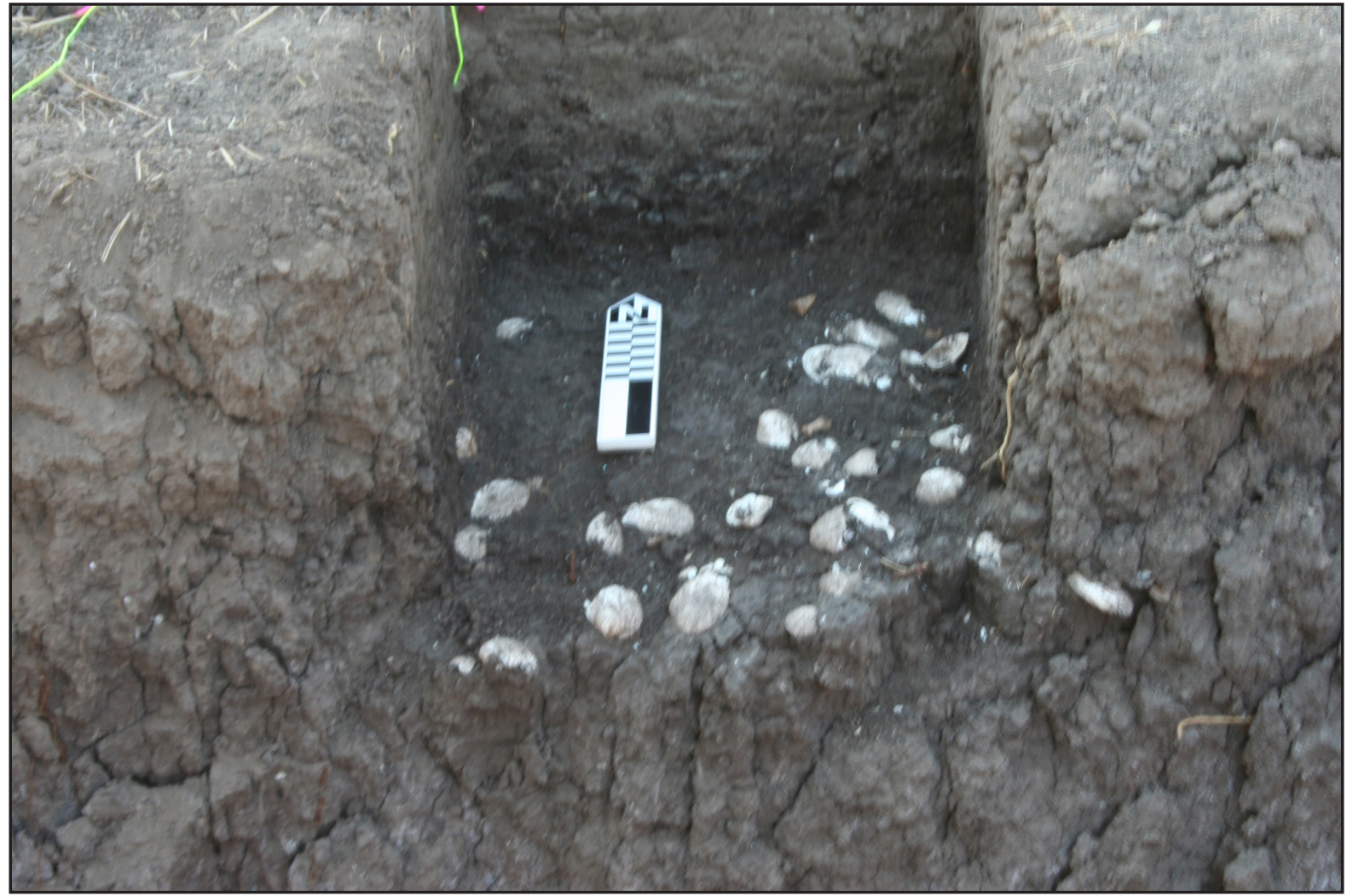

Figure 7-8. Photograph of the exposed top of Feature 16 mussel shell concentration within WC 2. 9/26/11. 


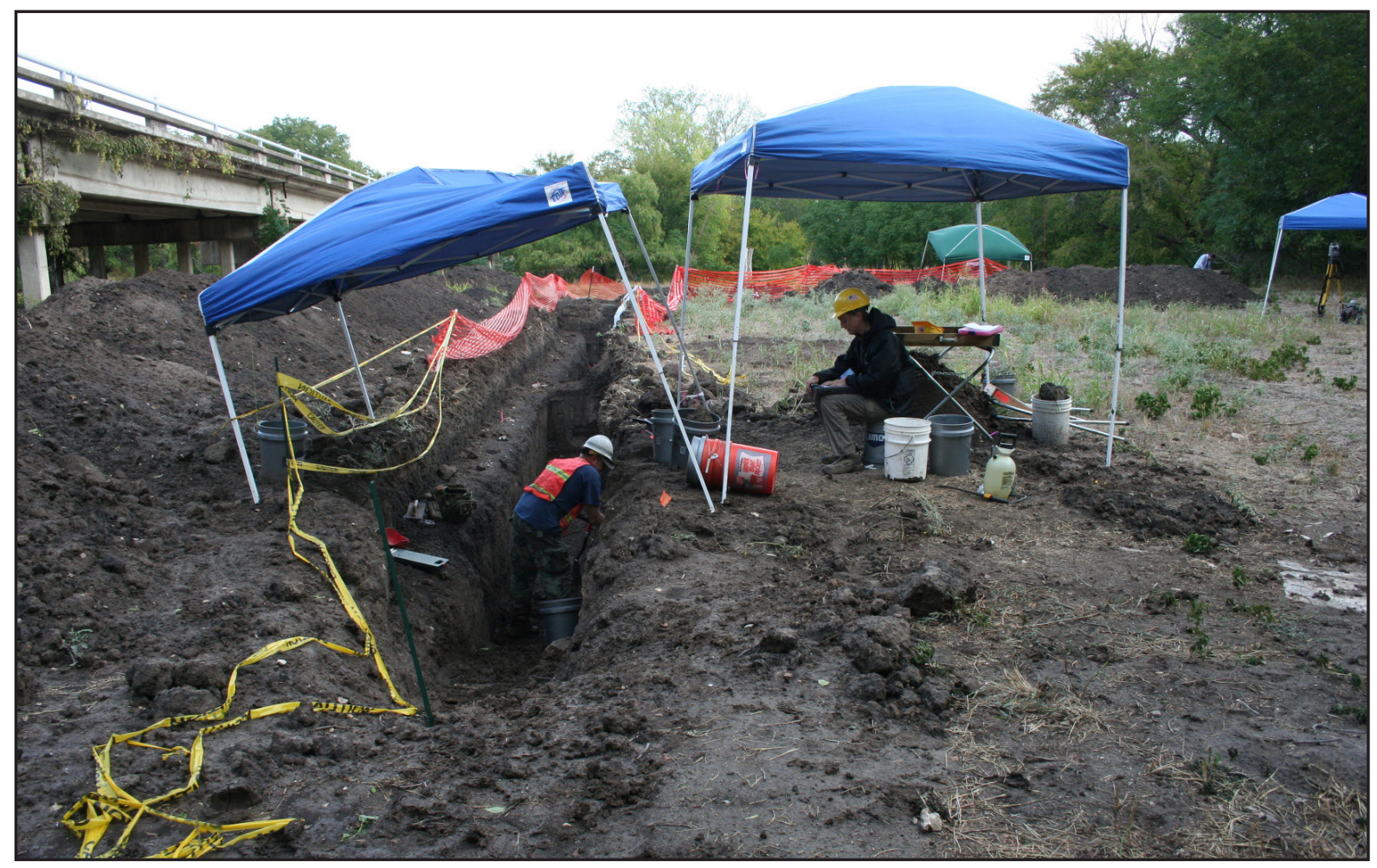

Figure 7-9. Photograph of Bo Nelson excavating WC 3 adjacent to the east wall of the southern part of BT 15. The green canopy in the distance is covering the excavation of WC 4 adjacent to BT 16. View to the north. 9/30/11.

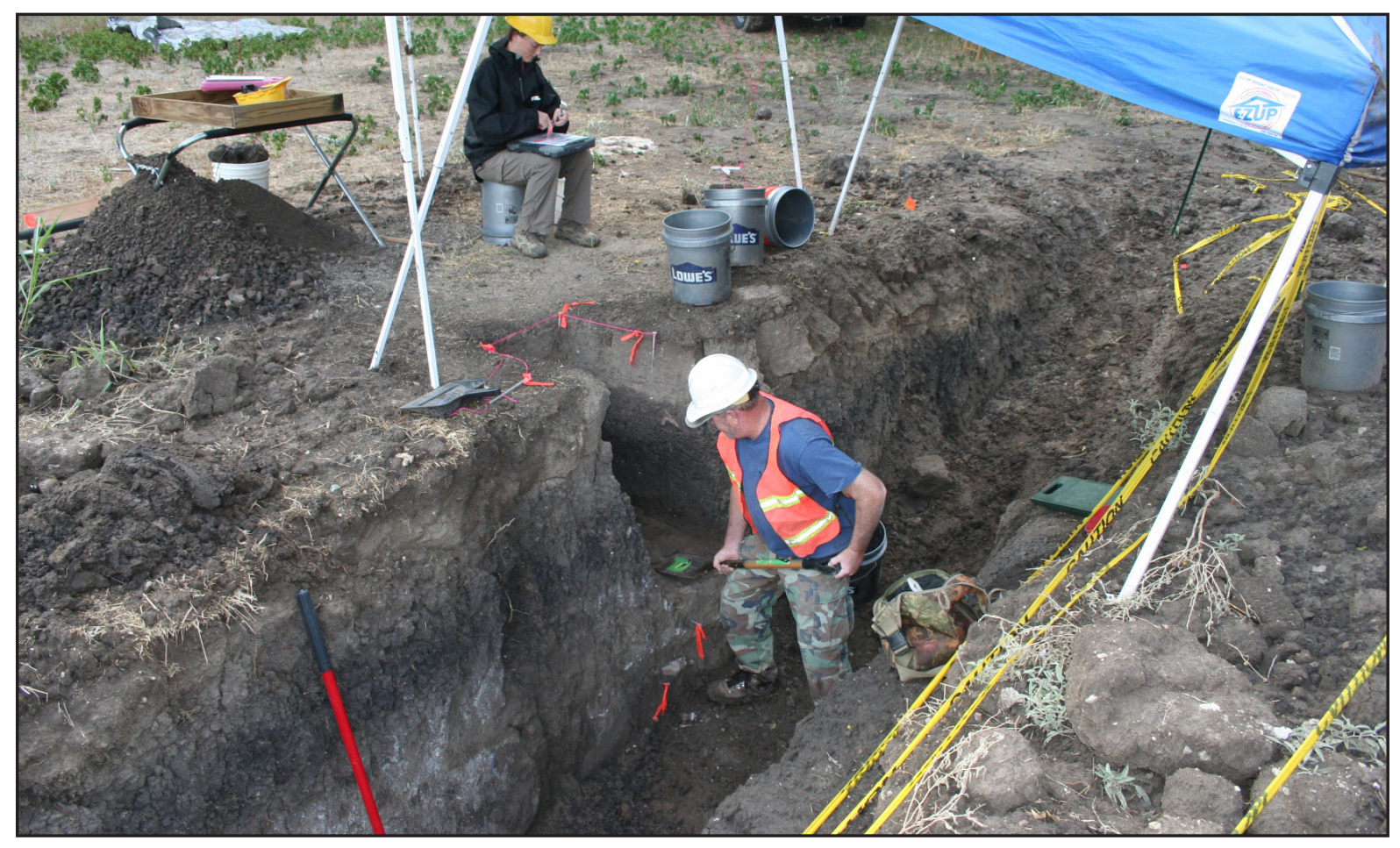

Figure 7-10. Photograph of Bo Nelson continuing to excavate WC 3 adjacent to the east wall of BT 15 with Stephanie McKernan taking notes. The pieces of orange flagging tape by Nelson's right foot mark the locations of Features 19 and 20. View to the southeast. 9/30/11. 

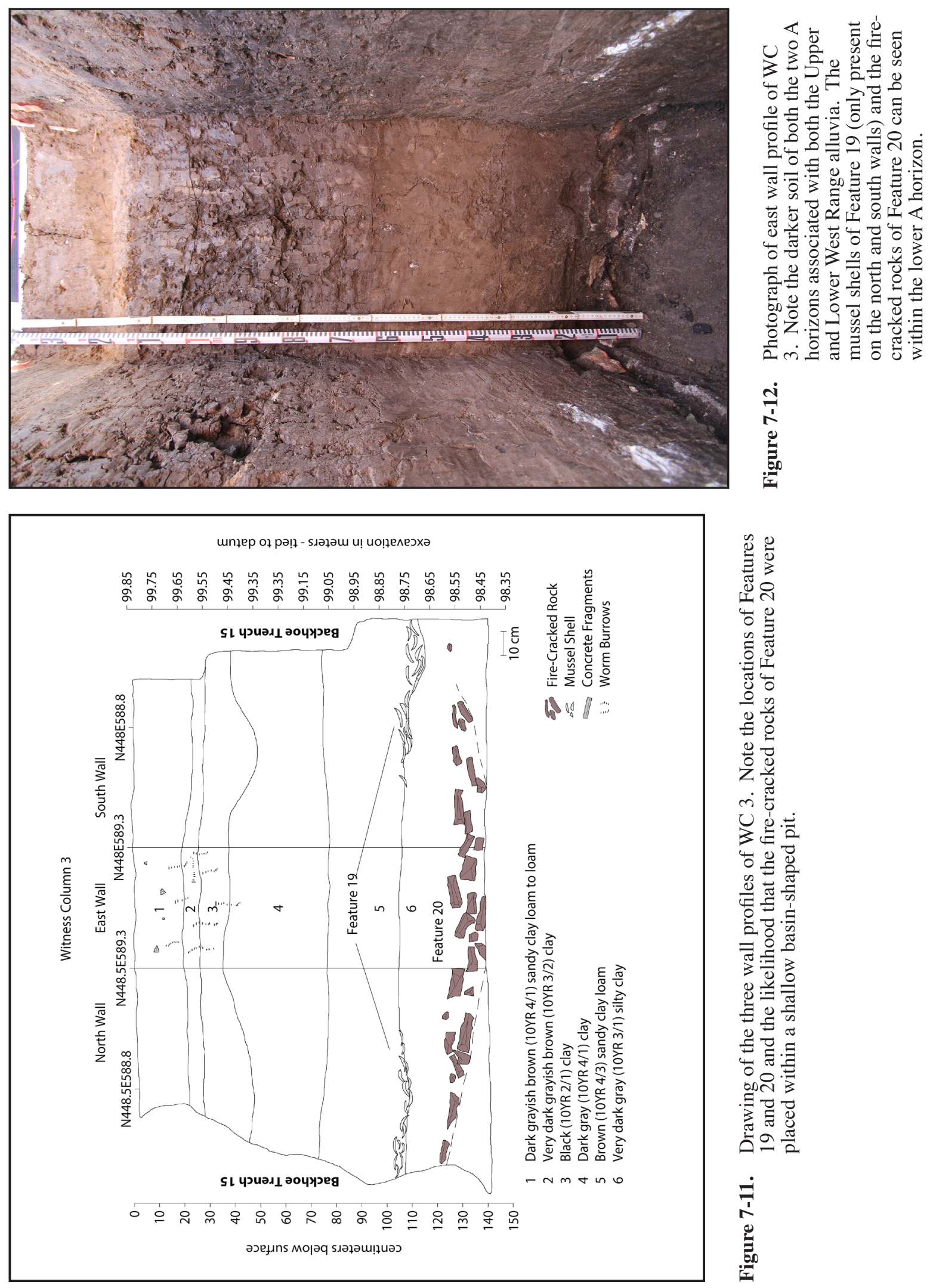

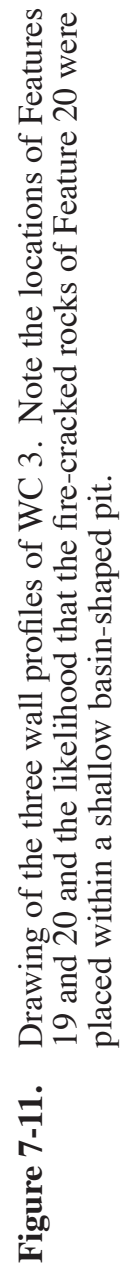




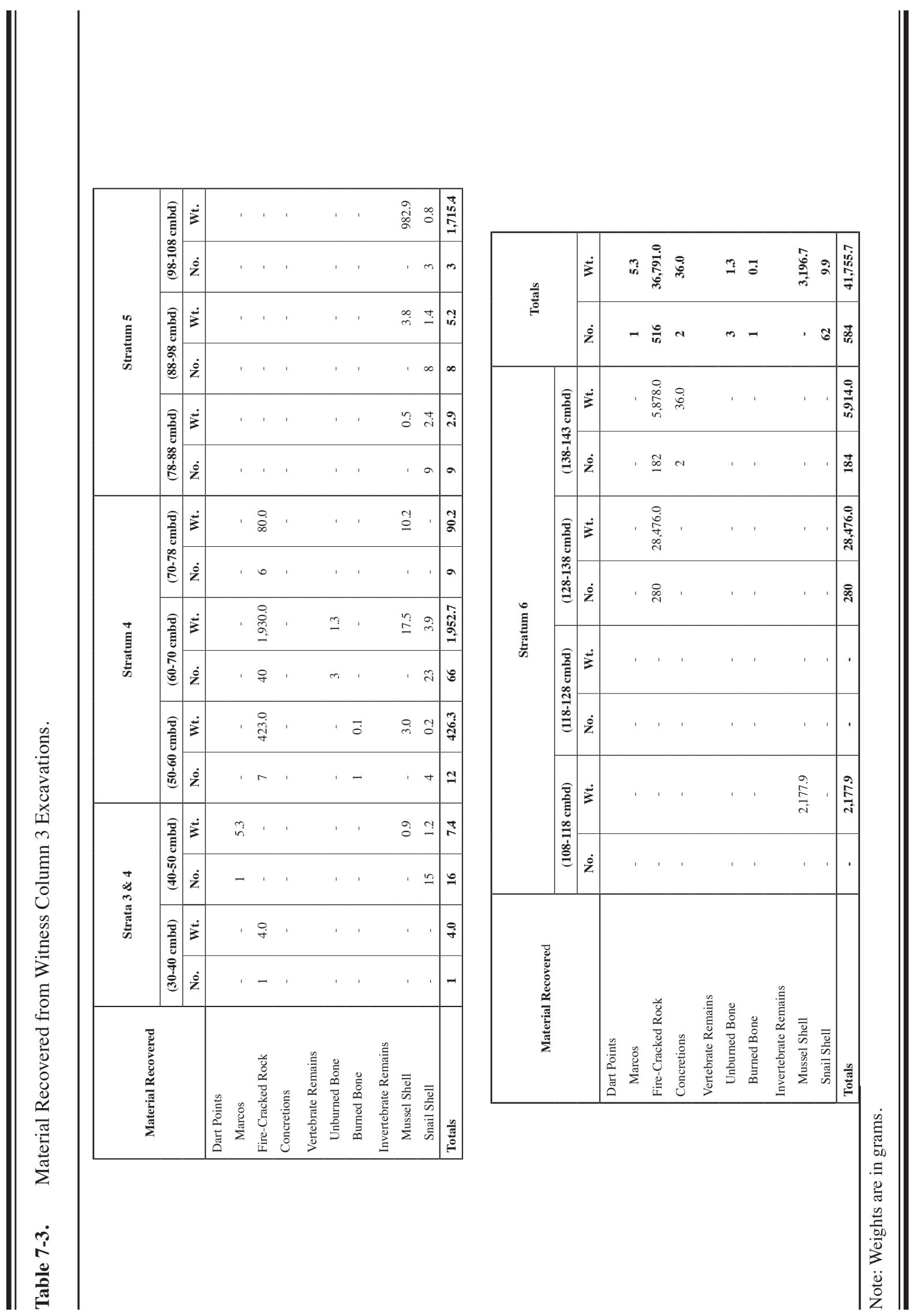


Table 7-4. Witness Column 3: Excavated Strata and Levels and Corresponding Natural Strata as Identified on Wall Profiles.

\begin{tabular}{|c|c|}
\hline $\begin{array}{c}\text { Excavated Strata } \\
\text { and Levels } \\
\text { (Depth Below WC Datum) }\end{array}$ & $\begin{array}{c}\text { Natural Strata on } \\
\text { Wall Profiles } \\
\text { (Elevation Based on Site Datum) }\end{array}$ \\
\hline $\begin{array}{c}\text { Stratum 1, Level A } \\
(0-30 \mathrm{~cm}) \\
\text { (Shoveled out }- \text { no material } \\
\text { saved or screened) }\end{array}$ & $\begin{array}{l}\text { Strata } 1 \mathrm{~A}, 1 \mathrm{~B}, \& 2 \\
\text { (Disturbed Ford Alluvium) } \\
(99.82 \text { to } 99.52 \mathrm{~m})\end{array}$ \\
\hline $\begin{array}{l}\text { Stratum 2, Level A } \\
\quad(30-40 \mathrm{~cm})\end{array}$ & $\begin{array}{c}\text { Strata } 3 \& 4 \\
\text { (Ford Alluvium, } \\
\text { A Horizon, West Range Alluvium) } \\
(99.52 \text { to } 99.42 \mathrm{~m})\end{array}$ \\
\hline $\begin{array}{l}\text { Stratum 2, Level B } \\
\quad(40-50 \mathrm{~cm})\end{array}$ & $\begin{array}{c}\text { Strata } 3 \& 4 \\
\text { (Ford Alluvium, } \\
\text { A Horizon, West Range Alluvium) } \\
(99.42 \text { to } 99.32 \mathrm{~m})\end{array}$ \\
\hline $\begin{array}{l}\text { Stratum 2, Level C } \\
\quad(50-60 \mathrm{~cm})\end{array}$ & $\begin{array}{c}\text { Stratum } 4 \\
\text { (A Horizon, West Range Alluvium) } \\
(99.32 \text { to } 99.22 \mathrm{~m})\end{array}$ \\
\hline $\begin{array}{l}\text { Stratum 2, Level D } \\
\quad(60-70 \mathrm{~cm})\end{array}$ & $\begin{array}{c}\text { Stratum } 4 \\
\text { (A Horizon, West Range Alluvium) } \\
(99.22 \text { to } 99.12 \mathrm{~m})\end{array}$ \\
\hline $\begin{array}{l}\text { Stratum 2, Level E } \\
\quad(70-78 \mathrm{~cm})\end{array}$ & $\begin{array}{c}\text { Stratum } 4 \\
\text { (A Horizon, West Range Alluvium) } \\
(99.12 \text { to } 99.04 \mathrm{~m})\end{array}$ \\
\hline $\begin{array}{l}\text { Stratum 3, Level A } \\
\quad(78-88 \mathrm{~cm})\end{array}$ & $\begin{array}{c}\text { Stratum 5 } \\
\text { (West Range Alluvium) } \\
\text { (99.04 to } 98.94 \mathrm{~m})\end{array}$ \\
\hline $\begin{array}{l}\text { Stratum 3, Level B } \\
\quad(88-98 \mathrm{~cm})\end{array}$ & $\begin{array}{c}\text { Stratum } 5 \\
\text { (West Range Alluvium) } \\
(98.94 \text { to } 98.84 \mathrm{~m})\end{array}$ \\
\hline $\begin{array}{l}\text { Stratum 3, Level C } \\
\text { (Includes upper F. 19) } \\
\quad(98-108 \mathrm{~cm})\end{array}$ & $\begin{array}{c}\text { Stratum } 5 \\
\text { (Includes upper F. 19) } \\
\text { (West Range Alluvium) } \\
(98.84 \text { to } 98.74 \mathrm{~m})\end{array}$ \\
\hline $\begin{array}{l}\text { Stratum 3, Level D } \\
\text { (Includes lower F. 19) } \\
\quad(108-118 \mathrm{~cm})\end{array}$ & $\begin{array}{c}\text { Stratum } 6 \\
\text { (Includes lower F. 19) } \\
\text { (West Range Alluvium) } \\
(98.74 \text { to } 98.64 \mathrm{~m})\end{array}$ \\
\hline $\begin{array}{l}\text { Stratum 4, Level A } \\
\text { (Includes upper F. 20) } \\
\quad(118-128 \mathrm{~cm})\end{array}$ & $\begin{array}{c}\text { Stratum } 6 \\
\text { (Includes upper F. 20) } \\
\text { (West Range Alluvium) } \\
\text { (98.64 to } 98.54 \text { m) }\end{array}$ \\
\hline $\begin{array}{l}\text { Stratum 4, Level B } \\
\text { (Includes middle F. 20) } \\
\quad(128-138 \mathrm{~cm})\end{array}$ & $\begin{array}{c}\text { Stratum } 6 \\
\text { (Includes middle F. 20) } \\
\text { (West Range Alluvium) } \\
(98.54 \text { to } 98.44 \mathrm{~m})\end{array}$ \\
\hline $\begin{array}{l}\text { Stratum 4, Level C } \\
\text { (Includes lower F. 20) } \\
\quad(138-143 \mathrm{~cm})\end{array}$ & $\begin{array}{c}\text { Stratum } 6 \\
\text { (Includes lower F. 20) } \\
\text { (West Range Alluvium) } \\
\text { (98.44 to } 98.39 \text { m) }\end{array}$ \\
\hline
\end{tabular}

Note: Depths based on elevations of the NE corner of the witness column, which served as the column's datum during excavation. 
was identified as Stratum 5 on the wall profiles. The deposit was almost completely devoid of cultural material (save for a few scattered pieces of mussel shell) until the top of F. 19 was encountered within the upper portion of the 108-to-118-cm level. As can be seen in Table 7-4 and as illustrated in Figures 7-13 and 7-14, the feature consisted of a 6- to 10-cm-thick layer of densely clustered mussel shells that covered the western three-quarters of the WC. It was taken out in the 98-to-108 and 108-to-118-cm levels. Originally, each shell within the upper portion of the feature was piece plotted with the TDS. However, when it became apparent that such a procedure would take an extremely long time, the decision was made for the TDS to record only the outer boundary of the remainder of the cluster. Although no artifacts were recovered in association with F. 19, a sample of organic sediment from the feature was submitted to Beta Analytic for ${ }^{14} \mathrm{C}$ dating. This sample (Beta-315690) produced an age of $2590 \pm 30 \mathrm{cal}$ B.P. with a 2-sigma range of between 2770 and 2704 cal B.P. (ca. 820 and 750 B.C.) at a 92.7 percent probability. Another ${ }^{14} \mathrm{C}$ sample consisting of one of the mussel shells from the feature also was submitted to Beta Analytic for dating. It produced an age of $2830 \pm 30 \mathrm{cal}$ B.P. and a 2-sigma range of between 3008 and 2856 cal B.P. (ca. 1060 and 910 B.C.) at a 93.6 percent probability (Beta-382994). Without getting into any details at this time, it is worth noting these two dates from Feature 19 make up one of the paired shell and non-shell dates used to tentatively predict a reservoir correction for mussel shells along this stretch of the Leon River. As touched upon in the discussion of WC 2, that correction would appear to be about 200 years (see Chapter 10 for detailed discussions on these radiocarbon dates and the resulting reservoir correction). Regardless of the 200-year difference between the two F. 19 dates, both fall within the Late Archaic 2 period of the Lohse et al. (2014a) cultural sequence for central Texas. This, furthermore, suggests that F. 19 is potentially contemporaneous with the Lange dart point found at roughly the same elevation approximately $16 \mathrm{~m}$ to the north along the east wall of BT 15 (see Figures 6-11, 6-16, and 6-17).

Below F. 19, the excavators removed a $10-$ to 15-cm-thick layer of apparently non-cultural alluvium (identified as Stratum 6) before encountering the upper portion of Feature 20. This feature consisted of a dense and thick deposit of fire-cracked rock located between ca. -120 and $-143 \mathrm{~cm}$ (Figures 7-15 through 7-17). As visible on Figure 7-11, most of the rocks appeared to slope downward toward the center of the feature suggesting that they might have been placed within a shallow, basin-shaped pit (although no soil change was noticed to indicate the unequivocal presence of a pit). Each individual rock was piece plotted via the TDS and removed separately. Excavation of the WC was terminated following removal of the last piece of fire-cracked rock, which was at a depth equal to the base of BT 15. As with F. 19, no diagnostic artifacts were found within the burned-rock cluster of F. 20.

As to be reviewed more fully in Chapter 10, a sample of charred material (most likely wood charcoal) from F. 20 was submitted for radiocarbon dating. The sample returned an age of $2540 \pm 30 \mathrm{cal}$ B.P. and a 2-sigma range of between 2749 and 2497 cal B.P. (ca. 800 and 550 B.C.) (Beta-315691). The earlier portion of this range overlaps almost exactly with the age range on the organic sediment from F. 19, thus suggesting that the two features are most likely contemporaneous and probably represent two elements within a single earth oven that appears to have been used to cook or steam open mussel shells during the Late Archaic 2 period. More will said of this possibility in the following chapter.

\section{Witness Column 4}

This column was positioned along the north wall of BT 16 directly above Feature 21, a layer of firecracked rock exposed in the lower part of the Upper West Range alluvium's A horizon (Figures 7-18 and 7-19; see Figure 7-1). Although projected to be 50 by $50 \mathrm{~cm}$ in size, the column actually measured ca. 60 $\mathrm{cm}$ north-south by $50 \mathrm{~cm}$ east-west. The WC's northwest corner (situated at N471E601.7) served as the column's specific datum; it was from this point that a line level was attached to measure depth during excavation. Overall, the $\mathrm{WC}$ was dug to $-1.77 \mathrm{~m}$.

Figures 7-20 and 7-21 illustrate the three walls of WC 4, while Table 7-5 lists artifacts and other cultural items recovered from the $\mathrm{WC}$ as either field specimens or material captured in the $1 / 4$-inch screen. As can be seen, seven separate strata were recognized on the wall profiles, and these match the same seven strata seen along the north wall of BT 16 (see Figure 6-12). Generally, the excavators were able to follow the strata breaks, although there were cases where levels crosscut strata lines (Table 7-6). For instance, after shoveling out the upper $28 \mathrm{~cm}$ of disturbed Ford alluvium (Stratum 1), the next two cuts (28-38 and $38-48 \mathrm{~cm}$ ) took out the remaining possibly undisturbed portion of the Ford alluvium (Stratum 1a). This was followed by five cuts $(51-61,61-71,71-83$, 


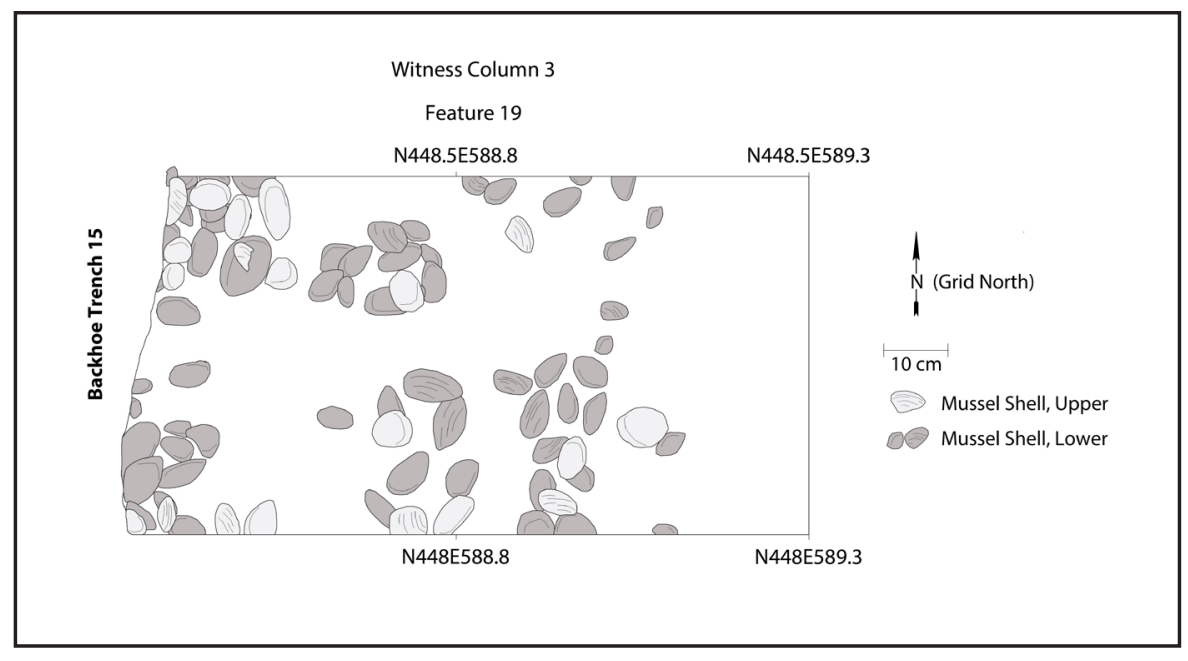

Figure 7-13. Plan view drawing of the Feature 19 shell concentration within the lower A horizon of WC 3 .

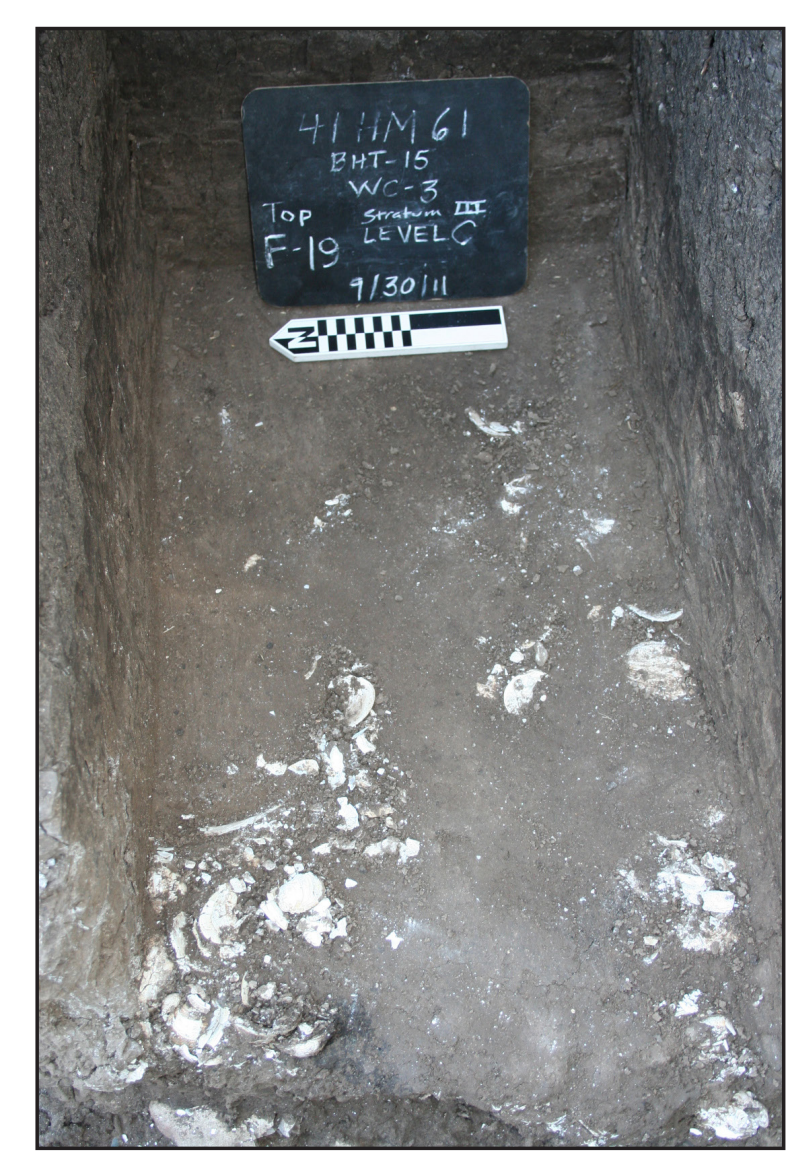

Figure 7-14. Photograph of the exposed top of the Feature 19 mussel shell concentration near the base of WC 3 within the
lower West Range alluvium. 9/30/11.

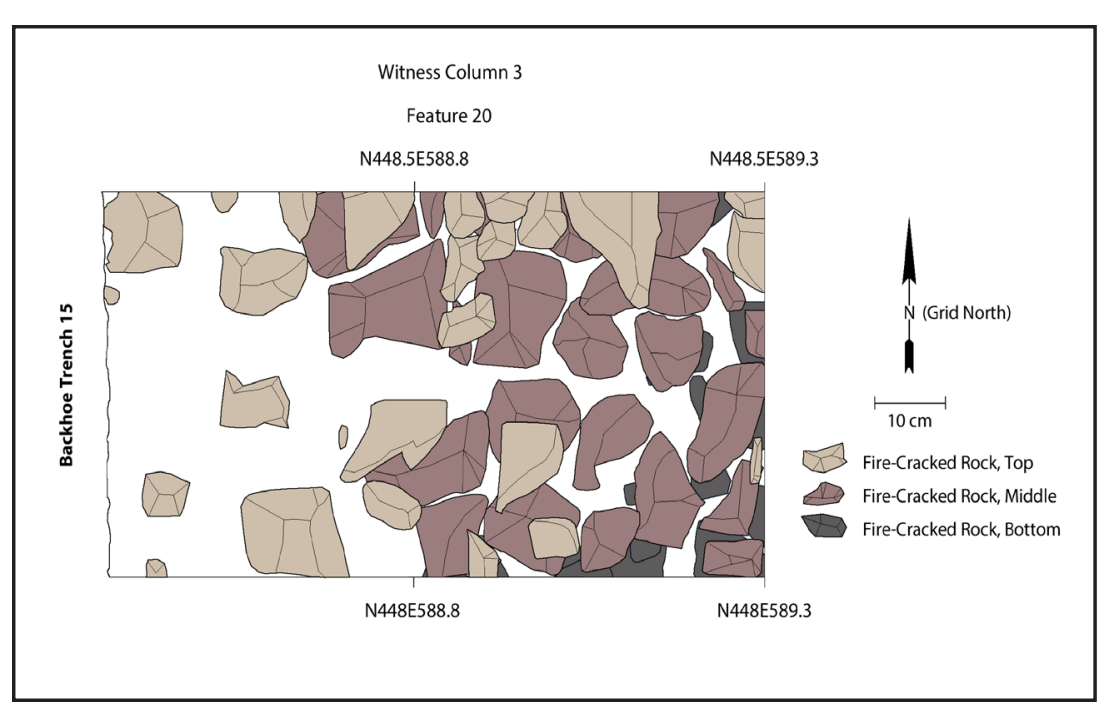

Figure 7-15. Plan view drawing of the distribution of the fire-cracked rock
associated with Feature 20 in WC 3 .

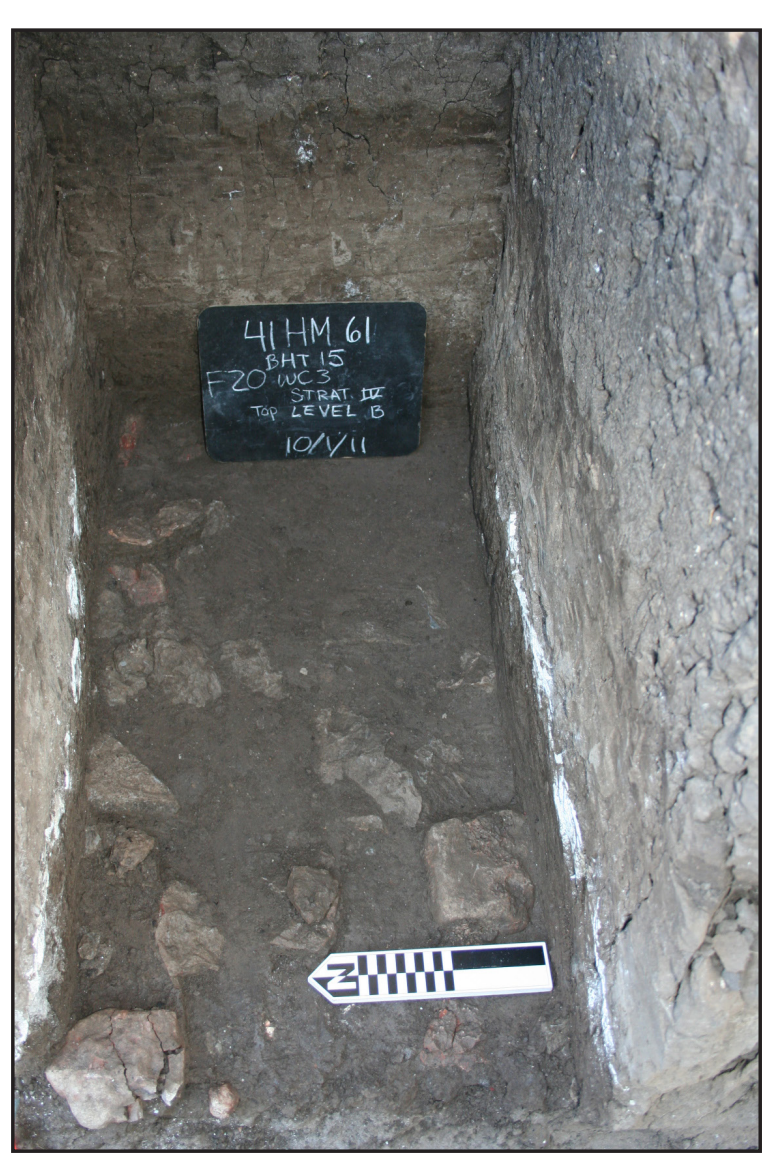

Figure 7-16. Photograph of the initial exposure concentration as exposed near the bottom of WC 3. Note the remains of the overlying mussel shells associated with Feature 19 along the north an

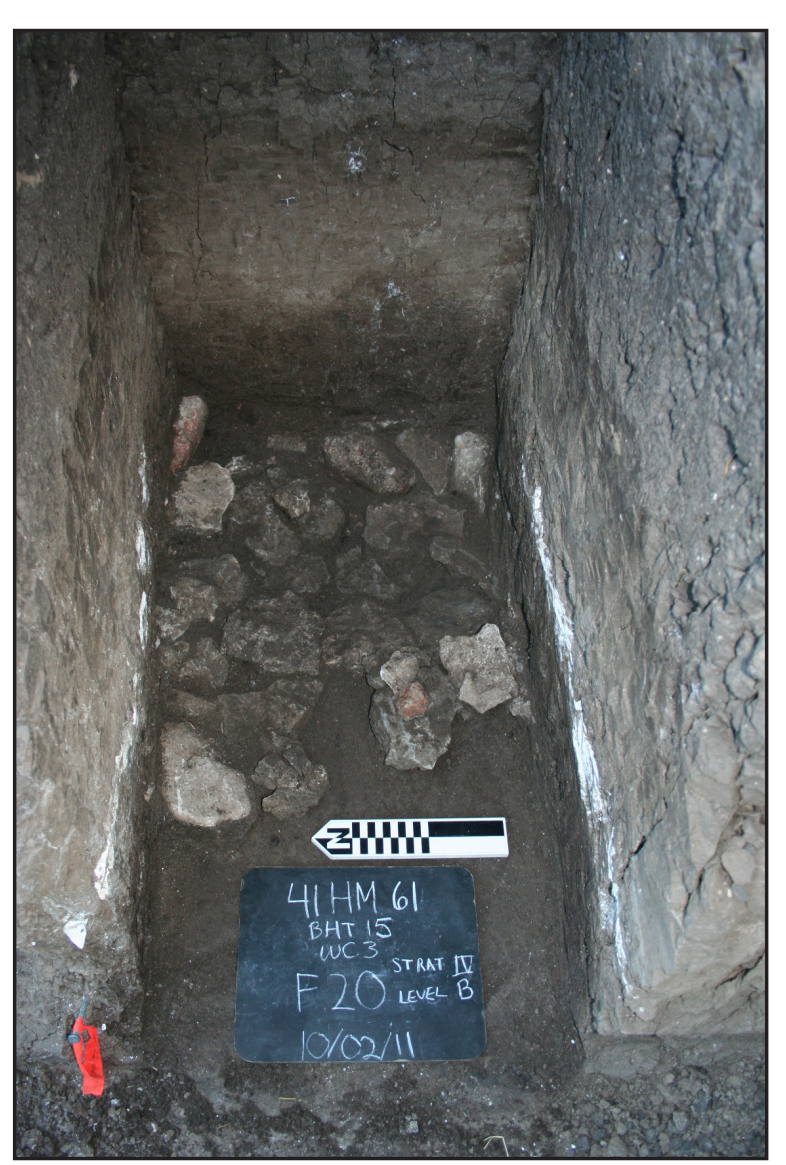

Figure 7-17. Additional photograph of the firecracked rock concentration of Feature layer of rock. Note that the second layer of rock is concentrated in the eastern portion of the WC. 10/2/11. 



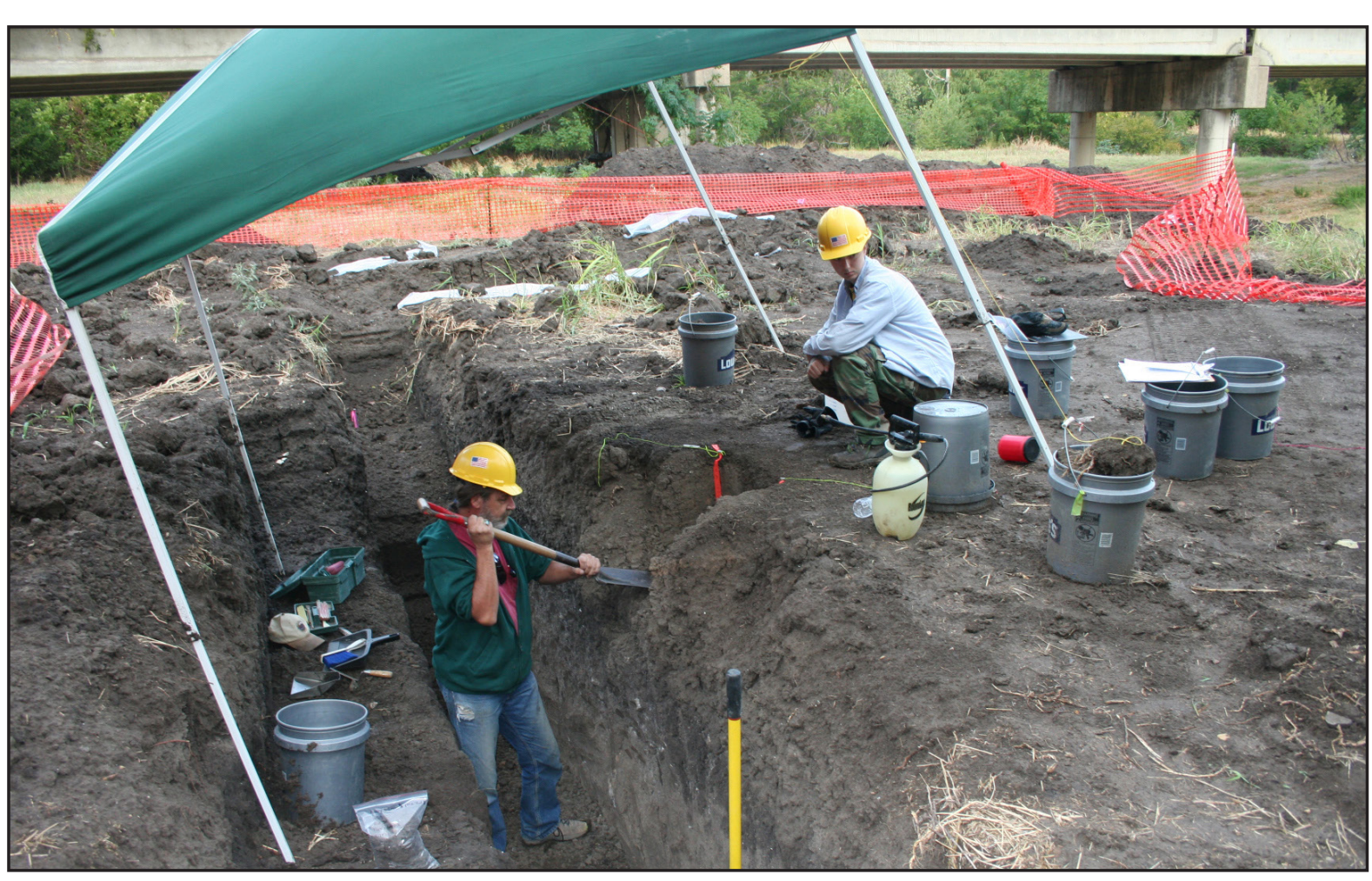

Figure 7-18. Photograph of Richard Walter excavating WC 4 adjacent to the north wall of BT 16. Note the
dark West Range A horizon visible along the wall of the trench. View to the west-northwest.

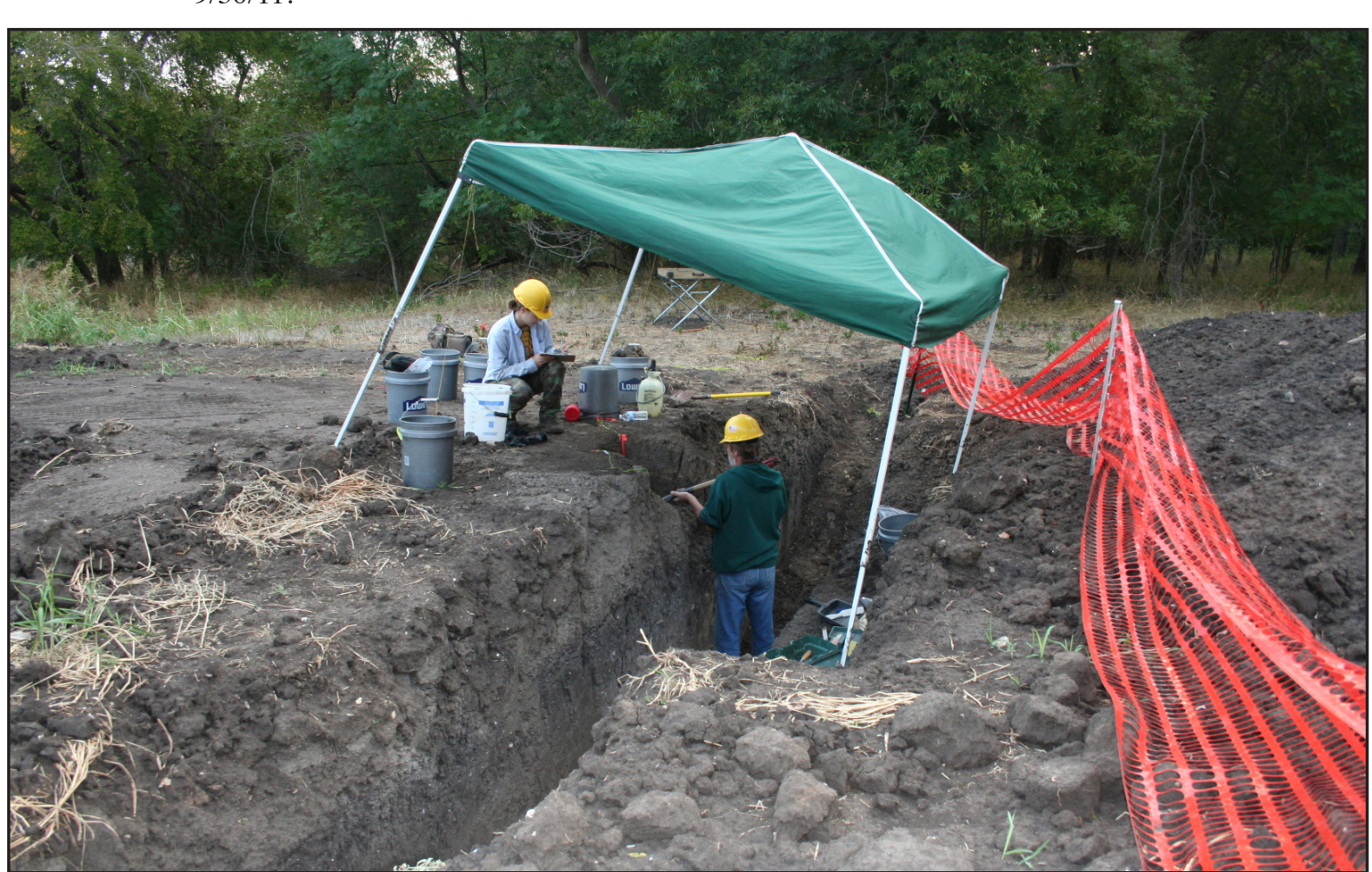
Figure 7-19. Another photograph of Richard Walter excavating WC 4 adjacent to the north wall of BT 16.
Sally Morehead is taking notes. View to the east-northeast. $9 / 30 / 11$.

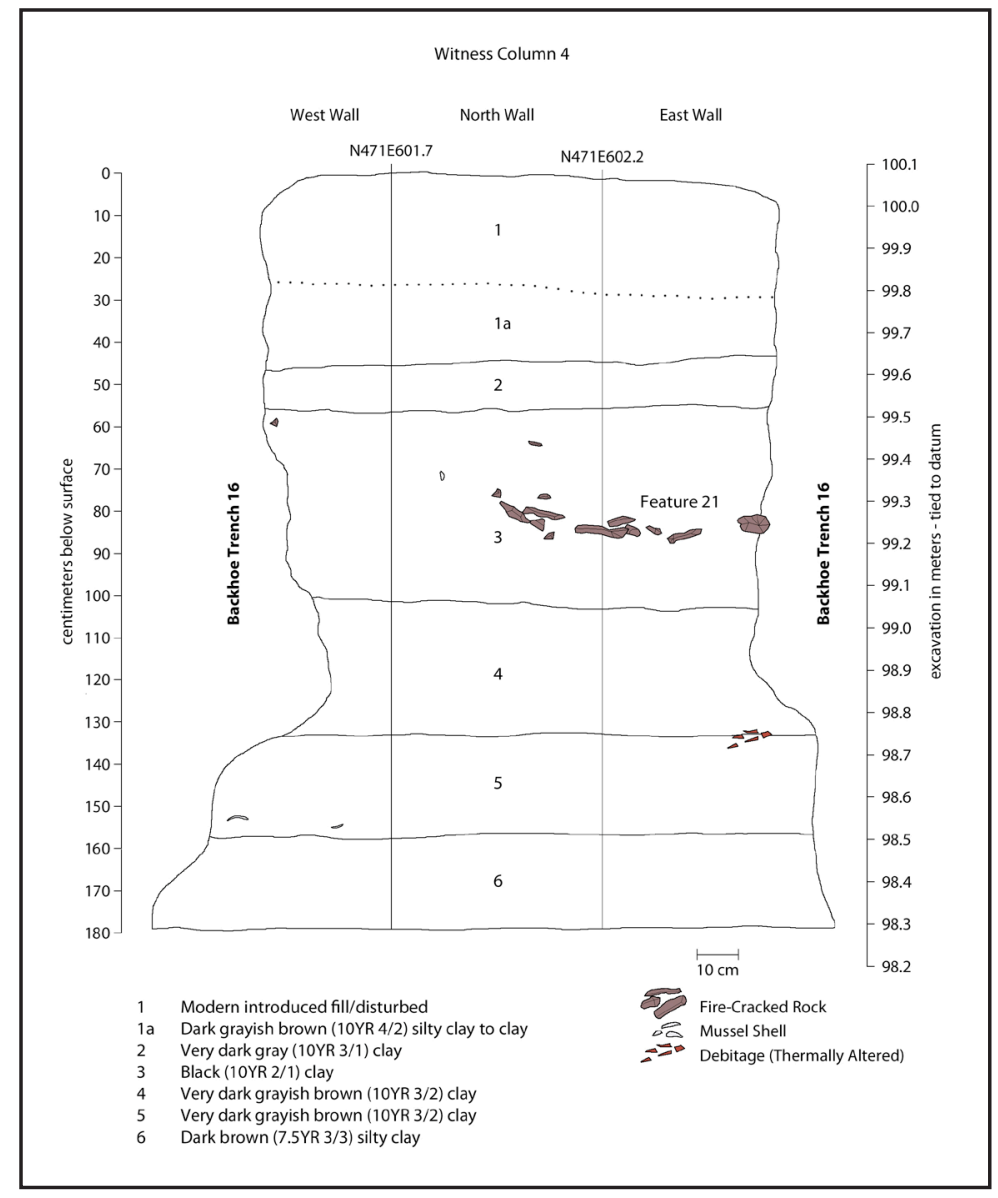
Figure 7-20. Profile drawing of the three walls of WC 4 . Note the
location of the Feature 21 layer of fire-cracked rock
within Stratum 3 .

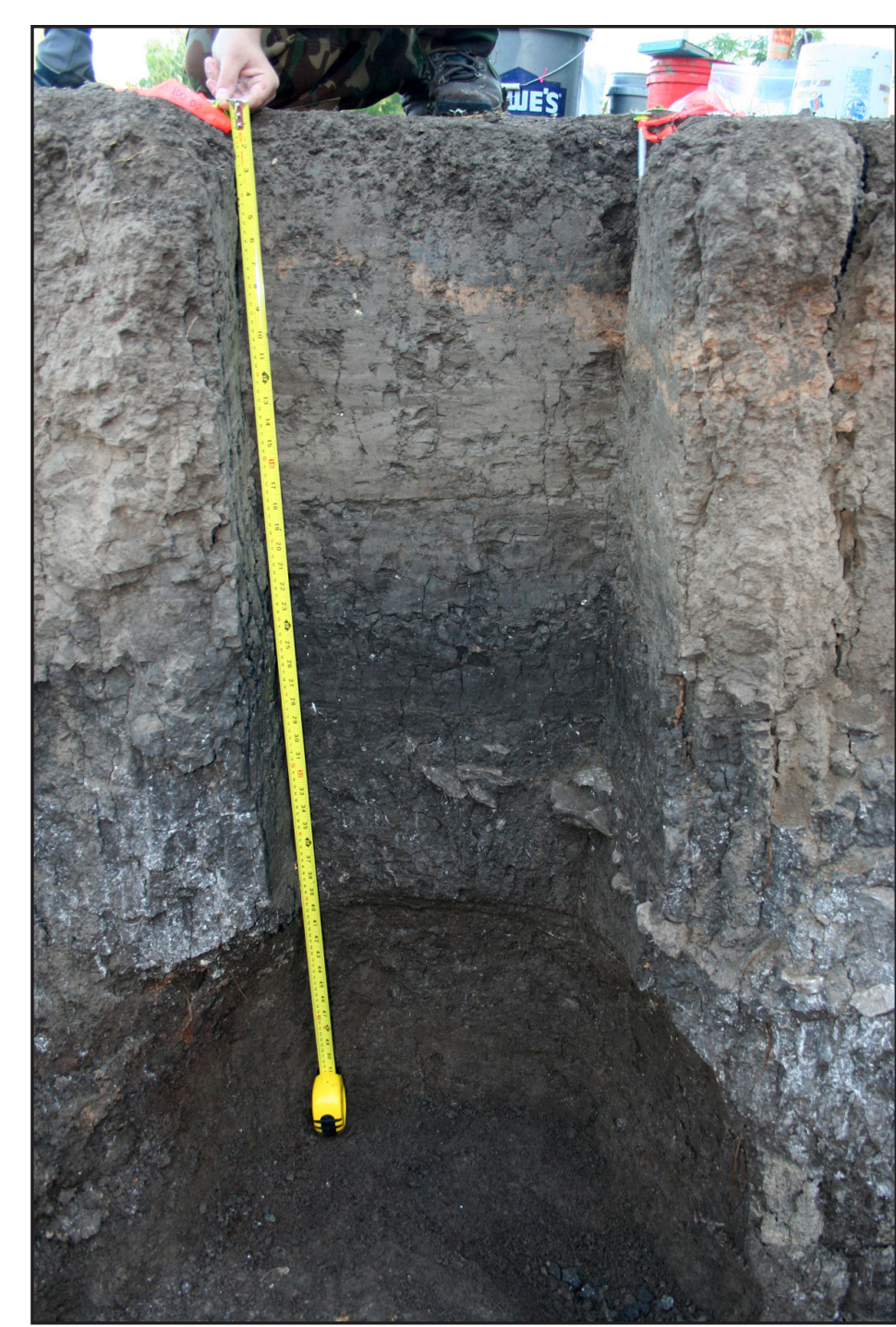

Figure 7-21. Photograph of the north wall profile of WC 4 . Note the dramatic color difference between the lighter overlying layers of Ford alluvium and the
darker West Range A horizon. Fire-cracked rock darker West Range A horizon. Fire-cracked rock
associated with Feature 21 can be seen near the associated with Feature 21 can be seen near the
base of the A horizon. Unfortunately, heavy rains the subsequent profiling, resulting in cavation and the subsequent profiling, resulting in
collapsed walls and the eroded section at the base 



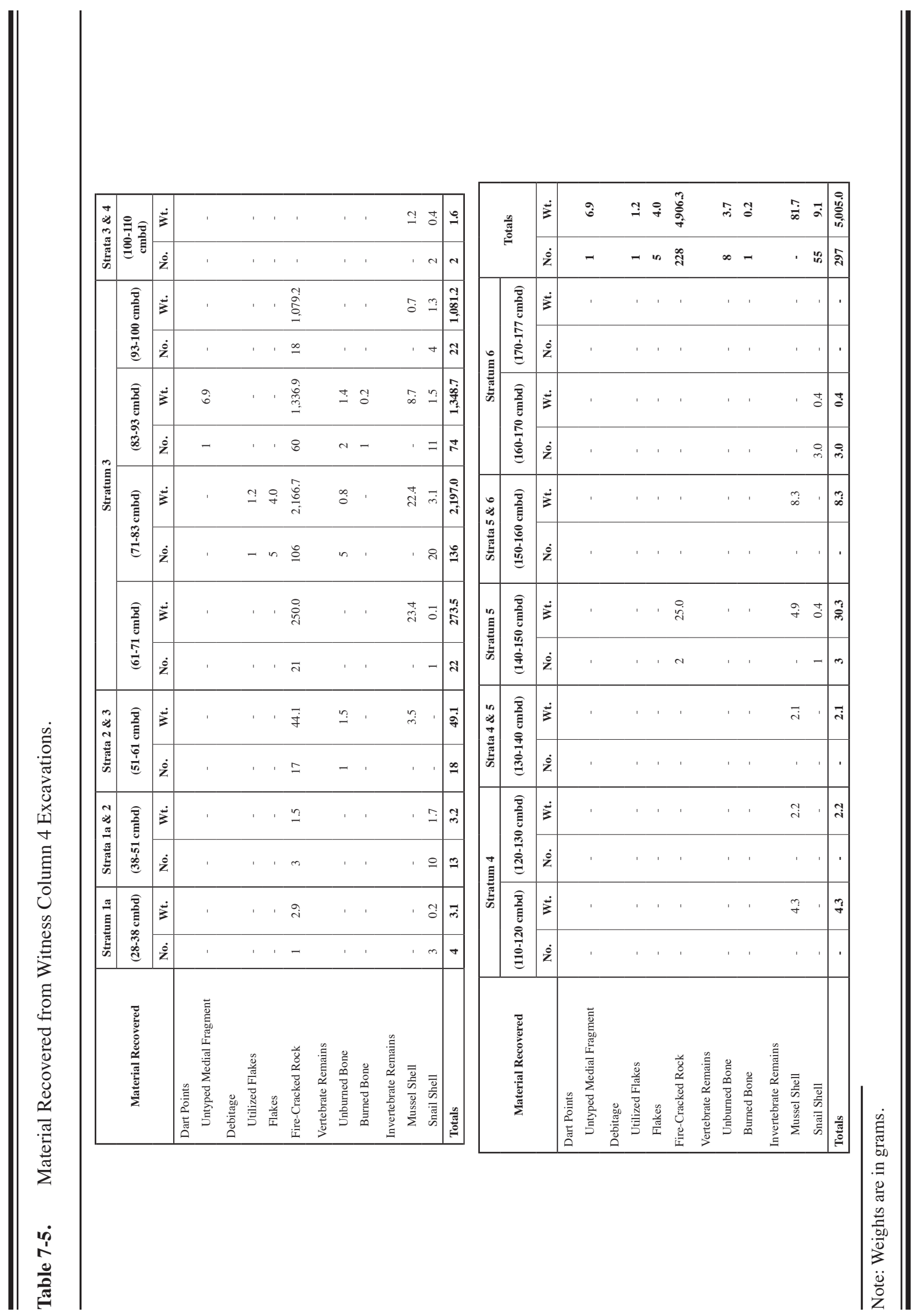


Table 7-6. Witness Column 4: Excavated Strata and Levels and Corresponding Natural Strata as Identified on Wall Profiles.

\begin{tabular}{|c|c|}
\hline $\begin{array}{c}\text { Excavated Strata } \\
\text { and Levels } \\
\text { (Depth Below WC Datum) }\end{array}$ & $\begin{array}{c}\text { Natural Strata on } \\
\text { Wall Profiles } \\
\text { (Elevation Based on Site Datum) }\end{array}$ \\
\hline $\begin{array}{c}\text { Stratum 1, Level A } \\
(0-28 \mathrm{~cm}) \\
\text { (Shoveled out }- \text { no material } \\
\text { saved or screened) }\end{array}$ & $\begin{array}{c}\text { Stratum } 1 \\
\text { (Disturbed Ford Alluvium) } \\
(100.08 \text { to } 99.80 \mathrm{~m})\end{array}$ \\
\hline $\begin{array}{l}\text { Stratum 2, Level A } \\
\quad(28-38 \mathrm{~cm})\end{array}$ & $\begin{array}{c}\text { Stratum 1a } \\
\text { (Disturbed Ford Alluvium?) } \\
(99.80 \text { to } 99.70 \mathrm{~m})\end{array}$ \\
\hline $\begin{array}{l}\text { Stratum 2, Level B } \\
\quad(38-51 \mathrm{~cm})\end{array}$ & $\begin{array}{c}\text { Strata 1a \& } 2 \\
\text { (Disturbed Ford Alluvium?, } \\
\text { Ford Alluvium) } \\
(99.70 \text { to } 99.57 \mathrm{~m})\end{array}$ \\
\hline $\begin{array}{l}\text { Stratum 3, Level A } \\
\quad(51-61 \mathrm{~cm})\end{array}$ & $\begin{array}{c}\text { Strata } 2 \& 3 \\
\text { (A Horizon, West Range Alluvium) } \\
(99.57 \text { to } 99.47 \mathrm{~m})\end{array}$ \\
\hline $\begin{array}{l}\text { Stratum 3, Level B } \\
\quad(61-71 \mathrm{~cm})\end{array}$ & $\begin{array}{c}\text { Stratum } 3 \\
\text { (A Horizon, West Range Alluvium) } \\
(99.47 \text { to } 99.37 \mathrm{~m})\end{array}$ \\
\hline $\begin{array}{c}\text { Stratum 3, Level C } \\
\text { (Includes upper F. 21) } \\
\quad(71-83 \mathrm{~cm})\end{array}$ & $\begin{array}{c}\text { Stratum 3 } \\
\text { (Includes upper F. 21) } \\
\text { (A Horizon, West Range Alluvium) } \\
(99.37 \text { to } 99.25 \mathrm{~m})\end{array}$ \\
\hline $\begin{array}{c}\text { Stratum 3, Level D } \\
\text { (Includes lower F. 21) } \\
\quad(83-93 \mathrm{~cm})\end{array}$ & $\begin{array}{c}\text { Stratum } 3 \\
\text { (Includes lower F. 21) } \\
\text { (A Horizon, West Range Alluvium) } \\
(99.25 \text { to } 98.15 \mathrm{~m})\end{array}$ \\
\hline $\begin{array}{l}\text { Stratum 3, Level E } \\
\quad(93-100 \mathrm{~cm})\end{array}$ & $\begin{array}{c}\text { Stratum } 3 \\
\text { (A Horizon, West Range Alluvium) } \\
(98.15 \text { to } 99.08 \mathrm{~m})\end{array}$ \\
\hline $\begin{array}{l}\text { Stratum 4, Level A } \\
\quad(100-110 \mathrm{~cm})\end{array}$ & $\begin{array}{c}\text { Strata } 3 \& 4 \\
\text { (A Horizon, West Range Alluvium, } \\
\text { West Range Alluvium) } \\
(99.08 \text { to } 98.98 \mathrm{~m})\end{array}$ \\
\hline $\begin{array}{l}\text { Stratum 4, Level B } \\
\quad(110-120 \mathrm{~cm})\end{array}$ & $\begin{array}{c}\text { Stratum } 4 \\
\text { (West Range Alluvium) } \\
(98.98 \text { to } 98.88 \mathrm{~m})\end{array}$ \\
\hline $\begin{array}{l}\text { Stratum 4, Level C } \\
\quad(120-130 \mathrm{~cm})\end{array}$ & $\begin{array}{c}\text { Stratum } 4 \\
\text { (West Range Alluvium) } \\
(98.88 \text { to } 98.78 \mathrm{~m})\end{array}$ \\
\hline $\begin{array}{l}\text { Stratum 4, Level D } \\
\quad(130-140 \mathrm{~cm})\end{array}$ & $\begin{array}{c}\text { Strata } 4 \& 5 \\
\text { (West Range Alluvium) } \\
(98.78 \text { to } 98.68 \mathrm{~m})\end{array}$ \\
\hline $\begin{array}{l}\text { Stratum 4, Level E } \\
\quad(140-150 \mathrm{~cm})\end{array}$ & $\begin{array}{c}\text { Stratum } 5 \\
\text { (West Range Alluvium) } \\
(98.68 \text { to } 98.58 \mathrm{~m})\end{array}$ \\
\hline $\begin{array}{l}\text { Stratum 4, Level F } \\
\quad(150-160 \mathrm{~cm})\end{array}$ & $\begin{array}{c}\text { Strata } 5 \text { \& } 6 \\
\text { (West Range Alluvium) } \\
(98.58 \text { to } 98.48 \mathrm{~m})\end{array}$ \\
\hline $\begin{array}{l}\text { Stratum 4, Level G } \\
\quad(160-170 \mathrm{~cm})\end{array}$ & $\begin{array}{c}\text { Stratum } 6 \\
\text { (West Range Alluvium) } \\
(98.48 \text { to } 98.38 \mathrm{~m})\end{array}$ \\
\hline $\begin{array}{l}\text { Stratum 4, Level H } \\
\quad(170-177 \mathrm{~cm})\end{array}$ & $\begin{array}{c}\text { Stratum } 6 \\
\text { (West Range Alluvium) } \\
(98.38 \text { to } 98.31 \mathrm{~m})\end{array}$ \\
\hline
\end{tabular}

Note: Depths based on elevations of the NW corner of the witness column, which served as the column's datum during excavation. 
83-93, and 93-100 $\mathrm{cm}$ ) into the Upper West Range's A horizon (Stratum 3) and another five levels (100$110,110-120,120-130,130-140$, and 140-150 cm) into the upper part of the deeper West Range alluvium (Strata 4 and 5). The next three levels (150-160, $160-170$, and $170-177 \mathrm{~cm}$ ) removed the very bottom of Stratum 5 and the uppermost part of Stratum 6 of the Lower West Range alluvium.

Regardless of the above, the distribution of artifacts throughout the column generally mirrored the results of WCs 2 and 3, i.e., virtually nothing in the Ford alluvium, a modest amount of material in the Upper West Range's A horizon, and then only scattered and sparse remains within the deeper West Range alluvium (save when specific features were present, i.e., Features 19 and 20 in WC 3) (see Table 7-6).

Of particular note was the presence of Feature 21 , the burned-rock cluster visible on the wall of BT 16 and the stimulus for the placement of WC 4 . The feature first appeared within the 71-to-83-cm level of Stratum 3 at an elevation of ca. $99.29 \mathrm{~m}$ and continued through almost all of the next level down to an elevation of ca. 99.20. As can be seen in Figures 7-22 and Figure 7-23, the feature was mainly concentrated within the southern portion of the $\mathrm{WC}$, although scattered rocks were present throughout. It also was mainly confined to the middle of the Upper West Range's A horizon, suggesting that it might be somewhat younger than the Marcos dart points found at the bottom of the Upper West Range's A horizon in the east wall of BT 15 and WC 3 (see discussion above). Also present within the feature were several small pieces of bone, mussel shell, and debitage. Interestingly, the excavators noted that the soil beneath the feature appeared lighter in color (10YR 2/2 within feature; 10YR 4/2 beneath feature), and that it might indicate the presence of oxidation and in situ burning. However, no evidence of charcoal was seen while digging, all of the bone fragments were unburned, and there was no obvious orange or reddish soil present. All of these latter facts would appear to negate the possibility of in situ firing.

Importantly, a piece of possumhaw (Ilex sp.) wood charcoal was recovered in a flotation sample removed from Feature 21 (see Chapter 12). This item produced a ${ }^{14} \mathrm{C}$ age of $1890 \pm 30$ cal B.P. and a calibrated 2-sigma age range of between 1894 and 1733 cal B.P. (ca. A.D. 60 and 220) at 95.4 percent probability (Beta-382995). If correct, this date suggests an association of F. 21 with the Late Archaic 3 period and likely confirmation that the feature dates later than the
Marcos dart points found at the base of the Upper West Range's A horizon. Also of interest was the discovery of a partial dart point at an elevation of $99.17 \mathrm{~m}$, immediately beneath the rocks of Feature 21. Since the point's base is missing, it is not possible to assign it to a known point type. Given the point's location within the middle of the upper A horizon and the radiocarbon date from F. 21, however, it may not be too outlandish to suggest that the dart fragment could be part of an Ensor point.

\section{Witness Column 5}

WC 5 was located along the east wall of expanded BT 11 above several vertically distinct layers of burned rocks present within the A horizon at the top of the Upper West Range alluvium (see Figures 6-10 and 7-1). These rock layers were thought to represent different living surfaces dating to the Late Archaic period. Although projected to be 50 by $50 \mathrm{~cm}$ in size, the column actually measured between 60 and 65 $\mathrm{cm}$ east-west by $50 \mathrm{~cm}$ north-south due to the need to place it slightly farther away from the slumping edge of BT 11. The WC's northeast corner (located at N473E595.8) served as the column's specific datum, and it was from this point that a line level was attached to measure depth during excavation. Overall, the WC was dug to $-1.40 \mathrm{~m}$.

Figures 7-24 and 7-25 illustrate the three walls of WC 5, while Table 7-7 lists artifacts and other cultural items recovered from the WC as either field specimens or material captured in the 1/4-inch screen. As can be seen, five separate strata were recognized on the wall profiles, and these match the same five strata seen along the east wall of BT 11 (see Figure 6-10). As shown in Table 7-8, the column's excavators generally were able to correctly identify strata breaks within the upper part of the WC, but missed the break between Strata 4 and 5 near the base of the excavation. Once again, the upper zone of disturbed Ford alluvium (Stratum 1) was shoveled out and discarded. Below that was a ca. 12- to $15-\mathrm{cm}-$ thick layer of undisturbed Ford alluvium (Stratum 2), followed by a relatively thick A horizon (Stratum 3 ) in the upper portion of the West Range alluvium. This A horizon was excavated by means of four cuts $(50-60,60-70,70-80$, and $80-90 \mathrm{~cm})$ that removed only that stratum and two other cuts (40-50 and 90$100 \mathrm{~cm}$ ) that took out both the A horizon and parts of the overlying Ford (Stratum 2) and underlying West Range (Stratum 4) alluvia, respectively. These latter cuts are not considered a problem, as it is almost certain that any artifacts found within them originated in 
the Stratum 3 A horizon. The failure to recognize the break between Strata 4 and 5 also is not considered a problem, as the 120-to-130-cm level removed only the upper 2 to $4 \mathrm{~cm}$ of Stratum 5. The final cut (130$140 \mathrm{~cm}$ ) was completely within Stratum 5.

As can be seen in Figure 7-24, there may be three separate living surfaces present within the Upper West Range A horizon-an upper surface at roughly the bottom of the 50-to-60-cm level, a middle surface within the 70-to-80-cm level, and a lower surface near the bottom of the $80-$ to- $-90-\mathrm{cm}$ level. Although the excavators found scattered firecracked rocks, mussel shells, and a few bone fragments within the levels that removed the upper and lower surfaces, there was not enough concentrated material for them to identify specific living layers. However, they did note a concentration of burned rocks, mussel shell, and bone within the middle level, and this was considered a potential occupation surface (Figures 7-26 and 7-27).

While the concentration of fire-cracked rocks and other material was not enough to warrant designation as a feature, a sample of organic sediment from within the surface was submitted to Beta Analytic for ${ }^{14} \mathrm{C}$ dating. The sample (Beta-315689) returned a ${ }^{14} \mathrm{C}$ age of $1720 \pm 30$ cal B.P. with a calibrated 2-sigma range of 1702 to 1560 cal B.P. (ca. A.D. 250 to 390) at 95.4 percent probability. Although more will be said of this date in Chapter 10, it is important to note that this age range is only slightly later than the range obtained on the possumhaw charcoal from F. 21 in WC 4, thus providing additional evidence that cultural remains associated with the middle part of the upper A horizon in the area of BTs 11 and 16 most likely date to the Late Archaic 3 period.

Below the A horizon, Stratum 4 was almost completely culturally sterile, with only a few scattered pieces of mussel and snail shells present (see Table 7-7). This lack of cultural material also is evident on the profiles of the WC (see Figures 7-24 and 7-25). Importantly, the excavators noted the presence larger mussel shell fragments within the level that removed Stratum 5 at the base of the WC. The profiles for the column also include a few pieces of mussel shell within the lowermost stratum (see Figure 7-24). Together, the notes and profiles suggest that a very minor occupation likely occurred within Stratum 5 of the Lower West Range alluvium. Excavation of the WC was terminated when it reached the same depth as the bottom of BT 11 .

\section{North Section}

\section{Witness Column 1}

WC 1 was located along the west wall of the southern part of combined BT 4/19, above several artifacts and bones protruding from a dark A horizon located at the top of the West Range alluvium (Figures 7-28 through 7-30; see Figure 6-28). Unlike the A horizons described for the previous WCs in the south part of the site (which contained artifacts and cultural material related to several Late Archaic occupations marked by the presence of Lange, Marcos, and Ensor dart points), the A horizon in the north part the site was identified as a Late Prehistoric, "Toyah-like" deposit. Several large mammal bones (deer and bison), along with at least one Perdiz arrow point, were exposed in the A horizon on the walls along the southern portion of BT 4/19. WC 1 was designed to acquire more data on this "Toyah" deposit.

Although projected to be 50 by $50 \mathrm{~cm}$ in size, the column actually measured between 60 and $70 \mathrm{~cm}$ east-west by $50 \mathrm{~cm}$ north-south due to the need to place it slightly farther away from the slumping edge of BT 4/19. The WC's southwest corner (located at N603E592.5) served as the column's specific datum, and it was from this point that a line level was attached to measure depth during excavation. The WC was dug to $-1.85 \mathrm{~m}$.

Figures 7-31 and 7-32 illustrate the three walls of WC 1, while Table 7-9 lists artifacts and other cultural items recovered from the $\mathrm{WC}$ as either field specimens or material captured in the $1 / 4$-inch screen. ${ }^{1}$ As can be seen, nine separate strata were recognized on the wall profiles, and these match the same nine strata seen along the west wall of BT 4/19 (see Figure 6-26). Unfortunately, there were several instances where the excavators either missed strata breaks or identified such breaks prematurely (Table 7-10). None of these is particularly troublesome, as the main cultural zone (Stratum 7) was identified and removed via three levels $(68-78,78-88$, and 88-97) that did not crosscut stra-

1 Note that the wall profiles for the WC indicate a depth of ca. $1.98 \mathrm{~m}$ while the excavation notes record a final depth of $1.85 \mathrm{~m}$. Although excavation of the $\mathrm{WC}$ had been completed, its wall profiles had not yet been recorded prior to the occurrence of a severe rainstorm on October 7 and 8 , 2011. It became necessary, therefore, to dig out a significant amount of clay and silt from the bottoms of both the trench and WC in order to conduct the profiling. Apparently, the bottom of the WC increased in depth when it was cleared of the clay and silt and the deeper WC is illustrated on the profiles.

(Text coninued on page 127) 


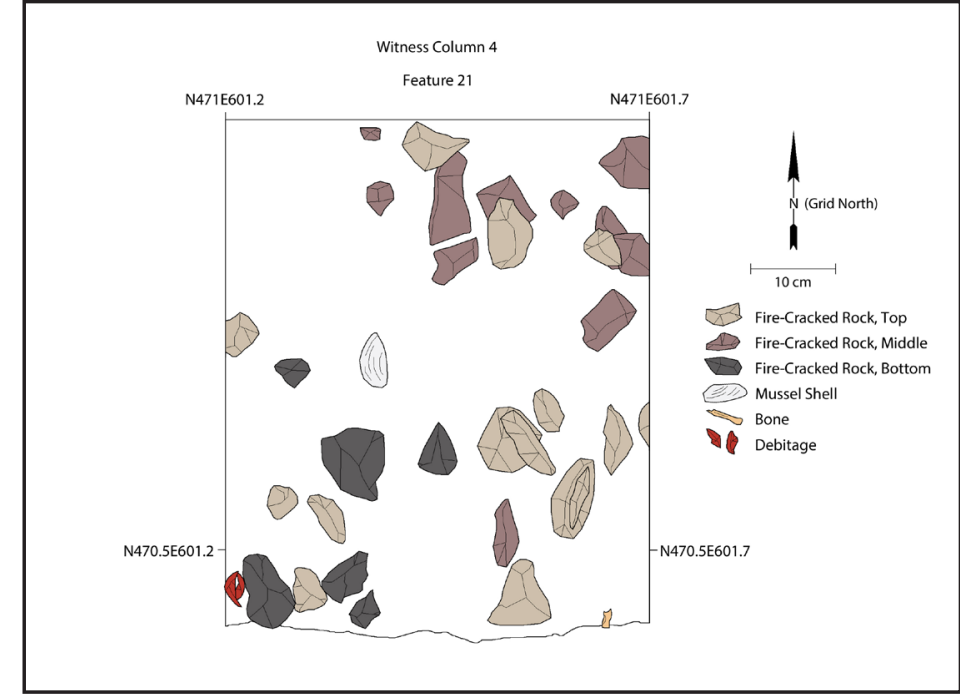

Figure 7-22. Plan view drawing of the Feature 21 burned-rock

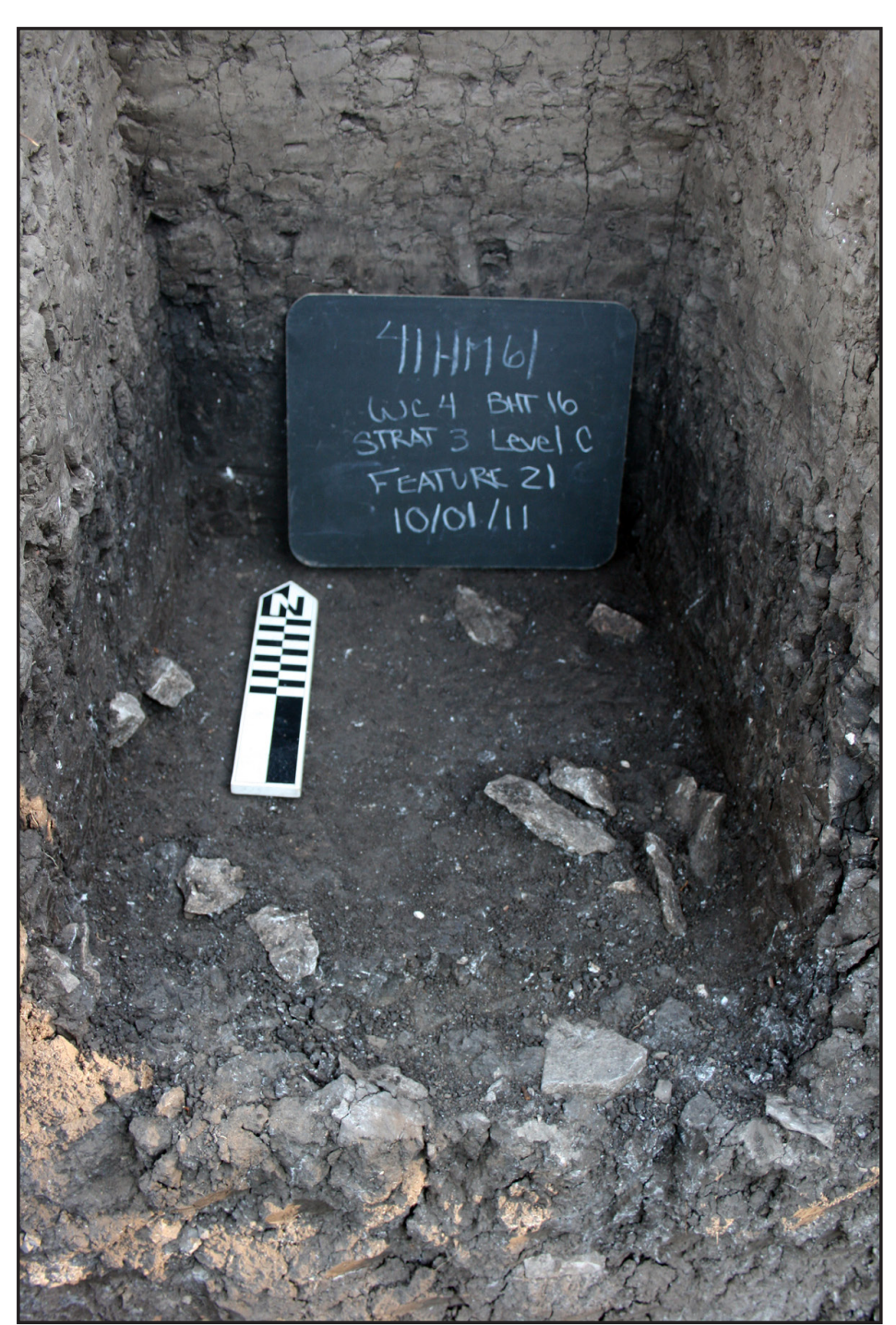

Figure 7-23. (Left) Photograph of the exposed top of the Fea-
ture 21 fire-cracked rock concentration within the West Range A horizon

North Wall East Wall South Wall

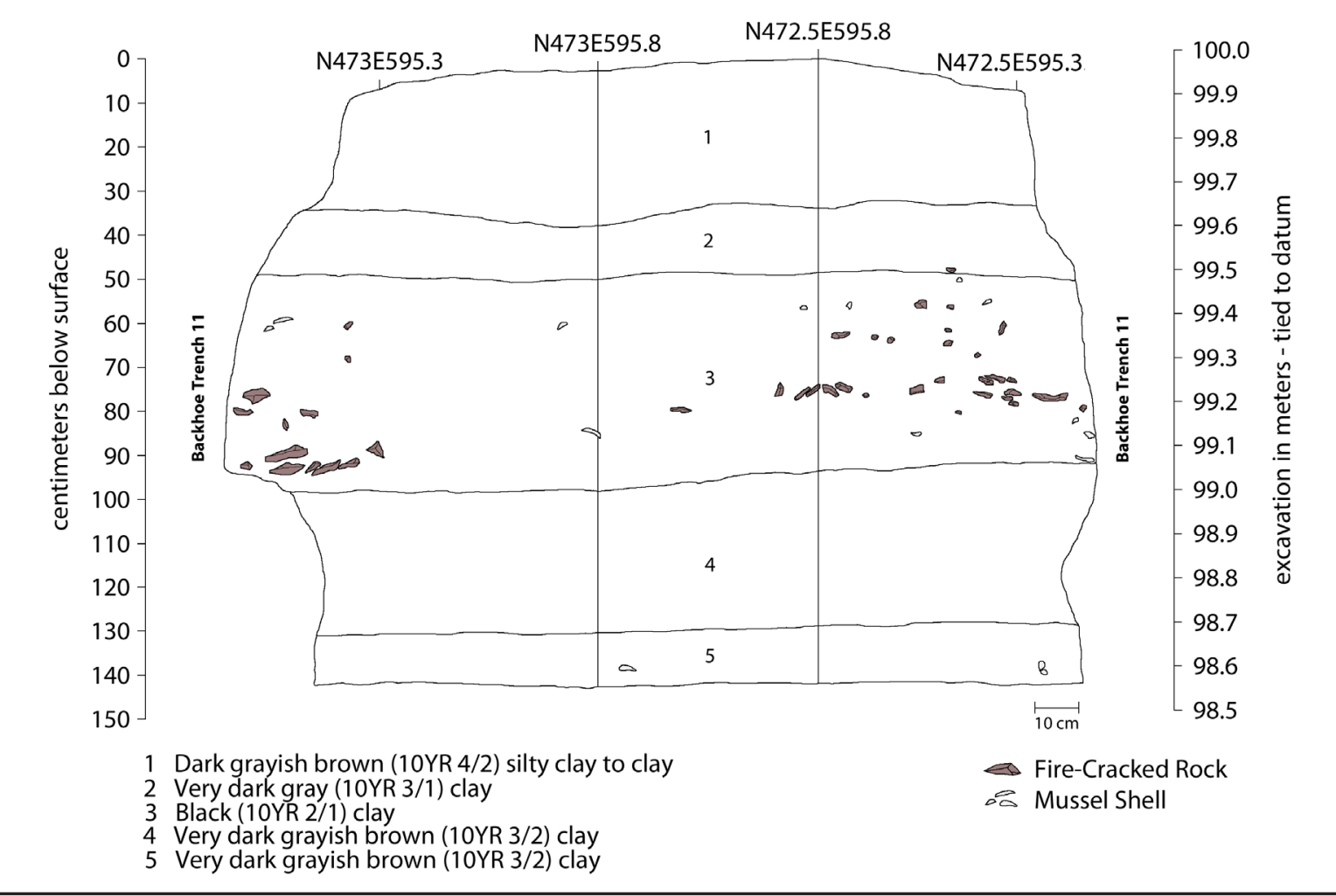

grayish brown (10YR 3/2) clay

Figure 7-25. (Right) Photograph of the east wall profile sharp contrast between the overlying Ford alluvium and the Upper zon. Several pieces of fire-cracked rock can be seen in the profile jutting out of the middle part represent several of the represent several of the
items used to identify the main Late Archaic living surface exposed WC 4, this photograph was not taken until after the heavy rains had collapsed some of the WC
Figure 7-24. (Left) Profile drawing 5. Note the concentration of fire-cracked about mid way within the Upper West Range A horizon. That rock marked the "living surthe excavation.

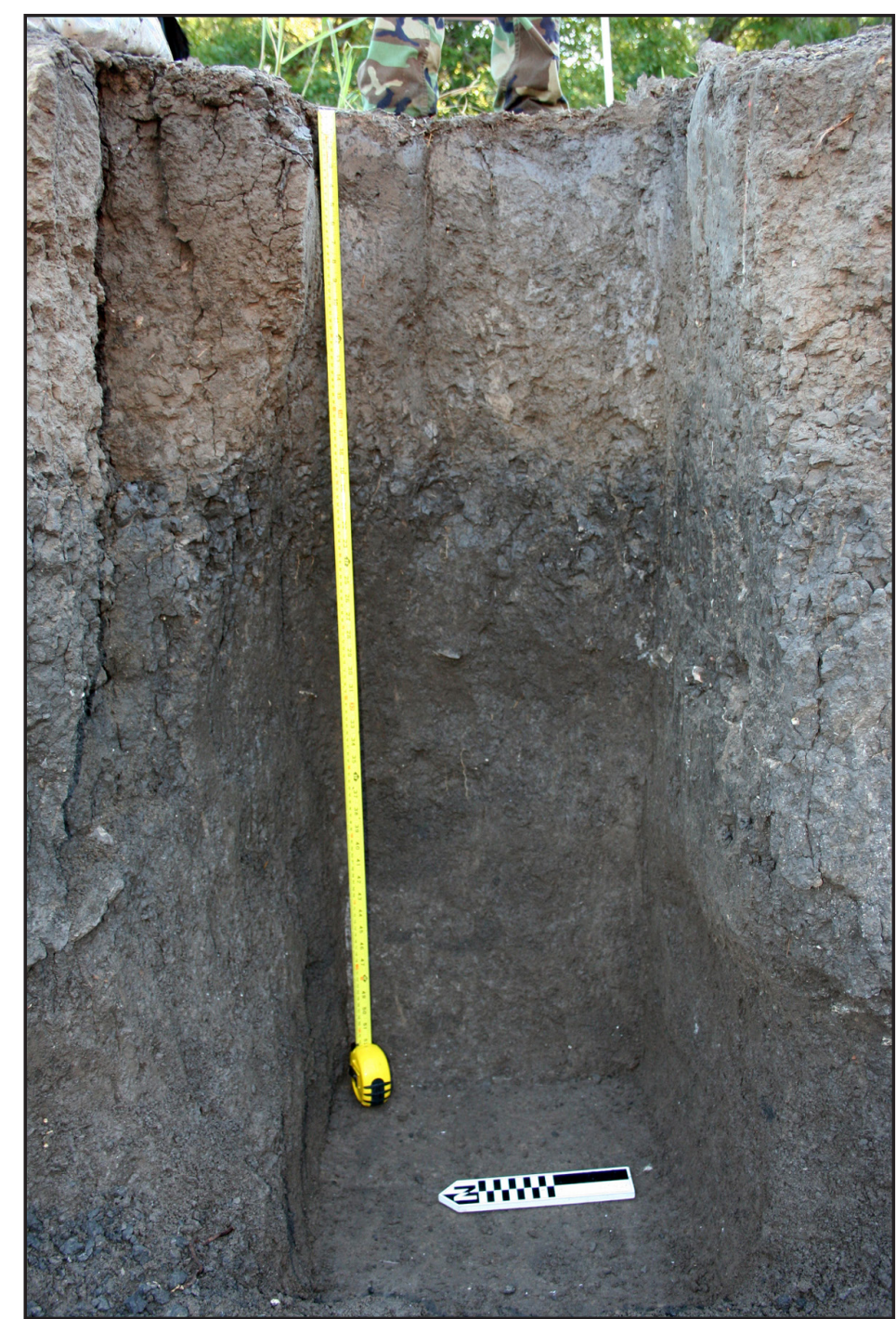





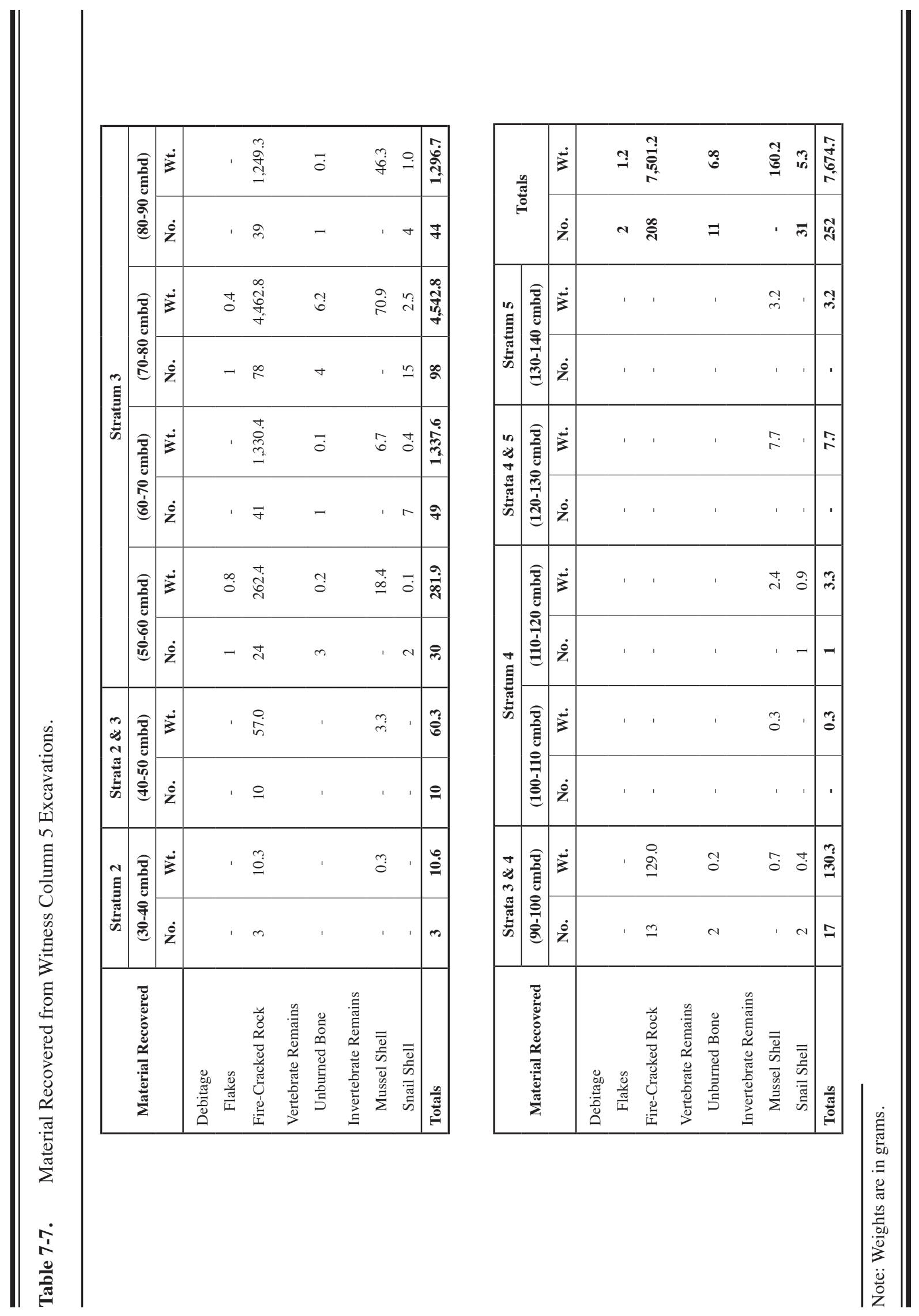


Table 7-8. Witness Column 5: Excavated Strata and Levels and Corresponding Natural Strata as Identified on Wall Profiles.

\begin{tabular}{|c|c|}
\hline $\begin{array}{c}\text { Excavated Strata } \\
\text { and Levels } \\
\text { (Depth Below WC Datum) }\end{array}$ & $\begin{array}{c}\text { Natural Strata on } \\
\text { Wall Profiles } \\
\text { (Elevation Based on Site Datum) }\end{array}$ \\
\hline $\begin{array}{c}\text { Stratum } 1, \text { Level A } \\
(0-30 \mathrm{~cm}) \\
\text { (Shoveled out }- \text { no material } \\
\text { saved or screened) }\end{array}$ & $\begin{array}{c}\text { Stratum } 1 \\
\text { (Disturbed Ford Alluvium) } \\
(99.97 \text { to } 99.67 \mathrm{~m})\end{array}$ \\
\hline $\begin{array}{l}\text { Stratum 2, Level A } \\
\quad(30-40 \mathrm{~cm})\end{array}$ & $\begin{array}{c}\text { Stratum } 2 \\
\text { (Ford Alluvium) } \\
(99.67 \text { to } 99.57 \mathrm{~m})\end{array}$ \\
\hline $\begin{array}{l}\text { Stratum 2, Level B } \\
\quad(40-50 \mathrm{~cm})\end{array}$ & $\begin{array}{c}\text { Strata } 2 \& 3 \\
\text { (Ford Alluvium \& } \\
\text { A Horizon, West Range Alluvium) } \\
(99.57 \text { to } 99.47 \mathrm{~m})\end{array}$ \\
\hline $\begin{array}{l}\text { Stratum 3, Level A } \\
\quad(50-60 \mathrm{~cm})\end{array}$ & $\begin{array}{c}\text { Stratum } 3 \\
\text { (A Horizon, West Range Alluvium) } \\
(99.47 \text { to } 99.37 \mathrm{~m})\end{array}$ \\
\hline $\begin{array}{l}\text { Stratum 3, Level B } \\
\quad(60-70 \mathrm{~cm})\end{array}$ & $\begin{array}{c}\text { Stratum } 3 \\
\text { (A Horizon, West Range Alluvium) } \\
(99.37 \text { to } 99.27 \mathrm{~m})\end{array}$ \\
\hline $\begin{array}{c}\text { Stratum 3, Level C } \\
\text { (Includes possible living surface) } \\
(70-80 \mathrm{~cm})\end{array}$ & $\begin{array}{c}\text { Stratum } 3 \\
\text { (Includes possible living surface) } \\
\text { (A Horizon, West Range Alluvium) } \\
(99.27 \text { to } 99.17 \mathrm{~m})\end{array}$ \\
\hline $\begin{array}{l}\text { Stratum 3, Level D } \\
\quad(80-90 \mathrm{~cm})\end{array}$ & $\begin{array}{c}\text { Stratum } 3 \\
\text { (A Horizon, West Range Alluvium) } \\
(99.17 \text { to } 99.07 \mathrm{~m})\end{array}$ \\
\hline $\begin{array}{l}\text { Stratum 3, Level E } \\
\quad(90-100 \mathrm{~cm})\end{array}$ & $\begin{array}{c}\text { Strata } 3 \& 4 \\
\text { (A Horizon, West Range Alluvium } \\
\text { \& West Range Alluvium) } \\
(99.07 \text { to } 98.97 \mathrm{~m})\end{array}$ \\
\hline $\begin{array}{l}\text { Stratum 4, Level A } \\
\quad(100-110 \mathrm{~cm})\end{array}$ & $\begin{array}{c}\text { Stratum } 4 \\
\text { (West Range Alluvium) } \\
\text { (98.97 to } 98.87 \mathrm{~m})\end{array}$ \\
\hline $\begin{array}{l}\text { Stratum 4, Level B } \\
\quad(110-120 \mathrm{~cm})\end{array}$ & $\begin{array}{c}\text { Stratum } 4 \\
\text { (West Range Alluvium) } \\
\text { (98.87 to } 98.77 \mathrm{~m})\end{array}$ \\
\hline $\begin{array}{l}\text { Stratum 4, Level C } \\
\quad(120-130 \mathrm{~cm})\end{array}$ & $\begin{array}{c}\text { Strata } 4 \& 5 \\
\text { (West Range Alluvium) } \\
\text { (98.77 to } 98.67 \mathrm{~m})\end{array}$ \\
\hline $\begin{array}{l}\text { Stratum 4, Level D } \\
\quad(130-140 \mathrm{~cm})\end{array}$ & $\begin{array}{c}\text { Stratum } 5 \\
\text { (West Range Alluvium) } \\
\text { (98.67 to } 98.57 \mathrm{~m})\end{array}$ \\
\hline
\end{tabular}

Note: Depths based on elevations of the NE corner of the witness column, which served as the column's datum during excavation. 


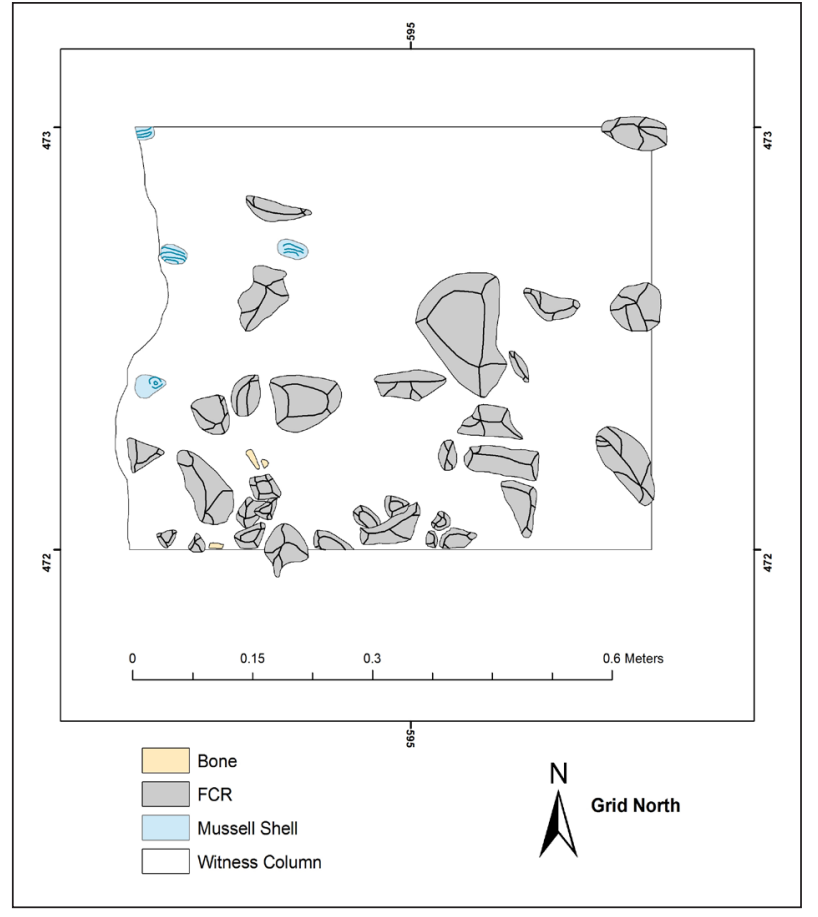

Figure 7-26. Plan view drawing of the top of the so-called "living surface" within WC 5 . mussel shell, and other cultural it rock, likely represents a Late Archaic 3 ocelpation that would appear to date slightly
later than the occupation responsible fo Feature 21 in WC 4.

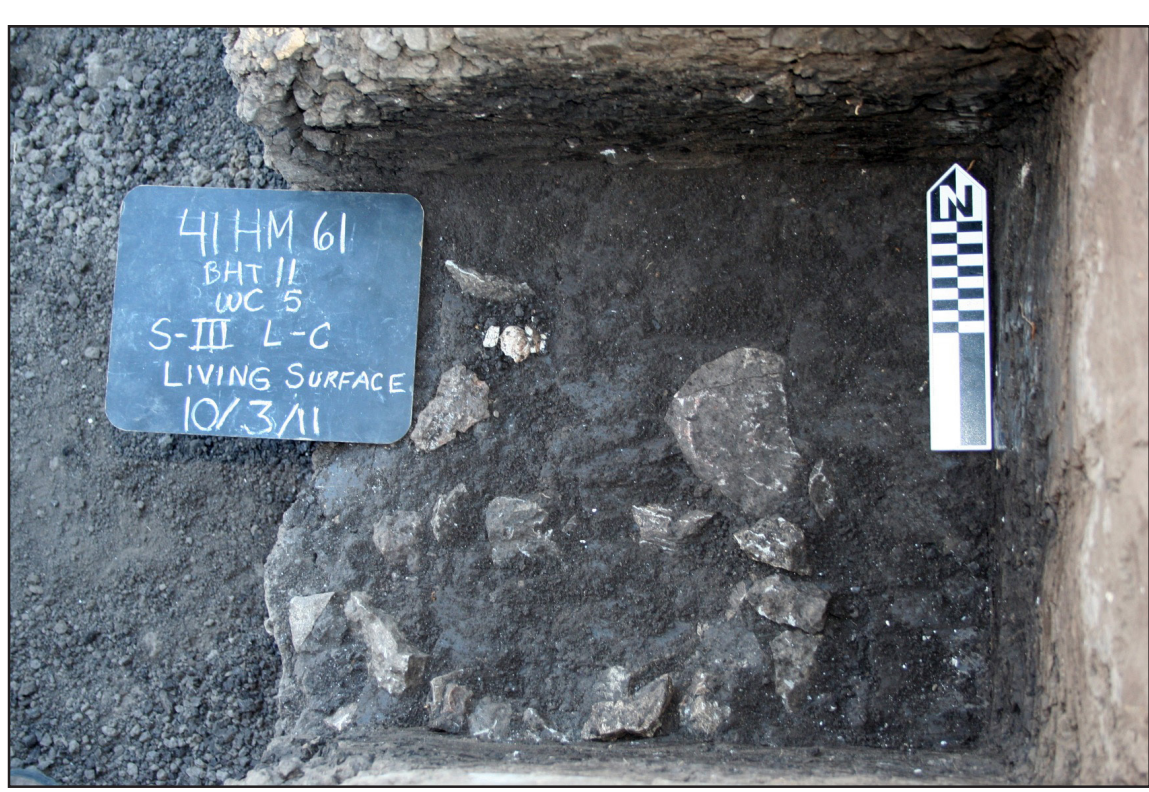

Figure 7-27. Photograph of the top of the concentration of fire-cracked rock and other artifacts found within the 70-to-80-cm level of WC 5 . Compare with Figure 7-26. 10/3/1

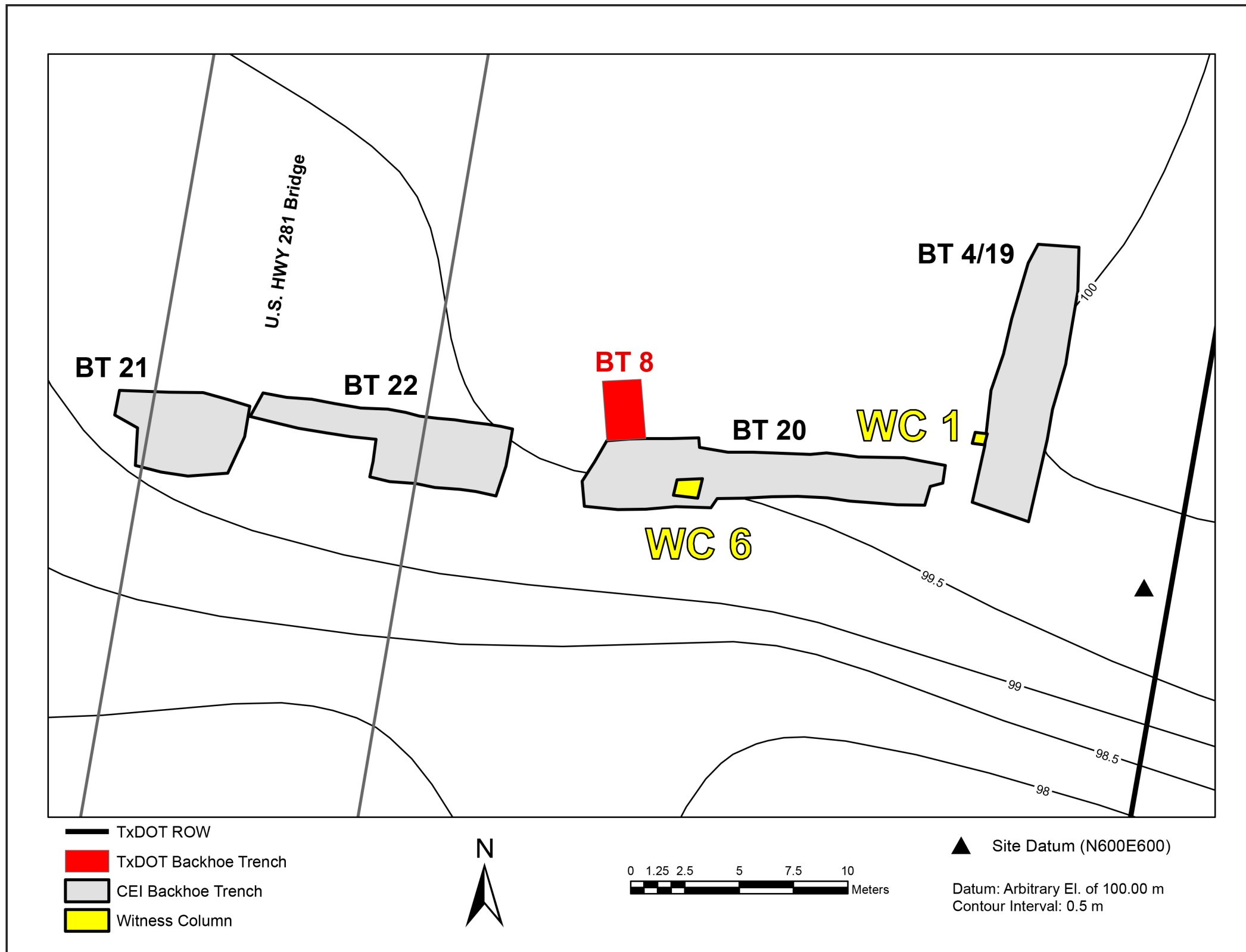

Figure 7-28. Map of a portion of the northern part of site 41HM61 showing backhoe trenches and witness columns. Note the locations of WC 1 along the west wall of BT 4/19 and WC 6 within BT 20 



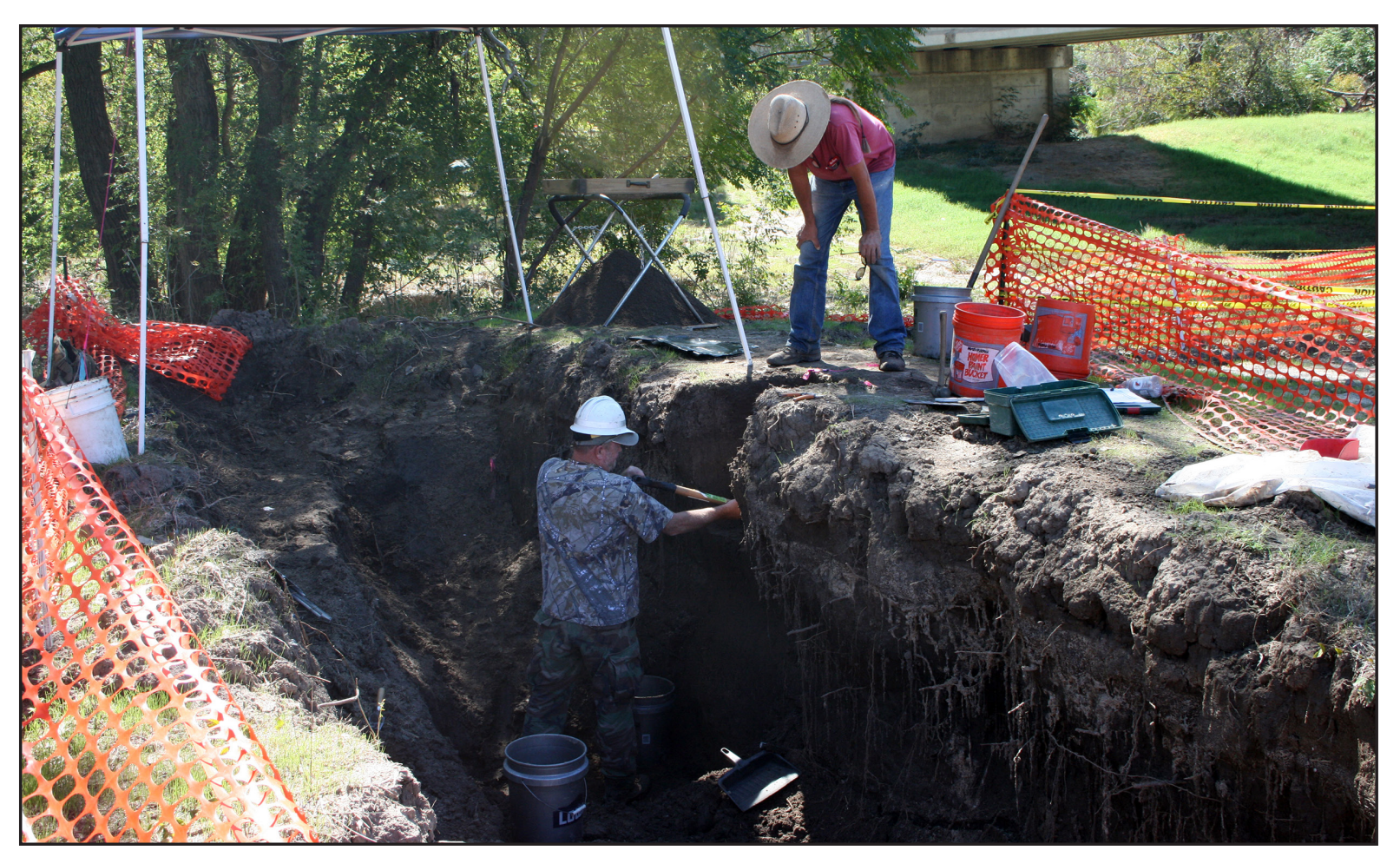

Figure 7-29. Photograph of Bo Nelson excavating WC 1 adjacent to the west wall of BT4/19 while Richard Walter assists from above. Note the collapsed and damaged walls of
heavy rains on October 7 and 8 . View to the southwest. 10/14/11.

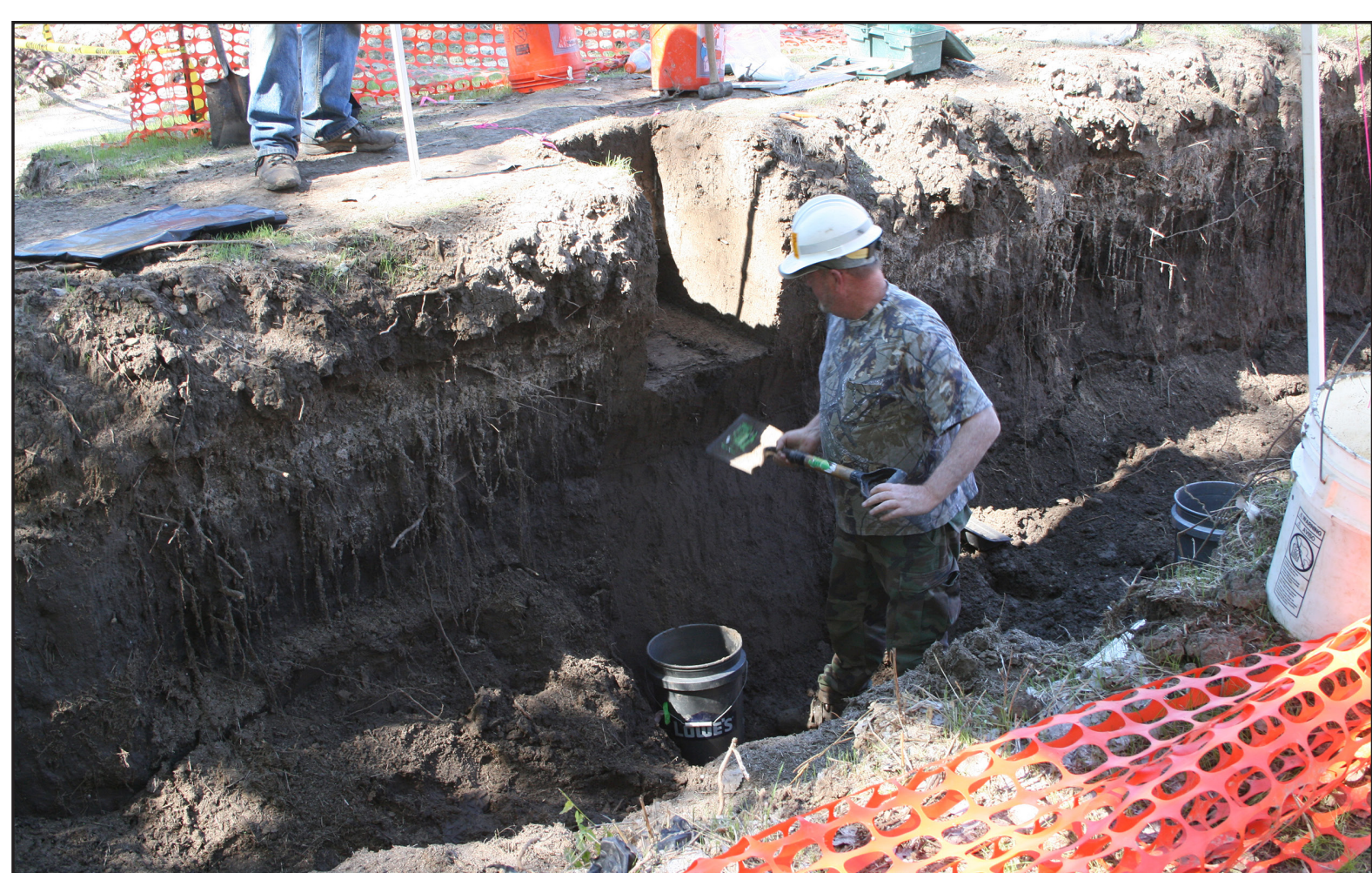

Figure 7-30. Photograph of Bo Nelson shovel skimming the Ford alluvium during the excavation of WC along the west wall of BT $4 / 19$. The excavator is just about on top of the A horizon, at which pare to the pre-inundation photographs in Figures 6-29 through 6-32. View to the northwest. pare to the 1014111

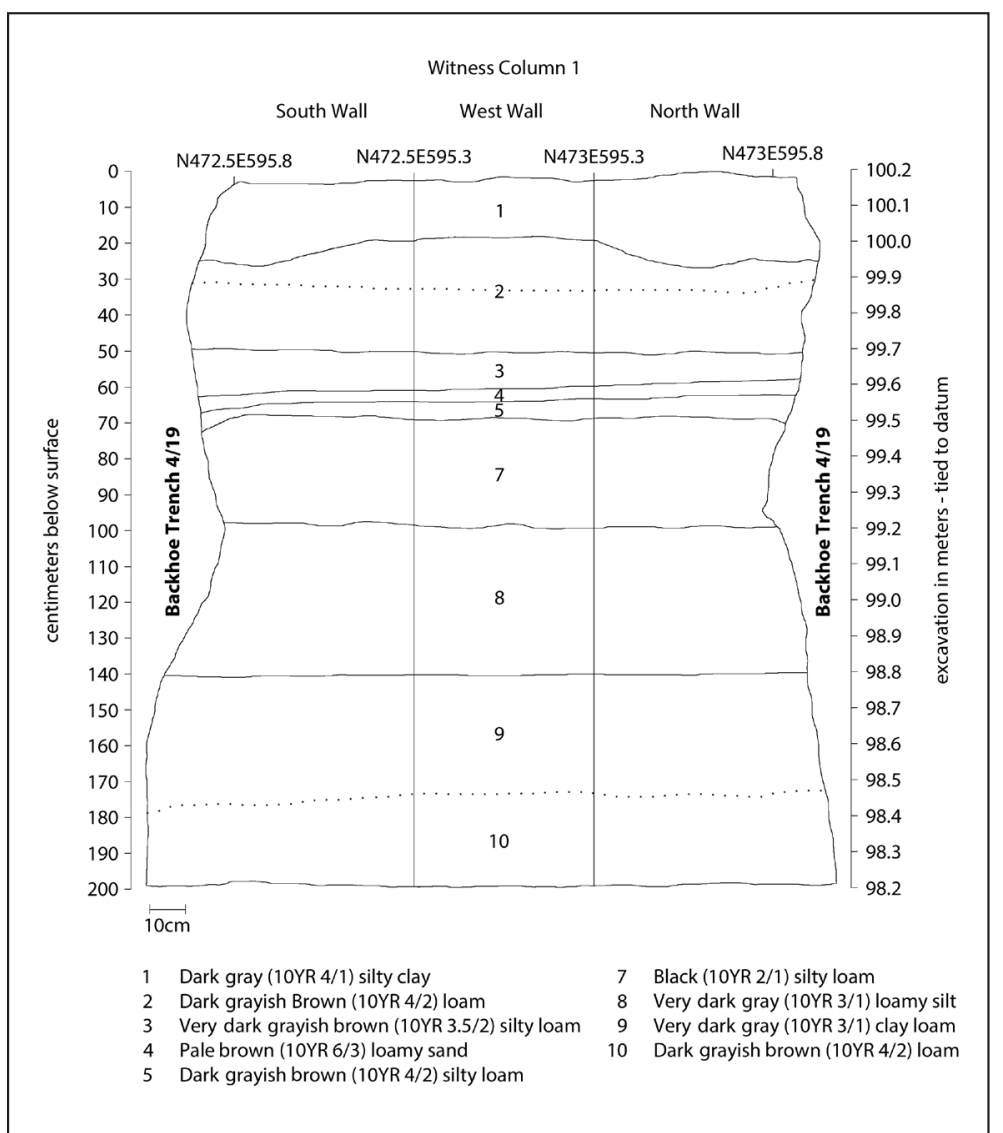

Figure 7-31. Profile drawing of the three walls of WC 1 . Stratum 7 contained the Toyah occupation.

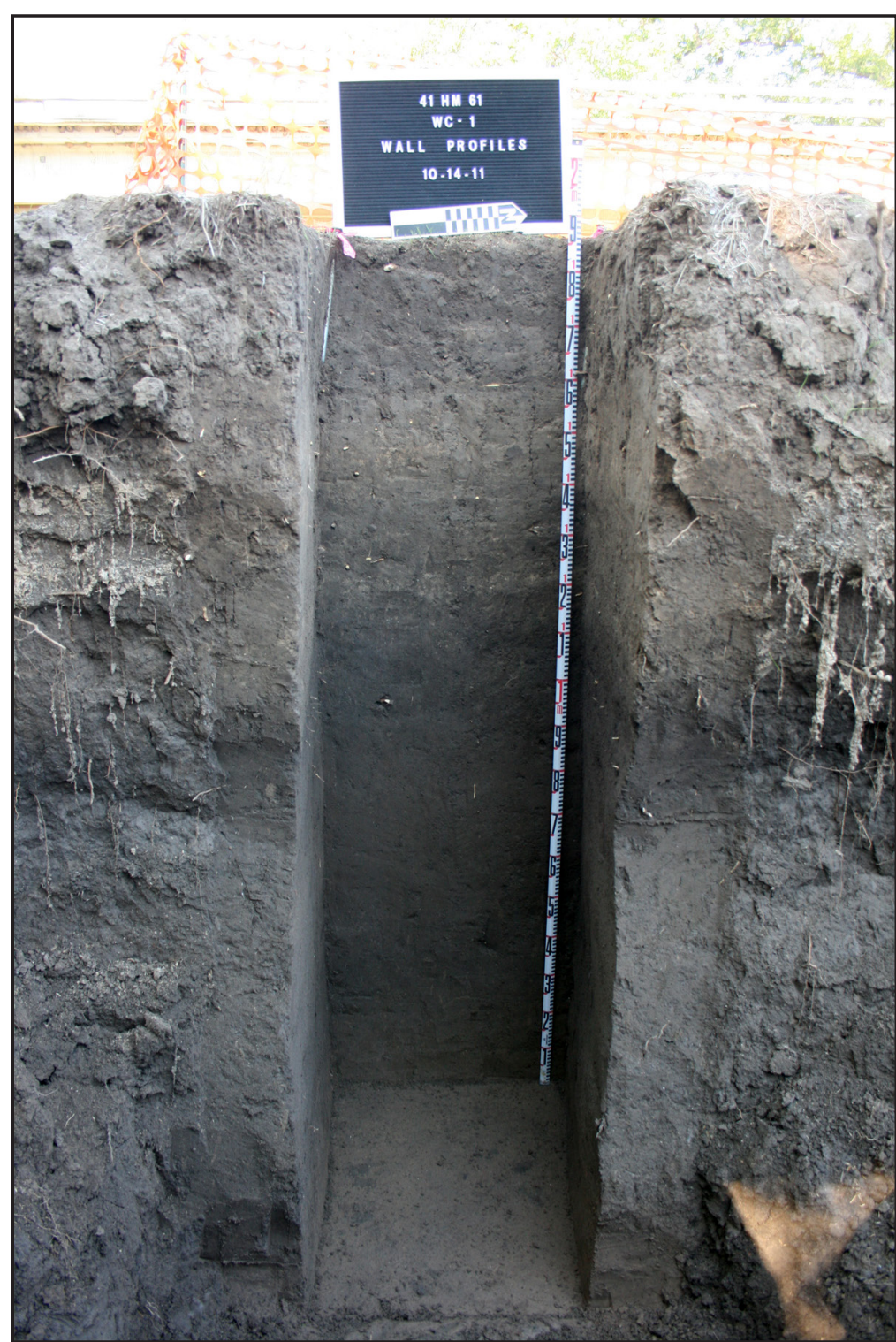

Figure 7-32. Photograph of the west wall profile of completed WC ing the Toyah occupation surface is clearly visible. 



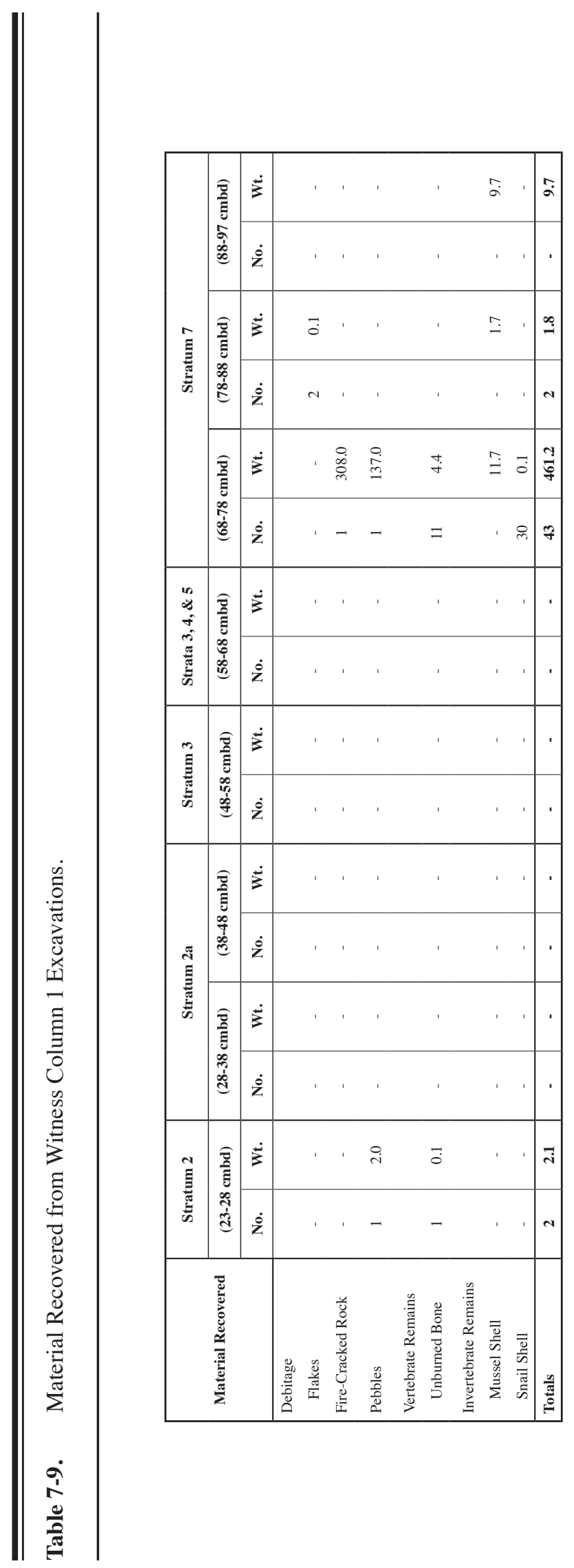

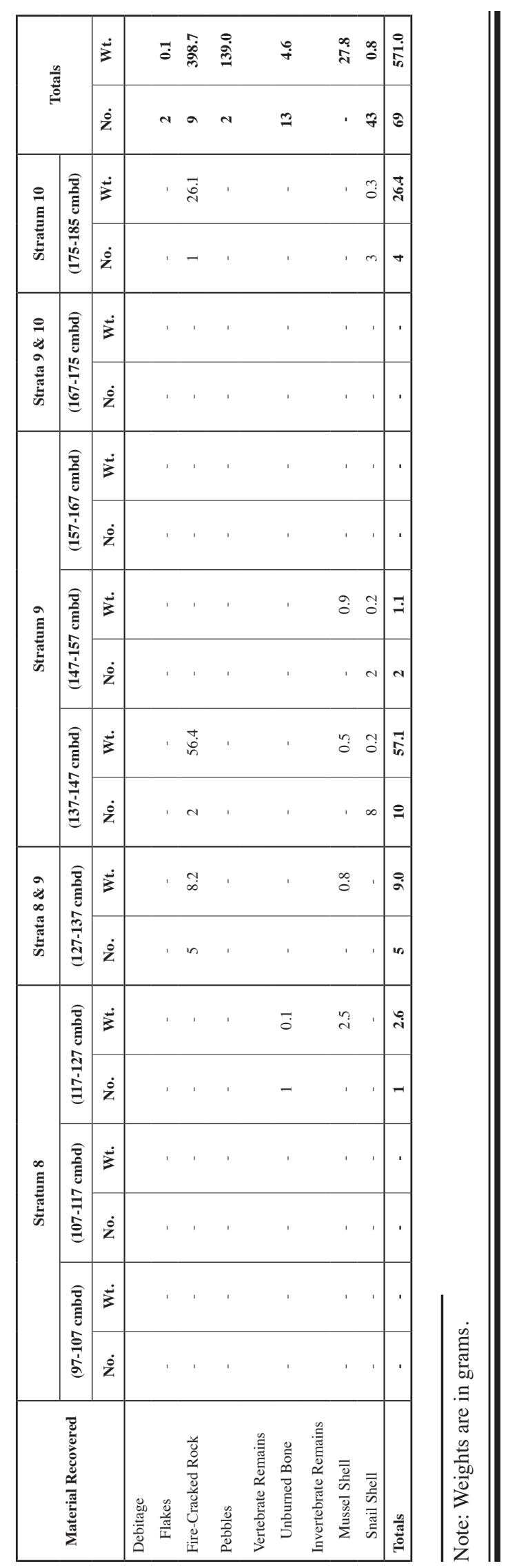


Table 7-10. Witness Column 1: Excavated Strata and Levels and Corresponding Natural Strata as Identified on Wall Profiles.

\begin{tabular}{|c|c|}
\hline $\begin{array}{c}\text { Excavated Strata } \\
\text { and Levels } \\
\text { (Depth Below WC Datum) }\end{array}$ & $\begin{array}{c}\text { Natural Strata on } \\
\text { Wall Profiles } \\
\text { (Elevation Based on Site Datum) }\end{array}$ \\
\hline $\begin{array}{c}\text { Stratum } 1, \text { Level A } \\
(0-23 \mathrm{~cm}) \\
\text { (Shoveled out }- \text { no material } \\
\text { saved or screened) }\end{array}$ & $\begin{array}{c}\text { Strata1 \& } 2 \\
\text { (Disturbed Ford Alluvium } \\
\text { \& Ford Alluvium) } \\
(100.17 \text { to } 99.94 \mathrm{~m})\end{array}$ \\
\hline $\begin{array}{l}\text { Stratum 2, Level A } \\
\quad(23-28 \mathrm{~cm})\end{array}$ & $\begin{array}{c}\text { Stratum } 2 \\
\text { (Ford Alluvium) } \\
(99.94 \text { to } 99.89 \mathrm{~m})\end{array}$ \\
\hline $\begin{array}{l}\text { Stratum 2, Level B } \\
\quad(28-38 \mathrm{~cm})\end{array}$ & $\begin{array}{c}\text { Stratum 2a } \\
\text { (Ford Alluvium) } \\
\text { (99.89 to } 99.79 \mathrm{~m})\end{array}$ \\
\hline $\begin{array}{l}\text { Stratum 3, Level A } \\
\quad(38-48 \mathrm{~cm})\end{array}$ & $\begin{array}{c}\text { Stratum 2a } \\
\text { (Ford Alluvium) } \\
(99.79 \text { to } 99.69 \mathrm{~m})\end{array}$ \\
\hline $\begin{array}{l}\text { Stratum 3, Level B } \\
\quad(48-58 \mathrm{~cm})\end{array}$ & $\begin{array}{c}\text { Stratum } 3 \\
\text { (Ford Alluvium) } \\
\text { (99.69 to } 99.59 \mathrm{~m})\end{array}$ \\
\hline $\begin{array}{l}\text { Stratum 3, Level C } \\
\quad(58-68 \mathrm{~cm})\end{array}$ & $\begin{array}{c}\text { Strata } 3,4, \& 5 \\
\text { (Ford Alluvium) } \\
\text { (99.59 to } 99.49 \mathrm{~m})\end{array}$ \\
\hline $\begin{array}{l}\text { Stratum 4, Level A } \\
\quad(68-78 \mathrm{~cm})\end{array}$ & $\begin{array}{c}\text { Stratum } 7 \\
\text { (A Horizon, West Range Alluvium) } \\
(99.49 \text { to } 99.39 \mathrm{~m})\end{array}$ \\
\hline $\begin{array}{l}\text { Stratum 4, Level B } \\
\quad(78-88 \mathrm{~cm})\end{array}$ & $\begin{array}{c}\text { Stratum } 7 \\
\text { (A Horizon, West Range Alluvium) } \\
(99.39 \text { to } 99.29 \mathrm{~m})\end{array}$ \\
\hline $\begin{array}{l}\text { Stratum 4, Level C } \\
\quad(88-97 \mathrm{~cm})\end{array}$ & $\begin{array}{c}\text { Stratum } 7 \\
\text { (A Horizon, West Range Alluvium) } \\
(99.29 \text { to } 99.20 \mathrm{~m})\end{array}$ \\
\hline $\begin{array}{l}\text { Stratum 5, Level A } \\
\quad(97-107 \mathrm{~cm})\end{array}$ & $\begin{array}{c}\text { Stratum } 8 \\
\text { (West Range Alluvium) } \\
(99.20 \text { to } 99.10 \mathrm{~m})\end{array}$ \\
\hline $\begin{array}{l}\text { Stratum 5, Level B } \\
\quad(107-117 \mathrm{~cm})\end{array}$ & $\begin{array}{c}\text { Stratum } 8 \\
\text { (West Range Alluvium) } \\
(99.10 \text { to } 99.00 \mathrm{~m})\end{array}$ \\
\hline $\begin{array}{l}\text { Stratum 5, Level C } \\
\quad(117-127 \mathrm{~cm})\end{array}$ & $\begin{array}{c}\text { Stratum } 8 \\
\text { (West Range Alluvium) } \\
(99.00 \text { to } 98.90 \mathrm{~m})\end{array}$ \\
\hline $\begin{array}{l}\text { Stratum 5, Level D } \\
\quad(127-137 \mathrm{~cm})\end{array}$ & $\begin{array}{c}\text { Strata } 8 \text { \& } 9 \\
\text { (West Range Alluvium) } \\
(98.90 \text { to } 98.80 \mathrm{~m})\end{array}$ \\
\hline $\begin{array}{l}\text { Stratum 5, Level E } \\
\quad(137-147 \mathrm{~cm})\end{array}$ & $\begin{array}{c}\text { Stratum } 9 \\
\text { (West Range Alluvium) } \\
(98.80 \text { to } 98.70 \mathrm{~m})\end{array}$ \\
\hline $\begin{array}{l}\text { Stratum 5, Level F } \\
\quad(147-157 \mathrm{~cm})\end{array}$ & $\begin{array}{c}\text { Stratum } 9 \\
\text { (West Range Alluvium) } \\
(98.70 \text { to } 98.60 \mathrm{~m})\end{array}$ \\
\hline $\begin{array}{l}\text { Stratum 5, Level G } \\
\quad(157-167 \mathrm{~cm})\end{array}$ & $\begin{array}{c}\text { Stratum } 9 \\
\text { (West Range Alluvium) } \\
(98.60 \text { to } 98.50 \mathrm{~m})\end{array}$ \\
\hline $\begin{array}{l}\text { Stratum 5, Level H } \\
\quad(167-175 \mathrm{~cm})\end{array}$ & $\begin{array}{c}\text { Strata } 9 \& 10 \\
\text { (West Range Alluvium) } \\
(98.50 \text { to } 98.42 \mathrm{~m})\end{array}$ \\
\hline $\begin{array}{l}\text { Stratum 6, Level A } \\
\quad(175-185 \mathrm{~cm})\end{array}$ & $\begin{array}{c}\text { Stratum } 10 \\
\text { (West Range Alluvium) } \\
(98.42 \text { to } 98.32 \mathrm{~m})\end{array}$ \\
\hline
\end{tabular}

Note: Depths based on elevations of the SW corner of the witness column, which served as the column's datum during excavation. 
ta boundaries. In those instances where strata boundaries were missed (i.e., the 58-to-68-cm level, which took out the bottom of Stratum 3 and all of Strata 4 and 5; the 127-to-137-cm level, which removed the lower part of Stratum 8 and the upper part of Stratum 9; and the 167-to- $175 \mathrm{~cm}$ level, which took out the bottom of Stratum 9 and the upper few centimeters of Stratum 10), the general lack of cultural remains within those levels renders such strata-recognition failures as relatively benign. Nevertheless, it is interesting to note that the levels between -117 and $-167 \mathrm{~cm}$ (within the lower portion of Stratum 8 and almost all of Stratum 9) produced minor amounts of mussel shell, snails, and a few pieces of fire-cracked rock. None of the levels that removed the upper part of Stratum 8 or all of Stratum 10 produced any similar material. Thus, it is possible that several very superficial occupations, potentially dating to the Archaic, occurred during the time when the alluvium that forms Strata 8 and 9 was being deposited.

Regardless of the above, it is the Toyah zone of Stratum 7 that produced the greatest amount of cultural material. As can be seen in Table 7-9, the stratum yielded several pieces of fire-cracked rock, mussel shells, charcoal, vertebrate faunal remains, and a smoothed stone. Importantly, the majority of these items came from the first $10-\mathrm{cm}$ cut the into the stratum (the 68-to-78-cm level), suggesting that a probable Toyah living surface was present within the uppermost part of the A horizon.

\section{Witness Column 6}

This WC was placed along the south edge of the western part of BT 20 (see Figure 7-28), above a prominent area of charcoal, ash, and burned earth present within the "deep Toyah" deposit exposed in the wall of that trench (Figures 7-33 and 7-34; see Figure 6-33). As reviewed previously under the section describing the trench excavations, WC 6 was designed to investigate the "deep Toyah" zone and to help determine if it was an in situ occupation surface or displaced material that had either washed or slumped down the bank of the Leon River or been thrown over the bank by residents residing in the area of $\mathrm{WC} 1$.

WC 6 differed from the other WCs in several respects. First, since the top of the deep Toyah zone was at a depth of ca. $1.4 \mathrm{~m}$ below ground surface, it was decided to simply shovel out and discard the upper portion of the WC down to near the top of the Toyah. Second, the excessive depth of the Toyah also necessitated a column size that was larger than usual for ease in excavation. Accordingly, WC 6 was dug as a pseudo 1-by-1-m unit that measured $100 \mathrm{~cm}$ east-west by between 85 and $100 \mathrm{~cm}$ north-south. The WC's northeast corner (located at N599.9E582) served as the column's specific datum, and it was from this point that a line level was attached to measure depth during excavation. The WC was dug to $-2.17 \mathrm{~m}$ in its northeast corner, but, because of the dramatic downward slope of the various strata encountered, it went to a depth of -2.52 in its southwest corner.

Figures 7-35 and 7-36 illustrate the three walls of WC 6, while Table 7-11 lists artifacts and other cultural items recovered from the WC as either field specimens or material captured in the 1/4-inch screen. As can be seen, eleven separate strata were recognized on the wall profiles, and these match the same eleven strata seen along the north wall of BT 20 (see Figure 6-33). Table 7-12 provides details on the relationship between the excavated strata and levels and the actual strata revealed on the profiles. It also indicates which strata were shoveled out and discarded vs. those that were carefully excavated and screened. In addition, the reader should note that the terminology utilized for the excavated strata (shown in the left-hand column on the table) differed from that employed in previous witness columns. This occurred because it was uncertain at the time of excavation if the strata uncovered in the witness column could be accurately tied to the strata revealed on the opposite wall of BT 20. Until such a relationship could be confirmed, it was decided to simply refer to all levels associated with (or possibly associated with) the Toyah zone as having come from the "Toyah" stratum. Likewise, the few remaining centimeters of the overlying non-cultural Ford alluvium (Stratum 6), removed by the 135-to-143-cm cut, was identified simply as "Ford Alluvium." Importantly, however, when the column's excavator recognized a potential stratum change, level designations were changed (as opposed to changing strata designations as in all previous WCs). Thus, for all intents and purposes, natural strata still were employed during the excavation of WC 6.

As seen in Table 7-12, the column's excavator generally was able to correctly identify the break between the Ford alluvium (Stratum 6) and the upper part of the Toyah zone (Stratum 7). After the upper 10 to $20 \mathrm{~cm}$ of the Toyah was removed, however, it became clear that the zone actually consisted of several distinct layers that differed slightly from each other by either color, material content, or both. Thus, Stratum 7 was recognized as a dark grayish brown (10YR 4/2) silty loam that contained one flake and two pieces of 
bone. It was removed by all of the $143-$ to- $153-\mathrm{cm}$ level and part of the 153-to-157-cm cut. Stratum 8 was recognized as a brown (10YR 4/3) silty loam that was only 4 to $6 \mathrm{~cm}$ in thickness. Although the 153 -to$157-\mathrm{cm}$ level was designed to only remove Stratum 8, comparison of the beginning depths for the level with the completed WC's wall profiles showed that the cut took out the lower few centimeters of Stratum 7 along with all of Stratum 8. No cultural remains were noted during excavation of the level, so it is likely that the mussel shell listed in Table 7-11 as having come from the 153-to-157-cm level actually originated in the lower part of Stratum 7.

The break between Strata 8 and 9 was accurately detected during excavation, with the result that the next level $(157-163 \mathrm{~cm})$ was confined entirely to Stratum 9. This stratum consisted of a very dark grayish brown (10YR 3/2) silty loam and included a significant amount of charcoal flecks, several bone fragments, and one relatively large area of ash, concentrated charcoal, and burned soil that was recognized as Feature 30 (Figure 7-37). The feature was located in the northeastern quadrant of the column and measured roughly 70 by $50 \mathrm{~cm}$ in size, by 2 to $3 \mathrm{~cm}$ in thickness. Several additional fragments of bone were found within it. At first, it was thought that the feature represented an in situ hearth, but subsequent examination showed that the burned soil was not in place. Instead, it appeared to represent a secondary deposit of hearth debris that had originated elsewhere.

Located only a few centimeters beneath Stratum 9 and F. 30 was a relatively thick layer of Toyahrelated material that was identified as Stratum 10. It consisted of a dark grayish brown (10YR 4/2) silt loam that was anywhere from 30 to $50 \mathrm{~cm}$ thick (see Figure 7-35). It was removed by the lower part of the 163-to-177-cm level, all of the 177-to-187and 187-to-197-cm levels, and the upper part of the 197-to-207-cm level (see Table 7-11). In addition to a general column-wide scatter of charcoal flecks and pieces of fired earth, Stratum 10 also yielded another concentration of ash, charcoal, and burned soil within its upper $20 \mathrm{~cm}$ or so, and this concentration was identified as Feature 31. F. 31 extended across the entire column in a north-south direction and was anywhere between 10 and $70 \mathrm{~cm}$ wide in an east-west direction (Figures 7-38 and 7-39). As can be seen on the column's profiles (see Figure 7-35), the feature was between 8 and $12 \mathrm{~cm}$ thick. Although no field specimens were found associated with the feature, several samples of charcoal and fired earth were collected. As with all other excavated features, a general soil sample was collected for flotation processing. Like Feature 30, F. 31 was thought originally to potentially represent the remains of an in situ hearth. However, after careful examination, including a lack of evidence for in situ burning and its general amorphous shape, it too was considered to be nothing more than a secondary deposit of hearth remains.

Stratum 10 continued to produce scattered pieces of charcoal, bone, and shell down to its contact with Stratum 11, the last stratum uncovered in WC 6. This latter stratum was represented by a brown (10YR 4/3) sandy silt that differed from most of the overlying "Toyah" strata by a general lack of cultural remains. In fact, although the final 207-to-217-cm level was designed to only remove Stratum 11, comparison of its depth measurements to the WC's wall profiles shows that it actually took out part of overlying Stratum 10 (see Figure 7-35). Thus it is possible that the one piece of bone plus the few pieces of charcoal and shell present within the level actually were associated with Stratum 10 and that Stratum 11 was culturally sterile.

Although neither F. 30 nor F. 31 was considered to be the result of an in situ hearth, it was decided to submit samples of several different types of material from the two features to Beta Analytic, Inc., and the Accelerator Mass Spectrometry (AMS) Laboratory at the University of California, Irvine, for ${ }^{14} \mathrm{C}$ dating. It was hoped that the resulting dates would allow for a determination of whether the "deep" Toyah material in WC 6 (and adjacent BT 21) was coeval with the Toyah horizon identified in BT 4/19 and WC 1 , or if it represented a different occupation. At that point in the fieldwork, it already had been decided to open up a block excavation into the area adjacent to WC 1 , so the ${ }^{14} \mathrm{C}$ samples from WC 6 eventually could be compared to similar samples obtained from that block.

Accordingly, two samples were submitted from F. 30-a bison rib bone and a piece of Pediomelum sp. tuber, the latter retrieved from the feature's flotation sample (see Chapters 10 and 12). The rib (UCIAMS-140841) returned a ${ }^{14} \mathrm{C}$ age of $335 \pm 20$ cal B.P., with a calibrated 2-sigma range of between 469 and 311 cal B.P. (ca. A.D. 1480 and 1640) at 95.4 percent probability. The Pediomelum tuber (Beta382996) produced a ${ }^{14} \mathrm{C}$ age of $290 \pm 30 \mathrm{cal} \mathrm{B}$.P., and a calibrated 2-sigma range of between 458 and 288 cal B.P. (ca. A.D. 1490 and 1660). Both dates are virtually identical and indicate that the refuse associated 


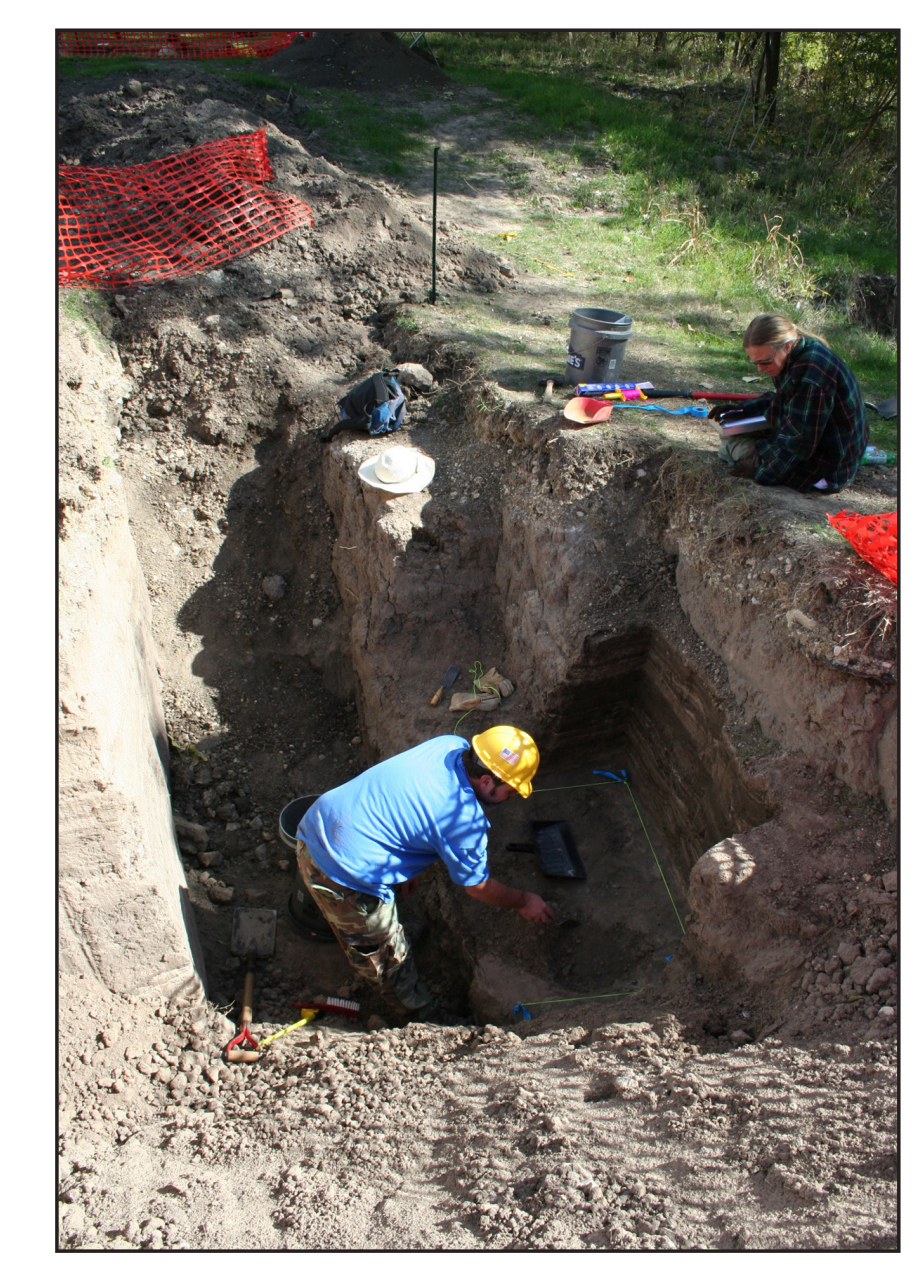

Figure 7-33. Photograph of Patrick Brogan beginning the excavation of WC 6 adjacent to the south
wall of BT 20 with Jennifer Kelly taking notes from above. At this point in the project, the east and west ends of BT 20 have been backfilled, leaving only a small window within which to excavate the witness col-
umn. View to the east-southeast. 11/11/11.

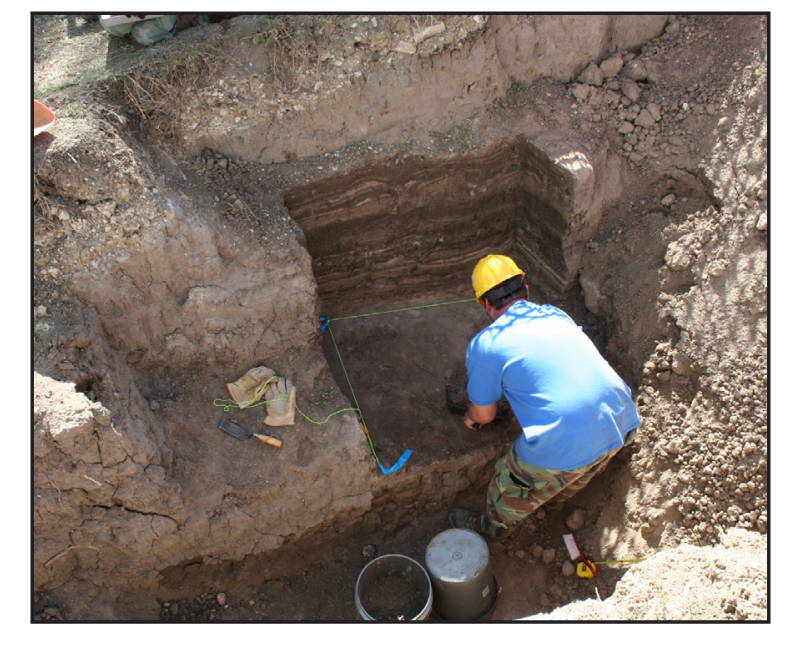

Figure 7-34. Photograph of Patrick Brogan continuing to excavate WC 6 . Note the
laminated nature of the overlying laminated nature of the overlying
Ford alluvium that was shoveled out prior to trowel excavation. The
string lines around the edges of the unit mark the point at which use
of the trowel began. View to the

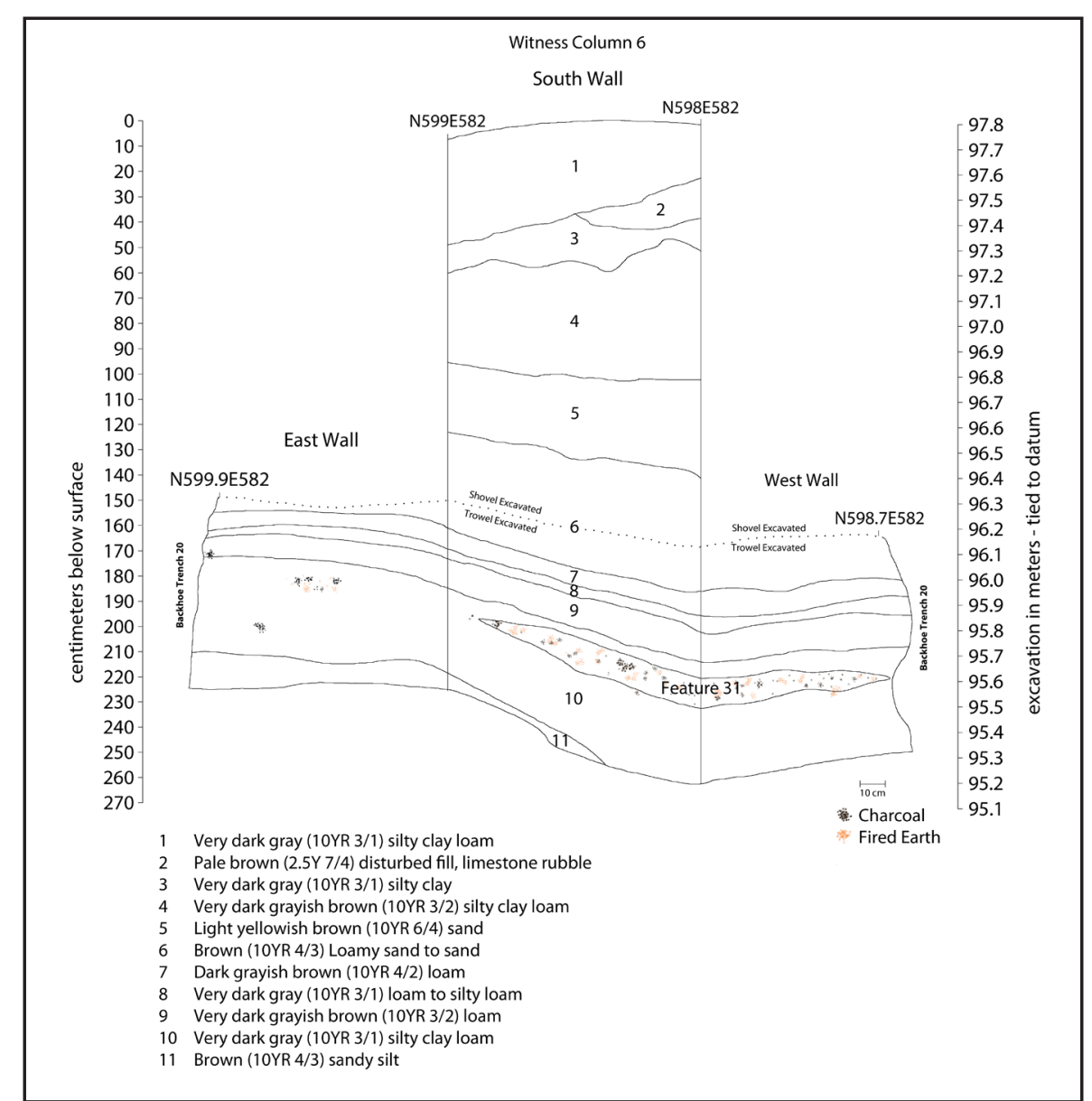

Figure 7-35. Profile drawing of the three walls of WC 6 . Note that only the south wall was completely drawn as the upper portions of the east and excavation of the column

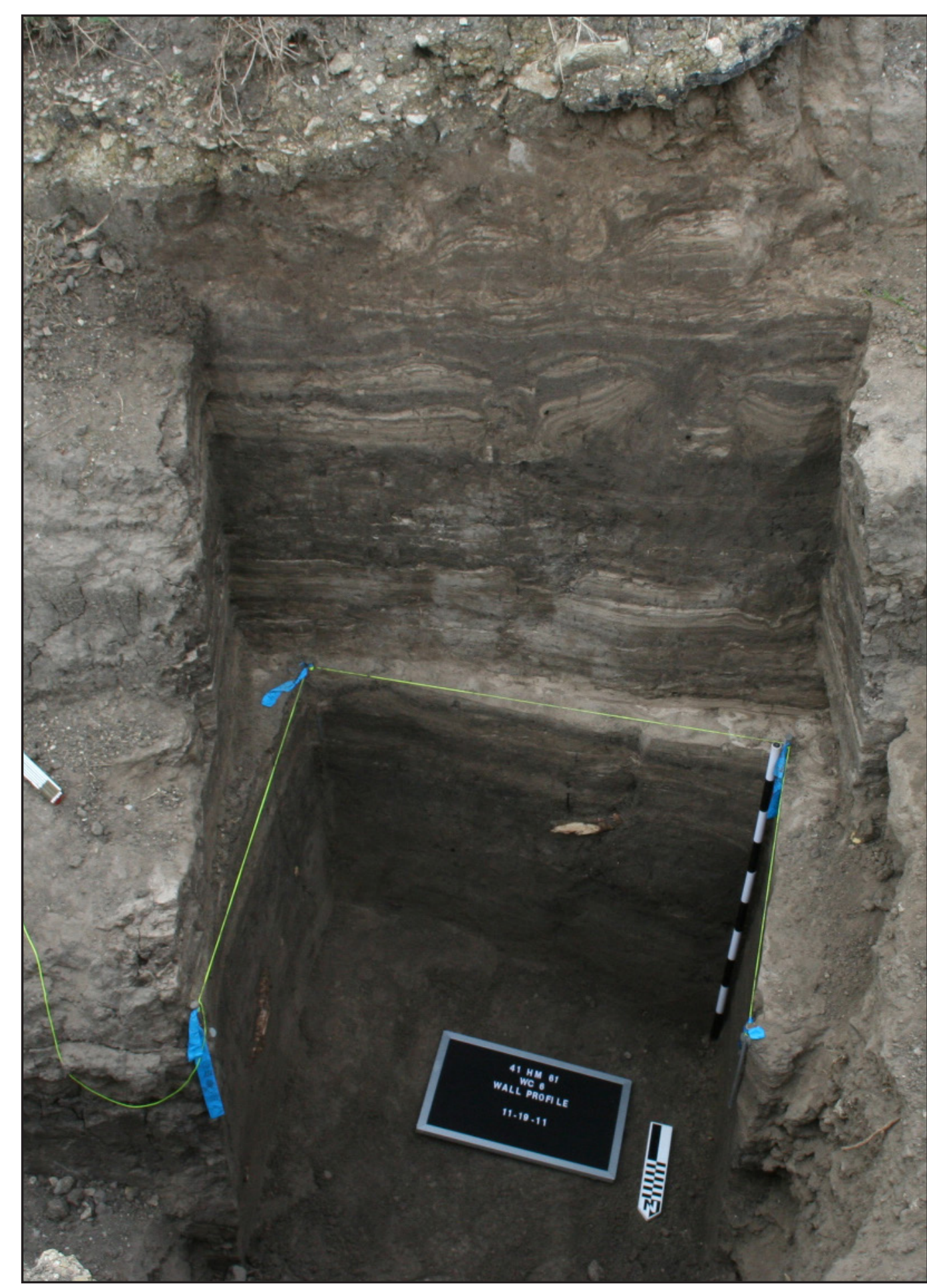

Figure 7-36. Photograph of the south wall profile of completed WC 6. The "Toyah" zone is the south-southeast 11/19/11. 



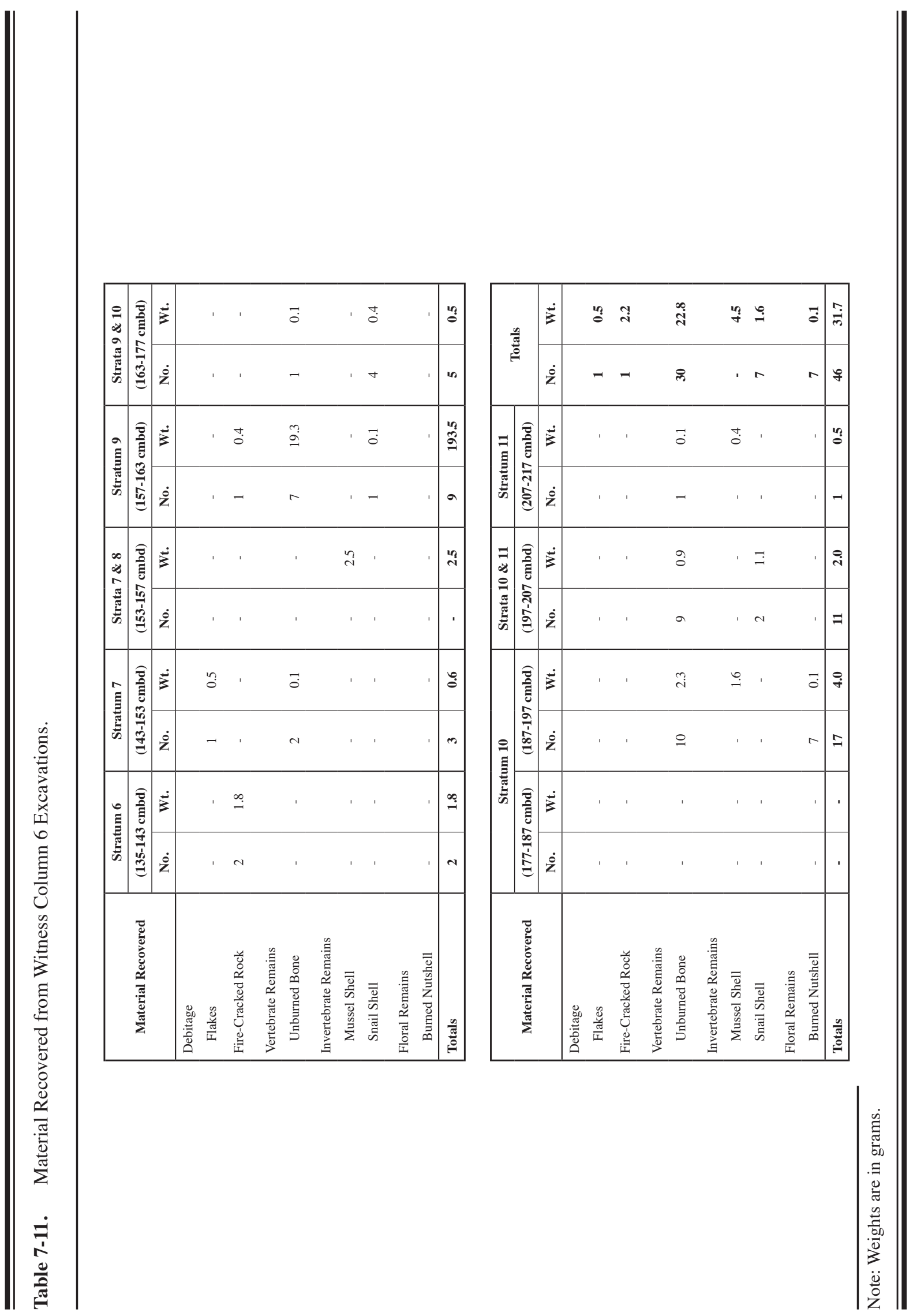


Table 7-12. Witness Column 6: Excavated Strata and Levels and Corresponding Natural Strata as Identified on Wall Profiles.

\begin{tabular}{|c|c|}
\hline $\begin{array}{c}\text { Excavated Strata } \\
\text { and Levels } \\
\text { (Depth Below WC Datum) }\end{array}$ & $\begin{array}{c}\text { Natural Strata on } \\
\text { Wall Profiles } \\
\text { (Elevation Based on Site Datum) }\end{array}$ \\
\hline $\begin{array}{c}\text { Overburden } \\
(0-135 \mathrm{~cm}) \\
\text { (Shoveled out }- \text { no material } \\
\text { saved or screened) }\end{array}$ & $\begin{array}{c}\text { Strata } 1 \text { to } 6 \\
\text { (Disturbed \& Ford Alluvium) } \\
(99.34 \text { to } 97.99 \mathrm{~m})\end{array}$ \\
\hline $\begin{array}{c}\text { Ford Alluvium } \\
(135-143 \mathrm{~cm}) \\
\text { (ca. 3/4 shoveled out, not } \\
\text { screened; ca. } 1 / 4 \text { screened) }\end{array}$ & $\begin{array}{c}\text { Stratum 6 } \\
\text { (Ford Alluvium) } \\
(97.99 \text { to } 97.91 \mathrm{~m})\end{array}$ \\
\hline $\begin{array}{l}\text { Toyah, Level A } \\
(143-153 \mathrm{~cm})\end{array}$ & $\begin{array}{c}\text { Stratum } 7 \\
\text { (A Horizon, Ford Alluvium) } \\
(97.91 \text { to } 97.81 \mathrm{~m})\end{array}$ \\
\hline $\begin{array}{l}\text { Toyah, Level B } \\
(153-157 \mathrm{~cm})\end{array}$ & $\begin{array}{c}\text { Strata } 7 \& 8 \\
\text { (A Horizon, Ford Alluvium) } \\
(97.81 \text { to } 97.77 \mathrm{~m})\end{array}$ \\
\hline $\begin{array}{l}\text { Toyah, Level C } \\
\text { (Includes F. 30) } \\
(157-163 \mathrm{~cm})\end{array}$ & $\begin{array}{c}\text { Stratum } 9 \\
\text { (Includes F. 30) } \\
\text { (A Horizon, Ford Alluvium) } \\
\text { (97.77 to } 97.71 \mathrm{~m} \text { ) }\end{array}$ \\
\hline $\begin{array}{l}\text { Toyah, Level D } \\
\text { (Includes upper F. 31) } \\
\quad(163-177 \mathrm{~cm})\end{array}$ & $\begin{array}{c}\text { Strata } 9 \& 10 \\
\text { (Includes upper F. 31) } \\
\text { (A Horizon, Ford Alluvium) } \\
(97.71 \text { to } 97.57 \mathrm{~m})\end{array}$ \\
\hline $\begin{array}{c}\text { Toyah, Level E } \\
\text { (Includes lower F. 31) } \\
\quad(177-187 \mathrm{~cm})\end{array}$ & $\begin{array}{c}\text { Stratum } 10 \\
\text { (Includes lower F. 31) } \\
\text { (A Horizon, Ford Alluvium) } \\
(97.57 \text { to } 97.47 \mathrm{~m})\end{array}$ \\
\hline $\begin{array}{l}\text { Toyah, Level F } \\
(187-197 \mathrm{~cm})\end{array}$ & $\begin{array}{c}\text { Stratum } 10 \\
\text { (A Horizon, Ford Alluvium) } \\
(97.47 \text { to } 97.37 \mathrm{~m})\end{array}$ \\
\hline $\begin{array}{l}\text { Toyah, Level G } \\
(197-207 \mathrm{~cm})\end{array}$ & $\begin{array}{c}\text { Strata } 10 \& 11 \\
\text { (A Horizon, Ford Alluvium } \\
\text { \& Ford Alluvium) } \\
(97.37 \text { to } 97.27 \mathrm{~m})\end{array}$ \\
\hline $\begin{array}{l}\text { Toyah, Level H } \\
(207-217 \mathrm{~cm})\end{array}$ & $\begin{array}{c}\text { Stratum } 11 \\
\text { (Ford Alluvium) } \\
\text { (97.27 to } 97.17 \mathrm{~m} \text { ) }\end{array}$ \\
\hline
\end{tabular}

Note: Depths based on elevations of the NE corner of the witness column, which served as the column's datum during excavation.

with F. 30 had been created sometime between the late 1400 s and the mid 1600 s.

Two samples were submitted for dating from underlying F. 31-charcoal pieces and a (Zea mays) corn kernel, the latter found within the feature's flotation sample (see Chapters 10 and 12). The charcoal sample (Beta-315693) yielded a ${ }^{14} \mathrm{C}$ age of
$380 \pm 30 \mathrm{cal}$ B.P. and a calibrated 2-sigma range of between 505 and 318 cal B.P. (ca. A.D. 1445 and 1630). The corn kernel (Beta-382997) produced a ${ }^{14} \mathrm{C}$ age of $300 \pm 30$ cal B.P. with calibrated a 2 -sigma range of between 458 and $288 \mathrm{cal} \mathrm{B.P.} \mathrm{(ca.} \mathrm{A.D.}$ 1490 and 1660). Again, these dates suggest deposition of the remains found in F. 31 sometime during the late 1400 s to the mid 1600 s. 

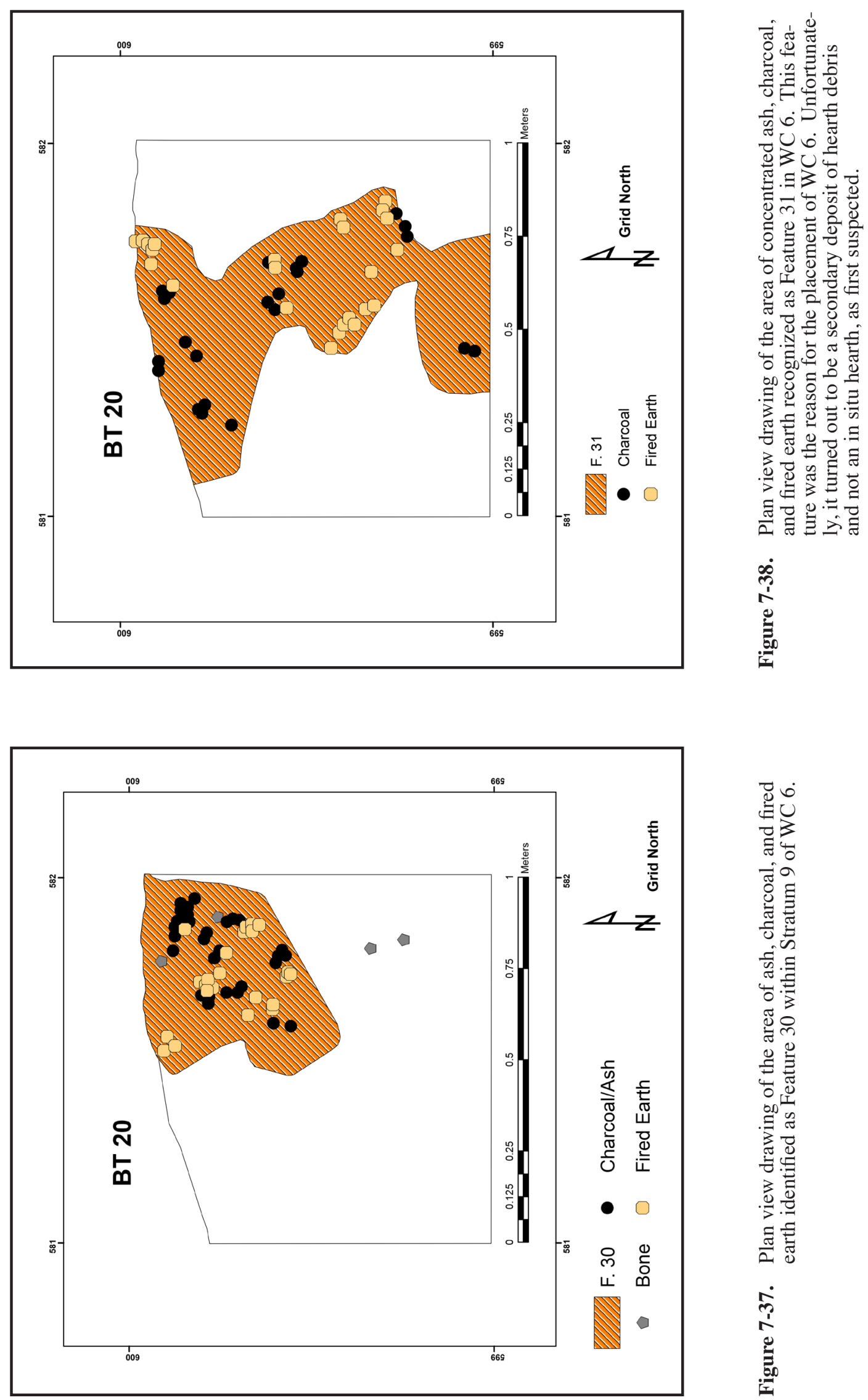

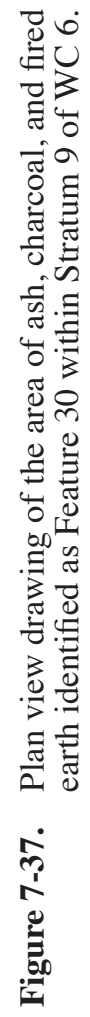




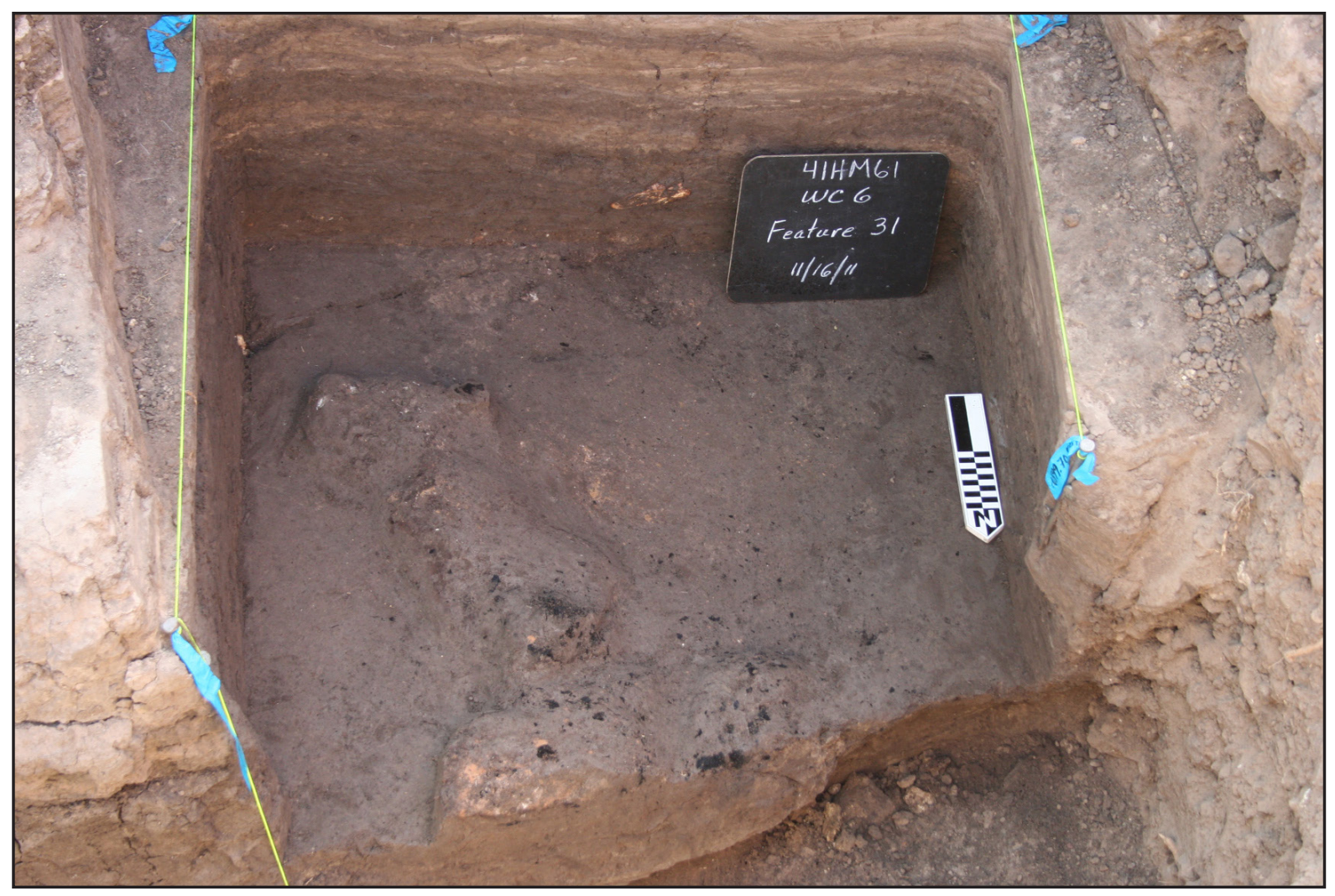

Figure 7-39. Photograph of the top of Feature 31 within Stratum 10 of the "Toyah" zone in WC 6. Note the pieces of fired earth and charcoal visible throughout the feature. View to the south. 11/16/11.

\section{Summary of Witness Columns}

Hand excavation of the six witness columns resulted in the removal of $4.92 \mathrm{~m}^{3}$ of soil. The columns also uncovered several distinct prehistoric components and associated features consisting of either clusters of freshwater mussel shells, burned rocks, or redeposited hearth refuse. Table 7-13 provides a list of the six WCs along with the quantity of hand-excavated soil removed from each, principal components uncovered, and features represented.

The only definite component uncovered in the northern part of the site was related to a "Toyah-like" occupation of Late Prehistoric period, or Temporal Interval $\mathrm{K}$ in the Fort Hood sequence. Although scattered fire-cracked rocks and mussel shells were uncovered within the West Range alluvium beneath the Toyah zone in WC 1, no diagnostic artifacts were recovered and the age of those items is unknown. Radiocarbon dates from Features 30 and 31 within WC 6 suggest that the Toyah occupation likely dates to sometime between the late A.D. 1400s and mid 1600s.
The south side of the site was completely different and significantly more complicated. There, a prominent and moderately thick A horizon was present atop the Upper West Range alluvium across all areas examined by CEI's trenches and the WCs. It contained a minor to moderate amount of cultural material, including clusters of fire-cracked rocks, mussel shells, scattered bone fragments, and lithic debitage. Importantly, several Marcos and Ensor dart points were found associated with the A horizon, with the Marcos points apparently located within the lower portion of the horizon and the Ensor points within the middle portion. Radiocarbon dates on the potential Ensor occupation from F. 21 in WC 4 and the "living surface" in WC 5 suggest an occupation range between ca. 1,600 and 2,000 years ago (between ca. A.D. 50 and 400). Although no diagnostic points were found in the upper part of the A horizon, $\mathrm{a}^{14} \mathrm{C}$ date on mussel shells from F. 16 yielded an age equivalent to the Late Archaic 4 period of the Lohse et al. (2014a) culture sequence for central Texas. When potentially corrected for the local reservoir effect, it can be suggested that this occupation occurred between ca. A.D. 
Table 7-13. Witness Columns Excavated at Site 41HM61, Including Column Size, Quantity of Hand-Excavated Soil, Features, and Principal Components Present.

\begin{tabular}{|c|c|c|c|}
\hline $\begin{array}{l}\text { Witness } \\
\text { Column }\end{array}$ & $\begin{array}{l}\text { Size of Column (Quantity } \\
\text { of Hand-Excavated Soil) }\end{array}$ & $\begin{array}{c}\text { Aboriginal } \\
\text { Features Present }\end{array}$ & $\begin{array}{c}\text { Principal } \\
\text { Components Present }\end{array}$ \\
\hline WC 1 & $\begin{array}{c}0.5 \text { by } 0.6 \text { by } 2 \mathrm{~m} \\
\left(0.6 \mathrm{~m}^{3}\right)\end{array}$ & None & $\begin{array}{l}\text { Late Prehistoric } \\
\text { (“Toyah-like”), } \\
\text { Temporal Interval K }\end{array}$ \\
\hline WC 2 & $\begin{array}{c}0.5 \text { by } 0.65 \text { by } 1.7 \mathrm{~m} \\
\left(0.55 \mathrm{~m}^{3}\right)\end{array}$ & F. 16 - Mussel shell concentration & $\begin{array}{l}\text { Late Archaic 4, } \\
\text { Temporal Interval I }\end{array}$ \\
\hline WC 3 & $\begin{array}{c}0.5 \text { by } 0.9 \text { by } 1.43 \mathrm{~m} \\
\left(0.64 \mathrm{~m}^{3}\right)\end{array}$ & $\begin{array}{l}\text { F. } 19 \text { - Mussel shell concentration } \\
\text { F. } 20 \text { - Burned-rock cluster }\end{array}$ & $\begin{array}{l}\text { Late Archaic 2, } \\
\text { Temporal Interval H }\end{array}$ \\
\hline WC 4 & $\begin{array}{c}0.5 \text { by } 0.65 \text { by } 1.7 \mathrm{~m} \\
\left(0.46 \mathrm{~m}^{3}\right)\end{array}$ & F. 21 - Burned-rock cluster & $\begin{array}{c}\text { Late Archaic 3, } \\
\text { Temporal Interval I } \\
\text { Temporal Interval H }\end{array}$ \\
\hline WC 5 & $\begin{array}{l}0.5 \text { by } 0.6 \text { by } 1.4 \mathrm{~m} \\
\left(0.42 \mathrm{~m}^{3}\right)\end{array}$ & $\begin{array}{l}\text { None, but several possible living } \\
\text { surfaces encountered }\end{array}$ & $\begin{array}{c}\text { Late Archaic 3, } \\
\text { Temporal Interval I } \\
\text { Temporal Interval H }\end{array}$ \\
\hline WC 6 & $\begin{array}{c}1.0 \text { by } 0.9 \text { by } 2.5 \mathrm{~m} \\
\left(2.25 \mathrm{~m}^{3}\right)\end{array}$ & $\begin{array}{l}\text { F. } 30-\text { Hearth refuse } \\
\text { F. } 31-\text { Hearth refuse }\end{array}$ & $\begin{array}{c}\text { Late Prehistoric (“Toyah- } \\
\text { like”), } \\
\text { Temporal Interval K }\end{array}$ \\
\hline
\end{tabular}

Note: Temporal Intervals after Collins et al. (2011).

890 and 1080. In one instance (in WC 5 and the along the adjacent walls of BT 11) several distinct living surfaces were present throughout the ca. 50 -cm thick A horizon, and each of these conceivably could relate to Late Archaic 2 (Marcos), Late Archaic 3 (Ensor), and Late Archaic 4 occupations.

Beneath the A horizon, the southern WCs uncovered a ca. 20- to 50-cm thick zone of lighter-colored West Range alluvium that included only minor amounts of mussel shell and burned rocks. No definitive occupation was noted within this zone. Below this lighter-colored soil was another A horizon that represents the top of the Lower West Range alluvium. Although not as dark in color or as easily recognizable as the A horizon associated with the Upper West Range alluvium, this lower A horizon included a modest amount of cultural material, including several intact features. Of particular note are the stratified concentrations of mussel shells (F. 19) and fire-cracked rocks (F. 20) that likely represent the remains of a Late Archaic earth oven. Although not associated with either F. 19 or F. 20, the Lange dart point probably is contemporary since it was found nearby at roughly the same depth in the wall of BT 15. Radiocarbon dates from F. 19 and F. 20 indicate that the earth oven was employed for cooking sometime between ca. 800 and 750 B.C., during the Late Archaic 2 period of the Lohse et al. (2014a) chronology or during Temporal Interval $\mathrm{H}$ of the Fort Hood chronology. In addition, at least one other shell concentration (F. 18) was exposed at a lower depth within the lower A horizon in the wall of BT 15 just north of WC 3 (see Figure 6-11). Given its stratigraphic position beneath both F. 19 and F. 20, it likely is associated with an earlier occupation.

With the knowledge gained from the backhoe trenches and witness columns, it became possible to select locations for the controlled excavation of several blocks of contiguous 1-by-1-m units. The blocks were designed to more thoroughly explore some of the features identified in the WCs and to open up areas where additional occupation surfaces and/or other features had been exposed in the walls of the BTs (particularly at the relatively deep F. 18 shell deposit). Overall, five block excavations were dug at the site. Their descriptions are provided in the following chapter. 


\title{
Chapter 8
}

\section{Block Excavations}

\author{
Richard A. Weinstein
}

Five block excavations were dug at site 41HM61, four on the south side of the channelized Leon River and one on the north side of the channel. As with the review of the witness columns, the four blocks located in the southern part of the site will be discussed first.

\section{South Section}

\section{Block 2}

Block 2 consisted of two contiguous 1-by-1-m units oriented in an east-west direction and positioned immediately north of WC 2 (Figures 8-1 and 8-2). ${ }^{1}$ The block was designed to more fully delineate the extent of the Feature 16 shell deposit uncovered within the upper portion of the Upper West Range alluvium's A horizon in WC 2. The two 1-by-1-m units comprising the block were identified by the grid coordinates of their northeast corners and consisted of Units N477E560 and N477E561. The northeast corner of Unit N477E561 served as the block's datum and it was from this point that a line level was attached to measure depth during excavation.

Figures 8-3, 8-4, and 8-5 illustrate the four walls of Block 2, while Table 8-1 lists artifacts and

In an effort to keep some consistency in identifying the excavations conducted at site 41HM61, a block positioned adjacent to a previous WC was labeled according to the number of the adjacent WC. For instance, Block 1 was placed across BT 4/19 from WC 1, Block 2 was placed adjacent to WC 2 , etc. Only Block 5 was not located near a previously excavated WC. Instead, it was positioned over the deep shell lens (F. 18) exposed in the east wall of BT 15. other cultural items recovered from the block as either field specimens or material captured in the 1/4inch screen. Similarly, Table $8-2$ provides details on the relationship between the excavated strata and levels and the actual strata revealed on the wall profiles. As with WC 2, all of the disturbed Ford alluvium (identified as Stratum 1) was shoveled out and discarded. It was not until the top of the Upper West Range's A horizon (Stratum 5) had been reached that controlled excavation began. Accordingly, Stratum 5 was removed in three consecutive $10-\mathrm{cm}-$ thick cuts down to the very top of the underlying West Range alluvium (Stratum 6), at which point excavation of Block 2 ceased. Overall, Block 2 was excavated to a depth of ca. $53 \mathrm{~cm}$.

As with WC 2, the few shells associated with F. 16 occurred within the first $10-\mathrm{cm}$ cut into the Upper West Range's A Horizon. Such can be seen clearly on the block's wall profiles (see Figures 8-3, 8-4 and 8-5), where exposed shells are visible within the upper 10 to $15 \mathrm{~cm}$ of Stratum 5. Unfortunately, the density of shell in Block 2 was far less than in the WC, suggesting that the major portion of the feature was removed by BT 17 . Figures 8-6 and 8-7 provide plan views of the distribution of shells in both WC 2 and Block 2. Note that most of the shells in Block 2 were found in the easternmost of the two 1-by-1-m units. This is reasonable, since the majority of the shells found in WC 2 were within the eastern portion of the column, which was located roughly south of the center of Unit N477E561. As with WC 2, the Block 2 shells of F. 16 also failed to produce any charcoal for ${ }^{14} \mathrm{C}$ dating. Thus, the lone age estimate for the feature must 

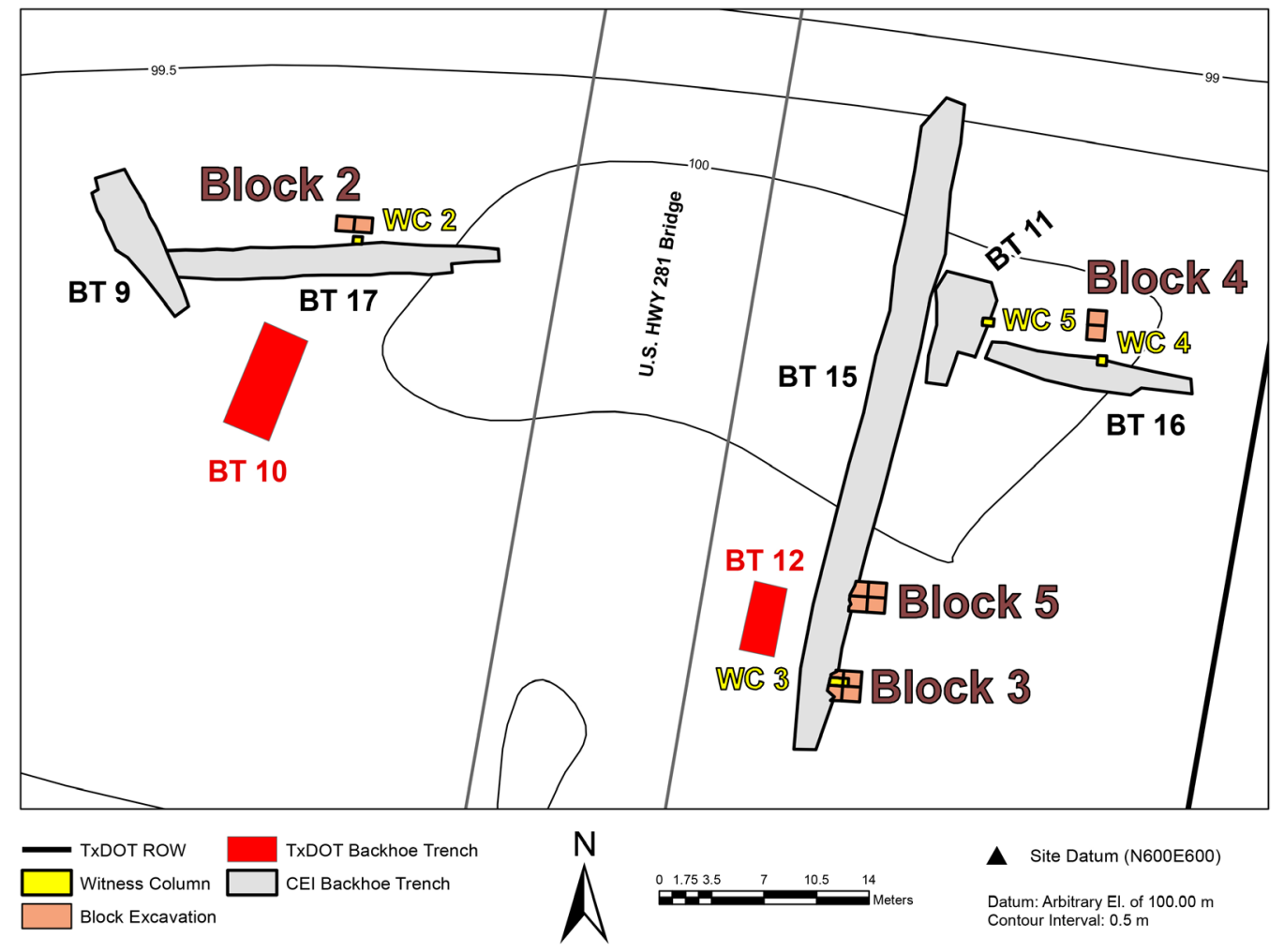

Site Datum (N600E600)
Datum: Arbitrary El. of $100.00 \mathrm{~m}$
Contour Interval: $0.5 \mathrm{~m}$

Figure 8-1. Contour map of the southern portion of site 41HM61 showing locations of backhoe trenches, witness columns, and block excavations. Note the location of Block 2 immediately to the north of Witness Column (WC) 2 and Backhoe Trench (BT) 17.

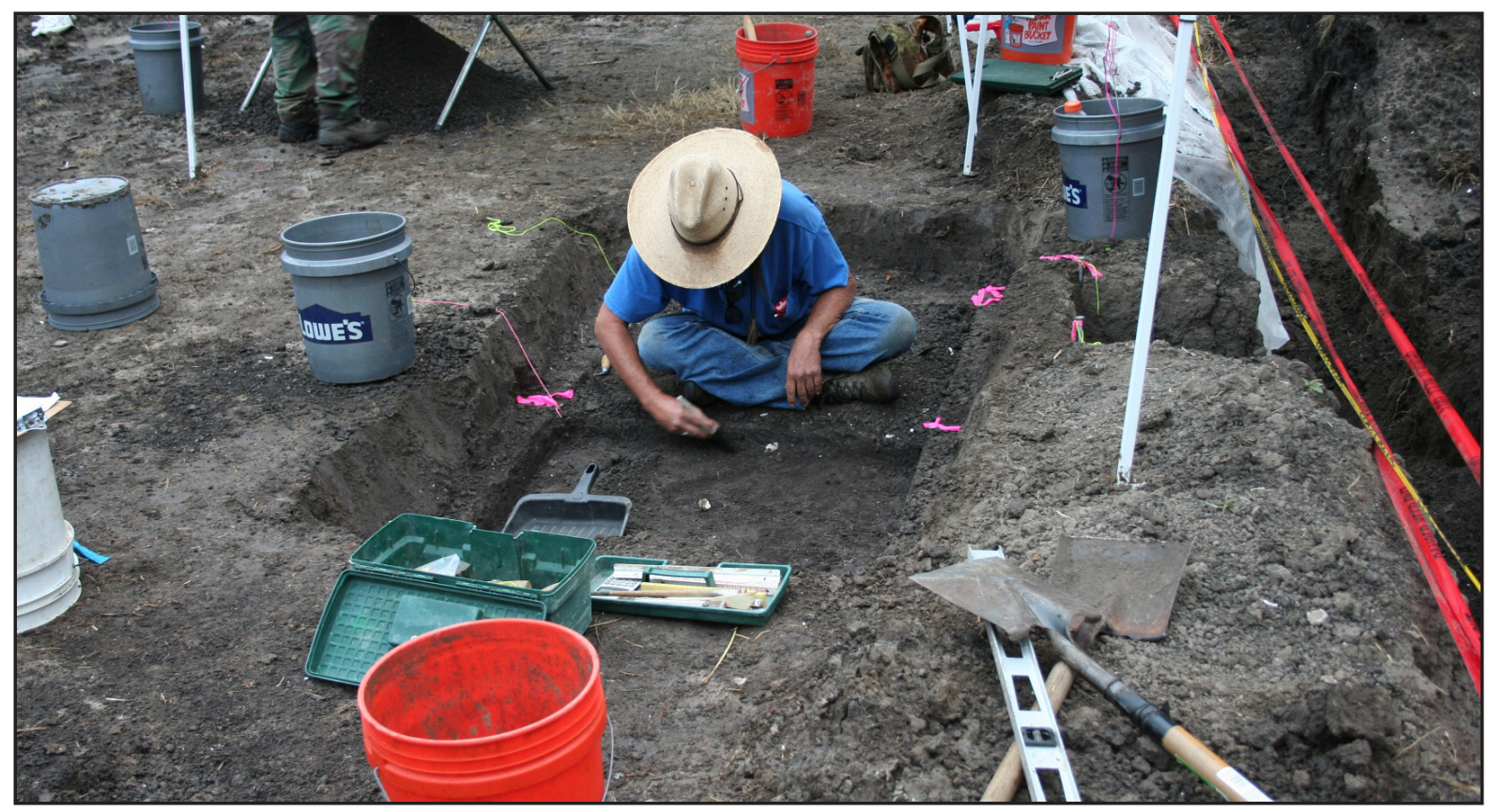

Figure 8-2. Photograph of the commencement of careful excavation of Block 2 following removal by shovel of the upper $20 \mathrm{~cm}$ or so. BT 17 and WC 2 can be seen to the right of the block. Looking to the west-northwest. 10/12/11. 
Block 2
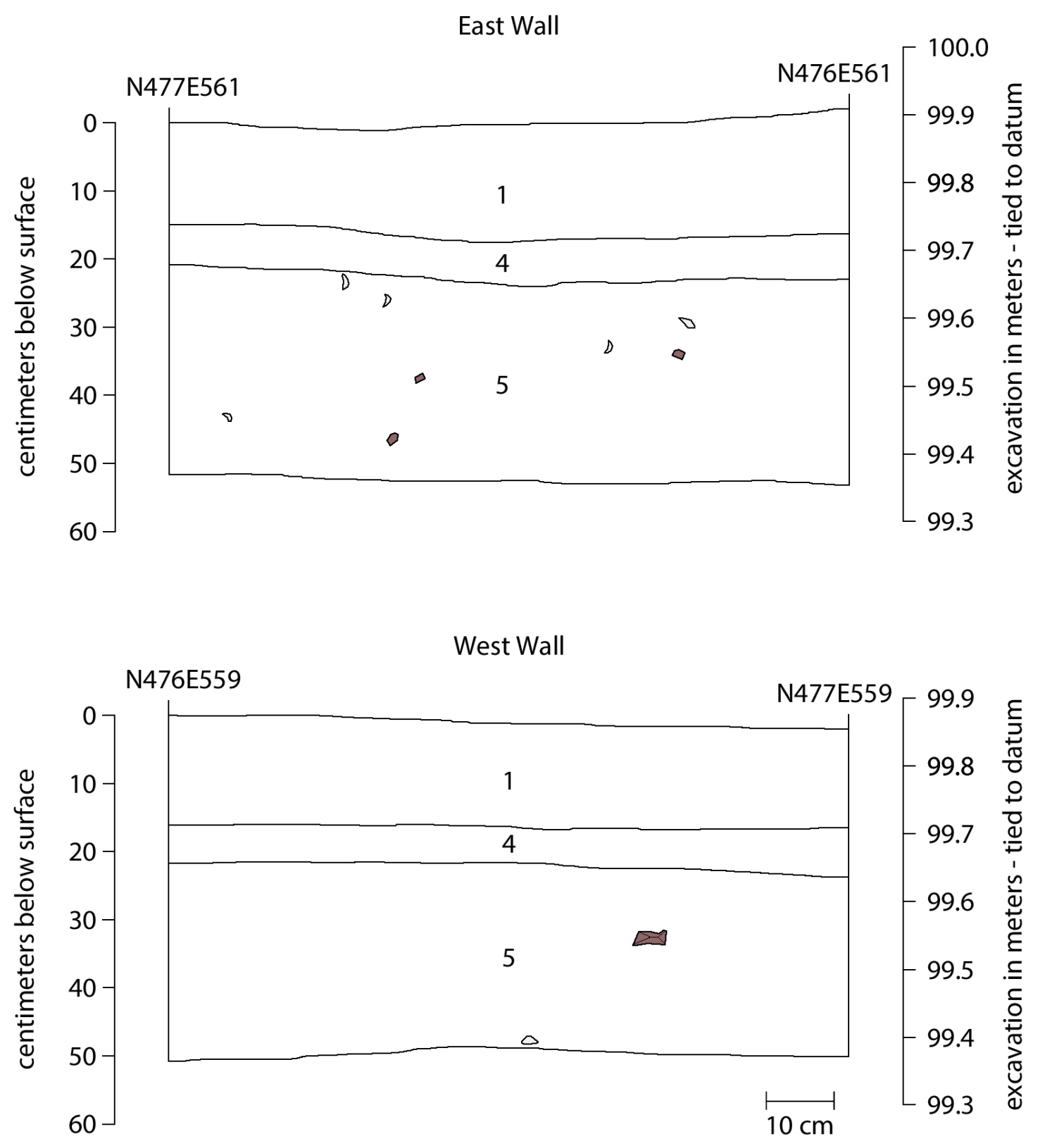

1 Dark grayish brown (10YR 4/2) silty clay

4 Very dark grayish brown (10YR 3/2) loam

5 Black (10YR 2/1) clay

Figure 8-3. Profile drawings of the east and west walls of Block 2. 

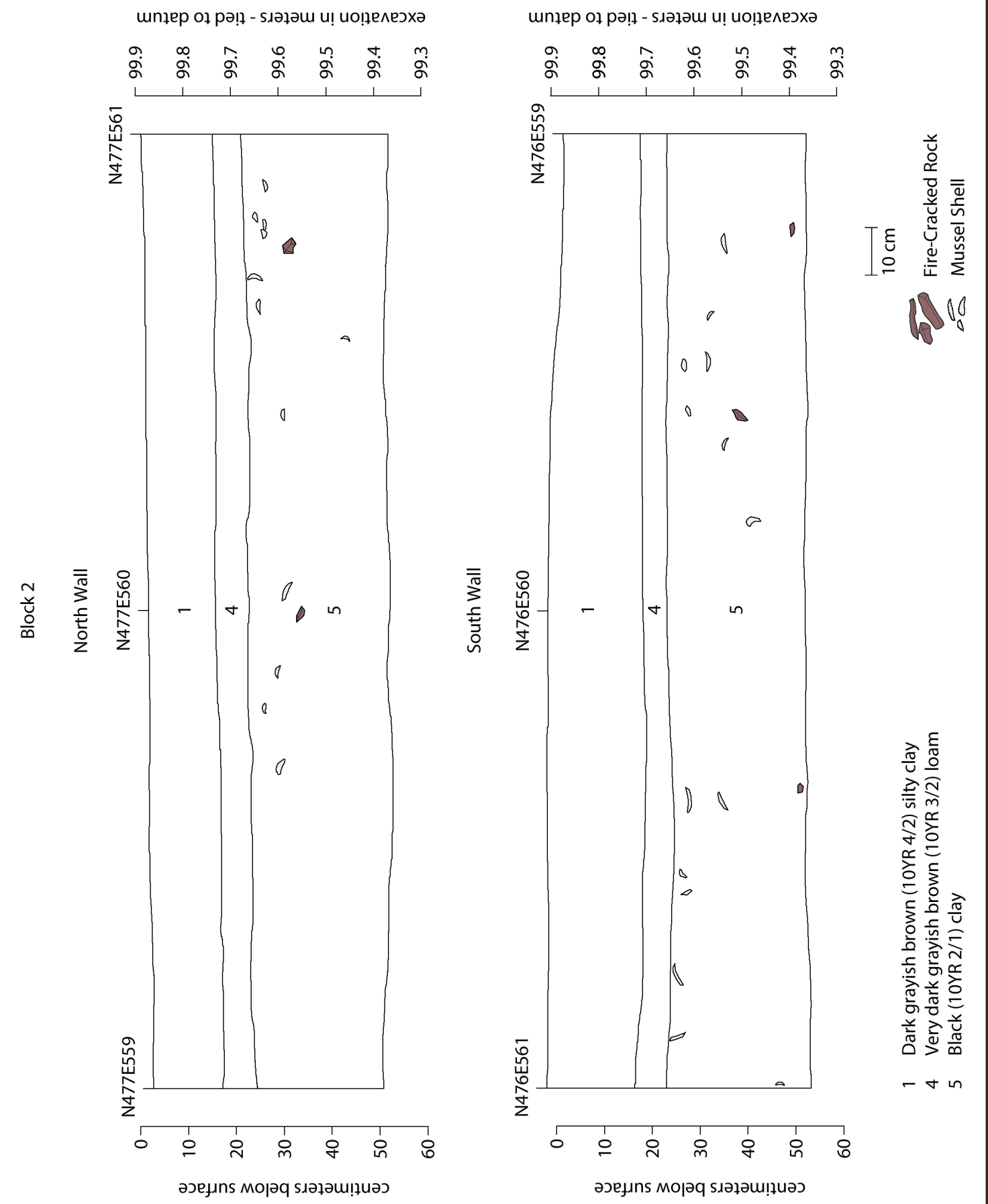

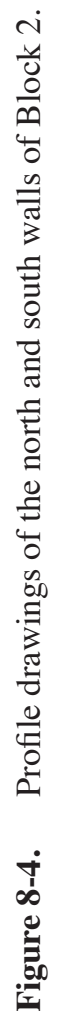




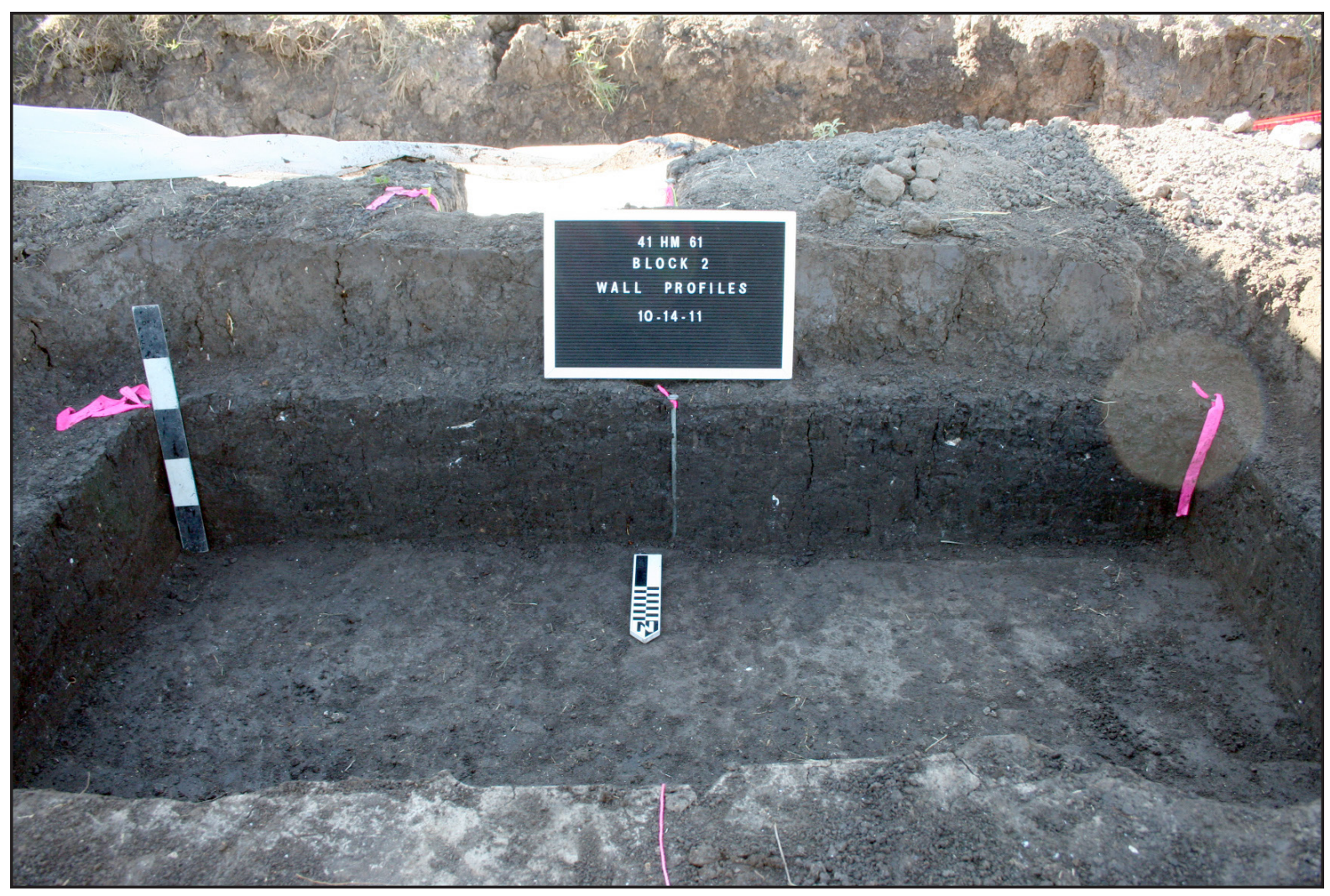

Figure 8-5. Photograph of the south wall profile of Block 2 with BT 17 and WC 2 in background. Note the overall lack of shell in the wall, an indication that most of the Feature 16 shell deposit was located to the south of the block. View to the south. 10/14/11.

rely upon the date obtained on the F. 16 mussel shell removed from WC 2, as noted previously in Chapter 7 and to be discussed in more detail later in Chapter 10.

Beneath the F. 16 shells, only a few scattered pieces of fire-cracked rock, lithic debitage, mussel shells, and snails were found and collected. These items likely were associated with occupation surfaces deeper within the Upper West Range A horizon, but pinpointing the exact depths of these surfaces is impossible with the data at hand. Overall, Block 2 was not as productive as originally hoped. Given such a relative dearth of new information obtained from the block, it was decided not to expand Block 2 beyond its initial two 1-by-1-m units.

\section{Block 3}

Block 3 was positioned around the former location of WC 3 in an effort to uncover more of the F. 19 shell deposit and the underlying F. 20 burnedrock cluster that were present within the deeper A horizon associated with the Lower West Range alluvium (Figures 8-8 and 8-9; see Figure 8-1). The block consisted of two complete 1-by-1-m units (N448E590 and N449E590) and two partial 1-by-1-m units (N448E589 and N449E589), with the latter two units located adjacent to BT 15. Because of the earlier excavation of WC 3, about half of Unit N449E589 and the southwestern quadrant of Unit N449E590 had been removed. To expedite the overall excavation, the backhoe was employed to remove about a meter of soil prior to the initiation of hand excavation. Thus, all of Strata 1 through 4, as identified in WC 3 (disturbed Ford alluvium, undisturbed Ford alluvium, and Upper West Range A horizon), was taken out completely by the backhoe, with subsequent hand excavation beginning within the upper portion of Stratum 5 (Lower West Range alluvium). The northeast corner of Unit N449E590 served as the block's datum and it was from this point that a line level was attached to measure depth during excavation.

Figures 8-10 and 8-11 illustrate the three walls of Block 3, while Table 8-3 lists artifacts and other cultural items recovered from the block as either field specimens or material captured in the 1/4-inch screen. Similarly, Table 8-4 provides details on the relation- 
Table 8-1. Material Recovered from the Block 2 Excavations.

\begin{tabular}{|c|c|c|c|c|c|c|c|c|}
\hline \multirow{3}{*}{ Material Recovered } & \multicolumn{6}{|c|}{ Stratum 5} & \multirow{2}{*}{\multicolumn{2}{|c|}{ Totals }} \\
\hline & \multicolumn{2}{|c|}{ (21-33 cmbd) } & \multicolumn{2}{|c|}{ (33-43 cmbd) } & \multicolumn{2}{|c|}{ (43-53 cmbd) } & & \\
\hline & No. & Wt. & No. & Wt. & No. & Wt. & No. & Wt. \\
\hline \multicolumn{9}{|l|}{ Debitage } \\
\hline Utilized Flakes & 1 & 3.4 & - & - & 1 & 3.2 & 2 & 6.6 \\
\hline Flakes & 7 & 9.6 & 1 & 2.5 & 2 & 1.9 & 10 & 14.0 \\
\hline Fire-Cracked Rock & 19 & 336.0 & 35 & 520.0 & 21 & 329.6 & 75 & $1,185.6$ \\
\hline \multicolumn{9}{|l|}{ Vertebrate Remains } \\
\hline Unburned Bone & 5 & 1.7 & 5 & 3.7 & 1 & 3.5 & 11 & 8.9 \\
\hline Burned Bone & - & - & 2 & 1.8 & - & - & 2 & 1.8 \\
\hline \multicolumn{9}{|l|}{ Invertebrate Remains } \\
\hline Mussel Shell & - & 346.4 & - & 73.0 & - & 92.0 & - & 511.4 \\
\hline Snail Shell & 19 & 2.0 & 43 & 6.9 & 26 & 11.0 & 88 & 19.9 \\
\hline Totals & 51 & 699.1 & 86 & 607.9 & 51 & 441.2 & 188 & $1,748.2$ \\
\hline
\end{tabular}

Note: Weights are in grams.

Table 8-2. Block 2: Excavated Strata and Levels and Corresponding Natural Strata as Identified on Wall Profiles.

\begin{tabular}{|c|c|}
\hline $\begin{array}{c}\text { Excavated Strata } \\
\text { and Levels } \\
\text { (Depth Below Block Datum) }\end{array}$ & $\begin{array}{c}\text { Natural Strata on } \\
\text { Wall Profiles }\end{array}$ \\
\hline $\begin{array}{c}\text { Stratum 1, Level A } \\
(0-21 \mathrm{~cm})\end{array}$ & $\begin{array}{c}\text { Stratum 1 } \\
\text { (Elevation Based on Site Datum) }\end{array}$ \\
$\begin{array}{c}\text { (Shoveled out - no material } \\
\text { saved or screened) }\end{array}$ & $\begin{array}{c}\text { (Disturbed Ford Alluvium) } \\
\text { (99.89 to 99.68 m) }\end{array}$ \\
\hline $\begin{array}{c}\text { Stratum 2, Level A } \\
\text { (Includes F. 16) } \\
(21-33 \mathrm{~cm})\end{array}$ & $\begin{array}{c}\text { Stratum 5 } \\
\text { (Includes F. 16) }\end{array}$ \\
\hline $\begin{array}{c}\text { Stratum 2, Level B } \\
(33-43 \mathrm{~cm})\end{array}$ & $\begin{array}{c}\text { Stratum 5 } \\
\text { (A Horizon, West Range Alluvium) } \\
\text { (99.68 to 99.56 m) }\end{array}$ \\
\hline $\begin{array}{c}\text { Stratum 2, Level C } \\
(43-53 \mathrm{~cm})\end{array}$ & $\begin{array}{c}\text { (A Horizon, West Range Alluvium) } \\
\text { (99.56 to 99.46 m) }\end{array}$ \\
\hline
\end{tabular}

Note: Depths based on elevations of the NE corner of Unit N477E561, which served as the block's datum during excavation. 


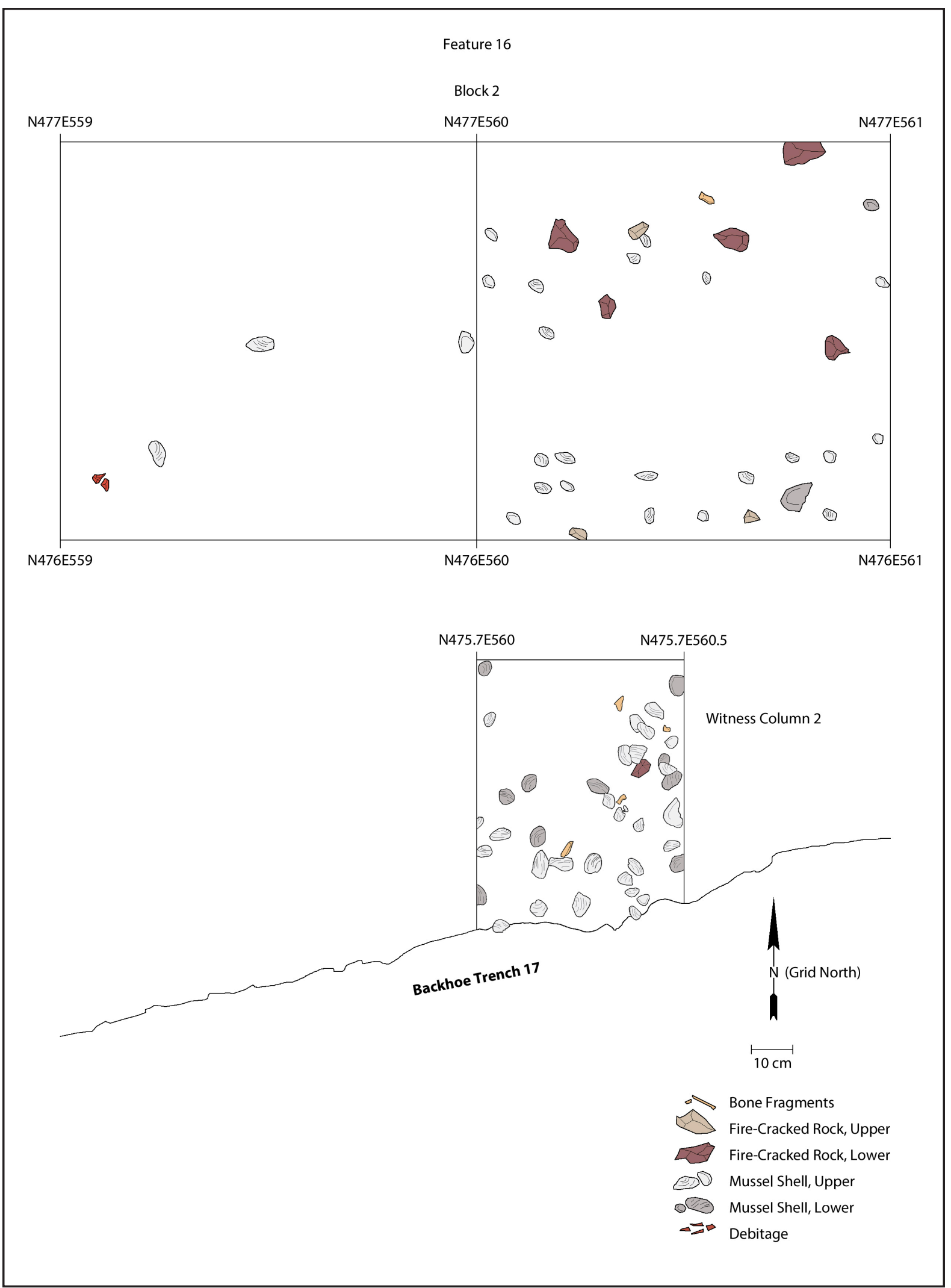

Figure 8-6. Plan view drawing of the Feature 16 shell uncovered in Block 2 along with those previously recorded in WC 2 . Note that only a few scattered shells were found within the block. 


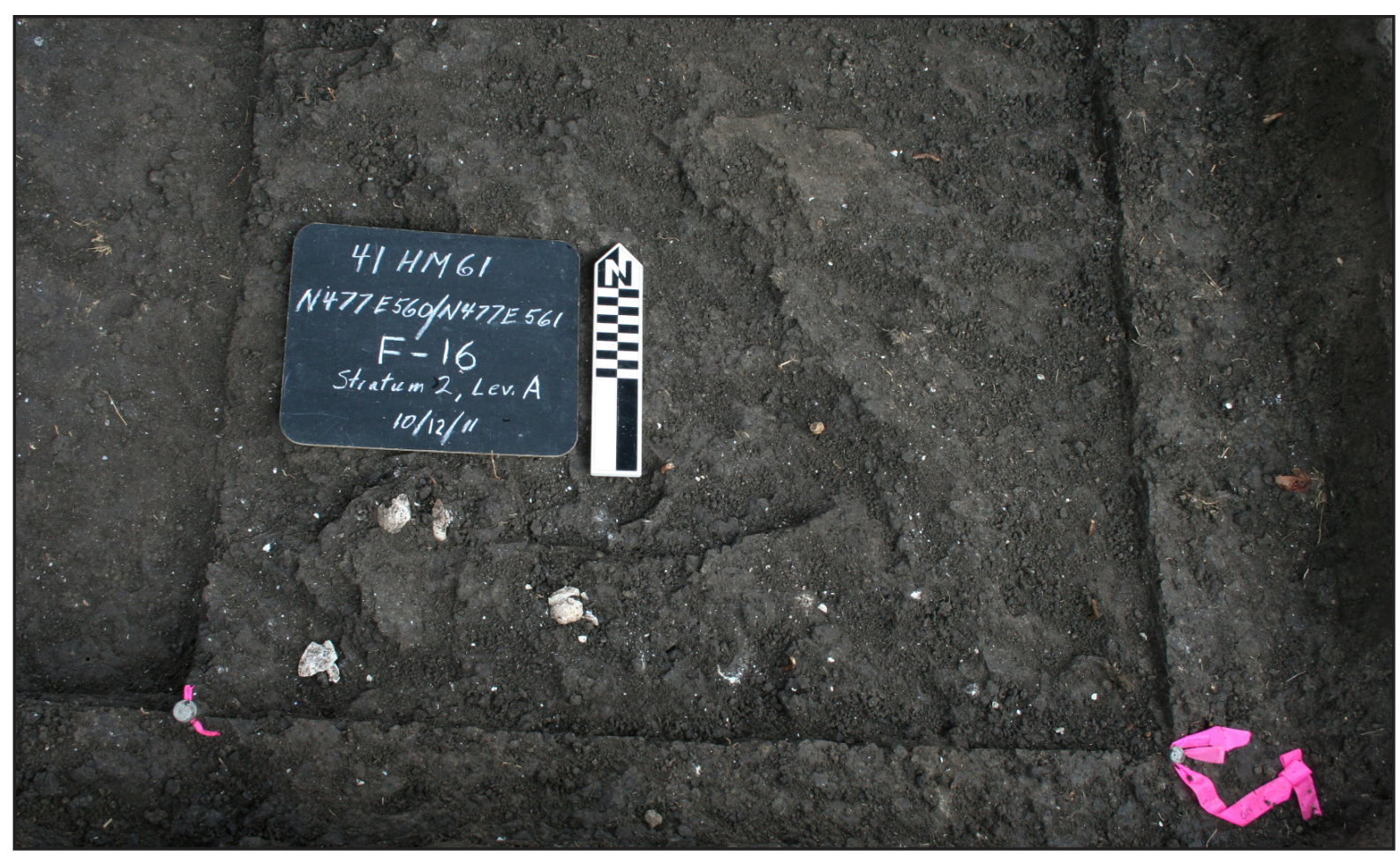

Figure 8-7. Photograph of the surface of the Feature 16 shell concentration within the southwestern quadrant of Unit N477E561 in Block 2. Note the scattered and sparse nature of the shell, indicating that the majority of the feature occurred to the south in WC 2 and BT 17. View to the north.

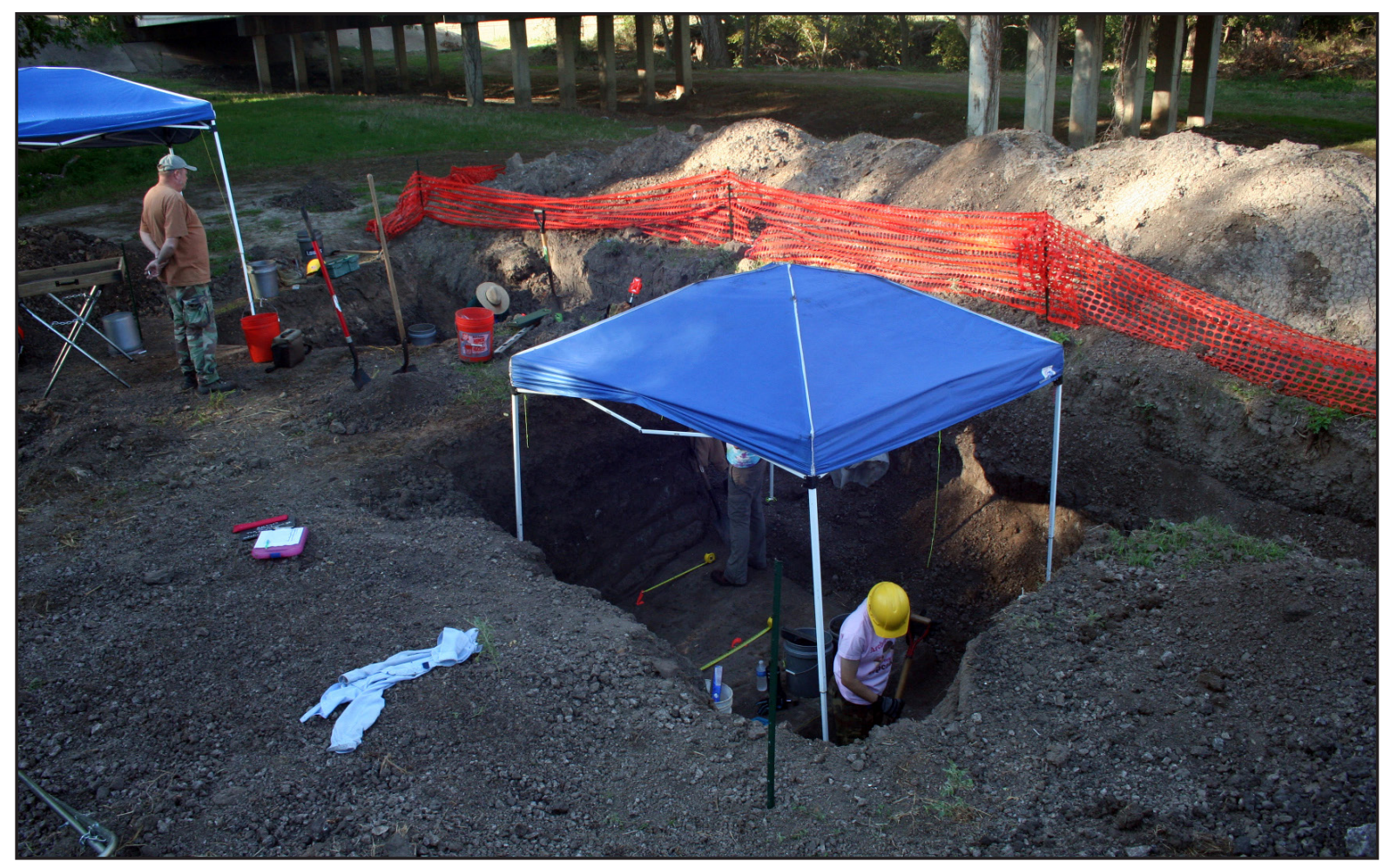

Figure 8-8. Photograph of the excavation of Blocks 3 (background) and 5 (foreground) along the east wall of BT 15. The backhoe was used to remove a meter or more of overburden prior to the hand excavations in these two blocks. View to the southwest. 10/25/11. 


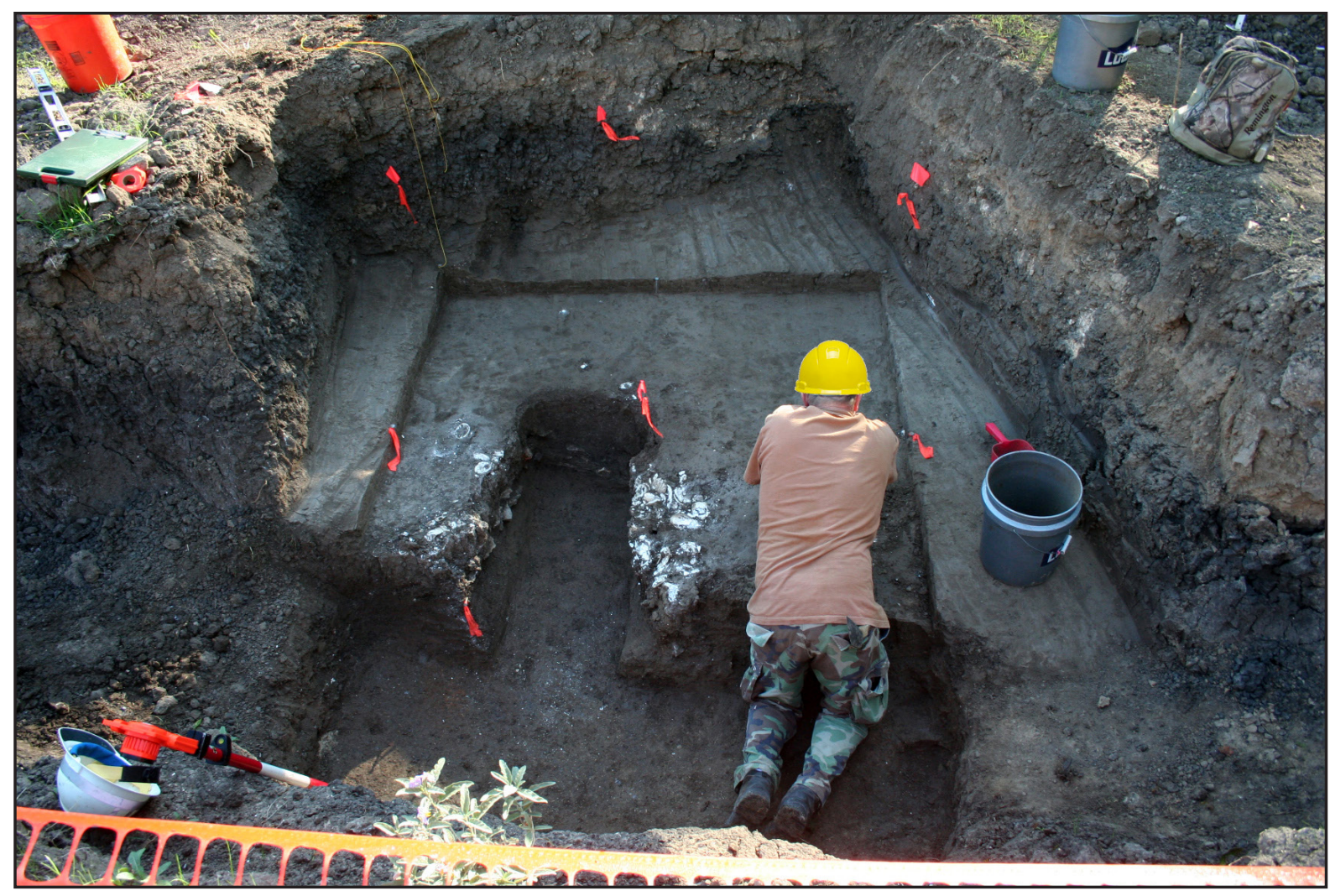

Figure 8-9. Photograph of Bo Nelson excavating Block 3 . This view clearly shows the area above the block removed by the backhoe, the former location of WC 3, and the four whole and partial 1-by-1-m units that comprised the hand-excavated block. At this point in the excavation, the soil overlying the Feature 19 shell concentration has been removed, and the floor of the block is being cleaned for photographs. View to the east. 10/25/11.

ship between the excavated strata and levels and the actual strata revealed on the wall profiles. Generally, the excavators were successful in recognizing the block's strata breaks and in defining the limits of Features 19 and 20 (Figures 8-12 through 8-15). Only the 122-to-133-cm level crosscut the lower portion of Stratum 5 and the upper part of Stratum 6. This is not considered a problem, however, as the only cultural remains associated with the level were from the upper portion of the F. 20 burned-rock feature. Excavation terminated after the last of the rocks related to F. 20 were removed.

As can be seen very clearly in Figures 8-12 through 8-15, excavation of WC 3 removed the majority of the mussel shells in F. 19 and the burned rocks in F. 20. Neither of the two features extended much beyond the edges of the WC, and overlapped to a considerable extent. This would appear to confirm the notion expressed in Chapter 7 that the two features are elements of a single earth oven that mainly was employed to cook or steam open the mussel shells of F. 19. Given that possibility, it can be surmised that most of the fire-crack rocks found scattered around the site likely served the same, or similar, purpose as those of F. 20. Furthermore, as discussed in Chapter 7, radiocarbon dates obtained from Features 19 and 20 suggest that the earth oven represented by the two features was in use sometime between ca. 800 and 750 B.C.

\section{Block 4}

This block consisted of two contiguous 1-by1-m units oriented north-south and positioned just north of WC 4 and BT 16 (Figures 8-16 and 8-17; see Figure 8-1. The block was designed to more fully delineate the extent of the Feature 21 burnedrock cluster uncovered within the lower portion of the Upper West Range alluvium's A horizon in WC 4. The two 1-by-1-m units comprising the block were identified by the grid coordinates of their northeast corners and consisted of Units N473E602 and N474E602. The northeast corner of the latter unit served as the block's datum and it was from this point that a line level was attached to measure depth during excavation. 


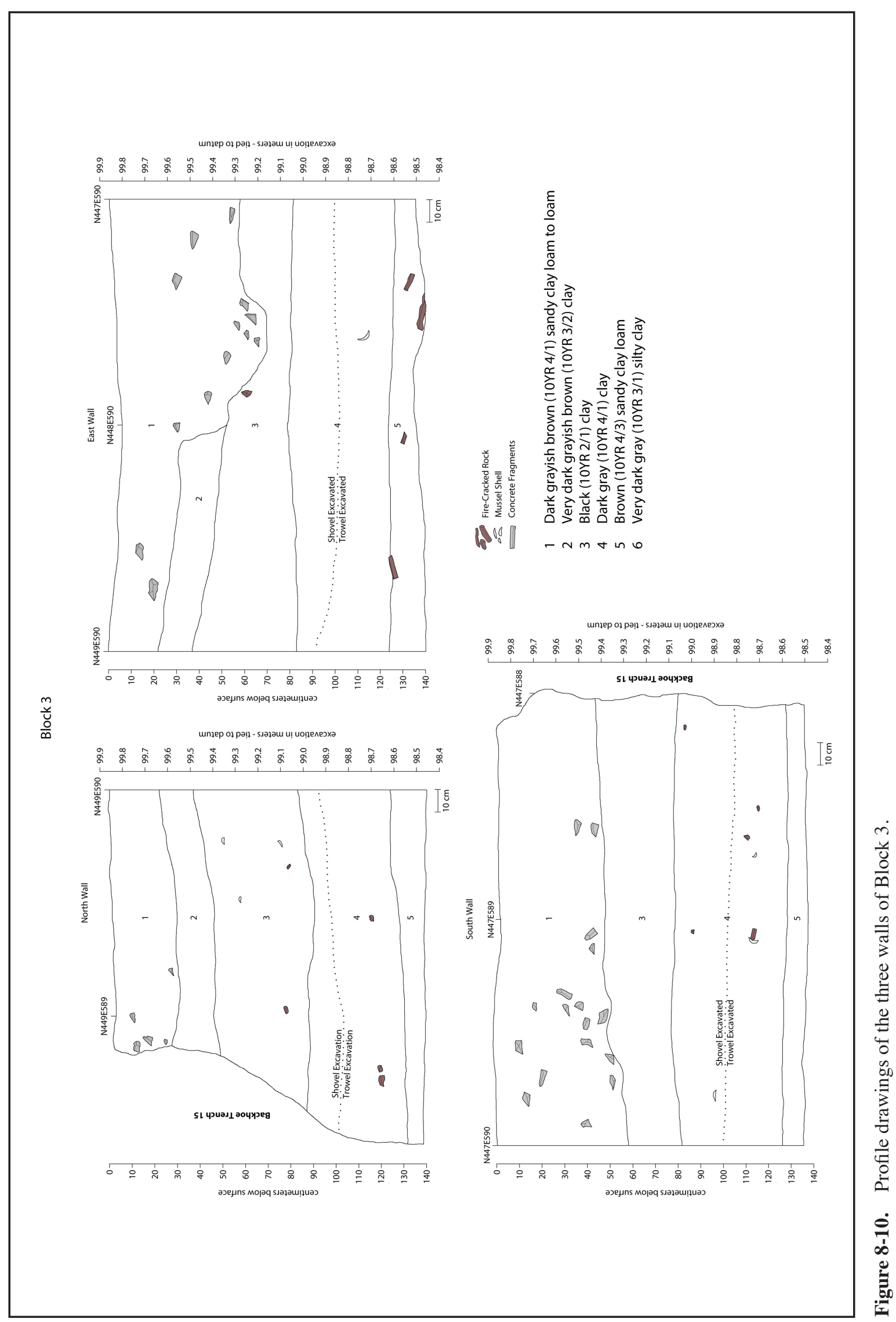




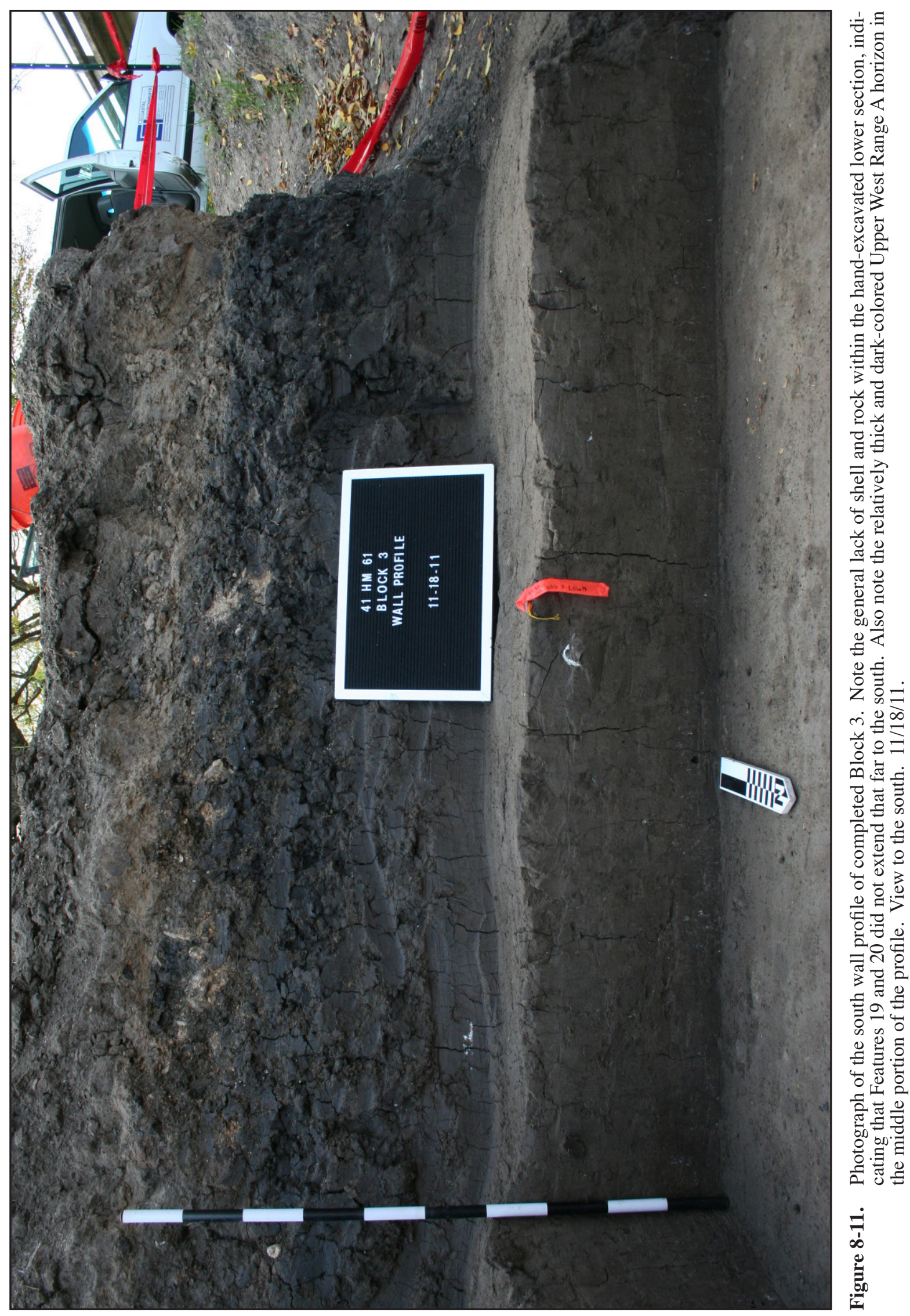


Table 8-3. Material Recovered from the Block 3 Excavations.

\begin{tabular}{|c|c|c|c|c|c|c|c|c|c|c|}
\hline \multirow{3}{*}{ Material Recovered } & \multicolumn{4}{|c|}{ Stratum 5} & \multirow{2}{*}{\multicolumn{2}{|c|}{$\frac{\text { Strata } 5 \text { \& } 6}{(122-133 \mathrm{cmbd})}$}} & \multirow{2}{*}{\multicolumn{2}{|c|}{$\frac{\text { Stratum } 6}{(133-143 \text { cmbd })}$}} & \multirow{2}{*}{\multicolumn{2}{|c|}{ Totals }} \\
\hline & \multicolumn{2}{|c|}{$(100-109$ cmbd $)$} & \multicolumn{2}{|c|}{ (109-122 cmbd) } & & & & & & \\
\hline & No. & Wt. & No. & Wt. & No. & Wt. & No. & Wt. & No. & Wt. \\
\hline Debitage & & & & & & & & & & \\
\hline Flakes & - & - & 1 & 0.4 & 3 & 1.4 & 1 & 0.9 & 5 & 2.7 \\
\hline Fire-Cracked Rock & - & - & 22 & 381.9 & 51 & 322.9 & 501 & $34,228.2$ & 574 & $34,933.0$ \\
\hline Vertebrate Remains & & & & & & & & & & \\
\hline Unburned Bone & - & - & 1 & 0.2 & 1 & 0.6 & 12 & 3.3 & 14 & 4.1 \\
\hline Invertebrate Remains & & & & & & & & & & \\
\hline Mussel Shell & - & 474.4 & - & 499.3 & - & 14.1 & - & 128.6 & - & 1116.4 \\
\hline Snail Shell & - & - & 22 & 8.2 & 28 & 6.9 & 21 & 4.3 & 71 & 19.4 \\
\hline Floral Remains & & & & & & & & & & \\
\hline Nutshell & - & - & 1 & 0.1 & - & - & - & - & 1 & 0.1 \\
\hline Totals & - & 474.4 & 47 & 890.1 & 83 & 345.9 & 535 & $34,365.3$ & 665 & $36,075.7$ \\
\hline
\end{tabular}

Note: Weights are in grams.

Table 8-4. Block 3: Excavated Strata and Levels and Corresponding Natural Strata as Identified on Wall Profiles.

\begin{tabular}{|c|c|}
\hline $\begin{array}{c}\text { Excavated Strata } \\
\text { and Levels } \\
\text { (Depth Below Block Datum) }\end{array}$ & $\begin{array}{c}\text { Natural Strata on } \\
\text { Wall Profiles } \\
\text { (Elevation Based on Site Datum) }\end{array}$ \\
\hline $\begin{array}{l}(0-100 \mathrm{~cm}) \\
\text { (Mechanically removed by } \\
\text { backhoe-no material } \\
\text { saved or screened) }\end{array}$ & $\begin{array}{l}\text { (Disturbed Ford Alluvium, } \\
\text { A Horizon, West Range Alluvium, } \\
\text { West Range Alluvium) } \\
\text { (99.86 to } 98.94 \mathrm{~m})\end{array}$ \\
\hline $\begin{array}{c}\text { Stratum 3, Level C } \\
(100-109 \mathrm{~cm}) \\
\text { (Shoveled out }- \text { no material } \\
\text { saved or screened) }\end{array}$ & $\begin{array}{c}\text { Stratum } 5 \\
\text { (West Range Alluvium) } \\
\text { (98.94 to } 98.79 \mathrm{~m} \text { ) }\end{array}$ \\
\hline $\begin{array}{l}\text { Stratum 3, Level D } \\
\text { (Includes F. 19) } \\
\quad(109-122 \mathrm{~cm})\end{array}$ & $\begin{array}{c}\text { Stratum 5 } \\
\text { (Includes F. 19) } \\
\text { (West Range Alluvium) } \\
\text { (98.79 to } 98.66 \mathrm{~m} \text { ) }\end{array}$ \\
\hline $\begin{array}{l}\text { Stratum 4, Level A } \\
\text { (Includes upper F. 20) } \\
\quad(122-133 \mathrm{~cm})\end{array}$ & $\begin{array}{c}\text { Strata } 5 \& 6 \\
\text { (Includes upper F. 20) } \\
\text { (West Range Alluvium) } \\
\text { (98.66 to } 98.55 \mathrm{~m} \text { ) }\end{array}$ \\
\hline $\begin{array}{l}\text { Stratum 4, Level B } \\
\text { (Includes lower F. 20) } \\
\quad(133-143 \mathrm{~cm})\end{array}$ & $\begin{array}{c}\text { Stratum } 6 \\
\text { (Includes lower F. 20) } \\
\text { (West Range Alluvium) } \\
\text { (98.55 to } 98.45 \mathrm{~m} \text { ) }\end{array}$ \\
\hline
\end{tabular}

Note: Depths based on elevations of the NE corner of Unit N499E590, which served as the block's datum during excavation. 


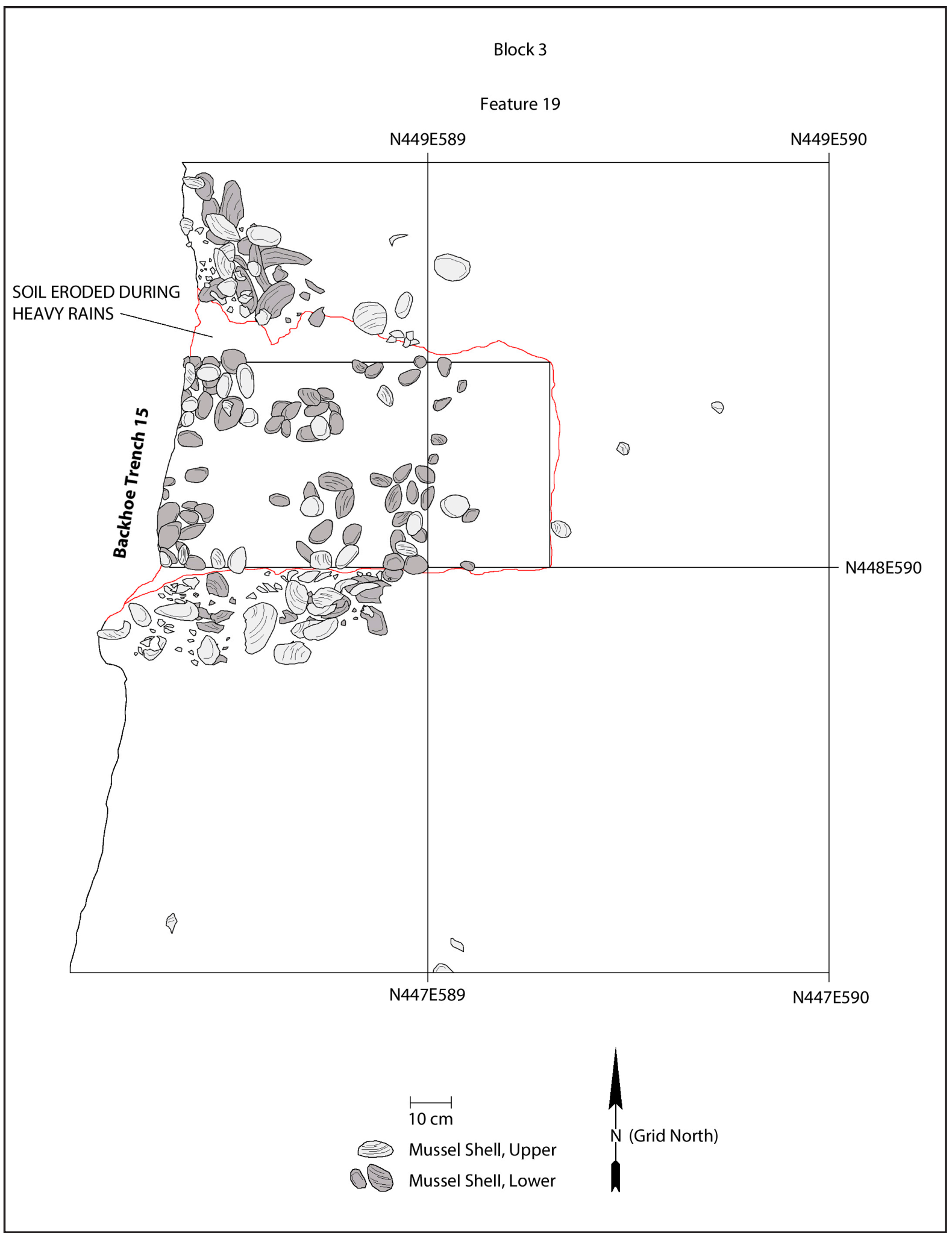

Figure 8-12. Plan view drawing of Block 3 showing the extent of mussel shells associated with Feature 19. The previous plan view of the Feature 19 shells, recorded during the excavation of WC 3, has been added to show the density and extent of shell for the entire feature. Due to heavy rains between the excavation of the WC and the excavation of the block, the edges of the WC eroded away slightly such that some soil from the feature was lost. This is particularly noticeable along the north edge of the WC. 


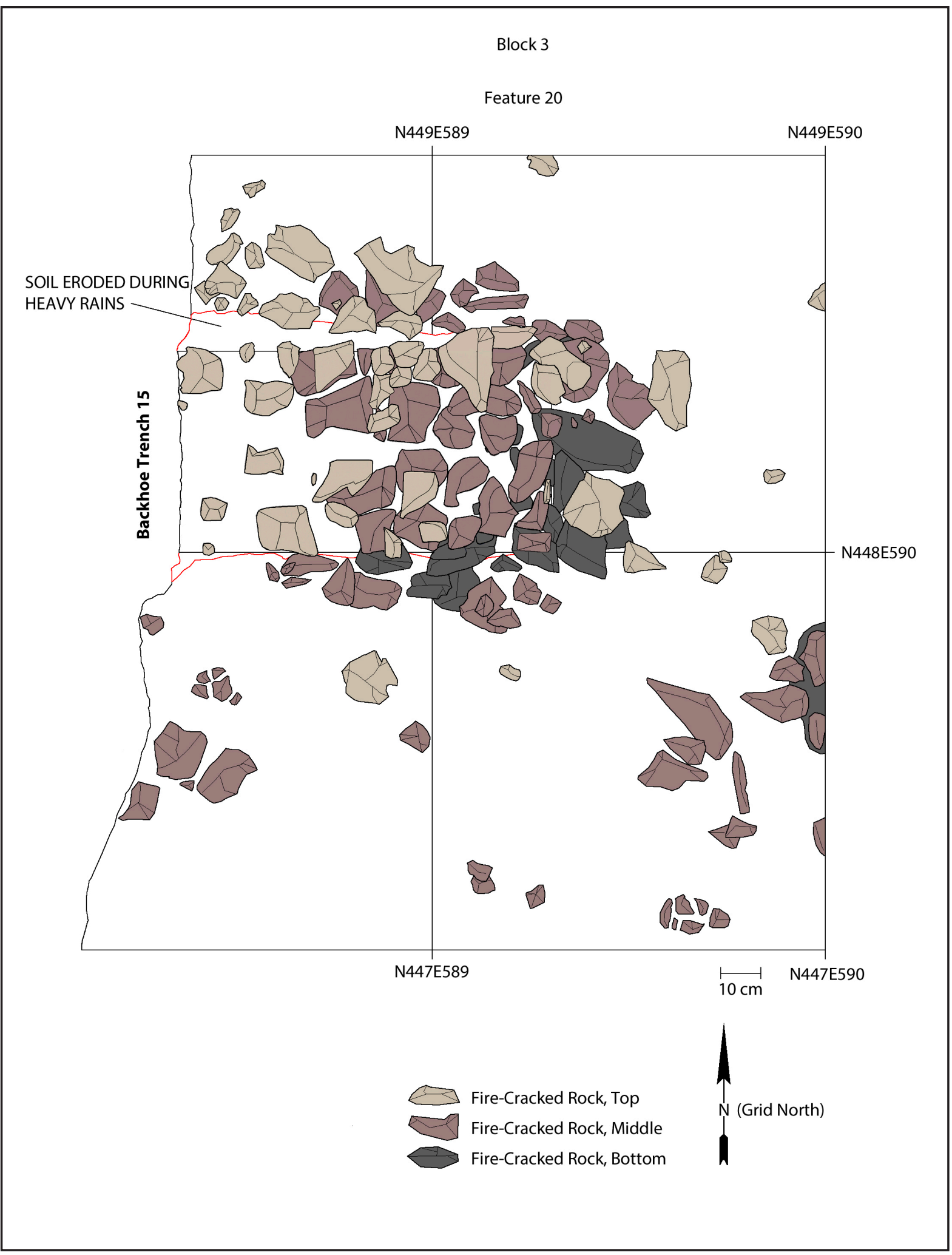

Figure 8-13. Plan view drawing of Feature 20 within Block 3. Again, that fire-cracked rock removed during excavation of WC 3 has been added to show the full extent and density of items associated with the feature. 


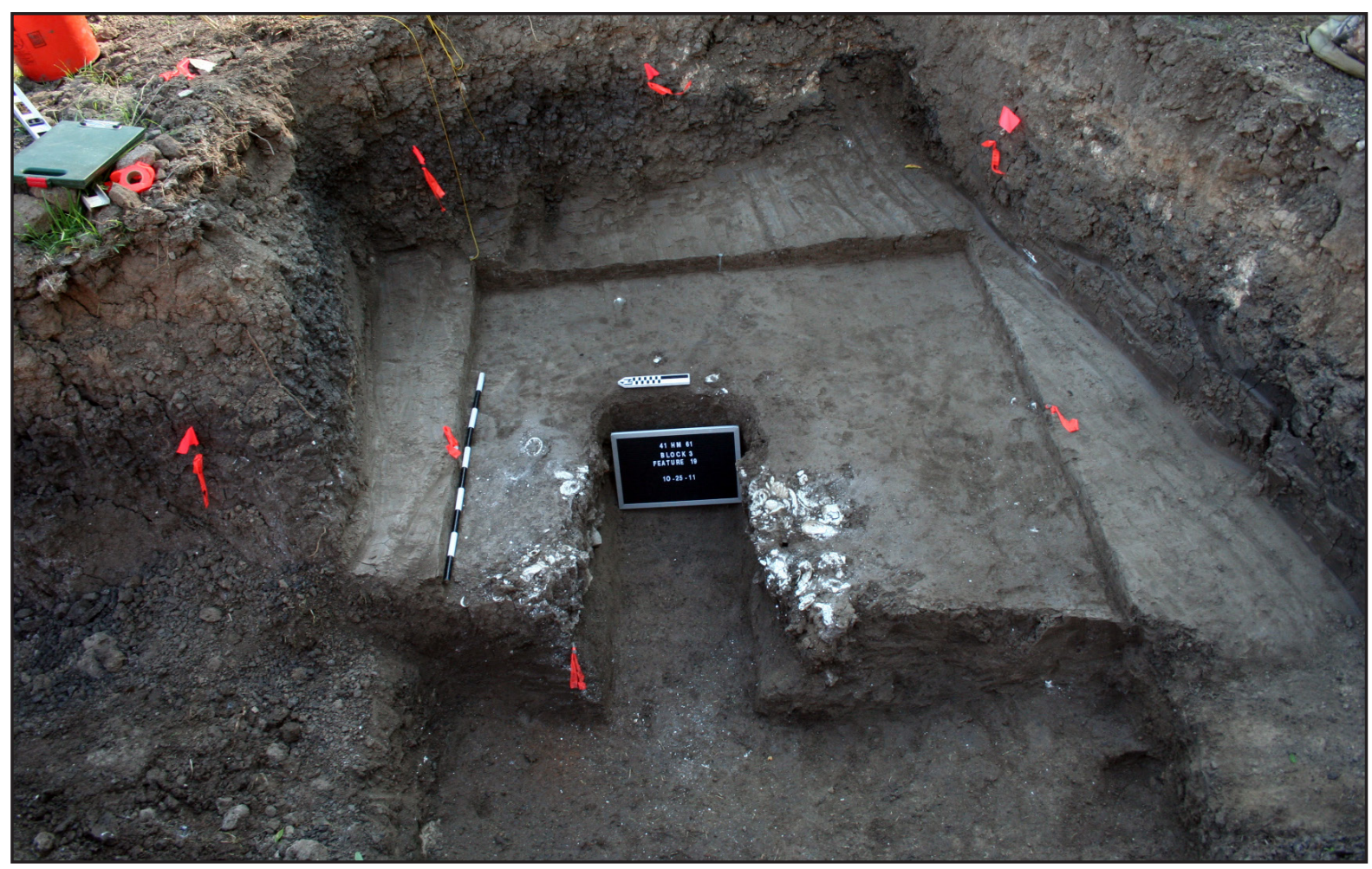

Figure 8-14. Photograph of the extent of the Feature 20 shell concentration following the removal of the overlying soil. Excavation of WC 3 removed the majority of the feature. View to the east. 10/25/11.

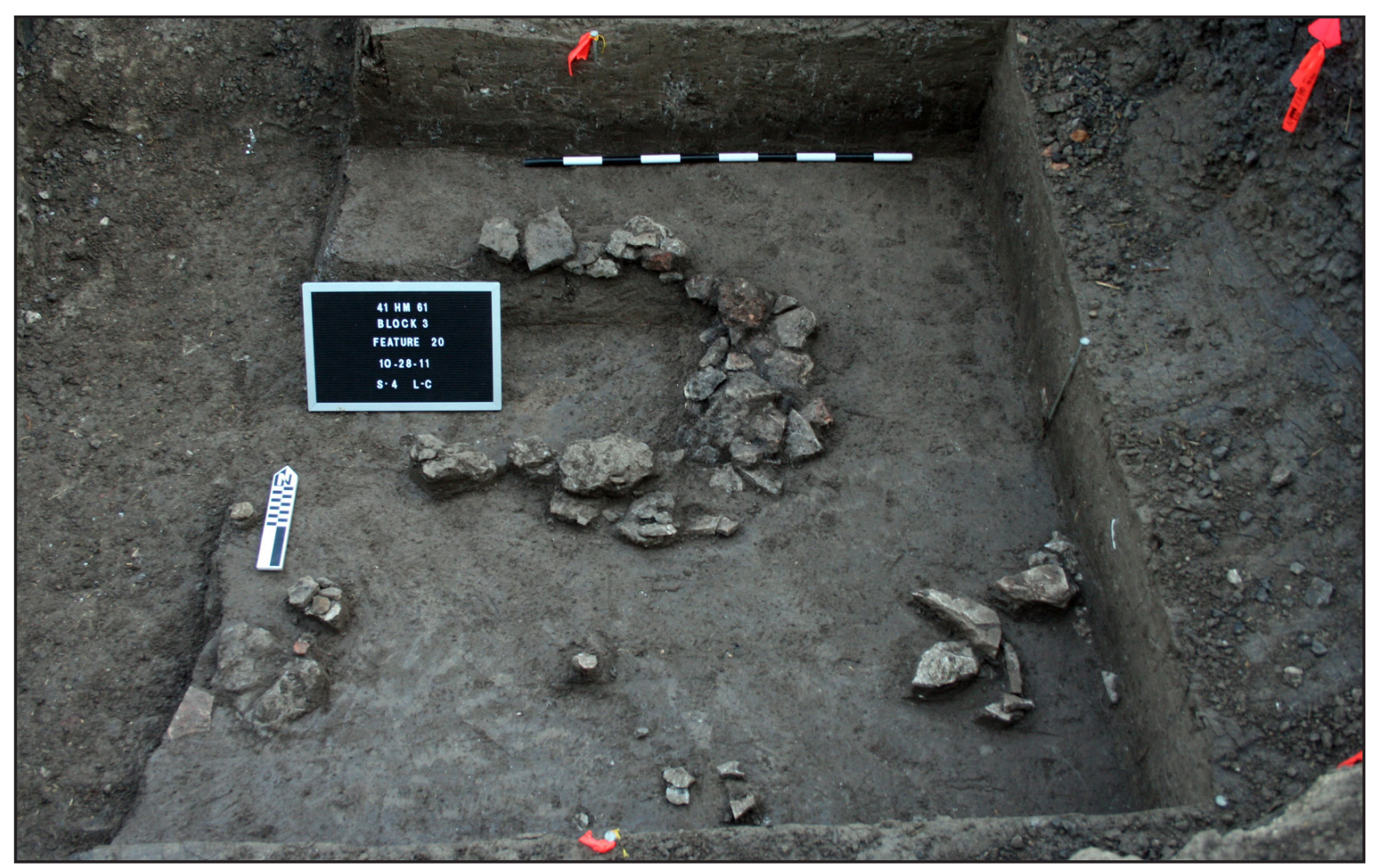

Figure 8-15. Photograph of Feature 20 and scattered fire-cracked rock near the base of Block 3 . Note the compact and concentrated nature of the rock within the feature. WC 3 again was responsible for the removal of most of the feature. The bottom of BT 15 can be seen to the left of the block. View to the north. 10/29/11. 


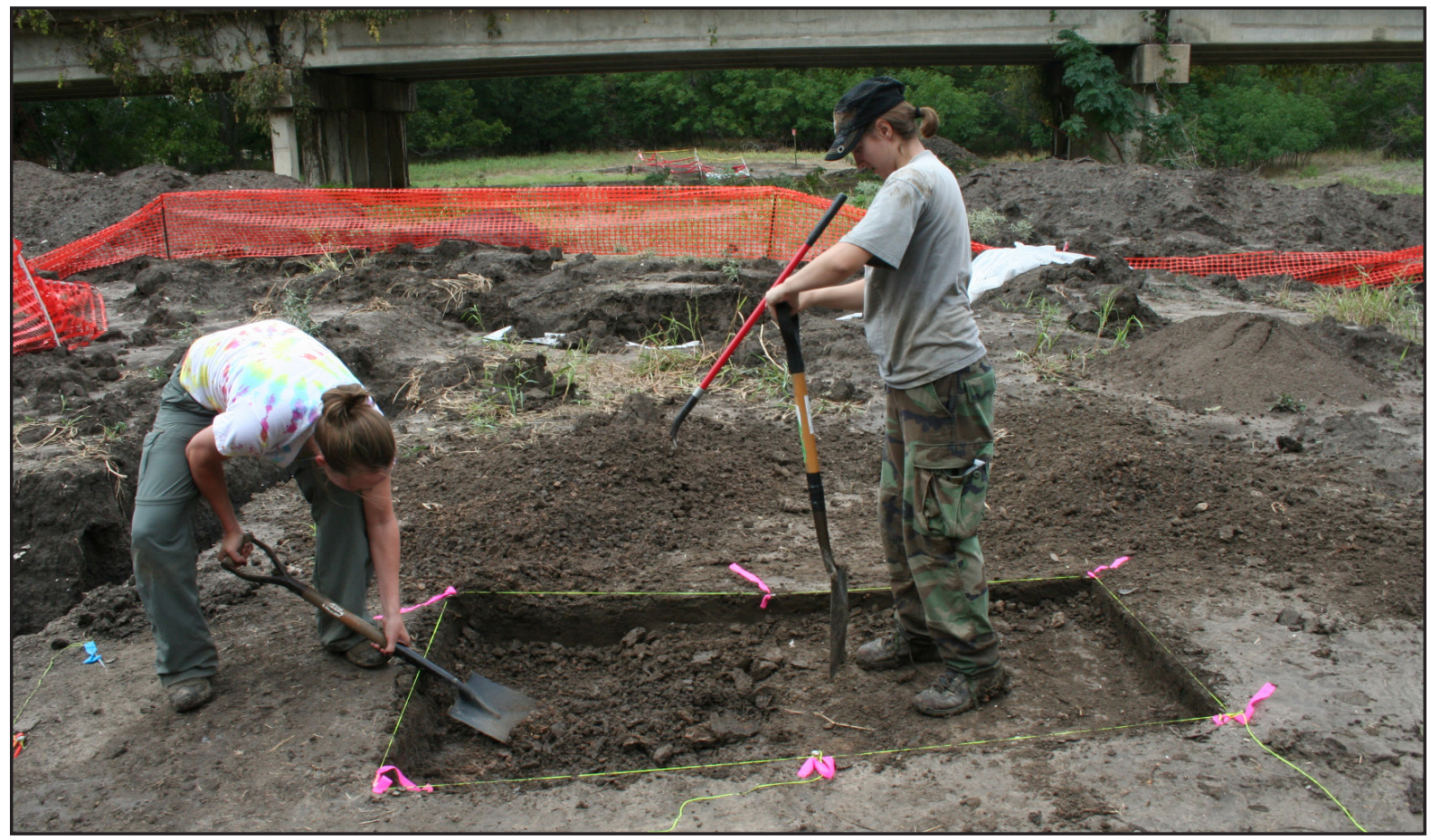

Figure 8-16. Photograph of Stephanie McKernan (left) and Sally Morehead beginning the excavation of Block 4 adjacent to WC 4 and BT 16. BTs 11 and 15 can be seen behind the excavators, with BT 17 visible in the far distance beyond the U.S. Highway 281 bridge. Note the slumped and damaged condition of the trench walls due to the heavy rains on October 7 and 8 . View to the west. $10 / 10 / 11$.

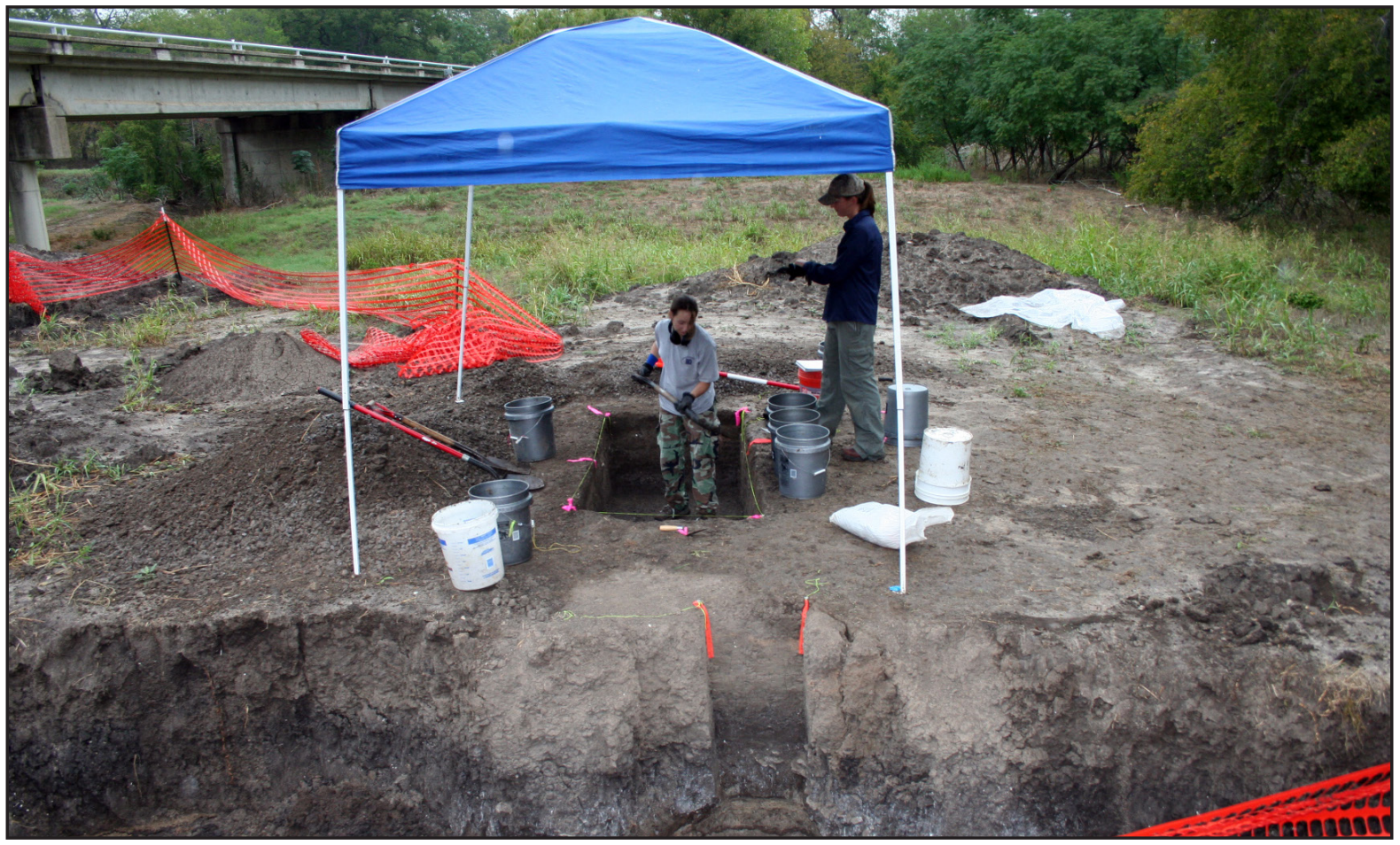

Figure 8-17. Photograph of the continuing excavation of Block 4 adjacent to the north wall of BT 16. The remains of WC 4 can be seen in the foreground, while the channelized Leon River is visible in the distance. Due to the slumping nature of BT 16's walls, the block was positioned about a meter from the trench. View to the north. 10/12/11. 
Figures 8-18 and 8-19 illustrate the four walls of Block 4, while Table 8-5 lists artifacts and other cultural items recovered from the block as either field specimens or material captured in the 1/4-inch screen. Table 8-6 provides details on the relationship between the excavated strata and levels and the actual strata revealed on the wall profiles. Once again, the upper $50 \mathrm{~cm}$ or so of the two units were removed by shovel and discarded in an effort expedite the excavation. The original plan called for controlled hand excavation to begin once the Upper West Range A horizon (Stratum 3) was encountered. However, the block's excavators were overly cautious and actually began the controlled excavation while still within the overlying Ford alluvium (Stratum 2). Thus, the first controlled cut $(53-61 \mathrm{~cm})$ took out the final $8 \mathrm{~cm}$ of the Ford alluvium, plus one or two centimeters of the underlying Stratum 3 A horizon. It was not until the subsequent 61-to-70-cm level that most of the upper part of the Upper West Range A horizon was removed, although that cut also took out a little of the very bottom of the Ford alluvium within the extreme northern part of the block. Nevertheless, the next three cuts (70-80, 80-90, and 90-95 cm) all were confined to the A horizon, with the first two removing the upper and lower portions of Feature 26 (a new concentration of burned rocks found in Unit N474E602) and the latter two removing the upper and lower portions of $\mathrm{F}$. 21 (which mostly occurred within Unit N474E602). The final cut $(95-105 \mathrm{~cm})$ was designed to remove the upper $10 \mathrm{~cm}$ of the underlying West Range alluvium of Stratum 4. However, a comparison of the level's depth measurements with the wall profiles indicates that the level actually took out the lower few centimeters of the A horizon along with the non-A horizon West Range alluvium. Excavation of the block ceased following removal of the 95-to-105-cm level.

Interestingly, and as briefly touched upon above, the two features identified in the block were encountered at different depths and appear to relate to two different occupation events. The uppermost, F. 26, initially was recognized at an elevation of $99.41 \mathrm{~m}$ within the 70-to-80-cm level. Figures 8-20 and 8-21 provide plan views of the feature and identify the individual artifacts piece plotted as feature components. On the other hand, fire-cracked rocks believed to represent an extension of F. 21 initially were encountered at an elevation of $99.30 \mathrm{~m}$ within the 80-to-90-cm level, mainly in the southeastern quadrant of Unit N473E602, although some were scattered across the remainder of the unit. In fact, other scattered rocks found within the lower part of the A horizon in adjacent Unit N474E602 may represent items once associated with F. 21 but displaced by subsequent human activity in the area. Even if not part of F. 21, these rocks most likely represent remains of the same occupation that was responsible for F. 21. Figure 8-22 illustrates the distribution of the piece-plotted items associated with F. 21 and its occupation surface.

As can be seen in Table 8-5, a modest amount of fire-cracked rock and other cultural remains were found within the upper 10 to $20 \mathrm{~cm}$ of the Stratum 3 A horizon (included in the 61-to-70- and 70-to-80$\mathrm{cm}$ levels). However, both the quantity and weight of these items increased slightly once the middle part of the A horizon was encountered. This slight increase may be related to the occupation surface associated with Feature 26, which seems to have been more pronounced than the surface related to overlying F. 26. As to be expected, the increase is particularly noticeable in the amount of fire-cracked rocks present in the 80-to-90-cm level.

Unfortunately, no charcoal was found directly associated with either F. 21 or F. 26, so it was not possible to provide a date for F. 26 or any additional dates related to F. 21. The date reported for the possumhaw from that portion of F. 21 within WC 4 will have to suffice as the potential age of that feature and the middle occupation layer in Block 4, i.e., ca. A.D. 60 to 220 during the Late Archaic 3 period.

\section{Block 5}

Unlike all other block excavations at site 41HM61, Block 5 was not positioned next to a WC. Instead it was placed adjacent to the east wall of BT 15 above the location of Feature 18, a linear deposit of shell exposed near the base of the trench (Figures 8-23 and 8-24; see Figures 6-11 and 8-1. As with nearby Block 3, the upper ca. $1.5 \mathrm{~m}$ of soil were removed by the backhoe to facilitate the expedient exposure of F. 18. The block initially consisted of three complete 1-by-1-m units aligned north-south in its eastern half (N453E591, N454E591, and N455E591) and three mostly complete 1-by-1-m units (N453E590, N454E590, and N455E590) also aligned north-south, but situated adjacent to BT 15 so that their extreme western edges had been cut away by the trench.

Since the backhoe had been utilized to remove overburden, all of Strata 1 through 5 (disturbed Ford alluvium, undisturbed Ford alluvium, and much of the West Range A horizon) was taken out completely by the backhoe and discarded. Interestingly, subsequent profiling of the walls of the block revealed that 
Block 4
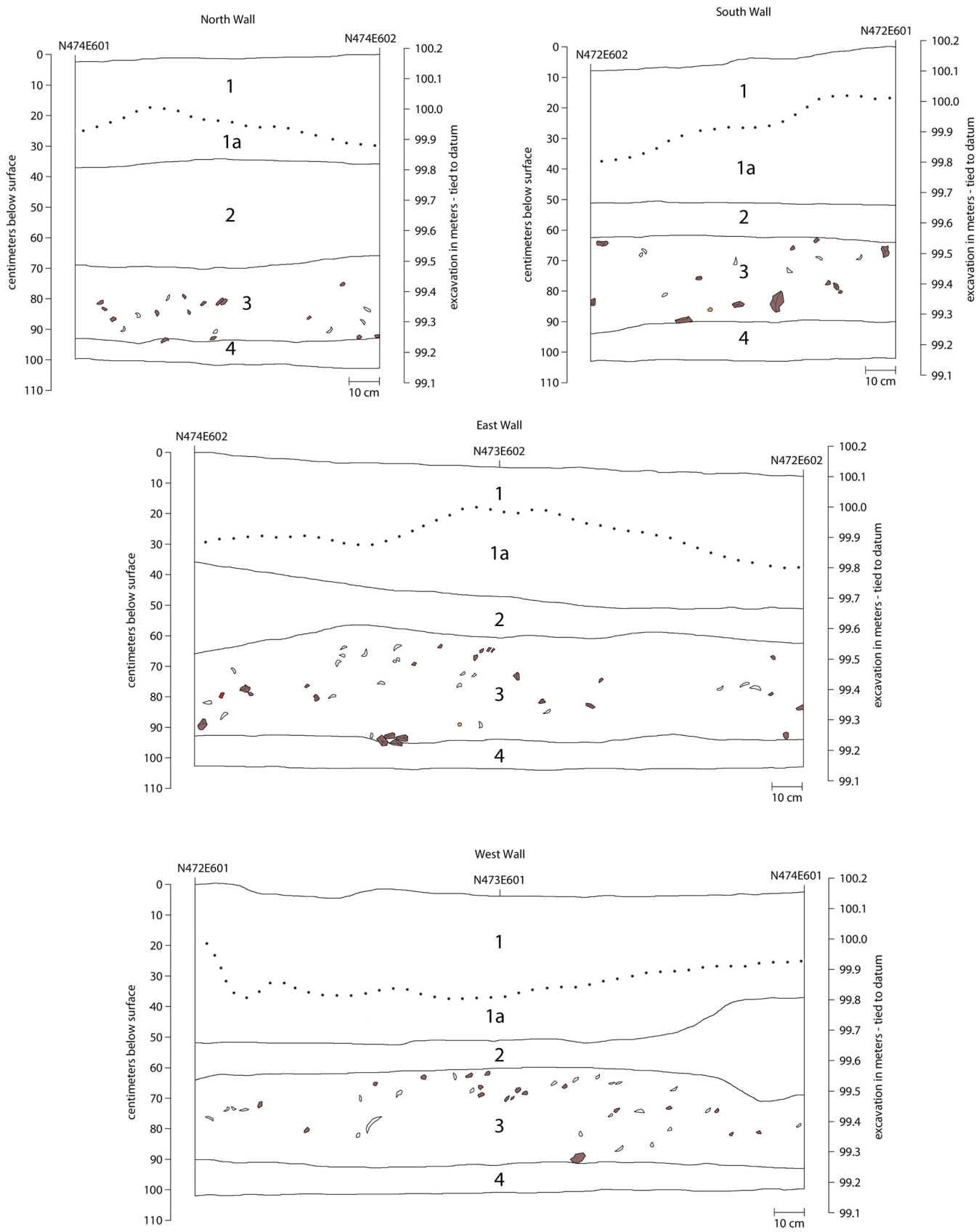

Modern introduced fill/disturbed

Dark grayish brown (10YR 4/2) silty clay to clay

Very dark gray (10YR $3 / 1$ ) clay

Black (10YR 2/1) clay

Very dark grayish brown (10YR 3/2)

Figure 8-18. Profile drawings of the four walls of Block 4 . 
at least one probable living surface was present within the lower 10 to $20 \mathrm{~cm}$ of the Upper West Range's A horizon (Stratum 3), as seen by a distinct layer of fire-cracked rocks and mussel shells on the south wall profile and a cluster of mussel shells on the southern portion of the east wall. Given what has been learned so far about the upper A horizon, this living surface may be associated with the Marcos occupation at the site during the Late Archaic 2 period.

Regardless of the possible living surface, once the backhoe had removed the ca. $1.5 \mathrm{~m}$ of overburden, hand excavation began within the upper portion of Stratum 6 (Lower West Range alluvium), with about 20 to $30 \mathrm{~cm}$ of that deposit removed by shovel and also discarded. It was not until the excavators began to come down on shells related to F. 18 that controlled excavation and soil screening commenced. However, even with the use of the backhoe to expedite excavation of the block, it still became necessary to eliminate two of the initial 1-by-1-m units in order to complete the fieldwork in a timely manner. Thus, no further excavation occurred within the two southernmost units (N453E590 and N453E591). At that point, the exposed surfaces in those two units simply were drawn and photographed. The northeast corner of Unit N455E591 served as the datum for the remaining four 1-by-1-m units and it was from this point that a line level was attached to measure depth during excavation.

Figures 8-25 and 8-26 illustrate the three walls of Block 5, while Table 8-7 lists artifacts and other cultural items recovered from the block as either field specimens or material captured in the 1/4-inch screen. Likewise, Table 8-8 provides details on the relationship between the excavated strata and levels and the actual strata revealed on the wall profiles following completion of the block. As noted in the table, only the very bottom of the block (the 171-to-180-cm level) was removed by controlled excavation. Included within that level, however, was all of that part of Feature 18 not cut away by BT 15 , plus much of a newly discovered shell deposit situated to the southeast of F. 18 and identified as Feature 28. Interestingly, an area of fired earth and charcoal was present within the upper Stratum 6 alluvium at the base of the backhoe cut. It was recognized as Feature 27, although it was uncertain if the fired earth and charcoal were the result of a possible hearth or a burned tree trunk. Since the majority of the feature occurred in the two southernmost units (those not subjected to controlled excavation, as discussed above), it was not possible to determine the feature's true nature. Still, its presence is noted in
Table $8-8$ for future reference should this area of the site ever be subjected to data-recovery excavations.

Regardless of the above, the remains of the Feature 18 shell deposit were found to cover an area that measured ca. $120 \mathrm{~cm}$ north-south by $70 \mathrm{~cm}$ eastwest, with the majority of the shells found within Unit N454E590 (Figures 8-27 and 8-28). Since BT 15 had removed the westernmost part of the deposit, it is possible that the original feature was close to a circular shape. Overall, the deposit was about $5 \mathrm{~cm}$ in thickness and occurred between elevations 98.17 and $98.12 \mathrm{~m}$. Although marked by a preponderance of freshwater mussel shells, F. 18 also contained a moderate quantity of bone, a few pieces of debitage, and several fragments of fire-cracked rock. In fact, one fairly large chunk of fire-cracked rock (Blk 5, FS 60) was present along the western edge of the feature.

Feature 28, the newly identified shell deposit, was located almost entirely in Unit N454E591, although shells likely related to it can be seen at the very base of the south wall's profile (see Figures 8-25 and 8-26). This suggests that the feature extends to the south beyond the limits of the controlled excavations. That part of the feature within Unit N454E591 covered an area measuring ca. $45 \mathrm{~cm}$ north-south by $40 \mathrm{~cm}$ eastwest. It was slightly deeper and thinner than F. 18, with elevations extending between 98.13 and $98.09 \mathrm{~m}$. It also had far fewer shells and other cultural remains associated with it. Perhaps its greatest concentration of shells occurs to the south in the area not excavated. In any case, excavation of Block 5 was terminated once the cultural remains from F. 18 and F. 28 had been removed.

Lastly, in an effort to obtain an age on the deposition of F. 18 (and presumably the occupation also responsible for F. 28), two $14^{\mathrm{C}}$ samples were processed; one on a tiny piece of organic sediment adhering to the inside of one of the feature's mussel shells (Blk 5, FS 16) (Beta-315692), and the other on one of the actual mussel shells from the feature (Beta-382992). The sediment sample yielded a ${ }^{14} \mathrm{C}$ age of $3860 \pm 30$ B.P. and a calibrated 2-sigma age range of 4411 to 4226 B.P. (ca. 2460 to 2275 B.C.) at 84.3 percent probability. The mussel shell produced a ${ }^{14} \mathrm{C}$ age of $4060 \pm 30$ B.P., and a calibrated 2-sigma range of 4628 to 4432 B.P. (ca. 2680 to 2480 B.C.) at 87.7 percent probability. As will be reviewed later, these are the earliest ${ }^{14} \mathrm{C}$ dates obtained at site 41HM61. Likewise, the dates indicate that Features 18 and 28 are the two earliest features found at the site during the testing project. They both can be related to a Middle Archaic occu- 


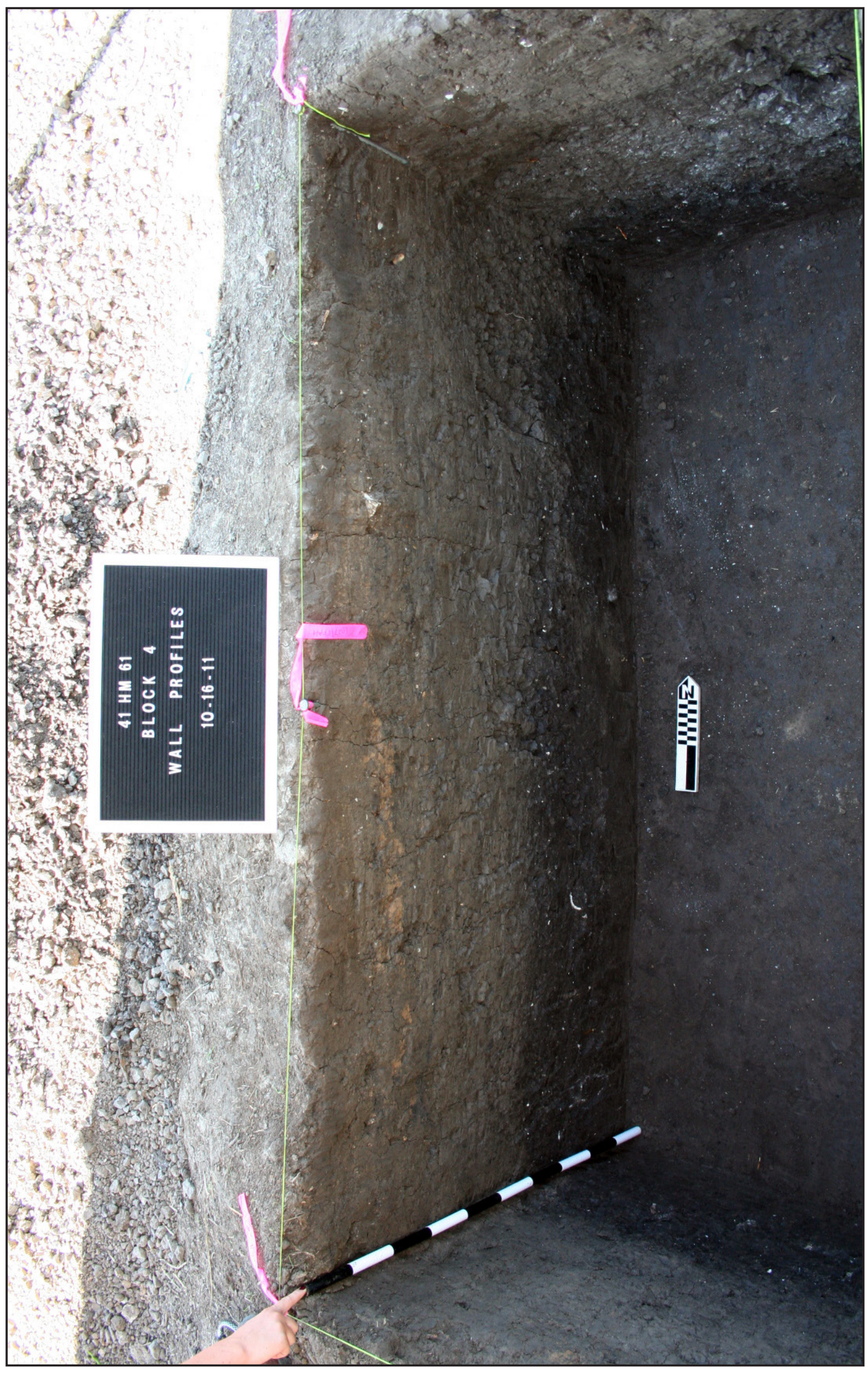

$\stackrel{\square}{\circ}$

오

范

릉

.

氙

흡

$\Xi$

亏픙

诺

픈

के

올

궁

멍

品

तै

$\approx$

ज放

3 의

$\dot{0}$

足

ڤิ్ㅡ

巳

पै

류

品

空

융

F 전

$\dot{\nabla}$

뉴

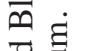

驻.

잉

苂흔

하뭉ㅇ

넝 玒

Q

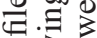

은

궁응

娄步

एँ

uี

당ㄱ

응

릉흐

on 0

온

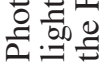

$\stackrel{0}{1}$

$\infty$

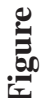




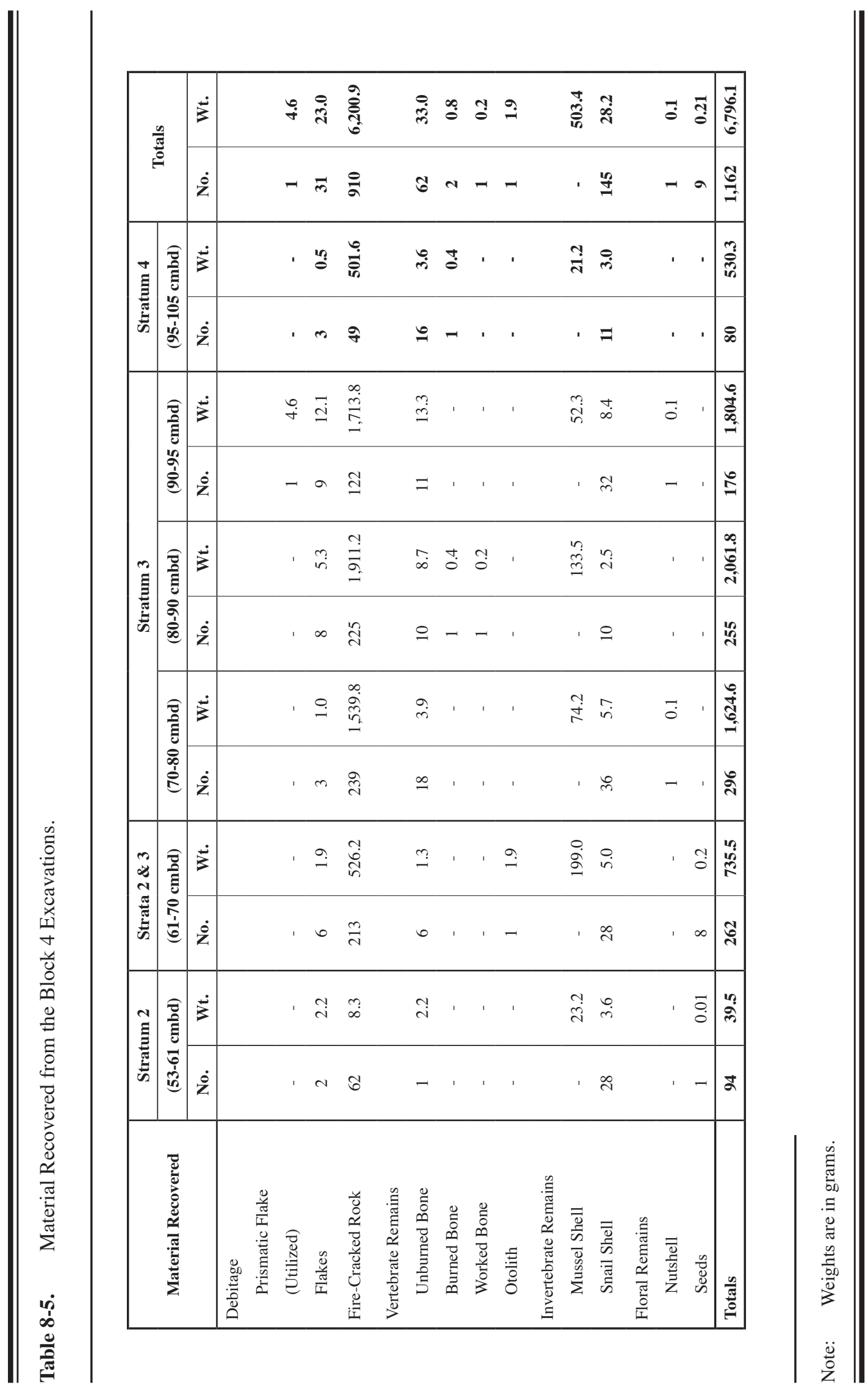


Table 8-6. Block 4: Excavated Strata and Levels and Corresponding Natural Strata as Identified on Wall Profiles.

\begin{tabular}{|c|c|}
\hline $\begin{array}{c}\text { Excavated Strata } \\
\text { and Levels } \\
\text { (Depth Below Block Datum) }\end{array}$ & $\begin{array}{c}\text { Natural Strata on } \\
\text { Wall Profiles } \\
\text { (Elevation Based on Site Datum) }\end{array}$ \\
\hline $\begin{array}{c}\text { Strata } 1 \text { and } 2 \\
(0-53 \mathrm{~cm}) \\
(\text { Shoveled out }- \text { no material } \\
\text { saved or screened) }\end{array}$ & $\begin{array}{c}\text { Strata 1, 1a, and } 2 \\
\text { (Disturbed Ford Alluvium \& } \\
\text { Ford Alluvium) } \\
(100.18 \text { to } 99.65 \mathrm{~m})\end{array}$ \\
\hline $\begin{array}{l}\text { Stratum 3, Level A } \\
\quad(53-61 \mathrm{~cm})\end{array}$ & $\begin{array}{c}\text { Stratum } 2 \\
\text { (Ford Alluvium) } \\
(99.65 \text { to } 99.57 \mathrm{~m})\end{array}$ \\
\hline $\begin{array}{l}\text { Stratum 3, Level B } \\
\quad(61-70 \mathrm{~cm})\end{array}$ & $\begin{array}{c}\text { Strata } 2 \text { and } 3 \\
\text { (Ford Alluvium \& } \\
\text { (A Horizon, West Range Alluvium) } \\
(99.57 \text { to } 99.46 \mathrm{~m})\end{array}$ \\
\hline $\begin{array}{l}\text { Stratum 3, Level C } \\
\text { (Includes upper F. 26) } \\
\quad(70-80 \mathrm{~cm})\end{array}$ & $\begin{array}{c}\text { Stratum } 3 \\
\text { (Includes upper F. 26) } \\
\text { (A Horizon, West Range Alluvium) } \\
(99.46 \text { to } 99.36 \mathrm{~m})\end{array}$ \\
\hline $\begin{array}{l}\text { Stratum 3, Level D } \\
\text { (Includes upper F. } 21 \& \\
\text { lower F. 26) } \\
(80-90 \mathrm{~cm})\end{array}$ & $\begin{array}{c}\text { Stratum } 3 \\
\text { (Includes upper F. 21 \& } \\
\text { \& lower F. 26) } \\
\text { (A Horizon, West Range Alluvium) } \\
\text { (99.36 to } 99.26 \mathrm{~m} \text { ) }\end{array}$ \\
\hline $\begin{array}{l}\text { Stratum 3, Level E } \\
\text { (Includes lower F. 21) } \\
\quad(90-95 \mathrm{~cm})\end{array}$ & $\begin{array}{c}\text { Stratum } 3 \\
\text { (Includes lower F. 21) } \\
\text { (A Horizon, West Range Alluvium) } \\
(99.26 \text { to } 99.21 \mathrm{~m})\end{array}$ \\
\hline $\begin{array}{l}\text { Stratum 4, Level A } \\
\quad(95-105 \mathrm{~cm})\end{array}$ & $\begin{array}{c}\text { Strata } 3 \text { and } 4 \\
\text { (West Range Alluvium) } \\
\text { (99.21 to } 99.11 \mathrm{~m} \text { ) }\end{array}$ \\
\hline
\end{tabular}

Note: Depths based on elevations of the NE corner of Unit N474E602, which served as the block's datum during excavation.

pation that would appear to be present at the bottom of the Lower West Range A horizon. Importantly, these two radiocarbon dates also formed the basis of a potential reservoir correction that can be applied to mussel shells from this stretch of the Leon River. As alluded to under the discussion of WC 2 in Chapter 7, and as reviewed more fully in Chapter 10, this correction for mussel shell dates appears to be on the order of ca. 200 years.

\section{North Section}

\section{Block 1}

This was the largest of the five blocks excavated at site 41HM61. Plus, it was the only block designed specifically to acquire data related to the Toyah component at the site. The block was positioned across BT 4/19 from WC 1, and extended from the eastern 


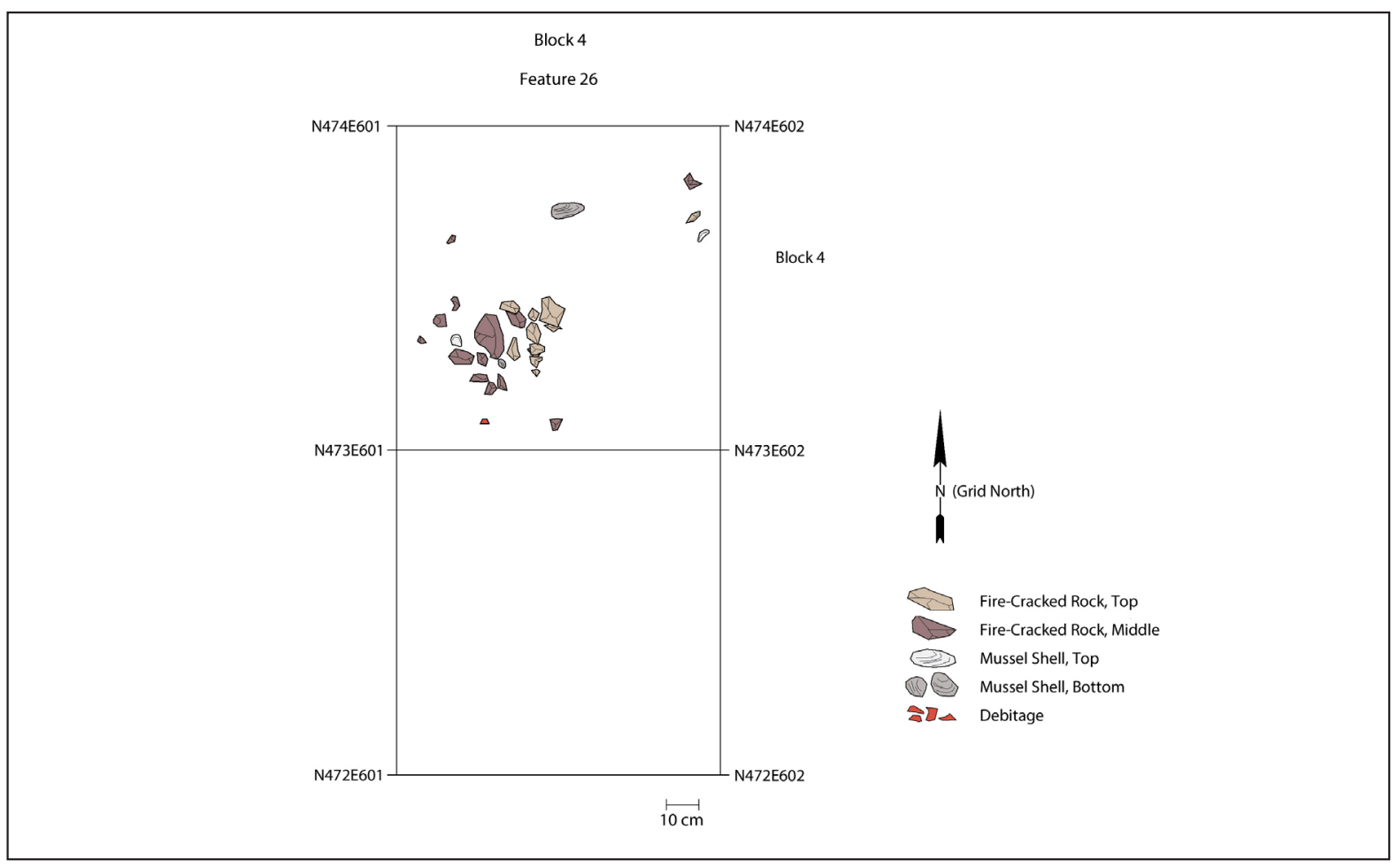

Figure 8-20. Plan view drawing of the Feature 26 cluster of fire-cracked rock in Block 4.

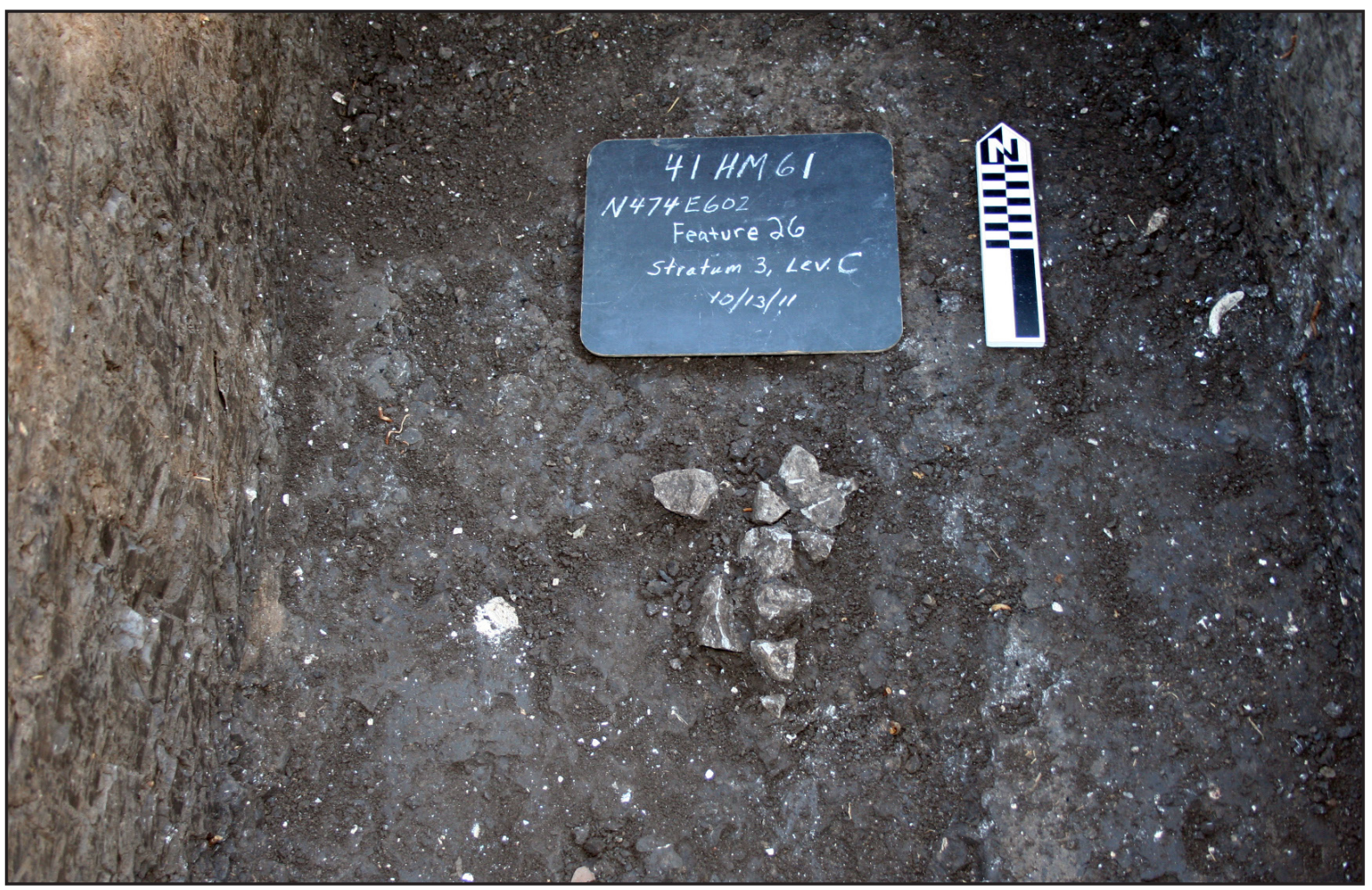

Figure 8-21. Photograph of the small concentration of fire-cracked rock identified as Feature 26 within the upper portion of the Upper West Range A horizon in Unit N474E602 of Block 4. View to the north. $10 / 13 / 11$. 


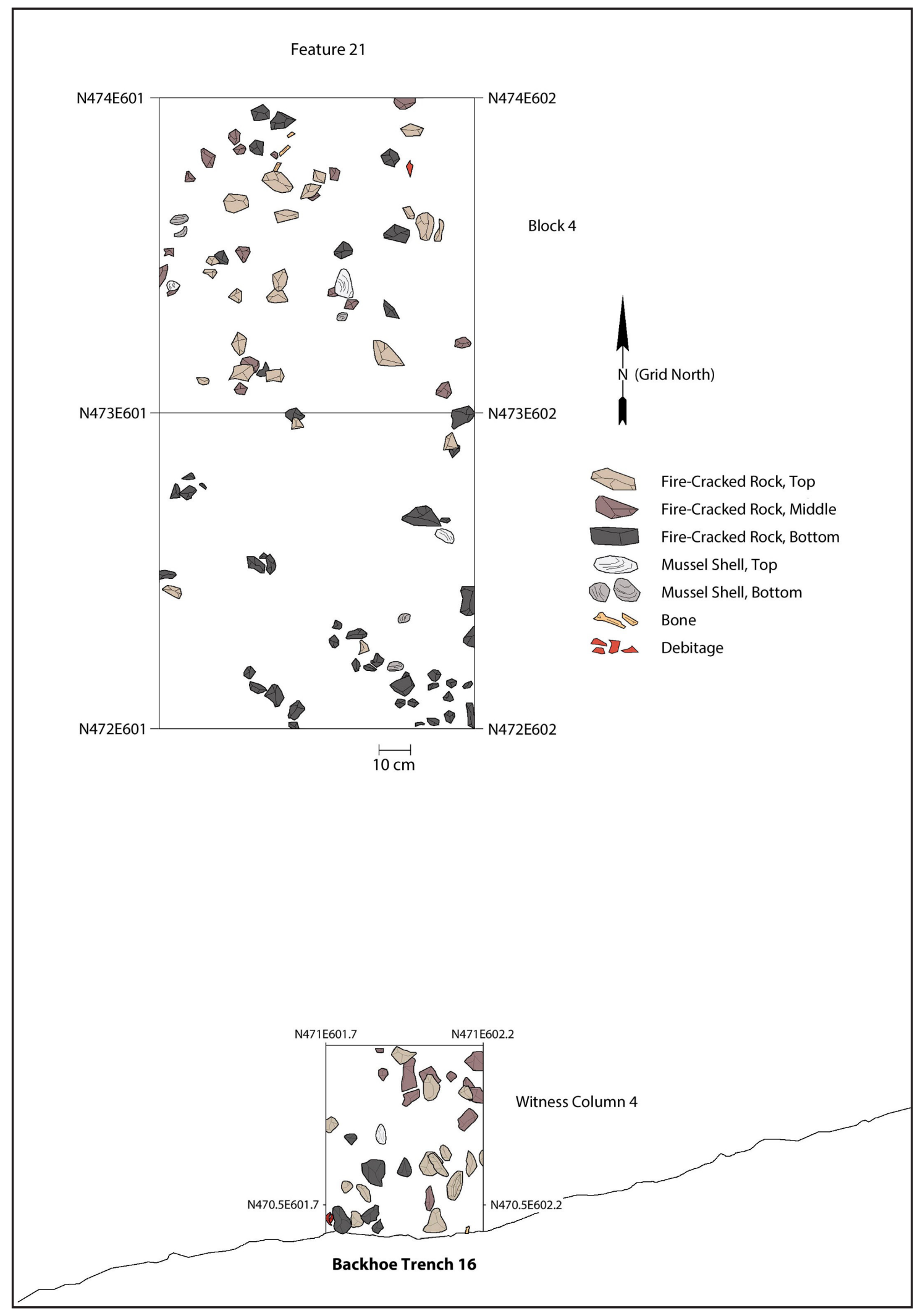

Figure 8-22. Plan view drawing of the fire-cracked rock within Block 4 thought to possibly be an extension of Feature 21 in WC 4. 


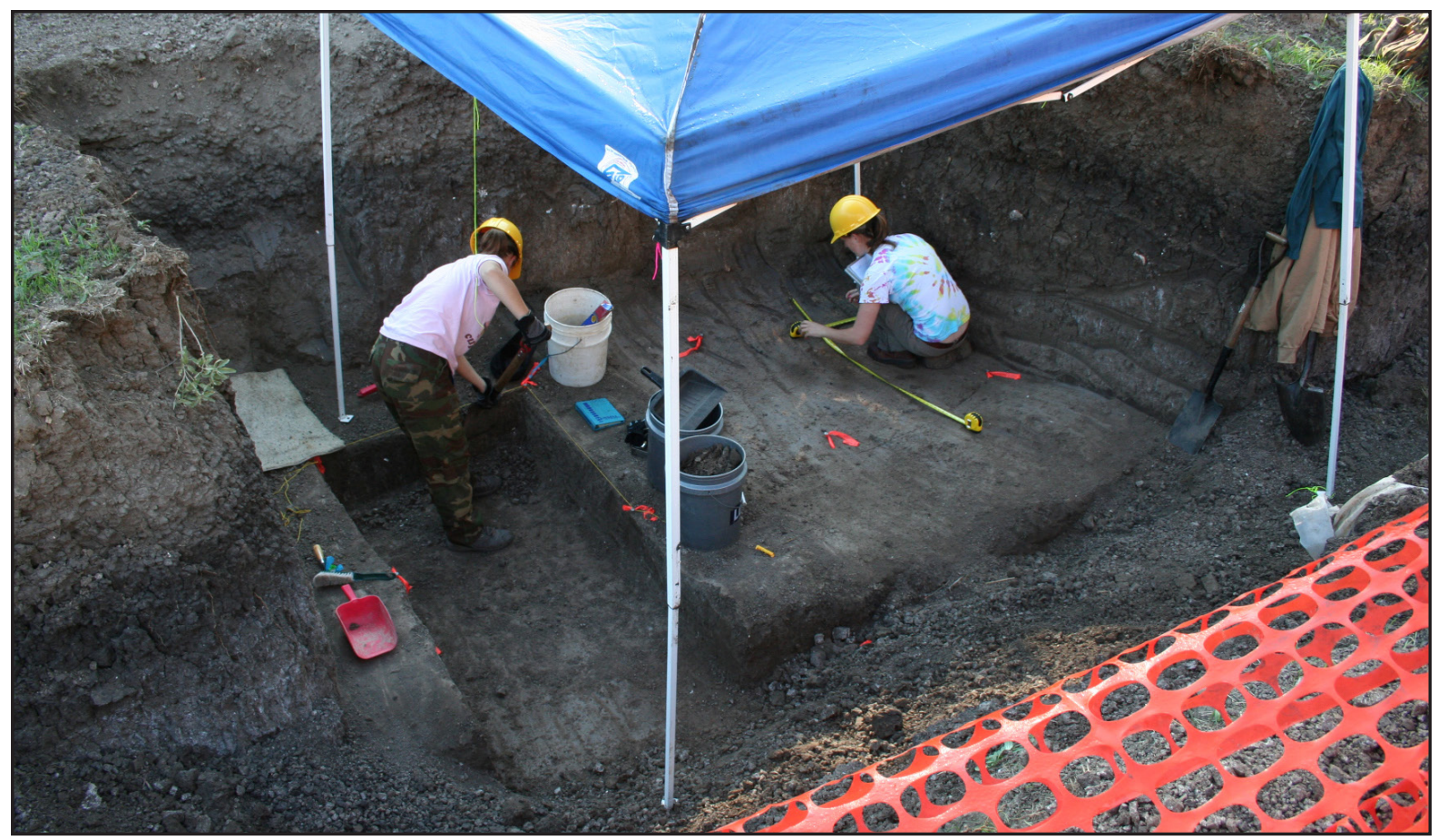

Figure 8-23. Photograph of Sally Morehead (left) and Stephanie McKernan working in Block 5. The backhoe has removed most of the West Range alluvium overlying the deep Archaic deposit, although another 20 to $30 \mathrm{~cm}$ still needed to be taken out to reach the Feature 18 shell deposit (as seen in the two northern 1-by-1-m units to the left). McKernan is recording the extent of Feature 27 in the two southern 1-by-1-m units to the right. View to the southeast. 10/25/11.

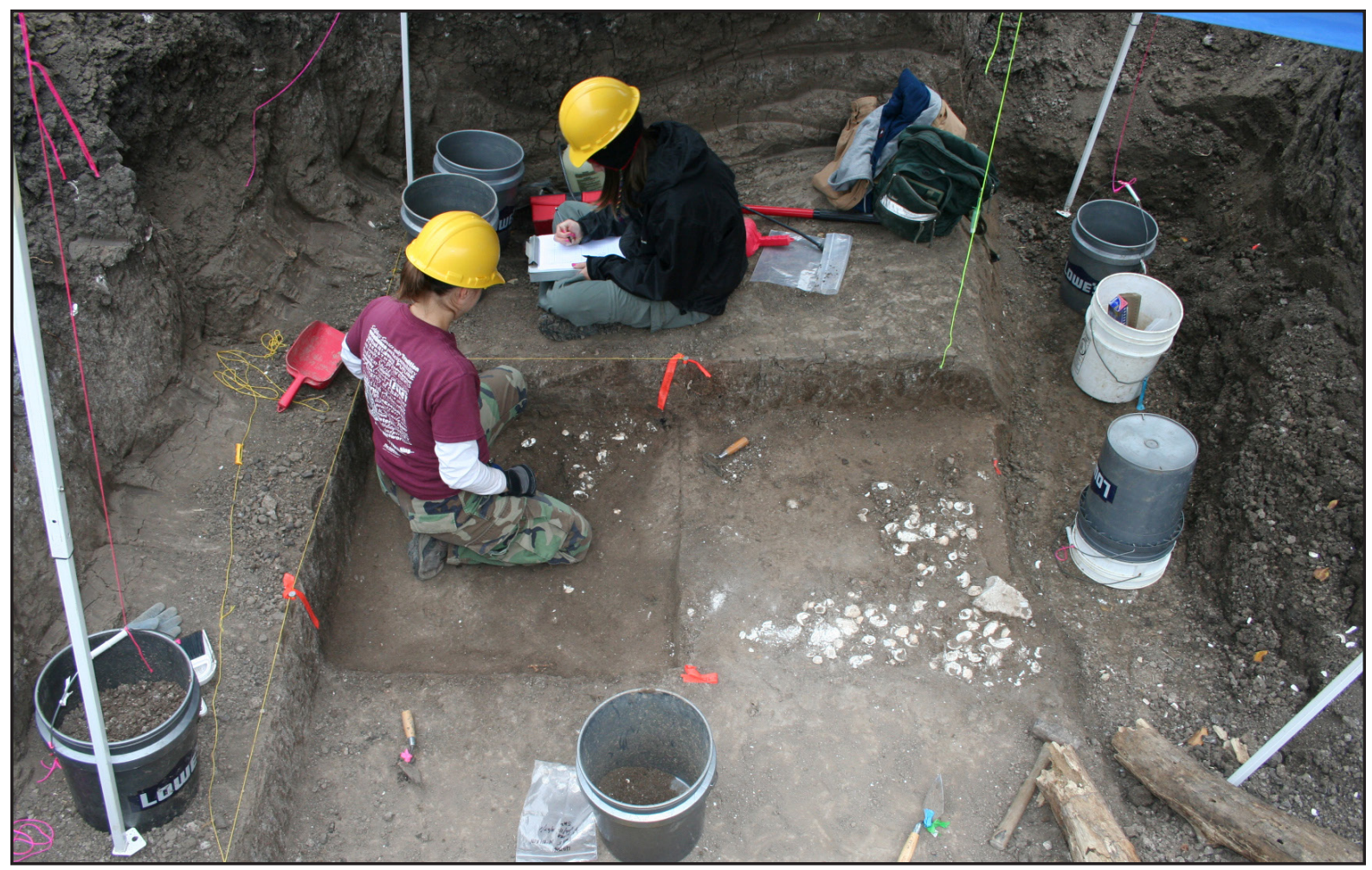

Figure 8-24. Photograph of the continuing excavation of Block 5. At this point, the Feature 18 shell deposit (to the right) has been almost entirely exposed, while Morehead is removing the soil overlying Feature 28. View to the south. 10/27/11. 
Block 5

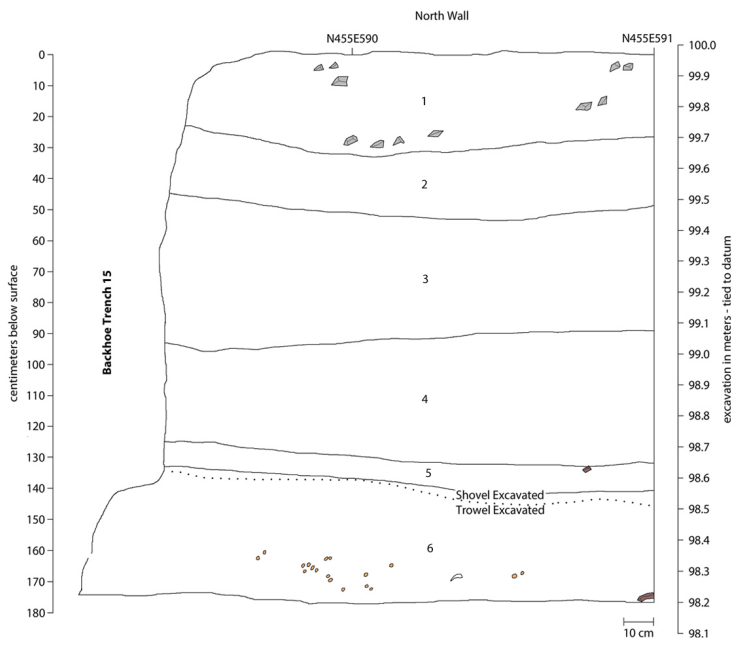

1 Dark grayish brown (10YR 4/2) sandy clay loam to loam

2 Very dark grayish brown (10YR 3/2) clay

3 Black (10Yr 2/1) clay

4 Dark gray (10YR 4/1) clay

5 Brown (10YR 5/3) sandy clay loam

6 Very dark gray (10YR 3/1) silty clay
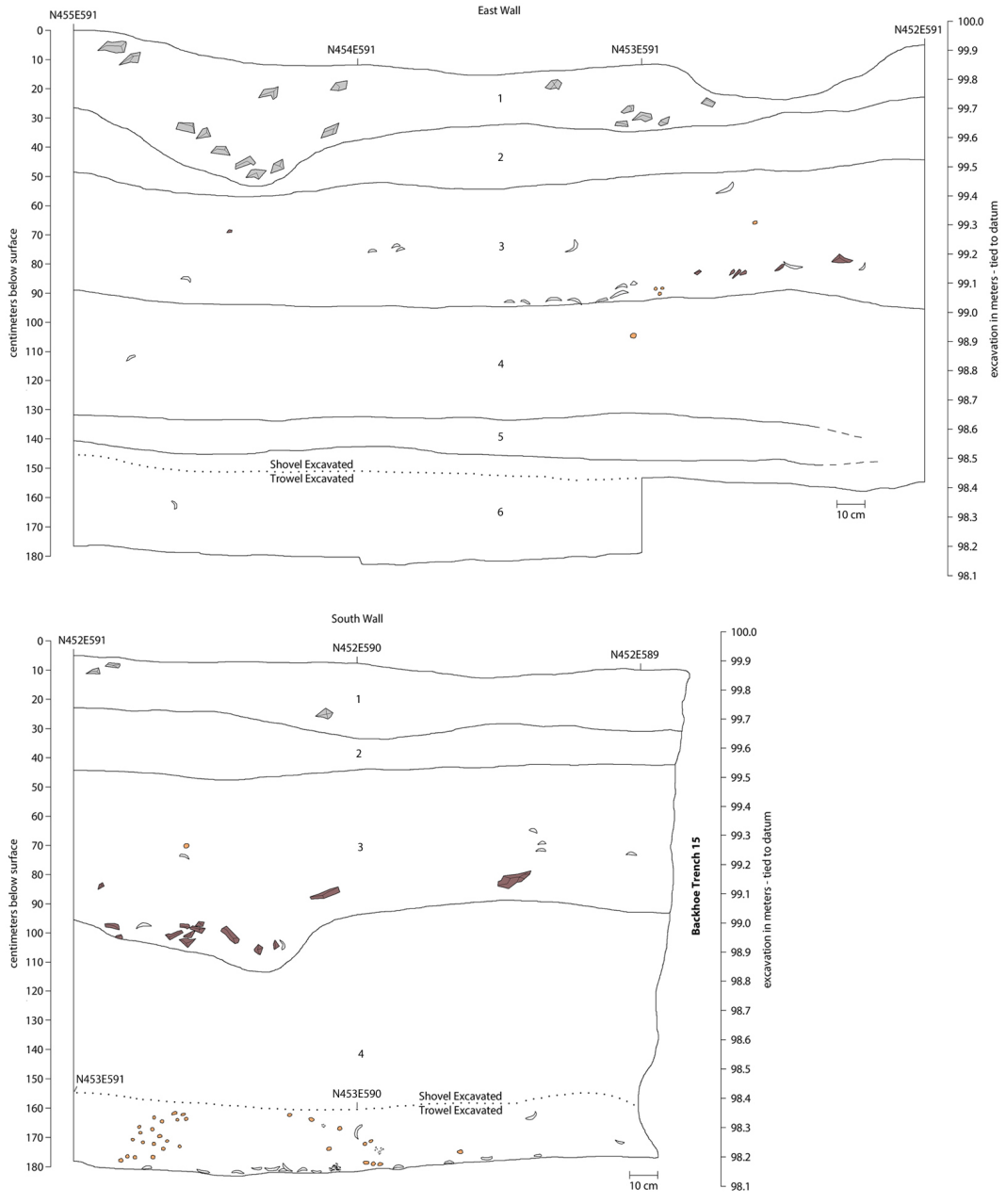

Figure 8-25. Profile drawings of the three walls of Block 5. Note the layer of mussel shell at the base of the south wall. These mark the location of Feature 28. 


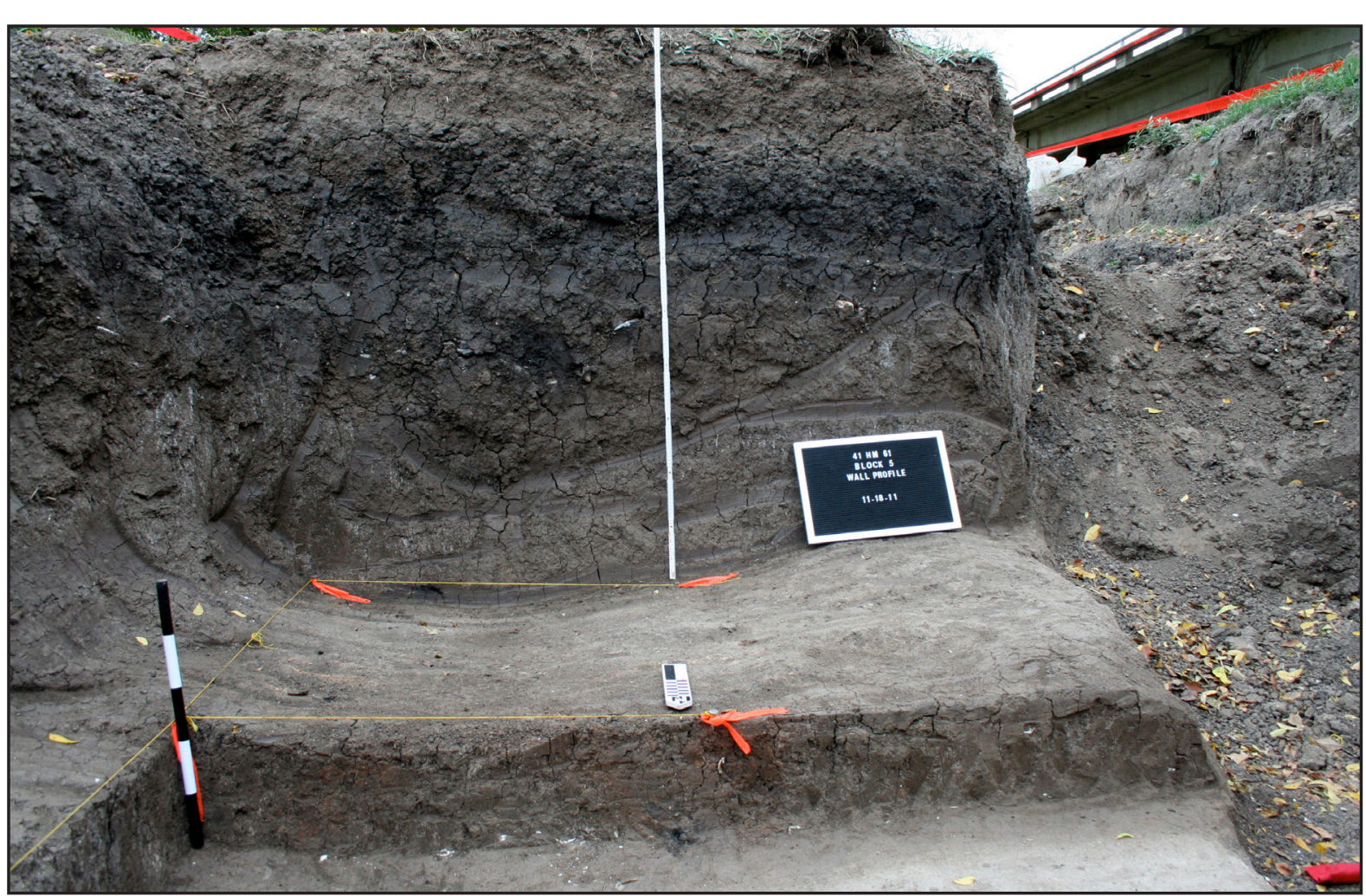

Figure 8-26. Photograph of the south wall profile of completed Block 5. Note the thin layer of shell related to Feature 28 in the foreground at the base of the hand-excavated area plus the layer of fire-cracked living surface that was cut through and removed by the backhoe. View to the south. 11/18/11.

\begin{tabular}{|c|c|c|}
\hline \multirow[t]{2}{*}{ Table 8-8. } & \multicolumn{2}{|c|}{$\begin{array}{l}\text { Block 5: Excavated Strata and Levels and Corresponding Natural Strata as Identified on Wall } \\
\text { Profiles. }\end{array}$} \\
\hline & $\begin{array}{c}\text { Excavated Strata } \\
\text { and Levels } \\
\text { (Depth Below NE Corner } \\
\text { of Unit N455E590) }\end{array}$ & $\begin{array}{l}\text { Natural Strata on } \\
\text { Wall Profiles } \\
\text { (Elevation Based } \\
\text { on Site Datum) }\end{array}$ \\
\hline & $\begin{array}{c}\text { Strata Not Defined } \\
(0-139 \mathrm{~cm}) \\
\text { (Mechanically removed by } \\
\text { backhoe -no material } \\
\text { saved or screened) }\end{array}$ & $\begin{array}{c}\text { Strata } 1 \text { to } 6 \\
\text { (Disturbed Ford Alluvium, } \\
\text { Ford Alluvium, } \\
\text { A Horizon, West Range Alluvium, } \\
\text { West Range Alluvium) } \\
\text { (99.97 to } 98.58 \mathrm{~m} \text { ) }\end{array}$ \\
\hline & 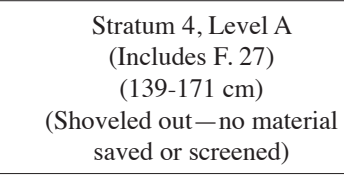 & $\begin{array}{c}\text { Stratum } 6 \\
\text { (Includes F.27) } \\
\text { (West Range Alluvium) } \\
\text { (98.58 to } 98.26 \mathrm{~m} \text { ) }\end{array}$ \\
\hline & $\begin{array}{c}\text { Stratum 4, Level B } \\
\text { (Includes F. } 18 \text { and F. 28) } \\
(171-180 \mathrm{~cm})\end{array}$ & $\begin{array}{c}\text { Stratum } 6 \\
\text { (Includes F. } 18 \text { and F. 28) } \\
\text { (West Range Alluvium) } \\
\text { (98.26 to } 98.17 \mathrm{~m} \text { ) }\end{array}$ \\
\hline
\end{tabular}

Note: Depths based on elevations of the NE corner of Unit N455E590, which served as the block's datum during excavation
Table 8-7. Material Recovered from the Block 5 Excavations

\begin{tabular}{|c|c|c|c|c|}
\hline \multirow{2}{*}{ Material Recovered } & \multicolumn{2}{|c|}{$\begin{array}{c}\text { Stratum } 6 \\
\text { (1717-180 cmbd) }\end{array}$} & \multicolumn{2}{|c|}{ Totals } \\
\hline & No. & Wt. & No. & Wt. \\
\hline Debitage & & & & \\
\hline Flakes & 2 & 3.7 & 2 & 3.7 \\
\hline Fire-Cracked Rock & 1 & $1,040.0$ & 1 & $1,040.0$ \\
\hline Vertebrate Remains & & & & \\
\hline Unburned Bone & 44 & 42.5 & 44 & 42.5 \\
\hline Invertebrate Remains & & & & \\
\hline Mussel Shell & - & $1,188.0$ & - & $1,188.0$ \\
\hline Snail Shell & 18 & 7.0 & 18 & 7.0 \\
\hline Totals & 65 & $2,281.2$ & 65 & $2,281.2$ \\
\hline
\end{tabular}

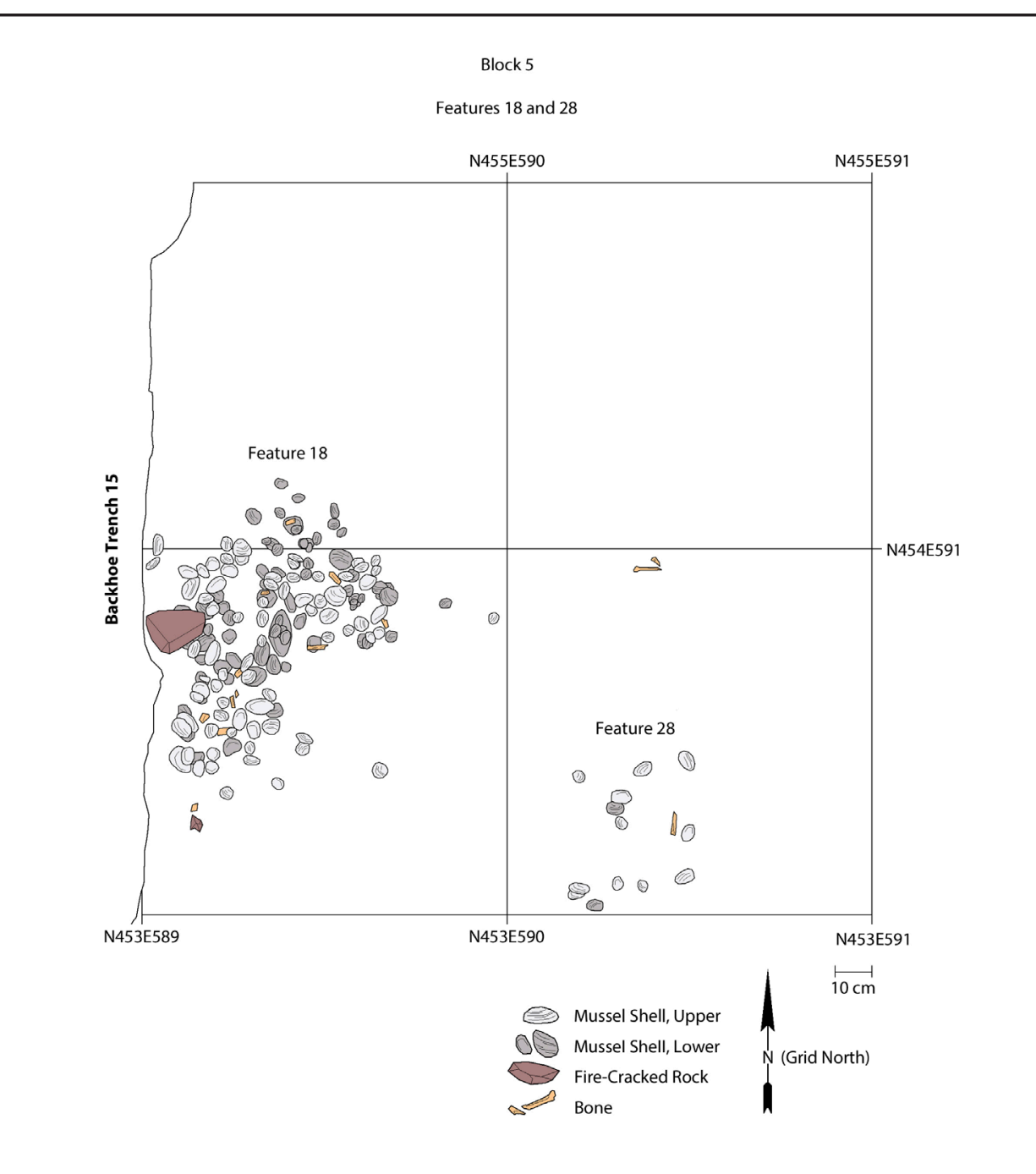

igure 8-27. Plan view drawing of the mussel shell associated with Features 18 and 



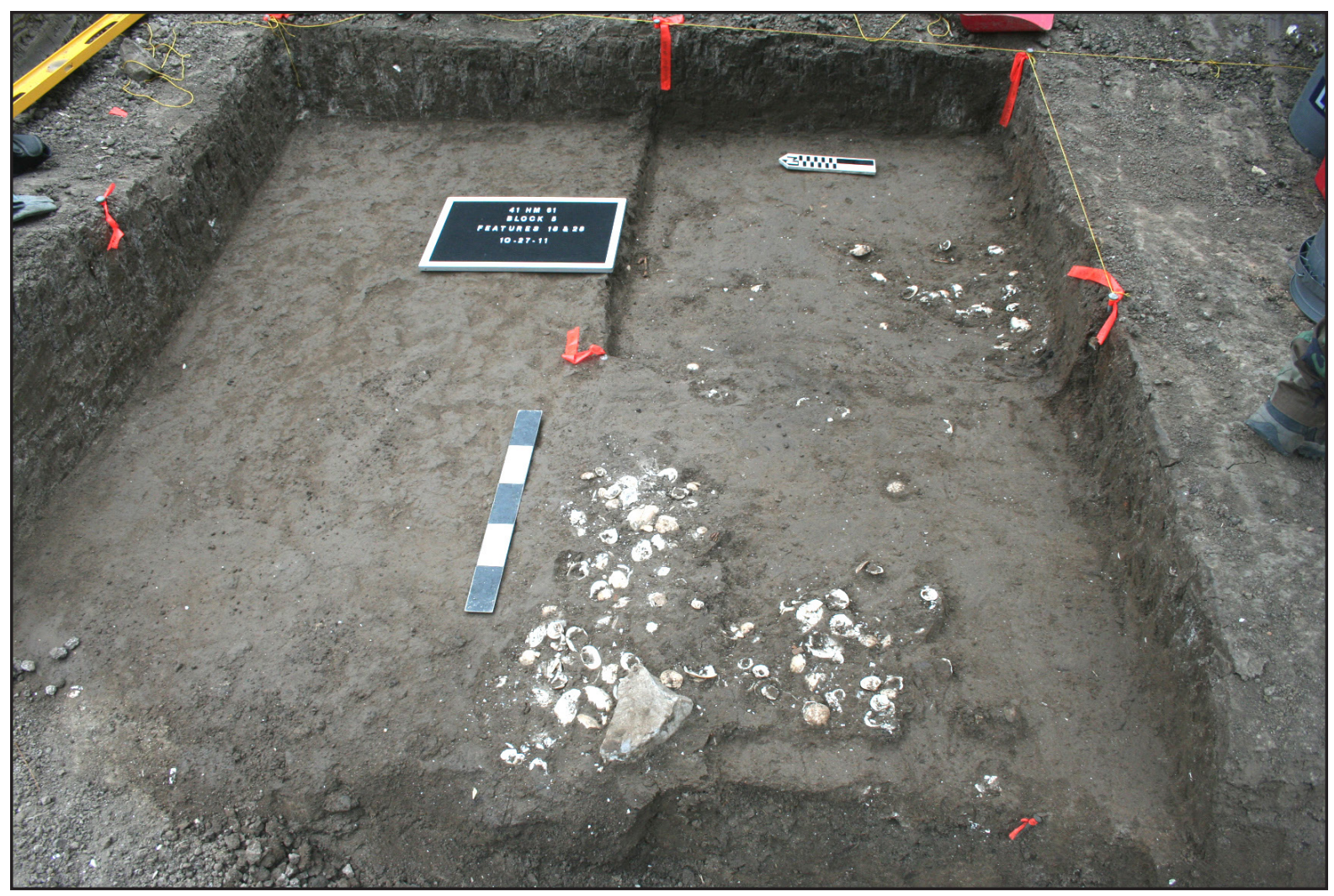

Figure 8-28. Photograph of the extent of Features 18 (foreground) and 28 (upper right) following the removal of overlying Stratum 6 soil. This view shows the four 1-by-1-m units comprising the hand-excavated part of Block 5. View to the east. 10/27/11.

(Text continued from page 158)

edge of the trench eastward for approximately 3.5 $\mathrm{m}$ (Figures 8-29 through 8-32). Initially, Block 1 contained six complete 1-by-1-m units (N601E596, N601E597, N601E598, N602E596, N602E597, N602E598, N603E596, N603E597, and N603E598) and three incomplete units situated at the western edge of the block adjacent to BT 4/19 (N601E595, N602E595, and N603E595). As usual, all of the units were identified by the grid coordinates of their northeast corners, while the northeastern corner for the entire block (at N603E598) served as the location for the line level used to record all depth measurements.

Figures 8-33 and 8-34 illustrate the three walls of Block 1, while Table 8-9 provides a list of artifacts and other cultural items recovered from the block as either field specimens or material captured in the 1/4-inch screen. Similarly, Table 8-10 provides details on the relationship between the excavated strata and levels and the actual strata revealed on the wall profiles. As done previously in Blocks 2 and 4, the upper 50 to 70 $\mathrm{cm}$ or so of the block were removed by shovel and discarded in an effort expedite the excavation. This resulted in the removal of Strata 1 through 4 and partial removal of Stratum 5. Since excavation of WC 1 had shown that these strata either represented disturbed construction layers or non-cultural Ford alluvium, removal by shovel was considered to be a quick and efficient means to reach the top of the West Range A horizon in which the Toyah occupation was located.

Controlled trowel excavation began within the lower few centimeters of Stratum 5 and continued into the subsequent A horizon of Stratum 7 (there was no Stratum 6 in the area of Block 1, though it was present elsewhere along the walls of combined BT 4/19) (Figure 8-35). Thus, the 42-to-48-cm level removed the last of the Ford alluvium in order to expose the top of the Stratum 7 A horizon. As a precaution to make sure the Ford alluvium truly was culturally sterile, all soil from this level was screened. Like the Ford alluvium in WC 1 , only a few pieces of fire-cracked rock and unburned bone came from the level that took out the Ford alluvium in the block (see Table 8-9). It is likely, however, that these items actually were associated with the underlying A horizon but wound up in the 


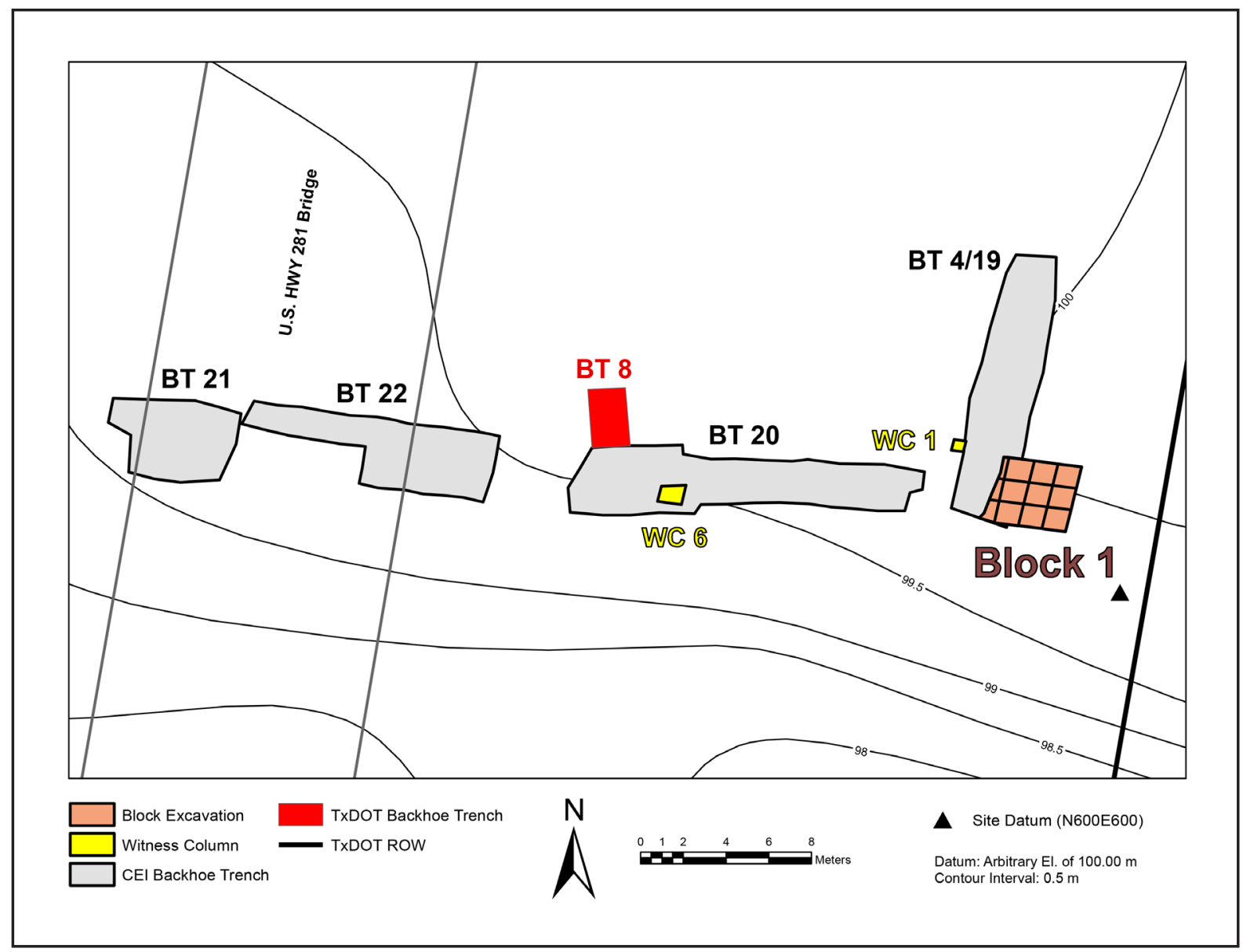

Figure 8-29. Contour map of a portion of the northern part of site 41HM61 showing locations of backhoe trenches, witness columns, and block excavations. Note the location of Block 1 immediately to the east of WC 1 and BT 4/19.

42-to-48-cm level when soil collected during cleaning of the A horizon's surface prior to photographs (including items from the A horizon) was screened and added to the 42-to-48-cm level.

Once the Ford alluvium had been removed, the top of the Stratum 7 A horizon was exposed across all of the western two-thirds of the block. However, it soon became obvious that the eastern third of the block had been completely disturbed by either a gully or a ditch, as a rubble-filled depression was present across the eastern portions of Units N601E597, N602E597, and N603E597. Probing with an iron rod and the excavation of small shovel holes in the easternmost units of the block showed that this rubble-filled depression continued all the way to the block's eastern wall. At that point, the decision was made to eliminate the easternmost units (N601E598, N602E598, and N603E598) from further excavation. Thus, that portion of Block 1 subjected to controlled hand excavation was reduced to the area between the eastern wall of BT 4/19 and the western edge of the rubble-filled depression. Figures 8-36 and 8-37 provide plan views atop the Stratum $7 \mathrm{~A}$ horizon and illustrate that portion of Block 1 removed by controlled excavation, while Figures 8-38 and 8-39 show crew members removing the A horizon.

The Stratum 7 A horizon was taken out by three consecutive cuts (48-to-59-, 59-to-69-, and 69-to-79$\mathrm{cm}$ levels), each of which was $10 \mathrm{~cm}$ thick. Since the A horizon was almost exactly $30 \mathrm{~cm}$ thick, there was no need to excavate any additional levels, and digging ceased once the top of the lighter-colored soil of the underling West Range alluvium was encountered. One thing that became clear during excavation of the A horizon was that the majority of the Toyah-related material ( $n=174)$ occurred within the first $10-\mathrm{cm}$ thick cut (the 48-to-59-cm level), with most found in the lower few centimeters of that level. The second 10-cm-thick cut (the 59-to-69-cm level) produced the next highest amount of material $(n=68)$, with most coming from the upper few centimeters within that 


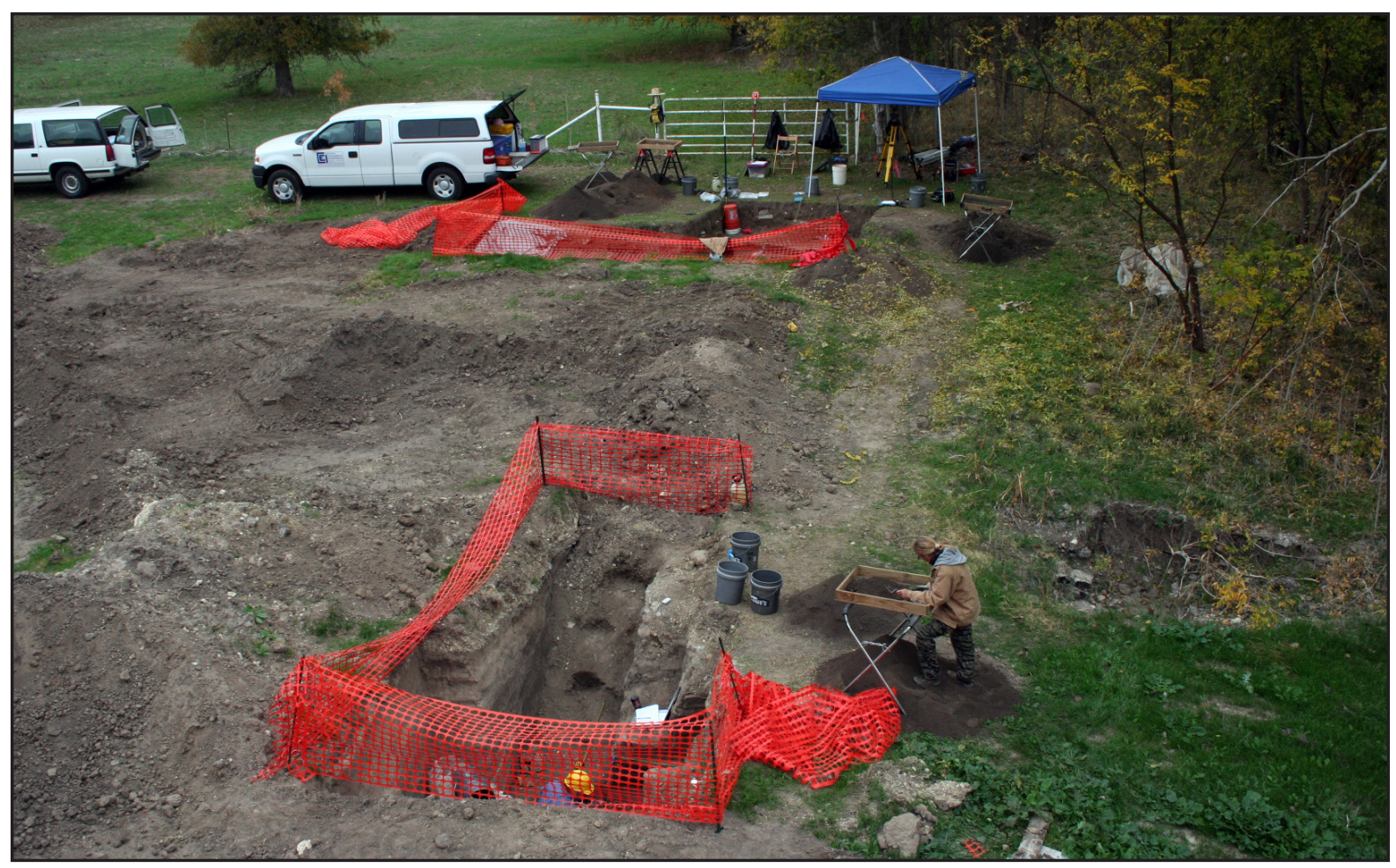

Figure 8-30. Photograph of Block 1 (in the distance in front of canopy) and WC 6 (in the foreground within BT 20) from the U.S. Highway 281 bridge. At this point during the fieldwork, most of BTs 4/19 and 20 had been backfilled. Looking east. 11/16/11.

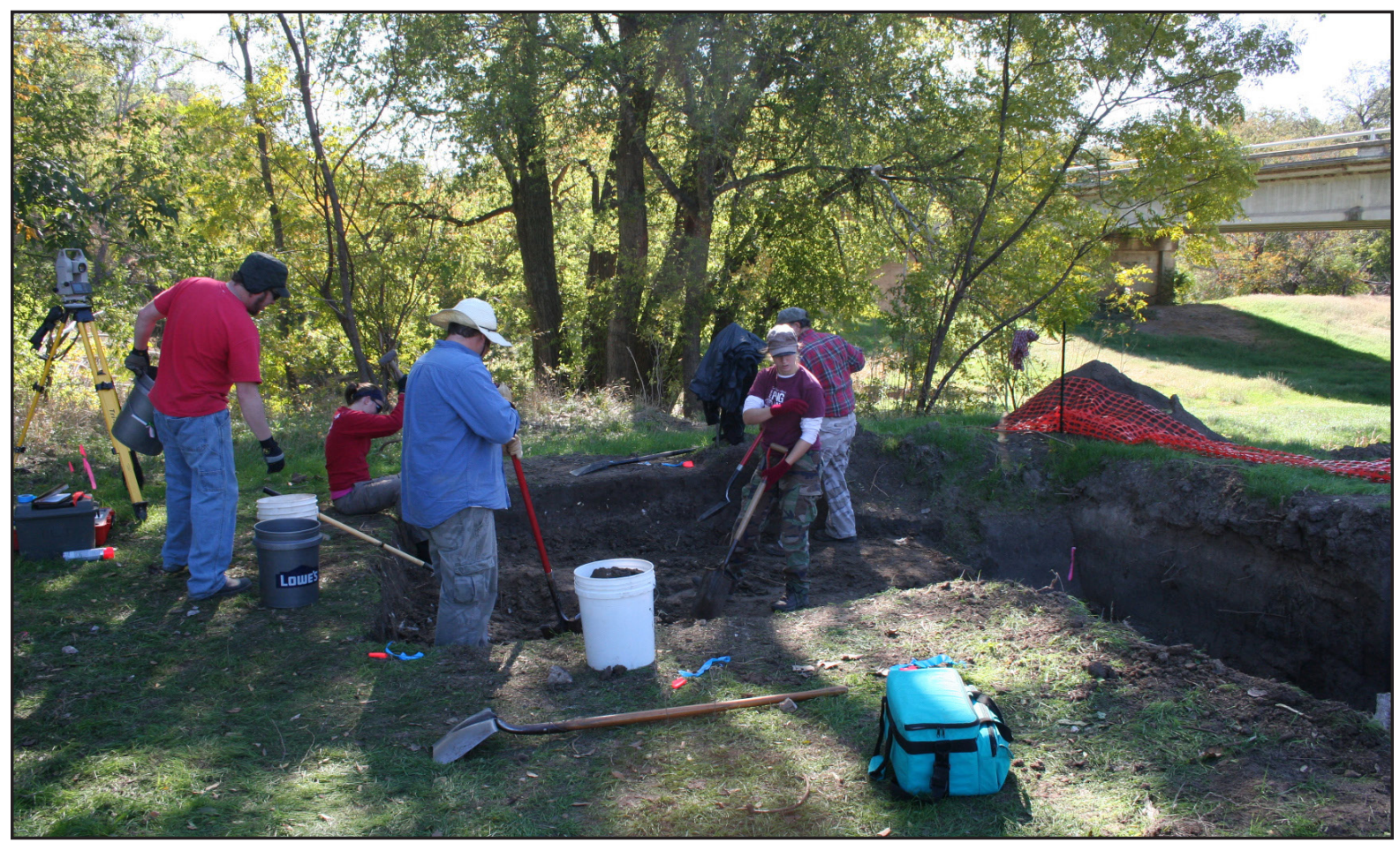

Figure 8-31. Photograph of crew members shoveling out the upper 50 to $70 \mathrm{~cm}$ of overburden in Block 1 to reach the top of the West Range A horizon containing the Toyah occupation. View to the south-southwest with the south end of BT 4/20 to the right. 11/10/11. 


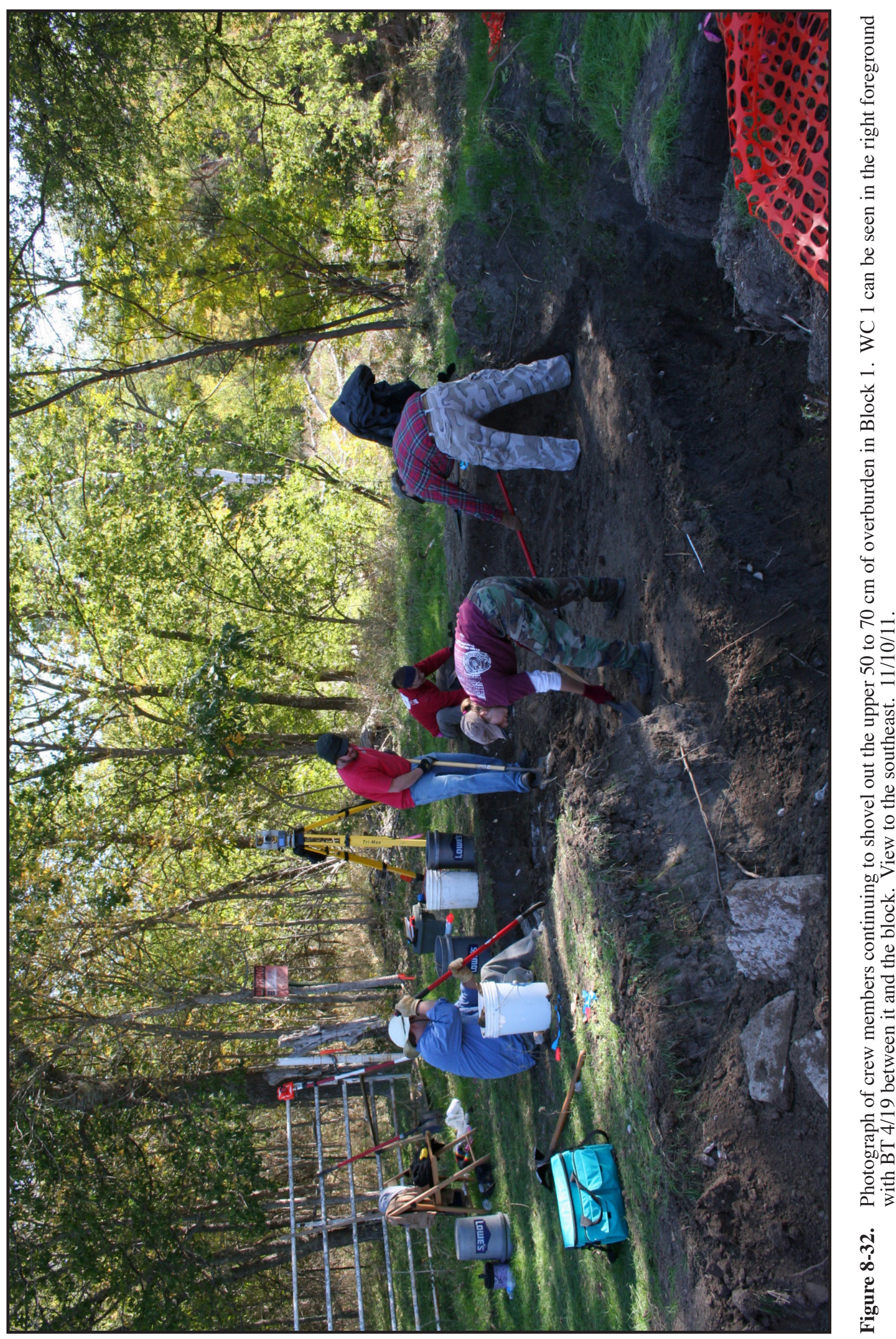



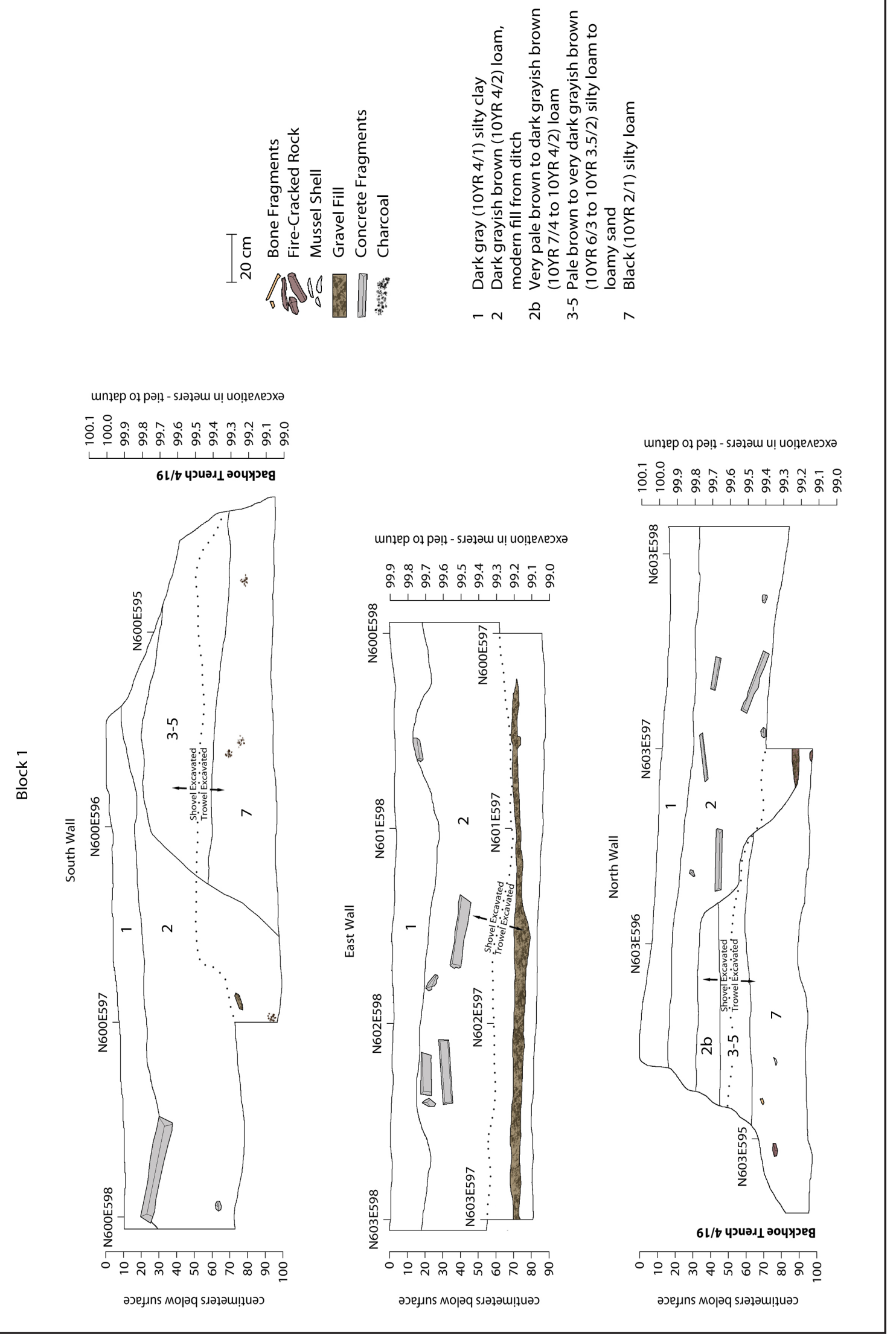

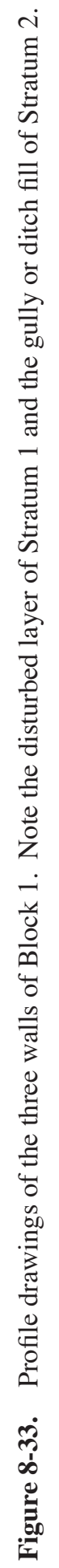




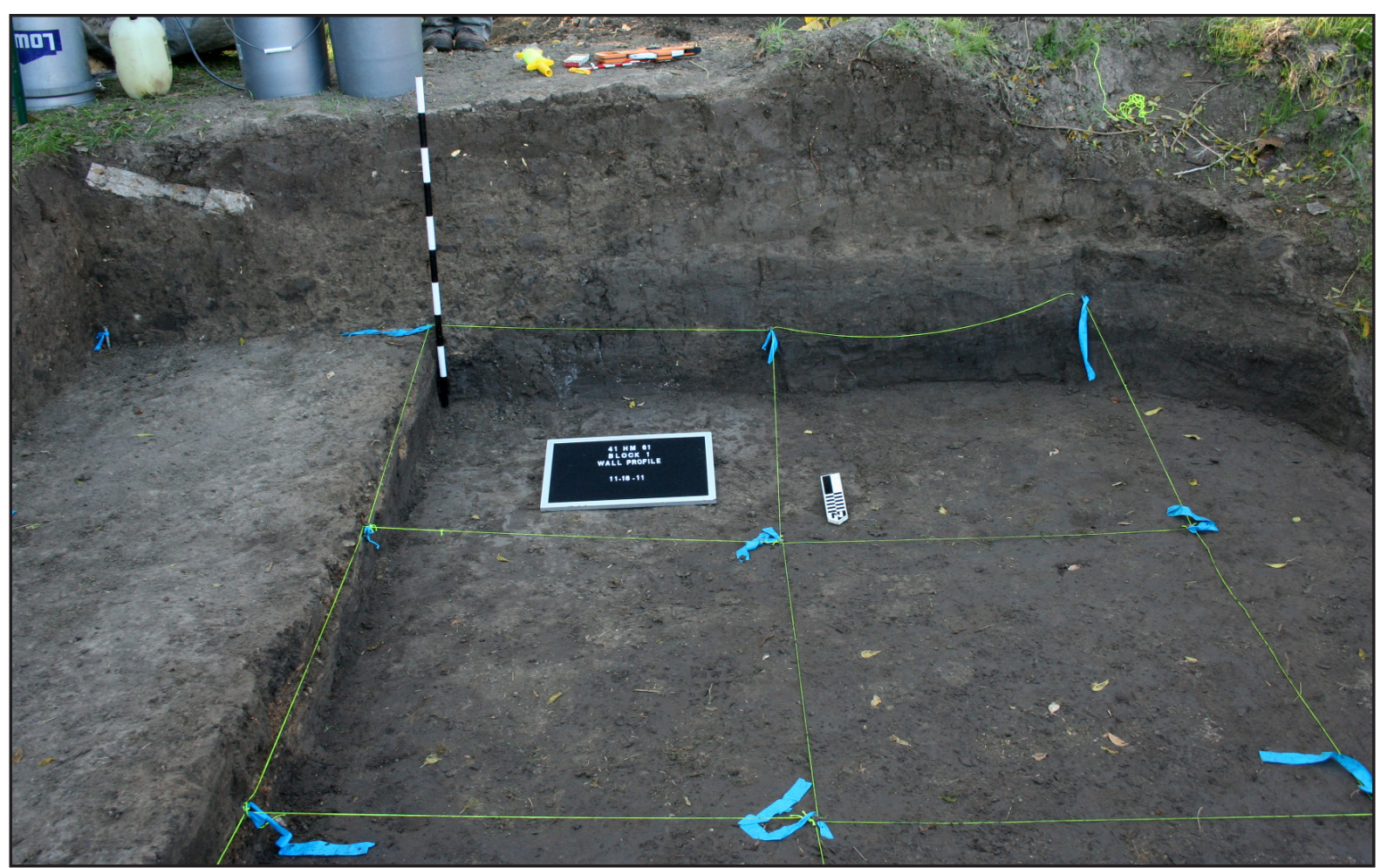

Figure 8-34. Photograph of the south wall profile of Block 1. Note the relatively thick zone of disturbed Ford alluvium at the top of the profile plus the large cement slab present within the gully or ditch fill in the upper left-hand corner of the profile. The dark soil of the West Range A horizon can be seen in the lower $30 \mathrm{~cm}$ of the profile. View to the south. 11/18/11.

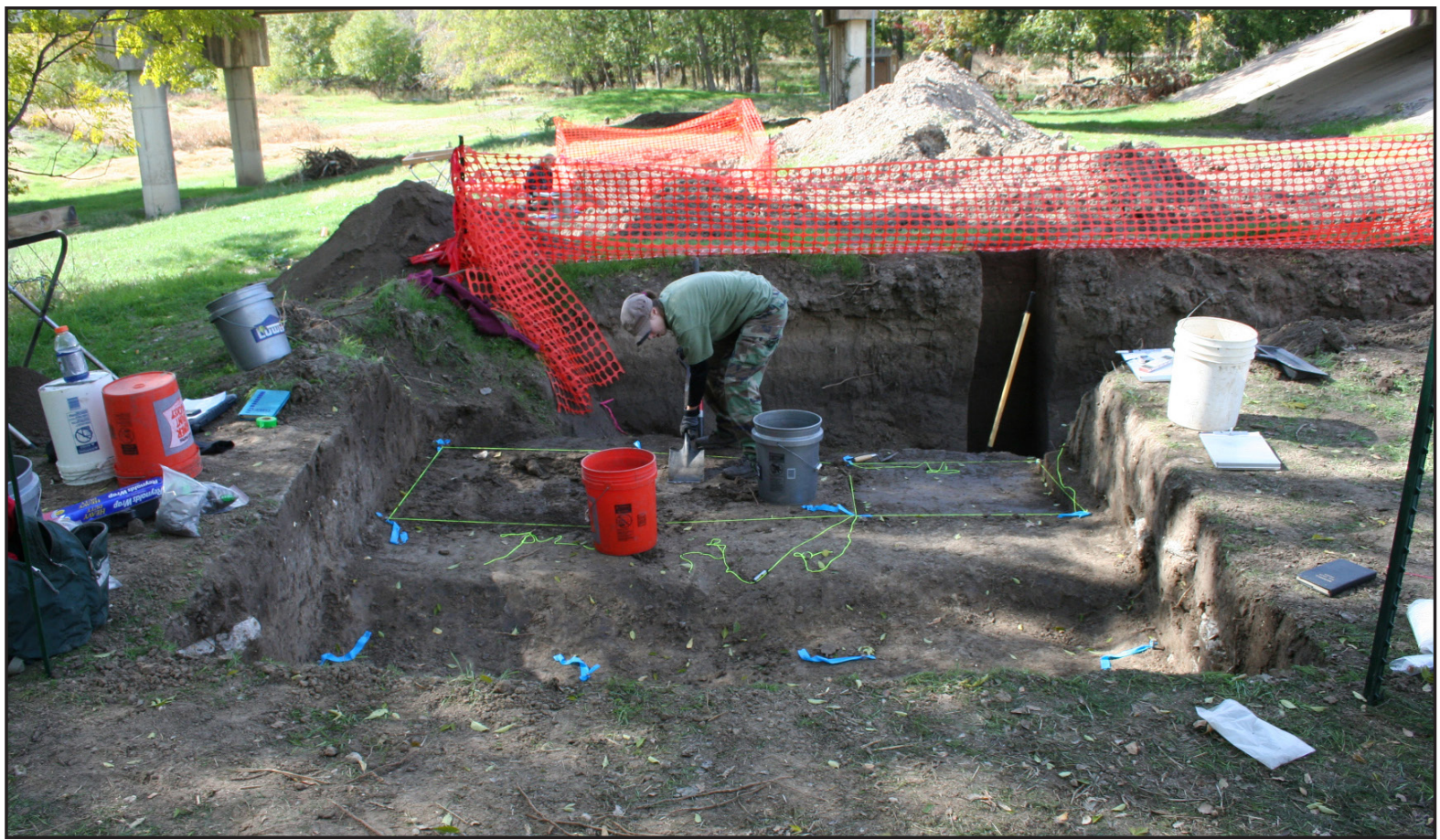

Figure 8-35. Photograph of the commencement of controlled excavations in Block 1 by shovel skimming and the use of trowels. In this photograph, the northernmost 1-by-1-m unit has been taken down to the top of the A horizon, while the excavator is removing the Ford alluvium in the other two units. View to the west. 11/11/11. 
Table 8-9. Material Recovered from the Block 1 Excavations.

\begin{tabular}{|c|c|c|c|c|c|c|c|c|c|c|}
\hline \multirow{3}{*}{ Material Recovered } & \multirow{2}{*}{\multicolumn{2}{|c|}{$\begin{array}{c}\text { Strata 3-5 } \\
(42-48 \mathrm{cmbd})\end{array}$}} & \multicolumn{6}{|c|}{ Stratum 7} & \multirow{2}{*}{\multicolumn{2}{|c|}{ Totals }} \\
\hline & & & \multicolumn{2}{|c|}{ (48-59 cmbd) } & \multicolumn{2}{|c|}{ (59-69 cmbd) } & \multicolumn{2}{|c|}{ (69-79 cmbd) } & & \\
\hline & No. & Wt. & No. & Wt. & No. & Wt. & No. & Wt. & No. & Wt. \\
\hline \multicolumn{11}{|l|}{ Bifacial Drill } \\
\hline (Distal End) & - & - & - & - & 1 & 1.2 & - & - & 1 & 1.2 \\
\hline Biface Fragments & - & - & 1 & 5.5 & 1 & 7.1 & - & - & 2 & 12.6 \\
\hline \multicolumn{11}{|l|}{ Debitage } \\
\hline Flakes & - & - & 10 & 17.0 & 6 & 11.0 & 6 & 8.8 & 22 & 36.8 \\
\hline Fire-Cracked Rock & 11 & 117.1 & 35 & $1,564.9$ & 3 & 156.0 & 5 & 14.8 & 54 & $1,852.8$ \\
\hline \multicolumn{11}{|l|}{ Vertebrate Remains } \\
\hline Unburned Bone & 13 & 7.1 & 146 & 494.4 & 64 & 152.9 & 23 & 14.4 & 246 & 668.8 \\
\hline Burned Bone & - & - & 4 & 2.5 & - & - & - & - & 4 & 2.5 \\
\hline \multicolumn{11}{|l|}{ Invertebrate Remains } \\
\hline Mussel Shell & - & 13.3 & - & 104.8 & - & 131.3 & - & 76.8 & - & 326.2 \\
\hline Snail Shell & 12 & 0.9 & 6 & 1.1 & 25 & 3.0 & 3 & 2.0 & 46 & 7.0 \\
\hline Totals & 36 & 138.4 & 202 & $2,190.2$ & 100 & 462.5 & 37 & 116.8 & 375 & $2,907.9$ \\
\hline
\end{tabular}

Note: Weights are in grams.

Table 8-10. $\quad$ Block 1: Excavated Strata and Levels and Corresponding Natural Strata as Identified on Wall Profiles.

\begin{tabular}{|c|c|}
\hline $\begin{array}{c}\text { Excavated Strata } \\
\text { and Levels } \\
\text { (Depth Below NE Corner } \\
\text { of Unit N602E596) }\end{array}$ & $\begin{array}{l}\text { Natural Strata on } \\
\text { Wall Profiles } \\
\text { (Elevation Based } \\
\text { on Site Datum) } \\
\end{array}$ \\
\hline $\begin{array}{c}\text { Strata Not Defined } \\
(0-42 \mathrm{~cm}) \\
\text { (Shoveled out }- \text { no material } \\
\text { saved or screened) }\end{array}$ & $\begin{array}{c}\text { Strata1 to } 5 \\
\text { (Disturbed Ford Alluvium } \\
\text { \& Ford Alluvium) } \\
\text { (100.01 to } 99.59 \mathrm{~m})\end{array}$ \\
\hline $\begin{array}{l}\text { Stratum 3, Level A } \\
\quad(42-48 \mathrm{~cm})\end{array}$ & $\begin{array}{c}\text { Strata } 3 \text { to } 5 \\
\text { (Ford Alluvium) } \\
(99.59 \text { to } 99.51 \mathrm{~m})\end{array}$ \\
\hline $\begin{array}{l}\text { Stratum 4, Level A } \\
\quad(48-59 \mathrm{~cm})\end{array}$ & $\begin{array}{c}\text { Stratum } 7 \\
\text { (A Horizon, West Range Alluvium) } \\
(99.51 \text { to } 99.40 \mathrm{~m})\end{array}$ \\
\hline $\begin{array}{l}\text { Stratum 4, Level B } \\
\quad(59-69 \mathrm{~cm})\end{array}$ & $\begin{array}{c}\text { Stratum } 7 \\
\text { (A Horizon, West Range Alluvium) } \\
(99.40 \text { to } 99.30 \mathrm{~m})\end{array}$ \\
\hline $\begin{array}{l}\text { Stratum 4, Level C } \\
\quad(69-79 \mathrm{~cm})\end{array}$ & $\begin{array}{c}\text { Stratum } 7 \\
\text { (A Horizon, West Range Alluvium) } \\
(99.30 \text { to } 99.20 \mathrm{~m})\end{array}$ \\
\hline
\end{tabular}

Note: Depths based on elevations of the NE corner of Unit N602E596, which served as the block's datum during excavation. 
Block 1

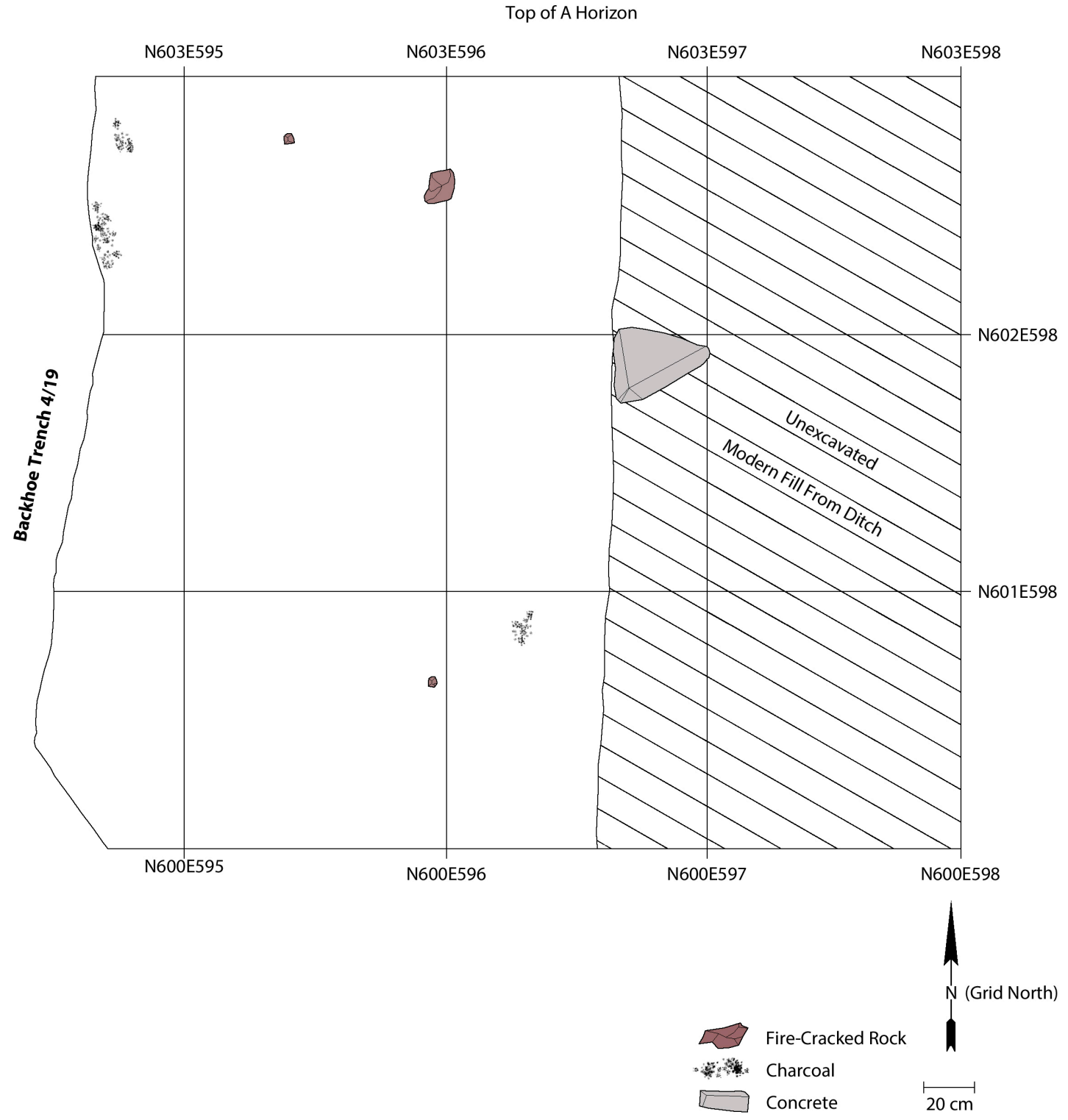

Figure 8-36. Plan view drawing of the top of the A horizon in Block 1. About a third of the potential Toyah zone had been destroyed by a rubble-filled gully or ditch in the eastern portion of the block. 


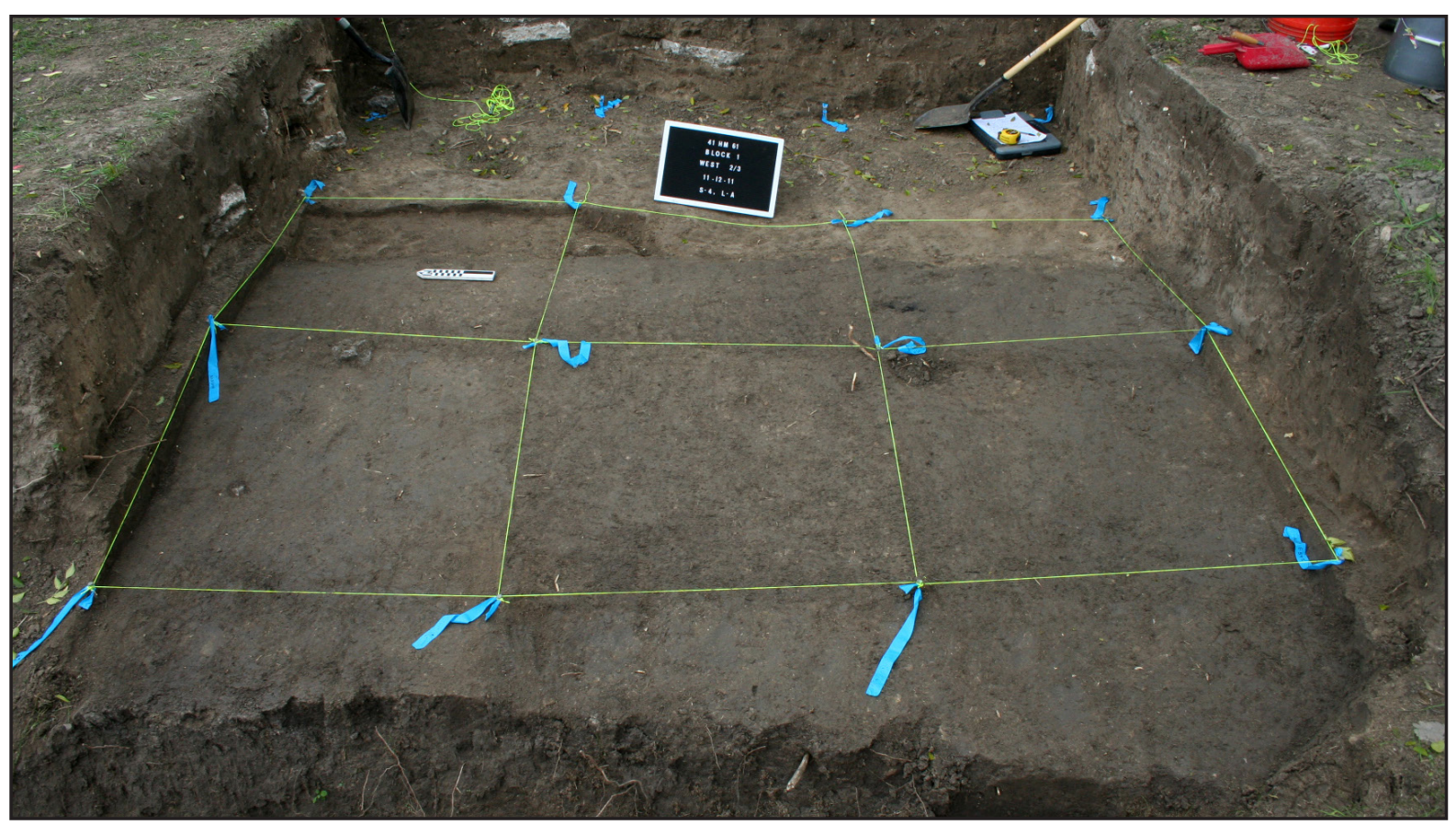

Figure 8-37. Photograph of the top of the Stratum 7 A horizon in Block 1 following the complete removal of the overlying Ford alluvium in the western two-thirds of the block. Note the distinctly lighter soil in the eastern one-third of the block. That area contained the remains of a gully or ditch filled with rubble and cement slabs likely related to highway construction. Some of the slabs are visible in the wall profiles in that area. View to the east. 11/12/11.

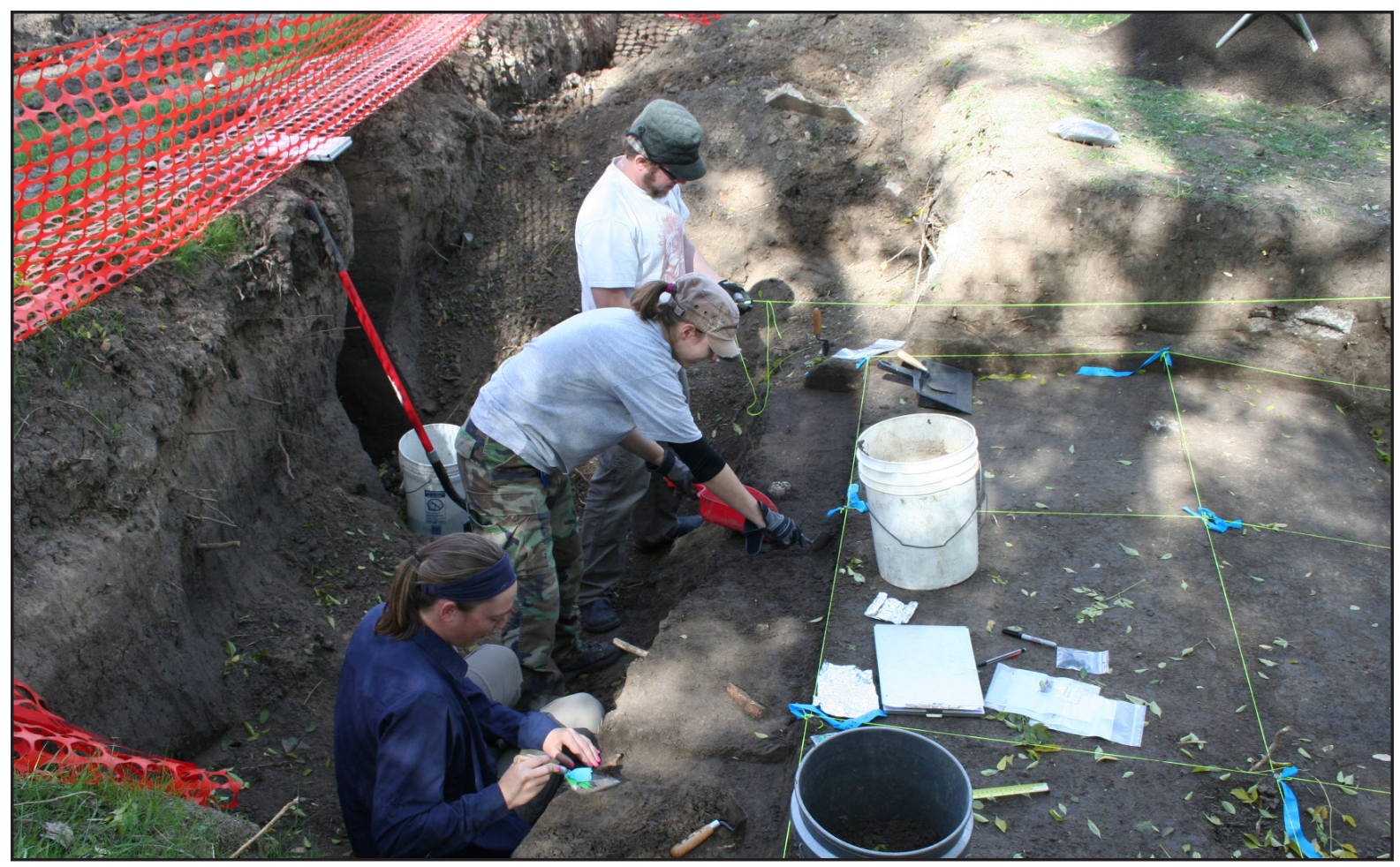

Figure 8-38. Photograph of crew members removing the first $10-\mathrm{cm}$ cut into the Stratum 7 A horizon in the three partial 1-by-1-m units adjacent to BT 4/19. The units to the right have been taken down to the top of the A horizon and are ready for subsequent excavation. View to the north. 11/12/11. 


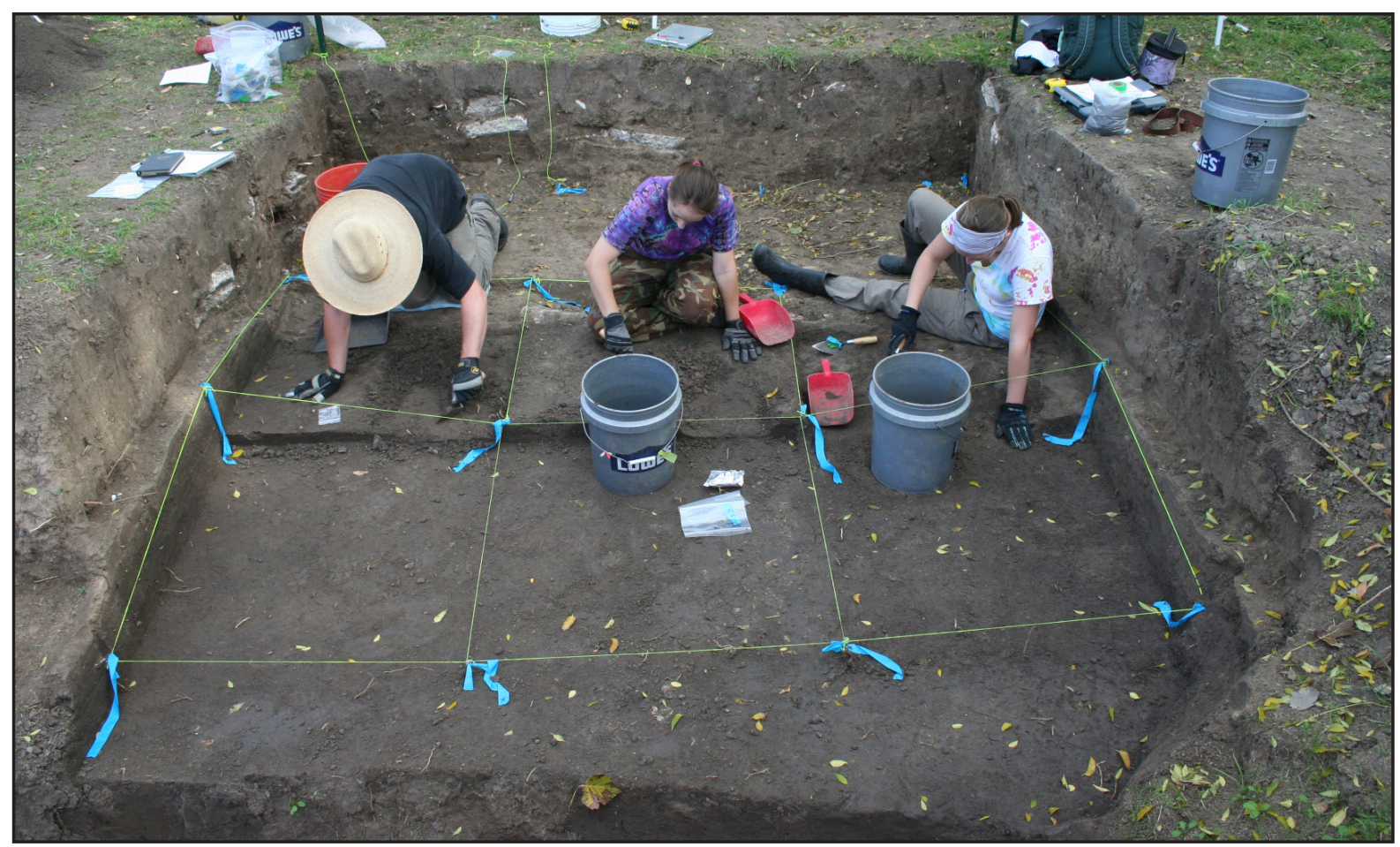

Figure 8-39. Photograph of crew members continuing to excavate the A horizon within Block 1. By the time of this photograph, all of the 48-to-59-cm level has been removed, and the crew is in the process of taking out the last of the $59-$ to- $69 \mathrm{~cm}$ level in the easternmost set of 1-by-1-m units. View to the east. $11 / 15 / 11$.

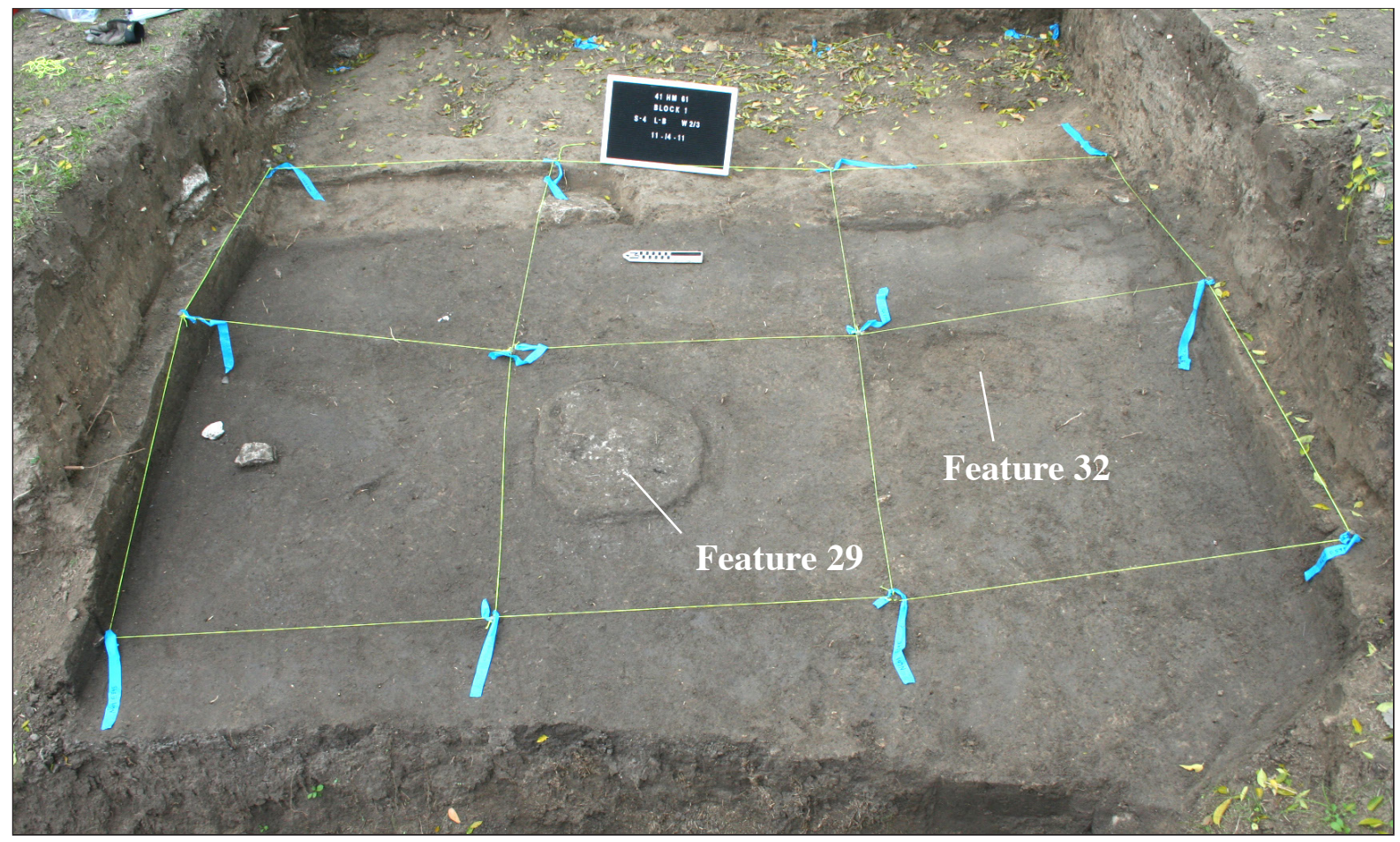

Figure 8-40. Photograph of Block 1 following the removal of the initial 10-cm-thick cut into the Stratum 7 A horizon. Feature 29, a concentration of ash and charcoal, can be seen in the center of the block, while Feature 32, a postmold likely related to a former power pole, is visible in the northeast corner of Unit N601E596. View to the east. 11/14/11. 


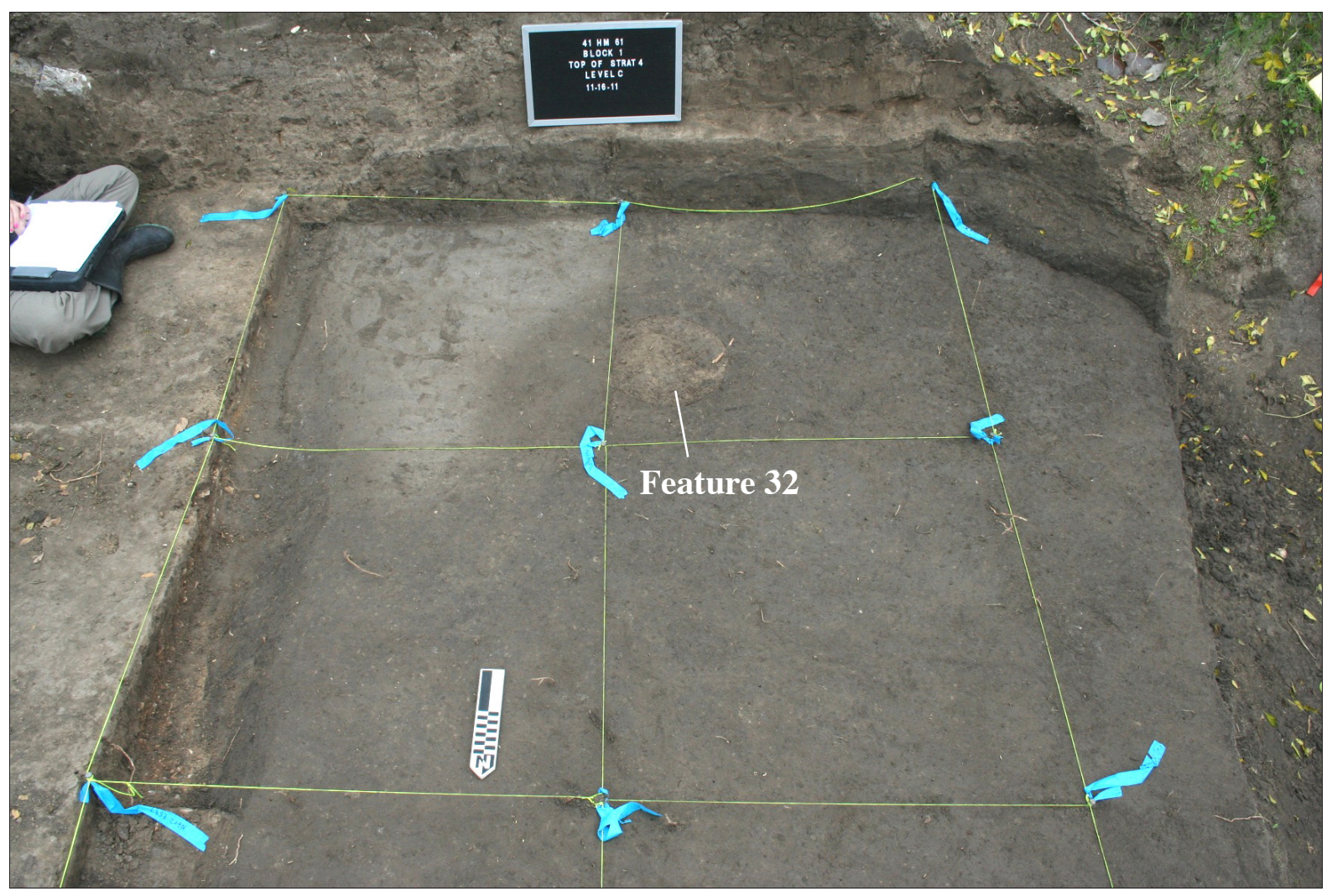

Figure 8-41. Photograph of the southern part of Block 1 after the removal of the upper ca. $20 \mathrm{~cm}$ of the Stratum 7 A horizon. The area of stiff gray clay can be seen to the east (left) of the Feature 32 postmold. View to the south. 11/14/11.

(Text continued from page 166)

level (see Table 8-10). Only 27 scattered cultural items (mostly bone) were found within the third cut (69-79-cm level). This suggests that a single Toyah living surface probably was responsible for the majority of the artifacts and bone within the A horizon, and that it represents a Late Prehistoric occupation that occurred near the top of the horizon.

Although Block 1 had its fair share of artifacts and other cultural remains, there were no concentrations of fire-cracked rocks or mussel shells as found in the Middle and Late Archaic deposits at the site. The only features identified consisted of a concentration of charcoal and ash (Feature 29) within the north-central portion of Unit N602E596 and an historic postmold (Feature 32) located mainly in the northeastern corner of Unit N601E596 (Figure 8-40). The former likely represents nothing more than scattered hearth debris, as opposed to an in situ hearth, as it was only a few centimeters in depth and lacked any surrounding fired soil. The postmold probably was the result of a power pole once present in the area; a guide-wire believed to be associated with the former pole had been un- covered previously in the eastern end of nearby BT 20. Interestingly, a rather large area of hard, tenacious clay (completely different in texture and color from the sandy silt of the A horizon) was found in the southeastern corner of the reduce-sized block, near the Feature 32 postmold (Figure 8-41). Although its true origin is unclear, it is suspected that the clay represents material brought up during the drilling of the hole for the power pole, likely from a clay source deep within the West Range alluvium or the underlying Fort Hood alluvium. No cultural remains were found within the clay, thus helping to support this hypothesis.

Since Block 1 covered the greatest area of any of the hand excavations at site 41HM61, and since it also produced a relatively large quantity of artifacts and other cultural remains, it was hoped that some type of patterning might emerge if all of the field specimens related to Stratum 7 were illustrated. Thus, Figure 8-42 shows the distribution of all of the FSs from the Stratum 7 Toyah component. Unfortunately, no clear evidence of patterning can be seen. About the only thing that can be said, is that mussel shells appear to be situated in the 

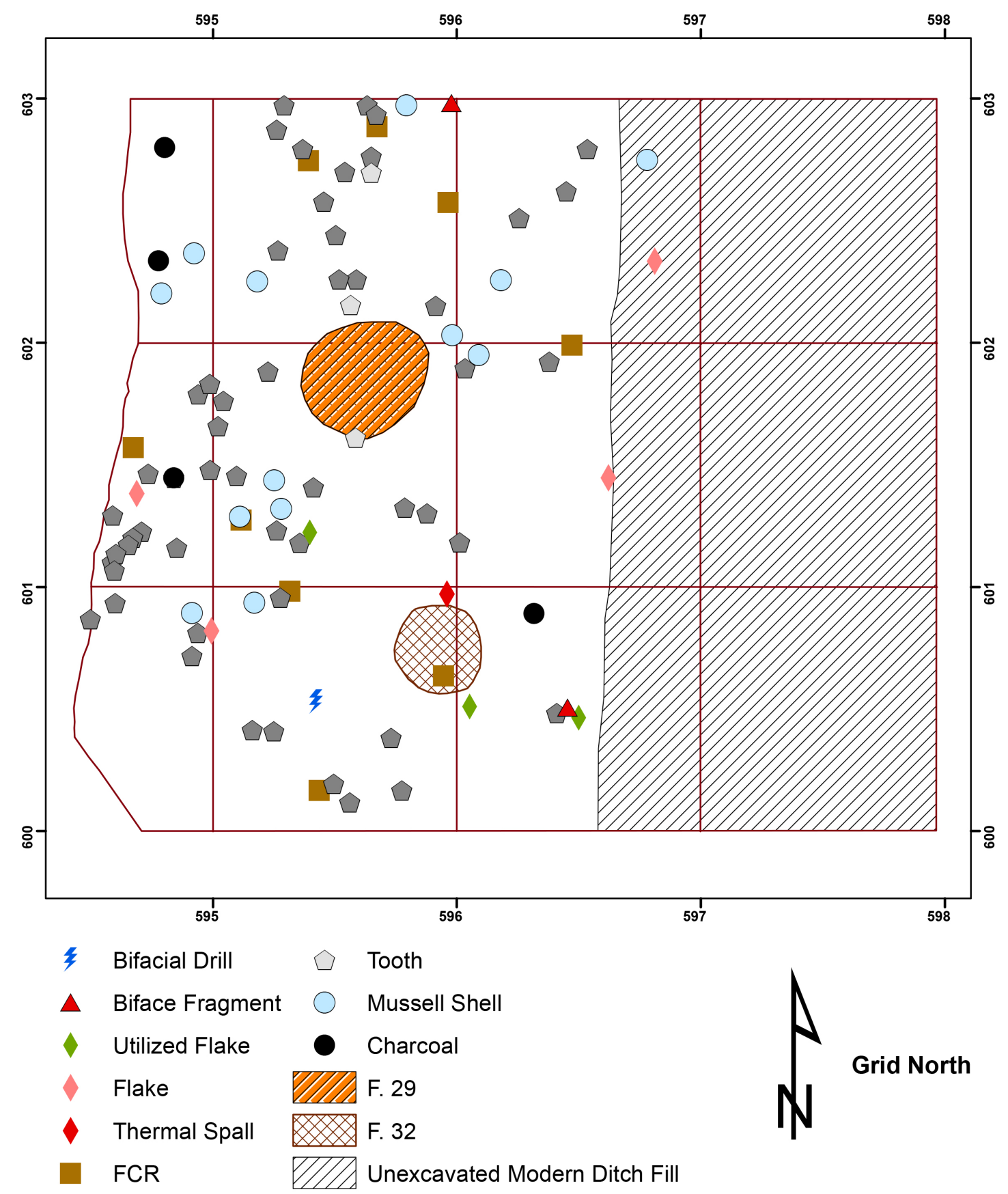

$\triangle$ Bone

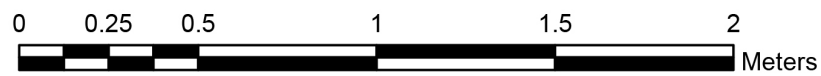

Figure 8-42. Plan view drawing showing the distribution of all field specimens related to the Stratum 7 Toyah occupation in Block 1. Also shown are Features 29 and 32 plus the unexcavated area of modern ditch fill. Unfortunately, no clear evidence of patterning can be seen. 
northern two thirds of the block. All other items seem to be randomly distributed. Regardless of the unenlightening results of the FS piece plotting, a few artifacts from the Toyah component should be noted. These include the distal end of a bifacial drill, two unidentified biface fragments, and 22 flakes (of which three were utilized) (see Table 8-9 and Chapter 11). In addition, 237 pieces of bone were recovered and are included in the vertebrate faunal analyses presented in Chapter 13.

Finally, in an effort to obtain an age for the Toyah occupation in Block 1 and to determine if it was of the same age as the hearth remains uncovered in Features 30 and 31 in WC 6, four radiocarbon samples from Stratum 7 were selected for dating. One sample consisted of charred material from the F. 29 concentration of ash and charcoal (Beta-315688). It yielded a ${ }^{14} \mathrm{C}$ age of $380 \pm 30$ B.P. and a calibrated two-sigma age range of 502 to 318 B.P. (ca. A.D. 1445 to 1630) (see Chapter 10). A second sample was run on a bison humerus from the top $10 \mathrm{~cm}$ of Stratum 7 (Beta-370012). It produced a ${ }^{14} \mathrm{C}$ age of $250 \pm 30$ B.P. and a calibrated 2-sigma age range of 429 to 150 B.P (ca. A.D. 1520 to 1800) at 91.5 percent probability. The final two samples consisted of a bison tibia and a bison patella, both also from the top $10 \mathrm{~cm}$ of Stratum 7. These samples actually were split, with one half of each bone sent to one laboratory and the other half sent to another laboratory to compare results based on different methods of pretreatment. Only the two assays deemed the most reliable are noted here (see Chapter 10 for a complete discussion of the pretreatment methods and the reasons why one method is considered more reliable than the other). The bison tibia yielded a ${ }^{14} \mathrm{C}$ age of $345 \pm 20$ B.P. (UCIAMS-140840) with a calibrated 2-sigma range of 483 to 288 B.P. (ca. A.D. 1490 to 1660 ). The bison patella produced a ${ }^{14} \mathrm{C}$ age of $335 \pm 20$ B.P. (UCIAMS-140842) and a calibrated 2-sigma range of 469 to 311 B.P. (ca. 1480 to 1640) at 95.4 percent probability. Save for the date on the bison humerus, which appears a bit too late, the other three dates are virtually identical to those from F. 30 and F. 31 in WC 6, thus providing extremely strong evidence that the cultural material found within the "deep" Toyah of WC 6 and BTs 20 and 21 represents material likely dumped over the edge of the former riverbank by the people who were responsible for the occupation within the "upper" Toyah zone uncovered in WC 1 and Block 1.

\section{Summary of Block Excavations}

Excavation of the five blocks resulted in the removal of ca. $25 \mathrm{~m}^{3}$ of soil. However, since two of the blocks initially were excavated by the backhoe, actual hand excavation removed $14.05 \mathrm{~m}^{3}$ of soil. When combined with the $4.92 \mathrm{~m}^{3}$ of hand-excavated soil from the six witness columns, the total amount of soil removed by hand for the entire site equaled 18.97 $\mathrm{m}^{3}$. The blocks also uncovered the same prehistoric components and features first excavated in the witness columns, along with several additional features not previously identified. As with the witness columns, the features consisted of clusters of freshwater mussel shells, burned rocks, or hearth debris. Table 8-11 provides a list of the five block excavations along with the quantity of hand-excavated soil removed from each, components uncovered, and features represented.

Since four of the five block excavations (Blocks 1 through 4) revealed the same components as previously identified in their adjacent WCs, there is little new occupation information to add. Basically, the blocks confirmed and expanded upon the data gained in the witness columns. The north side of the site primarily was the locus of what appears to be a single occupation related to the Late Prehistoric period's Toyah-like occupation of Temporal Interval K, while the south side revealed several Late Archaic occupations equivalent to the Late Archaic 3 and 4 periods (Temporal Intervals $\mathrm{H}$ and I) within the Upper West Range alluvium's A horizon, plus deeper occupations within the Lower West Range alluvium that can be related to the Middle Archaic and Late Archaic 2 periods (Temporals Intervals $\mathrm{G}$ and $\mathrm{H}$ ).

Importantly, the blocks provided enough excavated area to reveal the full extent of several of the features only partly investigated by the witness columns. In particular, the remains of Features 19 and 20 were exposed in their entirety in Block 3, while that part of Feature 18 not taken out by BT 15 was fully defined in Block 5. All proved to be discrete concentrations of either burned rocks or mussel shells, with the F. 20 burned-rock cluster having been deposited within a shallow basin-shaped depression. As such, it almost certainly represents the remains of an earth oven so common to the region. The other burned-rock clusters probably served the same purpose, although their less-discrete nature serves to hamper that interpretation to a small degree. Likely, they represent the scattered and ill-defined remains of other earth ovens.

The mussel shell concentrations represent a different story. Very few of the mussel valves, if any, appear to have been burned and there was virtually no charcoal found in association with the shell clusters. Thus, there does not seem to be any support for the possibility that the concentrations represent loci where 
Table 8-11. Blocks Excavated at Site 41HM61, Including Block Size, Quantity of Hand-Excavated Soil, Features, and Principal Components Present.

\begin{tabular}{|c|c|c|c|}
\hline Block Excavation & $\begin{array}{c}\text { Size of Block } \\
\text { (Quantity of Hand-Excavated Soil) }\end{array}$ & $\begin{array}{c}\text { Aboriginal } \\
\text { Features Present }\end{array}$ & Component Present \\
\hline Block 1 & $\begin{array}{c}\text { Overburden: } \\
3.0 \text { by } 3.0 \text { by } 0.55 \mathrm{~m} \\
\left(4.95 \mathrm{~m}^{3}\right) \\
\text { Controlled Excavation: } \\
3.0 \text { by } 2.4 \text { by } 0.4 \mathrm{~m} \\
\left(2.88 \mathrm{~m}^{3}\right)\end{array}$ & $\begin{array}{l}\text { F. } 29 \text { - Concentration of charcoal and ash } \\
\text { (hearth debris?) }\end{array}$ & $\begin{array}{c}\text { Late Prehistoric } \\
\text { (“Toyah-like”), } \\
\text { Temporal Interval K }\end{array}$ \\
\hline Block 2 & $\begin{array}{l}1.0 \text { by } 2.0 \text { by } 0.6 \mathrm{~m} \\
\left(1.2 \mathrm{~m}^{3}\right)\end{array}$ & F. 16 - Mussel shell concentration & $\begin{array}{l}\text { Late Archaic } 4 \text {, } \\
\text { Temporal Interval I }\end{array}$ \\
\hline Block 3 & $\begin{array}{l}2.0 \text { by } 1.8 \text { by } 0.45 \mathrm{~m} \\
\left(1.62 \mathrm{~m}^{3}\right)\end{array}$ & $\begin{array}{l}\text { F. } 19 \text { - Mussel shell concentration } \\
\text { F. } 20 \text { - Burned-rock cluster }\end{array}$ & $\begin{array}{l}\text { Late Archaic 2, } \\
\text { Temporal Interval H }\end{array}$ \\
\hline Block 4 & $\begin{array}{l}1.0 \text { by } 2.0 \text { by } 1.0 \mathrm{~m} \\
\left(2.0 \mathrm{~m}^{3}\right)\end{array}$ & $\begin{array}{l}\text { F. } 21 \text { - Burned-rock cluster } \\
\text { F. } 26 \text { - Burned-rock cluster }\end{array}$ & $\begin{array}{c}\text { Late Archaic 3, } \\
\text { Temporal Interval I } \\
\text { Temporal Interval H }\end{array}$ \\
\hline Block 5 & $\begin{array}{l}2.0 \text { by } 2.0 \text { by } 0.35 \mathrm{~m} \\
\left(1.4 \mathrm{~m}^{3}\right)\end{array}$ & $\begin{array}{l}\text { F. } 18 \text { - Mussel shell concentration } \\
\text { F. } 28 \text { - Mussel shell concentration }\end{array}$ & $\begin{array}{l}\text { Middle Archaic, } \\
\text { Temporal Interval G }\end{array}$ \\
\hline
\end{tabular}

Note: $\quad$ Temporal Intervals after Collins et al. (2011).

mussels were placed in a fire (or vice versa) as a means for steaming them open. Perhaps they represent the discarded remains of a single meal during which valves simply were dumped in one location following consumption of the mussel meat.

Despite the lack of evidence for burning within the mussel features, it seems very likely that the mussels of F. 19 were, in fact, associated with the burned rocks of F. 20. The two features are stacked almost directly atop one another with a thin layer of silt separating them. It would appear that the rocks were heated in a shallow, basin-shaped pit, a thin layer of soil was place over them, and then mussels were laid directly on the soil. If mussels then were covered with another layer of soil, they would have been sealed into a pit-like feature causing them to be steamed open and cooked. Since they were steamed, and not place directly in a fire, that would explain why no charcoal or ash was found in F. 19 or any of the other mussel features.

Potential support for the interpretation that Features 19 and 20 represent a single cooking (steaming) event comes from a very similar feature excavated at the Keller site (12D509) in Dearborn County, Indiana (Kerr and Bundy 2010). Feature 215 at that locale consisted of a straight-walled pit containing 
stratified layers of fire-cracked rock, silty loam, and mussel shells dating to Late Woodland times (ca. A.D. 780 to 1020) (Kerr and Bundy 2010:504, 508, Table 7.112, Figures 7.44, 7.58, 7.59). Although the pit appears to have been used as an earth oven on two separate occasions, the second (and uppermost) occasion included a lower layer (Stratum IV) of FCR, about $12 \mathrm{~cm}$ thick, containing abundant charcoal, an overlying deposit of silty loam about 15 to $20 \mathrm{~cm}$ thick (Stratum III), and an upper layer of abundant mussel shells ca. $35 \mathrm{~cm}$ thick (Stratum II). This is virtually identical to the stratigraphic sequence revealed in WC 3 and Block 3 during the excavation of Features 19 and 20. The main difference between Feature 215 at Keller and Features 19 and 20 at 41HM61 was the presence of burned earth along the walls of F. 215 indicating that an intense fire had taken place in that pit. As noted, such fired earth was missing from the edges of Features 19 and 20. It is important to note, also, that the archaeologists who described Feature 215 interpreted its upper portion (Strata II through IV) as the remains of a potential mussel-steaming event (Kerr and Bundy 2010:508).
In the case of Feature 18, the presence of a moderate quantity of vertebrate faunal material in association with the mussel shells suggests that the meat from other animals also may have been part of the potential meal and cooked with the mussel shells (see Chapter 13 for a more detailed discussion on the vertebrate fauna obtained from the site). Conversely, it is possible that the mussel shells simply served to reduce acidity in the surrounding soil, thus providing better preservation to the vertebrate material and giving the appearance of an association between the bones and the mussel shells than actually was the case. Regardless of their true nature, the presence of the mussel shell concentrations and the burned-rock clusters indicates that site 41HM61 contains intact features resulting from repeated visits to the site over several thousand years. There is no question that those parts of the site not affected by road construction and river channelization are in excellent condition, their associated occupation surfaces and features are intact, and they can provide a wealth of information on the Middle Archaic, Late Archaic, and Late Prehistoric periods along the Leon River in Hamilton County. 


\title{
Chapter 9
}

\section{GeoarchaEological INVESTIGATIONS}

\author{
Charles D. Frederick \\ Brittney Gregory
}

\section{Introduction}

This chapter reports the geoarchaeological findings of the testing excavations at site 41HM61. The general geologic setting of the site has been discussed in detail by Abbott (2011) and in Chapter 2, while the previous TxDOT trenching was presented in Chapter 5. This chapter builds on the data provided in those two chapters and incorporates the findings of CEI's testing project.

Overall, site 41HM61 is situated upon and within the floodplain of the Leon River on both sides of the modern river channel. For geographic simplicity, the following discussion divides the site into quadrants (e.g., northeast, northwest, southeast and southwest) with the modern Leon River serving as the dividing line between north and south, and U.S. Highway 281 as the dividing line between east and west.

As noted in Chapter 6, the initial testing involved reopening three of the 14 trenches previously examined by TxDOT (BTs 4, 9 and 11; see Abbott 2011) and then opening nine new trenches in order to search for in situ prehistoric cultural material (BTs 15 through 22). Since none of the trenches on the south side of the site was in excess of $2 \mathrm{~m}$ in depth, and since there was the potential for the new bridge bents in that area to extend to over $25 \mathrm{~m}$ below the surface, it was decided to return to the site in the late summer of 2013 to excavated one more trench in an effort to uncover even deeper cultural material within the West Range alluvium. This trench, identified as BT 23, will be discussed below.
Methods

\section{Field Methods}

Trench walls were either picked with a knife or shaved with a trowel in order to remove smear created by the backhoe bucket and prepare the walls for examination. The strata in each trench were described in general accordance with Schoeneberger et al. (2002) except that the fundamental unit of observation was a zone. For each zone, the texture, consistence, structure, boundary and pedofeatures were described. In most cases one wall of each trench was drawn with the aid of a string line and measuring tape, but two trenches (BTs 18 and 21) were recorded as vertical or column profiles. The detailed strata descriptions of each trench and witness columns are provided in Appendix C. Samples for physical analysis were collected in small 2-cm-diameter plastic paleomagnetic boxes that were pushed into the excavation wall. A few samples were also collected and placed into plastic bags. The nomenclature of the alluvial stratigraphy follows Nordt $(1992,2004)$.

\section{Backhoe Trench 23}

BT 23 was positioned at a roughly perpendicular angle across previously excavated BT 15 , between the locations of BT 11 and Block 5 (Figures 9-1 and 9-2). At its deepest point, the trench measured $3.8 \mathrm{~m}$ in depth. Because of this excessive depth, several safety benches had to be positioned both to the north and south of the main east-west 


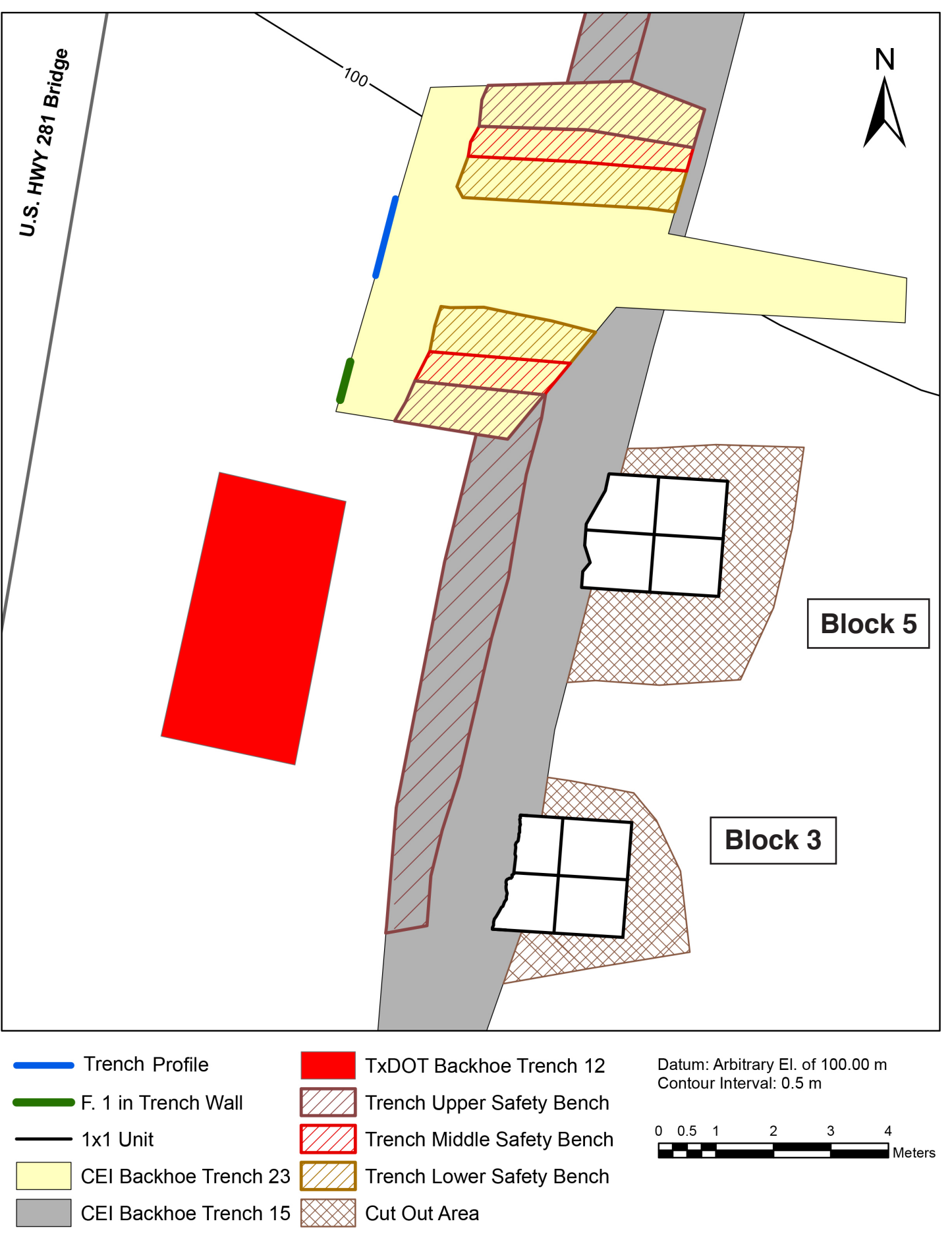

Figure 9-1. Map of a portion of the southeastern quadrant of site 41HM61 showing the location of Backhoe Trench (BT) 23 in relation to previously excavated BT 15 and Blocks 3 and 5. Note that BT 23 was excavated across and roughly perpendicular to BT 15 . 


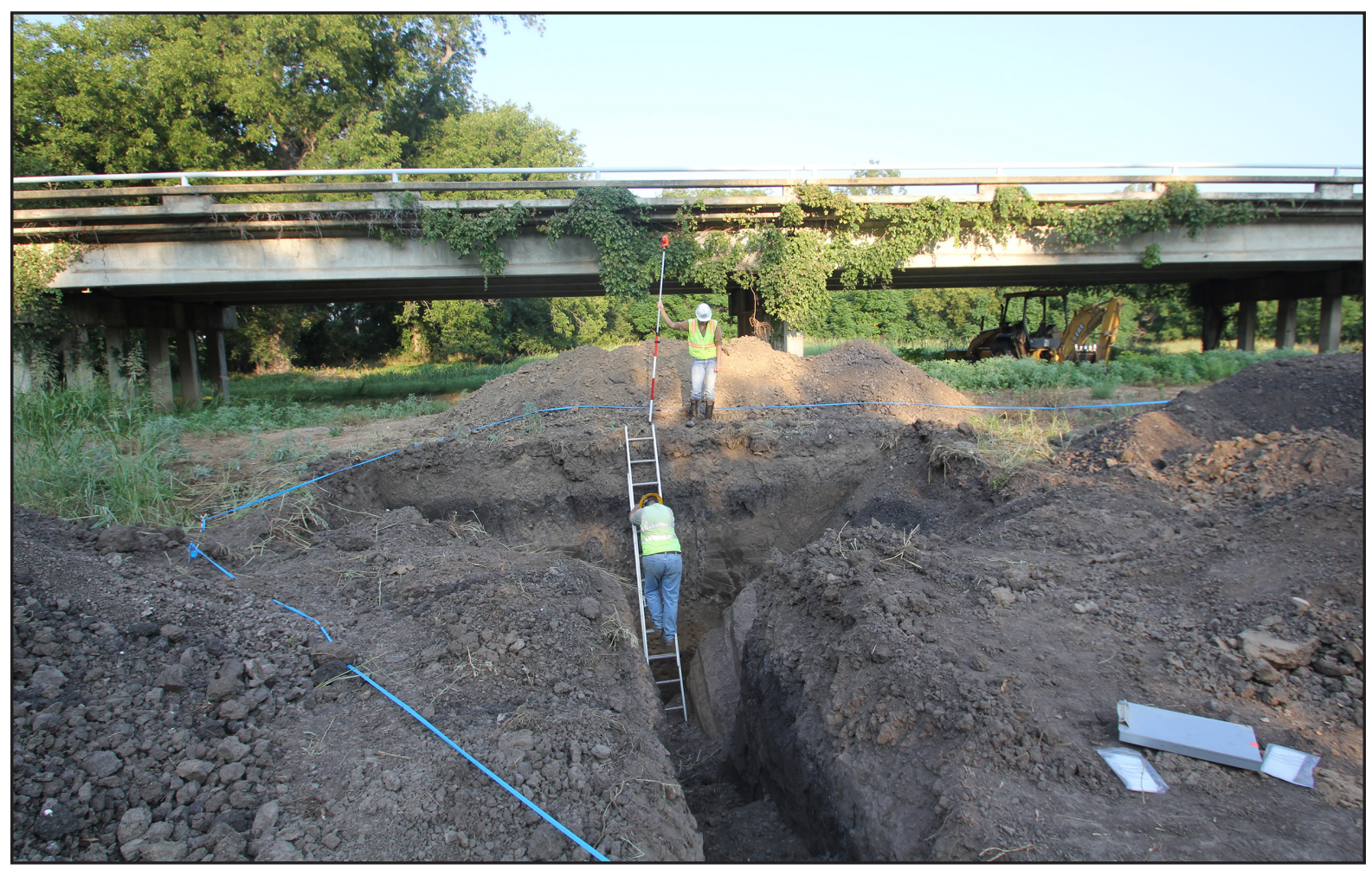

Figure 9-2. Photograph of Charles Frederick recording the stratigraphy of the cleared profile along the west wall of BT 23 with Brittney Gregory holding the TDS prism. View to the west-southwest. 9/11/13.

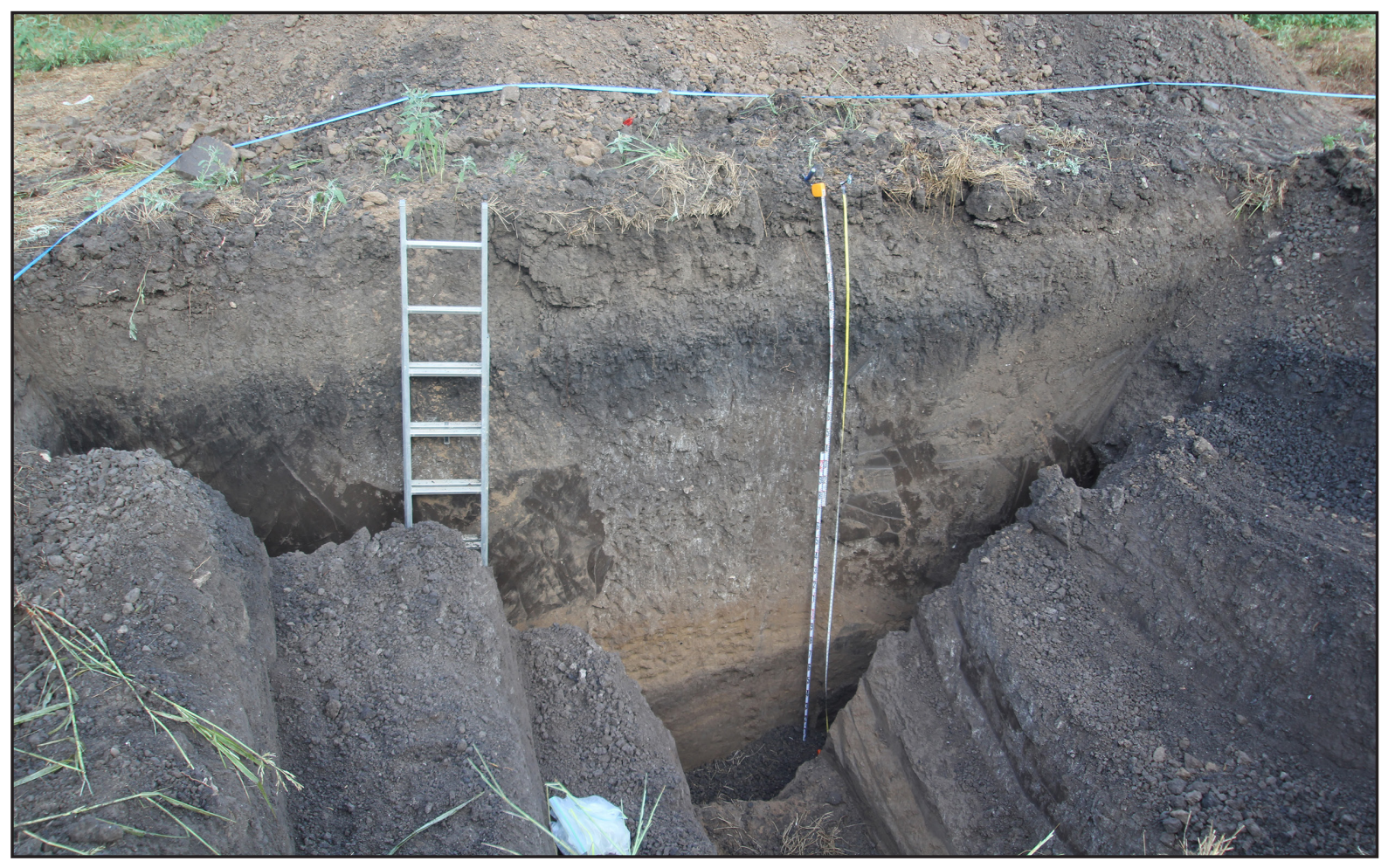

Figure 9-3. Close-up photograph of the cleared and picked profile along the west wall of BT 23. View to the west. 9/11/13. 
trench, thus requiring the excavation of a relatively wide area. The bottom of the main east-west trench extended upward in elevation towards the east in order to form a ramp for easy access. Overall, the main trench measured $7.9 \mathrm{~m}$ east-west, while its western wall measured ca. $6.2 \mathrm{~m}$ north-south. Although fully photographed, only a small section of the west wall was profiled and sampled for subsequent soil analyses (Figure 9-3).

\section{Laboratory Methods}

One hundred and ninety samples were collected in the field for detailed laboratory characterization. A suite of 36 samples was collected from the upper $1.5 \mathrm{~m}$ of the west wall of Witness Column 1 (adjacent to BT 19 in the northeast quadrant of the site) that exposed both the Ford alluvium and the West Range alluvium (Table 9-1). An additional 57 samples were collected from the south wall of Witness Column 6, which exposed a deeply buried portion of a Toyah occupation within the Ford alluvium (Table 9-2), while 23 more samples were collected from the deepest deposits exposed in BT 19 (Table 9-3). For each collected sample, two properties were analyzed: the magnetic susceptibility and the particle size distribution. Finally, 74 samples were collected from the west wall of BT 23, which, as noted, was a nearly 4-m-deep trench excavated in the late summer of 2013 in the southeast quadrant of the site to asses the nature of the deposits below $2 \mathrm{~m}$ depth. In addition to particle size and magnetic susceptibility, the samples from BT 23 were analyzed for calcium carbonate equivalent, organic carbon and stable carbon isotopes (Table 9-4).

In order to measure the magnetic susceptibility, the samples were first dried at low temperature and weighed, and then the low frequency $(470 \mathrm{~Hz})$ and high frequency $(4700 \mathrm{~Hz})$ magnetic susceptibility (kappa) was measured in SI units on the 0.1 setting on a Bartington MS2 meter and an MS2b sensor (see Dearing 1999a). The mass corrected magnetic susceptibility (chi, or $\mathrm{c}_{\mathrm{lf}}$ ) and coefficient of frequency dependency $\left(\mathrm{c}_{\mathrm{fd}}\right)$ were then calculated. The coefficient of frequency dependency $\left(\mathrm{c}_{\mathrm{fd}}\right)$ is the percent difference in magnetic susceptibility measured at low and high frequencies (calculated as: $\mathrm{c}_{\mathrm{fd}}=\left(\mathrm{c}_{\mathrm{lf}}-\mathrm{c}_{\mathrm{hf}}\right) /$ $\left.\left.\mathrm{c}_{\mathrm{lf}}\right) * 100\right)$. Elevated values of $\mathrm{c}_{\mathrm{fd}}(\mathrm{ca} .>10 \%$; Gale and Hoare 1991:213) are indicative of increased concentrations of fine-grained ferrimagnetic minerals, most often maghemite, in top soils (Dearing 1999b; Dearing et al. 1996). The $\mathrm{c}_{\mathrm{lf}}$ magnetic susceptibility values are reported in SI units $\left(10^{-8} \mathrm{~m}^{3} \mathrm{~kg}^{-1}\right)$.
The particle size distribution was determined using a Beckman-Coulter LS 13-320 laser particle sizer. Samples were first boiled with $5 \mathrm{ml}$ of 30 percent hydrogen peroxide on a hot plate and then about $5 \mathrm{ml}$ of a 5-percent solution of sodium hexametaphosphate dispersant was added prior to introducing the samples to the laser sizer. Samples were then dispersed with a 30 -second ultrasonic treatment and measured. The results are presented in percentages of sand, silt and clay, as well as by means of standard statistical measures employed in sediment analysis (e.g., mean, median, sorting (standard deviation), skewness and kurtosis, all in phi values) (see Tables 9-1 to 9-3).

The calcium carbonate content (or calcium carbonate equivalent) was determined by means of a Chittick apparatus (Dreimanis 1962; Machette 1986). A small split (either $1.7 \mathrm{~g}$ or $0.85 \mathrm{~g}$ ) of the ground $<2$ $\mathrm{mm}$ fraction of each soil sample was finely ground (to pass a $0.075 \mathrm{~mm}$ sieve), and then weighed, and placed into a small $(250 \mathrm{ml})$ Erlenmeyer flask. Once attached to the Chittick apparatus, the liquid level in the measuring burette was set to $-10 \mathrm{ml}$, then the stopcock was closed to prevent gas from leaving the system, and the leveling bulb was dropped in order to establish a vacuum inside the sample chamber. At this point the barometric pressure and temperature in the room were recorded. Then $10 \mathrm{ml}$ of $50 \%$ hydrochloric acid (ca. $6 \mathrm{~N} \mathrm{HCl}$ ) was delivered to the sample flask, which was agitated intermittently until the reaction had ceased (usually 1-2 minutes). At this point, the leveling bulb was raised to the point that the liquid level inside of it was equal in elevation to the liquid in the burette, and the volume of gas evolved was then measured and the calcium carbonate equivalent calculated.

In order to determine the carbon content of each sample, splits of the $<2-$ mm-sized fraction were submitted to the Analytical Chemistry Laboratory at the Institute of Ecology, University of Georgia. The carbon content was determined on a Micro-Dumas NA1500 Combustion Elemental $(\mathrm{C} / \mathrm{H} / \mathrm{N})$ Analyzer (Carlo Erba Strumentazione, Milan). Details of the procedures used at the laboratory may be found on the institute's web page (http://www.uga.edu/ sisbl/soilerb.html) and general aspects of the method are discussed by Schulte and Hopkins (1996). Calcium carbonate was removed from the samples by treating a split of the soil with concentrated hydrochloric acid. After repeated rinsing, each sample was dried and subsequently finely ground before analysis on the Elemental Analyzer.

The stable carbon isotopic value of the organic carbon for each sample was determined at the Stable 


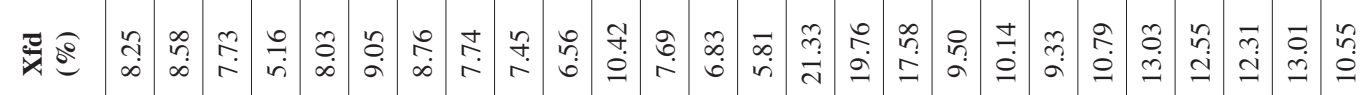

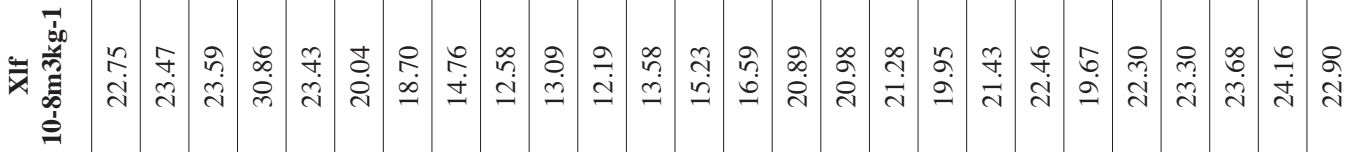

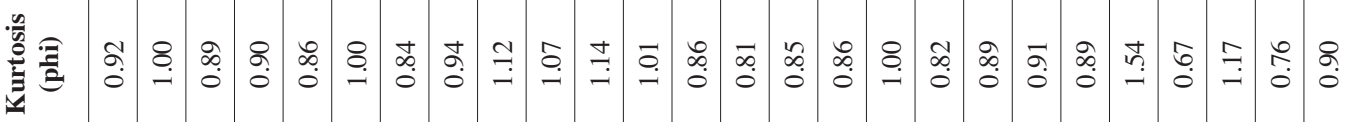

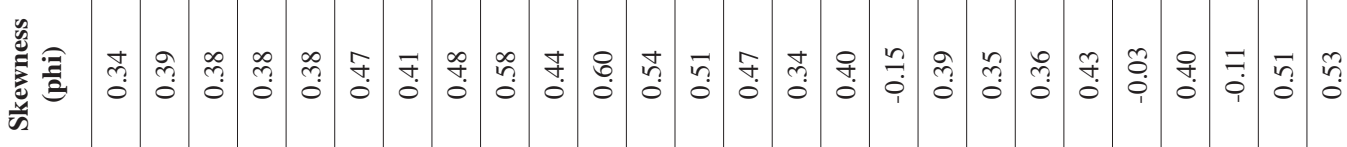

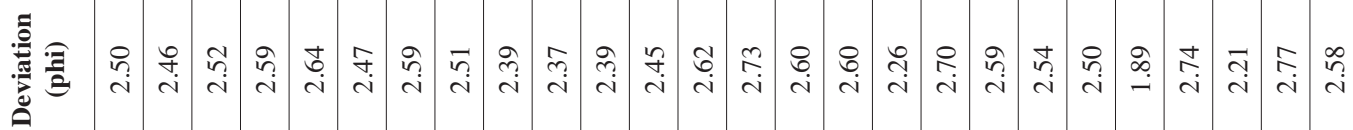

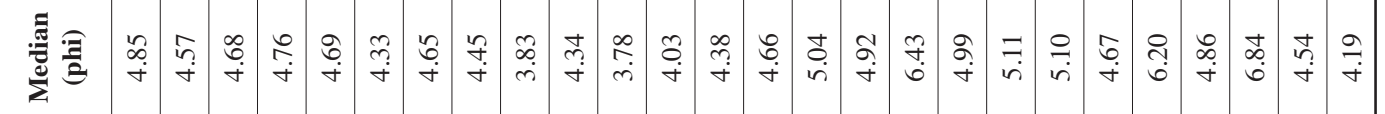

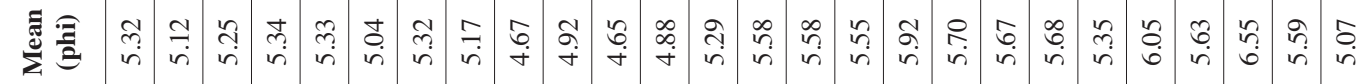

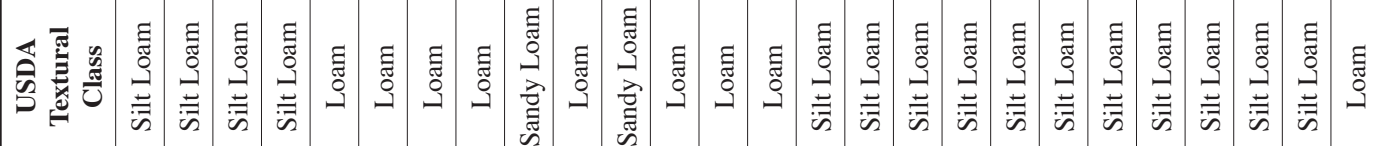

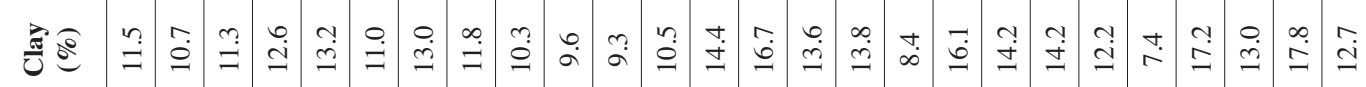

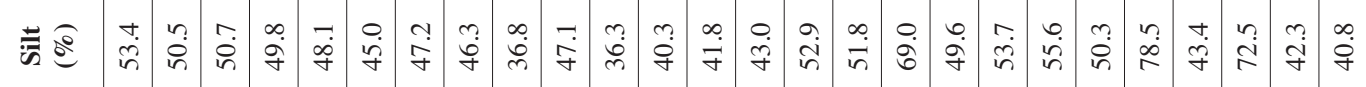

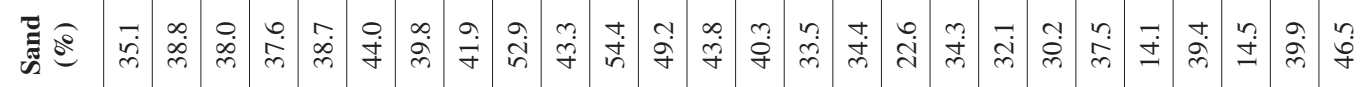

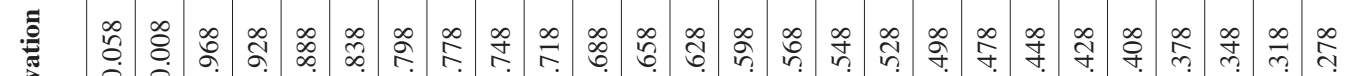

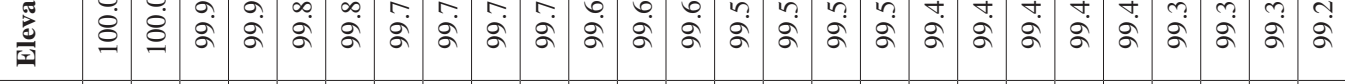

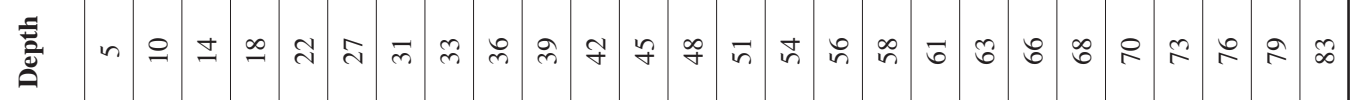




\begin{tabular}{|c|c|c|c|c|c|c|c|c|c|c|}
\hline $\bar{v} \precsim$ & 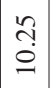 & $\stackrel{ \pm}{\stackrel{5}{0}} \stackrel{0}{\varrho}$ & 离 & 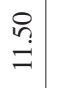 & $\begin{array}{l}\tilde{0} \\
\dot{0}\end{array}$ & $\begin{array}{l}\stackrel{0}{\stackrel{0}{0}} \\
\stackrel{0}{0}\end{array}$ & $\stackrel{\substack{+=}}{=}$ & $\stackrel{\text { n़? }}{=}$ & $\begin{array}{l}\stackrel{t}{a} \\
\stackrel{0}{O}\end{array}$ & $\stackrel{ \pm}{\stackrel{0}{0}}$ \\
\hline 壵 & 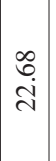 & 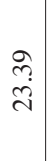 & $\begin{array}{l}\stackrel{+}{\mathrm{N}} \\
\stackrel{\mathrm{N}}{ }\end{array}$ & $\begin{array}{l}\stackrel{ }{\Delta} \\
\stackrel{i}{i}\end{array}$ & $\begin{array}{l}\stackrel{\overbrace{}}{\sim} \\
\dot{\sim}\end{array}$ & 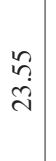 & $\begin{array}{l}\bar{n} \\
n \\
\end{array}$ & $\begin{array}{l}\hat{n} \\
\dot{0}\end{array}$ & $\begin{array}{l}n \\
\vec{i} \\
\text { m. }\end{array}$ & $\begin{array}{l}\stackrel{\leftrightarrow}{1} \\
\text { లె }\end{array}$ \\
\hline 量 & $\begin{array}{l}a \\
\stackrel{\infty}{0} \\
0\end{array}$ & $\stackrel{ \pm}{-}$ & $\stackrel{9}{=}$ & $\stackrel{\bullet}{-}$ & $\stackrel{\overbrace{}}{\exists}$ & $\stackrel{\infty}{\stackrel{\infty}{-}}$ & $\stackrel{\infty}{\stackrel{\infty}{-}}$ & $\stackrel{n}{o}$ & $\hat{\delta}$ & $\begin{array}{l}0 \\
\infty \\
0\end{array}$ \\
\hline 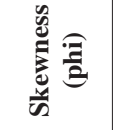 & $\begin{array}{l}n \\
0 \\
0\end{array}$ & กี & กี & ñ? & 古 & $\tilde{n}$ & $\bar{n}$ & $\stackrel{0}{0}$ & $\begin{array}{l}0 \\
0 \\
0 \\
0\end{array}$ & ले. \\
\hline 营 & $\begin{array}{l}\infty \\
\stackrel{\infty}{n} \\
\sim\end{array}$ & 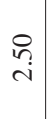 & 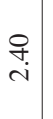 & $\underset{\mathrm{i}}{\stackrel{J}{\mathrm{i}}}$ & ते & $\underset{\mathrm{i}}{\stackrel{\sim}{i}}$ & 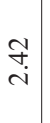 & $\tilde{\widehat{n}}$ & $\begin{array}{l}\stackrel{0}{0} \\
\stackrel{2}{i}\end{array}$ & $\underset{\text { ț }}{\text { i }}$ \\
\hline 苝 & $\underset{\sim}{+}$ & $\stackrel{\circ}{\underset{\sigma}{*}}$ & $\overrightarrow{\dot{~}}$ & $\begin{array}{l}\tilde{\sigma} \\
\dot{\tau}\end{array}$ & $\begin{array}{l}\infty \\
\dot{m} \\
\dot{m}\end{array}$ & $\begin{array}{l}\infty \\
\stackrel{+}{+} \\
\end{array}$ & $\stackrel{\infty}{\stackrel{+}{+}}$ & 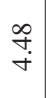 & $\stackrel{n}{n}$ & $\begin{array}{l}\vec{\infty} \\
\stackrel{+}{+}\end{array}$ \\
\hline 离 & $\begin{array}{l}\stackrel{0}{0} \\
\text { in }\end{array}$ & $\underset{+}{\stackrel{f}{+}}$ & $\stackrel{\mathbb{T}}{\dot{+}}$ & $\begin{array}{c}\stackrel{\infty}{\circ} \\
+ \\
+\end{array}$ & 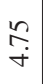 & $\begin{array}{l}\sim \\
\infty \\
\dot{f} \\
\dot{f}\end{array}$ & $\stackrel{\vartheta}{\dot{+}}$ & $\overrightarrow{\hat{n}}$ & $\begin{array}{c}\hat{n} \\
i\end{array}$ & 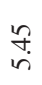 \\
\hline 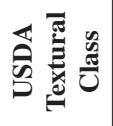 & 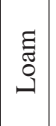 & 喜 & 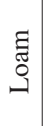 & 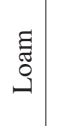 & $\begin{array}{l}\text { ב్๊ } \\
\text { త్ } \\
\end{array}$ & 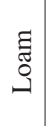 & 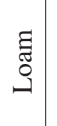 & 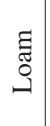 & 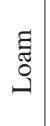 & 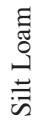 \\
\hline$\frac{E}{0}$ & $\stackrel{\infty}{=}$ & $\stackrel{\varrho}{\varrho}$ & $\ddot{a}$ & $\stackrel{\odot}{\ominus}$ & $\partial$ & $\stackrel{\odot}{\stackrel{9}{0}}$ & $\stackrel{n}{\varrho}$ & $\stackrel{\circlearrowright}{\mathrm{I}}$ & $\stackrel{\circlearrowright}{\mathrm{I}}$ & $\stackrel{0}{\stackrel{0}{\sim}}$ \\
\hline 泰 & $\stackrel{\vec{j}}{\mathrm{y}}$ & $\stackrel{m}{\forall}$ & $\begin{array}{l}\text { ra } \\
\stackrel{+}{a}\end{array}$ & $\begin{array}{l}0 \\
\dot{+} \\
\dot{+}\end{array}$ & $\begin{array}{l}0 \\
\dot{+}\end{array}$ & 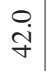 & $\ddot{\dot{q}}$ & $\stackrel{\text { Fे }}{\vec{f}}$ & $\begin{array}{l}\dot{0} \\
\dot{f}\end{array}$ & $\stackrel{m}{n}$ \\
\hline 鸰 & ֶֶ. & $\begin{array}{c}\stackrel{\infty}{\sim} \\
\stackrel{f}{f}\end{array}$ & $\overrightarrow{8}$ & $\begin{array}{l}\vec{q} \\
\vec{q}\end{array}$ & $\overrightarrow{\dot{n}}$ & $\begin{array}{c}\stackrel{0}{\circ} \\
\stackrel{\infty}{+}\end{array}$ & $\begin{array}{l}\infty \\
\dot{v} \\
\dot{f}\end{array}$ & ?? & $\begin{array}{l}\infty \\
\stackrel{m}{\circ}\end{array}$ & $\vec{\delta}$ \\
\hline 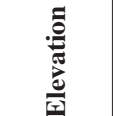 & $\begin{array}{l}\frac{\infty}{\lambda} \\
\stackrel{2}{\alpha}\end{array}$ & \begin{tabular}{l}
$\infty$ \\
$\stackrel{\infty}{=}$ \\
\hdashline \\
$\sigma$
\end{tabular} & $\begin{array}{l}\infty \\
\stackrel{\infty}{0} \\
\dot{\alpha}\end{array}$ & $\begin{array}{c}\infty \\
\vdots \\
\vdots \\
\vdots \\
\vdots\end{array}$ & $\begin{array}{l}\infty \\
ٌ \\
\alpha \\
\infty \\
\alpha\end{array}$ & $\begin{array}{l}\infty \\
\infty \\
\infty \\
\infty \\
\infty\end{array}$ & $\begin{array}{c}\infty \\
\infty \\
\infty \\
\infty \\
\infty\end{array}$ & $\begin{array}{l}\stackrel{\infty}{2} \\
\stackrel{0}{\infty} \\
\infty\end{array}$ & $\begin{array}{l}\infty \\
0 \\
0 \\
\infty \\
\sigma\end{array}$ & $\begin{array}{l}\infty \\
n \\
\infty \\
\infty \\
\infty\end{array}$ \\
\hline 言 & के & $\kappa$ & 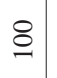 & $\stackrel{\infty}{\varrho}$ & $\stackrel{n}{=}$ & $\stackrel{\Xi}{I}$ & $\tilde{\Xi}$ & 昌 & 卞 & $n$ \\
\hline 竞 & $\bar{\lambda}$ & $\underset{\sim}{\infty}$ & ते & s. & $\bar{m}$ & $\tilde{m}$ & $m$ & ষ্ & $\stackrel{m}{m}$ & $\underset{m}{\infty}$ \\
\hline
\end{tabular}




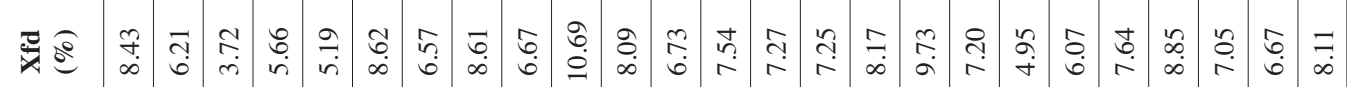

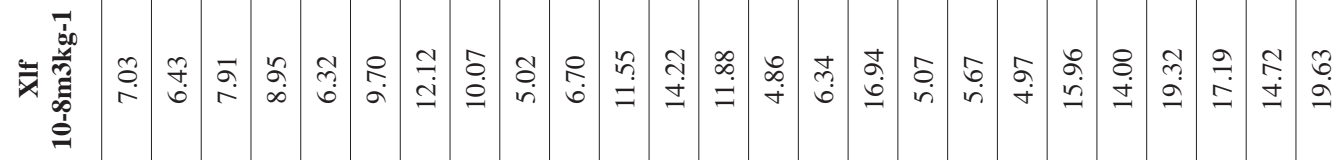

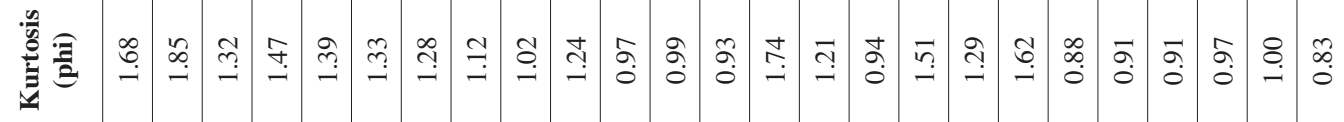

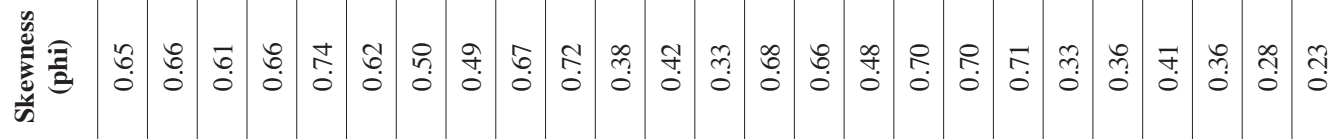

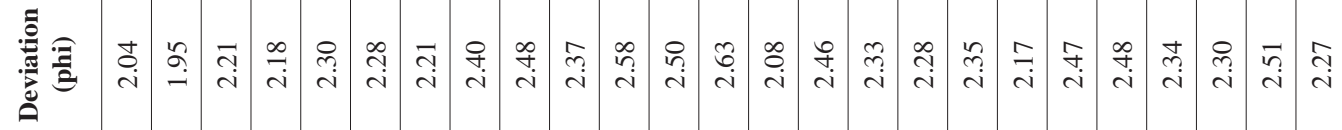

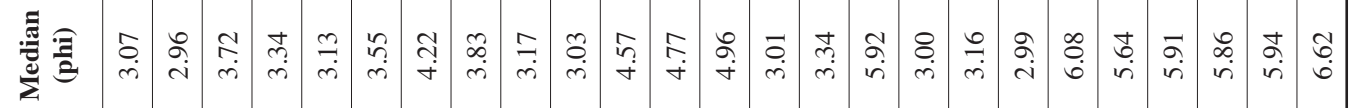

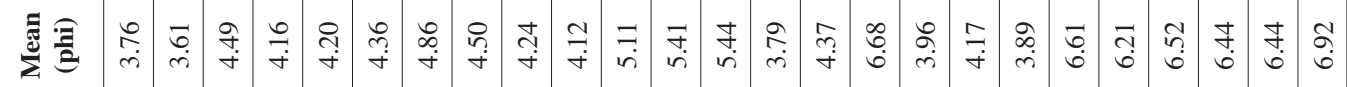

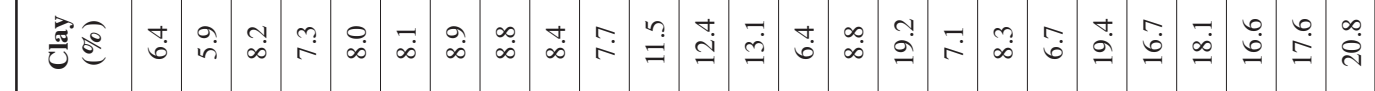

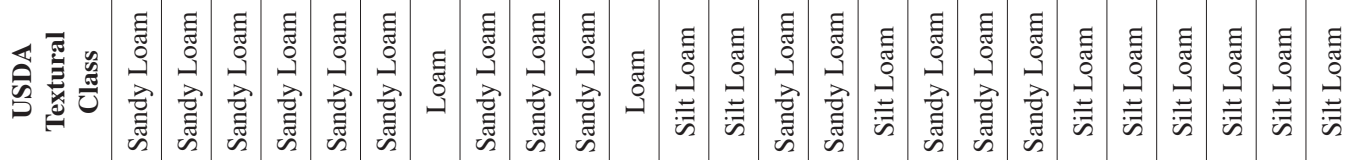

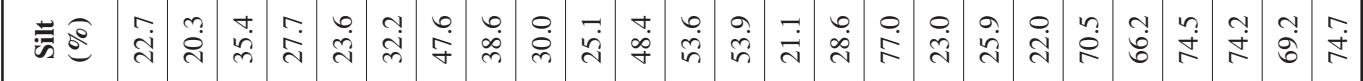

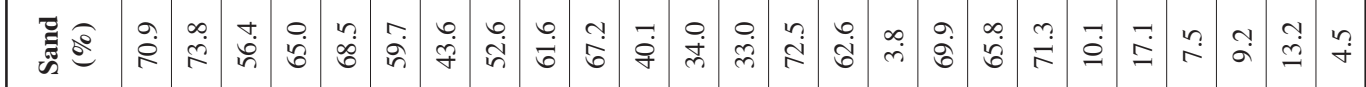

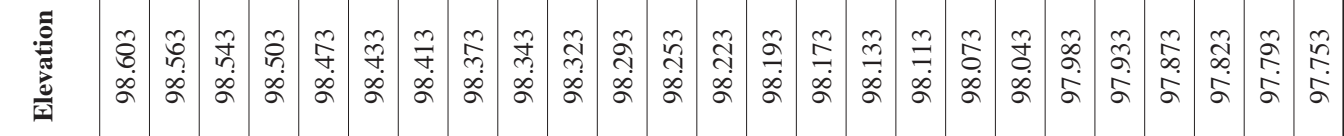

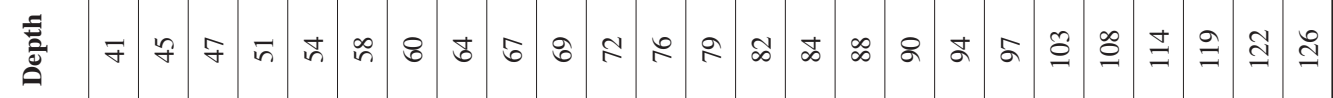
$\frac{\dot{\alpha}}{\frac{0}{0}}$

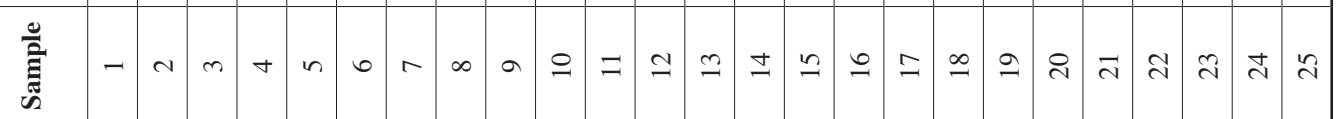


吾司

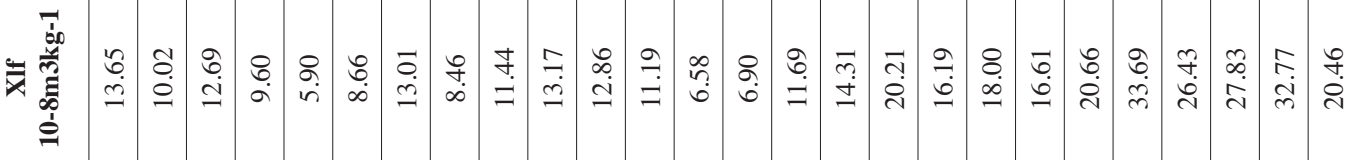

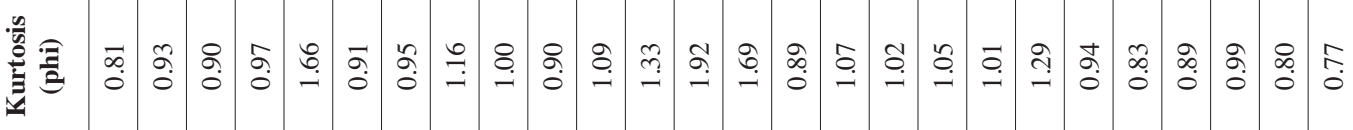

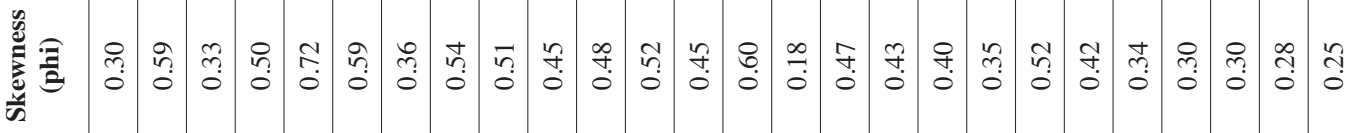

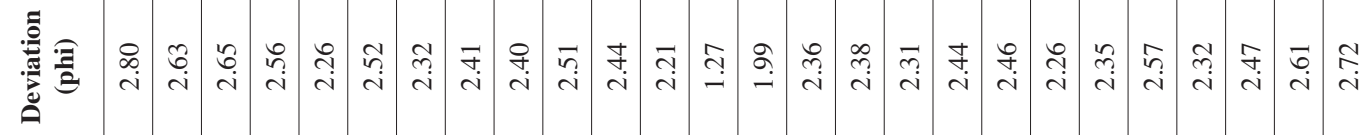

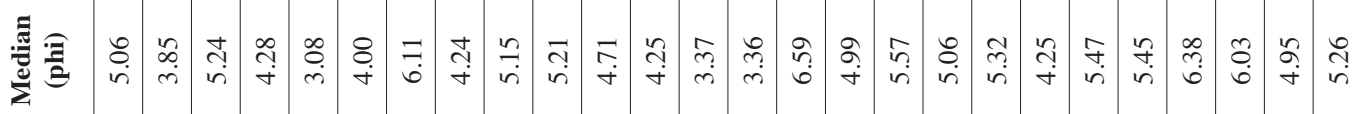

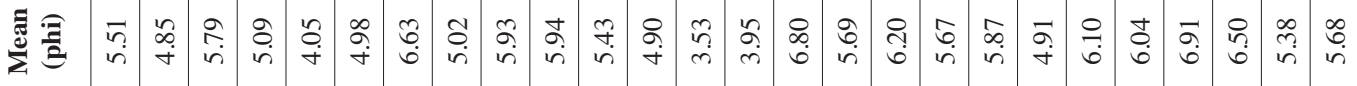

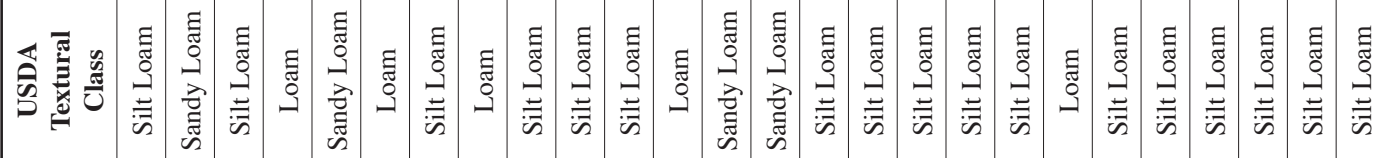

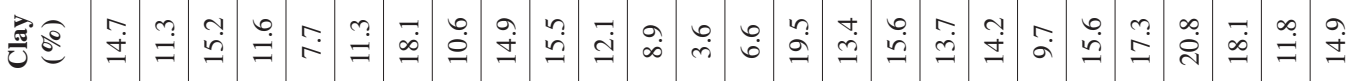

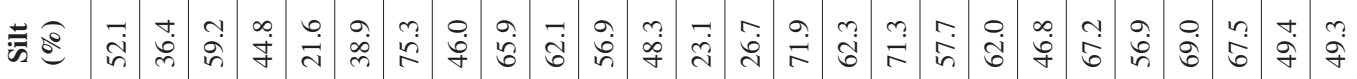

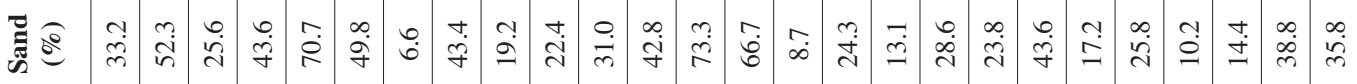

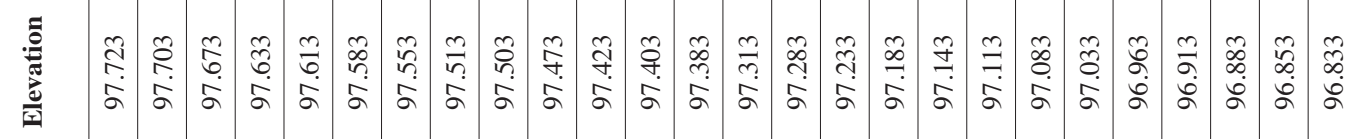

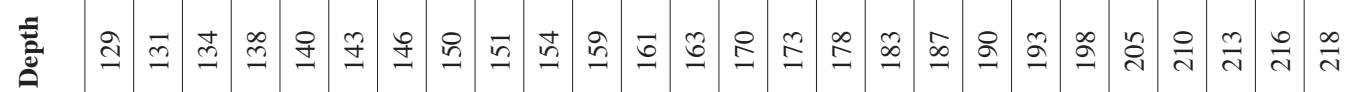

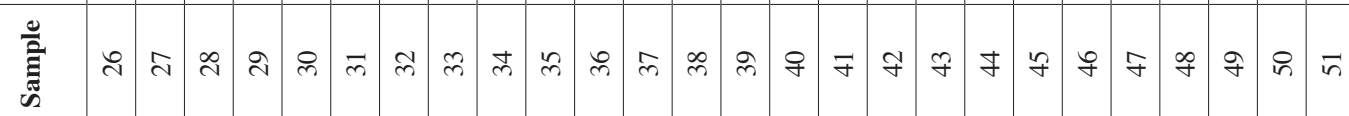




\begin{tabular}{|c|c|c|c|c|c|c|}
\hline 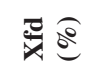 & $\stackrel{\substack{n \\
\infty}}{\infty}$ & 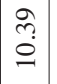 & $\begin{array}{l}\bar{m} \\
\infty\end{array}$ & તે. & $\stackrel{?}{\sim}$ & वे. \\
\hline 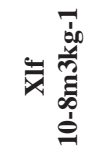 & $\begin{array}{l}\vec{a} \\
\dot{\phi} \\
\dot{d}\end{array}$ & 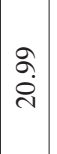 & $\begin{array}{l}n \\
m \\
\infty \\
\infty \\
-1\end{array}$ & $\stackrel{\overrightarrow{7}}{\stackrel{5}{\leftrightarrows}}$ & 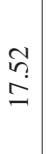 & 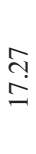 \\
\hline 曾 & $\begin{array}{l}\infty \\
\infty \\
0 \\
0\end{array}$ & $\stackrel{\varkappa}{\circ}$ & $\begin{array}{l}\infty \\
\stackrel{2}{\circ}\end{array}$ & o. & $\begin{array}{l}\hat{\infty} \\
\dot{0}\end{array}$ & $\begin{array}{l}\infty \\
\dot{0} \\
0\end{array}$ \\
\hline 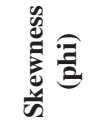 & $\stackrel{\text { Tे }}{\circ}$ & $\tilde{a}$ & $\begin{array}{l}\vec{F} \\
\dot{0}\end{array}$ & 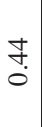 & ले & ڤn \\
\hline 产 & $\begin{array}{l}\widetilde{S} \\
\text { i }\end{array}$ & $\begin{array}{l}\hat{\sigma} \\
i\end{array}$ & $\hat{n}$ & 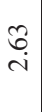 & $\stackrel{\hat{i}}{\mathrm{i}}$ & $\vec{i}$ \\
\hline 惡 & $\stackrel{f}{\stackrel{+}{+}}$ & $\vec{r}$ & $\stackrel{n}{r}$ & ঙे & $\stackrel{P}{\stackrel{P}{+}}$ & बे \\
\hline 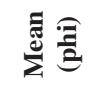 & oे. & 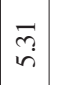 & $\underset{i n}{\overrightarrow{i n}}$ & oे & $\begin{array}{l}\stackrel{?}{q} \\
i \\
i n\end{array}$ & $\hat{\gamma}$ \\
\hline 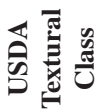 & 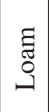 & 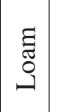 & $\begin{array}{l}\text { : } \\
\text { : }\end{array}$ & 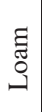 & 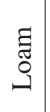 & 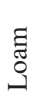 \\
\hline$\frac{E}{d}$ & $\stackrel{9}{=}$ & $\stackrel{\tilde{c}}{\sim}$ & $\stackrel{\cong}{\Xi}$ & $\stackrel{n}{\mathrm{I}}$ & $\begin{array}{l}n \\
\stackrel{n}{n}\end{array}$ & $\bar{m}$ \\
\hline 击 & $\begin{array}{l}\dot{\dot{q}} \\
\dot{q}\end{array}$ & 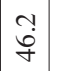 & $\begin{array}{l}m \\
b \\
b\end{array}$ & $\stackrel{\grave{j}}{\vec{q}}$ & $\begin{array}{l}\infty \\
\stackrel{i}{f}\end{array}$ & ऐें \\
\hline 馬 & $\vec{q}$ & $\mid \begin{array}{l}0 \\
\dot{q} \\
\dot{q}\end{array}$ & $\begin{array}{l}\tilde{n} \\
\stackrel{y}{y}\end{array}$ & $\begin{array}{l}\infty \\
\dot{+} \\
\dot{f}\end{array}$ & $\stackrel{\vec{j}}{\dot{\gamma}}$ & : \\
\hline 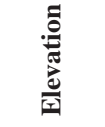 & $\begin{array}{l}\frac{m}{\alpha} \\
\dot{\alpha} \\
\dot{\alpha}\end{array}$ & 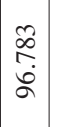 & $\mid \begin{array}{c}\hat{2} \\
\hat{\imath} \\
\delta \\
\sigma\end{array}$ & 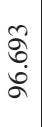 & $\begin{array}{l}\hat{\hat{b}} \\
\dot{0} \\
\alpha\end{array}$ & $\begin{array}{l}\text { r. } \\
\text { n. } \\
2\end{array}$ \\
\hline 节 & సิ & $\hat{\mathrm{\lambda}}$ & ì & $\tilde{\widetilde{\approx}}$ & సे & $\underset{\sim}{\stackrel{J}{\sim}}$ \\
\hline 产 & in & $\hat{n}$ & in & $i n$ & $\stackrel{i}{n}$ & in \\
\hline
\end{tabular}




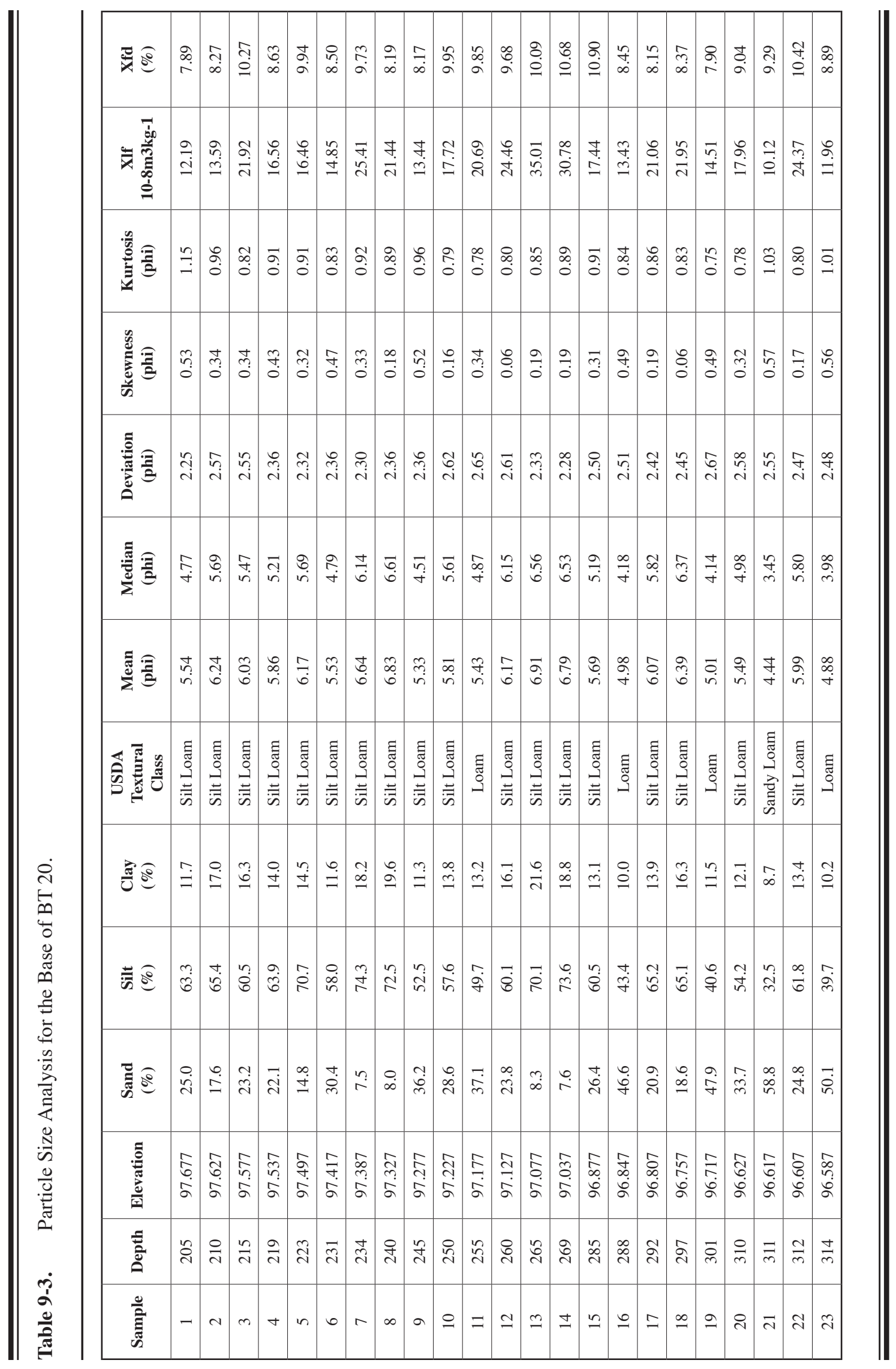


Table 9-4. Particle Size, Magnetic Susceptibility, Calcium Carbonate Equivalent, Organic Carbon, and Stable Carbon Isotope Analysis of Backhoe Trench 23.

\begin{tabular}{|c|c|c|c|c|c|c|c|c|c|c|c|c|c|c|c|c|c|}
\hline Sample & Zone & Elevation & Depth & $\begin{array}{l}\text { Sand } \\
(\%)\end{array}$ & $\begin{array}{l}\text { Silt } \\
(\%)\end{array}$ & $\begin{array}{l}\text { Clay } \\
(\%)\end{array}$ & $\begin{array}{l}\text { USDA Textural } \\
\text { Class }\end{array}$ & $\begin{array}{l}\text { Mean } \\
\text { (phi) }\end{array}$ & $\begin{array}{c}\text { Median } \\
\text { (phi) }\end{array}$ & $\begin{array}{c}\text { Sorting } \\
\text { (phi) }\end{array}$ & $\begin{array}{c}\text { Skewness } \\
\text { (phi) }\end{array}$ & $\begin{array}{c}\text { Kurtosis } \\
\text { (phi) }\end{array}$ & XIf & $\mathbf{X f d}$ & $\begin{array}{l}\text { CCE } \\
(\%)\end{array}$ & $\begin{array}{c}\text { Organic } \\
\text { Carbon }(\%)\end{array}$ & $\begin{array}{c}\text { d13C } \\
\text { per mil PDB }\end{array}$ \\
\hline 1 & 2 & 99.975 & 27.5 & 23.2 & 42.9 & 33.9 & Clay Loam & 6.22 & 6.03 & 2.70 & 0.15 & 0.84 & 23.06 & 10.02 & 21.7 & 1.21 & -20.42 \\
\hline 2 & 2 & 99.925 & 32.5 & 61.3 & 24.9 & 13.8 & Silt Loam & 4.03 & 3.32 & 2.52 & 0.51 & 1.24 & 18.79 & 10.16 & 27.8 & 0.96 & -19.88 \\
\hline 3 & 2 & 99.875 & 37.5 & 55.1 & 27.4 & 17.5 & Sandy Loam & 4.42 & 3.63 & 2.76 & 0.46 & 0.96 & 22.77 & 10.38 & 25.5 & 1.02 & -20.09 \\
\hline 4 & 2 & 99.825 & 42.5 & 48.1 & 31.8 & 20.1 & Loam & 4.81 & 4.12 & 2.76 & 0.42 & 0.92 & 24.45 & 9.89 & 22.7 & 1.01 & -19.62 \\
\hline 5 & 2 & 99.775 & 47.5 & 42.3 & 32.9 & 24.8 & Loam & 5.21 & 4.58 & 2.96 & 0.36 & 0.83 & 23.90 & 10.29 & 22.7 & 1.31 & -21.18 \\
\hline 6 & 2 & 99.725 & 52.5 & 47.5 & 32.3 & 20.2 & Loam & 4.71 & 4.20 & 2.89 & 0.31 & 0.87 & 20.12 & 9.37 & 22.7 & 1.13 & -21.07 \\
\hline 7 & 2 & 99.675 & 57.5 & 49.1 & 31.3 & 19.6 & Loam & 4.72 & 4.05 & 2.77 & 0.39 & 0.91 & 17.53 & 8.72 & 24.5 & 0.88 & -20.48 \\
\hline 8 & 2 & 99.625 & 62.5 & 38.6 & 35 & 26.4 & Loam & 5.33 & 4.81 & 2.91 & 0.31 & 0.83 & 22.45 & 10.44 & 28.1 & 0.91 & -20.14 \\
\hline 9 & 2 & 99.575 & 67.5 & 28.3 & 35.9 & 35.8 & Clay Loam & 6.12 & 6.10 & 3.02 & 0.07 & 0.81 & 23.74 & 10.20 & 24.9 & 1.20 & -19.70 \\
\hline 10 & 3 & 99.525 & 72.5 & 29.2 & 35.8 & 35 & Clay Loam & 5.97 & 6.04 & 3.09 & 0.05 & 0.79 & 32.13 & 11.05 & 25.2 & 1.48 & -20.25 \\
\hline 11 & 3 & 99.475 & 77.5 & 45.8 & 29.6 & 24.6 & Loam & 4.91 & 4.52 & 3.10 & 0.24 & 0.73 & 41.90 & 11.09 & 23.9 & 1.94 & -20.59 \\
\hline 12 & 3 & 99.425 & 82.5 & 41.6 & 32.5 & 25.9 & Loam & 5.16 & 4.87 & 3.07 & 0.19 & 0.72 & 50.78 & 11.13 & 21.4 & 2.38 & -21.18 \\
\hline 13 & 3 & 99.375 & 87.5 & 29.1 & 38.5 & 32.4 & Clay Loam & 5.86 & 5.94 & 2.75 & 0.02 & 0.75 & 52.72 & 11.76 & 20.9 & 2.22 & -21.16 \\
\hline 14 & 4 & 99.3 & 95 & 36.8 & 35.9 & 27.3 & Clay Loam & 5.36 & 5.14 & 3.01 & 0.16 & 0.77 & 51.62 & 11.34 & 24.7 & 1.67 & -20.98 \\
\hline 15 & 4 & 99.25 & 100 & 43.1 & 32.8 & 24.1 & Loam & 5.05 & 4.70 & 3.02 & 0.22 & 0.77 & 53.01 & 13.19 & 24.1 & 1.63 & -21.44 \\
\hline 16 & 4 & 99.2 & 105 & 41.5 & 32.4 & 26.1 & Loam & 5.16 & 4.85 & 3.04 & 0.20 & 0.74 & 49.72 & 11.67 & 24.4 & 1.38 & -21.07 \\
\hline 17 & 4 & 99.15 & 110 & 34.7 & 36.5 & 28.8 & Clay Loam & 5.53 & 5.39 & 2.95 & 0.14 & 0.77 & 46.29 & 11.08 & 24.4 & 1.24 & -21.50 \\
\hline 18 & 5 & 99.1 & 115 & 29.7 & 37.5 & 32.8 & Clay Loam & 5.93 & 5.79 & 2.95 & 0.12 & 0.82 & 43.79 & 11.90 & 25.0 & 1.16 & -21.47 \\
\hline 19 & 5 & 99.05 & 120 & 35.4 & 34.1 & 30.5 & Clay Loam & 5.59 & 5.21 & 3.07 & 0.23 & 0.79 & 39.91 & 11.10 & 25.0 & 0.99 & -20.81 \\
\hline 21 & 5 & 98.95 & 130 & 41.8 & 31.4 & 26.8 & Loam & 5.19 & 4.73 & 3.06 & 0.25 & 0.77 & 35.33 & 10.90 & 26.3 & 0.91 & -22.07 \\
\hline $22 \mathrm{~A}$ & 5 & 98.9 & 135 & 27.2 & 37.6 & 35.2 & Clay Loam & 6.10 & 6.31 & 2.85 & -0.02 & 0.81 & 35.55 & 10.49 & 25.3 & 0.71 & -20.84 \\
\hline $22 \mathrm{~B}$ & 5 & 98.9 & 135 & 30.7 & 37 & 32.3 & Clay Loam & 5.80 & 5.51 & 2.90 & 0.17 & 0.78 & 36.18 & 10.49 & 25.0 & 0.77 & -20.59 \\
\hline 23 & 5 & 98.85 & 140 & 27.4 & 35.8 & 36.8 & Clay Loam & 6.17 & 6.17 & 2.96 & 0.05 & 0.81 & 35.84 & 10.52 & 24.1 & 0.71 & -20.49 \\
\hline 24 & 5 & 98.8 & 145 & 37.6 & 33.5 & 28.9 & Clay Loam & 5.39 & 5.13 & 3.02 & 0.19 & 0.77 & 40.19 & 11.34 & 24.4 & 0.76 & -20.30 \\
\hline 25 & 6 & 98.75 & 150 & 23.4 & 43.2 & 33.4 & Clay Loam & 6.20 & 5.89 & 2.65 & 0.18 & 0.81 & 42.10 & 11.47 & 26.1 & 0.79 & -20.58 \\
\hline 26 & 6 & 98.7 & 155 & 16.4 & 45.1 & 38.5 & Silty Clay Loam & 6.65 & 6.52 & 2.60 & 0.09 & 0.88 & 41.11 & 10.85 & 28.7 & 1.15 & -21.66 \\
\hline 27 & 6 & 98.65 & 160 & 14.7 & 46.9 & 38.4 & Silty Clay Loam & 6.72 & 6.53 & 2.58 & 0.11 & 0.90 & 43.77 & 11.01 & 25.5 & 0.82 & -20.44 \\
\hline 28 & 6 & 98.6 & 165 & 14.6 & 44 & 41.4 & Silty Clay & 6.83 & 6.79 & 2.59 & 0.02 & 0.89 & 39.10 & 10.83 & 28.3 & 0.79 & -20.68 \\
\hline 29 & 7 & 98.55 & 170 & 13.1 & 46.1 & 40.8 & Silty Clay & 6.86 & 6.73 & 2.53 & 0.06 & 0.90 & 40.00 & 10.88 & 29.6 & 0.99 & -21.55 \\
\hline 30 & 7 & 98.5 & 175 & 8.63 & 41.37 & 50 & Silty Clay & 7.34 & 7.38 & 2.48 & -0.01 & 0.94 & 37.95 & 10.52 & 30.6 & 0.68 & -20.21 \\
\hline 31 & 7 & 98.46 & 179 & 11.2 & 44.3 & 44.5 & Silty Clay & 7.05 & 7.03 & 2.55 & 0.01 & 0.92 & 39.43 & 10.45 & 25.9 & 0.67 & -19.68 \\
\hline 32 & 7 & 98.4 & 185 & 9.8 & 43.1 & 47.1 & Silty Clay & 7.20 & 7.20 & 2.59 & 0.01 & 0.93 & 39.89 & 10.93 & 33.9 & 0.69 & -20.12 \\
\hline 33 & 7 & 98.35 & 190 & 8.62 & 44.98 & 46.4 & Silty Clay & 7.22 & 7.15 & 2.45 & 0.05 & 0.89 & 41.42 & 11.30 & 30.6 & 0.75 & -20.32 \\
\hline 34 & 7 & 98.3 & 195 & 15.7 & 46.1 & 38.2 & Silty Clay Loam & 6.66 & 6.50 & 2.65 & 0.07 & 0.94 & 41.90 & 11.15 & 31.5 & 0.79 & -22.07 \\
\hline 35 & 7 & 98.25 & 200 & 13.5 & 49.9 & 36.6 & Silty Clay Loam & 6.66 & 6.32 & 2.54 & 0.16 & 0.90 & 41.50 & 8.27 & 33.8 & 0.71 & -20.82 \\
\hline 36 & 7 & 98.2 & 205 & 17.3 & 42.2 & 40.5 & Silty Clay & 6.71 & 6.64 & 2.76 & 0.04 & 0.91 & 41.82 & 10.88 & 33.1 & 0.63 & -20.83 \\
\hline 37 & 7 & 98.15 & 210 & 15.3 & 46.3 & 38.4 & Silty Clay Loam & 6.67 & 6.49 & 2.57 & 0.10 & 0.87 & 41.93 & 10.93 & 26.1 & 0.76 & -21.89 \\
\hline 38 & 7 & 98.1 & 215 & 16.5 & 48 & 35.5 & Silty Clay Loam & 6.53 & 6.18 & 2.58 & 0.19 & 0.85 & 37.91 & 9.33 & 29.2 & 0.48 & -21.61 \\
\hline 39 & 7 & 98.05 & 220 & 19.3 & 45.7 & 35 & Silty Clay Loam & 6.41 & 6.13 & 2.67 & 0.16 & 0.88 & 34.40 & 10.89 & 26.0 & 0.60 & -21.24 \\
\hline 40 & 8 & 98 & 225 & 23.2 & 42.3 & 34.5 & Clay Loam & 6.23 & 6.03 & 2.78 & 0.12 & 0.87 & 30.86 & 10.89 & 29.5 & 0.61 & -22.91 \\
\hline
\end{tabular}



Table 9-4. (concluded).

\begin{tabular}{|c|c|c|c|c|c|c|c|c|c|c|c|c|c|c|c|c|c|}
\hline Sample & Zone & Elevation & Depth & $\begin{array}{l}\text { Sand } \\
(\%)\end{array}$ & $\begin{array}{l}\text { Silt } \\
(\%)\end{array}$ & $\begin{array}{l}\text { Clay } \\
(\%)\end{array}$ & $\begin{array}{l}\text { USDA Textural } \\
\text { Class }\end{array}$ & $\begin{array}{c}\text { Mean } \\
\text { (phi) }\end{array}$ & $\begin{array}{c}\text { Median } \\
(\text { phi) }\end{array}$ & $\begin{array}{c}\text { Sorting } \\
\text { (phi) }\end{array}$ & $\begin{array}{c}\text { Skewness } \\
\text { (phi) }\end{array}$ & $\begin{array}{c}\text { Kurtosis } \\
\text { (phi) }\end{array}$ & Xlf & Xfd & $\begin{array}{l}\mathrm{CCE} \\
(\%)\end{array}$ & $\begin{array}{c}\text { Organic } \\
\text { Carbon (\%) }\end{array}$ & $\begin{array}{c}d 13 \mathrm{C} \\
\text { per mil PDB }\end{array}$ \\
\hline 41 & 8 & 97.95 & 230 & 33.2 & 38.4 & 28.4 & Clay Loam & 5.59 & 5.16 & 2.92 & 0.23 & 0.84 & 28.70 & 10.62 & 27.9 & 0.36 & -21.17 \\
\hline 42 & 8 & 97.9 & 235 & 44.1 & 32.4 & 23.5 & Loam & 4.89 & 4.46 & 3.06 & 0.24 & 0.80 & 25.15 & 10.89 & 27.9 & 0.34 & -21.11 \\
\hline 43 & 8 & 97.85 & 240 & 45.8 & 31.6 & 22.6 & Loam & 4.78 & 4.29 & 3.06 & 0.27 & 0.81 & 26.15 & 10.22 & 26.0 & 0.37 & -20.71 \\
\hline 44 & 8 & 97.8 & 245 & 30.8 & 41 & 28.2 & Clay Loam & 5.70 & 5.21 & 2.78 & 0.26 & 0.86 & 27.33 & 10.91 & 26.9 & 0.37 & -20.22 \\
\hline 45 & 8 & 97.75 & 250 & 51.5 & 27.3 & 21.2 & Sandy Clay Loam & 4.53 & 3.88 & 3.08 & 0.34 & 0.81 & 22.10 & 11.47 & 29.5 & 0.31 & -19.60 \\
\hline 46 & 9 & 97.7 & 255 & 54.6 & 24 & 21.4 & Sandy Clay Loam & 4.40 & 3.52 & 3.12 & 0.42 & 0.80 & 16.18 & 10.55 & 32.3 & 0.21 & -19.91 \\
\hline 47 & 9 & 97.65 & 260 & 70.2 & 15 & 14.8 & Sandy Loam & 3.44 & 2.11 & 2.93 & 0.67 & 1.12 & 10.56 & 10.03 & 32.0 & 0.16 & -20.67 \\
\hline 48 & 9 & 97.6 & 265 & 71.2 & 15.1 & 13.7 & Sandy Loam & 3.37 & 2.12 & 2.80 & 0.68 & 1.18 & 11.56 & 10.86 & 32.9 & 0.51 & -23.10 \\
\hline 49 & 9 & 97.55 & 270 & 76.3 & 12.3 & 11.4 & Sandy Loam & 2.93 & 1.91 & 2.75 & 0.57 & 1.50 & 10.37 & 9.41 & 41.8 & 0.15 & -21.19 \\
\hline 50 & 9 & 97.51 & 274 & 78.1 & 11.7 & 10.2 & Sandy Loam & 3.13 & 2.37 & 2.21 & 0.63 & 1.96 & 9.81 & 10.44 & 24.3 & 0.17 & -20.27 \\
\hline 51 & 10 & 97.45 & 280 & 79.7 & 10.2 & 10.1 & Sandy Loam & 3.07 & 2.50 & 2.16 & 0.55 & 2.42 & 10.58 & 9.06 & 21.4 & 0.15 & -21.43 \\
\hline 52 & 10 & 97.4 & 285 & 79.2 & 10.92 & 9.88 & Sandy Loam & 2.99 & 2.30 & 2.14 & 0.64 & 2.02 & 7.78 & 10.33 & 26.5 & 0.14 & -22.06 \\
\hline 53 & 10 & 97.35 & 290 & 70.9 & 17.4 & 11.7 & Sandy Loam & 3.71 & 2.94 & 2.23 & 0.62 & 1.57 & 11.81 & 9.51 & 21.4 & 0.17 & -20.75 \\
\hline 54 & 11 & 97.33 & 292 & 41.6 & 36.6 & 21.8 & Loam & 5.20 & 4.42 & 2.56 & 0.46 & 0.93 & 19.60 & 9.27 & 21.7 & 0.31 & -19.93 \\
\hline 55 & $11 \mathrm{a}$ & 97.3 & 295 & 39.7 & 38.1 & 22.2 & Loam & 5.22 & 4.66 & 2.68 & 0.34 & 0.88 & 26.06 & 10.46 & 26.5 & 0.31 & -19.55 \\
\hline 56 & 11a & 97.28 & 297 & 33.7 & 36.8 & 29.5 & Clay Loam & 5.67 & 5.30 & 2.82 & 0.23 & 0.79 & 31.55 & 10.11 & 28.7 & 0.40 & -19.24 \\
\hline 57 & $11 \mathrm{a}$ & 97.25 & 300 & 33.6 & 39.6 & 26.8 & Loam & 5.63 & 5.16 & 2.75 & 0.27 & 0.82 & 35.03 & 9.71 & 29.0 & 0.42 & -19.15 \\
\hline 58 & $11 \mathrm{a}$ & 97.22 & 303 & 16.4 & 43.8 & 39.8 & Silty Clay Loam & 6.65 & 6.62 & 2.53 & 0.04 & 0.82 & 32.31 & 10.03 & 26.2 & 0.41 & -19.49 \\
\hline 59 & $11 \mathrm{a}$ & 97.2 & 305 & 25.5 & 45.7 & 28.8 & Clay Loam & 5.95 & 5.48 & 2.60 & 0.28 & 0.87 & 30.94 & 9.90 & 27.4 & 0.38 & -20.43 \\
\hline 60 & $11 \mathrm{~b}$ & 97.15 & 310 & 39.7 & 38 & 22.3 & Loam & 5.32 & 4.41 & 2.50 & 0.53 & 0.92 & 22.89 & 9.95 & 22.6 & 0.30 & -21.31 \\
\hline 61 & $11 \mathrm{~b}$ & 97.1 & 315 & 50.4 & 29.7 & 19.9 & Loam & 4.91 & 3.97 & 2.58 & 0.55 & 0.97 & 19.19 & 8.96 & 20.4 & 0.26 & -19.83 \\
\hline 62 & $11 \mathrm{a}$ & 97.05 & 320 & 33.4 & 41.1 & 25.5 & Loam & 5.55 & 5.08 & 2.61 & 0.29 & 0.83 & 29.24 & 10.16 & 24.9 & 0.36 & -20.19 \\
\hline 63 & $11 \mathrm{~b}$ & 97 & 325 & 58.4 & 24 & 17.6 & Sandy Loam & 4.56 & 3.50 & 2.52 & 0.64 & 1.03 & 17.90 & 10.74 & 17.6 & 0.25 & -20.08 \\
\hline 64 & 11a & 96.94 & 331 & 45.4 & 31.8 & 22.8 & Loam & 5.14 & 4.25 & 2.61 & 0.52 & 0.87 & 20.25 & 10.52 & 23.9 & 0.31 & -20.14 \\
\hline 65 & 11a & 96.9 & 335 & 36.1 & 39.5 & 24.4 & Loam & 5.47 & 4.88 & 2.71 & 0.33 & 0.87 & 26.02 & 10.98 & 27.8 & 0.41 & -19.91 \\
\hline 66 & $11 \mathrm{~b}$ & 96.84 & 341 & 43.8 & 38.5 & 17.7 & Loam & 4.96 & 4.26 & 2.40 & 0.48 & 1.09 & 22.11 & 10.41 & 27.8 & 0.33 & -20.11 \\
\hline 67 & 11a & 96.8 & 345 & 33.5 & 42 & 24.5 & Loam & 5.55 & 4.95 & 2.58 & 0.37 & 0.89 & 26.91 & 10.67 & 32.2 & na & na \\
\hline 68 & $11 \mathrm{a}$ & 96.75 & 350 & 34 & 41.6 & 24.4 & Loam & 5.52 & 4.84 & 2.55 & 0.40 & 0.87 & 23.57 & 10.66 & 28.7 & na & na \\
\hline 69 & 11a & 96.7 & 355 & 36.5 & 40.9 & 22.6 & Loam & 5.39 & 4.66 & 2.56 & 0.43 & 0.92 & 26.26 & 9.94 & 28.1 & na & na \\
\hline 70 & $11 \mathrm{~b}$ & 96.65 & 360 & 42.5 & 37.6 & 19.9 & Loam & 5.12 & 4.38 & 2.48 & 0.47 & 0.99 & 20.46 & 9.64 & 26.8 & na & na \\
\hline 71 & $11 \mathrm{a}$ & 96.62 & 363 & 40.9 & 31.8 & 27.3 & Clay Loam & 5.43 & 4.68 & 2.78 & 0.41 & 0.78 & 24.86 & 10.40 & 31.0 & na & na \\
\hline 72 & $11 \mathrm{~b}$ & 96.59 & 366 & 52.3 & 24.6 & 23.1 & Sandy Clay Loam & 4.96 & 3.83 & 2.71 & 0.60 & 0.80 & 18.78 & 10.00 & 27.4 & na & na \\
\hline 73 & $11 \mathrm{a}$ & 96.55 & 370 & 34.5 & 42.1 & 23.4 & Loam & 5.47 & 4.77 & 2.56 & 0.42 & 0.92 & 23.35 & 10.51 & 29.4 & na & na \\
\hline 74 & $11 \mathrm{a}$ & 96.5 & 375 & 36.6 & 39.9 & 23.5 & Loam & 5.40 & 4.74 & 2.61 & 0.39 & 0.89 & 22.46 & 10.55 & 29.4 & na & na \\
\hline
\end{tabular}



Isotope/Soil Biology Laboratory at the Institute of Ecology, University of Georgia. These values were determined from the carbonate-free $<2-\mathrm{mm}$ soil used to determine the organic carbon content and were determined on a element ratio mass spectrometer by converting the organic carbon to a gas phase by extremely rapid and complete flash combustion of the sample material. The results of the physical characterizations are plotted on Figures 9-4 through 9-6.

\section{Observations}

\section{Macrostratigraphy}

Testing excavations exposed three Leon River allostratigraphic units or alluvial fills originally named by Nordt (1991) that were previously identified by Abbott (2011) at this site (see Chapter 5). The oldest of these was the early-middle Holocene-age Fort Hood alluvium, followed by the middle-late Holocene-age West Range alluvium, and finally the Ford alluvium, which was deposited in the last millenium. Each of these alluvia is described below, followed at the end of the overall section by detailed stratigraphic descriptions of the backhoe trenches and witness columns.

\section{Fort Hood Alluvium}

Abbott (2011) (also see Chapter 5) originally identified the Fort Hood alluvium in TxDOT Trenches 5 and 6 in the northeast quadrant of the site. A single trench excavated during the current testing phase exposed the Fort Hood alluvium; this trench (BT 18) was situated between Trenches 4 and 6, north of the Leon River and east of U.S Hwy. 281. BT 18 revealed a thin veneer of younger alluvia draped across the top of the Fort Hood alluvium (see Figure 6-27). The top $43 \mathrm{~cm}$ of this profile was interpreted as the Ford alluvium, and an Ap-AC soil profile was noted within this deposit. The Ford alluvium rested upon a buried A horizon that was interpreted in the field as a compressed flood-basin facies of the West Range alluvium, but the fact that this deposit appears to have been significantly leached of calcium carbonate may mean that this is actually the top of the Fort Hood alluvium. Between 70 and $110 \mathrm{~cm}$, a second A horizon was present and this one contained a significant pedogenic calcium carbonate component (in the form of filaments) and therefore was inferred to be Fort Hood alluvium. Between 110 and $195 \mathrm{~cm}$, the deposits comprised a brown (7.5YR hue) silty clay that exhibited calcium carbonate filaments above $173 \mathrm{~cm}$ and filaments and small calcium nodules and masses below. No cultural material was observed within any of these deposits.
It should be noted, that the natural alluvial deposits were preserved in situ in the eastern third of the trench, but highway construction had removed the top $60 \mathrm{~cm}$ and replaced them with crushed limestone aggregate and a topsoil-like fill in the western two-thirds of the trench.

\section{West Range Alluvium}

Abbott (2011) (also see Chapter 5) observed the West Range alluvium within six of the trenches he excavated in the spring of 2011 and this deposit was present in four of the trenches excavated during the current testing (specifically BTs $15,16,17,19$, and 23). The West Range alluvium at the site consists entirely of flood-basin facies sediments that show little significant depth variation in texture and no traces of bedding. A prominent buried soil (informally termed "the upper paleosol") marks the top of the West Range alluvium, and below this A horizon the deposit becomes more brown and less melanized. However, several (if not most) trenches and witness columns revealed a slightly darker bed about 60 to $70 \mathrm{~cm}$ below the top of the West Range alluvium that looks like a faint buried A horizon (Figure 9-7). Unfortunately, this deposit was not always easy to see in the field owing to variable light conditions and differences in appearance due to presentation. Specifically, this deposit was often difficult to see on trench walls picked with a knife or pick, but it usually was visible on shaved faces (note that the unit is dashed in the southernmost section of BT 15 [see Figure 6-11], but clearly was evident in the profile of WC 3 in the same trench [see Figure 9-7]).

The hypothesis that this darker colored deposit is a buried soil (informally referred to hereafter as "the lower paleosol") was not ascribed much significance in the field given it was hard to consistently observe, but two observations from the post-excavation analysis support its presence. First, the radiocarbon ages obtained from Features 19/20 and 18, which bracket this deposit (above and below, respectively), returned ages consistent for the Upper West Range alluvium above this possible soil. Feature 19 yielded an age from organic sediment of $2590 \pm 30$ (ca. 2770-2700 cal B.P., Beta-315690) and an age from the feature's mussel shells of $2830 \pm 30$ (ca. $3000-2850$ cal B.P., Beta-382993) (see Table 10-1 in the following chapter). Similarly, Feature 20 yielded an age from charred material of $2540 \pm 30$ years B.P. (ca. 27502500 cal B.P., Beta-315691). The ages obtained from Feature 18 were roughly 1,000 years older, as a sample of organic sediment from the feature produced an age of $3860 \pm 30$ years B.P. (ca. 4410-4160 cal B.P., 


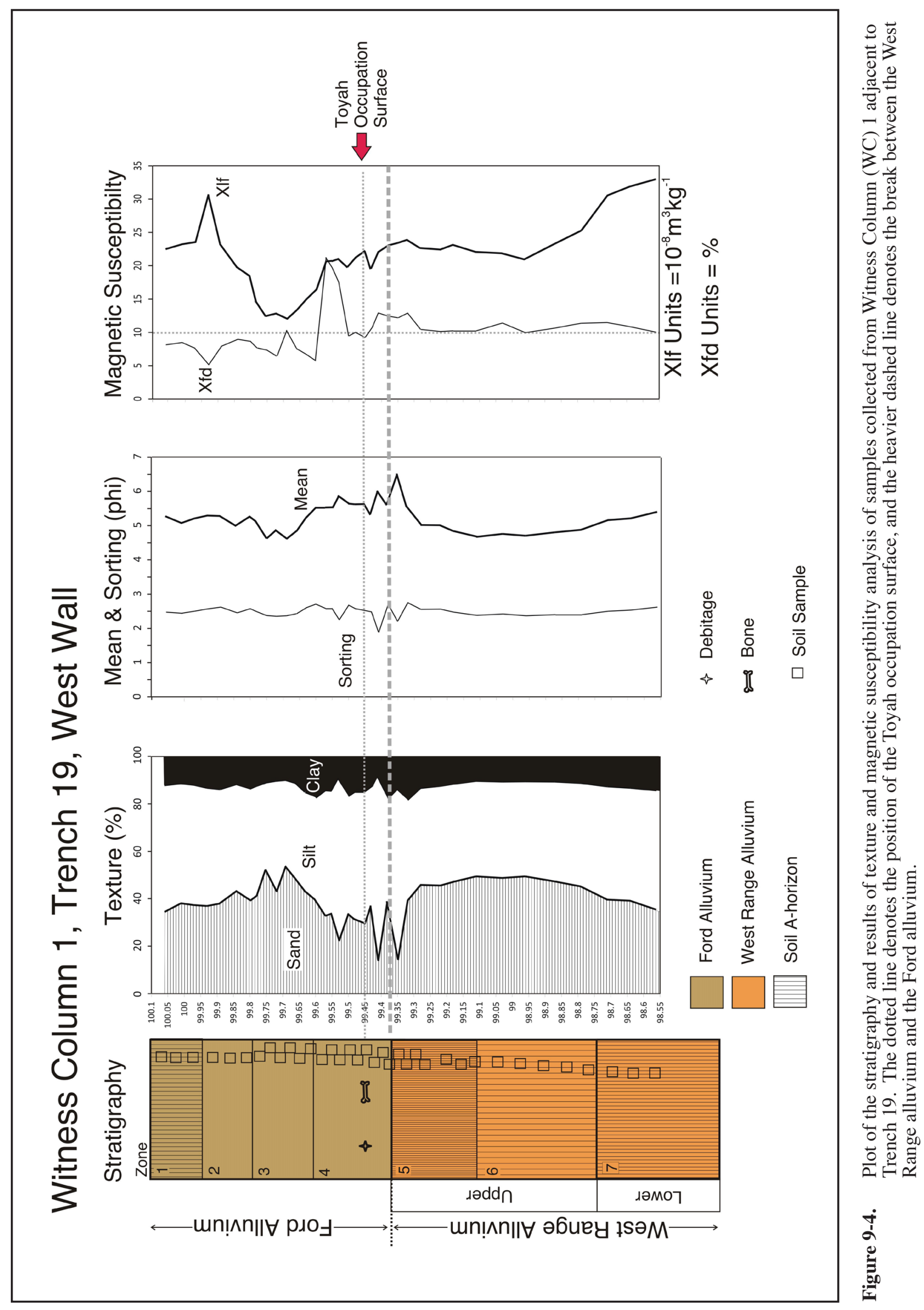




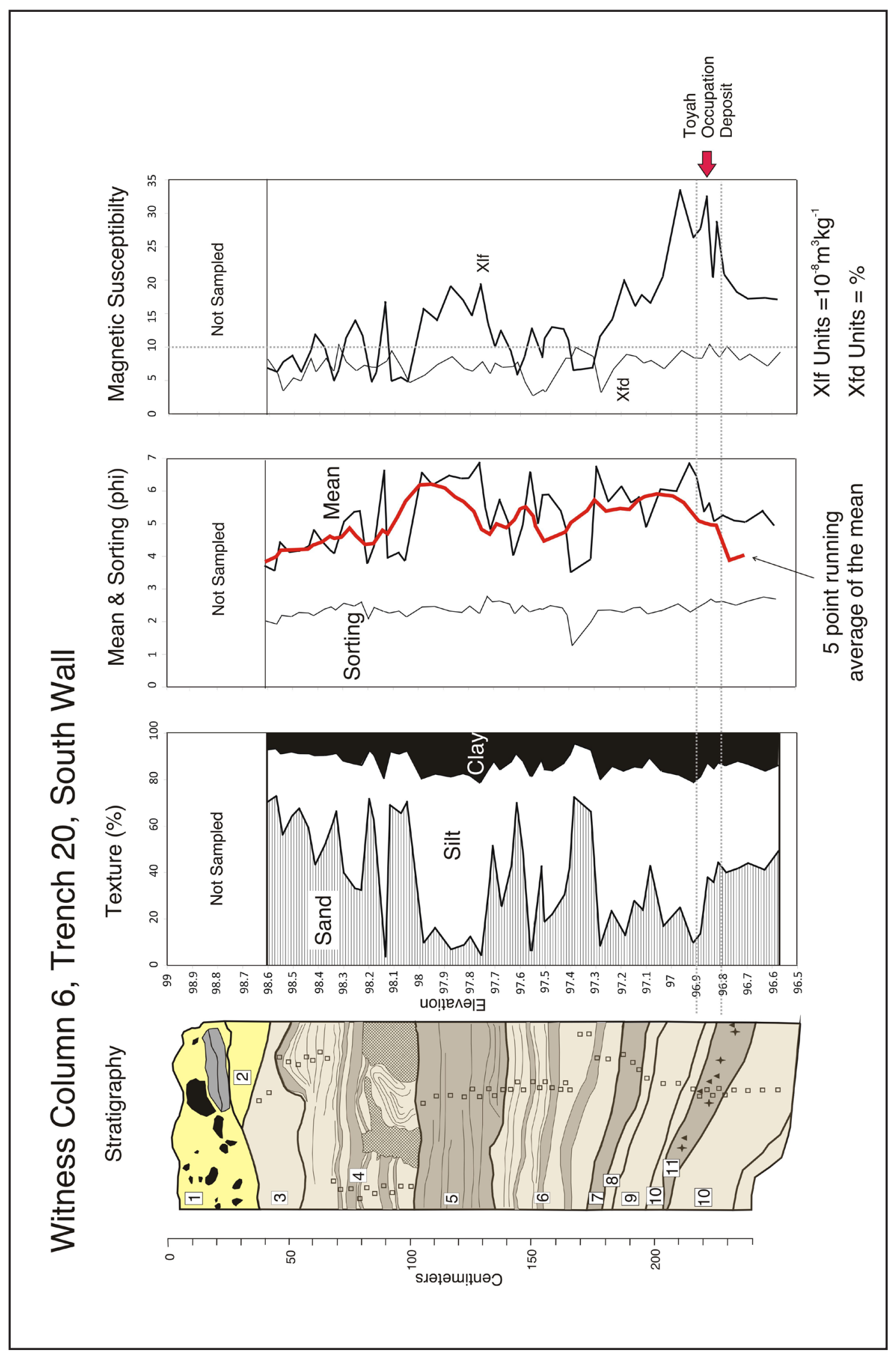

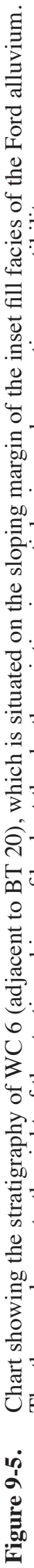




\section{Base of Trench 20}
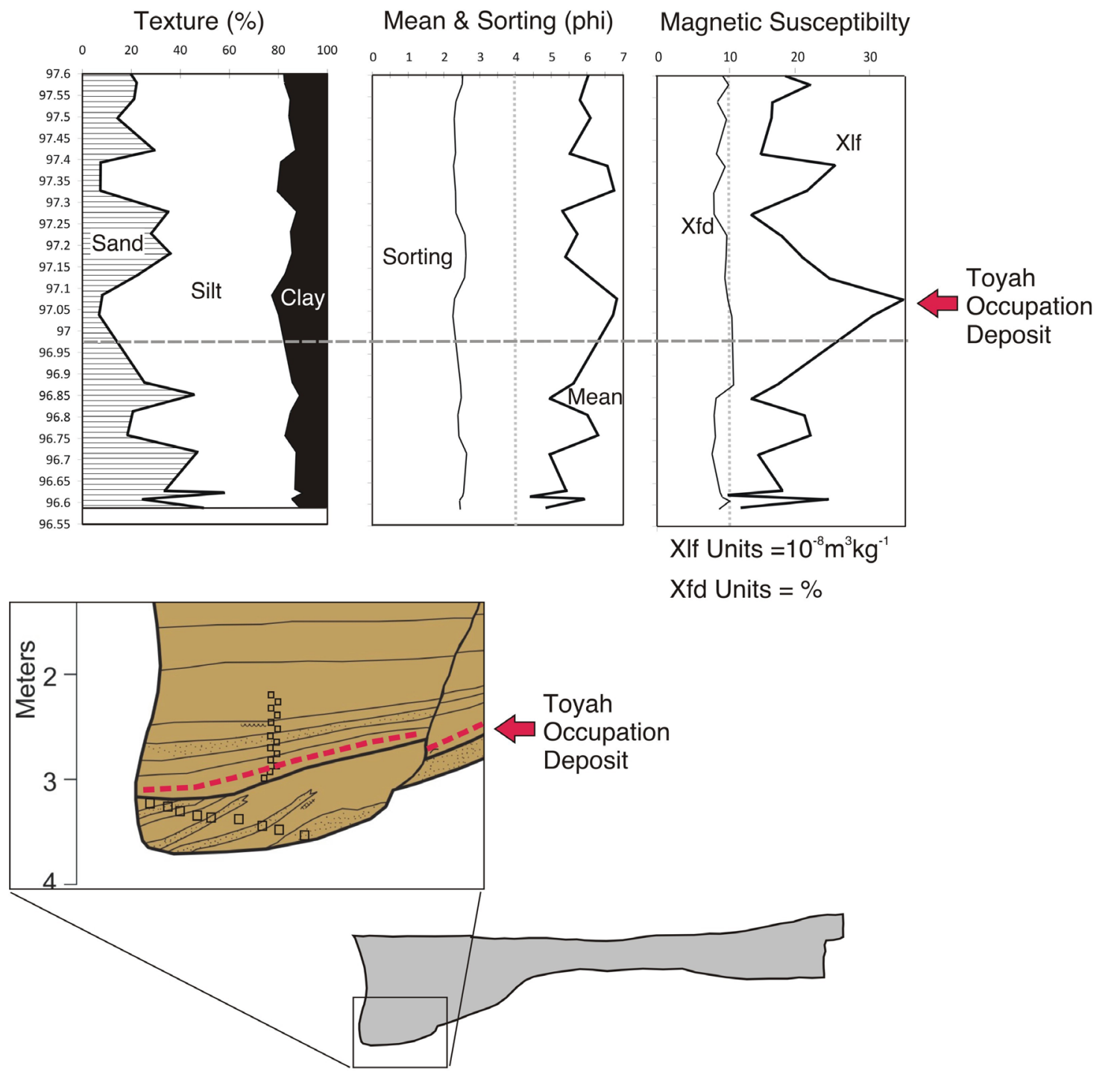

Figure 9-6. Plot of texture and magnetic susceptibility analysis of samples collected from strata exposed at the base of BT 20.

Beta-315692), while mussel shells from the feature yielded an age of $4060 \pm 30$ (ca. $4630-4430$ cal B.P., Beta-382992), both of which are consistent with the Lower West Range alluvium.

Nordt divided the West Range alluvium on Cowhouse Creek at Fort Hood into an upper and lower unit. The Lower West Range was radiocarbon dated by Nordt to the period between 4170 and 2380 years B.P., whereas deposition of the Upper West Range alluvium was dated to the period between 2380 and 600 years B.P. (Nordt 1992; 2004). The radiocarbon ages obtained at 41HM61 place the top of this possible soil within approximately 200 years of Nordt's temporal division between the two members of the West Range alluvium.

The second piece of information supporting the hypothesis that this stratum is a soil is analytical work performed on Witness Column 1, which obtained 


\section{Trench 15, East Wall}

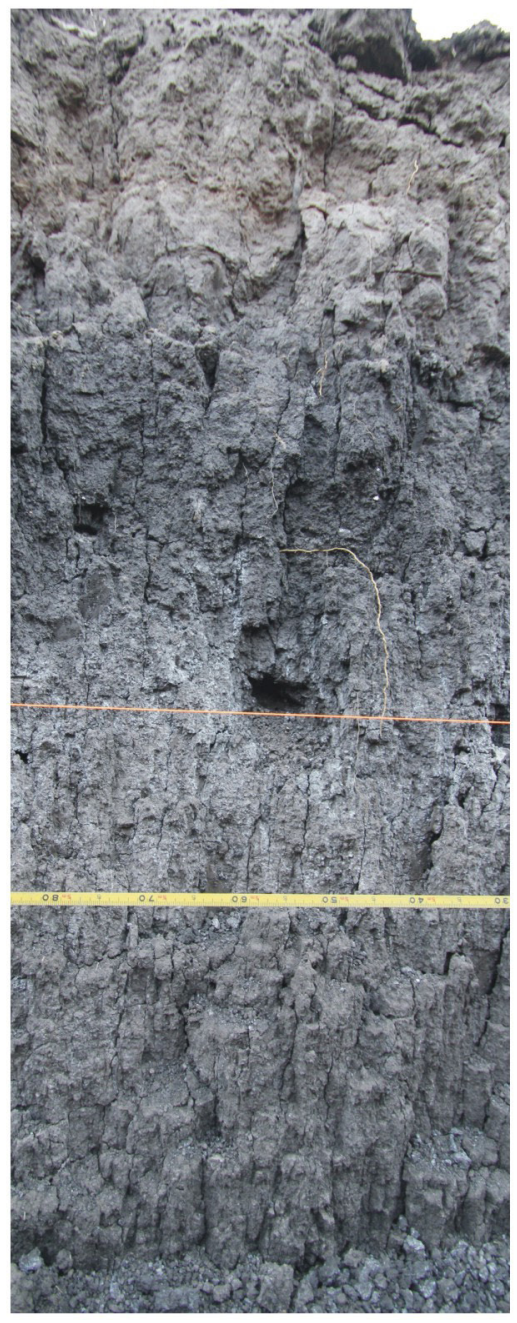

Dry, picked

\section{Witness Column 3}

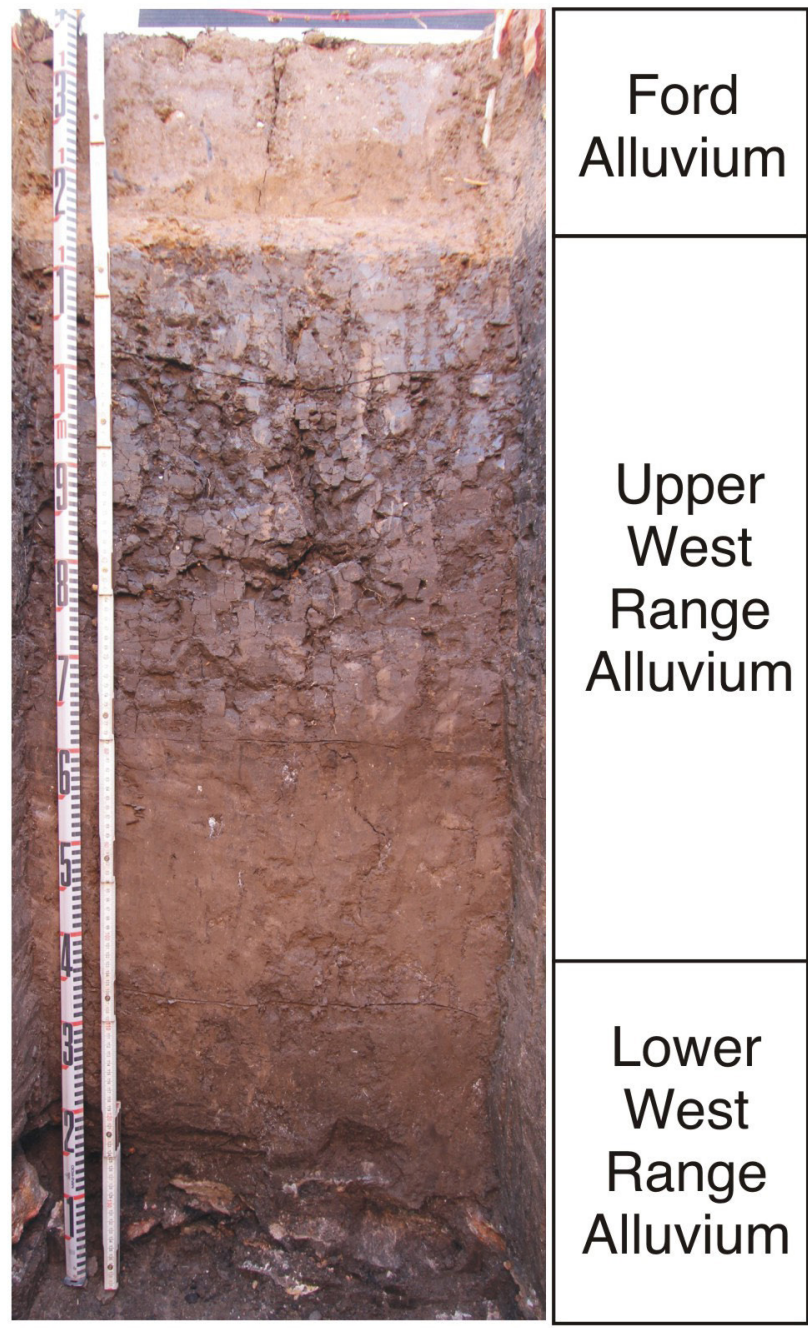

Moist, shaved

Figure 9-7. Expressions of the West Range alluvium in the southern part of 41HM61. Left-A photograph of a dry picked exposure of the West Range showing the Upper and Lower members. RightEast wall of WC 3 showing the same deposits, but shaved and in a moist state.

samples from the West Range alluvium that showed significantly enhanced magnetic susceptibility in the presumed paleosol (see Figure 9-4, Zone 7) which is often associated with former top soils.

Hence, in the discussion that follows the deposits above the presumed "lower paleosol" are here tentatively correlated with the Upper member of the
West Range alluvium and the deposits associated with the apparent paleosol are correlated with the Lower member of the West Range alluvium. The Upper West Range alluvium at Fort Hood, where defined by Nordt (1992), was in excess of $6 \mathrm{~m}$ thick on most streams, and the thin presentation of this deposit at 41HM61 suggests that it is a floodplain veneer resting upon an older unit. The Lower West 
Range was not completely exposed by the testing excavations, but understanding if this deposit, like the upper West Range, is a thin veneer perched upon an older, eroded alluvial deposit such as the Fort Hood, or a much thicker alluvial deposit, is of critical interest if any deeper impacts are to be performed at a later date. For this reason BT 23 was excavated perpendicularly across Trench 15 in the southeast quadrant of the site, and it revealed that the core of the deposit in this area is the Lower West Range alluvium.

Upper Member of the West Range Alluvium. The deposits of the Upper part of the West Range alluvium, as noted previously, consist of relatively homogeneous fine-grained alluvial sediment deposited by suspension from floodwater in a distal overbank setting. Two strata were consistently observed - a paleosol and a Bk horizon. The upper part of the Upper West Range consists of a prominent buried soil. This deposit is a black (10YR 2/1) silt loam, silty clay to clay, that exhibits prominent prismatic structure and numerous calcium carbonate filaments (Akb horizon). The underlying deposit is a very dark gray to very dark grayish brown (10YR $3 / 1$ to 10 YR $3 / 2$ ) silt loam to loam, that also exhibits prominent prismatic structure and significantly more calcium carbonate filaments; and often small discontinuous patchy coats of calcium carbonate on ped faces. No bedding structures were observed in this deposit, but multiple prehistoric occupation surfaces appeared to be present, especially within the upper paleosol.

Detailed examination of the deposits of the Upper member of the West Range alluvium in Witness Column 1 present a prominent contrast with the Ford Alluvium (see Figure 9-4). Where the Ford alluvium often exhibits traces of bedding, the West Range shows no evidence of discrete depositional events, and exhibits a very gradually coarsening-upward profile. The upper paleosol does exhibit slight magnetic susceptibility enhancement, and all the samples exhibit coefficient of frequency dependence that are consistent with pedogenic enhancement.

Lower Member of the West Range Alluvium. The "lower paleosol" is the primary deposit associated with the Lower member of the West Range alluvium at this site, although less melanized deposits were observed beneath it in several trenches (e.g., Zone 8 in BT 17, Zone 5 in TxDOT BT 6), but exposure of these underlying strata were generally insufficient to confidently assess their attributes.
The "lower paleosol" exhibited a wide range of colors, some with 10YR hues (e.g., black [10YR 2/1], dark gray [10YR 4/1] and very dark grayish brown [10YR 3/2]) and others with 7.5YR hues (e.g., dark brown [7.5YR 3/3]) and generally fine textures ranging from loam, to silt loam, silty clay and clay. It typically exhibited moderate to strong prismatic structure and about 5 to 7 percent calcium carbonate filaments. The Bk horizon beneath the "lower paleosol" was generally brown (7.5YR $4 / 3$ to $7.5 \mathrm{YR}$ 4/4) silt loam, silty clay to clay, and also possessed well-developed prismatic structure and about 7 to 10 percent calcium carbonate filaments. Like the Upper West Range deposits, none of the Lower West Range sediments exhibited evidence of sedimentary stratification or bedding.

As noted, Trench 23 was excavated across BT 15 , north of Block 5 and south of BT 11, and was terminated at a depth of $3.8 \mathrm{~m}$ (see Figure 9-1). The west wall of this trench was cleaned, described and sampled, and this excavation revealed about $2 \mathrm{~m}$ of the Lower West Range alluvium beneath thin veneers of spoil (derived from former BT 15), the Ford alluvium, and the Upper West Range alluvium (Figure 9-8). The top $0.8 \mathrm{~m}$ of the Lower West Range was the lower paleosol, which, as observed elsewhere, was clearly formed within massive floodplain muds. But this floodplain deposit is part of a prominent fining-upward depositional cycle that starts at $2.9 \mathrm{~m}$ below surface with a laminated loamy sand, after which the deposit gradually fines upward. A thin scatter of charcoal collected from the sandy bed near the base of this cycle was radiocarbon dated and yielded an age of $3610 \pm 30$ (ca. 3990-3840 cal years B.P., Beta382990) (see Table 10-1). The analytical work obtained from the analysis of the lower paleosol confirms that this is indeed a soil. The top of this deposit is slightly leached of calcium carbonate, exhibits a prominent magnetic susceptibility enhancement, and is characterized by an elevated amount of organic carbon that decreases with increasing depth.

Below a depth of $2.9 \mathrm{~m}$, the deposits of the Lower West Range alluvium consist of alternating thin beds of fine and coarse sediments that appear to have been deposited in a near-channel overbank setting, possibly at the rear of a point bar. The fine-grained beds consisted of dark gray $(10 \mathrm{YR} 4 / 1, \mathrm{~m})$ to dark grayish brown $(10 \mathrm{YR} 4 / 2, \mathrm{~m})$ loam and clay loam whereas the coarse beds consisted of brown $(10$ YR 5/3, m) loam to sandy loam. A bulk sediment sample was collected from near the base of the trench and yielded a radiocarbon age of 4450 \pm 30 (ca. 5290-4960 cal years B.P., Beta-382991) (see Table 10-1). 

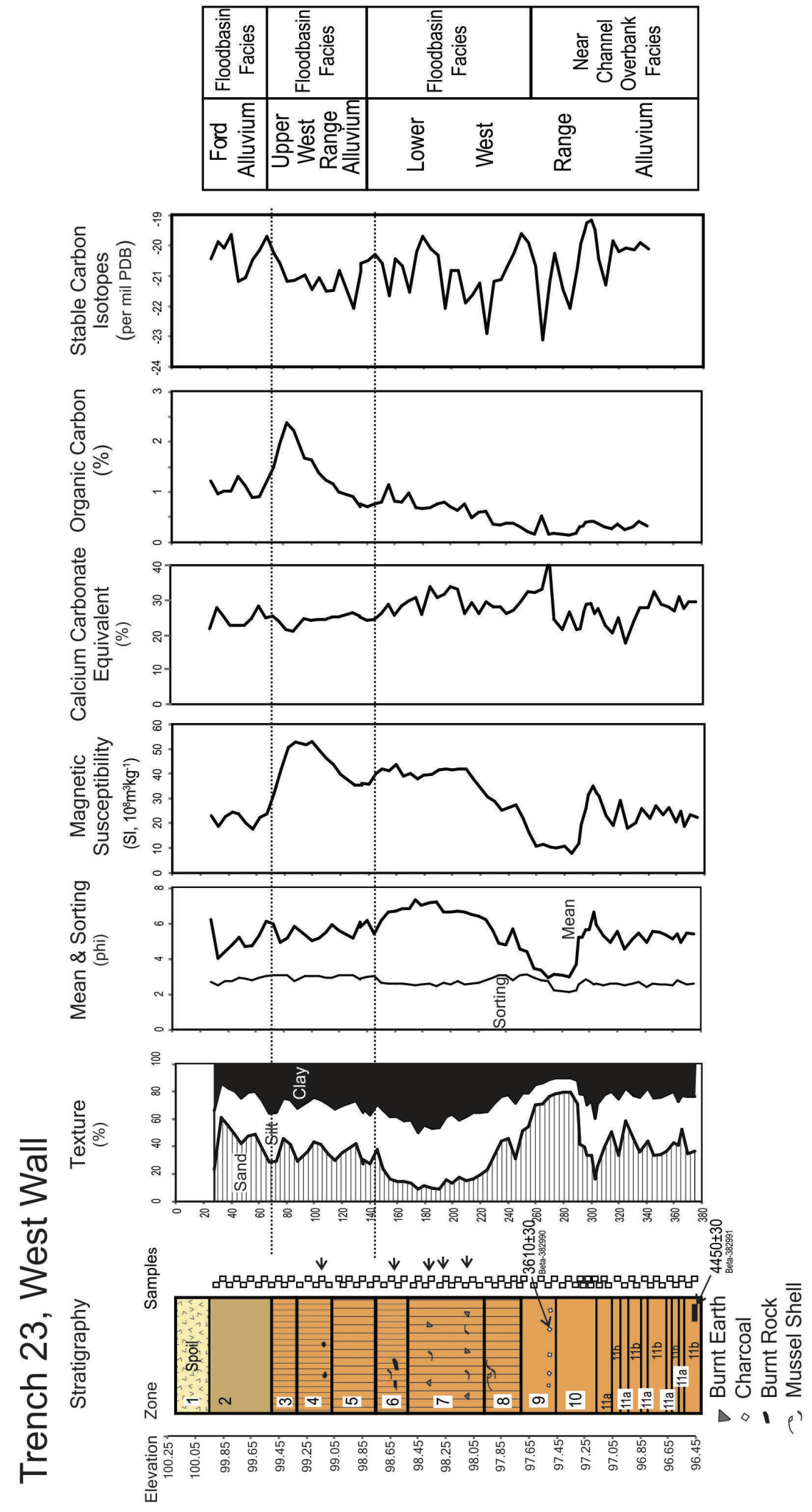

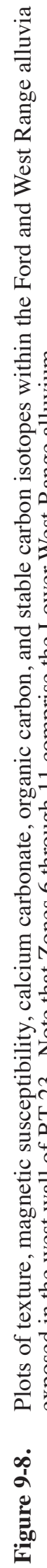


Three samples of the upper paleosol were collected in WC 1 (BT 19) (see Figure 9-4), and all three of these exhibit significantly higher magnetic susceptibility values than the Upper West Range deposits, plus they all also exhibit elevated values of the coefficient of frequency dependence, both of which are often attributed to top soils.

Cultural Inclusions Within the West Range Alluvium. Abbott (2011; also see Chapter 5) noted widely dispersed cultural material within the West Range alluvium, but the lack of features and remains in greater density led him to question if the observed cultural material was in primary context. It became clear soon after the additional trenching by CEI that there are multiple prehistoric occupation surfaces within the West Range alluvia (both Upper and Lower members) and that most of these contain features (either fire-cracked rock and/or mussel shell concentrations). Amazingly, several of these were found immediately outside Abbott's original trenches, which missed exposing them by mere centimeters in several cases.

The portion of the site with the greatest frequency of Archaic settlement remains is the southeast quadrant which appears to have been elevated ground during much of the period of West Range sedimentation, given the relationships observed in BT 17 (see Figure 6-19) where the soil formed at the top of the upper West Range dives and thickens considerably to the west, and pinches and thins to the east where the greatest concentration of cultural remains were found. In this portion of the site, cultural material was most ubiquitous in the "upper paleosol" of the Upper West Range, but BT 15, exposed several occupation surfaces within the Lower West Range that were unambiguously in situ and could be traced for about half the length of BT 15. In BT 23, the majority of the prehistoric occupation surfaces were observed within the lower West Range alluvium, floodplain facies with the deepest occupation located around $-2.3 \mathrm{~m}$ ( 97.95 m elevation).

\section{Ford Alluvium}

The Ford alluvium was identified by Abbott (2011; see Chapter 5) in 10 of the trenches he excavated in the spring of 2011, and it comprised the entirety of four of those (all of which were located on the western side of U.S. Hwy. 281). In the other six trenches, Abbott noted that the Ford alluvium formed a drape or veneer over the West Range alluvium. Excavations during the testing phase exposed the Ford alluvium in every trench, although the thickness of this deposit varied considerably. Two facies of the Ford alluvium were identified in the field, an inset fill facies and a terrace veneer facies.

During testing, a discrete, Late Prehistoric Toyah occupation was discovered in BT 19, which was a southward extension of Abbott's BT 4. This occupation was situated at the interface between the Ford alluvium and West Range alluvium. Figure 9-9 shows the macrostratigraphic relationship between the two facies of the Ford alluvium and the West Range alluvium, as well as the stratigraphic position of the Toyah occupation surface.

Inset Fill Facies. This portion of the Ford alluvium was deposited in a near-channel, overbank setting and consists of more than $4 \mathrm{~m}$ of highly stratified sediments deposited by suspension from flood water. This facies was observed in BTs 20, 21 and 22 in the northern half of the site. All exposures of this facies were composed of alternating fine and coarse sediments that often consisted of fining-upward couplets deposited by a single flood and there appear to be cycles of dominantly large floods (represented by coarser-textured couplets) and smaller floods (represented by finer-textured couplets) present within this facies of the Ford alluvium. The coarse-textured deposits in this facies are generally sands and sandy loams that range in color from brown $(10 \mathrm{YR} 5 / 3, \mathrm{~m})$, to pale brown $(10 \mathrm{YR} 6 / 3, \mathrm{~m})$ and very pale brown (10YR 7/3, 10YR 8/2). These deposits are often laminated (horizontal and ripple laminations are both present) and a few sections of the deposits, most notably in proximity to major bounding surfaces within the inset fill facies, exhibit contorted bedding that is interpreted as the result of trampling, most likely by hoofed animals. The fine-grained sediments of the inset fill facies vary from loam to silt loam and clay and range in color from brown (10YR 4/3), to dark grayish brown (10YR 4/2), very dark grayish brown (10YR 3/2) and black (10YR $2 / 1$ ), with an apparent correlation between color and texture where the finest sediments exhibited the darkest colors, as was also noted by Abbott (2011:18).

The complexity of the bedding within this facies makes simplified drawings (like that shown previously in Figure 6-33) and descriptions seem woefully inadequate. Figure 9-10 provides a slightly different rendition that, while still a generalization, more faithfully captures the highly stratified nature of these deposits. A yet different view of these deposits was presented earlier in Figure 9-5, which shows the results of the laboratory analysis of 57 samples collected from the south wall of WC 6. That WC was 


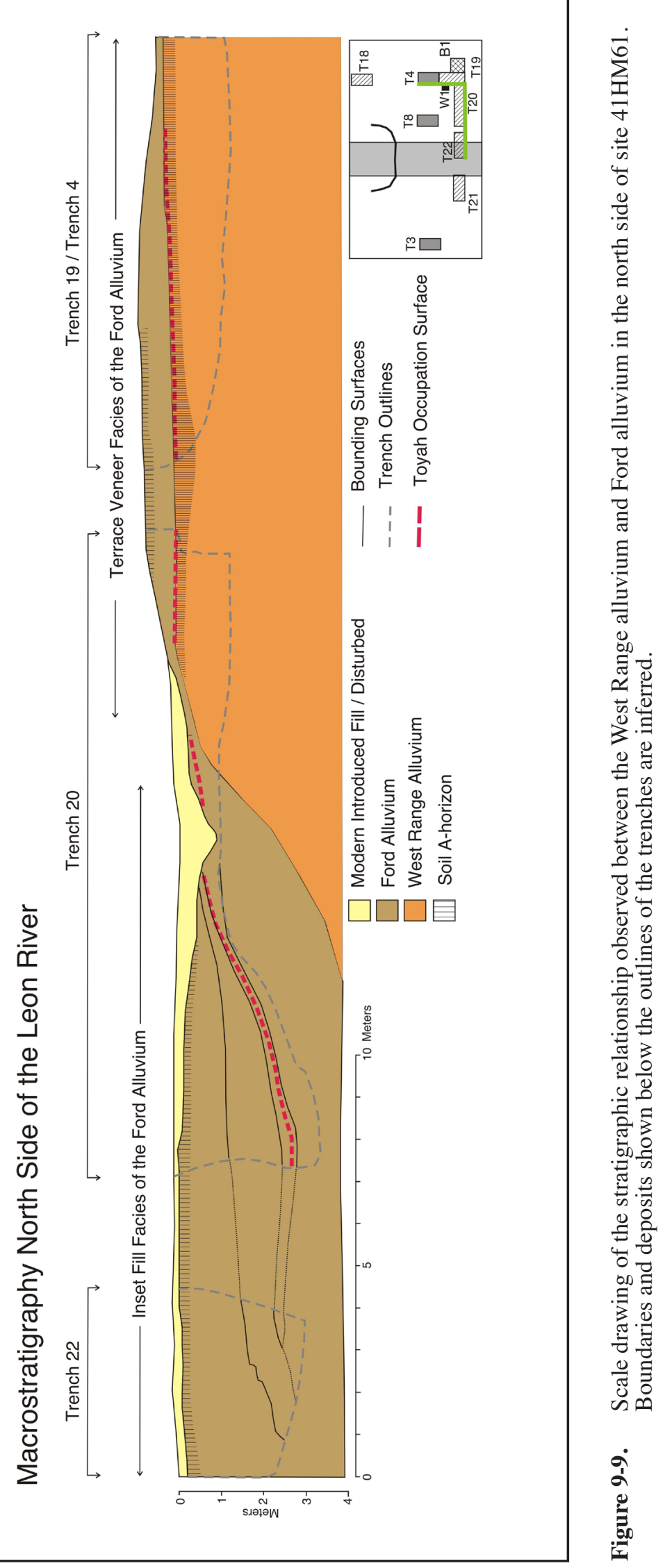



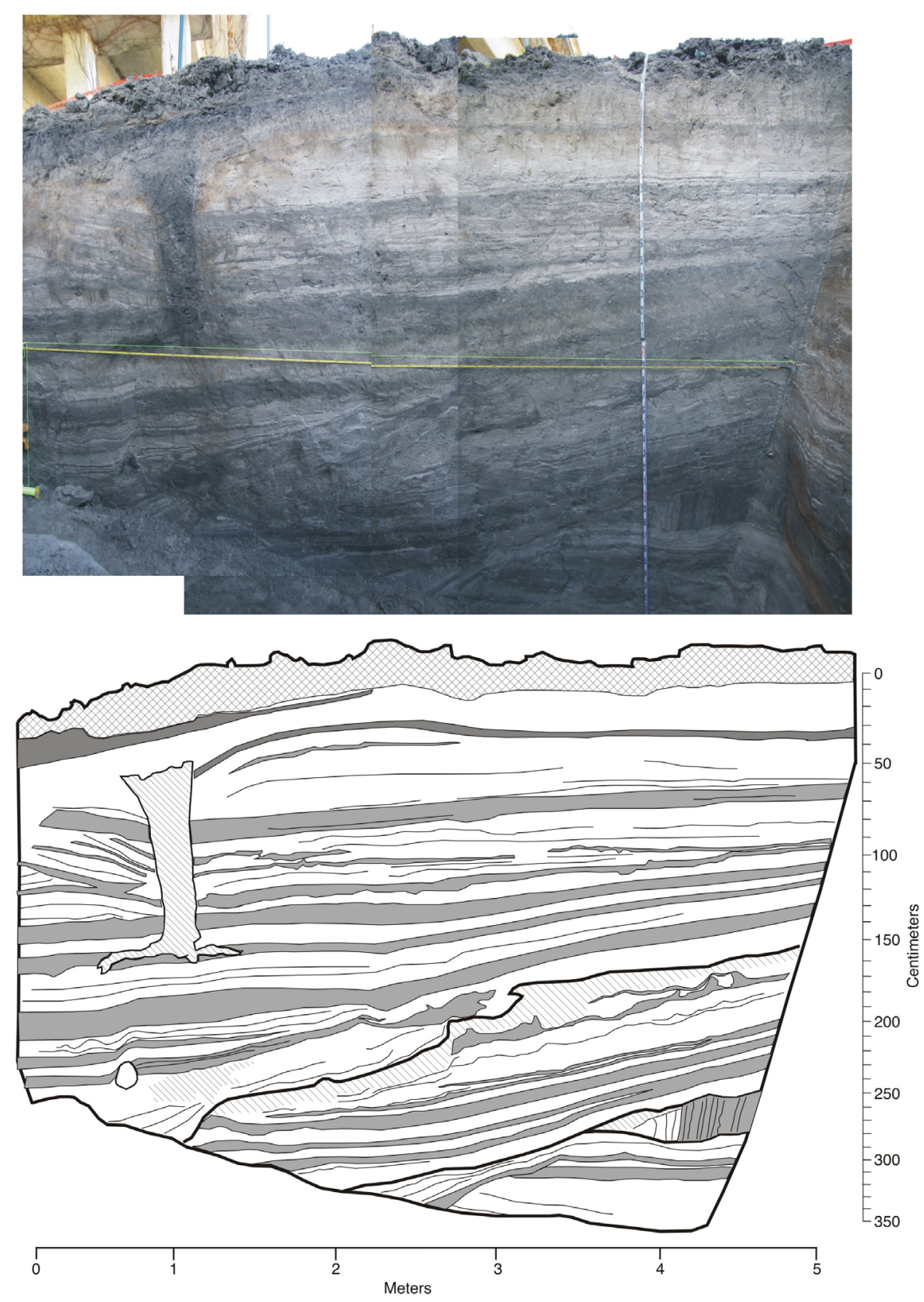

Trench 22, North Wall

Disturbed Deposits Introduced Fill
Dark Colored Beds

Light Colored Beds

Figure 9-10. Upper Panel-Photomosaic of the Inset Fill facies of the Ford alluvium exposed on the north wall of BT 22. Lower Panel-Interpretive line drawing derived from the photo in the upper panel, which depicts fine-textured deposits with a gray tone and coarse-textured deposits as white. Diagonal hatch and cross hatching denote disturbed deposits and fill, respectively. Several major bounding surfaces are exposed in this trench and these are denoted by heavy lines. An in-filled tree root mold is also present on the left (west) side of the drawing. 
placed on the sloping margin of the inset fill facies of the Ford alluvium in Trench 19. The particle size data (plotted as texture on the left and as mean particle size and sorting in the center) show the dramatic swings in particle size from one bed to the next, as well as the broadly cyclical trend between large and small floods that were visibly apparent in the field as broad variations in color of the deposits (see the heavy red line in Figure 9-5 which is a 5-point running average of the mean particle size). The magnetic susceptibility of the inset fill facies shows a moderate correlation with particle size (expressed in phi units; $r=0.657$ ), which in reality reflects that magnetic susceptibility increases as particle size decreases (Figure 9-11). The coefficient of frequency dependence, which is often used as in index of pedogenic alteration of soils, shows no correlation with particle size, and only four samples (of 57) had values in excess of 10 percent (the threshold often cited for samples that have susceptibility enhanced by pedogenesis).

The only soil formed in the inset fill facies of the Ford alluvium is present near the modern ground surface and ranged from an $\mathrm{A}-\mathrm{C}$ to an $\mathrm{A}-\mathrm{B} w-\mathrm{C} 1-\mathrm{C} 2$ profile (Figure 9-12). The A horizon is about $15 \mathrm{~cm}$ thick, preserved no vestiges of bedding, and is underlain by a very incipient cambic horizon that exhibits a slight development of color and preserves slight vestiges of bedding. The underlying $\mathrm{C}$ horizon can be divided into two parts, an upper one (C1) where bioturbation has significantly altered the preservation of bedding, and a lower one (C2) where bedding is well preserved and has been significantly less disturbed by post-depositional processes.

Terrace Veneer Facies. The terrace veneer facies of the Ford alluvium exhibits a gradational appearance. Where it is thin $(<0.5 \mathrm{~m}$; typically in distal floodplain settings), this deposit shows no evidence of bedding or sedimentary stratification (as was the case in BT 18) and minor pedogenic alteration (Ap-AC soil profile). Where the deposit is thickest (typically overlooking the modern floodplain), this facies often retains subtle (or even obvious) evidence of stratification. This can be seen clearly on previously presented Figure 6-28, where stratification of the Ford was visible at the southern end of the trench where it was thickest, but gradually became obscured as the deposit thinned up slope and away from the modern river. Sediments of the veneer ranged from a light yellowish brown (10YR 6/4) loamy sand, to brown (10YR 4/3) sandy loam and loam, and very dark gray (10YR 3/1) silt loam; and, like the inset fill facies, there is a relationship between the texture and the color of the sediment, with finer-textured deposits exhibiting darker colors. However, when the texture of the two facies are compared it is clear the veneer deposits exhibit a narrower range of size as well as sorting (Figure 9-13), which probably is the result of lower water depths, slower current velocities, and shorted hydroperiods (periods of standing water) in the veneer setting. The thinner deposit in the veneer setting is an indication that most floods that contributed to the inset fill facies did not inundate the adjacent terrace surface.

A detailed sample of the terrace veneer facies of the Ford alluvium was collected from the west wall of WC 1, adjacent to BT 19. The results of the analysis of these samples were shown earlier on Figure 9-4. Profiles were drawn of the east and west walls of this witness column and the east wall showed more evidence of stratification than the west wall, which was sampled for analysis. However, the laboratory analysis of the samples clearly shows vestiges of the episodic deposition that contributed to the creation of the veneer, but the amplitude of particle size variation is much smaller than observed in the inset fill facies (compare with Figure 9-5). In this profile the Ford alluvium appears to be coarsening upward, and exhibits a significant peak in magnetic susceptibility near the surface, although none of the deposits exhibiting elevated values of low-frequency magnetic susceptibility have coefficient of frequency dependence values greater than 10 percent.

The soil formed in the terrace veneer facies of the Ford alluvium is better developed than the inset fill facies soil, and exhibits an A-AC-C profile where the A horizon is again about $15 \mathrm{~cm}$ thick and the $\mathrm{AC}$ horizon is of similar thickness resulting in an upper melanized zone that is about $30 \mathrm{~cm}$ thick. The $\mathrm{C}$ horizon, where the veneer is thickest, preserves vestiges of bedding, albeit much less obviously than the inset fill facies (see Figure 9-12). Some of the faint, clearly bioturbated sand beds visible in the $\mathrm{C} 2$ horizon in this facies on Figure 9-12 are also clearly expressed in the texture analysis performed from this profile (see Figure 9-4), as are some that are not clearly visible in the $\mathrm{C} 1$ horizon.

Cultural Inclusions Within the Ford Alluvium. As noted previously, a single prehistoric component corresponding to a Toyah occupation was observed within the Ford alluvium at the site, and this was most clearly expressed north of the river in BTs 19 and 20. The component was discovered just south of Abbott's BT 4, although there was one bone (a rib) from this component in the re-excavated portion of BT 4 , but its proximity to disturbed sediments cast doubt on its 

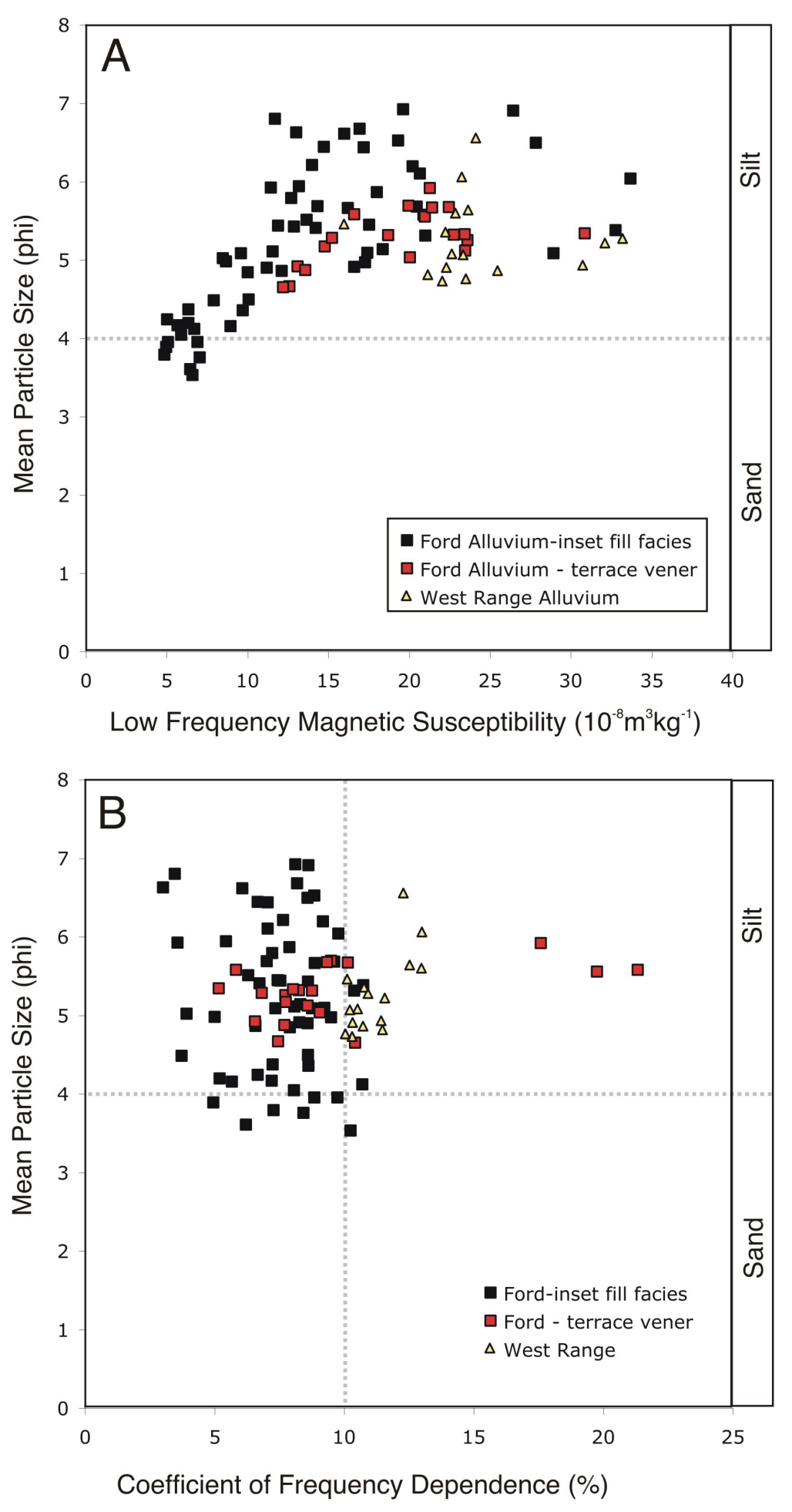

Figure 9-11. (A) Scatterplot of the relationship between the magnetic susceptibility and mean particle size for the Ford and West Range alluvial deposits. The horizontal dashed line is the break between sand and silt. (B) Scatterplot depicting the relationship between the coefficient of frequency dependence (\%) and mean particle size (in phi units) for the Ford alluvium and West Range alluvium. The horizontal dashed line is the break between sand and silt, and the vertical dashed line represents the $10 \%$ threshold often cited as the break between samples that have been pedogenically altered. 


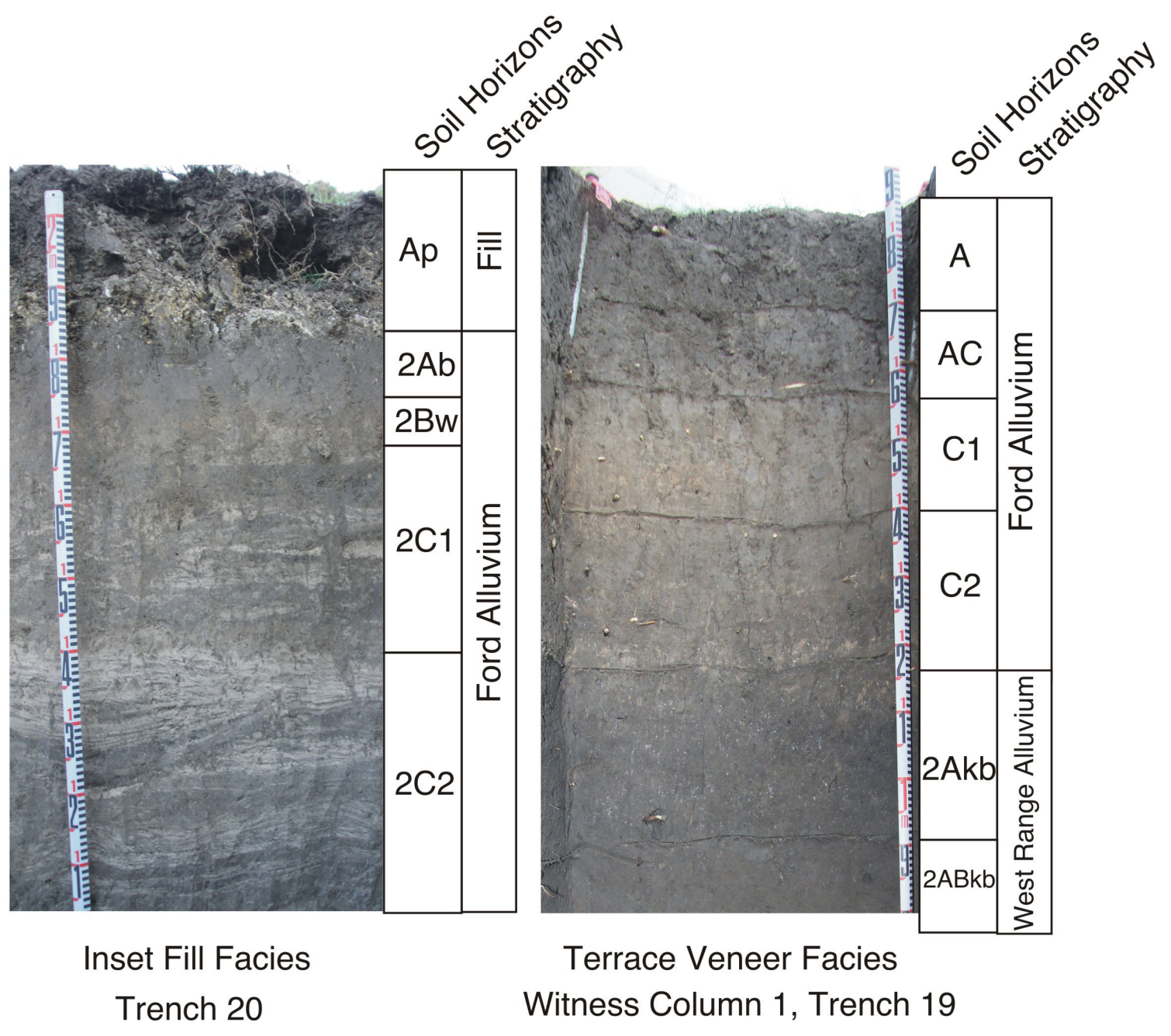

Figure 9-12. Left Side-Photograph of the soil formed in the inset fill facies of the Ford alluvium in BT 20. Right Side-Photograph of the west wall of WC 1 adjacent to BT 19 showing the soil formed in the terrace veneer facies of the Ford alluvium.

integrity. The Toyah occupation surface was about 5 $\mathrm{cm}$ thick in the terrace veneer facies, on the leading edge of the first terrace, and consisted of a light scatter of bone and lithic debitage, with at least two thermal features noted in the walls of BT 19. The same occupation surface could be traced into the inset fill facies (see Figure 9-9) where it dipped steeply and eventually disappeared from view at a depth of $2.8 \mathrm{~m}$ in the west end of BT 20. Presentation of this component in the inset fill facies was thicker, with material remains (specifically large pieces of charcoal, a few bones [that were helpfully removed from the trench profile by "visitors" prior to us examining them closely] and small accumulations of burnt earth that looked like vestiges of burnt surfaces beneath hearth-like features) scattered over as much as $20 \mathrm{~cm}$ of alluvial deposit (specifically, see Stratum 18 on Figure 6-33).

Two additional trenches (BTs 21 and 22) were excavated west of BT 20 in order to search for this deeply buried component. BT 21 was placed below the west side of the U.S. Hwy. 281 bridge and excavated to about $4 \mathrm{~m}$ depth, but could not be described immediately after it was excavated. A rain event completely filled this trench with water, and delayed the examination of the deposit. After re-excavating this 


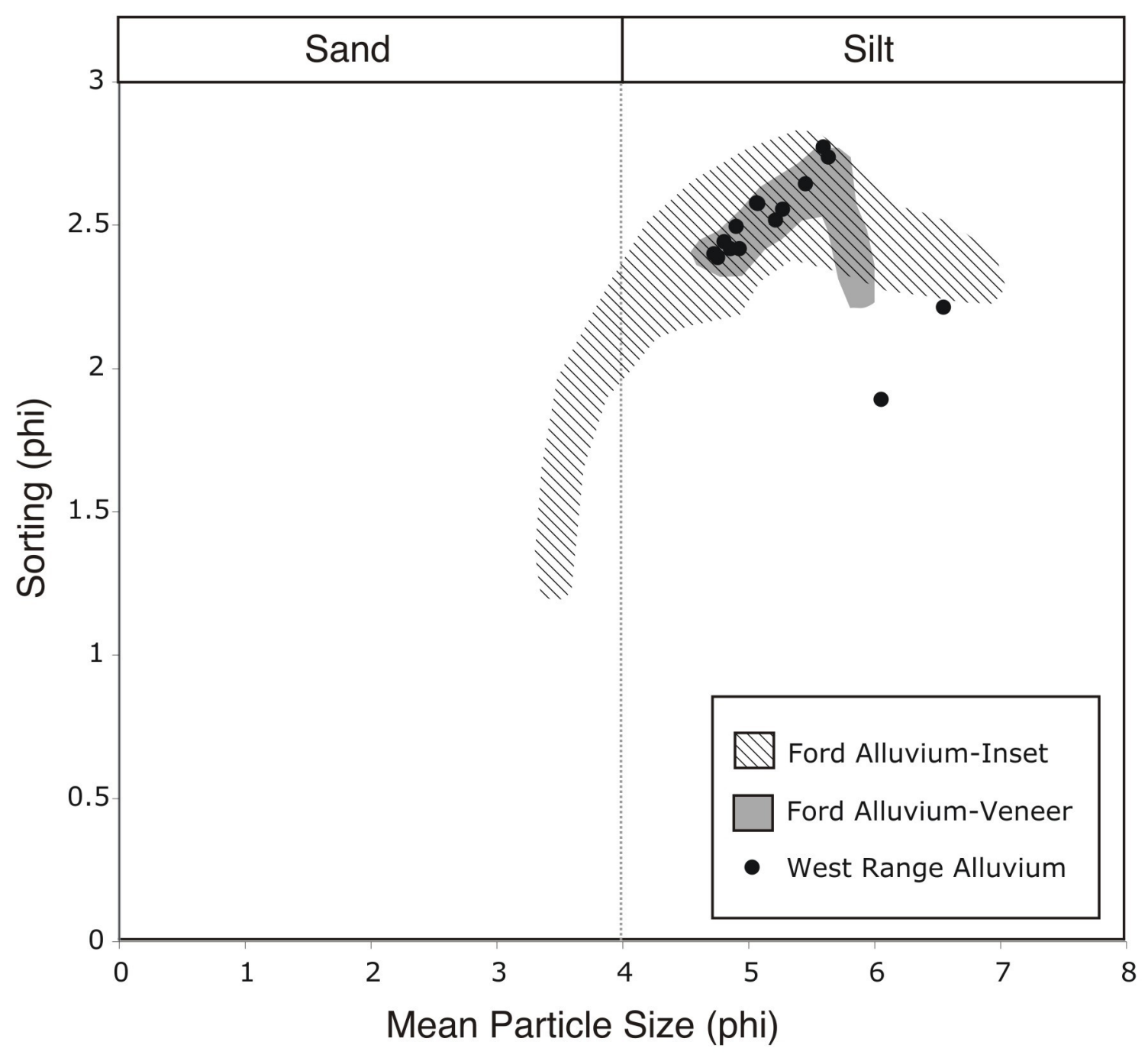

Figure 9-13. Plot of the mean particle size versus the sorting (or standard deviation of the particle size distribution) for the Ford alluvium (distinguished by facies) and the West Range alluvium.

trench a $2.5 \mathrm{~m}$ profile was described, but no obvious prehistoric occupation was present. During excavation of this trench, however, a bison pelvis was recovered from the floor of the trench at a depth of $2.5 \mathrm{~m}$, and a burned surface was noted at a depth of $1.8 \mathrm{~m}$; the latter consisted of a narrow (1- to $2-\mathrm{cm}$ thick) line of blackened earth and finely disseminated charcoal that was occasionally underlain by patches of reddened earth. Trench 22 was intended to search for this occupation surface between BTs 21 and 20, but failed to encounter the in situ occupation surface, from which it is inferred that this deposit was cut by a subsequent phase of erosion. BT 22 did reveal several bounding surfaces within the inset fill of the Ford alluvium that truncated older deposits and formed the base for deposition of new sediments (see Figures 9-9 and 9-10).

Radiocarbon ages obtained from charcoal collected from the Toyah occupation in both facies of the Ford alluvium yielded identical ages of $380 \pm 30$ years B.P. (ca. 510-320 cal B.P., Beta-315688 and -315693), while samples of bison bone from the same component yielded ages of $250 \pm 30$ (Beta-370012), $290 \pm$ 30 B.P. (Beta-370011, -370013, UCIAMS-140840), and $335 \pm 20$ (UCIAMS-140841, -140842). Lastly, a charred kernel of corn and a charred tuber fragment of Indian breadroot (Pediomelum sp.) from the same occupation yielded ages of $300 \pm 30$ B.P. and $290 \pm 30$ 
B.P. (Beta-382997 and -382996, respectively). All of these dates confirm the dramatic variation in presentation of this component owing to significant variations in the alluvial architecture of the Ford alluvium.

\section{Conclusions}

Contrary to the possibility that site 41HM61 represents nothing more than lag material washed downstream from the Sprague and/or Upper Sprague sites, the locale actually contains multiple prehistoric occupations of different ages, most of which are in good context and consist of stratified occupation surfaces in two alluvial fills of the Leon River. The majority of the occupations are situated within soils formed within the floodplain facies of the Upper West Range and Lower West Range alluvia. These sediments consist of massive, medium silt-sized overbank fines and most exhibit modest magnetic susceptibility enhancement (see Figures 9-4, 9-8, and 9-11).

The Upper West Range alluvium consists of a thin $(60-70 \mathrm{~cm})$ veneer that rests upon the Lower West Range alluvium. In the southeast quadrant of the site, between 3 and $4 \mathrm{~m}$ below the surface, the deposits of the Lower West Range alluvium represent a near-channel overbank environment, characterized by numerous thin beds of coarse and fine alluvium, and one massive sandy deposit that may represent a single large flood. Above this, the upper meter of the Lower West Range alluvium is represented by massive distal overbank alluvium that fines upward. The Ford alluvium presents two facies at the site: (1) a thin $(<1 \mathrm{~m})$ veneer on the first terrace, and (2) an inset fill on the leading edge of the first terrace and beneath the floodplain surface. The physical properties of the Ford alluvium suggest that it was deposited closer to the river channel than the West Range, in a near-channel overbank setting, and the inset fill facies contains a significantly wider range of particle size than either the terrace veneer facies or the West Range sediments. The sediments of the Ford alluvium are more stratified than the West Range, and generally exhibit little or no magnetic susceptibility enhancement, and a fairly strong correlation between magnetic susceptibility and grain size, with finer sediments yielding higher values (see Figures 9-4, 9-5, 9-6, 9-8, and 9-11). One Late Prehistoric occupation was encountered in the Ford alluvium and it was observed at shallow depths within the veneer facies and up to $2.8 \mathrm{~m}$ below the ground surface in the inset fill facies. In two of the three places at which this occupation surface was examined in detail, the sediments exhibited clear magnetic susceptibility enhancement that was most likely attributable to cultural activity. 


\title{
Chapter 10
}

\section{Radiocarbon Dating}

\author{
Jon C. Lohse \\ Richard A. Weinstein
}

The radiocarbon dating program for 41HM61 included three "phases" or rounds of sample submission. A first set of samples $(n=6)$ was submitted immediately following the testing of the site and a discussion of these was included in the interim report prepared for TxDOT (Weinstein et al. 2012). Subsequently, a second set of samples $(n=10)$ was submitted. This submission provided supplementary information regarding the timing and age of postulated site components. Additionally, samples in this phase were selected to evaluate the reliability of certain pre-treatment processes for bone so that future approaches to dating this material could be recommended. The third phase included samples $(n=10)$ selected to provide data from some features (F. 16, 19, 20, 21, 30, and 31); to evaluate visitation frequency for certain periods, including Toyah; and to gain a general understanding about the age of alluvial deposits below those that were examined during fieldwork. One of these samples was too small for dating, and only nine radiocarbon ages were returned. Overall, the dating program emphasized a corroborative approach in which duplicative samples were selected in order to better evaluate results.

Discussions of the contexts and interpretations of the Phase 1 submissions are based on Weinstein et al. (2012). The second and third phases are reported here for the first time. All samples are listed in Table 10-1, including field designation, measurement data, and calibrated results. Altogether, the site shows a very finely stratified series of short-term, generally ephemeral, occupations beginning in the Middle Archaic. For purposes of discussion, chronological periods generally follow those presented by Lohse et al. (2014a) as discussed earlier in Chapter 3.

\begin{abstract}
First Phase of Dating
In the first round of sample selection, six samples of charcoal or organic sediment were submitted to Beta Analytic, Inc. These results generally indicate a Late Prehistoric (Toyah) period of occupation; a Late Archaic 3 dating to $2150-1270$ cal B.P. (200 B.C. to A.D. 680); a Late Archaic 2 component (3100-2150 cal B.P., or 1150-200 B.C.); and a late-Middle Archaic component, represented by a single radiocarbon date of ca. 4410-4160 cal B.P. (2460-2200 B.C.) (Beta$315692)$. This period is very poorly dated in regional terms, and the presence of datable remains associated with cultural features and intact strata indicate that this site has the potential to contribute meaningfully to the regional sequence at this time. Importantly, temporally diagnostic artifacts and features are associated with all of these periods, with the exception of Middle Archaic points.
\end{abstract}

Two of the initial dates (Beta-315688 and -315693 ) are associated with the Toyah occupation on the north side of the current river channel. Both were run on charred material. The first is from the Feature 29 concentration of charcoal, ash, and fired earth within the Toyah zone of Block 1. The second came from a similar concentration of charcoal, ash, and fired earth, identified as Feature 31, in the "deep" Toyah deposit in WC 6. These samples returned identical calibrated 2-sigma date ranges between A.D. 1440 and 1520 (510 and 420 B.P.; $61.6 \%$ probability) and A.D. 1560 and 1630 (390 and 320 B.P.; $33.8 \%$ probability). These dates indicate that the material found in the "deep" Toyah deposit represents either an in situ burning episode along the edge of the old river channel or hearth 


\begin{tabular}{|c|c|c|c|c|c|c|c|}
\hline & 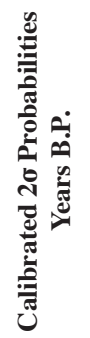 & 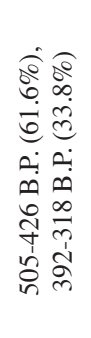 & 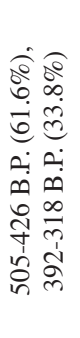 & 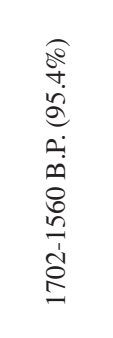 & 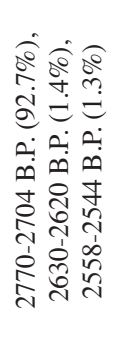 & 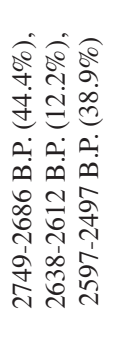 & 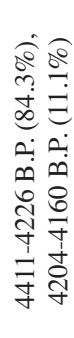 \\
\hline & 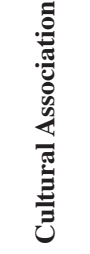 & 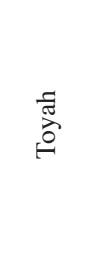 & 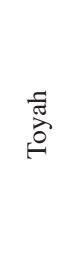 & 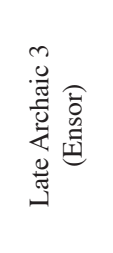 & 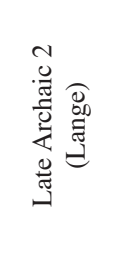 & 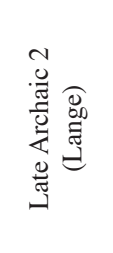 & 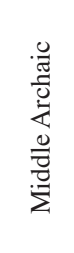 \\
\hline & 选 & 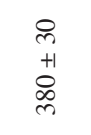 & $\begin{array}{l}0 \\
\infty \\
+1 \\
\infty \\
\infty \\
m\end{array}$ & $\begin{array}{l}\text { o } \\
+1 \\
\stackrel{1}{1} \\
\text { I }\end{array}$ & \begin{tabular}{l}
8 \\
r \\
+1 \\
8 \\
\multirow{2}{1}{}
\end{tabular} & 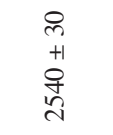 & $\begin{array}{l}0 \\
\text { + } \\
+1 \\
8 \\
\infty \\
\infty\end{array}$ \\
\hline & Z & ' & 1 & ' & , & ' & ' \\
\hline & $\stackrel{Z}{Z}$ & ' & ' & ' & 1 & ' & 1 \\
\hline & 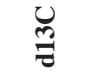 & ' & ' & ' & 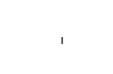 & ' & ' \\
\hline$\sum_{=}^{\bar{b}}$ & 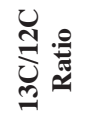 & $\begin{array}{l}\text { ठ̊. } \\
\text { ते }\end{array}$ & $\begin{array}{l}\stackrel{8}{\circ} \\
\text { }\end{array}$ & 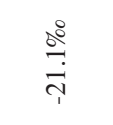 & $\begin{array}{l}\stackrel{8}{a} \\
\stackrel{\text { خे }}{1}\end{array}$ & $\begin{array}{l}\stackrel{8}{\circ} \\
\stackrel{+}{+} \\
i\end{array}$ & 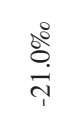 \\
\hline 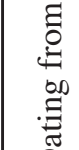 & 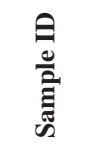 & 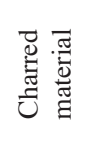 & 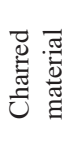 & 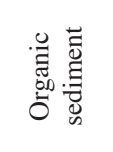 & 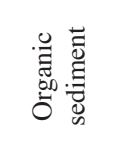 & 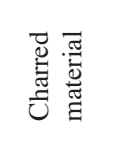 & 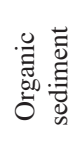 \\
\hline 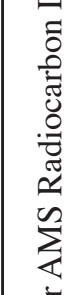 & 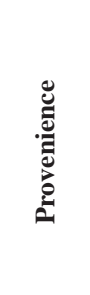 & 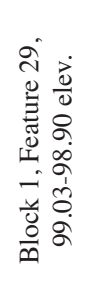 & 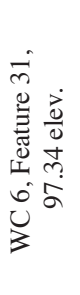 & 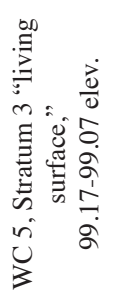 & 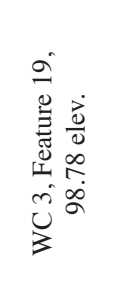 & 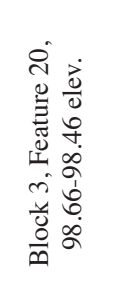 & 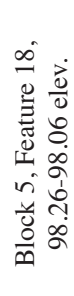 \\
\hline $\begin{array}{l}\frac{1}{0} \\
\frac{d}{0} \\
\frac{0}{0} \\
\infty \\
0\end{array}$ & $\begin{array}{l}\text { 目 } \\
\text { ज }\end{array}$ & 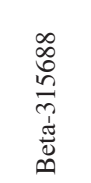 & 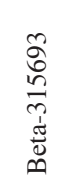 & 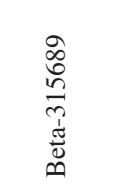 & 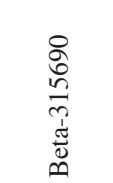 & 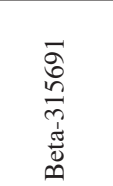 & 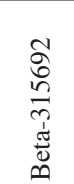 \\
\hline 点 & 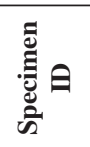 & ' & ' & ' & & ' & ' \\
\hline$\frac{0}{\frac{0}{2}}$ & & \multicolumn{6}{|c|}{ sәңеव I әsеपd } \\
\hline
\end{tabular}

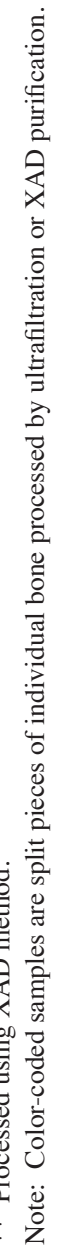




\begin{tabular}{|c|c|c|c|c|c|c|}
\hline 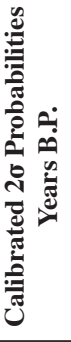 & 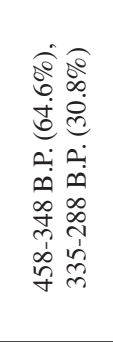 & 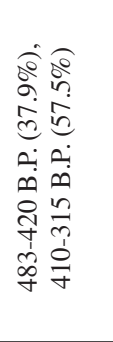 & 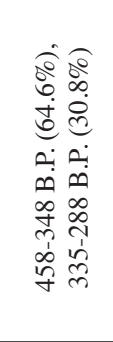 & 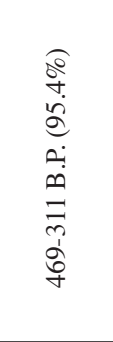 & 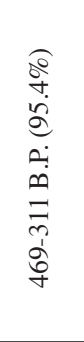 & 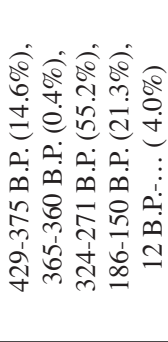 \\
\hline 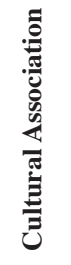 & $\begin{array}{l}\stackrel{\widetilde{\pi}}{\varrho} \\
\stackrel{0}{0}\end{array}$ & 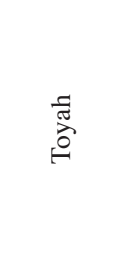 & $\begin{array}{l}\stackrel{\widetilde{\pi}}{\overparen{0}} \\
\stackrel{0}{\varphi}\end{array}$ & $\underset{\overparen{0}}{\stackrel{\widetilde{\sigma}}{0}}$ & 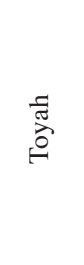 & $\begin{array}{c}\stackrel{\widetilde{\pi}}{0} \\
\stackrel{0}{\rho}\end{array}$ \\
\hline 离 & $\begin{array}{l}8 \\
\text { r } \\
+1 \\
8 \\
\text { i }\end{array}$ & $\begin{array}{l}\stackrel{i}{1} \\
+1 \\
\stackrel{1}{y} \\
m\end{array}$ & $\begin{array}{l}8 \\
\text { ले } \\
+1 \\
8 \\
\text { ते }\end{array}$ & $\begin{array}{l}\text { ते } \\
+1 \\
\cdots \\
m \\
m\end{array}$ & $\begin{array}{l}\stackrel{i}{1} \\
+1 \\
\cdots \\
m\end{array}$ & 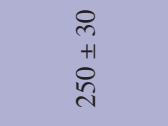 \\
\hline Z & ' & $\underset{m}{\stackrel{D}{m}}$ & ' & $\frac{0}{-1}$ & $\underset{m}{\stackrel{ \pm}{m}}$ & ' \\
\hline$\underset{n}{z}$ & . & $\ddot{n}$ & ' & $n$ & $\overrightarrow{6}$ & ' \\
\hline$\stackrel{ల}{=}$ & ' & $\hat{o}$ & ' & $\stackrel{\infty}{i}$ & $\stackrel{\circ}{i}$ & ' \\
\hline 氙 & $\frac{8}{9}$ & & $\stackrel{8}{\underset{m}{=}}$ & & & $\stackrel{8}{\rightrightarrows}$ \\
\hline 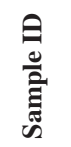 & 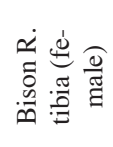 & 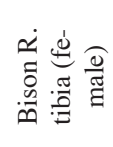 & 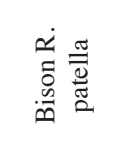 & 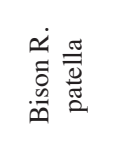 & 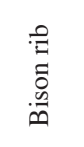 & 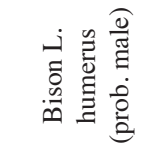 \\
\hline 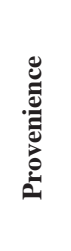 & 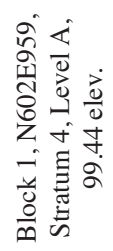 & 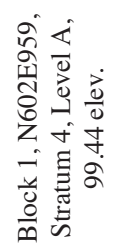 & 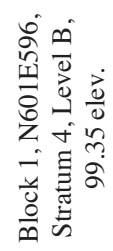 & 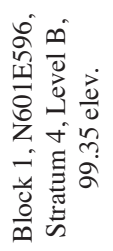 & 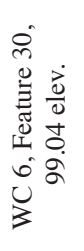 & 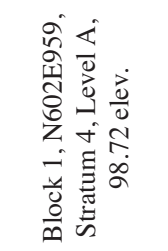 \\
\hline $\begin{array}{l}\hat{\text { O }} \\
\text { ज़ }\end{array}$ & 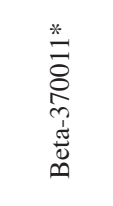 & 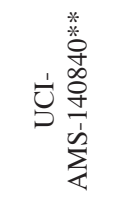 & 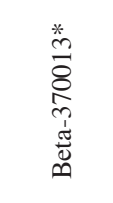 & 卷 & 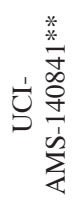 & 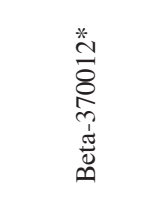 \\
\hline 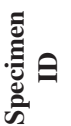 & $\begin{array}{l}\overleftrightarrow{\Xi} \\
\text { 告 }\end{array}$ & $\begin{array}{l}\stackrel{0}{\circ} \\
\stackrel{5}{1}\end{array}$ & 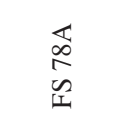 & 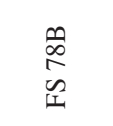 & $\begin{array}{l}n \\
n \\
n \\
n\end{array}$ & $\frac{\partial}{\vec{s}}$ \\
\hline & \multicolumn{6}{|c|}{ 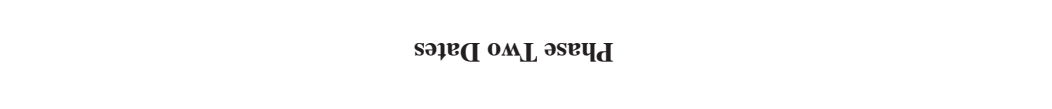 } \\
\hline
\end{tabular}




\begin{tabular}{|c|c|c|c|c|c|c|}
\hline 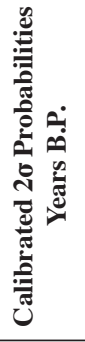 & 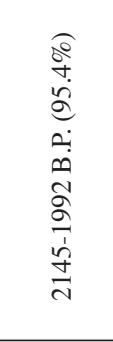 & 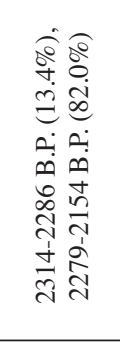 & 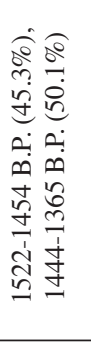 & 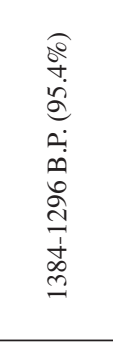 & 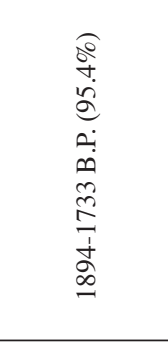 & 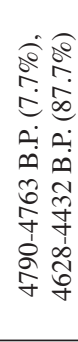 \\
\hline 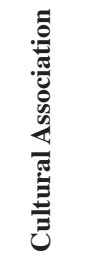 & 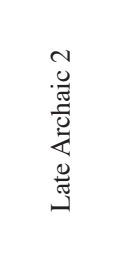 & 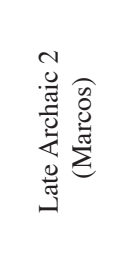 & 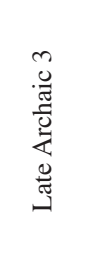 & 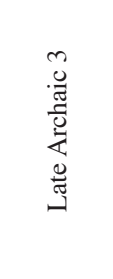 & 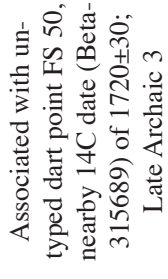 & 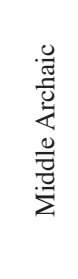 \\
\hline 离 & $\begin{array}{l}8 \\
\text { + } \\
+1 \\
8 \\
\stackrel{\text { d }}{ }\end{array}$ & 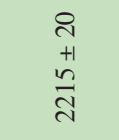 & $\begin{array}{l}\text { त } \\
+1 \\
n \\
\tilde{n} \\
\end{array}$ & $\begin{array}{l}0 \\
\text { r } \\
+1 \\
0 \\
0 \\
+\end{array}$ & $\begin{array}{l}0 \\
\text { r } \\
+1 \\
8 \\
\infty \\
\infty\end{array}$ & 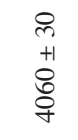 \\
\hline 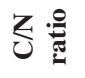 & ' & $\stackrel{\vec{े}}{\vec{m}}$ & $\stackrel{亏}{m}$ & ' & ' & \\
\hline$\underset{n}{Z}$ & ' & $\overrightarrow{0}$ & $\stackrel{\circ}{+}$ & ' & ' & \\
\hline$\stackrel{ల}{\Xi}$ & ' & $\stackrel{\partial}{\phi}$ & $\stackrel{\overbrace{}}{\stackrel{\leftrightarrow}{\oplus}}$ & ' & ' & ' \\
\hline 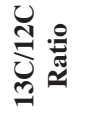 & $\begin{array}{l}\stackrel{8}{2} \\
\stackrel{2}{1}\end{array}$ & & & $\stackrel{\circ}{\stackrel{0}{े}}$ & 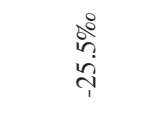 & $\frac{8}{\frac{0}{0}}$ \\
\hline 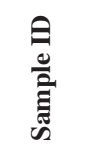 & 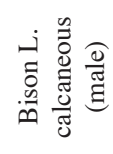 & 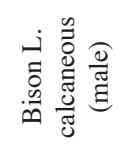 & 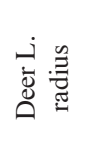 & 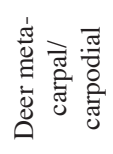 & 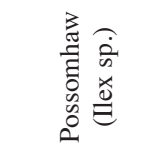 & 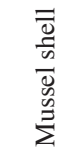 \\
\hline 这 & 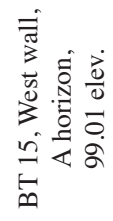 & 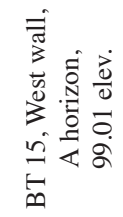 & 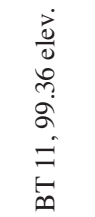 & 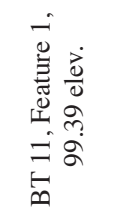 & 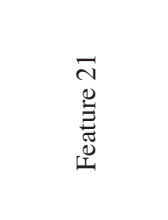 & 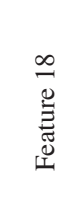 \\
\hline $\begin{array}{l}\text { 目 } \\
\text { ज़ }\end{array}$ & 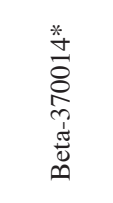 & 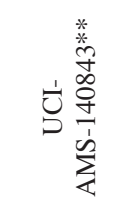 & 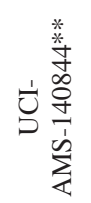 & 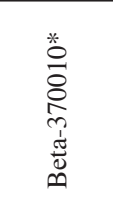 & 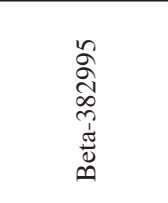 & 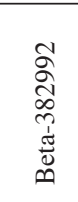 \\
\hline 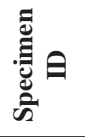 & 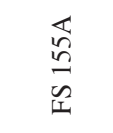 & $\begin{array}{l}n \\
n \\
n \\
w \\
w \\
\text { I }\end{array}$ & 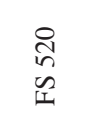 & $\sum^{1}$ & 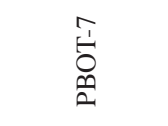 & $\sum^{\dot{1}}$ \\
\hline & \multicolumn{4}{|c|}{ 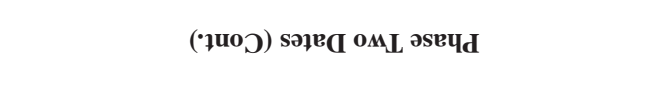 } & \multicolumn{2}{|c|}{ 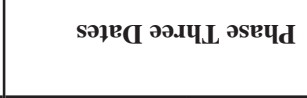 } \\
\hline
\end{tabular}




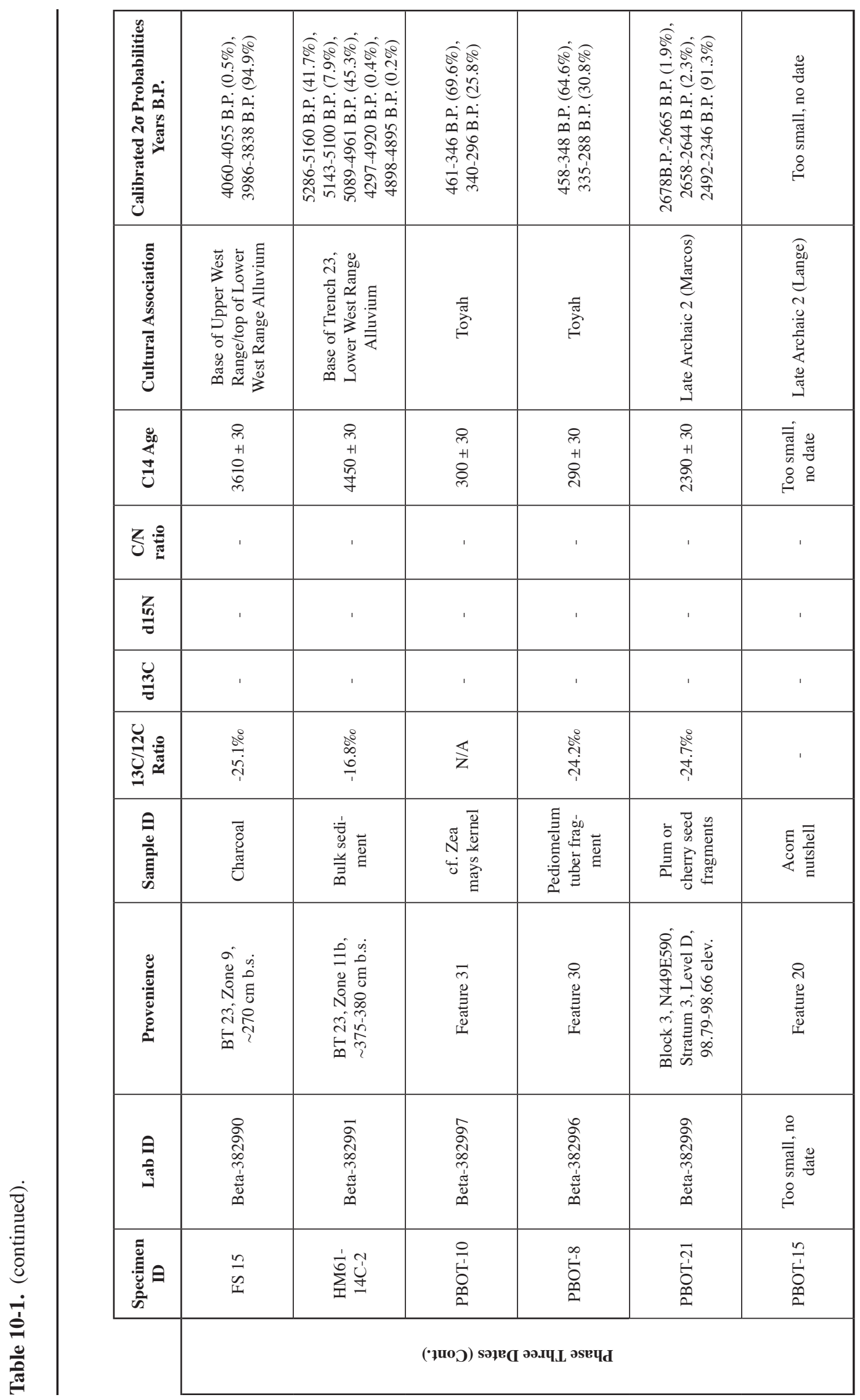




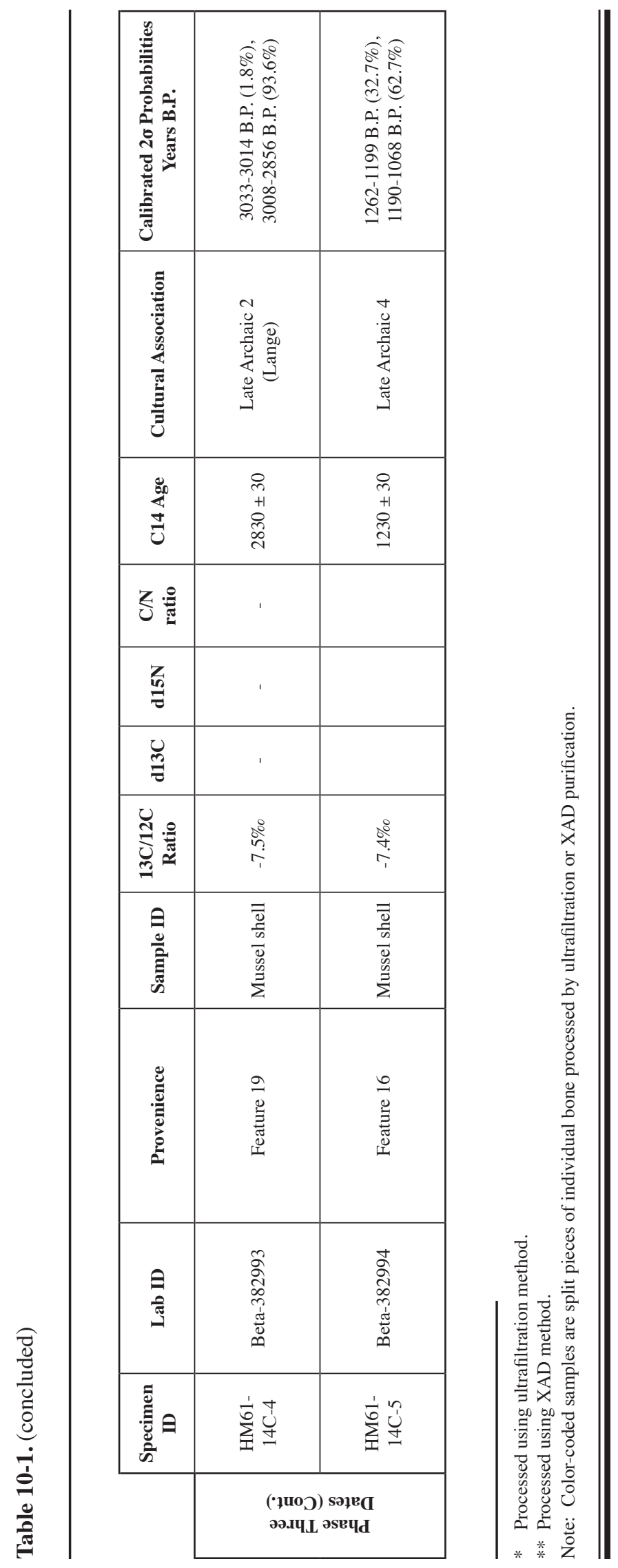


debris and other cultural remains that were tossed over the bank of the former river by the inhabitants of the Block 1/WC 1 area. Either way, the dates confirm that the "deep" Toyah deposit was contemporaneous with the Toyah occupation in Block 1 and WC 1.

Sample Beta-315689 was submitted from what was presumed to be the Marcos occupation in the A horizon of the West Range alluvium on the south side of the current river channel. The sample came from among the fire-cracked rocks identified as a "living surface" in WC 5. That surface occurred about midway within the A horizon, and was thought to represent the second of three living surfaces exposed in that area by expanded BT 11. It also was thought to correspond in depth to Feature 21 in WC 4, located about five meters to the east. An untyped dart point (lacking its tip and stem) was found immediately beneath the rocks of Feature 21, and it was hoped that the date from the living surface would help date this point and perhaps provide supporting data for one of the sequential Late Archaic occupations at the site. Calibrated at 2-sigma, this sample dates to ca. A.D. 260 to 380 (1690-1570 cal B.P.; 95.4\% probability). Following the regional chronology of Lohse et al. (2014a), this date is too young to be reliably associated with Marcos points, and is more likely to have been associated with the site's Ensor component.

Two dates (Beta-315690 on organic sediment and -315691 on charred material) come from Features 19 and 20 in the lower part of the West Range alluvium, in the south part of the site. Backhoe Trench 15 first exposed the two features, which were subsequently excavated in WC 3 and Block 3. Feature 19 consisted of a small deposit of freshwater mussel shells, while a cluster of fire-cracked rocks comprised Feature 20. The latter occurred ca. 10 to $15 \mathrm{~cm}$ beneath the former, with a layer of culturally sterile soil separating the two. These two samples produced nearly identical dates of $2590 \pm 30$ and $2540 \pm 30{ }^{14} \mathrm{C}$ B.P. (about $820-755$ and $800-735$ B.C.; 2770-2704 and 2749-2686 cal B.P.; 92.7 and $44.4 \%$ probability, respectively), indicating that these two features are of the same age and likely represent the same cooking event. Additional support for this interpretation comes from the fact that the two features were perfectly superimposed and that their compositions are functionally complementary, with the presumed heating element below the concentration of foodstuffs. If this interpretation is correct, it is possible that the feature represents a modified version of hot-rock cooking Scenario 3 provided by Black et al. (1997:68-69, 74, Figures
20-21; based on data from Sapir and Spier [1943] and Bean and Saubel [1972]). In this scenario, (1) a shallow pit is excavated, (2) wood is placed in the pit, set on fire, then allowed to die down, (3) rocks are added atop the ashes and coals, (4) a layer of leaves are added over the rocks, (5) fruit or other plant foods are placed over the leaves, (6) another layer of leaves is placed over the fruit or plant foods, (7) a layer of sand is added to keep in moisture, and (8) another fire is built over the layer of sand. While no evidence of fire-hardened or baked soil was found around the edges of Feature 20, there was a significant amount of charcoal found among the rocks of the feature. In this scenario, the food in Feature 19 appears to have been left in place without being consumed. The two dates provided by Beta-315690 and Beta-315691 also provide outstanding confirming evidence for the Lange point of the Late Archaic 2 period recovered from the A horizon in Trench 15.

Sample Beta-315692 came from Feature 18, a shell deposit originally exposed at the base of BT 15 and subsequently excavated in Block 5 . This sample consisted of a speck of organic sediment found clinging to the interior of one of the mussel shells. As discussed previously, this sample yielded a calibrated 2-sigma date range of ca. 2460 to 2200 B.C. (4410 to 4160 cal B.P.). No temporally diagnostic artifacts were recovered that correspond with this time period, but the presence of features and intact strata indicate that such remains could be present and should be expected in the event of future work.

\section{Second Phase of Dating}

In order to address some of the questions raised during the fieldwork and early assessment of 41HM61, a second group of radiocarbon samples was submitted. This sample included bone (bison and deer) in an effort to produce an accurate and reliable chronological understanding of certain parts of the site and its deposits, especially the Marcos/Ensor and Toyah components. Bone was selected for two reasons. First, charcoal from archaeological deposits is frequently incapable of yielding the kind of precision needed to address certain research questions. For example, carbon samples from the Little Paint site (41KM226), when calibrated, span the entire Toyah interval (Carpenter et al. 2012a:Table 5.19). However, based on the site's structure, Little Paint is interpreted as resulting from a single-occupation event (Carpenter 2012a:234). Investigators of Little Paint recognized this problem to be the result of "old wood," or long-dead fuel that had been gathered and used for camp or cooking fires and 
that does not represent the actual date at which those living (tree) organisms were burned. When suitably preserved, animal bone can provide a fairly precise age that is closely associated with the discrete human behavior that is targeted by the dating effort. Dating bone can, therefore, help archaeologists avoid problems associated with old wood and deflated or deconstructed feature contexts.

Additionally, bone was selected in order to address the usefulness of this material for archaeological dating across Texas. Historically, bone dates have been potentially unreliable as a result of molecular-level deterioration of non-exogenous carbon (present in the collagen portion of bone) and the possible replacement by exogenous carbons into bone matrices. In order to help resolve these concerns, improved collagen extraction and purification procedures have been developed, including ultrafiltration (Brown et al. 1988) and XAD purification (Stafford et al. 1988). However, questions exist regarding the reliability of ultrafiltration in relation to XAD, and to date few if any controlled studies have been conducted to evaluate the two techniques for accuracy and reliability.

Samples selected for ultrafiltration analyses were submitted to Beta Analytic, Inc. Until recently, Beta relied on the Longin (1971) method of collagen extraction, coupled with what was described as an "inspection of the quality of the collagen" (Darden Hood, personal communication to Jon Lohse 2013) and preparation for standard AMS measurement. Samples selected for XAD purification were submitted to Pennsylvania State University for pretreatment. AMS measurement of these samples was performed at the KCCAMS Facility at the University of California, Irvine, under long-standing agreement between these two institutions.

Ten (10) samples were submitted during the second round of radiocarbon dating; samples were taken from the Toyah component in Block 1 and from the stratified Late Archaic zone (Ensor and Marcos components) exposed in Trenches 11 and 15. Altogether, samples were taken from seven different contexts across the site. All but two samples (FS 520 and HM61-14C-1) were bison; the other two were deer. Of the bison samples, three large fragments were split with portions sent to the two laboratories. The two pieces of deer bone were selected from what was thought to be the same Late Archaic 3 component and one piece was submitted to each laboratory. The bone dating results clearly address both of the objectives defined for this phase.
Several conclusions may be drawn based on these results, both about each pretreatment technique and also about the site's chronology.

\section{Bone Dates and Pretreatment Procedures}

First, regarding the results according to the pretreatment technique, all five of the Beta samples are systematically younger than corresponding samples processed by XAD. This includes the three split samples (designated by A or B as part of their sample number), as well as samples from what are believed to be the same component. This difference gets larger as sample ages increase. However, when viewed as a percentage of the measured age of XAD samples, the differences decrease with age (Table 10-2). At least two conclusions can be made based on this progressive offset.

First, based on this admittedly small sample, differences in measured ages indicate the effectiveness with which each technique removes contaminants from target samples. That is, ultrafiltration seemingly fails to truly purify the sample, and at least some exogenous carbon seems to have remained in the samples as they were measured. If offsets were evenly distributed, with XAD dates being both older and younger than ultrafiltered ones, then it would not be possible to understand differences between the two techniques. However, ultrafiltration consistently produces ages that are younger than their comparative XAD samples. The most parsimonious explanation of this pattern is that ultrafiltration does not remove all exogenous carbon from treated samples, carbon that likely enters bone matrix as that bone becomes buried over time by sediments themselves containing younger humic and fulvic acids (contaminants). Second, differences in measured ages grow larger with sample age (with the exception of samples FS 19 and FS 55). However, they get smaller when considered as a percentage of the XAD dates. Both trends are true for the three split samples. This seems to suggest that much of the exogenous carbon leaches into archaeological bone relatively soon after deposition and that this process continues over time but at a slower rate. However, the effect of the increasing differences in radiocarbon years means that ultrafiltered dates grow increasingly inaccurate with age.

\section{Bone Dates and Site Chronology}

Even though discrepancies may seem insignificant for younger dates, there can still be enough error in resulting measurements that fine-grained changes in 
Table 10-2. Measured and Comparative Data for Bone Dates Processed by Different Methods.

\begin{tabular}{|c|c|c|c|c|}
\hline Sample No. & Lab Sample No. & 14C age (B.P.) & 14C Difference & Difference as \% of XAD date \\
\hline FS 19 (UF) & Beta-370012 & $250 \pm 30$ & & $25.3 \%$ \\
\hline FS 55 (XAD) & UCIAMS-140841 & $335 \pm 20$ & 85 & \\
\hline FS 10A (UF) & Beta-370011 & $290 \pm 30$ & & $15.9 \%$ \\
\hline FS 10B (XAD) & UCIAMS-140840 & $345 \pm 20$ & 55 & \\
\hline FS 78A (UF) & Beta-370013 & $290 \pm 30$ & & \\
\hline FS 78B (XAD) & UCIAMS-140842 & $335 \pm 20$ & $45.4 \%$ \\
\hline HM61 (UF) & Beta-370010 & $1440 \pm 30$ & & \\
\hline FS 520 (XAD) & UCIAMS-140844 & $1535 \pm 20$ & & \\
\hline FS 155A (UF) & Beta-370014 & $2090 \pm 30$ & & \\
\hline FS 155B (XAD) & UCIAMS-140843 & $2215 \pm 20$ & 125 & $5.1 \%$ \\
\hline
\end{tabular}

Note: $\quad$ UF indicates ultrafiltration and XAD indicates XAD-purified samples. Split samples are indicated with A and B. Samples in other comparative pairings are thought to be from the same component.

local or regional chronologies are lost due to different pretreatment standards for bone samples. Discussions of some of the important cultural transitions at the site illustrate this point. Lohse et al. (2014c) define a second period of Late Archaic bison exploitation $\left(\mathrm{LA}_{\mathrm{B}} 2\right)$ dating from about 2700-2150 cal B.P. (750-200 B.C.). The latter portion of this period is associated with Marcos points (Lohse et al. 2014a), such as from site 41TG91 (Creel 1990) and also 41HM61. Based on presently available bison data, this association does not extend to Ensor points (see extended discussion on this topic below). The transition between these point types is not well understood, but the presence or absence of bison would represent a significant environmental factor helping to explain changes to technological and stylistic tool design choices. Ultrafiltered bone date FS 155A (Beta-370014) is younger than any of the dated specimens comprising the $\mathrm{LA}_{\mathrm{B}} 2$ sample reported by Lohse et al. (2014c), and would seemingly establish an association between the Ensor type and bison in central Texas. The XAD-purified portion of this sample (FS 155B), however, is comfortably with- in the end of this period, further supporting the lack of association between bison and the Ensor type.

When calibrated, ultrafiltered and XAD-purified bison dates from the Toyah component are largely similar (Figure 10-1) but can differ by a few decades, depending on the shape of the calibration curve. Even this difference can obscure fine-grained chronological changes that may be present in the archaeological record.

A good case can be made that the five ultrafiltered dates should be disregarded from consideration when discussing this site's chronology. The increasing offset among the split samples and also among others thought to derive from the same contexts indicates that measurement differences are meaningful and likely reveal systematic contamination factors associated with archaeological bone. The possible exceptions are samples FS 19 and FS 55 (see Table 10-2). Because these samples are not split and it cannot be known for certain that these come from the same Toyah com- 


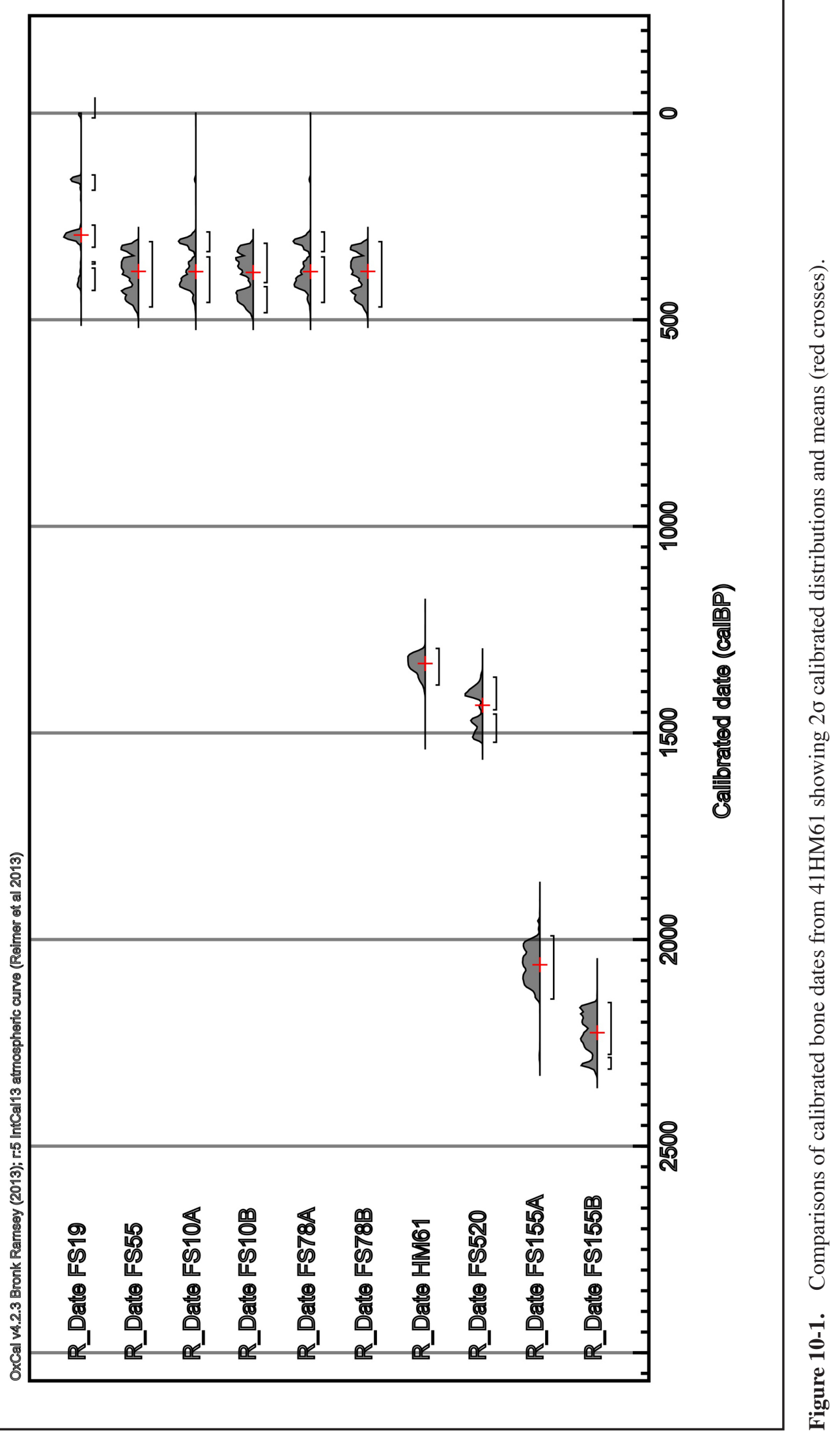


ponent, the differences in their measured ages might be an accurate indication of their true archaeological ages. However, considering the documented offsets between other samples, including the three split samples, this does not seem likely. Nevertheless, the results of FS 19 (Beta-370012) should be viewed with some skepticism until verified by additional data.

The remaining bone samples indicate a Toyah component containing bison (UCIAMS-140840 and -140842) that may contain evidence of multiple visitations, as well as a late Marcos component with bison (UCIAMS-140843) and a Late Archaic 3 component containing deer (UCIAMS-140844; $1535 \pm 20{ }^{14} \mathrm{C}$ B.P., $1522-1365 \mathrm{cal}$ B.P.). According to the regional chronology of Lohse et al. (2014a), this date is probably too young to be associated with the Ensor point type, but may only slightly post-date that point's period of common occurrence. The two Toyah bone dates correspond well with two other Toyah dates, Beta-315688 and Beta-315693 taken from Features 29 and 31, respectively, and discussed above under the first phase of dating. Lastly, the Marcos-period bison date conforms to regional records regarding the temporal occurrence of this point and its association with bison on the Edwards Plateau.

\section{Third Phase of Dating}

The third sample submission (also $n=10$ ) was designed to address questions that had emerged as analysis progressed. Samples were selected from the Lange, Marcos, and Toyah components, as well as from contexts without well-established age control. Samples without existing age control included two that were collected by Charles Frederick when he returned to the site to excavate BT 23 to deeper depths in order to explore the possibility that older stratified deposits were present that had not been reached during the testing. Trenching exposed buried alluvial deposits and also scatters of charcoal. A bulk sediment sample was collected from the Lower West Range alluvium and submitted for dating, as were charcoal fragments collected from the base of the Upper West Range/top of Lower West Range alluvium (see Chapter 9). Following paleobotanical analyses, several nut or plant remains were identified from various contexts. Some of these samples provide a means of evaluating previous assays, such as from the Toyah or Marcos components, to better evaluate visitation frequencies during those periods. Additionally, a number of mussel shells $(n=3)$ were submitted from features (F. 16, 18, and 19) as a way of dating these elements and perhaps providing a cor- rection factor for shells from that stretch of the Leon River in the site area.

The results of the third phase of submission are best understood in relation to the previous two phases, since many of the samples provide a means for evaluating earlier radiocarbon dates for different aspects of the site. Most of the questions addressed in this phase of submission involve determining whether multiple visitations can be demonstrated within certain periods, and providing resolution for poorly defined components of the site.

\section{Toyah Component Visitation}

Overall, a total of ten samples were submitted from the Toyah component (Table 10-3). These can be used to discuss the issue of multiple visitations during that period. For convenience, calibrated probabilities are discussed as encompassing the entire period rep-

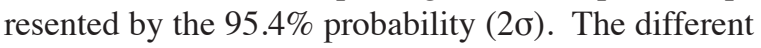
materials included among Toyah samples make it difficult to directly compare all radiocarbon results. We address the question of whether multiple visitations can be recognized by rating samples in terms of their relative reliability. In this context, "reliability" means that the radiocarbon (or calibrated) age (dated event) is thought to be an accurate or true indication of the target event. Reasons why the target and dated events might not be the same could include stratigraphic mixing of site deposits (relatively minimal at this site); reservoir effects for aquatic samples; uncertainty associated with terrestrial bulk sediment samples, where studies have shown that the downward translocation of water-soluble fulvic acid can significantly lower the ${ }^{14} \mathrm{C}$ dates of buried soils (Wang et al. 1996:287); old wood; and/or failure to remove all exogenous organic compounds from the treated sample. In this study, less reliable samples include those with unclassified charcoal and ultrafiltered bison specimens. More reliable samples include botanically identified taxa and XAD-purified bison dates (Wang et al. 1996:282-288).

By considering results from the so-called more reliable samples, the general range of Toyah occupation (in calibrated years B.P.) spanned the period from 483 to 288 B.P., or A.D. 1467-1662. This spread is only slightly more precise than if all dates, reliable and otherwise, were included (Figure 10-2). Including all dates gives a span of time from 505 to approximately 288 cal B.P., or A.D. 1445-1662. (There is a slight probability that the date range for Beta370012 extends to the modern era [post-1950], but this clearly is not possible considering that it is from 
Table 10-3. Radiocarbon Dates from the Toyah Component and Their Contexts or Comparative Criteria.

\begin{tabular}{|c|c|c|c|c|c|}
\hline Lab No. & C14 age & $\begin{array}{l}\text { Calibrated age range } \\
\qquad(2 \sigma)^{*}\end{array}$ & Material & Context & Comparative Assay \\
\hline Beta-315688 & $380 \pm 30$ & 505-318 B.P. ${ }^{2}$ & charcoal & Feature 29 & \\
\hline Beta-315693 & $380 \pm 30$ & 505-318 B.P. ${ }^{2}$ & charcoal & Feature 31 & Beta-382997 \\
\hline Beta-382997 & $300 \pm 30$ & 461-296 B.P. ${ }^{1}$ & cf. Zea mays kernel & Feature 31 & Beta-315693 \\
\hline Beta-382996 & $290 \pm 30$ & 458-288 B.P. ${ }^{1}$ & $\begin{array}{l}\text { Pediomelum tuber } \\
\text { fragment }\end{array}$ & Feature 30 & UCIAMS-140841 \\
\hline UCIAMS-140841 & $335 \pm 20$ & 469-311 B.P. ${ }^{1}$ & $\begin{array}{c}\text { Bison rib } \\
\text { (XAD-purified) }\end{array}$ & Feature 30 & Beta-382996 \\
\hline Beta-370011 & $290 \pm 30$ & 458-288 B.P. ${ }^{2}$ & $\begin{array}{l}\text { Bison tibia (ultra- } \\
\text { filtered) }\end{array}$ & $\begin{array}{c}\text { Block 1, } \\
\text { Unit N602E959, Stratum } \\
\text { 4, Level A, 99.44 elev. }\end{array}$ & UCIAMS-140840 \\
\hline UCIAMS- 140840 & $345 \pm 20$ & 483-315 B.P. ${ }^{1}$ & $\begin{array}{c}\text { Bison tibia } \\
\text { (XAD-purified) }\end{array}$ & $\begin{array}{c}\text { Block 1, } \\
\text { Unit N602E959, Stratum } \\
\text { 4, Level A, 99.44 elev. }\end{array}$ & Beta-370011 \\
\hline Beta-370013 & $290 \pm 30$ & 458-288 B.P. ${ }^{2}$ & $\begin{array}{l}\text { Bison patella (ultra- } \\
\text { filtered) }\end{array}$ & $\begin{array}{c}\text { Block 1, } \\
\text { Unit N601E596, } \\
\text { Stratum 4, Level B, } \\
99.35 \text { elev. }\end{array}$ & UCIAMS-140842 \\
\hline UCIAMS-140842 & $335 \pm 20$ & 469-311 B.P. ${ }^{1}$ & $\begin{array}{l}\text { Bison patella } \\
\text { (XAD-purified) }\end{array}$ & $\begin{array}{c}\text { Block 1, } \\
\text { Unit N601E596, Stratum } \\
\text { 4, Level B, 99.35 elev. }\end{array}$ & Beta-370013 \\
\hline Beta-370012 & $250 \pm 30$ & 429 B.P.-modern² & $\begin{array}{l}\text { Bison humerus } \\
\text { (ultrafiltered) }\end{array}$ & $\begin{array}{c}\text { Block 1, } \\
\text { Unit N602E959, Stratum } \\
\text { 4, Level A, 98.72 elev. }\end{array}$ & \\
\hline
\end{tabular}

Note: The notation ${ }^{1}$ indicates that these samples are considered "more" reliable; the notation ${ }^{2}$ indicates these samples are "less" reliable.

bison.) Even using the more exclusive set of dates, however, it is not possible to discern evidence for individual visitation events in the radiocarbon record. All assays overlap considerably at two standard deviations. Even the presence of two apparent features,
Features 30 and 31, located in the same excavation (Witness Column 6) and documented one above the other, cannot confirm multiple Toyah visitations, since these deposits were reinterpreted as secondary contexts that may have resulted from the same 


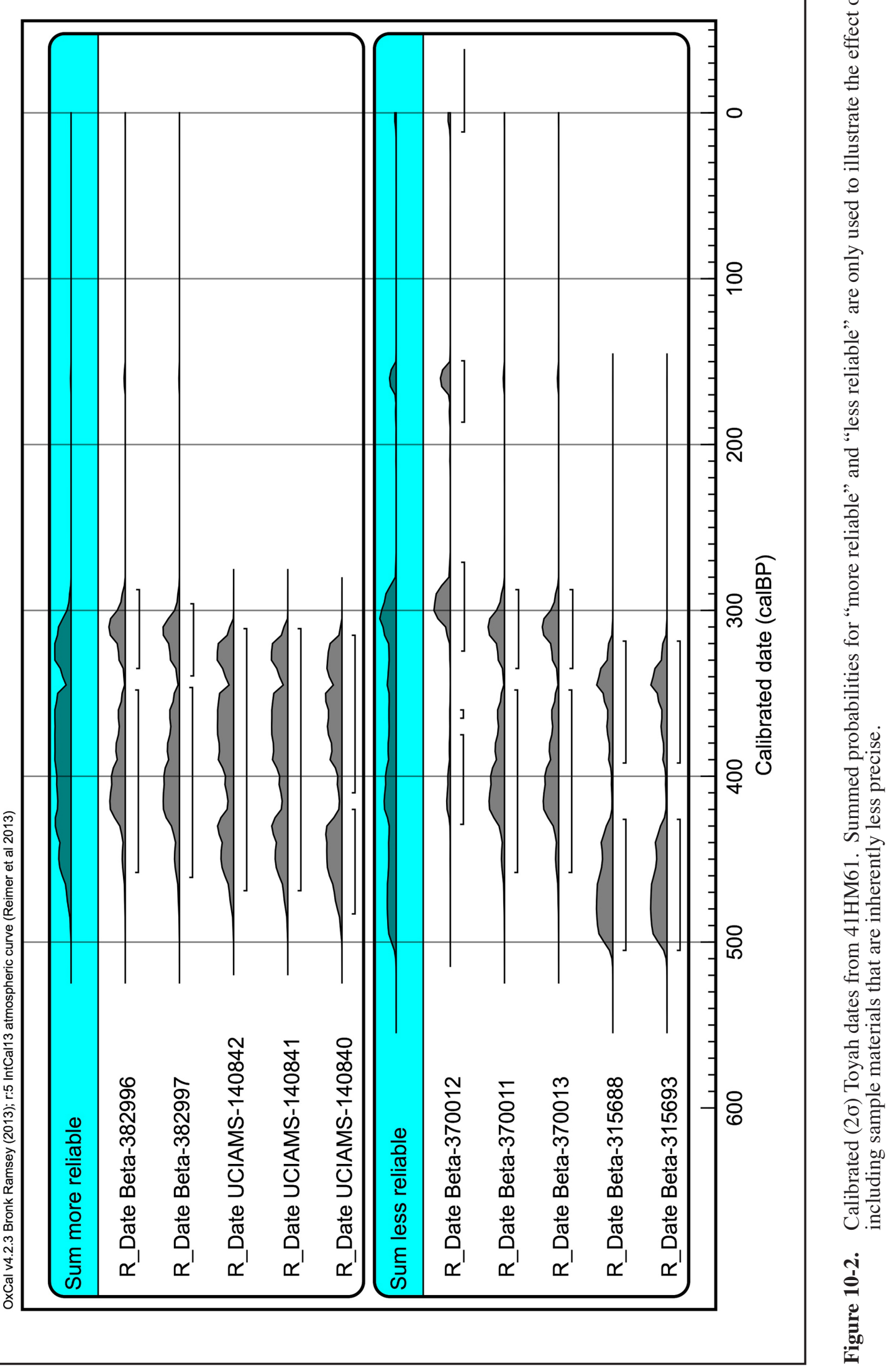




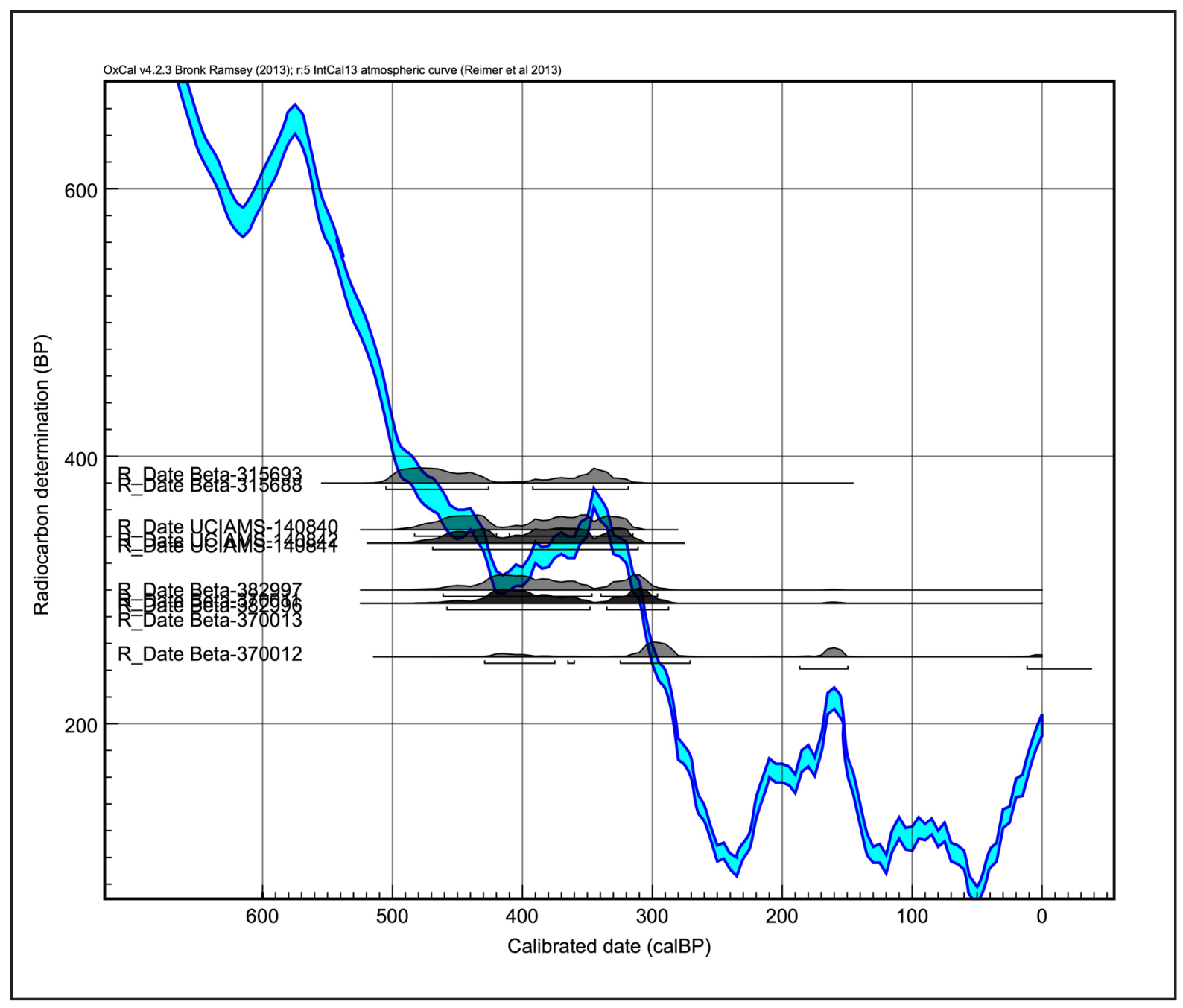

Figure 10-3. All Toyah dates (calibrated 2 $\sigma$ ) from site 41HM61 plotted on the latest calibration curve. The sharp reversal centered at $\sim 345$ cal B.P. produces the multiple intercepts that exist for virtually all of the dates (Beta-370012 has multiple intercepts because of the squiggles that occur later).

event. Given the substantial overlap together with contextual data for the "more" reliable ages, no clear evidence can be presented that the Toyah component here results from more than a single visitation. Such evidence, if present, would necessarily come from future excavations that documented stratigraphically ordered deposits that were dated using the same confidence-based protocols applied here.

It is somewhat disappointing that even the "more reliable" assays fail to provide greater resolution for Toyah occupation history than $\sim 195$ years. However, the reason for this has to do with the shape of the calibration curve at this point. The part of the Toyah horizon present at 41HM61 corresponds with a part of the calibration curve that is defined by a sharp reversal centered at approximately 345 cal B.P., followed by an- other reversal and some minor "squiggles" (Figure 103). These morphological features of the curve reflect variation in solar irradiance coming into the earth's atmosphere; reduced solar irradiance results in more cosmic rays entering the earth's atmosphere and increased production of the $\mathrm{C}^{14}$ isotope (Van Geel et al. 1998), which can be seen in these proportionally flat areas of the curve. Samples falling into these periods are notoriously difficult to date with precision.

Based on an assessment of the radiocarbon evidence, the Toyah component at 41HM61 reflects a moderately late visitation within the overall Toyah sequence for central Texas. By "late," we mean that the component seems to match the three-part Toyah chronology proposed by Lohse et al. (2014c) based on 61 XAD-purified AMS bison dates, including 20 


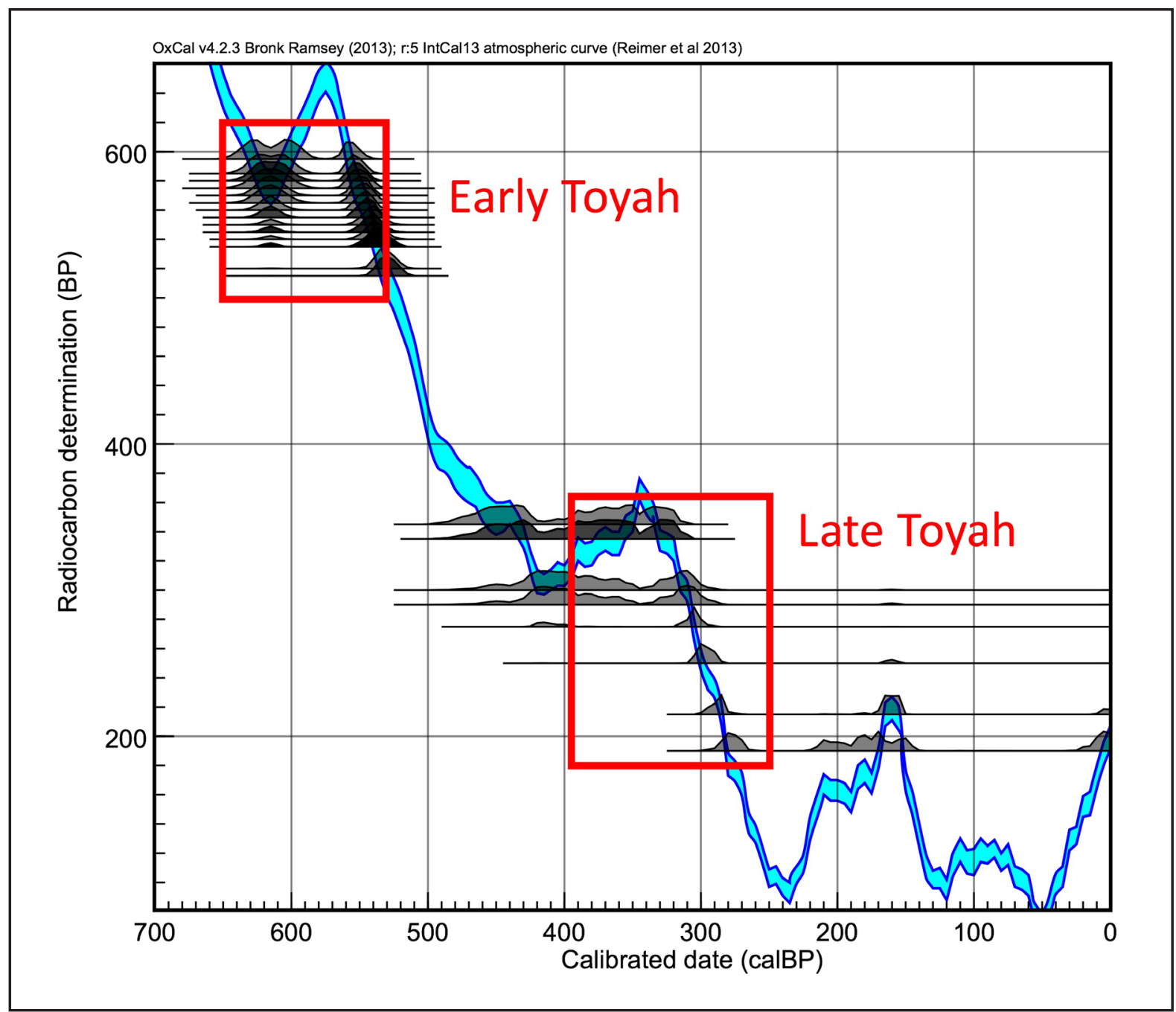

Figure 10-4. Proposed three-part Toyah chronology based on a total of 27 XAD-purified AMS dates on bison bone, including three from this study (other samples presented in Lohse et al. 2014c), as well as short-lived botanical taxa from 41HM61.

dating to Toyah times. In that sample, Toyah period bison dates are restricted to two intervals, one dating from ca. $650-530$ cal B.P. (A.D. 1300-1420), and a later one (comprised of only four assays at the time of the study) that falls into the early Historic period. Briefly, Lohse et al. (2014c) used the difference between the earliest and latest samples in a group (e.g., temporal period) to calculate that period's duration. This approach, which is only slightly less conservative than considering all dates at their full two-sigma calibrated ranges, uses the means of the earliest and last dates to define a period's beginning and ending date. Applying this approach to the 41HM61 data gives a date of ca. 395 cal B.P. (mean of 483-315, UCIAMS-140840) for the beginning of the Toyah component. Following the discussions by Arnn (2012), Kenmostu and Boyd (2012a), and others, we concur that Toyah was effec- tively over by A.D. 1700. Based on the present study, which includes highly reliable botanically identified samples as well as XAD-purified AMS bison dates, both from this study and from the database compiled by Lohse et al. (2014c), we suggest late Toyah dates to cover the period of about $395-250$ cal B.P. (A.D. 1555-1700) (Figure 10-4). To be sure, future analyses using what are described here as "reliable" dates could very well fill in the gap between the early and late periods. Such sampling may cause those dates used to define the beginning or end of one or more of these internal periods to be reevaluated, resulting in some change to the proposed boundary dates for early, middle, or late Toyah. The beginning of what we call late Toyah, in particular, seems to us to be based on too few dates and is therefore in need of future study. However, based on the best available evidence, this 
pattern seems to characterize Toyah chronologies for greater central Texas, including site 41HM61.

In addition to providing temporal control for the interpretation and analysis of Toyah remains at 41HM61, the precise chronology we present for Toyah can help contextualize other questions involving Toyah research elsewhere. For instance, Toyah is commonly understood as a period during which increased trade occurred with external regions (e.g., Kibler 2012). Does this also account for the appearance of maize in the central Texas region? Does trade appear in early Toyah as well as in later periods? With the proper dating procedures, future research may help answer these and other questions.

\section{Late Archaic 2, 3, and 4}

Following the regional chronology proposed by Lohse et al. (2014a), the Late Archaic 2 through 4 periods began immediately following the Bulverde and Pedernales point styles, about 3100 cal B.P. (ca. 1150 B.C.), and lasted until 650 cal B.P. (A.D. 1300). Testing at 41HM61 revealed a very well stratified series of deposits, including several features (but comparatively little artifact material), covering most of this time span. In addition to features and cultural material for these intervals, diagnostic dart points representing Lange, Marcos, and Ensor types were recovered. Regional chronologies for this period commonly lack this kind of fine-grained resolution, and this site has the potential to contribute meaningfully to questions about the Late Archaic, especially those involving the chronological placement of point styles and related subsistence practices. Radiocarbon dates for Late Archaic 2, 3, and 4 deposits at 41HM61, along with comparative contexts and assays, are presented in Table 10-4.

At 41HM61, Late Archaic occupation is first noted with the recovery of a Lange type dart point from the profile of BT 15 and at the same elevation as Features 19 and 20 in the same trench. For reasons discussed elsewhere, the Lange type was not included in the study by Lohse et al. (2014a) for their Archaic period radiocarbon chronology. However, regional models (e.g., Collins 1995; Prewitt 1981) place it approximately between Pedernales and Montell-Castroville-Marcos. Lohse et al. (2014a) define Late Archaic 2 as beginning with the hiatus in bison hunting that starts around 3100 cal B.P., and this hiatus is also found in the point types used for that study. Work at the Loma Sandia cemetery site (41LK28) recovered a number of Lange specimens, and dated them at approximately 850-600 B.C. (Taylor and
Highley 1995). Other well-dated contexts seem scarce. Dating this style more precisely in the present study is difficult because none of the three dates closely associated with this artifact (Beta-382993, Beta-315690, and Beta-315691; see Table 10-4) are considered highly reliable. Taken together, however, the three dates span the period from about 3032 to 2496 cal B.P., or 1083 to 547 B.C. Given the absence of a "more reliable" assay for comparative purposes, none of these three dates is discounted in the present study. Nonetheless, this interval overlaps with at least part of the hiatus between $\mathrm{LA}_{\mathrm{B}} 1$ and $\mathrm{LA}_{\mathrm{B}} 2$ proposed by Lohse et al. (2014c). It seems probable that future work at 41HM61 could well produce "reliable" assays associated with the Lange type that would be very important for defining this interval accurately and precisely as it occurred in central Texas.

With respect to the reliability of dates derived for the Lange component, Beta-382993 is from mussel shell from Feature 19 while Beta-315690 is from organic sediment collected from the same feature. These two samples yielded somewhat non-comparable dates of about 3008-2856 and 2770-2705 cal B.P., respectively (including only the age distribution of greatest probability for the purposes of discussion). Mussel shells from freshwater contexts commonly include old carbon from aquifer reservoirs that produce older age estimates than would normally be associated with these organisms. However, in such cases, correction factors can sometimes be calculated that would allow researchers to rely on radiocarbon ages from mussel shells as being more accurate than those from uncorrected samples or contexts. In this case, a provisional correction factor can be proposed simply by comparing the calibrated ages of these two samples. This factor assumes that sample Beta315690 does not suffer from inaccuracies resulting from the measurement of organics included in this sample that do not originate from the period of this soil's deposition. The median ages for each of these two dates is about 2932 and 2737 cal B.P., respectively. The difference between these two ages is approximately 200 calibrated years. Clearly, additional dates, ideally more reliable than sediment samples, would be needed to propose a more precise or accurate correction factor for this period and this part of the Leon River drainage. Nevertheless, this age difference can be used provisionally to understand the reservoir effect of older carbon in mussel shells consumed and deposited during this interval. Of potential importance is the fact that similar correction factors proposed for Feature 18 (see below) yield almost identical results. 
Table 10-4. Radiocarbon Dates with Contexts and Comparative Criteria Relevant for Understanding the Late Archaic 2 through 4 Periods at 41HM61.

\begin{tabular}{|c|c|c|c|c|c|}
\hline Lab No. & C14 Age & $\begin{array}{l}\text { Calibrated Age Range } \\
\qquad(2 \sigma)^{*}\end{array}$ & Material & Context & Comparative Assay \\
\hline Beta-382993 & $2830 \pm 30$ & 3033-2856 B.P. ${ }^{2}$ & Mussel shell & Feature 19 & $\begin{array}{l}\text { Beta-315690, } \\
\text { Beta-315691 }\end{array}$ \\
\hline Beta-315690 & $2590 \pm 30$ & $\begin{array}{c}2770-2704(92.7 \%), \\
2630-2620(1.4 \%), 2558- \\
2544(1.3 \%) \text { B.P.** }\end{array}$ & $\begin{array}{l}\text { Organic sedi- } \\
\text { ment }\end{array}$ & Feature 19 & $\begin{array}{l}\text { Beta-315691, } \\
\text { Beta-382993 }\end{array}$ \\
\hline Beta-315691 & $2540 \pm 30$ & $\begin{array}{c}2749-2686(44.4 \%), \\
2638-262-(12.2 \%), \\
2597-2497(38.9 \%) \\
\text { B.P. } * *\end{array}$ & Charcoal & Feature 20 & $\begin{array}{l}\text { Beta-315690, } \\
\text { Beta-382993 }\end{array}$ \\
\hline Beta-382999 & $2390 \pm 30$ & $\begin{array}{c}\text { 2678-2644 B.P. }(2.3 \%) \\
\text { 2492-2346 B.P. } \\
(91.3 \%)^{1 * *}\end{array}$ & $\begin{array}{l}\text { Plum or cherry } \\
\text { seed fragments }\end{array}$ & $\begin{array}{c}\text { Block 3, } \\
\text { Unit N449E590, } \\
\text { Stratum 3, Level D }\end{array}$ & \\
\hline $\begin{array}{c}\text { UCI- } \\
\text { AMS-140843 }\end{array}$ & $2215 \pm 20$ & 2314-2154 B.P. ${ }^{1}$ & $\begin{array}{l}\text { Bison, L. calca- } \\
\text { neous, XAD }\end{array}$ & $\begin{array}{l}\text { BT 15, W. wall, } \\
\text { A horizon, } \\
99.01 \text { elev. }\end{array}$ & Beta-370014 \\
\hline Beta-370014 & $2090 \pm 30$ & 2145-1992 B.P. ${ }^{2}$ & $\begin{array}{l}\text { Bison, L. } \\
\text { calcaneous, } \\
\text { ultrafiltered }\end{array}$ & $\begin{array}{l}\text { BT 15, W. wall, } \\
\text { A horizon, } \\
99.01 \text { elev. }\end{array}$ & UCIAMS-140843 \\
\hline Beta-382995 & $1890 \pm 30$ & 1894-1733 B.P. ${ }^{1}$ & $\begin{array}{l}\text { Possomhaw } \\
\text { (Ilex sp.) }\end{array}$ & $\begin{array}{l}\text { Feature } 21, \text { WC } 4 \text {, dart } \\
\text { point found under rocks } \\
\text { of this feature, } \\
99.30-99.20 \text { elev. }\end{array}$ & Beta-315689 \\
\hline Beta-315689 & $1720 \pm 30$ & $1702-1560$ B.P. ${ }^{2}$ & $\begin{array}{l}\text { Organic sedi- } \\
\text { ment }\end{array}$ & $\begin{array}{l}\text { WC 5, Stratum } 3 \text { "middle } \\
\text { living surface," } \\
99.17-99.07 \text { elev. }\end{array}$ & Beta-382995 \\
\hline $\begin{array}{c}\text { UCI- } \\
\text { AMS-140844 }\end{array}$ & $1535 \pm 20$ & 1522-1365 B.P. ${ }^{1}$ & $\begin{array}{c}\text { Deer, L. radius, } \\
\text { XAD }\end{array}$ & $\begin{array}{l}\text { BT 11, } \\
99.36 \text { elev. }\end{array}$ & $\begin{array}{c}\text { Beta-370010 (not split } \\
\text { sample) }\end{array}$ \\
\hline Beta-370010 & $1440 \pm 30$ & 1384-1296 B.P. ${ }^{2}$ & $\begin{array}{l}\text { Deer, metacar- } \\
\text { pal/ } \\
\text { Carpodial, ultra- } \\
\quad \text { filtered }\end{array}$ & $\begin{array}{l}\text { BT 11, Feature 1, } \\
\text { 99.39 elev. }\end{array}$ & $\begin{array}{l}\text { UCIAMS-140844 (not } \\
\text { split sample) }\end{array}$ \\
\hline Beta-382994 & $1230 \pm 30$ & 1262-1068 B.P. ${ }^{2}$ & Mussel shell & Feature 16 & \\
\hline
\end{tabular}

Note: The notation ${ }^{1}$ indicates that these samples are considered "more" reliable; the notation ${ }^{2}$ indicates these samples are "less" reliable. The notation ${ }^{* *}$ indicates that calibrated probabilities are given as percentages for these samples because of the extremely large span of time present between each of the intercept periods. 
During fieldwork, it was recognized that a distinct Marcos-related component was present, based on the recovery of several stemmed dart points identified as belonging to that type (Weinstein et al. 2012). Subsequent analysis indicates that some are more accurately identified as Ensors (see Chapter 11, below). These two types are sequential in the central Texas regional chronology (Collins 1995; Prewitt 1981; Turner et al. 2011), although precise dating of the two styles and knowing whether they overlap in time has remained unclear (see Lohse et al. 2014a). Based on "reliable" radiocarbon data, as well as the regional record for bison exploitation, this issue can be addressed to some degree at 41HM61.

Based on earlier discussions regarding the reliability of bone dates prepared using different pretreatment techniques, we conclude that sample Beta370014 should be excluded for consideration when assessing the archaeological age of this specimen. According to the regional chronology for bison presence and exploitation in central Texas compiled by Lohse et al. (2014c), this date appears to be too young to be reliably associated with Late Archaic bison. Lohse et al. (2014c) define a second phase of Late Archaic bison $\left(\mathrm{LA}_{\mathrm{B}} 2\right)$ that dates between approximately 2700 and $2150 \mathrm{cal}$ B.P. ( $\mathrm{LA}_{\mathrm{B}} 1$ dates to $3295-3130 \mathrm{cal}$ B.P.). Additionally, a review of radiocarbon data reliably associated with certain diagnostic point types (Lohse et al. 2014a) indicates that Marcos points are difficult to date but probably end by $2150 \mathrm{cal}$ B.P., and that Ensor most likely dates about $2150-1750$ cal B.P. While this span would seemingly accommodate Beta-370014, the fact that the date comes from bison suggests that it is too young to be considered accurate. In contrast, the XAD portion of this split sample (UCIAMS-140843) returned a date of about 2314-2154 cal B.P., more securely within the probable age range for Marcos than for Ensor and well within the $\mathrm{LA}_{\mathrm{B}} 2$ interval. Based on "reliable" dates from 41HM61, we therefore suggest that the Marcos component falls within the span of time indicated by samples Beta-382999 (probably 2492-2346 cal B.P.) and UCIAMS-140843. The fact that the calibrated age ranges of these two assays do not overlap indicates that there were, minimally, two occupation events during the Marcos period. Together these spanned the period of about 2490-2150 cal B.P., or about 500-200 B.C.

The best radiocarbon evidence for the Ensor component at the site comes from sample Beta-382995 from Feature 21. This sample, a short-lived possomhaw (Ilex sp.) fragment, dates to about 1894-1733 cal B.P., and is slightly older than comparative sample
Beta-315689 (organic sediment, 1702-1560 cal B.P.). These two samples were recovered from approximately the same elevation about five meters apart (Weinstein et al. 2012:218). However, considering the lower reliability of the sediment date compared with the botanically identified specimen, we use Beta-382995 to propose a date for the site's Ensor component. Still, we include Beta-315689 in our final model for Late Archaic site visitation history because it derives from a context for which there is no other truly adequate comparative assay.

The next confirmed visitation during the Late Archaic 3 period is indicated by the two dated deer-bone samples. These samples were not split but are believed to come from the same component; both are from BT 11 and from within a 3-cm elevation difference of each other. The sample pretreated by ultrafiltration (Beta370010) is slightly younger than the XAD sample (UCIAMS-140844; see discussion above), 1384-1296 compared with 1522-1365 cal B.P. Because these are not split samples, we cannot completely discount the ultrafiltered date. However, based on what appears as a systematic offset between XAD and ultrafiltered dates, we suggest that UCIAMS-140844 is probably more reliable for dating this component. This period, $1522-1365$ cal B.P., seemingly is slightly too young to be reliably associated with the Ensor type. However, Frio is tentatively dated to about $1550-1270$ cal B.P. (Lohse et al. 2014a). While no Frio points were recovered during excavations here, this date suggests serial visitations during archaeological periods associated with Ensor and Frio points. Future work at this site should bear this in mind and the possible recovery of Frio points should therefore be anticipated.

The final Late Archaic visitation to the site is represented by radiocarbon date Beta-382994 ( 12621068 cal B.P.) from a mussel shell from Feature 16. This calibrated age range corresponds with the earlier mode of a bimodal distribution of dates securely related to the Darl point type (Lohse et al. 2014a). No Darl points were recovered during testing at the site, and it is possible that this reported age is slightly misrepresentative as a result of the potential for there to be an uncorrected reservoir error. Nonetheless, this date is somewhat younger than the next-youngest "reliable" assay from the site (UCIAMS-140844), and the two do not statistically overlap, suggesting Late Archaic serial visitation extended up to and included the event that resulted in Feature 16.

Taken together, radiocarbon data from the Late Archaic indicates a series of visitations to the site 

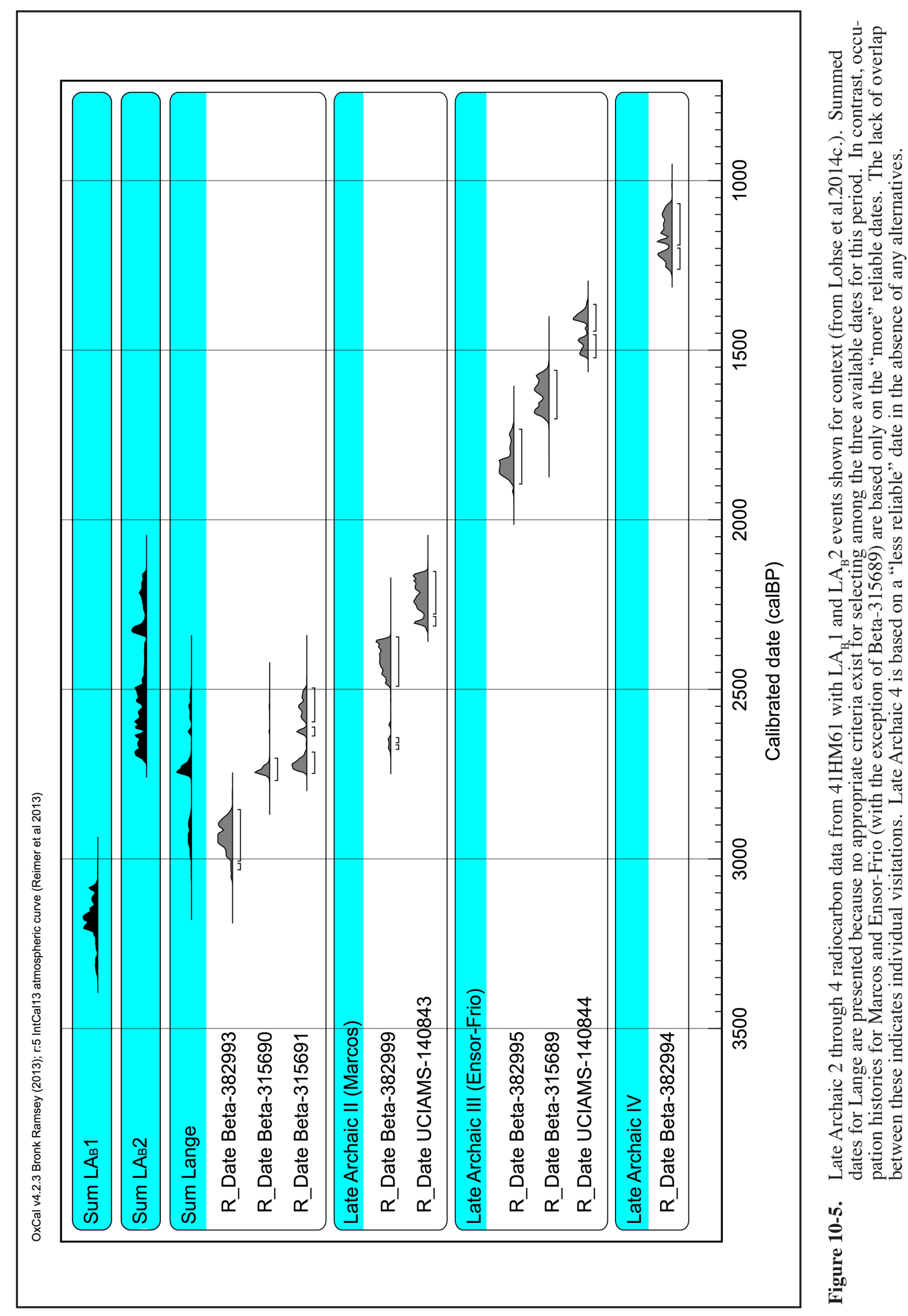
starting with Lange, as early as ca. 3000 cal B.P., and concluding by almost $1100 \mathrm{cal}$ B.P. The model of this history, presented in Figure 10-5, includes summed dates (also showing individual assays) for Lange, since each of these is considered "less" reliable and we cannot further differentiate them in an effort to increase the dating precision for this visitation(s). The occupation histories for the Marcos, Late Archaic 3, and Late Archaic 4 intervals are based on individual assays for reasons discussed above. Additionally, $\mathrm{LA}_{\mathrm{B}} 1$ and $\mathrm{LA}_{\mathrm{B}} 2$ events are included as a means of contextualizing this Late Archaic sequence in relation to reconstructed bison population histories in the region.

\section{Middle and Early Late Archaic}

Although no temporally diagnostic artifacts pre-dating the Lange point were recovered, cultural remains and features were documented in lower depths at the site. Moreover, fieldwork at 41HM61 failed to reach what can be confirmed as culturally sterile soil, and it remains a possibility that stratified deposits continue below those that are reported on here. The earliest directly dated cultural deposits include Feature 18, documented in Block 5. This shell deposit was dated twice, once by bulk sediments (Beta-315692) and again by mussel shell (Beta-382992). The first sample yielded a two-sigma range of about 4411 to $4226 \mathrm{cal}$. B.P. (84.3 percent probability), while the second produced a two-sigma range of about 4628 to 4432 cal B.P. (87.7 percent probability) (see Table 10-1). Neither of these dates is considered "highly reliable," and together these assays suggest a date for this feature of ca. 4628-4226 cal B.P. This long span is difficult to assess, but it does overlap with the end of the Middle Archaic and very early part of the Late Archaic as defined by Lohse et al. (2014a). That study places the beginning of the Late Archaic at about 4200-4100 cal B.P.; Feature 18 seems to represent the remains of regional subsistence behavior around this transitional time.
Interestingly, the date range on the mussel shell from Feature 18 is about 200 years earlier than the date range on the organic sediment. Although these two dates are not considered highly reliable, the earlier dates on the shell are not unexpected, given the potential for shellfish to build their shells out of "dead" carbon present in a river system (see earlier discussion for Feature 19). This "reservoir effect" is usually more pronounced for rivers that drain landforms containing limestone formations. Since central Texas has extensive deposits of Cretaceous-age limestone, the water in the Leon River undoubtedly is affected. What is somewhat surprising is the fact that the difference between the two dates is only 200 years; an older figure would have been expected based on reservoir effect studies conducted elsewhere (see Taylor and Bar-Yosef 2014:Figure 5.6). Obviously, more data will be needed from other sites and features in the region. For now, however, the 200-year-differences between the two sets of dates from Features 18 and 19 can be viewed as a starting point for developing a correction factor for this part of the Leon River.

The other two radiocarbon dates indicating early deposits at 41HM61 both come from samples taken from BT 23. Beta-382990 (4060-3838 cal B.P.), on charcoal, comes from the base of the Upper West Range alluvium or top of the Lower West Range alluvium at about $270 \mathrm{~cm}$ below the surface. Considering that it is from charcoal, this sample likely represents some cultural activity at this depth. Beta382991 (most likely 5286-4961 cal B.P.) is a bulk sediment date taken from the Lower West Range alluvium exposed at the bottom of BT 23, 375-380 cm below the surface. It is not clear whether this sample is associated with any cultural activity or not, but it does give an important indication that cleanly stratified Holocene alluvial deposits continue to some depth below the extent of fieldwork. 


\section{Chapter 11}

\section{Chipped Stone Artifacts}

Lithic artifacts were recovered from 41HM61 by piece plotting recognizable items as Field Specimens (FSs), screening sediments removed through controlled excavation, processing bulk sediment samples from excavation contexts by flotation, carefully inspecting exposed backhoe trench profiles, and examining backdirt from previous excavations and the spoil piles from mechanically excavated trenches and blocks. Through these various investigative techniques, different kinds of proveniences were recorded for artifacts loosely associated with controlled excavations as well as those from more precisely recorded locations. Overall, the assemblage of chipped stone artifacts from 41HM61 is small, numbering only 179 pieces of siliceous stone material (mostly chert) that indicate or may indicate cultural modification, alteration, or use. This small assemblage is divided into tools, i.e. pieces that show evidence either of modification through removal of flakes or probable use without specific modification, and debitage, i.e. flakes and flake fragments that were removed during the course of shaping larger, objective pieces.

Each category of lithic remains is assessed following the taxonomic approaches outlined in the draft TxDOT Lithics Protocol (LP). The LP details a number of measurements and observations that are to be recorded for tools of different form and perceived function, with the ultimate objective of facilitating, at some future point, accurate and meaningful regional inter-assemblage comparisons of prehistoric stone tool-related behavior.

\author{
Jon C. Lohse
Sean R. Nash
Timothy K. Perttula \\ Jon C. Lohse
Sean R. Nash
Timothy K. Perttula \\ Jon C. Lohse
Sean R. Nash
Timothy K. Perttula \\ Jon C. Lohse
Sean R. Nash
Timothy K. Perttula
}

Two brief comments precede the following discussion of the chipped stone artifacts from 41HM61. First, non-chipped stone items are included in this discussion even though these are not addressed in the LP. Pieces of interest include only a single hammerstone and a smooth pebble that seemed out of place in relation to its surrounding matrix. Second, while the sample size is very small, initial impressions are that little or no core, cobble, or biface reduction was taking place at the site. For example, no flake cores were recovered, and no production failures are included among the biface fragments. Most debitage appears to relate to tool retouch, and most tools, especially projectile points, appear to have been discarded as a result of having been broken during use. The sample size, however, is likely to be too small to draw meaningful conclusions about any possible changes in lithic-related behaviors at this site over time.

\section{Tools}

Following the taxonomy of the LP (Figure 11-1), "tools" in the present collection include both core-derived and core-based tools. A total of 20 artifacts are classified as "tools." These include six flake tools (referred to as core-derived tools in the LP), four bifaces and biface fragments, and nine projectile points and point fragments. It is possible that some of the biface fragments also represent broken pieces of projectile points. However, because none can be confidently identified as such, they are not included in the projectile point category. In addition to these chipped stone tools, a single hammerstone is presented here. 


\section{Technology (Chipped stone)}

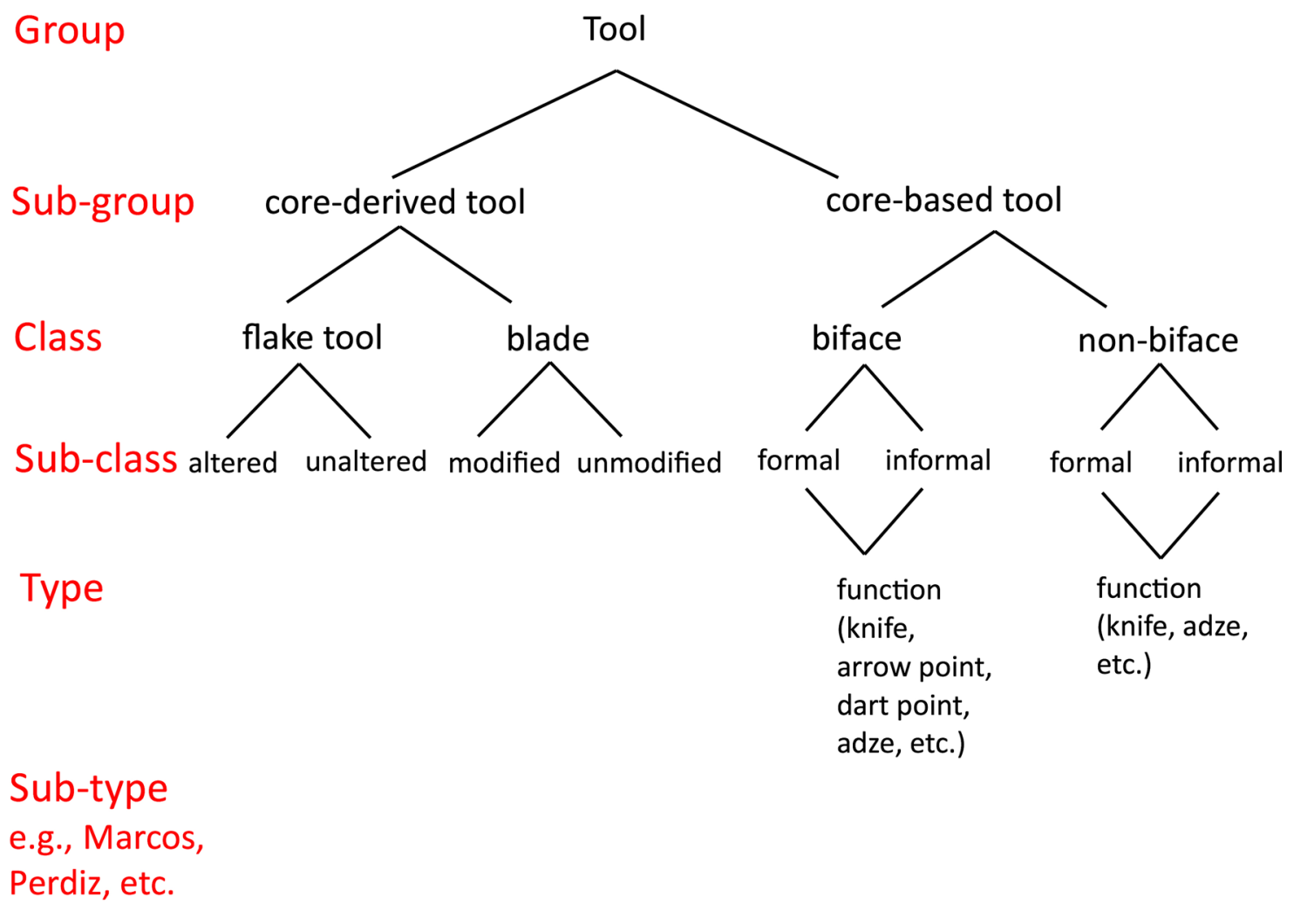

Figure 11-1. Analytic taxonomy for chipped stone tools as outlined in the TxDOT LP.

\section{Core-Derived Tools}

Six artifacts classified as core-derived (flake) tools were recovered from 41HM61 (Table 11-1). Alteration of core-derived tools is minimal and limited to two artifacts. One artifact (Object ID 001.62), from the backdirt of BT 11, resembles flakes described as steep-edge scrapers (Figure 11-2, a). Artifacts such as this one are common in Toyah assemblages (Barry 2011), though are not likely to be as temporally diagnostic as projectile points. Given that no Toyah component was uncovered in the southern portion of the site, it seems unlikely that this item can be tied to that occupation. This artifact was shaped by the unifacial removal of flakes around its entire perimeter, with the exception of the striking platform. The effect of this shaping creates a dome-shaped dorsal side. Most of the percussion bulb remains intact, which allows the striking platform to be easily identified.
The other modified flake tool is a drill (FS 66, Object ID 118.02) with a moderately long $(1.7 \mathrm{~mm})$ bit that shows a distinctive alternate bevel (Figure 11-2, $\mathrm{b}$; see Table 11-1). The proximal portion of this tool is broken, perhaps by exposure to heat. Small drills made on flakes, such as this one, are common in Toyah assemblages, and are distinguished from drills of earlier time periods that are often made on recycled bifaces (Shafer and Hester 2013). In this instance, the recovery of the item in Block 1 suggests that it is part of the Toyah component at the site.

Six utilized flakes are present (see Table 11-1). Two of the six utilized flakes exhibit flake removals that are consistent with modification prior to use. One of these two tools (FS 49; Object ID 121.02) exhibits relatively long flake scars originating from the left and right margins of the distal tip, intersecting and terminating on the dorsal face. This same specimen also exhibits 
Table 11-1. Core-Derived Tools from 41HM61.

\begin{tabular}{|c|c|c|c|c|}
\hline Provenience & Field Specimen & $\begin{array}{c}\text { Object ID } \\
\text { Number }\end{array}$ & Temporal Unit & Artifact Description \\
\hline Trench 11 , backdirt & - & 001.62 & - & Unifacial scraper \\
\hline $\begin{array}{l}\text { Trench 16, WC } 4 \text {, } \\
\text { St. 3, Lv. C }\end{array}$ & - & 075.25 & Late Archaic 3 & Utilized flake \\
\hline $\begin{array}{c}\text { Block 2, } \\
\text { Unit N477E560, } \\
\text { St. } 2, \text { Lv. C }\end{array}$ & - & 150.28 & - & Utilized flake \\
\hline $\begin{array}{c}\text { Block 2, } \\
\text { Unit N477E560, St. 2, } \\
\text { Lv. A }\end{array}$ & - & $148 . .37$ & - & Utilized flake \\
\hline $\begin{array}{c}\text { Block 1, } \\
\text { Unit N601E597, } \\
\text { St. 4, Lv. A }\end{array}$ & 49 & 121.02 & Toyah & Utilized Flake \\
\hline $\begin{array}{c}\text { Block 1, } \\
\text { Unit N601E597, } \\
\text { St. 4, Lv. B }\end{array}$ & 82 & 122.02 & Toyah & Utilized Flake \\
\hline $\begin{array}{c}\text { Block 1, } \\
\text { Unit N602E596, } \\
\text { St. 4, Lv. A }\end{array}$ & 44 & 129.10 & Toyah & Utilized Flake \\
\hline $\begin{array}{c}\text { Block 4, } \\
\text { Unit N474E602, } \\
\text { St. 3, Lv. E }\end{array}$ & 182 & 181.01 & - & Prismatic flake (possible blade), utilized \\
\hline $\begin{array}{c}\text { Block 1, } \\
\text { Unit N601E596, } \\
\text { St. 4, Lv. B }\end{array}$ & 66 & 118.02 & Toyah & Drill, modified flake \\
\hline
\end{tabular}

apparent notching flakes along the fractured proximal edge. The second flake that exhibits modification prior to use is FS 82 (Object ID 122.02). A steep edge was formed with unifacial pressure flaking along the thin, excurvate, distal edge. Fine, irregularly spaced hinge flakes that originate at the edge, but terminate within the larger, shaping flake scars, demonstrate subsequent use as an end scraper. Additionally, the same tool exhibits a $16-\mathrm{mm}$ area along the left margin of intentional dulling created by intentional hinge flakes and grinding. This dulled area is truncated by the proximal fracture and suggests the tool may have been hafted. These two utilized flakes, plus one more (FS 44; Object ID 129.10), exhibit irregular hinge and very small, steep conchoidal fractures originating at the utilized edge.
Regular edge attrition in the form of moderately steep edge wear is present on the other three cases. Four flakes retain some cortex. One of these (FS 44; Object ID 129.10) is wedge-shaped similar to a section of an orange that has been laterally sliced in half. Cortex covers the wide back of the wedge-shaped flake fragment. The two other tools exhibit small amounts (10 to 20 percent) of cortex along one or more lateral margin. FS 82 has an area of interior cortex that is visible on the dorsal and ventral faces and includes part of the distal tip. The expression of the modification and use-wear described above for the margin of FS 44 was not evident where the cortex surfaced. Two of the utilized flakes displayed no cortex whatsoever. 


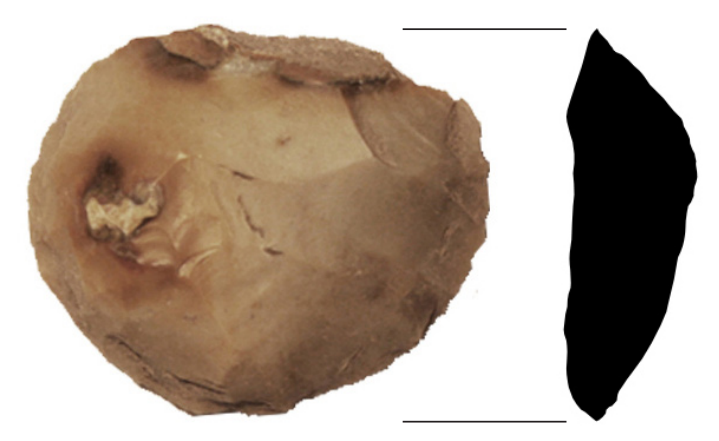

a

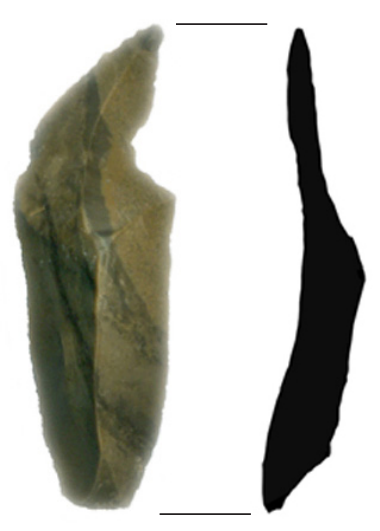

c

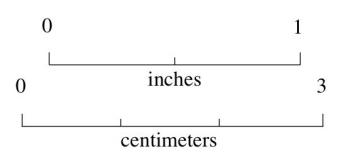

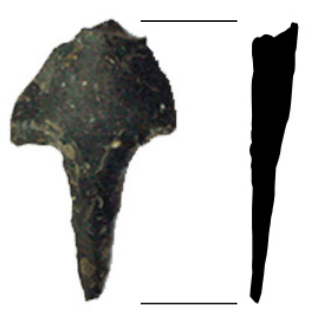

b

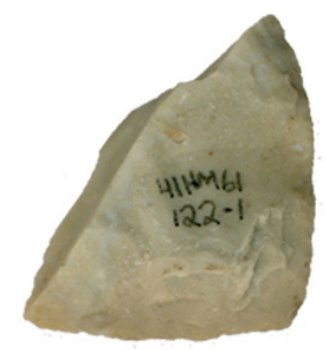

$\mathbf{e}$

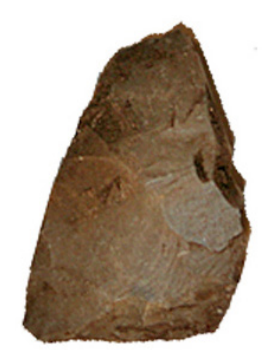

f

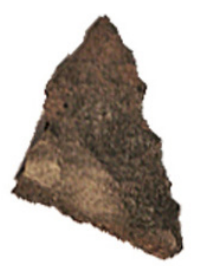

g

Figure 11-2. Core-derived and core-based tools from site 41HM61: (a) Steep-edge scraper, (b) Drill, (c) Prismatic flake, (d) Biface, (e-g) Biface fragments. (See Tables 11-1 and 11-2 for provenience information.)

The last core-derived tool is a prismatic flake (FS 182; Object ID 181.01) with near-parallel lateral edges and a strong dorsal ridge (Figure 11-2, c; see Table 11-1). This artifact resembles a blade. However, no other material clearly related to blade tech- nology, such as platform or core-face rejuvenation flakes, blade cores, or other blades, was recovered from the site. Prismatic flakes that resemble blades can occur in the absence of a "true" blade technology (Bradley et al. 2010; Collins and Lohse 2004), and 
Table 11-2. Bifaces and Biface Fragments from 41HM61.

\begin{tabular}{|c|c|c|c|c|}
\hline Provenience & Field Specimen & $\begin{array}{c}\text { Object ID } \\
\text { Number }\end{array}$ & Temporal Unit & Artifact Description \\
\hline $\begin{array}{c}\text { Block 1, } \\
\text { Unit N601E597, } \\
\text { St. 4, Lv. B }\end{array}$ & 81 & 122.01 & Toyah & Fragment, corner or tip, bending break \\
\hline $\begin{array}{c}\text { Block 1, } \\
\text { Unit N603E596, } \\
\text { St. 4, Lv. A }\end{array}$ & 46 & 141.17 & Toyah & Fragment, possible tip, possibly heated \\
\hline $\begin{array}{c}\text { Trench 16, } \\
\text { backdirt }\end{array}$ & - & 007.106 & - & Possible point tip (fragment), heat \\
damaged
\end{tabular}

confident classifications of blades should be made on the basis of more than a single artifact.

\section{Core-Based Tools}

Core-based tools are those implements that have been deliberately modified for use in such ways that they have lost their characteristics as flakes or other kinds of debitage. Core-based tools can include, for instance, unifaces like Clear Fork adzes that assume regular shapes in assemblages wherever they occur (Dial 1998; Hudler 1997). In the present assemblage, all core-based tools are bifaces and biface fragments, or projectile points.

\section{Bifaces}

Four bifaces and biface fragments were recovered from excavations (Table 11-2). The one nearly complete biface (Object ID 001.60) is missing its very distal tip, and shows evidence of resharpening on one basal corner and along both lateral margins (Figure $11-2$, d). This artifact was recovered from backdirt of Trench 11, and so cannot be associated with any of the site's dated deposits. The artifact measures $10.6 \mathrm{~cm}$ long by $3.5 \mathrm{~cm}$ wide and is $1.3 \mathrm{~cm}$ thick. Reasons for its having been discarded are unclear. The other three biface fragments represent corner portions or possibly distal tips (see Figure 11-2, e-g). None of these four artifacts is clearly heat-treated; two may have been exposed to, and/or damaged by, heat, perhaps after having been broken and discarded.

\section{Projectile Points}

Nine projectile points or point fragments were recovered from investigations at 41HM61 (Table 11-3; Figure 11-3). Two of these are arrow points, while seven are dart points or fragments of dart points. Together, these artifacts are important in that, along with radiocarbon and stratigraphic evidence, they help indicate temporal periods of site occupation. Based on these data, main periods of activity that seem best represented in the material evidence include Late Prehistoric Toyah and at least a couple of occupations in the latter part of the Late Archaic period, including what Lohse et al. (2014a) call Late Archaic 2 (Montell, Castroville, and Marcos types, as well as others including Lange), about 3100-2150 cal B.P. (1150200 B.C.), and Late Archaic 3 (Ensor, Fairland, Frio types), dating to about $2150-1270$ cal B.P. (200 B.C. to A.D. 680). At least one earlier occupation is represented by Feature 18, which is radiocarbon dated to about 4410-4160 cal B.P. (2460-2200 B.C.; Weinstein et al. 2012:Table 10-1) and 4790-4430 cal B.P. (see discussion in Chapter 10). Based on work conducted so far at the site, it is unclear whether this occupation is also associated with diagnostic points.

Marcos Points. Two Marcos points were recovered, both from Trench 15 (see Figure 11-3, a-b). Lohse et al. (2014a) ascribe Marcos points to the Late Archaic 2, and propose a date range of about 24502150 cal B.P. (ca. 500 to 200 B.C.). These are poorly dated, however, and their actual age could exceed 
Table 11-3. Projectile Points and Point Fragments from 41HM61.

\begin{tabular}{|c|c|c|c|c|}
\hline Type & Provenience & $\begin{array}{l}\text { Field Speci- } \\
\text { men }\end{array}$ & Figure & Artifact Description \\
\hline Marcos & $\begin{array}{l}\text { Trench 15, top of Upper West } \\
\text { Range alluvium, } 99.33 \text { m elev. }\end{array}$ & 371 & Figure $11-3$, a & $\begin{array}{c}\text { Tip and base are fractured from impact, } \\
\text { one barb also broken, resharpened blade, } \\
\text { shallow corner notching }\end{array}$ \\
\hline Marcos & $\begin{array}{c}\text { Trench } 15 \text {, WC } 3 \text {, } \\
\text { St. 3/4, } 40-50 \mathrm{cmbs} \text {, interface of } \\
\text { Ford alluvium's A horizon and } \\
\text { West Range alluvium, } \\
\text { 99.42-99.32 m elev. }\end{array}$ & - & Figure $11-3, \mathrm{~b}$ & $\begin{array}{l}\text { Complete, one shoulder resharpened, } \\
\text { straight base, shallow corner notching }\end{array}$ \\
\hline Ensor & $\begin{array}{l}\text { Trench } 15, \\
\text { backdirt }\end{array}$ & - & Figure 11-3, c & $\begin{array}{l}\text { Complete, very distal tip broken, resharp- } \\
\text { ened lateral margin on blade, convex base, } \\
\text { side notched }\end{array}$ \\
\hline Ensor & $\begin{array}{l}\text { Trench 15, A horizon, } \\
98.53 \mathrm{~m} \text { elev. }\end{array}$ & 176 & Figure $11-3, \mathrm{~d}$ & $\begin{array}{c}\text { Basal fragment, broken at stem, convex } \\
\text { base, side notched }\end{array}$ \\
\hline Lange & $\begin{array}{l}\text { Trench } 15 \text {, A horizon, } \\
\quad 98.46 \mathrm{~m} \text { elev. }\end{array}$ & 245 & Figure 11-3, e & $\begin{array}{l}\text { Complete, resharpened lateral margin, } \\
\text { convex edges, short expanding stem, } \\
\text { asymmetric barbed shoulders }\end{array}$ \\
\hline $\begin{array}{l}\text { Untyped dart } \\
\text { point }\end{array}$ & $\begin{array}{l}\text { Trench 16, WC 4, } \\
\text { St. 3, Lv. D, } \\
99.17 \text { m elev. }\end{array}$ & 50 & Figure $11-3, \mathrm{f}$ & $\begin{array}{l}\text { Tip and stem missing from impact, } \\
\text { recurved lateral margins, serrated edges, } \\
\text { beveled blade }\end{array}$ \\
\hline $\begin{array}{l}\text { Perdiz arrow } \\
\text { point }\end{array}$ & $\begin{array}{l}\text { Trench } 19, \\
\text { backdirt }\end{array}$ & - & Figure $11-3, \mathrm{~g}$ & $\begin{array}{l}\text { Contracting stem with pointed base, one } \\
\text { shoulder barb missing, unifacially flaked } \\
\text { blade with bifacially flaked stem }\end{array}$ \\
\hline $\begin{array}{l}\text { Perdiz arrow } \\
\text { point }\end{array}$ & $\begin{array}{l}\text { Trench 19, } \\
99.43 \text { m elev. }\end{array}$ & 24 & Figure $11-3, \mathrm{~h}$ & $\begin{array}{l}\text { Contracting stem with rounded base, distal } \\
\text { end missing from what looks like fresh } \\
\text { break, unifacial (flake) blade with bifacial- } \\
\text { ly flaked stem }\end{array}$ \\
\hline Dart point tip & $\begin{array}{l}\text { Trench 17, WC 2, } \\
\text { St. 2, Lv. B, } \\
\text { 99.59-99.49 m elev. }\end{array}$ & - & Figure $11-3, \mathrm{i}$ & Distal tip broken by snap fracture \\
\hline
\end{tabular}

this range. One Marcos point from 41HM61 (FS 371; Object ID 002.259) came from the top of the upper portion of the West Range alluvium in BT 15, and the other (Object ID 054.02) came from the interface between the Ford alluvium and the underlying West Range alluvium in WC 3. Geologically, these contexts are very comparable. The first has impact scarring on its tip and base, and was resharpened. This point measures $4.2 \mathrm{~cm}(\mathrm{~L})$ by $2.3 \mathrm{~cm}(\mathrm{~W})$ by $6 \mathrm{~mm}(\mathrm{Th})$, but the length and width dimensions are incomplete. The second is virtually complete, with only one shoulder barb missing and having been resharpened. This specimen measures $4.7 \mathrm{~cm}(\mathrm{~L})$ by $2.4 \mathrm{~cm}(\mathrm{~W})$ by 6 $\mathrm{mm}(\mathrm{Th})$. Both points are made on high-quality, gray, opaque chert that may have been heat treated based on its waxy appearance. These points are difficult to distinguish from Ensor points at the site because of their small, relatively narrow blades. However, we identify these specimens as Marcos primarily on the basis of corner, rather than side notching, at the base. Even this attribute, however, may be interpreted differently by different researchers. The Marcos dates from 41HM61, however, correspond perfectly with the age range discussed above for this type.

Ensor Points. Two points or point fragments are identified to the Ensor type (see Figure 11-3, c-d). This type follows Marcos in the central Texas chronological sequence and the two can be difficult to distinguish. Lohse et al. (2014a) ascribe Ensor to the Late 


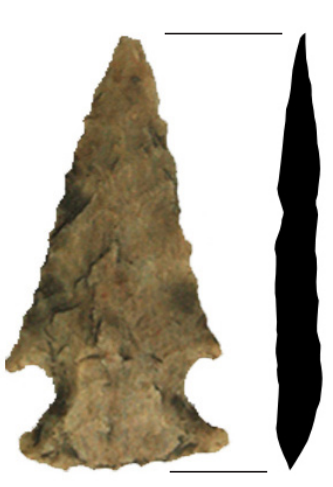

$\mathbf{a}$

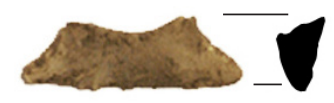

d

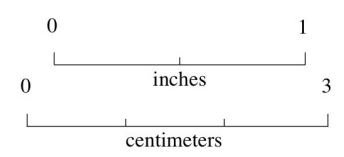

centimeters

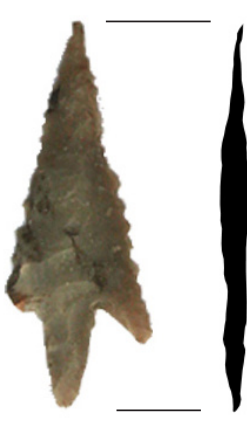

g

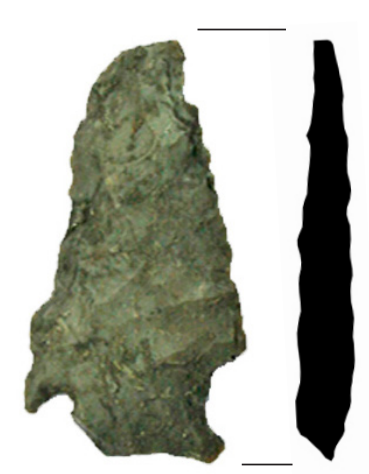

b

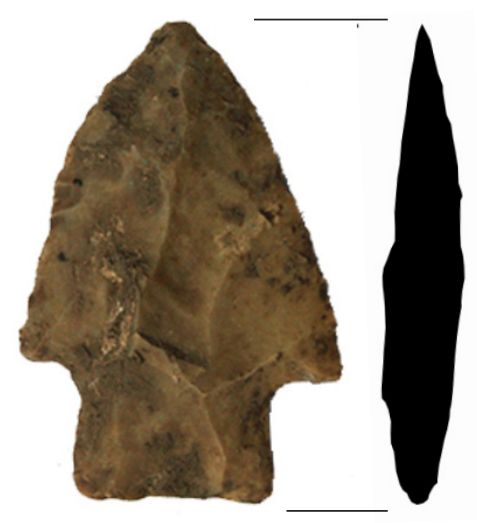

e

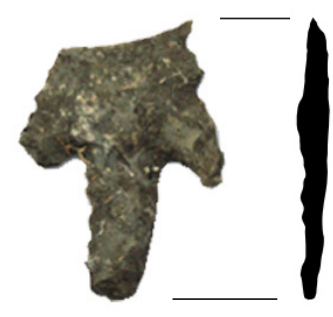

h

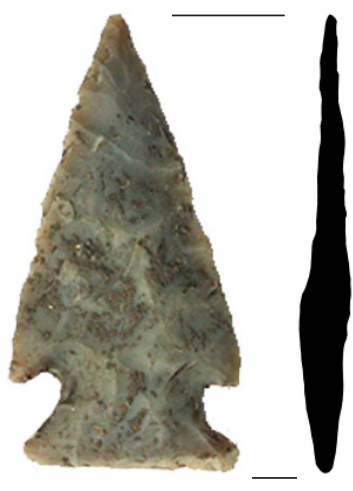

c

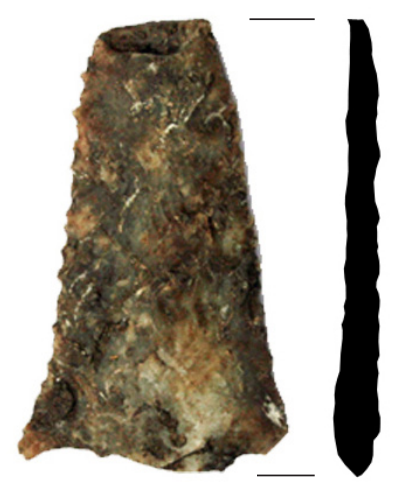

f

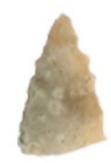

i

Figure 11-3. Projectile points from site 41HM61: (a-b) Marcos, (c-d) Ensor, (e) Lange, (f) Untyped dart point, (g-h) Perdiz, (i) dart point tip. (See Table 11-3 for provenience information.)

Archaic 3 period, and propose a date of $2150-1750 \mathrm{cal}$ B.P. (200 B.C. to A.D. 200) for the type. Although the overall form of Ensor points is similar to that of Marcos, Ensors are commonly side notched (versus corner notched) and have straight to convex bases. The side notching, in particular, is a key trait that can help distinguish between fragmented specimens. Unfortunately, one specimen (Object ID 002.315) was recovered from the backdirt of Trench 15 , and so its precise provenience is not known. This nearly complete specimen was made on a pale, buff-colored chert and measures $4.3 \mathrm{~cm}(\mathrm{~L})$ by $2.2 \mathrm{~cm}(\mathrm{~W})$ by $6 \mathrm{~mm}$ (Th).

The second specimen is represented only by the base (FS 176; Object ID 002.069); the stem has broken in a snap break, perhaps from impact, at the neck. This specimen was made on what appears to be the same pale gray chert as the Marcos points. Because 
this specimen is so incomplete, no measurements are recorded. This specimen was recovered from approximately $90 \mathrm{~cm}$ lower than Marcos point (FS 371), and so would seem to be out of stratigraphic order. However, careful inspection of the trench wall shows what appears to be some disturbance in the strata boundaries at this part of BT 15 (see Figure 6-11). Artifacts and bits of mussel shell extend downward through otherwise sterile (or nearly sterile) deposits, and the base of this Ensor point was recovered from at the bottom of this intrusion. We suggest that this artifact may have been redeposited in this location as the result of some cultural process that resulted in an intrusion into lower, intact deposits. Perhaps it was the excavation and backfilling of TxDOT BT 11 that caused the disturbance and displaced the Ensor. As can be seen on the profile in Figure 6-11, clear evidence of disturbance related to BT 11 was noted near the top of BT 15 immediately above the location of the Ensor. Available radiocarbon dates indicate the presence of Ensor-period deposits and cultural features at the site (e.g., Feature 21), so it is likely this point is associated with those deposits.

Lange Point. This point (Object ID 002.137; see Figure 11-3, e) was provisionally identified as a Bulverde following the testing of the site (Weinstein et al. 2012). The point was recovered from near the floor of Trench 15, about a meter below the surface (Weinstein et al. 2012:56). This specimen has a short, expanding stem with a broad blade and prominent barbed shoulders. However, the stem lacks the wedge-like cross-section and contracting attributes that typify most Bulverde specimens (Turner et al. 2011:67). This specimen more closely resembles the Lange type, although these points have much internal variation. Lange points are not well dated but have been placed at ca. 850-600 B.C. (2800-2550 cal B.P.) (Taylor and Highley 1995), pre-dating Marcos points. However, two features in Trench 15, Features 19 and 20, returned dates of 2760-2620 cal B.P. (810670 B.C.) and 2740-2500 cal B.P. (790-550 B.C.), respectively (Weinstein et al. 2012:Figure 6-11). A mussel shell from Feature 19 was also dated to about 3000-2855 cal BP (see Chapter 10). This date seems too old for Lange, but may be affected by carbon reservoir issues. Features 19 and 20 are interpreted as parts of the same earth oven feature, and dates for this context indicate the presence of a Lange-age component in Trench 15. This specimen has a convex triangular blade with asymmetric barbed shoulders and a short, expanding stem. It measures $4.9 \mathrm{~cm}$ (L) by $3.3 \mathrm{~cm} \mathrm{(W)} \mathrm{by} 7 \mathrm{~mm}$ (Th) and was made on a light buff-gray colored chert.
Untyped Point. The untyped point is a medial section (FS 50; Object ID 076.01); the stem and tip are missing as a result of impact as evidence from bend fractures (see Figure 11-3, f; see Table 11-3). The blade is proportionally long and slender, and has recurved margins that are serrated. Light barbs are slightly out-flaring, and the thin blade has a distinct twist or bevel. It was made on a light brown-gray chert with small white, circular inclusions, and measures $4.6 \mathrm{~cm}$ (L) by $2.7 \mathrm{~cm}$ (W) by $5 \mathrm{~mm}$ (Th). However, because this specimen is broken, none of these dimensions is complete. Without characteristic stem attributes, this specimen cannot be identified to type.

Perdiz Points. Two Perdiz arrow points were recovered, both associated with Trench 19 in the northern part of the site. Both specimens have long contracting stems and flaring barbed shoulders (see Figure 11-3, g-h). One specimen (Object ID 011.32) is missing one shoulder and has a pointed stem base. This artifact was recovered from the backdirt pile of Trench 19. The other specimen (Object ID 011.23) is missing its distal tip and has a rounded stem base. This artifact was recovered in situ from the wall of the same trench. Both have unifacial blades with bifacially flaked stems; this trait is common to the type. Object ID 011.32 measures $3.9 \mathrm{~cm}$ (L) by $1.5 \mathrm{~cm}$ (W) by $3 \mathrm{~mm}(\mathrm{Th})$. The width dimension is incomplete. Object ID 011.23 measures $2.9 \mathrm{~cm}$ (L) by $2.1 \mathrm{~cm}$ (W) by $2 \mathrm{~mm}$ (Th); the length dimension is incomplete for these measurements. The points are almost certainly part of the site's Toyah occupation.

Dart Point Tip. This specimen (Object ID 039.03) is the distal end of a dart point (see Figure $11-3, i$ ). With only the tip present, it cannot be typed. The break is a snap fracture, and may represent an impact. No other information is available, and no measurements are recorded because of its incomplete nature.

\section{Debitage}

The debitage recovered from 41HM61 was analyzed using the approach outlined in the Debitage portion of TxDOT's LP. The LP details a method of mass analysis designed to accommodate large to very large assemblages derived from sites where lithic-production activities were carried out. By design, the mass analysis system efficiently processes assemblages of large numbers of debitage in a time-efficient manner. The system focuses analytical effort on creating standardized categories of information that can be used to compare inter- as well as intra-site 
assemblages. For example, rather than recording measurements of individual pieces of debitage, the system tallies the number in each size group derived from size-grading the assemblage through nested screens of standard sizes. With those data, the analysis focusses on size categories and not individual pieces of debitage.

Based on the very small amount of debitage present at 41HM61, lithic production was very unlikely to have been a major activity at the site. Nevertheless, as with tools from the site, CEI followed the LP methods for this category of artifacts. Similar to the tools, the ultimate goal of the Debitage section of the LP is to contribute data from individual assemblages to an easily searchable database that can be used at some point to address larger cultural questions, such as the social organization and gender roles within the human groups that left the artifacts behind. Additionally, the LP results in data that will provide evidence to support site-specific analysis such as the stage of production occurring at the site as represented by the debitage size, presence of cortex, and platform type. Appendix D provides the resulting data from each piece of debitage collected according to TxDOT's LP.

\section{Methods}

Prior to the analysis, debitage was grouped into specific time periods. These groupings are based on the natural stratigraphy as well as the record of radiocarbon dates, and are here termed "Provenience" groups. Disturbed levels near the surface were not screened and no artifacts from these levels are included. Given the very small sample available with which to work, as well as the ephemeral nature of virtually all of the Late Archaic period deposits, this analysis focuses on two temporal groups, called "Provenience 1" and "Provenience 2." Provenience 1 includes all debitage from the Toyah component located north of the Leon River, while Provenience 2 contains all of the Archaic debitage from south of the river (see Appendix D for the exact proveniences of the items assigned to each provenience group). Clearly, Provenience 2 includes a very long time span that seemingly reduces the utility of resulting interpretations or conclusions. However, because of very small sample sizes, no meaningful statements are warranted for any individual Late Archaic occupation (e.g., Lange, Marcos, Ensor, Late Archaic 4). Grouping these periods together provides a somewhat larger sub-assemblage for interpretation. Proveniences 1 and 2 were then sorted to ascertain the minimum number of lithic nodules (MNN) required to account for the debitage.

\section{Minimum Number of Nodules and Size Grading}

MNN is derived by grouping pieces of debitage that appear to have come from the same nodule. Using attributes that can be recognized visually and under low-power microscopy, the site collection is judged to be composed entirely of chert or visually similar microfibrous and/or cryptocrystalline quartz materials. Similarities in color, cortex, texture, and inclusions were used to judge if the debitage derived from the same nodule. Because the goal was to determine a "minimum" number, the analyst judged that if any two attributes matched and no other attributes clearly conflicted, the pieces were considered to be from the same nodule.

Each potential nodule was assigned a letter designation. Each piece of debitage from the same nodule was then size-graded by sorting through stacked screens of one inch, three-quarters inch, half inch, and one-quarter inch mesh. Due to the exceedingly small sample size, those few pieces of debitage that fell through the quarter-inch mesh were included in that size category. Thus, items listed as one-quarter inch actually include both items captured by that screen and items less than a quarter inch in size. These four groups were then subdivided into thermal-alteration categories based on presence or absence of a waxy luster, iron oxidation causing a reddish tinge, crazing and/or other indicators of heat exposure. Next, the percentage of cortex on the dorsal face was estimated for each piece and the assemblage was divided again into groups according to five categories as described in the LP. The first category included pieces having no cortex, the second category contained one to 25 percent cortex, the third category exhibited 26 to 50 percent cortex, and the final two categories included those with 51 to 75 and 76 to 100 percent cortex. Finally, the groups already divided by nodule, size, thermal alteration, and cortex were separated according to platform type and each resulting group was weighed.

\section{Raw Material}

The vast majority of the debitage pieces exhibit colors and textures that are consistent with Edwards chert. One group of opaque gray chert, deriving its color from iron depletion, was distinct from the majority of items that were colored by oxidized iron and exhibited various reds, browns, and creams. However, 
the grays and the other colors are almost all typical of Edwards chert. One opaque, fossiliferous, dark reddish brown flake (Object ID 122.04) plus a modified flake from the same context (FS 29) were not consistent with typical Edwards chert but could not be assigned to a known chert type. The cortex on all of the pieces was relatively thick and white with a brown surface, consistent with nodules typically found on or near the surface of the Edwards Plateau and eroded from that formation.

\section{Platforms}

The LP also provides definitions and descriptions for platforms as Cortical, Flat (single facet), Faceted (multiple facets), Abraded (any type that has been ground or smoothed), Complex, Rejuvenated, and Indeterminate platforms. Complex platforms exhibit "pressure or light percussion scars on the proximal-dorsal flake surface originating from the platform edge" that indicate considerable effort to isolate and orient the platform for a precise removal. Rejuvenated platforms are those with indications from use-wear that the flakes were removed from the edge of a tool that had already been used, such as the edge of a biface that was retouched. There were no pieces in the collection in either provenience group that met this description.

\section{Results}

All blocks, witness columns, trenches, and all levels within these excavations were included for the initial sorting of the debitage in order to obtain a total MNN without regard to provenience. A total of 164 specimens were examined to determine the total MNN. These 164 specimens originated from at least 139 different nodules. However, in the process of separating the collection into Proveniences 1 and 2 for the LP analysis, 28 pieces were eliminated from consideration because they were out of context or because of their technological attributes. Examples of the latter include seven pieces recognized as thermal spalls, two pieces identified as pebbles, and another identified as a blocky fragment of chert (Object ID 001.61) that may be debitage but its attributes were not amenable to the LP process. Following the initial screening, a total of 136 pieces (Provenience $1=39$, Provenience $2=97$ ) of debitage were included in the analysis (see Appendix D).

The total weight of debitage included in this analysis was $126.8 \mathrm{~g}$ (Provenience $1=32.2 \mathrm{~g}$, Provenience $2=93.7 \mathrm{~g}$ ). The average weight per piece of debitage for Provenience 1 was $.85 \mathrm{~g}$ and for Provenience 2 it was $.97 \mathrm{~g}$. In provenience 2 there is a single flake weighing $21.2 \mathrm{~g}$. When that outlier is removed the average weight for Provenience 2 is $.78 \mathrm{~g}$. Interestingly, every piece of flaking debris that was large enough to assess its attributes, as well as the previously mentioned pieces not included in the analysis, appeared to have been heated either as part of a process of heat treatment or other intentional or incidental exposure to high heat. Even primary flakes and other pieces with significant amounts of cortex on the dorsal face exhibited signs of heat alteration.

Based on the size groupings and various amounts of cortex remaining on the specimens, different stages of core or cobble reduction appear to be represented. For example, there were 47 pieces (35 percent of Proveniences 1 and 2) from the one-quarter-inch screen group, with the bulk of these most likely representing bifacial edge retouch or fine biface thinning. However, there were 36 pieces ( 27 percent of Proveniences 1 and 2) from the 1 -inch screen and these are likely from early- to middle-stage reduction. Thirty-two pieces (23 percent of Proveniences 1 and 2) exhibited some amount of cortex. The majority of these $(n=25)$ are from the .75- and 1-inch screens and are likely associated with early-stage reduction. Comparing Proveniences 1 and 2 shows only a few minor distinctions between the groups.

Within Provenience 1, the MNN came to 31. There were ten pieces from the one-inch screen, six from the three-quarters-inch screen, six from the halfinch screen, and 17 from the quarter-inch screen, totaling 39 (see Appendix D). A total of 19 pieces were complete or essentially complete and about the same number $(n=20)$ were broken. Of those twenty broken pieces, eight (40 percent) were missing the platform. Seven pieces exhibited cortex on the ventral face, including one covering greater than 50 percent, thus suggesting early-stage reduction. As expected in a debitage collection, most of the Provenience 1 specimens, 32 pieces ( 82 percent), exhibit no cortex at all (see Appendix D). Table 11-4 shows the number of platforms by category.

In Provenience 2, the MNN is 80 . There was a total of 97 pieces weighing a total of $93.7 \mathrm{~g}$ (see Appendix D). Included in the Provenience 2 debitage is a primary flake weighing $21.8 \mathrm{~g}$. Twenty-six pieces were recovered from the one-inch screen, 24 from the .75-inch screen, 19 from the .5 -inch screen, and 30 were collected from the .25 -inch screen (some of these passed through this screen). Similar to Provenience 
Table 11-4. Provenience 1 Platforms by Category.

\begin{tabular}{|l|c|c|}
\hline \multicolumn{1}{|c|}{ Category } & $f$ & $\%$ \\
\hline Flat-Single Facet (FLT) & 7 & $18 \%$ \\
\hline Faceted Multiple Facets (FAC) & 9 & $23 \%$ \\
\hline Cortex (CRT) & 5 & $13 \%$ \\
\hline Complex (CPX) & 1 & $3 \%$ \\
\hline Abraded (ABR) & 5 & $13 \%$ \\
\hline Missing (MSG) & 8 & $20 \%$ \\
\hline Indeterminate (IND) & 4 & $10 \%$ \\
\hline Total & 39 & $100 \%$ \\
\hline
\end{tabular}

1 , about half of the pieces were broken and were not classifiable under the LP methods (see Appendix D). Forty-seven pieces were complete or essentially complete and 50 were broken. This is a similar ratio to Provenience 1. Twenty-six of the 50 pieces ( 52 percent of pieces classified as broken) were missing the platform. Also, similar to Provenience 1, most pieces (73 or 75 percent of Provenience 1), exhibited no cortex. Ten pieces (10 percent) exhibited more than 50 percent cortex on the dorsal face and 14 (14 percent) exhibited cortex covering less than 50 percent (see Appendix D). Twelve pieces had cortical platforms, 16 (16 percent) exhibited a simple, single facet platform, eleven were multi-faceted, seven were abraded, and nine were complex (Table 11-5). Two platforms (Object ID 007.005 and .086.37) were successful flakestack removals. The platforms were stacks of hinge flake scars and were categorized as indeterminate for lack of a more appropriate group. The platforms of twelve additional pieces (12 percent) were also categorized as indeterminate for various reasons including crushing and minor post-depositional damage.

The average weight per piece of the two provenience groups is strikingly similar at $.85 \mathrm{~g}$ for Provenience 1 and an adjusted $.78 \mathrm{~g}$ for Provenience 2 (.97 $\mathrm{g}$ before the adjustment). The roughly equal proportions of broken and complete pieces in each provenience group suggest that both groups have been subject to similar preservation conditions (see Appendix D). Similar average weights per piece for the two provenience groups suggests that these data do not represent evidence of change between the two time periods. The percentage of pieces exhibiting cortex in each group is close at 18 percent for Provenience 1 and 25 percent in Provenience 2. A few flake types

are better represented, as a percentage of the group, in one provenience than the other. Similar percentages of single-facet and cortex platforms occur in each group. In the Provenience 1 group, multifaceted and abraded platforms represent a larger percentage of the total than in Provenience 2. The Provenience 2 group has a higher percentage of complex platforms. A total of three pairs of debitage pieces resulted from the LP analysis process. Each of the three pairs shared Object ID numbers and were from Provenience 1. In one of the pairs (Object ID 024.03) both items were missing their platforms and a second pair (Object ID 141.22) consisted of two flakes less than .25 inches in shortest dimension that had indeterminate platforms. The third pair (Object ID 01.122) was the only complete pair. That pair came from Block 1, Unit N601E597, Stratum 4, Level B (see Appendix D). Although a few minor differences exist between the provenience groups, the small sample size makes these observations only anecdotal. However, once these data are included in the larger TxDOT database, they will help to address larger cultural questions.

\section{Conclusions}

The debitage collection was divided into two provenience groups. Provenience 1 represents all debitage found in the Toyah cultural deposits. The remaining part of the collection, Provenience 2, was from Late Archaic contexts. Although the time frame represented by Provenience 2 is much, much longer than Provenience 1, comparisons of the two groups represent a real contrast in chronological affiliations. Although every attempt was made to follow the LP as closely as possible, processing the collection follow-

Table 11-5. Provenience 2 Platforms by Category.

\begin{tabular}{|l|r|c|}
\hline \multicolumn{1}{|c|}{ Category } & $\boldsymbol{f}$ & $\boldsymbol{\%}$ \\
\hline Flat-Single Facet (FLT) & 16 & $16 \%$ \\
\hline Faceted Multiple Facets (FAC) & 11 & $11 \%$ \\
\hline Cortex (CRT) & 12 & $12 \%$ \\
\hline Complex (CPX) & 9 & $9 \%$ \\
\hline Abraded (ABR) & 7 & $7 \%$ \\
\hline Missing (MSG) & 29 & $30 \%$ \\
\hline Indeterminate (IND) & 13 & $13 \%$ \\
\hline Total & 97 & $98 \%$ \\
\hline
\end{tabular}


ing the LP resulted in only three groups of two flakes each that were likely to have come from the same nodule, as they were similar in size, cortex coverage, and platform. As discussed above, two of these three pairs are not useful as analytical data. The final groups of similar pieces, or lack thereof, are not thought to be amenable to statistical analysis. Specific to 41HM61, the small sample of Provenience 2 spread over multiple occupations that cover over a thousand years only allows for general observations regarding tool production and/or maintenance at the site, plus some casual comparisons between the Late Archaic and Late Prehistoric periods.

The condition of the flakes, both complete verses broken, plus the absence of water wear, suggest relatively rapid burial of both provenience groups. Percussion flaking is evidenced by obvious percussion bulbs and pronounced ripples. These contrast with pressure retouch and fine biface-thinning flakes that exhibit much less pronounced bulbs, if any. Both types of flaking are represented in both proveniences. Biface thinning and retouch are clearly indicated in both proveniences, but primary and other flakes with partial cortex suggest some early-stage reduction was also pursued, again in both Provenience groups. However, no flake cores or failed biface-reduction stages are present to corroborate debitage data concerning the working of nodules at the site. The relatively even count of early-, middle-, and late-stage reduction debitage, as represented by size distribution and amount of cortex, suggests the site was not used as a quarry or retooling locale. Based on the debitage data, lithic strategies focusing on tool refurbishment are postulated for 41HM61. No remarkable differences between the two proveniences were evident. 


\title{
Chapter 12
}

\section{Plant Remains}

\author{
Leslie L. Bush
}

Twenty-five flotation samples, three botanical lots, and a single piece of charcoal from site 41HM61 were submitted for analysis. The flotation samples represent 101.25 cubic decimeters ("liters") of fill from selected features or excavation levels. The site is multi-component with many recurring visitations starting at least by the end of the Middle Archaic. The majority of components included in this analysis date to different periods of the Late Archaic and to the Late Prehistoric Toyah horizon.

\section{Environment and Preservation}

As noted in Chapter 2, site 41HM61 is located north of Hamilton, Texas, near the northwestern edge of the Lampasas Cut Plain, a vegetation area grouped variously with the Edwards Plateau (Riskind and Diamond 1988) or the Cross Timbers (Diggs et al. 1999; Gould 1962). Because of its location and topographic diversity, the vegetation in the Lampasas Cut Plain is variable, resembling that on the Edwards Plateau, the Blackland Prairie, or the Cross Timbers. In northwestern Hamilton County, the resemblance is more to the Cross Timbers where a mosaic of grasslands and woodlands would have characterized the upland vegetation in pre-Columbian times. Native grasslands in Hamilton County tend toward mixed prairie, with tall, medium, and short grasses present. Upland tree species consist primarily of oaks, especially post oak (Quercus stellata) and Plateau live oak (Quercus fusiformis). Ashe juniper (Juniperus ashei) and honey mesquite (Prosopis glandulosa) are more common now than they were in the past (Diggs et al. 1999). Riparian vegetation near the Leon River would have been significantly different, however, characterized by species that thrive in moist, disturbed environments. Typical riparian trees of central Texas are willows (Salix spp.), cottonwood (Populus deltoides), and sycamore (Platanus occidentalis), with buttonbush (Cephalanthus occidentalis) situated nearest the river channels and oaks (Quercus spp.), pecan (Carya illoinensis), hackberry (Celtis spp.), elms (Ulmus spp.), and ashes (Fraxinus spp.) located on the higher floodplains and terraces.

\section{Methods}

Flotation samples from site 41HM61 were processed at CEI's laboratory in Corpus Christi, Texas, in a machine with 1/16-inch (1.6-mm) heavy-fraction mesh. Carbonized material was removed from the heavy fractions and sent to Macrobotanical Analysis along with the flotation light fractions.

Flotation samples were sorted according to standard procedures at the Macrobotanical Analysis laboratory in Manchaca, Texas (Pearsall 2000). Heavyand light-fraction materials were combined prior to size-sorting through a stack of graduated geologic mesh for ease of identification. Materials that did not pass through the No. 10 mesh (2-mm square openings) were completely sorted under a Micros stereozoom microscope at 7 to $45 \mathrm{x}$, and all carbonized botanical remains were counted, weighed, recorded, and labeled. Weights were measured on an Ohaus Scout II 200 x 0.01 g electronic balance. Uncarbonized botanical materials that did not pass through the 2-mm mesh (rootlets, soil clumps, and 
gastropods) were weighed, recorded, and labeled as "contamination." Materials that fell through the 2-mm mesh ("residue") were examined for carbonized botanical remains not previously identified in the larger size fraction. Carbonized botanical material from the residue not previously identified in the larger size fraction was counted, weighed, recorded, and labeled. Uncarbonized macrobotanical remains (other than rootlets) in the flotation light fractions were recorded on a presence/absence basis on laboratory forms. Uncarbonized plant material removed from the heavy fractions and submitted for analysis under individual item numbers was counted, weighed, recorded, and labeled in the same manner as carbonized material.

The three botanical lots were sorted on freshly washed glassware, handled only with latex gloves or metal forceps, and contact with paper was avoided. Writing instruments used in data entry were plastic mechanical pencils. Botanical lots were sieved through a No. 10 mesh. Soil clumps and wood charcoal larger than $2 \mathrm{~mm}$ were separated by hand. Material that fell through the mesh was scanned for plant parts other than material that was also present in the larger size fraction. After examination, the residue was weighed, recorded, and labeled.

Identification was attempted for twenty arbitrarily selected wood charcoal specimens lager than $2 \mathrm{~mm}$ from each sample. When fewer than 20 fragments larger than $2 \mathrm{~mm}$ were present, identification was attempted for progressively smaller fragments taken from the residue until identification became impractical or until 20 fragments were identified. Wood charcoal fragments were snapped to reveal a transverse section and examined under a stereoscopic microscope at 28 to $180 \mathrm{x}$ magnification. When necessary, tangential or radial sections were examined for ray seriation, presence of spiral thickenings, types and sizes of intervessel pitting, and other minute characteristics that can only be seen at the higher magnifications of this range.

Botanical materials were identified to the lowest possible taxonomic level by comparison to materials in the Macrobotanical Analysis comparative collection and through the use of standard reference works (e.g., Core et al. 1979; Davis 1993; Hoadley 1990; InsideWood 2004-onwards; Martin and Barkley 1961; Panshin and de Zeeuw 1980; Wheeler 2011). Plant nomenclature follows the PLANTS database (NRCS 2014)

\section{Results}

Identifications of material from the 41HM61 samples are given by component, as shown in Table 12-1, with subsequent Tables 12-2 through 12-9 providing detailed information on the counts and weights for each component. This includes a single piece of charcoal recovered via 1/4-inch screen from the Late Archaic 2, Marcos-age component (reported below with Sample 21 in Tables 12-4 and 12-5). The specimen appears to have broken in transit, but it is probably a plum or cherry pit.

Uncarbonized plants, other than rootlets, are listed in Table 12-10. As discussed below, these are interpreted as modern. Two of the three botanical lots contained no charcoal and are included only in Table 12-10. Bone and lithic materials present in the samples are listed in Table 12-11. Additional faunal material was encountered in most samples in the form of gastropods and the occasional mussel shell fragment.

\section{Modern Seed Rain}

Uncarbonized pecan nutshell and six taxa of uncarbonized seeds and an unknown (non-native?) uncarbonized fruit were recovered in the samples (see Table 12-10). Four of the five known seeds belong to annual, herbaceous taxa and are interpreted here as modern seed rain. The tougher pecan nutshell and hackberry seeds, however, may represent ancient plants. Hackberry seeds, with their high mineral content, survive well in the soil and frequently appear in geological deposits in North America (Wang et al. 1997). Hackberry family wood and pecan nutshell were found among the carbonized remains on the site, so the trees were present in the site area during ancient times. As noted above, however, they are also present in modern times. In the interest of caution, the uncarbonized pecan nutshell and hackberry seeds are interpreted with the other uncarbonized plants as modern. In any event, conditions at the site seem to have provided a favorable environment for pecans and hackberries in both ancient and modern times.

\section{Late Archaic 2, Lange Component}

The Lange component was represented by seven samples from two features totaling 27.75 cubic decimeters of fill (see Tables 12-2 and 12-3). The sample from the Feature 19 shell deposit produced no carbonized plants. The six samples from the underlying Feature 20 FCR layer produced wood charcoal and 
Table 12-1. Index of Tables of Archaeological Plant Remains from Site 41HM61 by Component.

\begin{tabular}{|c|c|c|}
\hline Component(s) & Flora by Count & Flora by Weight \\
\hline Lange & Table 12-2 & Table 12-3 \\
\hline Marcos & Table 12-4 12-5 \\
\hline $\begin{array}{c}\text { Toyah } \\
\text { Samples and Samples of Indeterminable } \\
\text { Components }\end{array}$ & Table 12-6 & Table 12-7 \\
\hline
\end{tabular}

Table 12-2. Archaeological Plant Remains from the Lange Component at 41 HM61 by Number of Fragments.

\begin{tabular}{|c|c|c|c|c|c|c|c|c|}
\hline Feature \# & 19 & 20 & 20 & 20 & 20 & 20 & 20 & \multirow{2}{*}{$\begin{array}{c}\text { Componen } \\
\text { Totals }\end{array}$} \\
\hline Sample \# & 14 & 2 & 3 & 4 & 5 & 6 & 15 & \\
\hline Liters & 8.5 & 4 & 5 & 0.25 & 0.5 & 2 & 7.5 & 27.75 \\
\hline \multicolumn{9}{|l|}{ Nutshell } \\
\hline Acorn (Quercus sp.) & - & - & - & - & - & - & 1 & 1 \\
\hline \multicolumn{9}{|l|}{ Wood } \\
\hline Hickory/pecan (Carya sp.) & - & - & 1 & - & - & - & - & 1 \\
\hline Legume family (Fabaceae) & - & - & - & - & - & 4 & - & 4 \\
\hline Mulberry (Morus sp.) & - & - & - & - & - & - & 8 & 8 \\
\hline Oak (Quercus sp.) & - & 1 & - & - & - & - & - & 1 \\
\hline Elm/hackberry family (Ulmaceae) & - & 2 & - & 4 & - & - & - & 6 \\
\hline Elm (Ulmus sp.) & - & - & 1 & - & - & - & 2 & 3 \\
\hline Hardwood, indeterminable & - & 6 & 5 & 1 & 4 & 3 & 3 & 22 \\
\hline Botanical, indeterminable & - & - & 1 & - & - & - & - & 1 \\
\hline
\end{tabular}


Table 12-3. Archaeological Plant Remains from the Lange Component at $41 \mathrm{HM} 61$ by Weight (g).

\begin{tabular}{|c|c|c|c|c|c|c|c|c|}
\hline Feature \# & 19 & 20 & 20 & 20 & 20 & 20 & 20 & \multirow{2}{*}{$\begin{array}{l}\text { Component } \\
\text { Totals }\end{array}$} \\
\hline Sample \# & 14 & 2 & 3 & 4 & 5 & 6 & 15 & \\
\hline Liters & 8.5 & 4 & 5 & 0.25 & 0.5 & 2 & 7.5 & 27.75 \\
\hline \multicolumn{9}{|l|}{ Nutshell } \\
\hline Acorn (Quercus sp.) & - & - & - & - & - & - & 0.01 & 0.01 \\
\hline \multicolumn{9}{|l|}{ Wood } \\
\hline Hickory/pecan (Carya sp.) & - & - & 0.01 & - & - & - & - & 0.01 \\
\hline Legume family (Fabaceae) & - & - & - & - & - & 0.02 & - & 0.02 \\
\hline Mulberry (Morus sp.) & - & - & - & - & - & - & 0.02 & 0.02 \\
\hline Oak (Quercus sp.) & - & 0.01 & - & - & - & - & - & 0.01 \\
\hline Elm/hackberry family (Ulmaceae) & - & 0.01 & - & 0.01 & - & - & - & 0.02 \\
\hline Elm (Ulmus sp.) & - & - & 0.01 & - & - & - & 0.01 & 0.02 \\
\hline Hardwood, indeterminable & - & 0.01 & 0.01 & 0.01 & 0.01 & 0.02 & 0.01 & 0.07 \\
\hline Botanical, indeterminable & - & - & 0.01 & - & - & - & - & 0.01 \\
\hline Residue $<2 \mathrm{~mm}$ & 1.2 & 0.19 & 0.23 & 0.03 & 0.05 & 0.16 & 0.18 & 1.86 \\
\hline Contamination $>2 \mathrm{~mm}$ & 0.97 & 0.07 & 0.04 & - & 0.05 & 0.25 & 0.09 & 1.47 \\
\hline
\end{tabular}

Table 12-4. Archaeological Plant Remains from the Marcos Component at 41HM61 by Number of Fragments.

\begin{tabular}{|c|c|c|c|c|c|c|}
\hline Feature \# & - & - & - & -- & - & \multirow{2}{*}{$\begin{array}{l}\text { Component } \\
\text { Totals }\end{array}$} \\
\hline Sample \# & 21 & 22 & 23 & 24 & 25 & \\
\hline Liters & 2.5 & 1.5 & 2 & 1 & 6.5 & 13.5 \\
\hline \multicolumn{7}{|l|}{ Seed } \\
\hline Indeterminable & $12^{*}$ & - & - & - & - & 12 \\
\hline \multicolumn{7}{|l|}{ Wood } \\
\hline Hardwood, indeterminable & 10 & - & 5 & 6 & - & 21 \\
\hline Botanical, indeterminable & & 1 & 1 & - & - & 2 \\
\hline
\end{tabular}

* Seedcoat fragments, probably plum/cherry (Prunus sp.) are not from flotation.

Note: Sample 28 (Non-flotation sample, Marcos component) contained no carbonized plant remains. 
Table 12-5. Archaeological Plant Remains from the Marcos Component at 41HM61 by Weight (g).

\begin{tabular}{|l|c|c|c|c|c|c|}
\hline \multicolumn{1}{|c|}{ Feature \# } & -- & -- & - & - & - & $\begin{array}{c}\text { Component } \\
\text { Totals }\end{array}$ \\
\hline \multicolumn{1}{|c|}{ Sample \# } & 21 & 22 & 23 & 24 & 25 & 13.5 \\
\hline \multicolumn{1}{|c|}{ Liters } & 2.5 & 1.5 & 2 & 1 & 6.5 & \\
\hline Seed & & & & & & \\
\hline Indeterminable & $0.01^{*}$ & - & - & - & - & 0.01 \\
\hline Wood & & & & & & \\
\hline Hardwood, indeterminable & 0.01 & - & 0.01 & 0.01 & - & 0.03 \\
\hline Botanical, indeterminable & - & 0.01 & 0.01 & - & - & 0.02 \\
\hline Residue $<2$ mm & 0.16 & 0.5 & 0.13 & 0.87 & 0.1 & 1.94 \\
\hline Contamination $>2 \mathrm{~mm}$ & 0.83 & 0.09 & - & - & 0.36 & 1.36 \\
\hline
\end{tabular}

* Seedcoat fragments, probably plum/cherry (Prunus sp.) are not from flotation.

Note: Sample 28 (Non-flotation sample, Marcos component) contained no carbonized plant remains.

\begin{tabular}{|c|c|c|c|c|c|c|c|c|c|c|c|c|}
\hline Feature \# & 29 & 29 & 29 & 29 & 30 & 30 & 30 & 31 & - & - & - & \\
\hline Sample \# & 11 & 12 & 13 & Total & 8 & 9 & Total & 10 & 18 & 19 & 20 & Totals \\
\hline Liters & 2 & 2 & 1.5 & 5.5 & 1 & 3.5 & 4.5 & 34 & 2.5 & 1 & 1 & 48.5 \\
\hline \multicolumn{13}{|l|}{ Nutshell } \\
\hline Pecan (Carya illinoinensis) & - & 2 & & 2 & - & - & - & 1 & - & & & 3 \\
\hline Hickory/walnut family (Juglandaceae) & 2 & 12 & 1 & 15 & - & - & - & - & - & - & & 15 \\
\hline Acorn (Quercus sp.) & - & - & - & - & & & & 1 & & - & - & 1 \\
\hline \multicolumn{13}{|l|}{ Seeds } \\
\hline Daisy family (Asteraceae) & - & & & - & 1 & - & 1 & - & - & - & & 1 \\
\hline 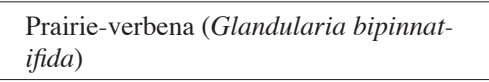 & - & - & - & - & 1 & - & 1 & - & - & - & - & 1 \\
\hline Indterminable & & & & - & - & - & - & 4 & - & & & 4 \\
\hline Grape (Vitis sp.) & & & & - & & 1 & 1 & - & & & & 1 \\
\hline cf. Corn kernel (Zea mays) & - & & & - & - & - & - & 1 & - & - & & 1 \\
\hline \multicolumn{13}{|l|}{ Other } \\
\hline Indian Breadroot tuber (Pediomelum sp.) & & & & - & 7 & & 7 & - & & & & 7 \\
\hline Grass stem (Poaceae) & - & & & - & - & - & - & 1 & - & - & & 1 \\
\hline Fruit, indeterminable & - & & & - & - & - & - & - & - & 1 & & 1 \\
\hline Bark & - & & & - & - & - & - & - & - & 1 & & 1 \\
\hline \multicolumn{13}{|l|}{ Wood } \\
\hline Hawthorn (Crataegus sp.) & - & & & - & - & - & - & - & - & 1 & & 1 \\
\hline Legume family (Fabaceae) & - & 1 & & 1 & - & & & - & - & - & & 1 \\
\hline Juniper (Juniperus ashei) & - & & & - & - & - & - & - & - & - & 1 & 1 \\
\hline Mulberry (Morus sp.) & & & & - & & & & - & 20 & & & 20 \\
\hline Plateau live oak (Quercus fusiformis) & & 2 & & 2 & & & & - & & & & 2 \\
\hline Oak (Quercus sp.) & 3 & 3 & & 6 & - & - & - & - & - & & 1 & 7 \\
\hline Red group oak (Quercus subg. Lobatae) & - & - & - & - & & & & - & - & 3 & & 3 \\
\hline $\begin{array}{l}\text { White group oak (Quercus subg. Quer- } \\
\text { cus) }\end{array}$ & - & 3 & 2 & 5 & - & 13 & 13 & 20 & - & - & 3 & 41 \\
\hline Hardwood, indeterminable & 3 & - & - & 3 & 1 & 5 & 6 & - & - & 2 & 2 & 13 \\
\hline Not examined for species & - & & & - & - & - & - & 979 & - & - & & 979 \\
\hline Botanical, indeterminable & 3 & 2 & 3 & 8 & - & 3 & 3 & 6 & - & - & 4 & 21 \\
\hline
\end{tabular}



Table 12-7. Archaeological Plant Remains from the Toya Component at $41 \mathrm{HM} 61$ by Weight $(\mathrm{g})$.

\begin{tabular}{|c|c|c|c|c|c|c|c|c|c|c|c|c|}
\hline Feature \# & 29 & 29 & 29 & \multirow{2}{*}{$\begin{array}{l}29 \\
\text { Total }\end{array}$} & \multirow{2}{*}{\begin{tabular}{|c|}
30 \\
8 \\
\end{tabular}} & \multirow{2}{*}{$\begin{array}{c}30 \\
9 \\
\end{array}$} & \multirow{2}{*}{$\begin{array}{c}30 \\
\text { Total }\end{array}$} & \multirow{2}{*}{$\begin{array}{c}31 \\
10\end{array}$} & \multirow{2}{*}{$\begin{array}{l}-- \\
18\end{array}$} & \multirow{2}{*}{$\begin{array}{l}-- \\
19\end{array}$} & \multirow{2}{*}{$\frac{-}{20}$} & \multirow{2}{*}{$\begin{array}{c}\text { Component } \\
\text { Totals }\end{array}$} \\
\hline Sample \# & 11 & 12 & 13 & & & & & & & & & \\
\hline Liters & 2 & 2 & 1.5 & 5.5 & 1 & 3.5 & 4.5 & 34 & 2.5 & 1 & 1 & 48.5 \\
\hline \multicolumn{13}{|l|}{ Nutshell } \\
\hline Pecan (Carya illinoinensis) & - & 0.01 & & 0.01 & & - & - & 0.01 & - & - & & 0.02 \\
\hline Hickory/walnut family (Juglandaceae) & 0.01 & 0.01 & 0.01 & 0.03 & & - & - & - & - & - & - & 0.03 \\
\hline Acorn (Quercus sp.) & - & & & - & & - & - & 0.01 & - & - & - & 0.01 \\
\hline \multicolumn{13}{|l|}{ Seed } \\
\hline Daisy family (Asteraceae) & - & - & & - & 0.01 & - & 0.01 & - & - & - & - & 0.01 \\
\hline Prairie-verbena (Glandularia bipinnatifida) & - & - & & - & 0.01 & - & 0.01 & - & - & - & - & 0.01 \\
\hline Indterminable & - & - & & - & & - & - & 0.01 & - & - & - & 0.01 \\
\hline Grape (Vitis sp.) & - & - & & - & & 0.01 & 0.01 & - & - & - & & 0.01 \\
\hline cf. Corn kernel (Zea mays) & & & & - & & - & - & 0.01 & - & - & & 0.01 \\
\hline \multicolumn{13}{|l|}{ Other } \\
\hline Indian Breadroot tuber (Pediomelum sp.) & - & & & - & 0.11 & - & 0.11 & - & - & - & & \\
\hline Grass stem (Poaceae) & - & & & - & - & - & - & 0.01 & - & - & & 0.01 \\
\hline Fruit, indeterminable & - & & & - & - & - & - & - & - & 0.12 & & 0.12 \\
\hline Bark & - & & & - & - & - & - & - & - & 0.01 & - & 0.01 \\
\hline \multicolumn{13}{|l|}{ Wood } \\
\hline Hawthorn (Crataegus sp.) & - & & & - & - & - & - & - & - & 0.01 & - & 0.01 \\
\hline Legume family (Fabaceae) & - & 0.01 & & 0.01 & - & - & - & - & - & - & - & 0.01 \\
\hline Juniper (Juniperus ashei) & - & - & & - & - & - & - & - & - & - & 0.01 & 0.01 \\
\hline Mulberry (Morus sp.) & - & - & & - & - & - & - & - & 0.16 & - & - & 0.16 \\
\hline Plateau live oak (Quercus fusiformis) & & 0.02 & & 0.02 & - & - & - & - & - & - & & 0.02 \\
\hline Oak (Quercus sp.) & 0.01 & 0.01 & & 0.02 & - & - & - & - & - & - & 0.01 & 0.03 \\
\hline Red group oak (Quercus subg. Lobatae) & - & & & - & - & - & - & - & - & 0.02 & & 0.02 \\
\hline White group oak (Quercus subg. Quercus) & - & 0.01 & 0.01 & 0.02 & - & 0.06 & 0.06 & 0.48 & - & - & 0.01 & 0.57 \\
\hline Hardwood, indeterminable & 0.01 & & & 0.01 & 0.01 & 0.02 & 0.03 & - & - & 0.01 & 0.01 & 0.06 \\
\hline Not examined for species & - & & & - & - & - & - & 10.38 & - & - & - & 10.38 \\
\hline Botanical, indeterminable & 0.01 & 0.01 & 0.01 & 0.03 & - & 0.01 & 0.01 & 0.03 & - & - & 0.01 & 0.08 \\
\hline Residue $<2 \mathrm{~mm}$ & 0.09 & 0.17 & 0.1 & 0.36 & 0.61 & 2.18 & 3.42 & 17.67 & 0.41 & 0.29 & 0.13 & 21.65 \\
\hline Contamination $>2 \mathrm{~mm}$ & 0.01 & 0.08 & 0.01 & 0.1 & 0.23 & 0.14 & 0.37 & 1.47 & - & 0.04 & 0.02 & 2.00 \\
\hline
\end{tabular}

$\overline{\text { Table 12-8. Archaeological Plant Remains from Single-Sample and Samples of Indeterminable Components at }}$ $41 \mathrm{HM} 61$ by Number of Fragments.

\begin{tabular}{|c|c|c|c|c|c|}
\hline Component & 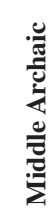 & 言 & 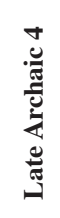 & 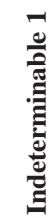 & 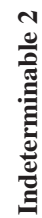 \\
\hline Feature \# & 18 & 21 & 16 & -- & 28 \\
\hline Sample \# & 16 & 7 & 1 & 26 & 17 \\
\hline Liters & 4 & 4 & 1.5 & $\mathrm{nf}$ & 2 \\
\hline \multicolumn{6}{|l|}{ Wood } \\
\hline Diffuse-porous hardwood & - & 5 & & - & - \\
\hline Possumhaw (Ilex sp.) & & 1 & - & - & \\
\hline Plateau live oak (Quercus fusiformis) & & - & - & - & 8 \\
\hline Oak (Quercus sp.) & & - & - & - & 2 \\
\hline White group oak (Quercus subg. Quercus) & & - & 10 & 13 & \\
\hline Hardwood, indeterminable & 6 & & 5 & & 8 \\
\hline
\end{tabular}

Note: Sample 27 (Non-flotation [nf] sample, Indeterminate 1 component) contained no carbonized plant remains and had no residue. 



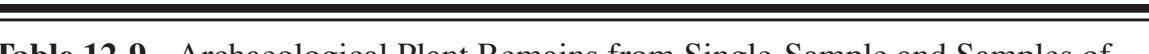
Archaeological Plant Remains from Single-Sample and Samples of
Indeterminable Components at $41 \mathrm{HM} 61$ by Number of Fragments.

\begin{tabular}{|c|c|c|c|c|c|}
\hline Component & 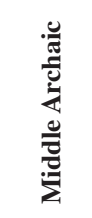 & 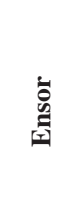 & 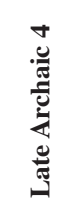 & 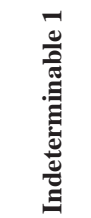 & 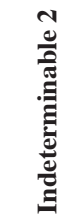 \\
\hline Feature \# & 18 & 21 & 16 & -. & 28 \\
\hline Sample \# & 16 & 7 & 1 & 26 & 17 \\
\hline Liters & 4 & 4 & 1.5 & nf & 2 \\
\hline \multicolumn{6}{|l|}{ Wood } \\
\hline Diffuse-porous hardwood & & 0.01 & & & \\
\hline Possumhaw (Ilex sp.) & & 0.01 & & & \\
\hline Plateau live oak (Quercus fusiformis) & & & & & 0.02 \\
\hline Oak (Quercus sp.) & & & & & 0.01 \\
\hline White group oak (Quercus subg. Quercus) & & & 0.06 & 0.50 & \\
\hline Hardwood, indeterminable & 0.02 & & 0.01 & & 0.01 \\
\hline Soil (with charcoal flecks) & & & & 96.09 & \\
\hline Residue $<2 \mathrm{~mm}$ & 0.75 & 0.17 & 0.18 & & 0.17 \\
\hline Contamination $>2 \mathrm{~mm}$ & 0.09 & 0.43 & 0.08 & & 0.05 \\
\hline
\end{tabular}
Note: Sample 27 (Non-flotation [nf] sample, Indeterminate 1 component) contained no carbonized plant
remains and had no residue.
Table 12-10. Uncarbonized Plant Remains from All Components at $41 \mathrm{HM} 61$ by Number with Weights in Grams in Parentheses.

\begin{tabular}{|c|c|c|c|c|c|c|c|c|c|c|}
\hline Component & 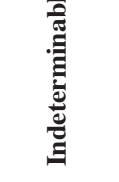 & 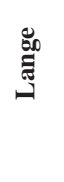 & $\begin{array}{l}\text { 品 } \\
\text { 莺 }\end{array}$ & 葛 & 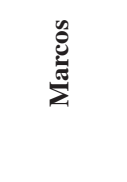 & 范 & 范 & 䭆 & 震 & 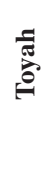 \\
\hline Feature & - & 19 & 20 & - & - & - & - & 31 & - & - \\
\hline Sample & 27 & 14 & 5 & 22 & 24 & 25 & 28 & 10 & 18 & 20 \\
\hline Liters & nf & 8.5 & 0.5 & 1.5 & 1 & 6.5 & $\mathrm{nf}$ & 34 & 2.5 & 1 \\
\hline \multicolumn{11}{|l|}{ Nutshell } \\
\hline Pecan (Carya illinoinensis) & & & & - & - & $1(0.03)$ & - & - & - & \\
\hline \multicolumn{11}{|l|}{ Seed } \\
\hline Daisy family (Asteraceae) & & $\mathrm{p}$ & - & - & & & & - & - & $\mathrm{p}$ \\
\hline Hackberry (Celtis sp.) & $6(0.01)$ & & & - & $\mathrm{p}$ & - & $25(0.17)$ & $\mathrm{p}$ & - & \\
\hline Goosefoot (Chenopodium sp.) & - & - & - & - & & & & $\mathrm{p}$ & - & - \\
\hline Grass family (Poaceae) & - & $\mathrm{p}$ & & - & - & - & - & - & - & \\
\hline Coneflower (Rudbeckia hirta) & - & - & - & - & - & - & - & $\mathrm{p}$ & - & - \\
\hline Unknown & & & $1(0.09)$ & & $1(0.08)$ & & & & $1(0.13)$ & \\
\hline \multicolumn{11}{|l|}{ Fruit } \\
\hline Unknown & & & - & - & & & & $1(0.02)$ & - & \\
\hline
\end{tabular}

$\mathrm{nf}=$ non-flotatio

$\mathrm{p}=$ present

Note: Uncarbonized seeds and fruits removed from flotation samples at Coastal Environments were counted and weighed, but those discovered at Macrobotanical Analysis were recorded only as present. 

Table 12-11. Bone and Lithics from Flotation and Botanical Samples, All Components at Site 41HM61 by Number with Weights in Grams in Parentheses.

\begin{tabular}{|c|c|c|c|c|c|c|c|}
\hline Component & 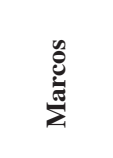 & $\begin{array}{l}\text { 茄 } \\
\text { 莺 }\end{array}$ & $\begin{array}{l}\text { 获 } \\
\text { 芯 }\end{array}$ & $\begin{array}{l}\dot{\circ} \\
\text { 亲 }\end{array}$ & 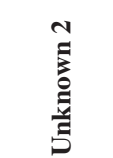 & 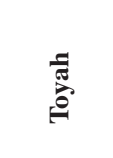 & 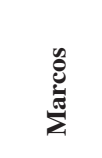 \\
\hline Feature & 16 & 20 & 20 & 21 & 28 & -- & -- \\
\hline Sample & 1 & 3 & 6 & 7 & 17 & 20 & 25 \\
\hline Liters & 1.5 & 5 & 2 & 4 & 2 & 1 & 6.5 \\
\hline Bone & $2(0.01)$ & - & - & $2(0.01)$ & $2(0.01)$ & $1(0.01)$ & - \\
\hline Tooth, burned & - & - & - & - & - & - & $1(0.01)$ \\
\hline Probable fauna, unknown & - & - & - & - & $2(0.01)$ & - & - \\
\hline Lithic & & & & & & & - \\
\hline Black pebbles & - & $3(0.06)$ & $9(0.09)$ & - & - & - & $1(0.01)$ \\
\hline
\end{tabular}

(Text continued from page 244)

acorn nutshell. A minimum of five types of wood was present: mulberry, elm, pecan, oak, and a member of the legume family such as redbud. All these trees would have been common in the site area for much of the Holocene. As fuel, different woods have different burning properties. In general, softwoods such as juniper ignite more easily than hardwoods (Collier and Turner 1981). Heat value is directly related to wood density (Marcouiller and Anderson n.d.). Coaling properties, which are especially important in earthoven cooking, relate to the third stage of the burning process. After evaporation of within-cell moisture (first stage), wood is converted to charcoal (second stage, signified by flames). In the third stage, the glowing coals burn slowly, without flame, and can be left for hours without attention (Collier and Turner 1981, Marcouiller and Anderson n.d.). Of the woods in the Lange component, oaks burn at high heat and have very hot, long-lasting coaling properties. Pecan also burns hot but produces only moderately good coals. Mulberry and elm burn at medium heat and produce good (elm) to excellent (mulberry) coals. Pecans, oaks, and mulberries produce edible fruits, one of which (acorn) is represented in the flotation samples from the Lange component. Sheets of bark from various species of elms were used to cover wigwams and, in smaller strips, for matting, ropes, and cordage (Moerman 1998).

\section{Late Archaic 2, Marcos Component}

Five flotation samples representing 13.5 cubic decimeters of soil were analyzed from the Marcos component (see Tables 12-4 and 12-5). None was from a feature context. The plant remains consisted of wood charcoal that could only be identified as some type of hardwood and a crushed botanical fragment that is probably a plum or cherry pit. The genus Prunus, which includes both plums and cherries, is important for its medicinal uses as well as its edible fruits. Medicines derived from cherry or plum bark treat a variety of complaints, especially coughs (Moerman 1998).

\section{Late Prehistoric, Toyah Component}

Nine samples from three feature and three non-feature contexts were examined from the Toyah component (see Tables 12-6 and 12-7). Toyah features examined 


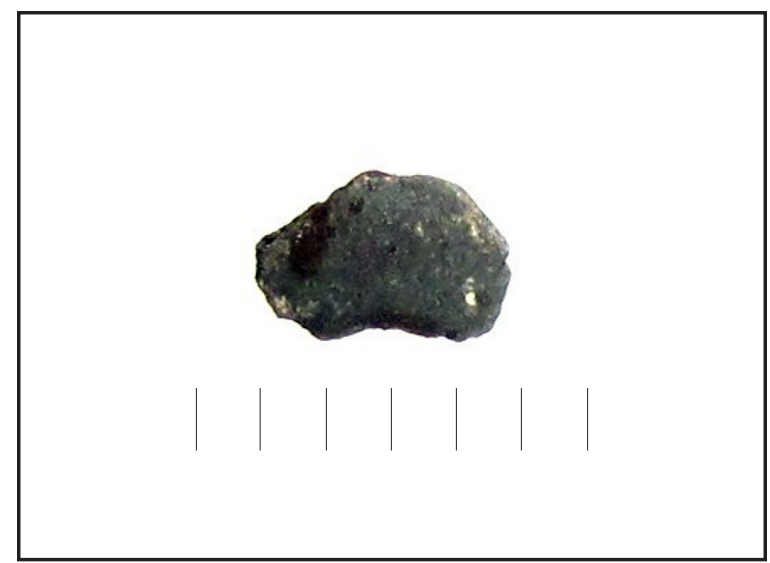

Figure 12-1. Photograph of the possible corn kernel fragment from Feature 31 at 41HM61. Scale in mm.

included F. 29, 30, and 31. Total soil volume was 48.5 $\mathrm{cu} \mathrm{dm}$. Archaeological plants in the Toyah component consisted of seeds, fruit, nutshell, bark, gall fragments, a grass stem, bark, and wood charcoal. Several of the more interesting items are discussed below.

\section{Possible Corn Kernel Fragment (Zea mays)}

One fragment of a large starchy seed was recovered from Feature 31 (Figure 12-1). The fragment is consistent with the size, shape, and texture of the upper central portion of a corn kernel just above the embryo (Figure 12-2). The surface, however, is too eroded to show the diagnostic dimpled pattern of Zea mays.

\section{Indian Breadroot}

Seven tuber fragments recovered from Feature 30 are identifiable as Indian breadroot (Pediomelum sp., formerly genus Psoralea). Indian breadroot was an important food source across the Great Plains. "Psoralea has so important a place in the economy of the Plains tribes and has had for so long a time that it enters into their mythology, folklore, stories, and sleight-of-hand tricks" (Gilmore 1991:41). The tubers can be eaten fresh, cooked or uncooked, or they can be dried and stored for future use (Moerman 1998).

\section{Seeds and Fruit}

One specimen each of grape, prairie-verbena, and daisy-family seeds were recovered from the Toyah component, along with four indeterminable seeds (three probably grasses) and an indeterminable fruit.

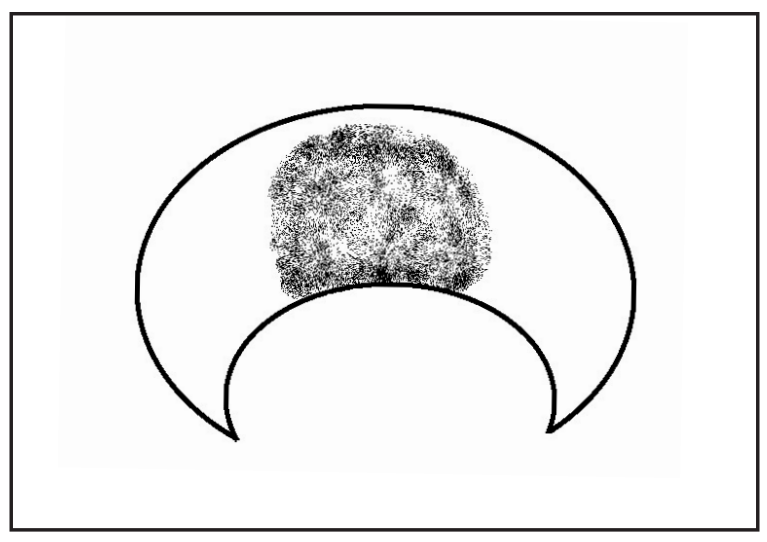

Figure 12-2. Drawing showing the location of the possible corn kernel fragment on the kernel (embryo not present) from Feature 31 at $41 \mathrm{HM} 61$.

Grapes have obvious food uses, and their vines are an important source of cordage. Daisy- and grass-family seeds are often edible as well.

\section{Nutshells}

Nutshells consisted of one acorn fragment, three pecan fragments, and fifteen nutshell fragments that are probably also pecan but were so small that they could be identified only to the botanical family Juglandaceae, which includes pecans, other hickories, and walnut. Although pecans grow throughout central Texas, pecan nutshell is not terribly common on prehistoric sites. Nutritionally, pecans are similar to hickory nuts, and both are more similar to walnut than to acorn (Table 12-12). Grant Hall (2000) points out that the nutrients in pecan and other hickories, especially linolenic fatty acids, would have been particularly important for hunter-gatherers who relied on lean meat for a portion of the year.

Traditional hickory processing methods used by the Iroquois, Choctaws, Cherokees, and many other tribes involved pounding hickory nuts into small pieces and then heating them in water, where the oil could be skimmed off, the nutmeat retrieved from suspension, and the shells allowed to sink to the bottom (Fritz et al. 2001; Moerman 1998). Experiments by archeologists show that this process yields a much larger number of calories per labor invested than does cracking and picking (Talalay et al. 1984:353). Other common nuts cannot be processed in this manner because either their meats float (acorn, hazelnut) or the nuts become bitter (walnut). These hickory-processing methods also work for pecan nuts. 
Table 12-12. Proximate Analysis of Four Edible Tree Nuts and Cornmeal per $100 \mathrm{~g}$ Dry Weight (USDA, ARS 2013).

\begin{tabular}{|l|c|c|c|c|c|}
\cline { 2 - 6 } \multicolumn{1}{c|}{} & Pecan & Hickory & Walnut & Acorn & $\begin{array}{c}\text { Yellow } \\
\text { Cornmeal }\end{array}$ \\
\hline Fat $(\mathrm{g})$ & 72 & 64 & 59 & 31 & 4 \\
\hline Protein $(\mathrm{g})$ & 9 & 13 & 24 & 8 & 8 \\
\hline Carbohydrate $(\mathrm{g})$ & 14 & 18 & 10 & 53 & 77 \\
\hline Water $(\mathrm{g})$ & 4 & 2 & 5 & 5 & 4 \\
\hline Energy (kcal) & 691 & 657 & 618 & 509 & 362 \\
\hline
\end{tabular}

In Texas today, pecans and other hickories are typically available for collection from mid-October through the first week in December (McEachern et al. 1977). In good years, harvest can begin as early as late September. The earliest possible harvest is best since it minimizes loss to foraging animals, such as squirrels.

\section{Wood Charcoal}

Identifiable wood charcoal in the Toyah component consisted of oak $(n=53)$, mulberry $(n=20)$, and one fragment each of hawthorn, legume, and juniper. The most common type of oak was the white group, probably Quercus stellata, but red and live oak groups also were represented.

\section{Components Represented by Single Samples}

Three components are represented by a single flotation sample each (see Tables 12-8 and 12-9). A sample from Feature 18 (Middle Archaic; $4 \mathrm{cu} \mathrm{dm}$ ) yielded fragments of wood charcoal identifiable only as a hardwood. The sample from Feature 21 (Late Archaic 3, Ensor Component; $4 \mathrm{cu} \mathrm{dm}$ ) contained possumhaw wood charcoal, a type that was not represented in any other context at the site. A small sample from Feature 16 (Late Archaic 4; $1.5 \mathrm{cu} \mathrm{dm}$ ) yielded wood charcoal from an oak of the white group.

\section{Samples from Indeterminable Components}

Two of the samples belonged to components that could not be associated with diagnostic artifacts or radiocarbon dates, although indeterminable 2 (F. 28) came for a cluster of mussel shells found near F. 18 at about the same depth and likely dates to the Middle Archaic (see Tables 12-8 and 12-9). One was a flota-
Table 12-13. Total Plant Weight per Cubic Decimeter of Processed Fill at Site 41HM61 by Compotent.

\begin{tabular}{|c|c|}
\hline Component & Plant Density (g/cu. dm.) \\
\hline Lange & 0.007 \\
\hline Marcos & 0.004 \\
\hline Toyah & 0.241 \\
\hline
\end{tabular}

tion sample $(2 \mathrm{cu} \mathrm{dm})$ that yielded wood charcoal from white- and live-group oaks, and one was a botanical lot that contained wood charcoal from an oak of the white group $(0.50 \mathrm{~g})$.

\section{Comparisons}

\section{Intrasite Comparison}

The main components with plant remains at site 41HM61 show an increase in plant density between the Late Archaic 2 period's Lange and Marcos occupations and the Late Prehistoric period's Toyah occupation (Table 12-13). Actual increased plant use is one possible explanation for the trend. Cooking fires would have been necessary throughout the occupation sequence, but it is possible that activities during the Toyah occupation had a special focus on cooking. The more exclusive use of oak wood during this time suggests a more deliberate selection for wood with excel- 
lent coaling qualities. Of course, a more important factor in the trend toward increased plant materials in the Toyah period may be better preservation in these relatively recent deposits.

\section{Intersite Comparison}

Plant remains in the Toyah component at site 41HM61 are similar to those in the Late Prehistoric component at the Jayroe site (41HM51), approximately ten kilometers northwest of 41HM61 and also situated on the Leon River (see Chapter 4 for a review of 41HM51). Pecan and acorn nutshell, seeds, and wood charcoal were recovered at that site. The white-oak group dominated wood charcoal recovered from
Jayroe, as it does in the Toyah component at site 41 HM61.

\section{Summary}

Plant remains from site 41HM61 consisted of wood charcoal, nutshell, seeds, fruits, a grass stem, bark, and tuber fragments. High-quality oaks dominate the wood charcoal assemblage, especially in the Toyah component, but other species such as mulberry and elm also are present. Botanical density is much greater in the Toyah component than in the site's older components, possibly due to increased plant-related activities, but more likely due to better preservation in younger deposits. Plant remains in the Toyah component include Indian breadroot tuber fragments and part of a large, starchy seed that may be corn. 


\title{
Chapter 13
}

\section{Vertebrate Faunal Remains}

\author{
Susan L. Scott
}

A small sample of vertebrate faunal remains (1,519 fragments weighing 2,212.4g) was recovered during CEI's test excavations at 41HM61. The sample is from a series of components that span the late Middle Archaic to Late Prehistoric periods. Because the overall site occupation was lengthy, the stratigraphy complex, and diagnostic artifacts sparse, it has not yet been possible to assign some of the materials recovered to a specific time period. For that reason, two additional categories, "Unknown age" and "Disturbed deposits," were assigned to accommodate this issue. The faunal remains from both identified components and the unassigned samples are included in Table 131. Listed in the table are the total number of identified specimens (NISP) and total weight (in grams) for the entire site. These same samples are included again separately in Table 13-2, which identifies species composition by temporal period. However, the unknown and disturbed samples are left out of the discussion of trends in vertebrate faunal use through time.

\section{Material and Methods}

In the field, all soil matrix was dry screened through 1/4-inch hardware cloth, and numerous flotation samples were collected, with small bone fragments subsequently recovered in nested 1/4-, 1/8-, and 1/16-inch screens. The flotation samples produced 187 identifiable fragments, allowing a glimpse of unusual, small subsistence resources not otherwise represented. Remains from all of these samples are collapsed analytically without consideration of screen size, but since the float samples produced fragments of bone weighing little, their overall economic significance is probably relatively accurately reflected in bone weight.
All of the faunal remains were identified using the comparative collection at the University of Southern Mississippi. Bones were identified to the most specific level possible given the surviving morphology of the fragment. Element, side, degree of fragmentation, portion, age, and sex were recorded for birds and mammals when possible. For fish, length was estimated by comparing the fragment to a range of specimens of different size. Vertebral diameter was recorded for fish vertebrae. Carnivore and rodent gnawing was noted, along with charring and the occasional butchering mark, or worked bone.

Preservation at the site was excellent, with no evidence of leaching, and only an occasional bone exhibiting erosion. Nineteen unique taxa were identified, although the bulk of the bone was produced by mammalian taxa, especially deer and bison. Using NISP as a measure of relative frequency, the order of contribution, from most to least is: deer and pronghorn (collectively), bison, rats and mice (collectively), and jackrabbits. The remaining taxa identified generally produced fewer than four fragments.

\section{Natural and Cultural Modification}

A few bone fragments exhibited modification. Three bison bones and a large mammal long bone exhibited minor rodent gnawing, and one male bison tibia exhibited signs of carnivore gnawing. Cut marks were observed on one large mammal long bone. Other evidence of butchering practices is apparent on a nearly complete bison patella with all of the cortical bone missing at locations of tendon attachments, producing ragged tearing rather than cut marks. Such a pattern would likely occur if lever- 
Table 13-1. Count (NISP) and Weight (g) for all Analyzed Vertebrate Fauna at 41HM61.

\begin{tabular}{|c|c|c|c|}
\hline Identification & NISP & Charred & Weight (g) \\
\hline Ud Rat/Mouse (Cricetidae) & 1 & 0 & 0.1 \\
\hline Ud Rat (Cricetidae) & 7 & 0 & 0.4 \\
\hline Ud Mouse (Cricetidae) & 2 & 0 & 0.2 \\
\hline Cotton Rat (Sigmodon hispidus) & 4 & 0 & 0.3 \\
\hline Ud Micromammal (Mammalia) & 22 & 2 & 1.3 \\
\hline Ud Small Mammal (Mammalia) & 7 & 0 & 0.6 \\
\hline Ud Rabbit (Leporidae) & 1 & 0 & 0.2 \\
\hline Jackrabbit (Lepus sp.) & 10 & 5 & 4.8 \\
\hline Beaver (Castor canadensis) & 1 & 0 & 1 \\
\hline Raccoon (Procyon lotor) & 1 & 0 & 0.1 \\
\hline Dog/Coyote (Canis sp) & 2 & 0 & 5.2 \\
\hline Ud Medium Mammal (Mammalia) & 67 & 8 & 6.4 \\
\hline Whitetail Deer (Odocoileus virginianus) & 25 & 1 & 72.6 \\
\hline Pronghorn (Antilocapra americana) & 1 & 0 & 2.4 \\
\hline Deer/Pronghorn (Odocoileus/Antilocapra) & 10 & 1 & 17.3 \\
\hline Ud Large Mammal (Mammalia) & 122 & 20 & 56.7 \\
\hline Bison (Bison bison) & 35 & 0 & $1,477.1$ \\
\hline Ud Very Large Mammal (Mammalia) & 307 & 7 & 520.1 \\
\hline Ud Sm/Med Mam/Bird (Mammalia/Aves) & 46 & 14 & 2.5 \\
\hline Ud Large Bird (Aves) & 1 & 0 & 0.1 \\
\hline Ud Medium Bird (Aves) & 3 & 1 & 0.3 \\
\hline Wild Turkey (Meleagris gallopavo) & 1 & 0 & 0.3 \\
\hline Ud Reptile (Reptilia) & 1 & 0 & 0.2 \\
\hline Mud-Musk Turtle (Kinosternidae) & 4 & 1 & 1 \\
\hline Map Turtle (Graptemys sp) & 1 & 0 & 0.1 \\
\hline Softshell Turtle (Apalone sp) & 1 & 0 & 0.6 \\
\hline Ud Turtle (Testudines) & 47 & 4 & 5.1 \\
\hline Non-viper Snake (Colubridae) & 4 & 0 & 0.4 \\
\hline Racer/Coachwhip (Coluber/Masticophis sp) & 2 & 0 & 0.2 \\
\hline King/Rat/Corn Snake (Lampropeltis/Elaphe sp) & 1 & 0 & 0.1 \\
\hline Ud Snake (Serpentes) & 5 & 0 & 0.5 \\
\hline Ud Frog/Toad (Anura) & 1 & 0 & 0.1 \\
\hline Gar (Lepisosteus sp) & 2 & 1 & 0.4 \\
\hline Minnow (Cyprinidae) & 2 & 0 & 0.2 \\
\hline Finfish (Perciformes) & 1 & 0 & 0.1 \\
\hline Ud Fish (Pisces) & 16 & 0 & 0.8 \\
\hline Total NISP (Number of Identified Specimens) & 764 & 65 & $2,179.8$ \\
\hline Ud bone & 755 & 151 & 32.6 \\
\hline TOTAL BONE & 1,519 & 216 & $2,212.4$ \\
\hline
\end{tabular}

$\mathrm{Ud}=$ unidentified 
Table 13-2. NISP, Weight (g), and MNI of Vertebrate Faunal Remains, by Time Period, from Site 41HM61.

\begin{tabular}{|c|c|c|c|}
\hline \multicolumn{4}{|c|}{ Toyah } \\
\hline Identification & NISP & Weight & MNI \\
\hline Ud Rat/Mouse & - & - & - \\
\hline Ud Rat & - & - & - \\
\hline Ud Mouse & 1 & 0.1 & 1 \\
\hline Cotton Rat & 3 & 0.2 & 1 \\
\hline Ud Micromammal & - & - & - \\
\hline Ud Small Mammal & - & - & - \\
\hline Ud Rabbit & - & - & - \\
\hline Jackrabbit & - & - & - \\
\hline Beaver & - & - & - \\
\hline Raccoon & - & - & - \\
\hline Ud Dog/Coyote & - & - & - \\
\hline Coyote & - & - & - \\
\hline Ud Medium Mammal & 5 & 0.9 & 1 \\
\hline Whitetail Deer & 12 & 31.1 & 4 \\
\hline Antelope & - & - & - \\
\hline Deer/Antelope & 4 & 1.7 & - \\
\hline Ud Large Mammal & 44 & 22.1 & - \\
\hline Bison & 17 & 540.2 & 3 \\
\hline Ud Very Lg Mammal & 126 & 233.7 & - \\
\hline Ud Sm/Med Mam/Bird & 8 & 0.4 & - \\
\hline Ud Large Bird & 1 & 0.1 & 1 \\
\hline Ud Medium Bird & 1 & 0.1 & 1 \\
\hline Wild Turkey & - & - & - \\
\hline Ud Reptile & - & - & - \\
\hline Mud-Musk Turtle & - & - & - \\
\hline Map Turtle & 1 & 0.6 & 1 \\
\hline Softshell Turtle & 1 & 0.1 & 1 \\
\hline Ud Turtle & 10 & 1.8 & - \\
\hline Non-viper Snake & - & - & - \\
\hline Racer/Coachwhip & - & - & - \\
\hline King/Rat/Corn Snake & - & - & - \\
\hline Ud Snake & 2 & 0.2 & 1 \\
\hline Ud Frog/Toad & - & - & - \\
\hline $\operatorname{Gar}(50-60 \mathrm{cmTL})$ & 2 & 0.2 & 1 \\
\hline Minnow & - & - & - \\
\hline Finfish (5-10mmSL) & 1 & 0.1 & 1 \\
\hline Ud Fish & 9 & 0.2 & - \\
\hline Total NISP & 248 & 834 & 15 \\
\hline Ud bone & 204 & 9.1 & \\
\hline TOTAL BONE & 452 & 843.1 & \\
\hline
\end{tabular}

(continued) 
Table 13-2. (continued).

\begin{tabular}{|c|c|c|c|}
\hline \multicolumn{4}{|c|}{ Late Archaic 4} \\
\hline Identification & NISP & Weight & MNI \\
\hline Ud Rat/Mouse & 1 & 0.1 & 1 \\
\hline Ud Rat & - & - & - \\
\hline Ud Mouse & - & - & - \\
\hline Cotton Rat & - & - & - \\
\hline Ud Micromammal & - & - & - \\
\hline Ud Small Mammal & - & - & - \\
\hline Ud Rabbit & - & - & - \\
\hline Jackrabbit & - & - & - \\
\hline Beaver & - & - & - \\
\hline Raccoon & - & - & - \\
\hline Ud Dog/Coyote & - & - & - \\
\hline Coyote & - & - & - \\
\hline Ud Medium Mammal & - & - & - \\
\hline Whitetail Deer & 5 & 10.9 & 1 \\
\hline Antelope & - & - & - \\
\hline Deer/Antelope & - & - & - \\
\hline Ud Large Mammal & - & - & - \\
\hline Bison & - & - & - \\
\hline Ud Very Lg Mammal & - & - & - \\
\hline Ud Sm/Med Mam/Bird & 3 & 0.1 & 1 \\
\hline Ud Large Bird & - & - & - \\
\hline Ud Medium Bird & - & - & - \\
\hline Wild Turkey & - & - & - \\
\hline Ud Reptile & - & - & - \\
\hline Mud-Musk Turtle & - & - & - \\
\hline Map Turtle & - & - & - \\
\hline Softshell Turtle & - & - & - \\
\hline Ud Turtle & - & - & - \\
\hline Non-viper Snake & 1 & 0.1 & 1 \\
\hline Racer/Coachwhip & - & - & - \\
\hline King/Rat/Corn Snake & - & - & - \\
\hline Ud Snake & 1 & 0.1 & - \\
\hline Ud Frog/Toad & - & - & - \\
\hline Gar & - & - & - \\
\hline Minnow & - & - & - \\
\hline Finfish & - & - & - \\
\hline Ud Fish & - & - & - \\
\hline Total NISP & 11 & 11.3 & 4 \\
\hline Ud bone & 15 & 0.3 & \\
\hline TOTAL BONE & 26 & 11.6 & \\
\hline
\end{tabular}

(continued) 
Table 13-2. (continued).

\begin{tabular}{|c|c|c|c|}
\hline \multicolumn{4}{|c|}{ Late Archaic 3 or 4} \\
\hline Identification & NISP & Weight & MNI \\
\hline Ud Rat/Mouse & - & - & - \\
\hline Ud Rat & - & - & - \\
\hline Ud Mouse & - & - & - \\
\hline Cotton Rat & - & - & - \\
\hline Ud Micromammal & - & - & - \\
\hline Ud Small Mammal & 1 & 0.1 & - \\
\hline Ud Rabbit & - & - & - \\
\hline Jackrabbit & 1 & 0.1 & 1 \\
\hline Beaver & - & - & - \\
\hline Raccoon & - & - & - \\
\hline Ud Dog/Coyote & - & - & - \\
\hline Coyote & - & - & - \\
\hline Ud Medium Mammal & 2 & 0.3 & - \\
\hline Whitetail Deer & - & - & - \\
\hline Antelope & - & - & - \\
\hline Deer/Antelope & - & - & - \\
\hline Ud Large Mammal & 20 & 8.6 & 1 \\
\hline Bison & - & - & - \\
\hline Ud Very Lg Mammal & 1 & 4.2 & 1 \\
\hline Ud Sm/Med Mam/Bird & 1 & 0.1 & - \\
\hline Ud Large Bird & - & - & - \\
\hline Ud Medium Bird & - & - & - \\
\hline Wild Turkey & - & - & - \\
\hline Ud Reptile & - & - & - \\
\hline Mud-Musk Turtle & - & - & - \\
\hline Map Turtle & - & - & - \\
\hline Softshell Turtle & - & - & - \\
\hline Ud Turtle & - & - & - \\
\hline Non-viper Snake & - & - & - \\
\hline Racer/Coachwhip & - & - & - \\
\hline King/Rat/Corn Snake & - & - & - \\
\hline Ud Snake & - & - & - \\
\hline Ud Frog/Toad & - & - & - \\
\hline Gar & - & - & - \\
\hline Minnow & - & - & - \\
\hline Finfish & - & - & - \\
\hline Ud Fish & 1 & 0.1 & 1 \\
\hline Total NISP & 27 & 13.5 & 4 \\
\hline Ud bone & 66 & 1.3 & \\
\hline TOTAL BONE & 93 & 14.8 & \\
\hline
\end{tabular}

(continued) 
Table 13-2. (continued).

\begin{tabular}{|c|c|c|c|}
\hline \multicolumn{4}{|c|}{ Late Archaic 3} \\
\hline Identification & NISP & Weight & MNI \\
\hline Ud Rat/Mouse & - & - & - \\
\hline Ud Rat & 1 & 0.1 & 1 \\
\hline Ud Mouse & - & - & - \\
\hline Cotton Rat & - & - & - \\
\hline Ud Micromammal & 3 & 0.2 & - \\
\hline Ud Small Mammal & 3 & 0.2 & 1 \\
\hline Ud Rabbit & - & - & - \\
\hline Jackrabbit & - & - & - \\
\hline Beaver & - & - & - \\
\hline Raccoon & 1 & 0.1 & 1 \\
\hline Ud Dog/Coyote & - & - & - \\
\hline Coyote & 1 & 1.6 & 1 \\
\hline Ud Medium Mammal & 11 & 1.2 & - \\
\hline Whitetail Deer & - & - & - \\
\hline Antelope & - & - & - \\
\hline Deer/Antelope & 3 & 5.9 & 1 \\
\hline Ud Large Mammal & 20 & 9.5 & - \\
\hline Bison & - & - & - \\
\hline Ud Very Lg Mammal & 2 & 6.2 & 1 \\
\hline Ud Sm/Med Mam/Bird & 10 & 0.7 & - \\
\hline Ud Large Bird & - & - & - \\
\hline Ud Medium Bird & 1 & 0.1 & 1 \\
\hline Wild Turkey & - & - & - \\
\hline Ud Reptile & - & - & - \\
\hline Mud-Musk Turtle & - & - & - \\
\hline Map Turtle & - & - & - \\
\hline Softshell Turtle & - & - & - \\
\hline Ud Turtle & 3 & 0.3 & 1 \\
\hline Non-viper Snake & 2 & 0.2 & - \\
\hline Racer/Coachwhip & 1 & 0.1 & 1 \\
\hline King/Rat/Corn Snake & - & - & - \\
\hline Ud Snake & - & - & - \\
\hline Ud Frog/Toad & - & - & - \\
\hline Gar & - & - & - \\
\hline Minnow & - & - & - \\
\hline Finfish & - & - & - \\
\hline Ud Fish & - & - & - \\
\hline Total NISP & 62 & 26.4 & 9 \\
\hline Ud bone & 140 & 2 & \\
\hline TOTAL BONE & 202 & 28.4 & \\
\hline
\end{tabular}

(continued) 
Table 13-2. (continued).

\begin{tabular}{|c|c|c|c|}
\hline \multicolumn{4}{|c|}{ Late Archaic 2 or 3} \\
\hline Identification & NISP & Weight & MNI \\
\hline Ud Rat/Mouse & - & - & - \\
\hline Ud Rat & 1 & 0.1 & - \\
\hline Ud Mouse & 1 & 0.1 & 1 \\
\hline Cotton Rat & 1 & 0.1 & 1 \\
\hline Ud Micromammal & - & - & - \\
\hline Ud Small Mammal & - & - & - \\
\hline Ud Rabbit & - & - & - \\
\hline Jackrabbit & - & - & - \\
\hline Beaver & - & - & - \\
\hline Raccoon & - & - & - \\
\hline Ud Dog/Coyote & - & - & - \\
\hline Coyote & - & - & - \\
\hline Ud Medium Mammal & 3 & 0.5 & 1 \\
\hline Whitetail Deer & 2 & 1.8 & 1 \\
\hline Antelope & - & - & - \\
\hline Deer/Antelope & 1 & 5.5 & - \\
\hline Ud Large Mammal & 11 & 6.6 & - \\
\hline Bison & - & - & - \\
\hline Ud Very Lg Mammal & 3 & 8.7 & 1 \\
\hline Ud Sm/Med Mam/Bird & 10 & 0.4 & - \\
\hline Ud Large Bird & - & - & - \\
\hline Ud Medium Bird & 1 & 0.1 & - \\
\hline Wild Turkey & - & - & - \\
\hline Ud Reptile & - & - & - \\
\hline Mud-Musk Turtle & 1 & 0.1 & 1 \\
\hline Map Turtle & - & - & - \\
\hline Softshell Turtle & - & - & - \\
\hline Ud Turtle & 1 & 0.2 & - \\
\hline Non-viper Snake & - & - & - \\
\hline Racer/Coachwhip & - & - & - \\
\hline King/Rat/Corn Snake & - & - & - \\
\hline Ud Snake & - & - & - \\
\hline Ud Frog/Toad & 1 & 0.1 & 1 \\
\hline Gar & - & - & - \\
\hline Minnow (0-5mmSL) & 2 & 0.2 & 1 \\
\hline Finfish & - & - & - \\
\hline Ud Fish & 3 & 0.2 & - \\
\hline Total NISP & 42 & 24.7 & 8 \\
\hline Ud bone & 74 & 1.4 & \\
\hline TOTAL BONE & 116 & 26.1 & \\
\hline
\end{tabular}

(continued) 
Table 13-2. (continued).

\begin{tabular}{|c|c|c|c|}
\hline \multicolumn{4}{|c|}{ Late Archaic 2} \\
\hline Identification & NISP & Weight & MNI \\
\hline Ud Rat/Mouse & - & - & - \\
\hline Ud Rat & - & - & - \\
\hline Ud Mouse & - & - & - \\
\hline Cotton Rat & - & - & - \\
\hline Ud Micromammal & 2 & 0.2 & 1 \\
\hline Ud Small Mammal & - & - & - \\
\hline Ud Rabbit & - & - & - \\
\hline Jackrabbit & 1 & 0.5 & 1 \\
\hline Beaver & - & - & - \\
\hline Raccoon & - & - & - \\
\hline Ud Dog/Coyote & - & - & - \\
\hline Coyote & - & - & - \\
\hline Ud Medium Mammal & - & - & - \\
\hline Whitetail Deer & - & - & - \\
\hline Antelope & - & - & - \\
\hline Deer/Antelope & 1 & 0.8 & 1 \\
\hline Ud Large Mammal & 8 & 0.9 & - \\
\hline Bison & - & - & - \\
\hline Ud Very Lg Mammal & - & - & - \\
\hline Ud Sm/Med Mam/Bird & - & - & - \\
\hline Ud Large Bird & - & - & - \\
\hline Ud Medium Bird & - & - & - \\
\hline Wild Turkey & - & - & - \\
\hline Ud Reptile & - & - & - \\
\hline Mud-Musk Turtle & - & - & - \\
\hline Map Turtle & - & - & - \\
\hline Softshell Turtle & - & - & - \\
\hline Ud Turtle & - & - & - \\
\hline Non-viper Snake & - & - & - \\
\hline Racer/Coachwhip & - & - & - \\
\hline King/Rat/Corn Snake & - & - & - \\
\hline Ud Snake & 1 & 0.1 & 1 \\
\hline Ud Frog/Toad & - & - & - \\
\hline Gar & - & - & - \\
\hline Minnow & - & - & - \\
\hline Finfish & - & - & - \\
\hline Ud Fish & 1 & 0.1 & 1 \\
\hline Total NISP & 14 & 2.6 & 5 \\
\hline Ud bone & 54 & 3.7 & \\
\hline TOTAL BONE & 68 & 6.3 & \\
\hline
\end{tabular}

(continued) 
Table 13-2. (continued).

\begin{tabular}{|c|c|c|c|}
\hline \multicolumn{4}{|c|}{ Unknown Late Archaic } \\
\hline Identification & NISP & Weight & MNI \\
\hline Ud Rat/Mouse & - & - & - \\
\hline Ud Rat & - & - & - \\
\hline Ud Mouse & - & - & - \\
\hline Cotton Rat & - & - & - \\
\hline Ud Micromammal & 11 & 0.7 & 1 \\
\hline Ud Small Mammal & 1 & 0.1 & - \\
\hline Ud Rabbit & 1 & 0.2 & 1 \\
\hline Jackrabbit & - & - & - \\
\hline Beaver & 1 & 1 & 1 \\
\hline Raccoon & - & - & - \\
\hline Ud Dog/Coyote & - & - & - \\
\hline Coyote & - & - & - \\
\hline Ud Medium Mammal & 31 & 1.5 & - \\
\hline Whitetail Deer & - & - & - \\
\hline Antelope & - & - & - \\
\hline Deer/Antelope & - & - & - \\
\hline Ud Large Mammal & 9 & 4 & 1 \\
\hline Bison & - & - & - \\
\hline Ud Very Lg Mammal & - & - & - \\
\hline Ud Sm/Med Mam/Bird & 3 & 0.2 & - \\
\hline Ud Large Bird & - & - & - \\
\hline Ud Medium Bird & - & - & - \\
\hline Wild Turkey & - & - & - \\
\hline Ud Reptile & - & - & - \\
\hline Mud-Musk Turtle & 1 & 0.1 & 1 \\
\hline Map Turtle & - & - & - \\
\hline Softshell Turtle & - & - & - \\
\hline Ud Turtle & 11 & 0.7 & - \\
\hline Non-viper Snake & - & - & - \\
\hline Racer/Coachwhip & - & - & - \\
\hline King/Rat/Corn Snake & 2 & 0.2 & 1 \\
\hline Ud Snake & - & - & - \\
\hline Ud Frog/Toad & - & - & - \\
\hline Gar & - & - & - \\
\hline Minnow & - & - & - \\
\hline Finfish & - & - & - \\
\hline Ud Fish & - & - & - \\
\hline Total NISP & 71 & 8.7 & 6 \\
\hline Ud bone & 61 & 1.5 & \\
\hline TOTAL BONE & 132 & 10.2 & \\
\hline
\end{tabular}

(continued) 
Table 13-2. (continued).

\begin{tabular}{|c|c|c|c|}
\hline \multicolumn{4}{|c|}{ Middle Archaic } \\
\hline Identification & NISP & Weight & MNI \\
\hline Ud Rat/Mouse & - & - & - \\
\hline Ud Rat & 5 & 0.2 & 1 \\
\hline Ud Mouse & - & - & - \\
\hline Cotton Rat & - & - & - \\
\hline Ud Micromammal & 6 & 0.2 & - \\
\hline Ud Small Mammal & 2 & 0.2 & - \\
\hline Ud Rabbit & - & - & - \\
\hline Jackrabbit & 8 & 4.2 & 1 \\
\hline Beaver & - & - & - \\
\hline Raccoon & - & - & - \\
\hline Ud Dog/Coyote & - & - & - \\
\hline Coyote & - & - & - \\
\hline Ud Medium Mammal & 13 & 1.4 & - \\
\hline Whitetail Deer & - & - & - \\
\hline Antelope & 1 & 2.4 & 1 \\
\hline Deer/Antelope & 1 & 3.4 & 1 \\
\hline Ud Large Mammal & 3 & 1.7 & - \\
\hline Bison & - & - & - \\
\hline Ud Very Lg Mammal & - & - & - \\
\hline Ud Sm/Med Mam/Bird & 8 & 0.3 & - \\
\hline Ud Large Bird & - & - & - \\
\hline Ud Medium Bird & - & - & - \\
\hline Wild Turkey (female) & 1 & 0.3 & 1 \\
\hline Ud Reptile & 1 & 0.2 & - \\
\hline Mud-Musk Turtle & 1 & 0.4 & 1 \\
\hline Map Turtle & - & - & - \\
\hline Softshell Turtle & - & - & - \\
\hline Ud Turtle & 22 & 2.1 & - \\
\hline Non-viper Snake & - & - & - \\
\hline Racer/Coachwhip & - & - & - \\
\hline King/Rat/Corn Snake & - & - & - \\
\hline Ud Snake & 1 & 0.1 & 1 \\
\hline Ud Frog/Toad & - & - & - \\
\hline Gar & - & - & - \\
\hline Minnow & - & - & - \\
\hline Finfish & - & - & - \\
\hline Ud Fish & 2 & 0.2 & 1 \\
\hline Total NISP & 75 & 17.3 & 8 \\
\hline Ud bone & 66 & 1.9 & \\
\hline TOTAL BONE & 141 & 19.2 & \\
\hline
\end{tabular}

(continued) 
Table 13-2. (continued).

\begin{tabular}{|c|c|c|c|}
\hline \multicolumn{4}{|c|}{ Unknown } \\
\hline Identification & NISP & Weight & MNI \\
\hline Ud Rat/Mouse & - & - & - \\
\hline Ud Rat & - & - & - \\
\hline Ud Mouse & - & - & - \\
\hline Cotton Rat & - & - & - \\
\hline Ud Micromammal & - & - & - \\
\hline Ud Small Mammal & - & - & - \\
\hline Ud Rabbit & - & - & - \\
\hline Jackrabbit & - & - & - \\
\hline Beaver & - & - & - \\
\hline Raccoon & - & - & - \\
\hline Ud Dog/Coyote & 1 & 3.6 & 1 \\
\hline Coyote & - & - & - \\
\hline Ud Medium Mammal & 2 & 0.6 & - \\
\hline Whitetail Deer & 6 & 28.8 & 1 \\
\hline Antelope & - & - & - \\
\hline Deer/Antelope & - & - & - \\
\hline Ud Large Mammal & 6 & 3.2 & - \\
\hline Bison & 17 & 853.2 & 1 \\
\hline Ud Very Lg Mammal & 174 & 265.2 & - \\
\hline Ud Sm/Med Mam/Bird & - & - & - \\
\hline Ud Large Bird & - & - & - \\
\hline Ud Medium Bird & - & - & - \\
\hline Wild Turkey & - & - & - \\
\hline Ud Reptile & - & - & - \\
\hline Mud-Musk Turtle & 1 & 0.4 & 1 \\
\hline Map Turtle & - & - & - \\
\hline Softshell Turtle & - & - & - \\
\hline Ud Turtle & - & - & - \\
\hline Non-viper Snake & - & - & - \\
\hline Racer/Coachwhip & - & - & - \\
\hline King/Rat/Corn Snake & - & - & - \\
\hline Ud Snake & - & - & - \\
\hline Ud Frog/Toad & - & - & - \\
\hline Gar & - & - & - \\
\hline Minnow & - & - & - \\
\hline Finfish & - & - & - \\
\hline Ud Fish & - & - & - \\
\hline Total NISP & 207 & 1155 & 4 \\
\hline Ud bone & 73 & 11.3 & \\
\hline TOTAL BONE & 280 & 1166.3 & \\
\hline
\end{tabular}

(continued) 
Table 13-2. (concluded).

\begin{tabular}{|c|c|c|c|}
\hline \multicolumn{4}{|c|}{ Disturbed } \\
\hline Identification & NISP & Weight & MNI \\
\hline Ud Rat/Mouse & - & - & - \\
\hline Ud Rat & - & - & - \\
\hline Ud Mouse & - & - & - \\
\hline Cotton Rat & - & - & - \\
\hline Ud Micromammal & - & - & - \\
\hline Ud Small Mammal & - & - & - \\
\hline Ud Rabbit & - & - & - \\
\hline Jackrabbit & - & - & - \\
\hline Beaver & - & - & - \\
\hline Raccoon & - & - & - \\
\hline Ud Dog/Coyote & - & - & - \\
\hline Coyote & - & - & - \\
\hline Ud Medium Mammal & - & - & - \\
\hline Whitetail Deer & - & - & - \\
\hline Antelope & - & - & - \\
\hline Deer/Antelope & - & - & - \\
\hline Ud Large Mammal & 1 & 0.1 & 1 \\
\hline Bison & 1 & 83.7 & 1 \\
\hline Ud Very Lg Mammal & 1 & 2.1 & - \\
\hline Ud Sm/Med Mam/Bird & 3 & 0.3 & 1 \\
\hline Ud Large Bird & - & - & - \\
\hline Ud Medium Bird & - & - & - \\
\hline Wild Turkey & - & - & - \\
\hline Ud Reptile & - & - & - \\
\hline Mud-Musk Turtle & - & - & - \\
\hline Map Turtle & - & - & - \\
\hline Softshell Turtle & - & - & - \\
\hline Ud Turtle & - & - & - \\
\hline Non-viper Snake & 1 & 0.1 & 1 \\
\hline Racer/Coachwhip & - & - & - \\
\hline King/Rat/Corn Snake & - & - & - \\
\hline Ud Snake & - & - & - \\
\hline Ud Frog/Toad & - & - & - \\
\hline Gar & - & - & - \\
\hline Minnow & - & - & - \\
\hline Finfish & - & - & - \\
\hline Ud Fish & - & - & - \\
\hline Total NISP & 7 & 86.3 & 4 \\
\hline Ud bone & 2 & 0.1 & \\
\hline TOTAL BONE & 9 & 86.4 & \\
\hline
\end{tabular}

$\mathrm{Ud}=$ unidentified 
age (and brute force) were used in disarticulating the "knee" joint.

Very few bone fragments exhibited charring or other indicators of heat. Overall, 14.2 percent of the sample was charred, with a large contribution made by unidentifiable bone (151 of 755 fragments) at 20 percent of the total charred. It is not uncommon for this to be true of most sites because heat makes bone fragments more brittle and subject to breakage (and consequently, also less identifiable). Of the identified taxa, small mammals and birds, collectively, showed the highest frequency of exposure to heat, at 17 percent. This includes several jackrabbit bones that exhibited a tan discoloration that presumably was due to roasting. Large mammal and turtle remains exhibited charring on 14 percent and 9 percent of the identified fragments, respectively. Most of the rest of the assemblage was either not burned at all (snakes, frog/toad) or very rarely: 7 of 342 bison/ very large mammal bones and 1 of 21 fish bones (a gar skull fragment in a Toyah deposit).

\section{Subsistence Change Through Time}

One of the most interesting aspects of central Texas prehistory is the intermittent presence of bison in the region, presumably due to relatively short-term climatic perturbations. Lohse et al. (2014b) have proposed that periodic availability was in response to cooler ambient temperture in the region. With bison available as a resource, the carrying capacity for humans was greatly enhanced. The ability of bison to convert grassland, otherwise utilized only by much smaller vertebrate prey, into protein and fat was an enormous boon to all apex predators.

Although the prehistoric chronology of central Texas is still being refined (Lohse et al. 2014a), and the present sample is very small, the patterning observed at 41HM61 appears to be in accord with previous studies. Table 13-2 shows the entire sample broken down into time periods based on association with diagnostic artifacts, stratigraphic correlation, or radiocarbon dates. Two of the samples are very small, especially those dated to Late Archaic 2 (NISP=14) and Late Archaic $4(\mathrm{NISP}=11)$ periods. Nonetheless, as shown in Figures 13-1 and Figure 13- 2, several patterns are apparent.

First, in observing percent bone weight, which relatively accurately represents the importance of various taxonomic groups to the subsistence economy, bison/vlm (very large mammal), when present, comprise a significant portion of the samples, ranging from 23.5 percent in Late Archaic 3, to 92.8 percent in the Toyah sample. Furthermore, Figure 13-1 shows a great deal of variability in bison abundance through time. With the exception of the Toyah occupation, deer/pronghorn/lm (large mammal) also is consistently important, always above 43 percent, even in the Late Archaic 2/3 sample, when bison appears to have been relatively abundant. Over time, looking at the combination of large game (bison, deer, and pronghorn) collectively, with the exception of a slight dip in Late Archaic 3, there appears to be a consistent trend through time toward greater use of large game. This trend continues even through Late Archaic 4, during a time period in which bison are thought to be absent from the study area (Lohse et al. 2014a).

Even though large mammals supplied the bulk of the meat consumed, smaller game were also pursued, as is indicated in Figure 13-2, which shows percent NISP through time. Small and medium-sized mammals (jackrabbit, raccoon, cf. coyote and even beaver) are represented, and a female turkey was identified. Turtles (map, softshell, and mud-musk) are present, although their relative abundance is variable. The only snakes identified (racer/coachwhip and king/ corn or milk snake) may or may not be commensal inclusions as none of the vertebrae were burned, but with such a low incidence of charred bone at the site, it seems likely they were consumed. Finally, a few fish bones were recovered, all from flotation samples with the exception of a gar parasphenoid in the Toyah deposits (Witness Column 6). At least one minnow was recovered from Late Archaic 2/3 (Unit N477E561, Stratum 2, Levels B and C). Finally, a finfish (Perciformes) was identified in Feature 29 (Toyah). All fish vertebrae recovered were less than $2 \mathrm{~mm}$ in diameter, and with the exception of the gar (50-60 cm total length [TL]), all estimated fish lengths were less than $10 \mathrm{~cm}$ Standard Length (SL).

\section{Seasonality}

At least two of the occupations at 41HM61 have definite warm-season components: Toyah and the Middle Archaic. Deer and deer/pronghorn fawns in Toyah deposits are estimated to be from two individuals, one 1 to 2 months old, the other 3 to 4 months old. In contrast, the Middle Archaic sample is heavily skewed toward warm-season fauna due to Feature 18, which produced 47 identifiable bones, 19 of them turtles and fish. In addition Feature 18 yielded a very young pronghorn estimated to be between 1 and 2 


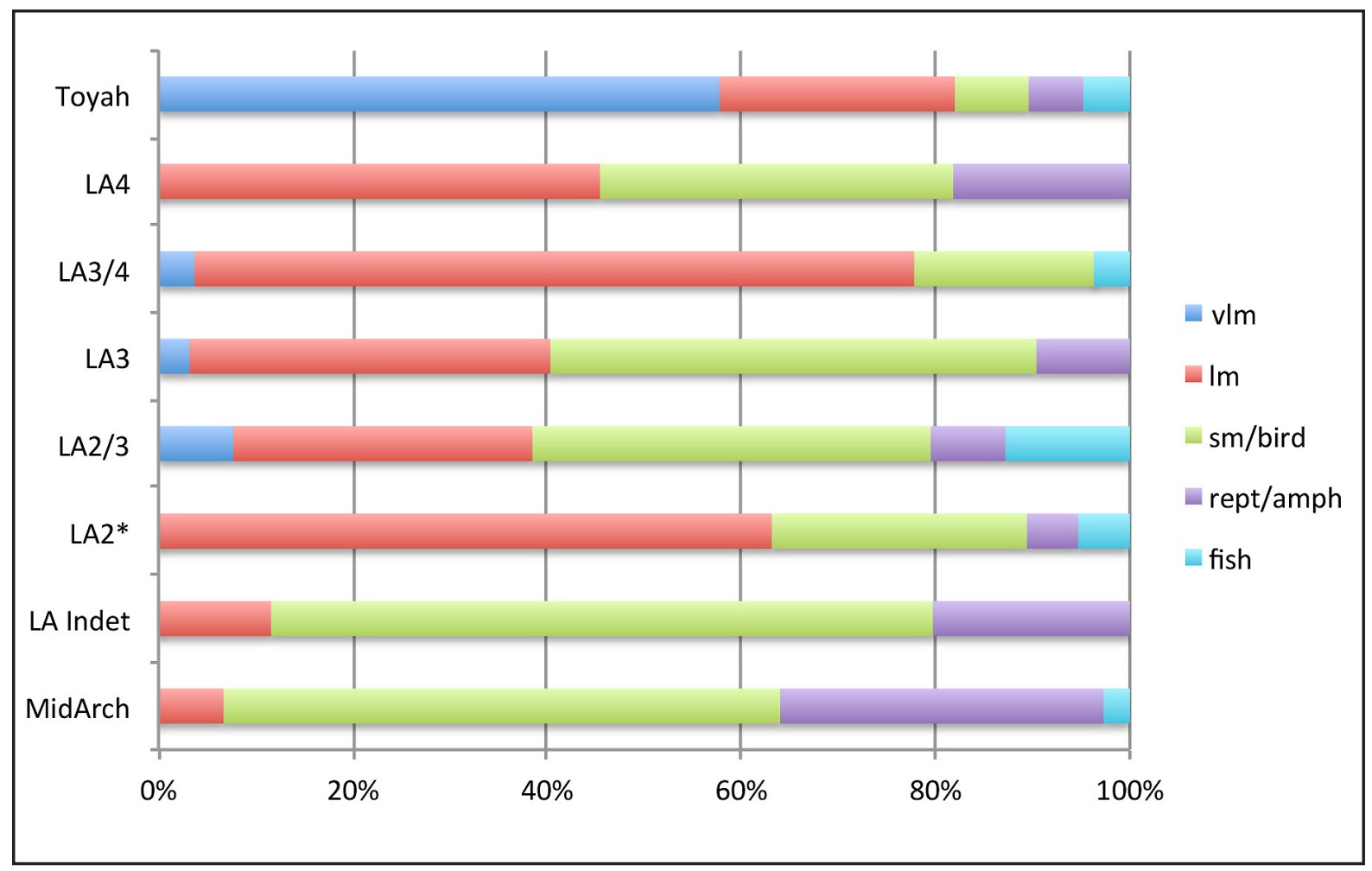

Figure 13-1. Bar graph depicting relative bone weight by time period at 41HM61.

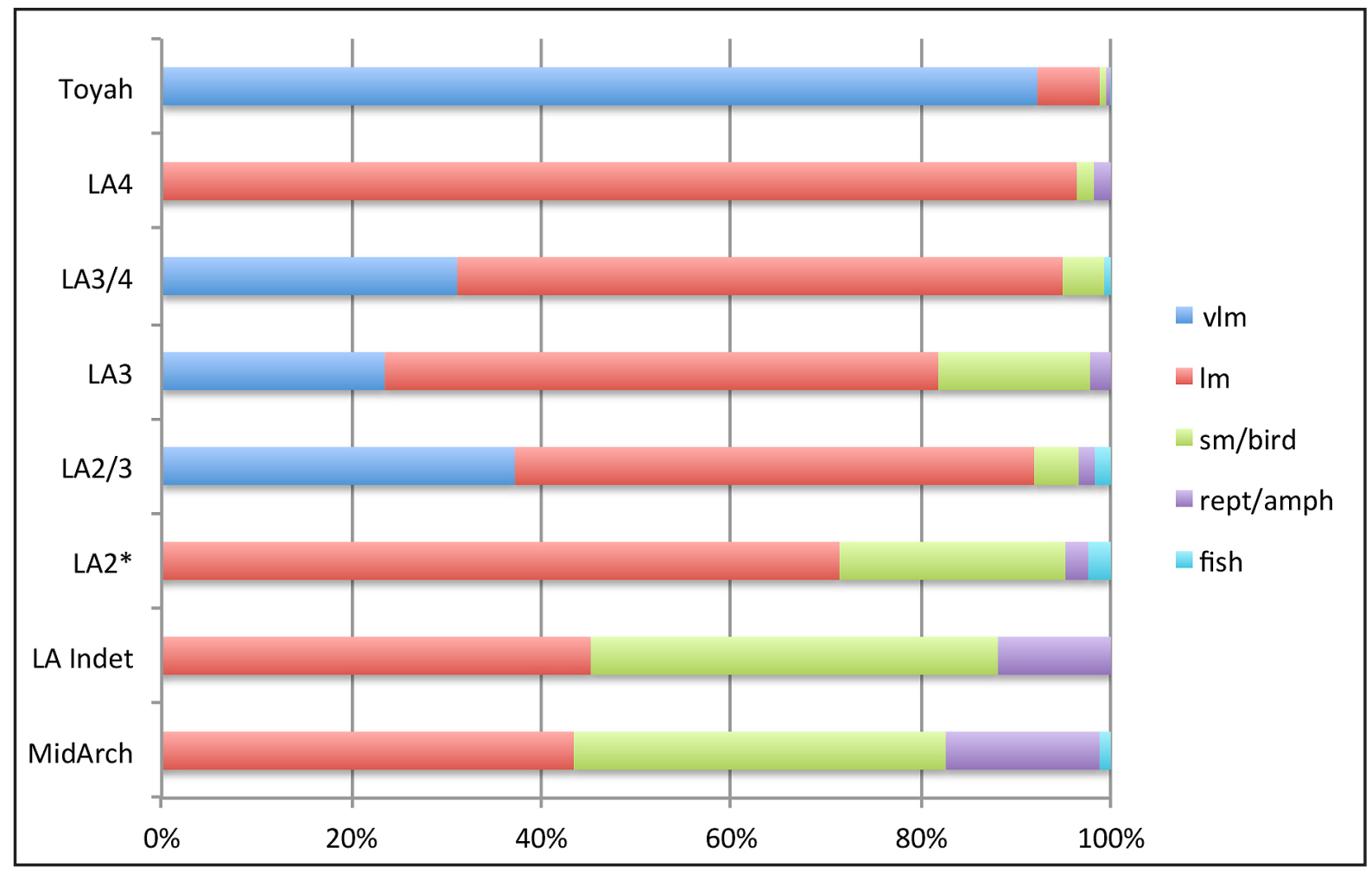

Figure 13-2. Bar graph depicting number of identified specimens (NISP) by time period from $41 \mathrm{HM} 61$. 
months old. Other contents of Feature 18 are mostly small game: small and medium mammals and the sole identifiable bird bone, a female turkey.

\section{Paleoenvironment}

In order to assess change through time using variation in the presence and frequency of small game and micro-mammals, a much larger sample of bone is required. It can be stated firmly, however, that the presence of turkey, raccoon and beaver indicate a riparian habitat with running water and some tree cover in the vicinity of the site during occupation. Other identifiable taxa, cf. coyote, jackrabbit and cotton rats, are all typically found in open, prairie habitat. From the perspective of climatic influences on the zooarchaeological assemblage, we expect that periods of bison presence in the assemblage to correspond with cool periods, each characterized by varying degrees of effective moisture (Lohse et al. 2014b). Conversely, periods without bison are likely to correspond with global, or at least regional, warm periods.

\section{Discussion}

Even though this vertebrate faunal sample is small, it does convey differences in the vertebrate resources available and exploited through time. As is true of other sites in central Texas, bison were an intermittent resource. Their documented presence at 41HM61 corresponds sharply with the latest model of regional bison presence. During the Toyah occupation, bison were a reliable resource. It is important to note, however, that the Toyah component at 41HM61 falls within the late Toyah interval (see Chapter 10); variation in terms of bison presence is to be expected in slightly earlier Late Prehistoric intervals (e.g., middle Toyah). The site probably was occupied nearly year round during the Toyah occupation, but may have been a warm-season camp during the Middle Archaic. Species present indicate a riparian habitat surrounded by prairie. Although aquatic taxa never contributed much to subsistence, fish and turtles were included in the diet for a bit of variety. Hopefully, with further research in the area and larger vertebrate assemblages with which to work, more detail can be added to this general analysis. 


\title{
Chapter 14
}

\section{Freshwater Mussel Remains}

\author{
Traci Popejoy \\ Charles R. Randklev \\ Steve Wolverton
}

This chapter describes the freshwater mussel fauna from site 41HM61, as requested by CEI. An analysis of the taphonomic processes affecting the assemblage is included to describe potential preservation effects on unionid species representation. Descriptions of the paleoenvironment and the human subsistence represented by the freshwater mussel fauna are included to expand upon the primary data generated in the analysis.

\section{Materials and Methods}

Freshwater mussel (or "unionid") is the common term for bivalves in the family Unionidae. These organisms have two calcium carbonate shells that preserve in archaeological assemblages (Claassen 1998). Specimens are counted using two quantitative units: non-repetitive element (NRE), and number of specimens (NSP) (Giovas 2009; Lyman 1994a; Mason et al. 1998). Non-repetitive elements by definition represent one individual and can be identified to fine taxonomic levels (most often to species). In unionids, NRE is tallied as the number of umbos; which are indicative of either the left or right shell of one organism. NSP is used to count identified and unidentified specimens within the assemblage. NSP is not indicative of a single organism, as there may be numerous unidentifiable or identifiable fragments from one shell (unlike umbos, which usually survive intact). In the case of 41HM61, NSP often comprises tallies of outer (ventral/anterior/dorsal) margins that are not identifiable to taxon. (Note that Appendix E provides a series of spreadsheets listing the basic data used for the interpretations and discussion in this chapter. The reader is referred to those spreadsheets for detailed information on the provenience of a particular specimen, its size, weight, etc.)

Additionally, the number of taxa represented (NTAXA) is a measure of species richness represented within an assemblage (Lyman 2008 and references within). Archaeologists use NTAXA to analyze ecological community richness and the diet breadth of human occupants. A change in ecological community richness through time could be indicative of environmental change, such as habitat degradation. Human subsistence can be analyzed through changes in diet breadth; an increase in diet breadth is indicative of dietary stress, generally (Schoener 1971; Hames and Vickers 1982).

Samples from the 41HM61 assemblage were sieved in the laboratory through a $1.2-\mathrm{cm}(1 / 2-\mathrm{in})$ sieve, to eliminate excessively small fragments. All specimens retained in the $1.2-\mathrm{cm}$ sieve were identified, counted, and measured along the length, width, and height axes. NRE (usually umbos) of shells from smaller species that fell through the mesh were also identified, counted, and measured. After each specimen was identified and measured, it was grouped by weight and size class into its respective taxon (Claassen 2000; Glassow 2000). Each taxon of freshwater mussel remains was weighed by the following size classes: <2 mm, 2-4 mm, 4-6 mm, 6-12 mm. This allowed for the inclusion of small NISP that were not identified and measured; often, small specimens were unidentifiable shell fragments that would not contribute to the overall findings of this report. Different 
Table 14-1. Freshwater Mussel Taxa Present at 41HM61.

\begin{tabular}{|c|c|c|c|}
\hline Abbreviation & Scientific Name & Common Name & NRE \\
\hline UAP & Amblema plicata & Threeridge & 93 \\
\hline UAC & Arcidens confragosus & Rock Pocketbook & 1 \\
\hline UCT & Cyrtonaias tampicoensis & Tampico Pearlymussel & 2 \\
\hline UFM & Fusconaia mitchelli* & Central Texas False Spike & 9 \\
\hline Lss & Lampsilis sp. & & 37 \\
\hline ULH & Lampsilis hydiana & Louisiana Fatmucket & 10 \\
\hline ULT & Lampsilis teres & Yellow Sandshell & 34 \\
\hline UMN & Megalonaias nervosa & Washboard & 16 \\
\hline Qss & Quadrula sp. & & 34 \\
\hline UQA & Quadrula apiculata & Southern Mapleleaf & 13 \\
\hline UQH & Quadrula houstonensis* & Smooth Pimpleback & 20 \\
\hline UQV & Quadrula verrucosa & Pistolgrip & 38 \\
\hline Tos & Toxolasma sp. & - & 2 \\
\hline UTM & Truncilla macrodon* & Texas Fawnsfoot & 5 \\
\hline QAV & Q. apiculata or $Q$. verrucosa & - & - \\
\hline UAM & A. plicata or M. nervosa & - & 25 \\
\hline UNI & Unidentifiable specimen & - & 60 \\
\hline \multicolumn{3}{|c|}{ TOTAL } & 399 \\
\hline
\end{tabular}

Note: Abbreviations are used throughout the rest of the report and in Appendix E. NRE represents one umbo/shell. A single asterisk (*) indicates the species is listed as threatened by the State of Texas.

analyses were conducted in order to understand paleoenvironmental conditions for 41HM61, how preservation and other taphonomic factors affect the collection, and what assemblage variation may mean for regional diet and subsistence over time.

\section{Freshwater Mussel Diversity}

A summary of the unionid diversity found within 41HM61 is provided in Table 14-1 and Figures 14-1 and 14-2. Threeridge (Amblema plicata), Pistolgrip (Quadrula verrucosa), and Yellow Sandshell (Lampsilis teres) are the most abundant species-level taxa in the 41HM61 assemblage. In total, there are eleven species present, though evenness is low across the assemblage. When evaluating the overall site assemblage data, it is important to remember that "zooarchaeological measures of taxonomic abundance are ordinal scale, at best" (Grayson 1984:106; also Wolverton et al. 2014:1). Often, archaeomalacological data are more reliably interpreted biogeographically at nominal (presence-absence) scale (Peacock et al. 2012; Randklev and Lundeen 2012; Randklev et al. 2010).

It is commonly understood that, in any particular assemblage in zooarchaeology, the analyst's ability to identify faunal remains improves during the process of the analysis (Driver 2011; Lyman 2011). Following Driver $(1992,2011)$ and Wolverton (2013), two pro- 


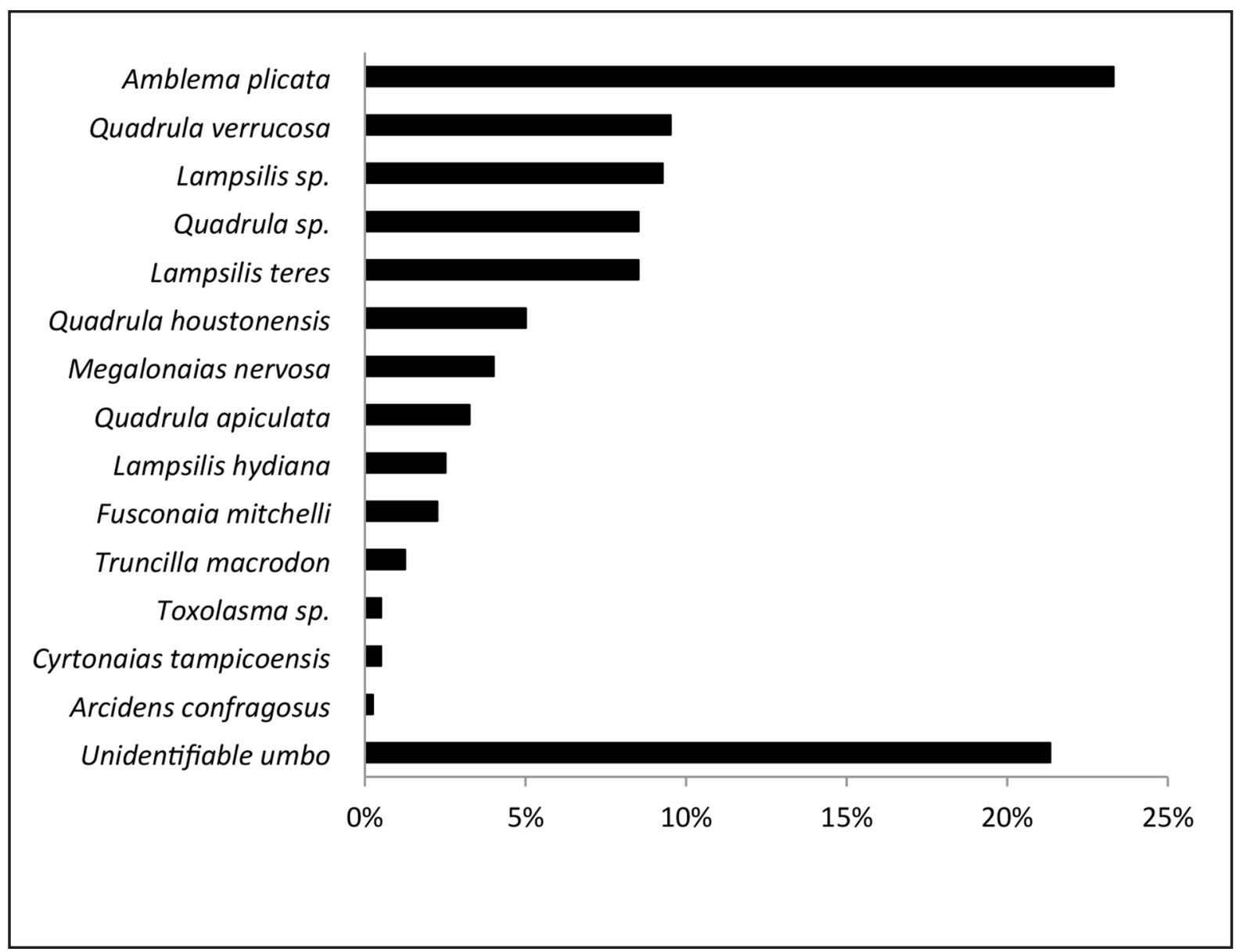

Figure 14-1. Histogram of taxonomic diversity of freshwater mussels 41HM61. A. plicata dominates the 41HM61 assemblage, followed by $Q$. verrucosa and Lampsilis sp. Note that only species-level taxa are included in this histogram.

cedures were adopted to ensure data quality: re-analysis of a portion of the assemblage to assess identification-error rate, as well as crafting of a detailed systematic paleontology. Driver $(1992,2011)$ makes recommendations for how to improve data quality. Data quality was analyzed by re-identifying two medium-sized samples, representing 10.8 percent of the 41HM61 assemblage, as suggested by Wolverton (2013). The data-quality analysis found that 14 percent of the specimen's reanalyzed were identified differently (more conservatively during the data-quality assessment). Given this moderate identification-error rate, the highly problematic identifications that may have been too liberal were checked throughout the assemblage. Additionally, Lyman (2011) recommends that a systematic paleontology that covers biological information and morphological criteria used for making identifications be included in any faunal report. We provide a systematic paleontology in accordance with this recommendation.

\section{Unionid Use Through Time}

To take full advantage of the faunal data generated for this report, a temporal analysis of subsamples within the 41HM61 assemblage was conducted to analyze potential ecological community change or human subsistence change. Shifts in the NTAXA in an assemblage are clear indicators of human subsistence change as it indicates increased diet breadth and increased search time by occupants. From a human subsistence standpoint, it appears that the human occupations represented by the 41HM61 assemblage experienced an increase in dietary stress over time (Tables 14-2 and 14-3; plus see further discussion of these tables below). However, conclusions based on changes in NTAXA through time are potentially influenced by sample-size bias in the 41HM61 assemblage.

Analyzing change in taxonomic richness and abundance through time in zooarchaeological assemblages 


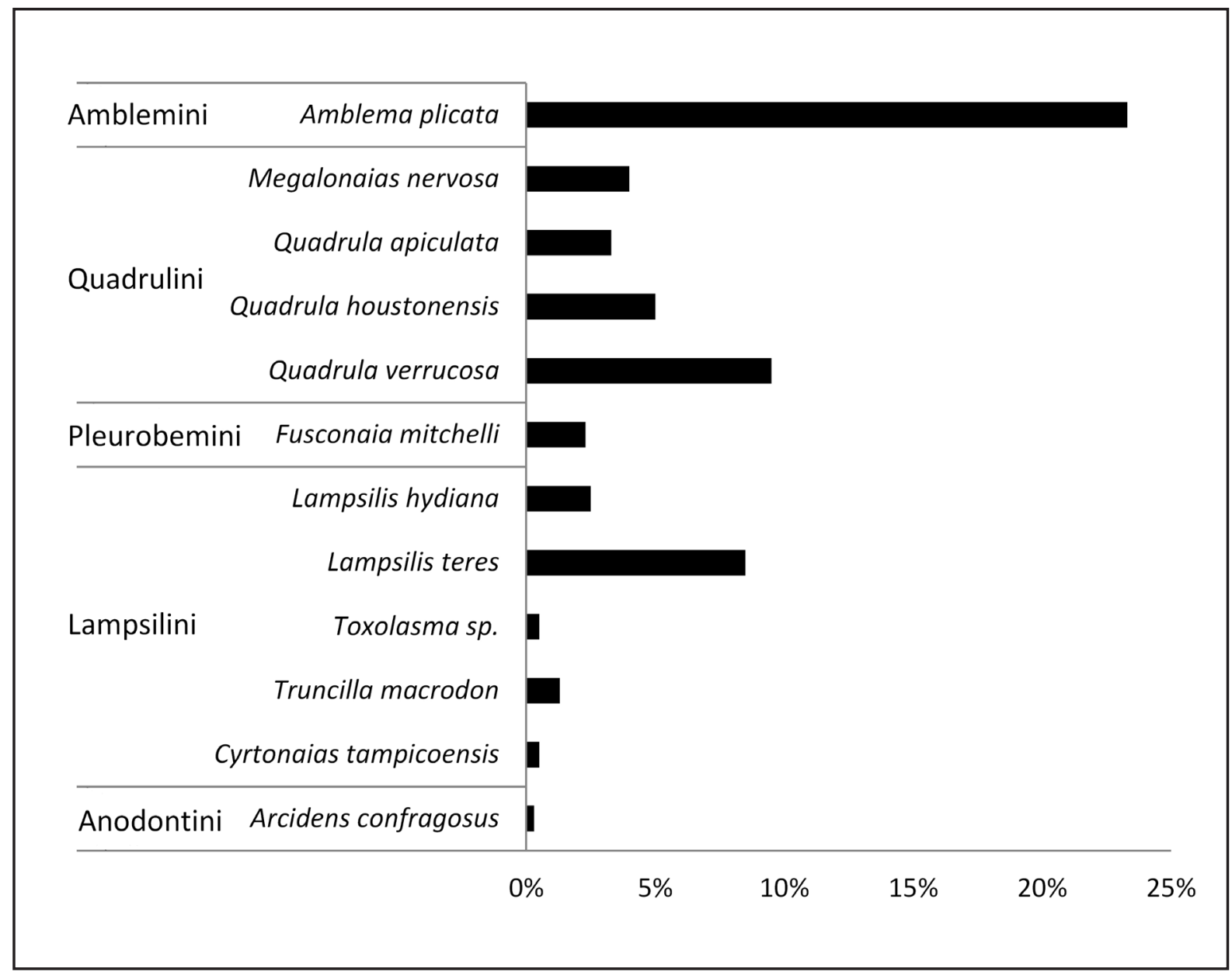

Figure 14-2. Unionid taxonomic diversity of 41HM61 by tribe. Taxa are arranged in evolutionary relationships to understand types of mussels present in the 41HM61 assemblage. Tribes are used to group similar taxa; tribe designation based on Haag (2012).

is problematic; generally, these analyses require highly representative samples from multiple spatial and temporal contexts in order to produce valid results (Lyman 2008; Peacock and Chapman 2001). As a limited number of taxa can be represented by a limited NRE, NTAXA is highly influenced by sample size. This influence is shown through the logistic relationship between NRE and NTAXA. Until samples can be considered representative (by reaching the asymptote in an NRE vs. NTAXA scatterplot [Figure 14-3]), it is inappropriate to compare NTAXA as measures of the ecologic community and human subsistence. These sample-size effects make extrapolation for ecological community change or human subsidence change through time difficult to impossible (Lyman and Ames 2007).

\section{Feature Analysis}

Site 41HM61 included many features that contained a high proportion of unionid remains; using these features as evidence for human subsistence could illuminate how occupants used freshwater mussels as a food source. As evident in Table 14-2, unionid remains were greatest in Feature 19, which is part of the Lange component dating to the Late Archaic 2 period. Feature 19 had a total of 131 NRE and represented 10 taxa total. Feature 18, which dated to the Middle Archaic period, had a total of 47 NRE represented by eight taxa. While this might indicate that freshwater mussels were used for subsidence more during Late Archaic 2 then the Middle Archaic, such a statement is difficult to corroborate since NSP increases with NTAXA (see Figure 14-3).

\section{Occupation Analysis}

Analysis of the unionid remains found in different contexts could elucidate how different people used unionids as a food source during different occupations. To complete this analysis, samples were ag- 
Table 14-2. Feature Analysis of Taxonomic Richness for 41HM61.

\begin{tabular}{|c|c|c|c|c|c|}
\hline & $\begin{array}{c}\text { Feature } 16 \\
\text { Late Archaic } 4\end{array}$ & $\begin{array}{c}\text { Feature } 18 \\
\text { Middle Archaic }\end{array}$ & $\begin{array}{c}\text { Feature } 19 \\
\text { Late Archaic } 2\end{array}$ & $\begin{array}{c}\text { Feature } 21 \\
\text { Late Archaic } 3\end{array}$ & $\begin{array}{c}\text { Feature } 28 \\
\text { Middle Archaic }\end{array}$ \\
\hline Amblema plicata & 1 & 7 & 39 & 1 & 2 \\
\hline Arcidens confragosus & - & - & - & - & - \\
\hline Cyrtonaias tampicoensis & - & - & 1 & - & - \\
\hline Fusconaia mitchelli & - & 2 & - & - & 2 \\
\hline Lampsilis sp. & - & 5 & 3 & - & 2 \\
\hline Lampsilis hydiana & - & - & 1 & - & - \\
\hline Lampsilis teres & - & 9 & 7 & - & - \\
\hline Megalonaias nervosa & - & - & 11 & - & - \\
\hline Quadrula sp. & - & 3 & 14 & - & - \\
\hline Quadrula apiculata & - & 3 & 3 & - & - \\
\hline Quadrula houstonensis & - & 7 & 4 & - & - \\
\hline Quadrula verrucosa & - & 6 & 21 & - & 1 \\
\hline Unidentifiable umbo & - & 10 & 27 & 1 & 2 \\
\hline NRE Total & 1 & 47 & 131 & 2 & 9 \\
\hline Species Richness & 1 & 8 & 10 & 1 & 5 \\
\hline NRE:NSP & 0.33 & 0.55 & 0.20 & 0.50 & 0.60 \\
\hline
\end{tabular}

Note: NRE are listed by taxon for selected features. Feature 19 has the highest taxonomic richness at 41HM61. Differences in taxonomic composition among levels potentially contribute information about mussel harvest through time. Notice that specimens richness increases with the total NRE and NISP from the feature.

gregated into assumed occupations; Table 14-4 lists the aggregated samples by their occupation. The general Late Archaic 3/4 occupation exhibits the highest NRE at 137 and taxonomic richness of 13 taxa. The Lange occupation consists of $131 \mathrm{NRE}$, but is only represented by 10 taxa. The Ensor occupation is of interest as it contained 63 NRE with 12 taxa represented. This makes the Ensor occupation more taxonomically rich than the Lange occupation, though the Lange occupation had a larger sample size. This occupation departs from the expected NRE:NTAXA relationship (as NSP increases, so does NTAXA). The greater NTAXA present in the Ensor occupation could indicate that the occupants were using unionids more intensely, that ecological degradation had reduced unionid populations, or that the occupants sampled a higher diversity of habitats.

\section{Taphonomy}

Taphonomy "is the study of the transition, in all details, of organics from the biosphere into the lithosphere or geological record" (Lyman 1994b:1). As different unionid species have shells with distinctive preservation potential (Wolverton et al.2010), whether or not shells are well preserved must be assessed (Lyman 1984). Wolverton et al. (2010) analyzed the preservation potential of freshwater mussel shells based on two physical characteristics: shell sphericity and shell density. Those authors found that as shell sphericity increases, preservation potential also increases, regardless of shell density. In addition, as shell density increases so does preservation potential. When testing their conceptual model, the authors quantified the shell density and sphericity of the modern freshwater mussel community of the Brazos River. As the Leon River is a tributary of the Brazos River, Wolverton et al.'s calculated density and sphericity values will be used at an ordinal scale. A taphonomic analysis was conducted for the freshwater mussel assemblage from 41HM61 using Wolverton et al.'s conceptual model and data from the Brazos River (Figure 14-4). Relative abundance was plotted as the $\mathrm{z}$ axis in a 3D scatterplot of density vs. sphericity for the 41HM61 assemblage to assess the degree of differential preservation among species represented within the assemblage. 
Table 14-3. Occupation Analysis of Taxonomic Richness for 41HM61.

\begin{tabular}{|c|c|c|c|c|c|c|}
\hline & $\begin{array}{l}\text { Middle } \\
\text { Archaic }\end{array}$ & Lange & $\begin{array}{c}\text { Marcos/ } \\
\text { Ensor }\end{array}$ & Ensor & $\begin{array}{c}\text { Late } \\
\text { Archaic 3/4 }\end{array}$ & $\begin{array}{c}\text { Late } \\
\text { Archaic } 4\end{array}$ \\
\hline Amblema plicata & 9 & 39 & - & 12 & 31 & 1 \\
\hline Arcidens confragosus & - & - & - & 1 & - & - \\
\hline Cyrtonaias tampicoensis & - & 1 & - & - & 1 & - \\
\hline Fusconaia mitchelli & 4 & - & - & 1 & 4 & - \\
\hline Lampsilis sp. & 7 & 3 & 1 & 6 & 20 & - \\
\hline Lampsilis hydiana & - & 1 & - & 1 & 8 & - \\
\hline Lampsilis teres & 9 & 7 & - & 7 & 11 & - \\
\hline Megalonaias nervosa & - & 11 & - & 1 & 4 & - \\
\hline Quadrula sp. & 3 & 14 & 3 & 7 & 7 & - \\
\hline Quadrula apiculata & 3 & 3 & - & 2 & 5 & - \\
\hline Quadrula houstonensis & 7 & 4 & 1 & 5 & 3 & - \\
\hline Quadrula verrucosa & 2 & 21 & - & 9 & 5 & - \\
\hline Toxolasma sp. & - & - & - & - & 2 & - \\
\hline Truncilla macrodon & - & - & - & 1 & 4 & - \\
\hline Unidentified Umbo & 12 & 27 & 4 & 10 & 32 & - \\
\hline Grand Total & 56 & 131 & 9 & 63 & 137 & 1 \\
\hline Richness & 8 & 10 & 3 & 12 & 13 & 1 \\
\hline
\end{tabular}

Note: NRE are listed by taxon for samples aggregated by occupation. The general Late Archaic 3/4 period has the most NRE and taxonomic richness. The Lange occupation also had the most NRE, but was not as taxonomically rich as the Ensor occupation. Differences in taxonomic composition among levels potentially contribute information about mussel harvest through time. Notice that species richness increases with total NRE and NISP from the occupation.

The taphonomic analysis of the shells from 41HM61 is shown in Figure 14-5. As can be seen, the preservation potential of species increases upward and to the right on the $x-y$ plane. The presence of fragile species indicates that preservation potential is moderately high in this assemblage, though it should be noted that the fragile species have low relative abundance. As expected based on shell structure, the robust species have higher relative abundances than species with fragile shells. Also interesting is the high relative abundance of Lampsilis species, which generally have low preservation potential. As Lampsilis teres, a species with relatively low preservation potential, has the third highest relative abundance, it can be concluded that the 41HM61 assemblage is moderately well preserved.

It is important to note, however, that the 41HM61 assemblage was highly fragmented $(1,517.4 \mathrm{~g}$ of the assemblage was in the $<1.2-\mathrm{cm}$ size class). Fragmen- tation of archaeological assemblages can be quantified through a ratio comparing the total number of identified shells (NRE) represented in the assemblage to the total number of unidentifiable and identifiable specimens in the assemblage: i.e., NRE:NSP (Randklev et al. 2010). The 41HM61 assemblage had a fragmentation ratio of $399: 1054$. This ratio reduces to 37.8 percent identifiability, which indicates a high rate of fragmentation within the overall assemblage.

\section{Paleoenvironmental Reconstruction}

A paleoenvironmental reconstruction based upon relative abundances generated from the 41HM61 assemblage was derived using Warren's (1991) software program UNIO (Version 3) (Warren 1991). UNIO assesses four habitat variables based on either NTAXA or NRE: water depth, current velocity, substrate composition and habitat type. Water depth was quantified between $0.0 \mathrm{dm}$ to $46 \mathrm{dm}(0.0 \mathrm{~m}$ to $4.6 \mathrm{~m})$. Current 


\section{Feature Analysis Sampling Bias}

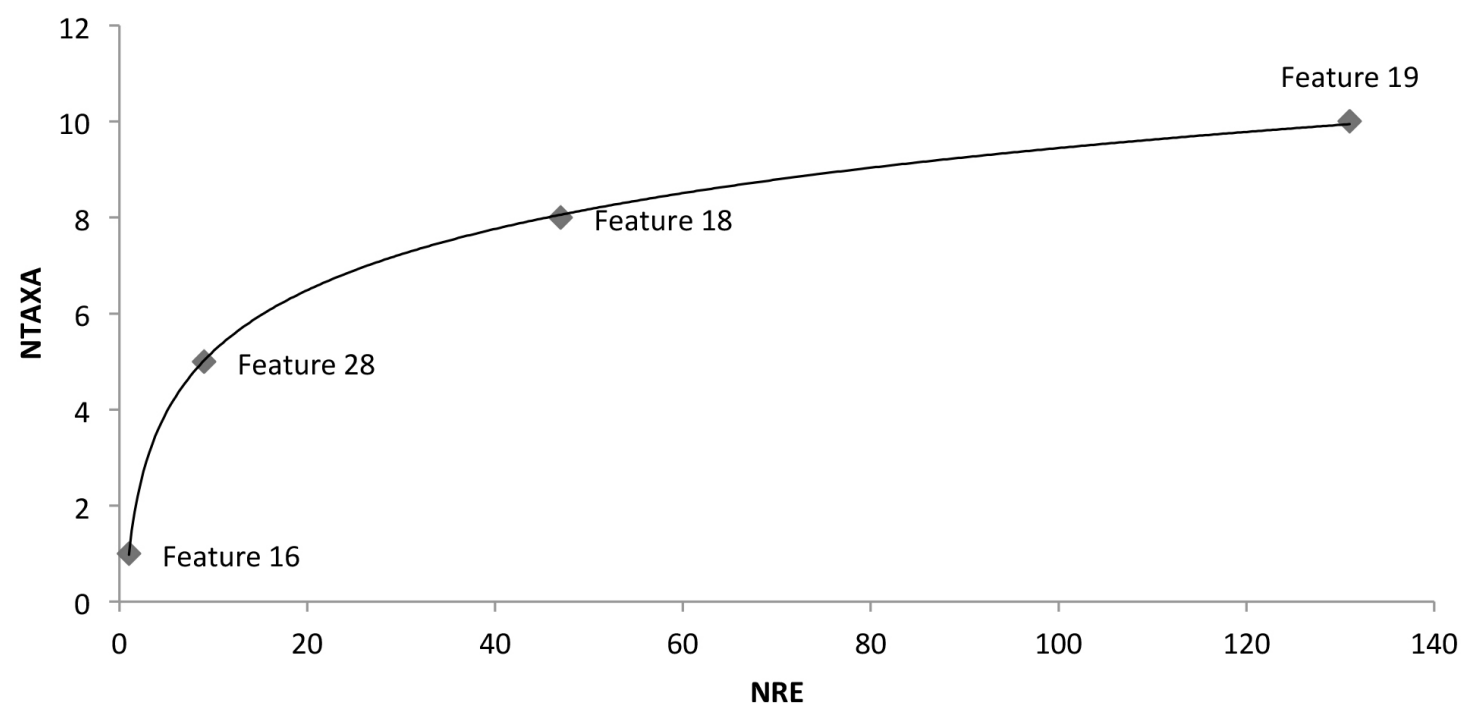

\section{Occupation Analysis Sampling Bias}

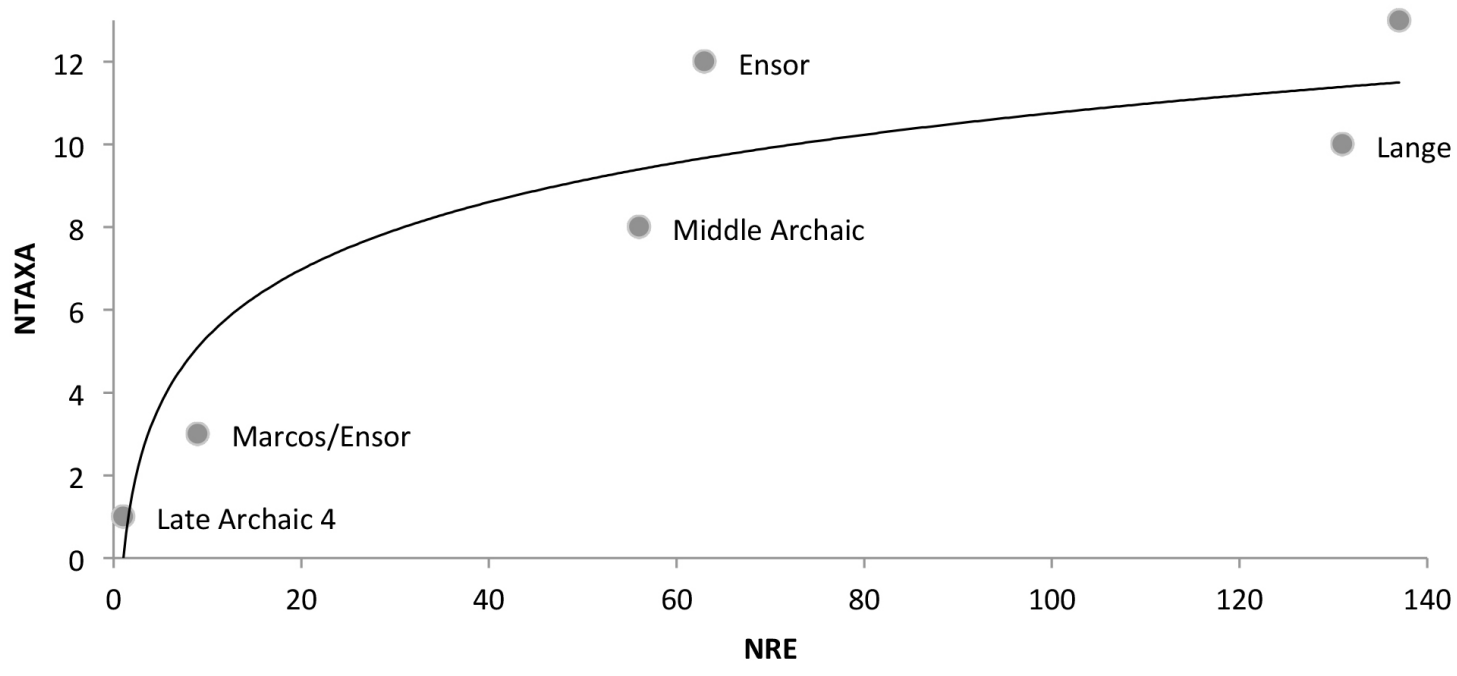

Figure 14-3. Sample size bias in the 41HM61 temporal analysis. As discussed in Grayson (1981) and Lyman (2008), sample size can heavily affect derived measures often used in zooarchaeology (in particular taxanomic richness and relative abundance). This scatter plot shows the relationship between NTAXA and sample size: as sample size increases, NTAXA is likely to increase as well. NTAXA representing more than one species were excluded from this scatterplot.

velocity was categorized as strong "SW," moderate "MO," slow "SL," and standing "ST." Substrate composition was defined as cobble-gravel "C-G," gravel "G," gravel-sand "G-S," sand "S," sand-mud "S-M," and mud "M." Finally, water body type was defined as large river "LR," medium river "MR," small river "SR," large creek "LC," small creek "SC," and lake "L." Species were assigned numerical weights 
Table 14-4. Samples Aggregated by Occupation for the Analysis of Unionid Use by Occupation.

\begin{tabular}{|c|c|c|}
\hline Occupation & Sample \# & Lot \# \& Object I.D. \\
\hline \multirow{6}{*}{ Middle Archaic } & 16 & CAS.2015.01.193.30-40 \\
\hline & 16 & CAS.2015.01.193.41-43 \\
\hline & 16 & CAS.2015.01.193.45-49, 51-56 \\
\hline & 16 & CAS.2015.01.193.57-60 \\
\hline & 17 & CAS.2015.01.197.16-25 \\
\hline & 47 & CAS.2015.01.190.135-141 \\
\hline \multirow{4}{*}{ Lange } & 14 & CAS.2015.01.168.17-25 \\
\hline & 39 & CAS.2015.01.109.02-11 \\
\hline & 40 & CAS.2015.01.066.04-21 \\
\hline & 44 & CAS.2015.01.168.29-38 \\
\hline Marcos/Ensor & 33 & CAS.2015.01.149.27-34 \\
\hline \multirow{8}{*}{ Ensor } & 7 & CAS.2015.01.086.53-57 \\
\hline & 7 & CAS.2015.01.086.58-59 \\
\hline & 24 & CAS.2015.01.095.17 \\
\hline & 25 & CAS.2015.01.175.26-30 \\
\hline & 31 & CAS.2015.01.094.70-75 \\
\hline & 42 & CAS.2015.01.151.43-51 \\
\hline & 48 & CAS.2015.01.148.38-50 \\
\hline & 49 & CAS.2015.01.175.32-42 \\
\hline \multirow{3}{*}{ Late Archaic 3/4 } & 23 & CAS.2015.01.173.50-52 \\
\hline & 45 & CAS.2015.01.173.55-73 \\
\hline & 46 & CAS.2015.01.179.28-44 \\
\hline Late Archaic 4 & 1 & CAS.2015.01.052.16-18 \\
\hline
\end{tabular}

Note: Samples are listed by sample number and lot number; these sample numbers represent provenience information found in Appendix E.

$(0,0.5$, and 1$)$ based on published habitat preferences. If a species was routinely reported to occur in a gravel-sand substrate, then a score of 1 would be assigned for that environmental variable. Conversely, if a particular species was rarely documented as inhabiting a gravel-sand substrate, then a score of 0.5 was given. In total, UNIO determines the percentage of an archaeological assemblage that is adapted to a particular habitat category (see Morey and Crothers 1998; Warren 1991 for an in-depth discussion of UNIO). As the UNIO program was not created for Texas freshwater mussel communities, some Mississippi taxa were used a proxies for endemic Texas species. The following species are not included in the UNIO pro- gram: Cyrtonaias tampicoensis, Fusconaia mitchelli, Lampsilis hydiana, Quadrula apiculata, Q. houstonensis, Truncilla macrodon and Toxolasma sp. For $L$. hydiana, F. mitchelli, Q. apiculata, Q. houstonensis, Truncilla macrodon, and Toxolasma sp., the following species were used instead, respectively, because they share similar ecological requirements: L. siliquoidea, $F$. cuneolus, $Q$. quadrula, $Q$. pustulosa, Truncilla donaciformis, and Toxolasma texasense (Howells 2013; Howells et al. 1996; Williams et al. 2008). Cyrtonaias tampicoensis was omitted from the analysis because little is known about its habitat preferences; as C. tampicoensis represents a small proportion (NRE of 3 ) of the assemblage, this exclusion is acceptable (Howells et al. 1996). NRE values were multiplied by weighted habitat variables and summed across taxa within these categories. Once substitutions were made and values entered, percentage NRE was then graphed against each habitat variable (Figure 14-6).

Based on the results generated by the UNIO program, it is evident that the assemblage from site 41HM61 represents a freshwater mussel community that presumably prefers small rivers to large creeks (see Figure 14-6, A). All taxa found at 41HM61 presumably prefer a water depth below 9 decimeters, which is expected due to mussel ecology (see Figure 14-6, C). This also could be indicative of mussel harvest in shallow waters by native peoples. Most of the 41HM61 assemblage represents mussel taxa that prefer slow current velocities (see Figure 14-6, B). The substrate preference of taxa represented at 41HM61 is unclear, though the gravel-to-mud spectrum seems to be the most preferred. Generally, Arcidens confragosus, L. hydiana, Q. apiculata and M.nervosa are often found in shallow, slow to still waters, backwater areas, or in protected parts of streams (Howells et al. 1996; Williams et al. 2008). However, the presence of $Q$. houstonensis and F. mitchelli suggests that portions of the Leon River had at least moderate flows during the late Holocene.

\section{Human Subsistence}

Freshwater mussels may have provided marginal foodways for native groups in central Texas (Howells et al. 1996) in terms of caloric intake, though they may provide micronutrients that are of limited availability on the landscape. Given that freshwater mussels are filter feeders, which micronutrients are abundant in soft tissues is likely to vary according to water chemistry and composition of substrate. Nonetheless, the potential that freshwater mussels would be targeted as a resource rich in trace nutrients, particularly miner- 


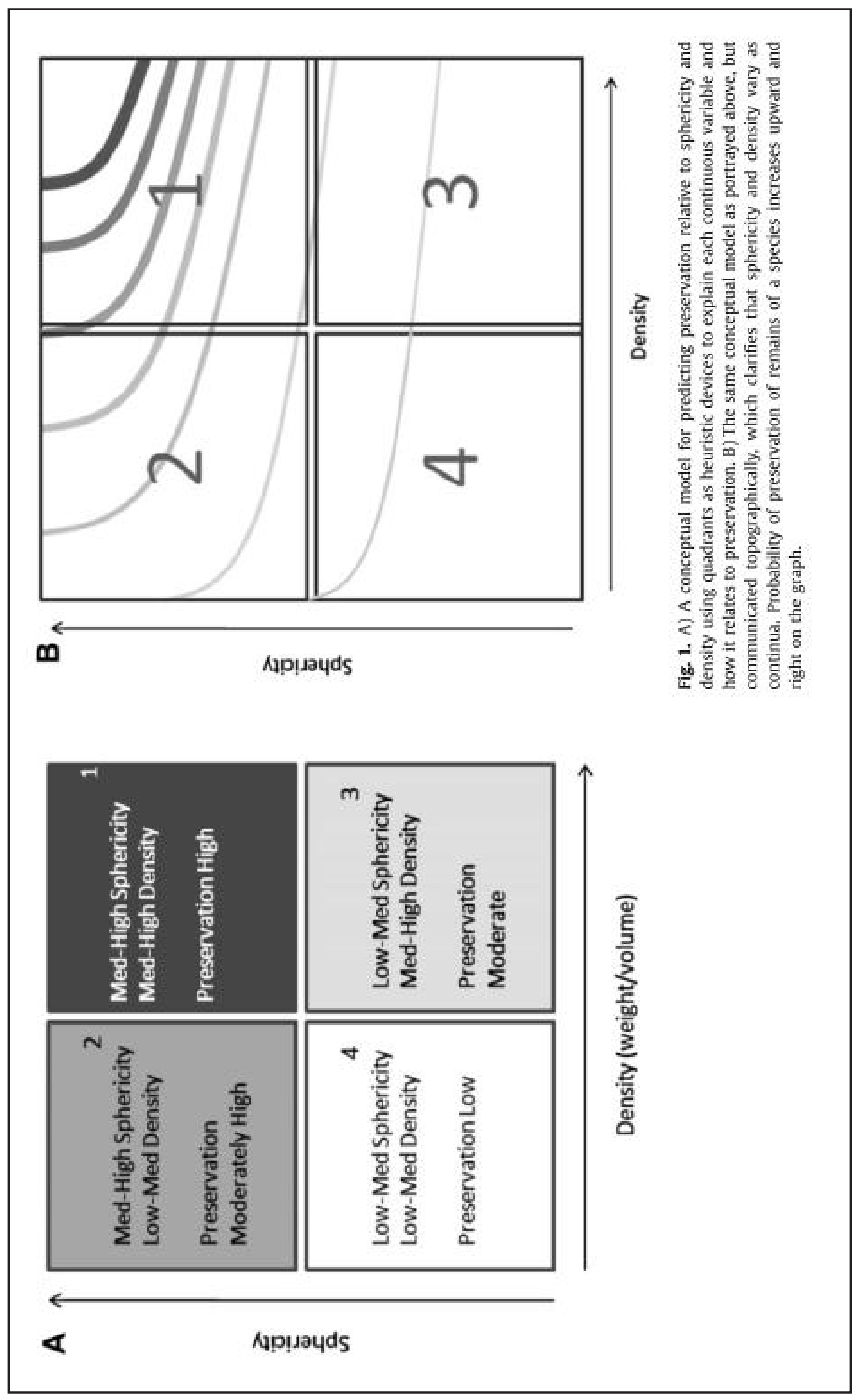

 


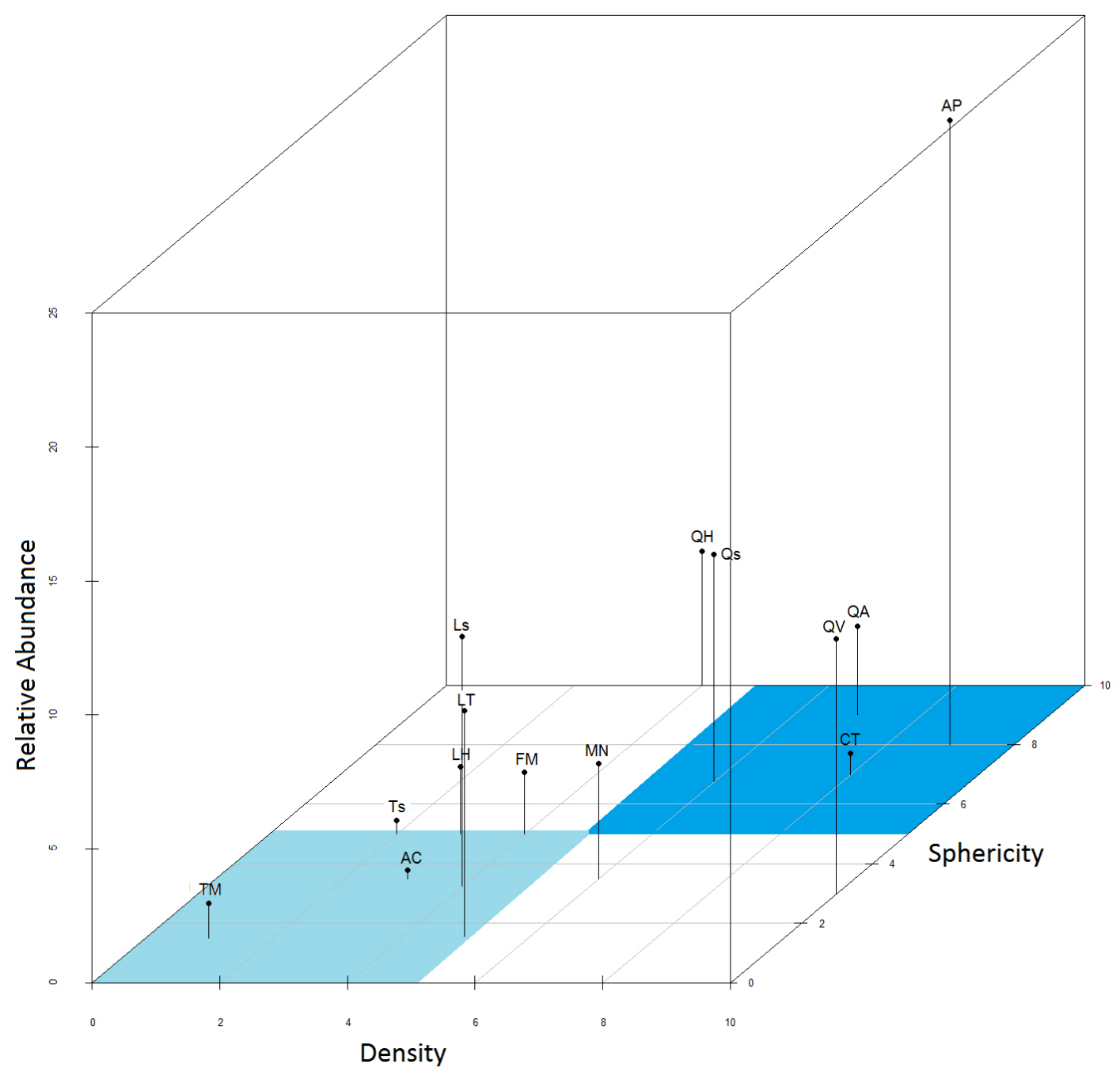

Figure 14-5. Taphonomic analysis of 41HM61. A 3D scatterplot of sphericity, density, and relative abundance addresses the preservation effect inherent within 41HM61. By overlaying the conceptual model with this 3D scatter plot, the preservation effect can be addressed. The darker blue area represents higher preservation potential of more robust (dense and spherical) shells. The lighter blue area represents lowest preservation potential of fragile (less dense and less spherical) shells. As such, the presence of species considered typically fragile indicates that the preservation of the assemblage is relatively good. Robust species include A. plicata (UAP) and Q. apiculata (UQA). Fragile species include T. macrodon (UTM), A. confragosus (UAC), and Lampsilis hydiana (ULH). 


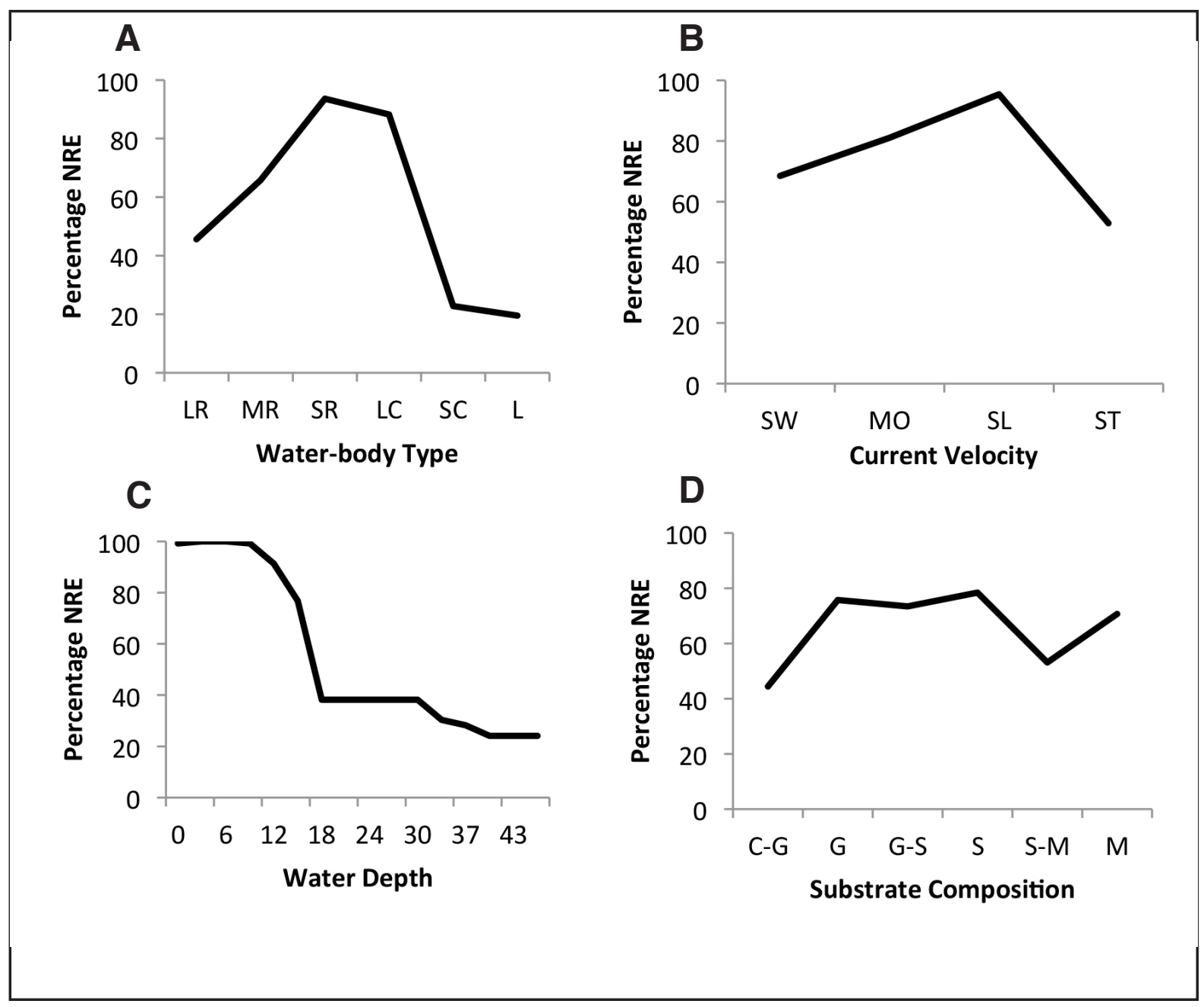

Figure 14-6. Paleoenvironmental reconstruction based on UNIO calculations. Using Robert Warren's UNIO program, habitat preferences were recorded based on the relative abundance of species or proxy species found at site 41HM61.

al nutrients related to the substrates of their beds and surrounding water columns exists, though the precise nature of this nutritional value deserves and requires a great deal of future study (see the summary by Lohse in Chapter 16, below). Parmalee and Klippel (1974) describe the use of freshwater mussels as a staple food source as highly unlikely due to their poor calorie content compared to other meat sources. Women and children are thought to have gathered freshwater mussels from the substrate in shallow areas of rivers. As they are found in multispecies beds and provide small packets of food, they are thought to be a low-priority item (Peacock et al. 2012). As such, freshwater mussels probably provided a reliable food source during times of stress. Freshwater mussel shells have been found in burial sites in central Texas, but the artifact function is uncertain (Bement 1994). The 41HM61 shell assemblage has no evidence of artifact use, and mussel remains from the site most likely represent food waste.

While freshwater mussels are poor in carbohydrates and protein, they contain a higher proportion of other nutrients than other food sources (see Chapter 16). Freshwater mussels uptake strontium at a higher portion than other food items at similar trophic levels (Schoeninger and Peebles 1981). To address the potential use of freshwater mussels as nutrient supplements, we calculated the meat weight and nutrient value provided by the freshwater mussel remains from 41HM61. For 399 NRE in the 41HM61 assemblage, the meat weight is 236.05 grams. The average meat weight of each NRE is 0.59 grams. Data for Quadrula sp. from Lintz (1996) and Lohse (see Chapter 16) was 
used as a proxy for the nutrient analysis of the unionid remains for this assemblage, as nutrient data were available and 26.3 percent of the 41HM61 assemblage represents species from the Quadrulini subfamily (see Chapter 16). The unionid remains represented a total of $18,884 \mathrm{kcal}, 2,903.4 \mathrm{~g}$ of protein, and $731.8 \mathrm{~g}$ of lipids. In terms of minerals and vitamins, these unionid remains represented $240.8 \mathrm{~g}$ of calcium, $15.8 \mathrm{~g}$ of iron, $19.8 \mathrm{~g}$ of sodium, $944.2 \mathrm{mg}$ of Vitamin C and 18,884 IU of Vitamin A. While this analysis potentially provides further insight into the foodways of the site's occupants when combined with a diet content inventory of other food items found at the site, it also is plagued by data limitations that are discussed below.

This analysis of nutrient supplements and meat weight is problematic for many reasons. For one, meat weight is derived from the average volume of shell found in the assemblage. In the 41HM61 assemblage, volume is a tricky value to calculate because many of the shell remains were not full shells and had been heavily fragmented. The fragmentation rate of this assemblage was 0.38 . As such, the average volume for this assemblage possibly misrepresents the actual volume of the original shells. Thus, fragmentation makes this nutrient analysis an inappropriate analysis. The fact remains that zooarchaeological data is ordinal at best, so averages are not appropriate as they can be influenced by outliers (Grayson 1984a; Lyman 2008; Wolverton et al. 2014). Reiterating the fact that zooarchaeological data is ordinal at best, any mathematical relationship between derived values must be ordinal as well (Lyman 2008). Since the meat-weight calculation is derived from NRE, meat-weight measurement minimally adds to the discussion of human-use of freshwater mussels. Meat-weight calculations depend upon the assumption that mussels contain the same meat weight per shell volume and nutrients across time and across species. This assumption is possibly inappropriate, but difficult to test under these circumstances. The meat weights calculated from archaeological assemblages provide information at an inappropriate scale for zooarchaeology in this context (Lyman 1979; Grayson 1984b). Combining this nutrient analysis with a inventory of dietary content for other fauna present at 41HM61 might provide insight into the subsistence of the site's Archaic occupants, with heavy limitations.

\section{Systematic Paleontology}

Paleontology has had a standard protocol for reporting identifications. In a typical paleontological study there is a section entitled "Descriptive Paleontology" or "Sys- tematic Paleontology." There, all identified specimens are listed under each taxon, each specimen is described, and the anatomical and morphometric criteria used to make the identification are described verbally and exemplary specimens are illustrated (R. Lee Lyman, in Comments on Driver 2011:34).

As Driver (1992, 2011) and Wolverton (2014) discuss, zooarchaeology often deals with unreliable data. The original death assemblage is subjected to taphonomic processes that alter the resulting assemblage. As such, zooarchaeological data is ordinal scale at best (Grayson 1984a). As a way to make data more accessible and verifiable, a systematic paleontology is included with this report. This work lists all criteria used to identify specimens. It also includes any labeling that might be seen within the data, but not within the actual report.

\section{Identified Taxa \\ Order: Bivalvia; Family: Unionidae}

\section{Genus: Amblema}

\section{Species: Amblema plicata}

Shell shape is oval to rectangular. The beak is above the hinge line and often appears bulbous (very round and inflated). Shells often have three to seven diagonal ridges on the outer margins, but can be unsculptured. The posterior ridge is obscure. The pseudocardinal teeth are divergent, triangular and massive. The left pseudocardinal teeth tend to be slightly oblique; the right pseudocardinal tooth points toward the post-ventral margin, which is useful for differentiating it from Megalonaias nervosa and Quadrula verrucosa. A. plicata prefers mud, sand, and gravel substrates; this species can be found in medium-sized creeks to reservoirs.

\section{Genus: Arcidens}

\section{Species: Arcidens confragosus}

A. confragosus shell is thin and rectangular to quadrate in shape. The beak is above the hinge with diagnostic nodular sculpture. The outer shell is sculptured with radiating ridges. The pseudocardinal teeth are compressed, almost parallel to the hinge. A. confragosus prefers gravel, sand or mud substrate in medium-sized creeks to large rivers, with preferences to larger bodies of water. It is never extremely abundant in freshwater mussel communities. 


\section{Genus: Cyrtonaias}

\section{Species: Cyrtonaias tampicoensis}

Shell shape is oval, where the umbo is inflated and roughly symmetrical. The pseudocardinal teeth are slightly compressed, but more massive than Potamilus purpuratus. The right valve has one pseudocardinal tooth that is teardrop shaped and points to the ventral margin. The left valve has two pseudocardinal teeth that are moderately compressed. C. tampicoensis prefers mud, sand, and gravel substrates and is found in streams and rivers.

\section{Genus: Fusconaia}

\section{Species: Fusconaia mitchelli}

Description: F. mitchelli shells are rectangular. The umbo is above the hinge line and has W-shaped, double-looped beak sculpture. The teeth are 'fusconaia' like, as they are between compressed and massive. The right valve has one pseudocardinal tooth that is roughly triangular and the left valve has two pseudocardinal teeth. F. mitchelli is found in sand, gravel or cobble substrates in larger creeks to rivers. F. mitchelli was redesignated as Fusconaia from Quadrula mitchelli; as Q. mitchelli was listed as Threatened in the state of Texas and a candidate for federal listing, it is assumed $F$. mitchelli will assume those classifications as well (U.S. Fish and Wildlife Service 2014).

\section{Genus: Lampsilis}

Specimens identified as Lampsilis sp. exhibit compressed pseudocardinal teeth. The umbo is often low, with the pseudocardinal teeth close to the beak with no interdentum. Lampsilis sp. also have a weak, double-looped beak sculpture. There are two Lampsilis sp. present in the Leon River basin: Lampsilis hydiana and Lampsilis teres.

\section{Species: Lampsilis hydiana}

L. hydiana shells are oval and inflated. The umbo is often low and deep, with a larger area under the umbo than $L$. teres. The beak has double-loop sculpturing. The pseudocardinal teeth are generally thicker than $L$. teres. The right valve has one pseudocardinal tooth that is often approximately parallel to the hinge line; the left valve has two pseudocardinal teeth. L. hydiana prefers clay, mud, sand, and gravel substrates with slow to moderate currents. It is considered stable throughout its range in Texas, though less common in central Texas.

\section{Species: Lampsilis teres}

L. teres shells are oval-eliptical shaped. The umbo is very low and shallow. The beak has thin double-loop sculpturing. The pseudocardinal teeth are thin and compressed. The right valve has one pseudocardinal tooth that is often parallel to the hinge line; the left valve has two pseudocardinal teeth that are thin, compressed, and parallel. L. teres is often found in mud, sand, and gravel substrates in medium creeks to large rivers. L. teres is considered stable and abundant in central Texas.

\section{Genus: Megalonaias}

\section{Species: Megalonaias nervosa}

M. nervosa shells are thick and rectangularly shaped. They often contain radiating ridges and sculpturing in the middle margin. The umbo is low on the shell and shallow. Beak sculpture is double-looped to nodular. The pseudocardinal teeth are molar-like. The right valve has one pseudocardinal tooth that points left of the center of the ventral margin (towards the anterior margin). The left valve has two pseudocardinal teeth; the posterior tooth is often larger than the anterior tooth. M. nervosa is often found in sand to gravel substrates in medium creeks to large rivers. It is considered stable throughout its range in Texas.

\section{Genus: Quadrula}

Quadrulids have diagnostic pseudocardinal teeth. The right valve has a triangular pseudocardinal tooth that is often torn. The left valve has two pseudocardinal teeth. Of these two left teeth, the anterior pseudocardinal tooth is noticeably larger than the posterior pseudocardinal tooth. There are three quadrulid species present in the Leon River basin: $Q$. apiculata, $Q$. houstonensis, and $Q$. verrucosa.

\section{Species: Quadrula apiculata}

Q. apiculata is quadular to triangular in shape. The pseudocardinal teeth are typical of the genus. The right valve has one pseudocardinal tooth that is shaped like an isosceles triangle, and is often torn; the left valve is typical of other quadrulids (see above). It often has diagnostic pustules covering a majority of the outer shell surface, including throughout the sulcus. These pustules are regular and small. Q. apiculata can be found in a large variety of habitats: from medium creeks to reservoirs, in mud, sand, and gravel. It is considered common throughout its range in Texas. 


\section{Species: Quadrula houstonensis}

Description: $Q$. houstonensis is quadular to triangular in shape. The pseudocardinal teeth are typical of the genus. The left valve's pseudocardinal teeth include the typical size differentiation; the anterior pseudocardinal tooth is usually much larger than the posterior pseudocardinal tooth. Pustules can occur on the outer shell surface of this species, but are at lower densities than pustules on both $Q$. apiulata and $Q$. verrucosa. $Q$. houstonensis is found in mud, sand and gravel in medium-sized creeks to large rivers. Q. houstonensis is listed as Threatened by the state of Texas and is a candidate for federal listing (U.S. Fish and Wildlife Service 2014).

\section{Species: Quadrula verrucosa}

Q. verrucosa shells have an oval to oblong shape. The beak is pointed and low over the hinge line. Shells have many pustules on them with fluting on the entire post-ventral margin. Pustules can continue until the ventral margin. The posterior ridge is very strong, which is useful for differentiating it from Megalonaias nervosa. The pseudocardinal teeth are strong and divergent. The right pseudocardinal tooth is very triangular, with a flat edge on the anterior side; the left pseudocardinal teeth are massive and divergent. Q. verrucosa is found in sand and gravel habitats, most often in large creeks and small rivers, though there is variation among habitats. $Q$.verrucosa is most often found in riffles. It is considered stable across its range in Texas at this time.

\section{Genus: Toxolasma}

Toxolasma sp. shells are elliptical and compressed. The umbo is slightly elevated with a 4 to 8 , bold, single-looped beak sculpture. The pseudocardinal teeth are compressed and peg-like. The right side has one pseudocardinal tooth; the left side has two pseudocardinal teeth. The entire shell did not preserve in either specimen identified to Toxolasma sp. at 41HM61, therefore identification to the species level was not possible. There are two species of unionid in the Toxolasma genus in Texas: T. parvum and $T$. texasense. Both species are found in mud, sand, or finer gravels, and in small creeks to reservoirs. Both species are considered stable across their ranges in Texas.

\section{Genus: Truncilla}

\section{Species: Truncilla macrodon}

T. macrodon shells are thin, elongated ovals. The beak is low, extremely shallow and has fine, single-looped beak sculpture. The pseudocardinal teeth are compressed. The right valve has one pseudocardinal tooth that is small and triangular; the left valve has two pseudocardinal teeth that are thin, roughly parallel, and sometimes exhibit fluting. T. macrodon is often found in mud, sand and gravel substrates in medium-sized creeks and rivers. T. macrodon is listed as Threatened by the state of Texas and is a candidate for federal listing (U.S. Fish and Wildlife Service 2014).

\section{Mixed Taxa}

These designations were used when taxa couldn't be determined to species level. Often, comments within the data will explain why the designation was given due to individual characteristics of the shell fragment. Preservation within the sample often limited the confidence with which a species-level label would have been appropriate.

\section{Species: Amblema plicata or Megalonaias nervosa}

This categorization was used for shells that exhibited characteristics similar to both A. plicata and $M$. nervosa. These characteristics included similarities between the pseudocardinal teeth. If the left pseudocardinal teeth were massive and angled, they looked like both of these species. Often, the beak/umbo is the first to erode. As the beak above the hinge line is useful for differentiating these two species, this erosion causes problems. The presence of hatchmark sculpture is diagnostic of M. nervosa, but within this sample this sculpture was eroded away. Without these distinguishing characteristics, these elements were placed within this broader category for more confident and precise data.

\section{Species: Quadrula apiculata or Quadrula verrucosa}

This categorization was used for specimens that had pustules extending to the ventral margin. These specimens were roughly oblong in shape and represented ventral margins that contained the pallial line.

\section{Conclusions}

The freshwater mussel remains from site 41HM61 represent a diverse community of unionids from the Leon River. The assemblage is dominated by Amblema plicata, Quadrula verrucosa, and Lampsilis teres. A temporal analysis of taxa richness is difficult due to sample-size effects present among subsamples of 41HM61. Feature 19 of the Lange component in- 
cluded ten taxa, with a total of 131 NRE. Shells associated with the Ensor occupation are of interest as they included 63 NRE, but with 12 taxa represented; this pattern could indicate that the Ensor occupation might have utilized freshwater mussel resources more intensely. Taphonomically, the 41HM61 assemblage preserved fairly well, as many fragile species are evident and at times abundant. A paleoenvironmental reconstruction was conducted using Warren's UNIO program. The reconstruction indicates that the Leon River was most likely a small river to large creek; freshwater mussels were collected from areas in the river with shallow water depth and slow water veloc- ities. The freshwater mussel remains of 41HM61 are valuable as they provide further evidence for the presence of F. mitchelli, L. hydiana, and C. tampicoensis in the Leon River during the late Holocene. These three species were not recorded in a modern survey conducted by Randklev et al. in 2011 (Randklev et al. 2013). Site 41HM61 also includes species that are of important conservation concern; $Q$. houstonensis, $F$. mitchelli, and T. macrodon are listed as Threatened by the State of Texas. In conclusion, the freshwater mussel fauna of 41HM61 provides a valuable snapshot of the freshwater mussel community of the Leon River during the Archaic, particularly the Late Archaic. 


\title{
Chapter 15
}

\section{TerRestrial AND Aquatic Gastropods}

\author{
Evan Peacock \\ Sarah K. Gilleland \\ Mary Madden
}

The analysis of snail shells from archaeological sites has a long history in Europe (e.g., Davies 2008; Evans 1972), but the pursuit historically has not been so well-developed in the United States (Bobrowsky 1984). There are exceptions, of course (e.g., Baerreis 1973, 2005; Mead 1991; Peacock and Gerber 2008; Peacock et al. 2005; Snyder 2012), and although Texas has seen its share of CRM projects in which snails have been discarded without analysis (Brown 2006:981), in relative terms the state has been at the forefront regarding snail analysis (Brown 2006:Table 8.2; Malof 2014, and references therein).

One reason that land snail analysis remains a relatively esoteric enterprise in American archaeology is that habitat data are still poorly developed for many species. While some field studies have been carried out specifically to address this lacuna (e.g., Theler et al. 2004; Peacock 2015; Snyder 2012), it remains the case that much work still needs to be done before archaeological gastropod assemblages can be used to their full potential. In the meantime, however, the recovery and basic reporting of snail assemblages, like the one from site 41HM61, provides a valuable corpus of basic data for contemporary and future researchers.

In this chapter, we describe the gastropod assemblage recovered from 41HM61, including discussion of recovery biases, paleoenvironmental characteristics, and change through time. According to some sources, the site lies in the Cross Timbers physio- graphic province (Gould et al. 1960), but other provinces (the Blackland Prairie, the Rolling Plains, the Edwards Plateau) are close at hand, and other sources show finer-scale variability indicating that the site occupies an ecotone between various environmental settings (e.g., the Oak Woods and Prairies, Edwards Plateau, and the Blackland Prairies [LBJ School of Public Affairs 1978]), thus making it an interesting case for paleoenvironmental analysis.

\section{The Assemblage}

Snails were analyzed by the authors using standard guides (e.g., Pilsbry 1940, 1946, 1948), with a number of identifications being checked or provided by Dr. Jochen Gerber, invertebrate specialist with the Field $\mathrm{Mu}-$ seum of Natural History in Chicago. The work reported here does not cover all the snails recovered from the investigations at 41HM61, but only those shells that had been sorted and sent to the authors within the timeframe of the contract. This included flotation and non-flotation samples from several contexts. Not all of the samples sent contained identifiable snails; those that did not are not discussed any further. Those contexts from which identifiable snails were recovered and analyzed are shown in Table 15-1. In total, 5,095 specimens representing a minimum of 30 taxa were identified. Unless otherwise specified, nomenclature follows Turgeon et al. (1998), which differs in various ways from earlier literature (e.g., Anguispira strongylodes in Hubricht [1985] and elsewhere now being A. strongyloides). 
Table 15-1. Gastropods in Order of Abundance.

\begin{tabular}{|c|c|c|}
\hline Taxon & No. & General Habitat Type \\
\hline Hawaiia minuscula & 2,191 & $\mathrm{C}$ \\
\hline Strobilops texasianus & 685 & W \\
\hline Gastrocopta procera & 660 & G/OW, D \\
\hline Lucilla sp. & 447 & G/OW \\
\hline Gastrocopta contracta & 422 & $\mathrm{~F}, \mathrm{Ms}$ \\
\hline Gastrocopta pellucida & 278 & G/OW, D \\
\hline Glyphyalinia cf. indentata & 82 & $\mathrm{C}$ \\
\hline Oligyra orbiculata & 65 & G/OW, D \\
\hline Rabdotus dealbatus & 42 & G/OW \\
\hline Planorbidae & 40 & A \\
\hline Pupoides albilabris & 38 & $\mathrm{O}, \mathrm{D}$ \\
\hline Anguispira strongyloides & 22 & W \\
\hline Millerelix dorfeuilliana & 21 & W \\
\hline Punctum minutissimum & 18 & $\mathrm{C}$ \\
\hline Praticolella berlandieriana & 15 & OW, D \\
\hline Rabdotus sp. & 11 & $\mathrm{G} / \mathrm{OW}$ \\
\hline Euchemotrema leai & 8 & W \\
\hline Hydrobiidae & 8 & A \\
\hline Millerelix sp. & 7 & $\mathrm{~W}$ \\
\hline Succineidae & 6 & $?$ \\
\hline Millerelix mooreana & 5 & W \\
\hline Patera roemeri & 4 & W \\
\hline Cincinnatia integra & 3 & A \\
\hline Helicodiscus eigenmanni & 3 & W \\
\hline Glyphyalinia cf. roemeri & 2 & $\mathrm{~W}$ \\
\hline Euconulus trochulus & 2 & W \\
\hline Polygyriidae & 2 & W \\
\hline Zonitoides arboreus & 2 & OW, D \\
\hline Gastrocopta cf. cristata & 1 & G/OW, D \\
\hline Gastrocopta tappaniana & 1 & $\mathrm{~F}, \mathrm{M}$ \\
\hline Glyphyalinia sp. & 1 & $\mathrm{C}$ \\
\hline cf. Polygyra tholus & 1 & W \\
\hline Praticolella sp. & 1 & $\mathrm{O}$ \\
\hline cf. Pupisoma sp. & 1 & $?$ \\
\hline Strobilops sp. & 1 & $\mathrm{~W}$ \\
\hline Total & 5,095 & \\
\hline
\end{tabular}

\section{Habitat Key:}

A Aquatic

C Catholic

D Dry

F Floodplain

G Grassland

M Moist

Ms Mesic

O Open

OW Open Woodland

W Woodland 


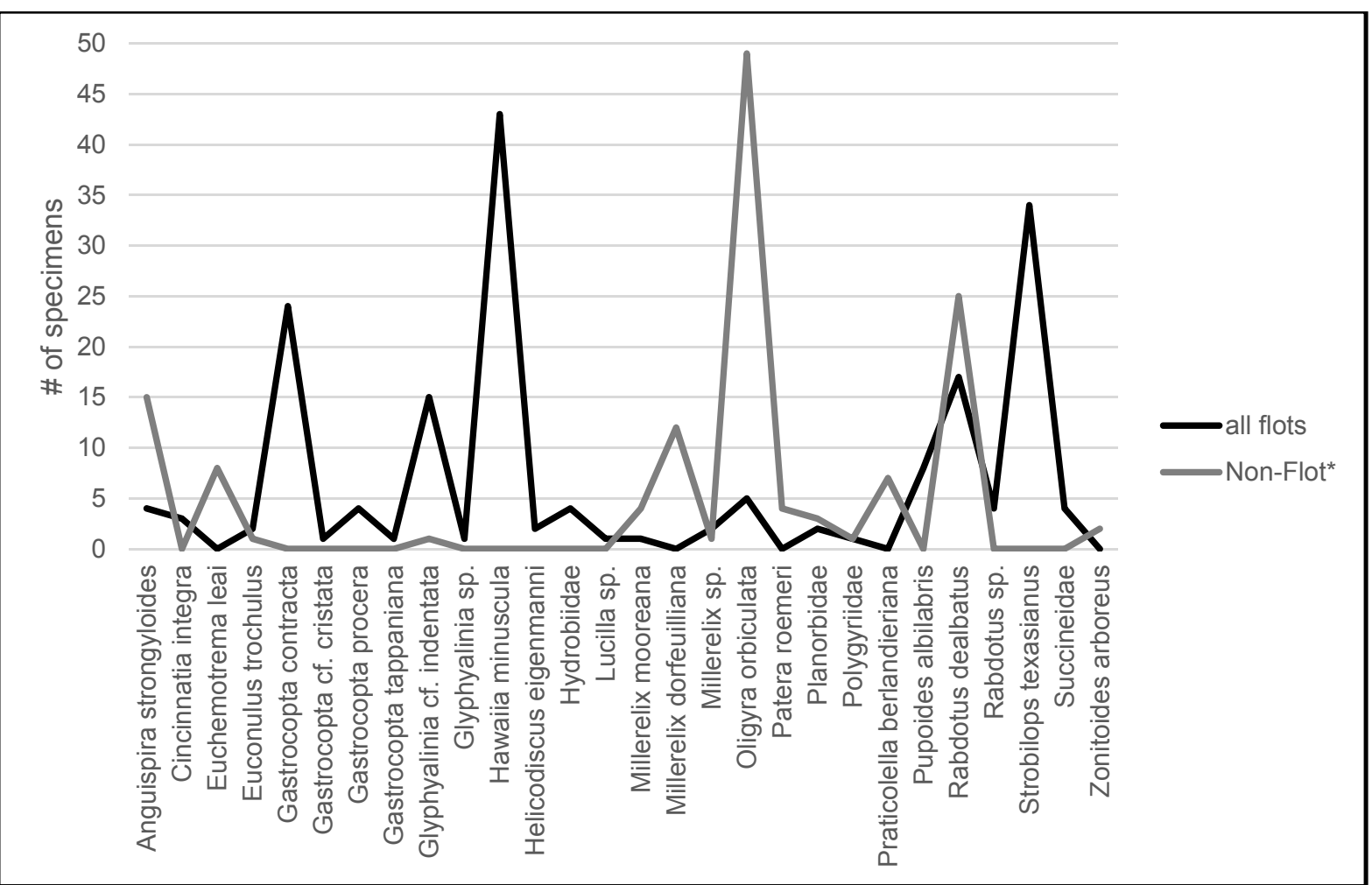

Figure 15-1. Line graph of snail shell recovery in flotation (heavy fraction) vs. non-flotation samples from 41HM61.

\section{Recovery Biases}

Snails were recovered via three primary methods: hand-collecting and/or recovery from quarter-inch mesh during excavation (the "non-flotation" samples in Table 15-1), sieving of the heavy fraction of flotation samples through stacked quarter-inch, eighth-inch, and sixteenth-inch mesh, and hand-sorting of shells from the light fraction of flotation samples. Many samples provided to us only contained small, unidentifiable shell fragments, and those were not analyzed in any way. Those that did contain identifiable snails clearly display the need to employ gentle processing (e.g., via flotation) and fine screens in recovery. Figure 15-1 compares recovery from the non-flotation and heavy-fraction flotation samples (excluding one sample from Block 4, Unit N473E602, Stratum 3, Level C, that combined hand-collected and sixteenth-inch mesh). The differences are striking, to say the least. Without flotation, the assemblage would have been dominated by relatively large, hardy shells (Oligyra orbiculata, Rabdotus dealbatus), while the flotation samples are dominated by small species (e.g., Gastrocopta contracta, Hawaiia minuscula, Strobilops texasianus). It also is clear that simple flotation is not, in itself, sufficient; proper screen sizes must be used in recovery. This is shown in Figure 15-2, where sixteenth-inch mesh was necessary to catch the majority of the shells. What this fact illustrates, unfortunately, is that many, if not most, reported snail assemblages in the archaeological literature are extremely biased due to insufficient recovery methods.

While processing of snails via heavy fraction flotation paid good dividends at 41HM61 in terms of sample adequacy, it is nonetheless instructional to consider also the shells recovered from light-fraction flotation. Omitting these from the analysis would have led to extraordinary bias in the samples, as what Brown (2006) describes as "microsnails" (e.g., many members of Vertiginidae, Hawaiia minuscula, etc.) exist in great abundance in the light fraction (see discussion in Brown 2006). Light-fraction snails compose approximately 93.6 percent of the total assemblage recovered $(4,767$ of 5,095 snails $)$, which of course greatly alters any interpretations that can be provided by these fauna. This sampling effect is illustrated in Figure 15-3. As discussed below, inclusion of the light-fraction microsnails expands what can be done in terms of comparing the assemblage from 41HM61 to other archaeological and mod- 


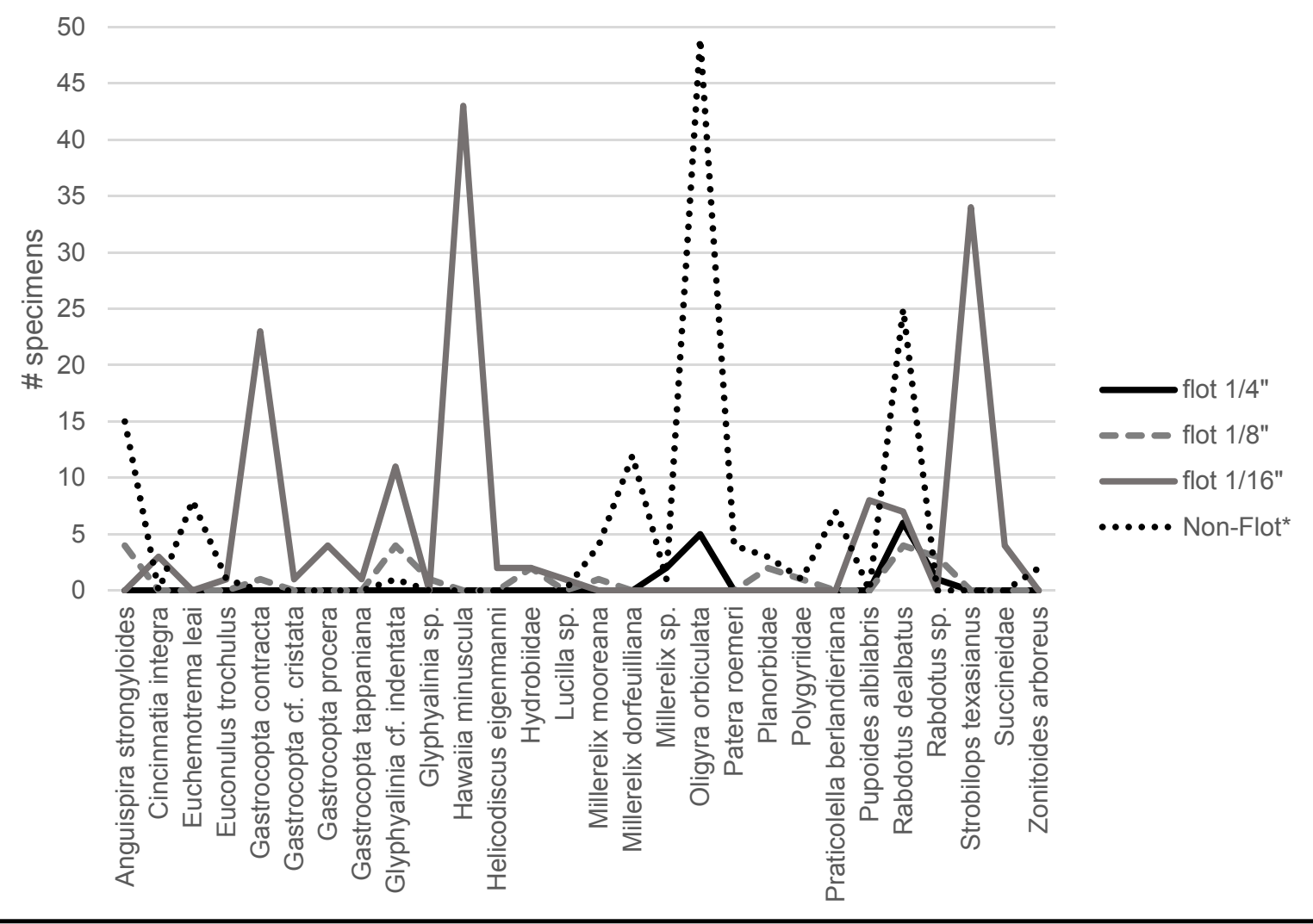

Figure 15-2. Line graph of snail shell recovery in flotation (heavy fraction) samples by size-grade vs. non-flotation samples from 41HM61.

ern assemblages (e.g., via correspondence analysis [Brown 2006; Peacock and Melsheimer 2003; Peacock and Gerber 2008]).

\section{Discussion of Species}

The species recorded (combined from all recovery techniques) are shown in order of abundance in Appendix F, along with general habitat information derived from the literature. Terrestrial snails are described and grouped by family. Since there were so few aquatic snails recovered, they simply are described as a group following the terrestrial snails.

\section{Terrestrial Snails}

\section{Helicinidae}

Oligyra orbiculata. The globular drop is a very widespread species in the Southeast and westward into eastern and central Texas (Hubricht 1985:Map 2). There is some disagreement in the literature about the habitat preferences of this species. Neck (1994:494) describes it as a "wide-ranging...species that requires large amounts of calcium in the substrate but otherwise is very tolerant of environmental conditions." Brown (2006) also describes it as a cosmopolitan species that usually occurs in localized colonies, "usually on limestone, in deciduous or juniper woodlands." Others report it as a calciphile that prefers open areas such as "sunny situations, roadsides, and glades" (Hubricht 1985:3) or "grassland with only scattered shrubs or trees" (Brown 2006). While some have noted that it occurs in woodlands (e.g., Allen and Cheatum 1961:309), it does not do so in particular abundance. For example, Peacock and Gerber (2008) and Peacock (2015) report it as being a cedar-glade species in the Mississippi Black Prairie, where it is almost absent in other habitats (i.e. lowland and upland hardwood forest, Osage orange groves, pine stands, open prairie), while Allen and Cheatum (1961:294) described it as usually occupying "sparsely wooded areas" in Texas, and Malof (2014) notes that it "prefers sun." Hubricht $(1985: 3)$ reports that it is "sometimes semiarboreal" in Texas, while Allen and Cheatum (1961:309) mention its "arboreal habits." Brown notes that the species is "well-equipped to limit water loss and is very drought resistant," echoing Allen and Cheatum (1961) who de- 


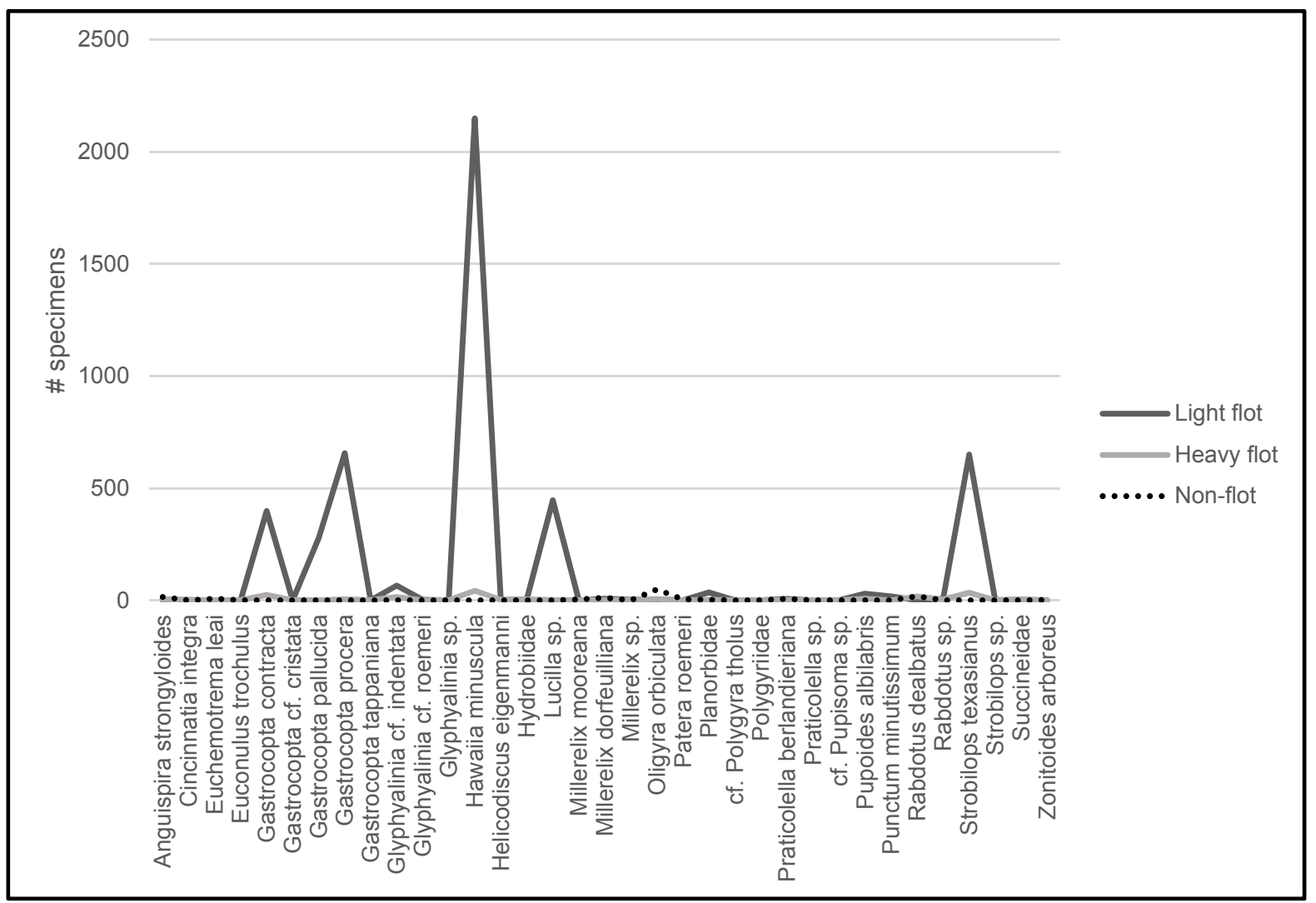

Figure 15-3. Line graph of snail shell recovery in flotation (light fraction) samples vs. flotation (heavy fraction) samples and non-flotation samples from 41HM61.

scribe it as "almost drought resistant because of the operculum." It does not extend north into the Southern Plains (Theler et al. 2004).

Archaeologically, the species is a common one in Texas. Brown (2006) reports that tens of thousands of specimens were recovered from the Rice's Crossing (Brown and Hughes 2003), Smith Creek Bridge (Brown 2002) and Wilson-Leonard (Shaw et al. 1998) sites. Henry (1995) discusses snails from several sites along Hog Creek, noting that $O$. orbiculata increased over time relative to Rabdotus mooreanus (see also Malof 2014), suggesting that this shift was most likely a result of "open grassland progressively [giving] way to woodland." It was virtually absent from archaeological contexts in the Mississippi Black Prairie (Peacock and Melsheimer 2003), despite being locally common in cedar-glade habitats in the province today (Peacock and Gerber 2008; Peacock 2015).

\section{Strobilopsidae}

Strobilops texasianus. The southern pinecone is widespread across the Southeast, from central Texas to the Atlantic (Hubricht 1985:Map 104). Branson (1960) considered this species to fall within the normal range of variation for S. labyrinthicus, but other authors consider it to be a valid species "not readily confused with other species" (Brown 2006). It is generally considered to be a leaf-litter species, found commonly around and under rotten logs, loose bark, and litter (Allen and Cheatum 1961; see discussion in Brown 2006).

This species has been reported from midden samples at the Mustang Branch site (Neck 1994) and a few other sites in Texas (Brown 2006).

\section{Pupillidae}

Pupoides albilabris. The white-lip dagger is a very widespread species, including all of Texas and the Southern Plains, stretching north to northeastern Wisconsin and east to the Atlantic (Hubricht 1985:Map 38; Nekola 2004; Theler et al. 2004). Hubricht (1985:8) describes it as a species of "bare ground, roadsides, old quarries, glades, and waste ground, usually in calcareous areas." It is quite tol- 
erant of arid conditions (Branson 1960:52; Brown 2006; Theler et al. 2004:9). Despite Allen and Cheatum's (1961:305) claim that it is primarily a woodland species, it can be extremely common in prairie and other grassland settings, especially where there are calcareous substrates and bare ground (e.g., Branson 1960:52; Brown 2006:967; Theler et al. 2004; Malof 2014; Nekola and Coles 2010:43; Peacock and Melsheimer 2003; Peacock and Gerber 2008). It has been reported at a number of archaeological sites, including the Mustang Branch site (Neck 1994) and site 41BL116 (Malof 2014) in Texas.

$\boldsymbol{c f}$. Pupisoma $\boldsymbol{s p}$. One specimen recovered from the flotation light fraction was tentatively identified as a babybody snail. If correct, it likely is a specimen of $P$. dioscoricola, the yam babybody, following Brown (2006). Brown (2006:1093) identified nine specimens of this minute species in the bench deposits at Berger Bluff, noting that it had not previously been listed in archaeological reports from Texas or "nearby states." He considers it to be an indicator of mesic floodplain habitats (Brown 2006:1093). Because we have not identified this specimen with certainty, we do not include it in discussions of habitat at 41HM61.

Gastrocopta contracta. The bottleneck snaggletooth is an extremely widespread species, ranging from south and central Texas northward into Canada and eastward to counties bordering the Atlantic Ocean (Brown 2006:Figure 8.6; Hubricht 1985:Map 42). Not surprisingly, it has been reported from a range of habitats (Archer 1939; Goodrich 1943; Hubricht 1985; Nekola 2003, 2004; Nekola and Coles 2010:37), from river terraces covered in hackberry, maples and cane (Baerreis 2005) to bottomland hardwoods, Osage-orange groves, and cedar glades (Peacock and Gerber 2008), to "deep woodlands," sparsely wooded areas, and woodland margins (Allen and Cheatum 1961), to secondary hardwood-forest growth (Baerreis 2005). While Allen and Cheatum (1961:303) state that it "prefers a wooded protected area," Baerreis (2005) describes it as having "open habitat tendencies," although modern samples from the Savannah River valley were evenly split between open and wooded habitats. Nekola and Coles (2010:37) note that it does not require forest cover, and Snyder (2012) and Theler et al. (2004) note that it was not found west of north-central Oklahoma in their survey of the Southern Plains. Where it was found by Theler et al., it had an affinity for riparian woodlands and toe slopes. If a preference can be noted for this species, it is for calcium-rich areas (Branson 1960:55).
Archaeologically, the species has been reported from Protohistoric and early Historic Indian deposits in the Mississippi Black Prairie (Peacock and Melsheimer 2003), in midden levels at the Mustang Branch site (Neck 1994), in the Archaic-age Stallings Island site and other sites in the Savannah River Valley in Georgia (Snyder 2012), and elsewhere. Interestingly, neither it nor any other pupillid snails were found in the rock shelters in central Texas, as discussed by Henry (1995).

Gastrocopta $\boldsymbol{c} f$. cristata. Hamilton County is on the eastern edge of the range for the crested snaggletooth in the United States (Hubricht 1985:Map 47; Nekola and Coles 2010:Figure 9). The specimen from 41HM61 has the "strong, whitish crest parallel to and behind the lip, and separated from it by a marked contraction" characteristic of the species (Pilsbry 1948:911). In addition, the angulo-parietal lamella is not bifid and is more deeply recessed than is the case in G. procera (Pilsbry 1948:913). We thus are reasonably sure of the identification. Allen and Cheatum (1961) show it as a woodland-edge and "deep woodlands" species, but this is an unusual characterization. The species is more frequently described as a calciphile and "a species of grassy places, often where it is quite dry" (Hubricht 1985:10). Nekola and Coles (2010) list it as a "more xeric" species than other members of the genus, noting that it resides on sandy floodplains. Theler et al. (2004) found it in riparian woodlands, pastures/broad plains, and rarely in dunes. Branson (1960) states that its habitat preferences are essentially the same as for $G$. procera. The species has been little reported from archaeological contexts in central or eastern Texas.

Gastrocopta pellucida. The slim snaggletooth is prevalent mainly in tropical and subtropical regions of the Southern Plains and along the Gulf Coast, including Hamilton County, although it is also known prehistorically from northern regions of Texas and on into Oklahoma (Hubricht 1985:Map 49). It is described as a hardy species, being more arid- and drought-tolerant than G. procera (Neck 1994; Nekola and Coles 2010), preferring a drier environment than even G. contracta (Brown 2006). It is commonly noted as being associated with grass roots or grasslands (Brown 2006; Cheatum and Fullington 1973; Neck 1994; Nekola and Coles 2010), although Allen and Cheatum (1961:305) report it as being found "also in deep woodlands," while Brown (2006) reports that it may be found on rock ledges, and Branson (1961:59) describes it as being found "under rocks and piles of Bermuda grass." 
Gastrocopta procera. The wing snaggletooth is a very widespread species, occurring over the eastern United States and into the Great Plains (Hubricht 1985:Map 46). As with G. cristata, sources indicate both wooded and open environments (e.g., Cheatum and Fullington 1973). Hubricht (1985:9) describes it as a calciphile, "usually found on rather dry ground with sparse vegetation." Branson (1960:58) states, "This species lives in wooded areas which border streams and ponds." Cheatum and Fullington (1973:20) note that it is "frequently found under limestone rock on sloping hillsides with sparse trees and shrubs." It is relatively tolerant of dry conditions (Theler et al. 2004:9; see discussion in Brown 2006), often occurring with Pupoides albilabris (Hubricht 1985:9) and other pupillid snails in prairie or dry, open woodland settings (e.g., Peacock and Melsheimer 2003; Theler et al. 2004). For example, Peacock and Gerber (2008) report it in low numbers in upland and lowland hardwood settings, but note that it is quite abundant in blackland prairie or cedar-glade habitats in the Mississippi Black Prairie. Brown (2006) lists a number of archaeological sites in Texas and elsewhere from which the species has been recovered.

Gastrocopta tappaniana. The white snaggletooth has a widespread, if spotty, distribution in the eastern United States, with Hamilton County located on the western edge of its range (Hubricht 1985:Map 57). Hubricht (1985:9) describes it as a calciphile, "usually found in wet places, margins of ponds, floodplains of streams, and marshes." It can occupy a range of habitats (e.g., Nekola 2004), but does seem to prefer either wooded or open wetlands, such as "riparian floodplains and swamp woodlands, mesic and wet prairies, open shoreline...fens, pocosins, and Sphagnum bogs" (Nekola and Coles 2010:10) or rock outcrops around springs (Basch et al. 1961). Although Brown (2006) considers it a terrestrial snail, he notes that it "could perhaps [be] classified as amphibious." He discusses its presence in a few archaeological and paleontological sites, but notes further that it is "fairly uncommon" in the archaeological record.

\section{Succineidae}

Four specimens of amber snail shells were recovered from 41HM61. Unfortunately, these snails cannot reliably be identified to species using shell characteristics alone. Brown (2006) characterizes the succineids as "amphibious and characteristic of damp ground," but in fact succineid shells are very common in dry, grassland settings like the Mississippi Black Prairie (Peacock 2015; Peacock and Melsheimer 2003; Pea- cock and Gerber 2008; Peacock et al. 2005) and the Southern Plains (Theler et al. 2004). This is probably $S$. indiana, the xeric ambersnail in both cases, which Hubricht (1985:15) describes as "usually found in rather dry, sunny situations on bare ground." As we cannot ascertain with certainty the species found at 41HM61, these are not considered in the general discussion of paleoenvironment below, although we do include them in the correspondence analysis.

\section{Bulimulidae}

Rabdotus dealbatus. The whitewashed rabdotus is a species common to central and southern Texas, southern New Mexico, eastern Oklahoma, and the Black Belt Prairie of Mississippi and Alabama (Hubricht 1985:Map 355). We have not tried to distinguish between $R$. dealbatus, $R$. mooreanus, or $R$. alternatus because, as Brown (2006) notes, "The three species are only weakly differentiated. They overlap greatly in size and shape, and because of bleaching and loss of pigmentation, archaeological samples are difficult to speciate." Many of our specimens display the "gray-brown stripes" characteristic of $R$. dealbatus (Brown 2006), so we have chosen that form for reporting the specimens from 41HM61.

Rabdotus dealbatus is a mesic-adapted calciphile (Brown 2006; Hubricht 1985:36). "In Texas it is generally found along stream bottoms and in similar open woodlands within the prairie" (Fullerton and Pratt 1974:16). It is a common species in eroded, chalky areas in the blackland prairies of Mississippi and Alabama; it was not recovered in litter samples in forested stands in that province except in open, cedar-glade settings (Peacock 2015; Peacock and Gerber 2008; Peacock and Melsheimer 2003). Malof (2014) describes members of the genus as being "semi-arboreal" and favored by grasses and shrubs, while Allen and Cheatum (1961:301) state that "this snail...is characteristic of semi-arid open country and is often called the "prairie snail."' Brown (2006) assigns all specimens from Berger Bluff to Rabdotus sp., rather than distinguishing between $R$. dealbatus and $R$. mooreanus. He is correct that distinguishing between these two taxa is difficult, but we are reasonably confident that our whole, mature specimens conform to the descriptions for $R$. dealbatus. We leave fragmentary or immature specimens in Rabdotus sp.

This genus has received more attention in the archaeological literature of North American than any other taxon due to suggestions that it was a food source for Native peoples (Clark 1973; Malof 2014; Neck 1994:496; 
Simmons 1956). This suggestion is based on the relatively large size of the snail (by North American standards), by it great numbers in some archaeological sites, by evidence of burning of the shells, by skewed size distributions between contexts within particular sites (e.g., Neck 1994:496), and by ethnographic observations (Clark 1976; Hester and Hill 1975; Honea 1962). It also has been used for paleoenvironmental purposes, such as Henry's (1995) suggestion that a relative decline in Rabdotus (R. mooreanus) and a concomitant increase in Oligyra orbiculata over time at several sites in north-central Texas represented climate change leading to increased woodland. Exploring this topic via size distributions requires, of course, that recovery methods be adequate for juvenile and fragmentary shells.

\section{Helicodiscidae}

Helicodiscus eigenmanni. The Mexican coil is found in south-central Texas, with Hamilton County situated on the northeastern edge of its range in North America (Hubricht 1985:Map 180). Hubricht (1985:21) describes it as a calciphile, "found under leaf litter in ravines and on river bluffs." Allen and Cheatum (1961:307) give its habitat as "near the edges of streams and lakes." A single specimen of this species was reported from a midden sample at the Mustang Branch site (Neck 1994).

Lucilla $\boldsymbol{s} \boldsymbol{p}$. In this category we include snails that in earlier studies (e.g., Brown 2006; Peacock and Melsheimer 2003; Peacock et al. 2005) tend to be identified as Helicodiscus singleyanus or H. inermis, archaeological specimens, which are difficult to distinguish. This follows the recommendation of Dr. Jochen Gerber and is based on recent taxonomic literature (see discussion in Peacock and Gerber 2008) that supersedes Turgeon et al. (1998). The single specimen at 41HM61 is probably L. singleyanus, which has a widespread but oddly spotty distribution in North America (Hubricht 1985:Map 179), possibly due to identification difficulties (even with modern specimens), given the size of this very small snail. Hubricht (1985:220 describes it as "a species of open, grassy places... and meadows," while Peacock and Melsheimer (1985) and Peacock and Gerber (2008) report it from cedar glades. It is a common species in archaeological contexts in the Mississippi Black Prairie (Peacock and Melsheimer 1985; Peacock and Gerber 2008).

\section{Discidae}

Anguispira strongyloides. The southeastern tigersnail is found from Texas east to South Carolina and north to central Missouri (Hubricht 1985:Map
104). According to Hubricht's map, Hamilton County is on the western edge of the range; Brown (2006) attributes this to moister conditions prevailing in eastern Texas. The species has a wide tolerance of environmental conditions (Malof 2014), but is chiefly a woodland species (see discussion in Brown 2006). It has been reported from a number of sites in central and eastern Texas (see Brown 2006), where it sometimes is listed as A. alternata (e.g., Henry 1995).

\section{Euconulidae}

Euconulus trochulus. The silk hive occurs from central Texas across the Southeastern states (Hubricht 1985:Map 332). Hubricht (1985:33) describes it (and most members of the genus) as a species found "in moist leaf litter on wooded hillsides and in ravines." Allen and Cheatum (1961) list it (as E.chersinus) as a "deep woodlands" species. It apparently is quite rare in archaeological deposits in Texas, as it is not mentioned in any of the references given in the present chapter.

\section{Oxychilidae}

Glyphyalinia $c f$. indentata. The carved glyph is shown by Hubricht (1985:Map 222) as only occurring on the very eastern and northern fringes of Texas. As he notes (Hubricht 1985:24), however, what "has been called Gyphyalinia indentata...is a series of anatomical species, with little or no shell differences." Brown (2006) elaborates on this situation, noting that in many archaeological and modern cases in Texas different names (e.g., G. umbilicata, Retinella indentata paucilirata) have been used. As Brown (2006) further states, "Unfortunately, the persistent taxonomic confusion in the literature makes it difficult to discern exactly what has been recovered archeologically." It is generally a leaf-litter species, but may be found in a variety of settings, from hardwoods to cedar glades (e.g., Baerreis 2005; Theler et al. 2004; Nekola 2004; Peacock and Gerber 2008; Peacock and Melsheimer 2003). Brown (2006) notes instances where $G$. indentata has been reported from archaeological contexts in Texas. The single specimen of Glyphyalinia sp. from 41HM61 likely is a fragmentary specimen of $G$. cf. indentata.

Glyphyalinia $\boldsymbol{c} f$. roemeri. The pretty glyph is a terrestrial species that prefers moist, protected areas (Neck 1994). Hubricht (1985) describes its habitat as sheltered under rocks, in moist leaves, and in wooded areas. According to Brown (2006), the current range of this species is primarily the Edwards Plateau, a geographic area of central to southwestern Texas (Neck 
1994). Although Hamilton County does not fall in this geographic area, the range of Glyphyalinia roemeri extends past the plateau and farther to the north (Hubricht 1985:Map 224), plus Hamilton County is near the Edwards Plateau. As Pilsbry (1946) records it as being located in central Texas, it may be more accurate to include all of central and southwest Texas in its range.

\section{Pristilomatidae}

Hawaiia minuscula. The minute gem is an extremely widespread species (Hubricht 1985:Map 289), including most of Texas. Hubricht (1985:29) describes it as "a species of bare ground...never found... in leaf litter." Conversely, Peacock (2015; Peacock and Gerber 2008) collected this species in litter samples from a variety of settings, as did Nekola (2004). Baerreis (2005) collected it from riverbank settings in mixed hardwood forests. Theler et al. (2004) found it on protected, rocky, grass-covered toe slopes and in cottonwood debris in riparian woodlands. Brown (2006:944) describes this species as being "aridity tolerant."

\section{Polygyridae}

Euchemotrema leai. The lowland pillsnail is generally found from central and eastern Texas northward to eastern Kansas and east to the western edge of Georgia (Hubricht 1985:Map 427 [as Stenotrema leai aliciae - see Pratt 1981 for a discussion of Polygyrid taxonomy in Texas]). Hubricht (1985:41) describes it as being "usually found in meadows, along roadsides, and near springs, but also found in floodplain woods." Nekola (2004) reports this species from farther north than indicated by Hubricht (1985), showing it as having been collected from a variety of upland and lowland forest and grassland habitats. Brown (2006) lists it as a woodland species, as do Allen and Cheatum (1961). It was found in very low numbers in cedar-glade, upland mixed hardwood, and canebrake settings in the Mississippi Black Prairie (Peacock and Melsheimer 1985; Peacock and Gerber 2008).

Millerix dorfeuilliana. The oakwood liptooth occurs in a northeast-southwest band running from eastern Missouri to central Texas (Hubricht 1985:Map 393 [as Polygyra dorfeuilliana]). True to its name, Hubricht characterizes it as a species of dry, upland woods.

Millerelix mooreana. The grassland liptooth is a species of central to southeastern Texas (Hubricht
1985:Map 389 [as Polygyra mooreana]). Hubricht (1985) describes it as being "found under leaf litter, rocks, and logs from river bluffs to hilltops, usually in wooded areas." Neck (1994) reports small numbers from non-midden lots at the Mustang Branch site.

Patera roemeri. The Texas oval is a central/ southeastern Texas species (Hubricht 1985:Map 474 [as Medoson roemeri]). Hubricht (1985) describes it as being "found under rocks, leaf litter, and logs on wooded slopes near streams," the latter characterization being seconded by Malof (2014). Allen and Cheatum (1961:309) denote it as a woodland species.

$\boldsymbol{c f}$. Polygyra tholus. This is an old name (e.g., Hubricht 1985; Pilsbry 1940) for an apparently rare drift snail described for south-central/southeast Texas, but not one currently in use in the taxonomic literature. Pratt (1981) discusses Millerelix tholus, a "probably extinct species of the coastal plain," which closely resembles Millerelix mooreana in its shell characteristics. Pilsbry (1940:624-625) also describes it as being similar to Polygyra [= Millerelix] mooreana, but with a distinctively larger umbilicus. Over time it has been variously listed as Helix tholus, Polygyra mooreana tholus, Daedalochila tholus, and Daedalochila mooreana tholus. While the specimen from 41HM61 appears different enough to us to separate it from Millerelix mooreana, we are uncertain as to its proper taxonomic assignment, and this specimen will not figure into discussions of the site's paleoenvironment or in the correspondence analysis.

Praticolella berlandieriana. The banded scrubsnail occurs in central to south-central Texas (Hubricht 1985:Map 432). Hubricht (1985) describes it as being "usually found in woods near streams, but also in open places," a habitat assignment basically repeated by Malof (2014). Brown (2006) characterizes it as being found in wooded floodplains, in brush thickets, or in grasslands. Neck (1994) reports this species in low numbers from midden columns at the Mustang Branch site, while it also was present in very low numbers at several rock shelters in central Texas (Henry 1995). We have chosen not to follow Brown (2006) in assigning our specimens to P. pachyloma, as we are not able to make the distinctions he saw in his samples from Berger Bluff.

\section{Punctidae}

Punctum minutissimum. The small spot is fairly widespread over the eastern United States and is still present across the Great Plains, although in less 
proliferation (Hubricht 1985:Map 200). Hubricht's findings did not place this snail in Hamilton County, but several specimens were recovered at 41HM61. Punctum minutissimum appears to have initially been equated with the European species $P$. pygmaeum until the early 1900s (Pilsbry 1948). Its habitat is reported as "deep pockets of leaf litter" (Hubricht 1985:22), and it appears to prefer dense hardwood growths (Peacock and Gerber 2008; Pilsbry 1948), although Peacock and Gerber (2008) also found it to be common in cedar glades.

\section{Zonitidae}

Zonitoides arboreus. The quick gloss has a huge range in North America, including central and eastern Texas (Hubricht 1985:Map 321). As the name implies, it is generally a woodland species. This species seems to be relatively quite rare in archaeological deposits in Texas.

\section{Aquatic Snails}

A total of 51 aquatic snails were in the materials we examined. Due to time constraints and the relative difficulty with specific identification of freshwater gastropods, we have not treated these in detail. They include 40 undetermined planorbid snails (probably Helisoma and Gyraulus and/or Planorbella sp.), eight undetermined Hydrobiidae, and three specimens confidently identified as Cincinnatia integra, the midland siltsnail. This is an important identification for biogeographical purposes. According to Brown (2006:1124):

Fullington (1978b:37) points out that it [C. integra] is a fairly common Pleistocene fossil in north Texas, but he could find no definite living populations in the state and tentatively regarded it as extirpated in Texas. He remarked that "However, it probably will be found alive in the streams of northeastern or central Texas... it is strongly suspected that relict colonies might exist in some northern Hill County streams." Seven specimens were found in the Preiss Ranch drift sample..., and if these are not subfossil, possibly they indicate the presence of a recent population in the Coleto Creek basin. Hershler and Thompson (1996:50, Fig. 70) show the species as widely distributed in the Mississippi River basin and Midwest and present across the south-central part of Texas in an irregular band from Chambers County in the east to Kinney County in the west. They list it as occurring in Cardenas Creek, Goliad County, Ripley Lake and Garcitas Creek (Victoria County) and the Guadalupe River. In Kansas, it occurs in the eastern half of the state, but may be declining (Angelo, Cringan and Fry 2002:249).

The species, as reported in the literature, has a wide range of habitat tolerances (see discussion in Brown [2006]). We therefore simply consider it along with the other aquatic specimens as a group.

\section{Paleoenvironment}

Using the general habitat assignments outlined previously in Table 15-1 (derived from Brown [2006] and other sources), the assemblage as a whole (Figure 15-4) is balanced between woodland-habitat species and those that represent either open woodlands and/or grassland. This is an expected pattern, given the site's location in what can be considered an ecotonal area for several different physiographic provinces. The "floodplain, mesic" category consists solely of Gastrocopta contracta, which could be found in either or both of the other two general areas. A low proportion of certain taxa (e.g., Pupoides albilabris) likely represent open conditions.

When shells from those contexts for which a temporal assignment can be made (see Appendix F) are combined into overall habitat types (combining Woodland with Floodplain taxa, and Grassland with Open Woodland and Open taxa, while disregarding the aquatic snails), some useful data emerge (Figure 15-5). Because of small sample sizes, we are combining data from the various Late Archaic contexts at the site. While the numbers remain small, conditions seem to have been considerably drier, with less tree cover, during the Middle Archaic. Drying seems to have continued into the Late Archaic. During the hiatus between Late Archaic and the Late Prehistoric Toyah occupation, the area seems to have become more heavily forested, with Woodland/Floodplain taxa being more common during this last occupation.

Another way to analyze snail assemblages is via correspondence analysis (e.g., Brown 2006), a method that has proved especially useful for comparing archaeological and modern assemblages (Peacock and Gerber 2008). It is difficult to find other archaeological assemblages for comparison, however, because, as discussed above, unless microsnails are hand-picked out of the light fraction of flotation samples or otherwise systematically recovered through very fine 


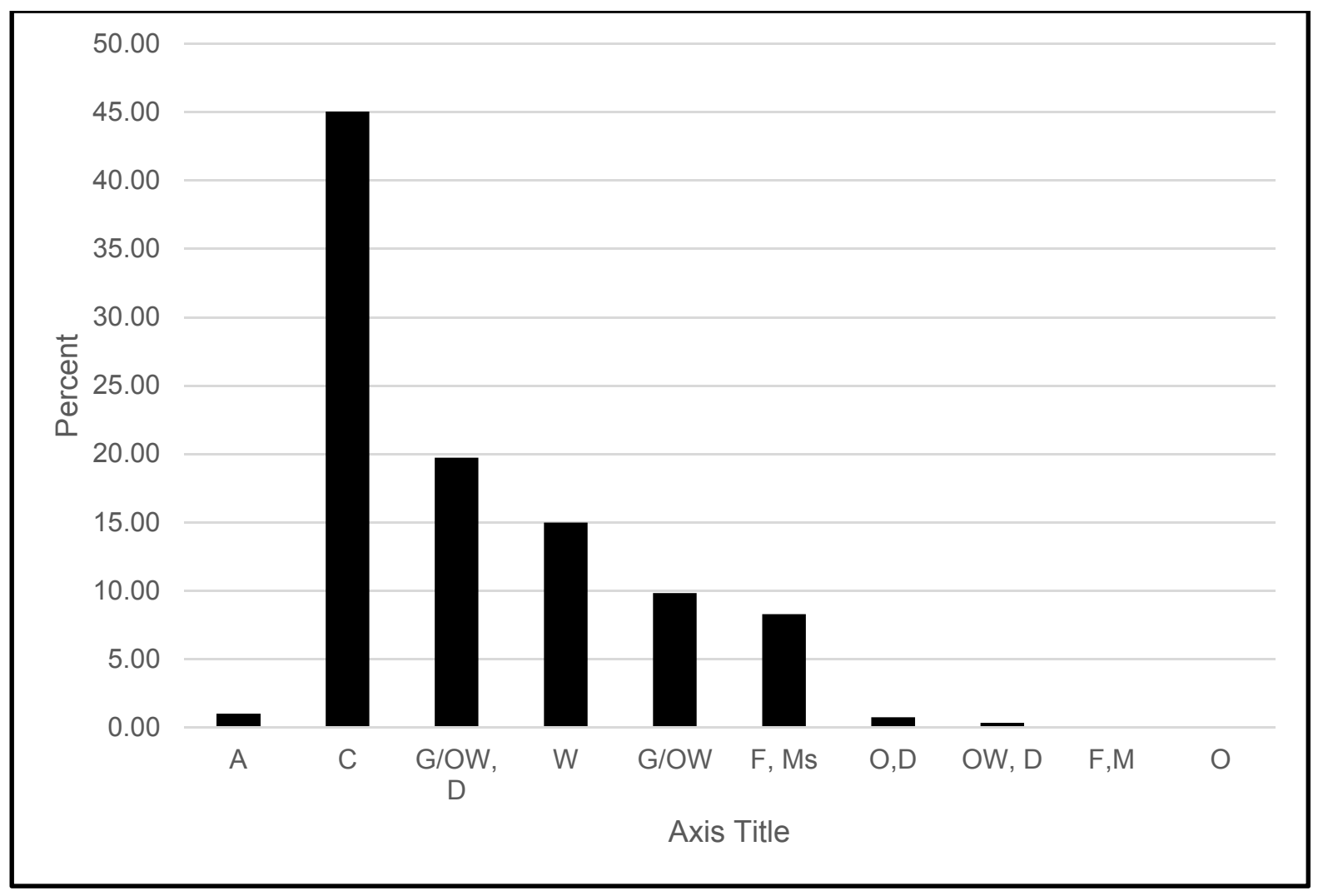

Figure 15-4. Bar graph of proportions of taxa by general habitat type for the total identified assemblage at site 41HM61. A - Aquatic; W - Woodland; G/OW/D - Grassland/Open Woodland, Dry; C - Catholic; F, Ms - Floodplain, Mesic; O, D - Open, Dry; G/OW - Grassland, Open Woodland; F, M - Floodplain, Moist; O - Open.

screens with little mechanical force, the assemblages cannot be considered representative of what was at the sites when they were occupied. Here, we compare the three lots (Middle Archaic, Late Archaic, and Toyah) from 41HM61 to assemblages from specific habitats collected by Theler et al. (2004) in their Southern Plains Gastropod Survey. We did not include data from "mixed" habitats in their report. We also include lots from the late Pleistocene/Early Holocene Berger Bluff geological deposits on the Gulf Coastal Plain near Victoria, Texas (Brown 2006). Much of Brown's (2006) data are derived solely from quarter-inch samples; here, we use only that small amount of data derived from Brown's fine-screening of matrix samples, which are subdivided into mesic woodlands (Strata 1, 2A, 2B), transitional mesic woodlands/dry woodlands (Stratum 2C), and dry woodlands (Strata 2D, 3).

We exclude samples that include mixes from these groups, as well as the few specimens tabulated by Brown under "calc" unless a stratum designation also is given (Brown 2006). We also include modern data from the Black Prairie of Mississippi (Peacock and Gerber 2008), despite the distance from Hamil- ton County, as recovery was comparable to what is reported here and, as noted above, since 41HM61 lies on an ecotone that includes the Oak Woods and Prairies, the Edwards Plateau, and the Blackland Prairies. The latter province has interesting parallels with the Black Prairie of Mississippi, with numerous shared faunal and floral characteristics. For example, contra Schambach (2003), Osage orange (Maclura pomifera) existed in both areas in prehistoric times (Seltzer 2007), and one habitat type collected for snails in the Black Prairie is Osage-orange groves (Peacock and Gerber 2008). We do not include the archaeological assemblages from the Mississippi Black Prairie (Peacock and Gerber 2008), as their environmental characteristics are inferred from the modern Black Prairie samples. We exclude data from canebrakes and pine stands from the Mississippi data set, as those habitat types are unlikely to have been present in the Hamilton County study area, and we do not include aquatic or amphibious species due to uncertainty about how they come to be included in archaeological deposits plus difficulties in species identifications (except for Succineidae, which, as noted above, may be common in prairie settings). For comparability with Brown 


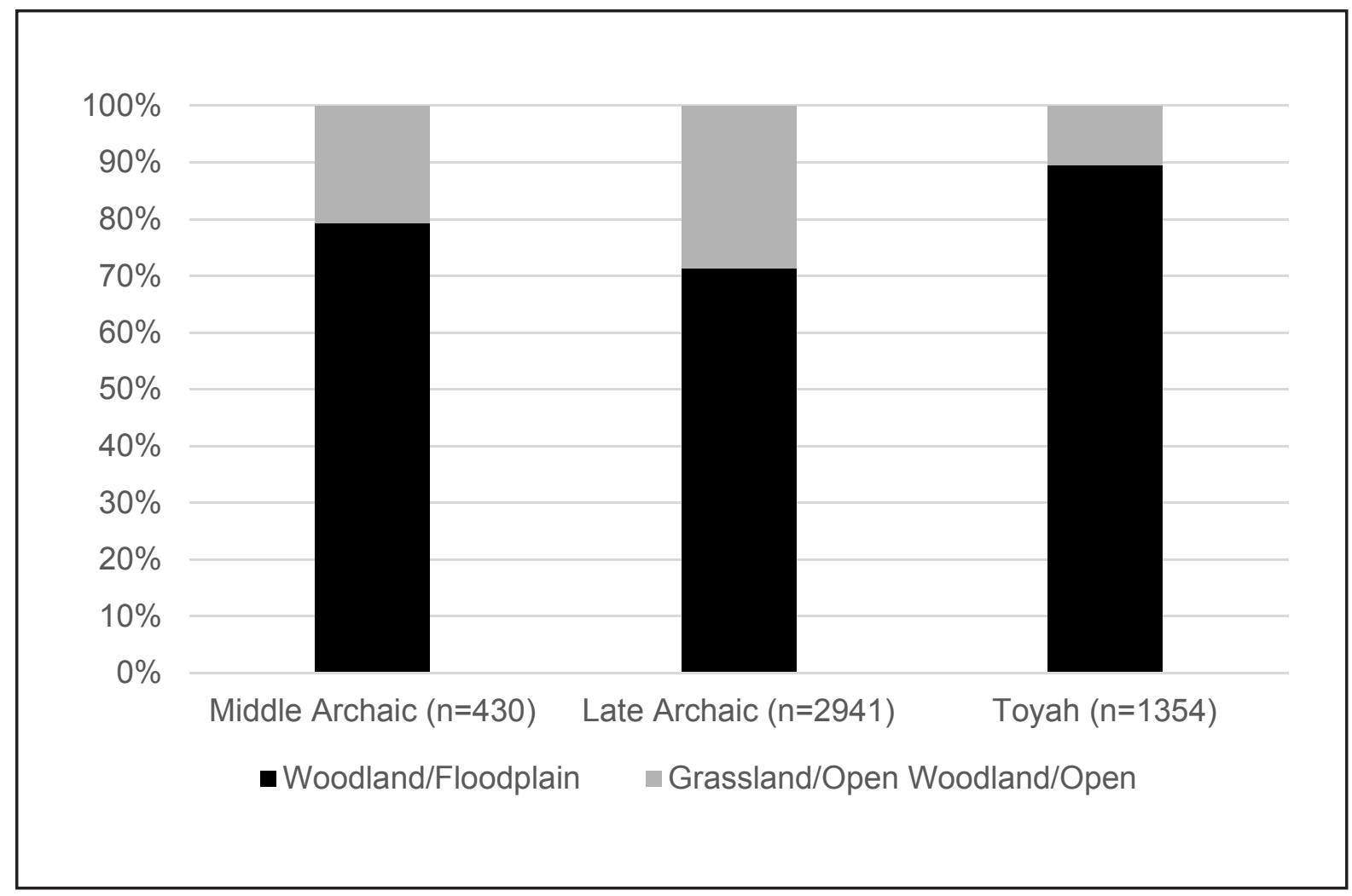

Figure 15-5. Bar graph of proportions of Woodland/Floodplain species to Grassland/Open Woodland/Open species by time period.

(2006), we combine all Rabdotus under Rabdotus sp. We do not include our single specimen of cf. Pupisoma sp. due to uncertain identification; accordingly, we also do not include the specimens so identified at Berger Bluff by Brown (2006).

Analysis was run using PC-Ord 6.08 (McCune and Mefford 2011). We conducted a Bray-Curtis ordination using a relative Sorenson distance measurement, Bray-Curtis original endpoint selection, Euclidian axis projection geometry, and cityblock residual distance calculation (see McCune and Mefford 2011 for discussion of analytical choices and relevant literature citations).

The first ordination, illustrated in Figure 15-6, used all lots mentioned above. These included: (1) three lots from the combined Middle Archaic, Late Archaic, and Toyah deposits at 41HM61; (2) seven lots from the Southern Plains Gastropod Survey by Theler et al. (2004) (signified by the SP prefix), with data from individual samples combined into seven different distinct habitat types as defined by Theler et al. (2004) (i.e. $\mathrm{D}=$ dunes, $\mathrm{MT}=$ mesa tops, $\mathrm{PB}=$ pastures $/$ broad plains, $\mathrm{RW}=$ riparian woodlands, $\mathrm{RL}=$ rock ledges,
$\mathrm{TS}=$ toe slopes, and WD = wooded dunes); (3) six lots from the Mississippi Black Prairie (Peacock and Gerber 2008) (signified by the prefix BP and divided into six habitat types $(\mathrm{CG}=$ cedar glade; $\mathrm{OO}=$ Osage orange glade; $\mathrm{P}=$ prairie; $\mathrm{BH}=$ bottomland hardwoods; $\mathrm{UH}=$ upland hardwoods; $\mathrm{UM}=$ upland mixed forest); and (4) three lots from Berger Bluff (Brown 2006) (signified by the prefix $\mathrm{BB}$; with three habitat types (DW = dry woodlands; $\mathrm{MW}=$ mesic woodlands; $\mathrm{MW} /$ $\mathrm{DW}=$ mixed mesic and dry woodlands).

The results, as shown in Figure 15-6, display an interesting separation of gross habitat areas, with the Mississippi Black Prairie samples being positive along Axis 1 (which accounted for 46.92 percent of the variance in the data), while the Southern Plains samples are positive, and the Berger Bluff samples strongly negative, both along Axis 2 (which accounted for an additional 39.12 percent of the variance, for a cumulative 86.04 percent). The only "outlier" consists of the Southern Plains "Wooded Dune" samples, which are distinct from all others, being strongly negative along Axis 1. Interestingly, the two Archaic period lots from 41HM61 fall between all other lots, which is a strong indication that the site area was indeed "ecotonal" 


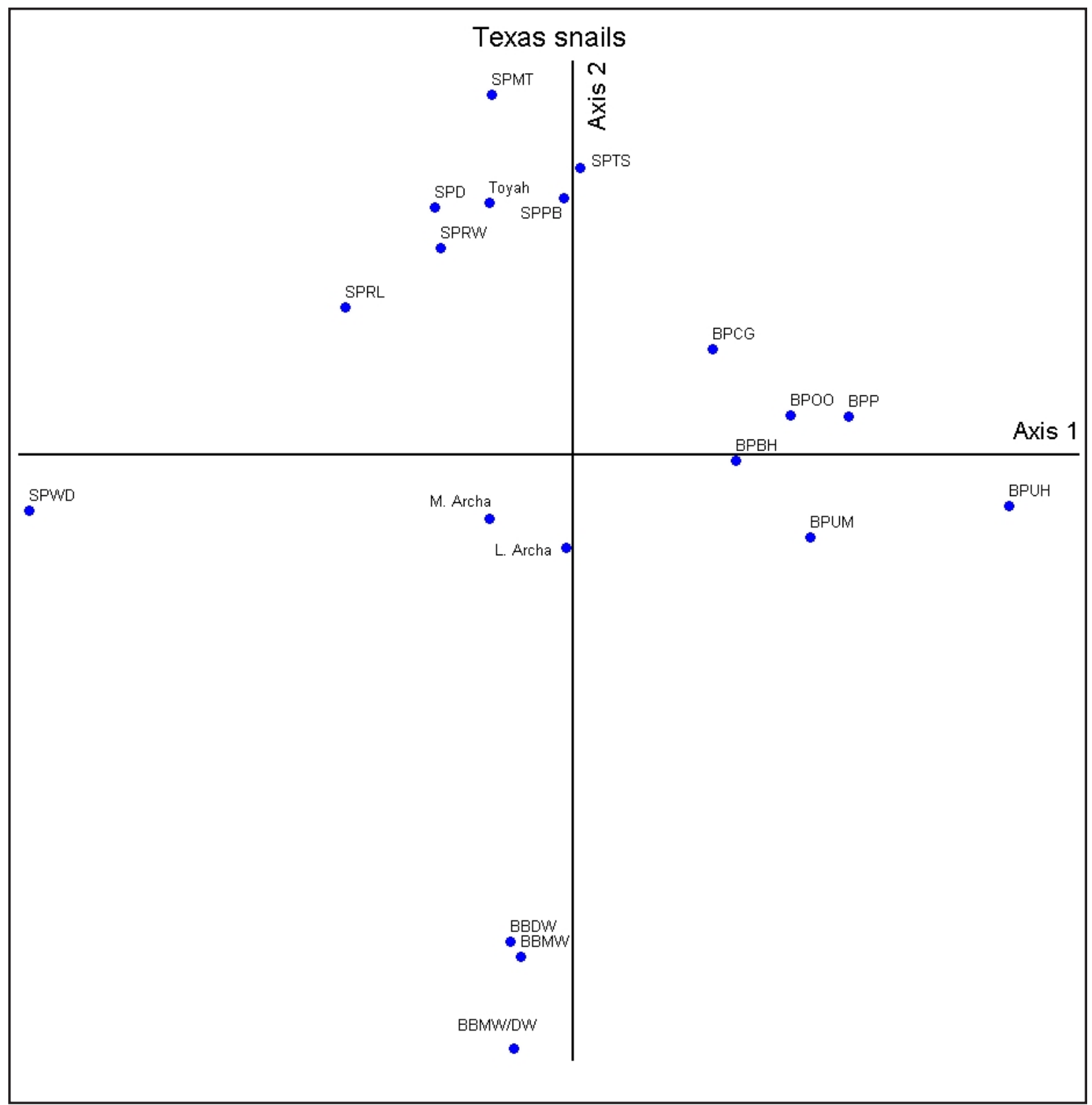

Figure 15-6. Ordination diagram of snail lots from Berger Bluff (Brown 2006), the Southern Plains Gastropod Survey (Theler et al. 2004), the Mississippi Black Prairie (Peacock and Gerber 2008), and site 41HM61.

during the mid- to early late Holocene. The Toyah lot, on the other hand, falls in with the majority of the Southern Plain samples.

To clarify the distinction between the Archaic and Toyah lots from 41HM61, the analysis was rerun using only the lots from Texas and the Southern Plains (i.e., removing all the Mississippi lots). The results are shown in Figure 15-7, in which Axis 1 accounts for 53.60 percent and Axis 239.03 percent of the variance in the data, for a cumulative total of 92.62 percent. The Coastal Plain, Berger Bluff lots remain distinct, being strongly negative along Axis 2 . The Southern Plains samples again are positive along Axis 2, although there is now considerable spread of habitat types along Axis 1 as well. The Toyah lot from 41HM61 falls in very closely with the dunes and mesa tops samples, suggesting little forest cover and/or drier conditions at that time. (Theler et al. [2004:7] describe mesa tops as having "thin soil cover" and dunes as being "excessively well-drained.) Again, the Archaic period lots appear to represent "ecotonal" conditions from the mid- to the initial part of the late Holocene. 


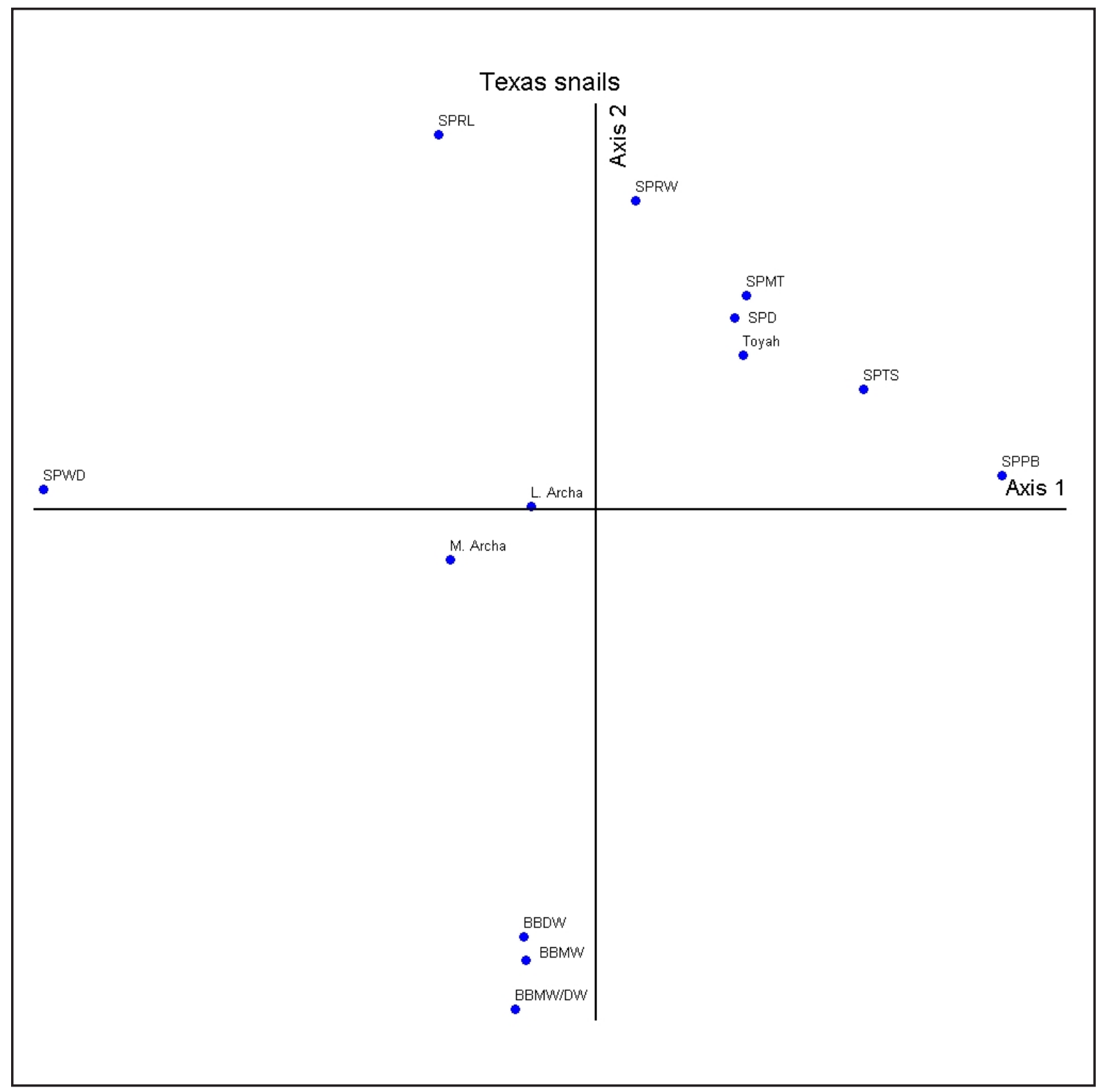

Figure 15-7. Ordination diagram of snail lots from Berger Bluff (Brown 2006), the Southern Plains Gastropod Survey (Theler et al. 2004), and site 41HM61.

\section{Discussion Conclusions}

The gastropod assemblage from 41HM61 is a welcome addition to the growing corpus of data from archaeological contexts in Texas. There is no evidence (burning, clustering) of Rabdotus being eaten at 41HM61. The few aquatic snails recovered are interesting, but were not recovered in enough numbers to indicate whether they represent flooding or incidental recovery along with mussels or other riverine resources. There is no evidence that they were being eaten at the site.
It is starkly evident that recovery methods can drastically alter the composition of archaeological land-snail assemblages. An unfortunate reality is that any reported assemblages that only reflect recovery through quarter-inch mesh, or that only include the heavy fraction of flotation samples, are simply not going to be interpretable in any rigorous way (unless one is focusing solely on questions for which such remains are pertinent, such as whether Rabdotus snails were a food source). Both in terms of density and taxonomic makeup, assemblages must include either gently recovered, very fine screen materials or shells recovered 
from the light fraction of flotation samples, in addition to materials recovered via other means.

Environmental data derived from the gastropod shells yield two starkly different results depending on the analytical method used. Characterization of habitat conditions using general species preferences garnered from the literature - i.e., a fairly informal approach that as often as not presents apparent contradictions in what different species "prefer" - is contradicted by the mathematically more robust polar ordination which uses more "local scale" analogical data to provide an assessment of environmental conditions as they existed over time at 41HM61. This contradiction cannot be solved at present except, perhaps, via comparison with other environmental data sets from the site. Unfortunately, unlike land snails, other materials may reflect cultural factors as much as, or more than, local environmental conditions, and/or may be more affected by formation processes (e.g., Bush, Chapter 12 in this volume, notes that "High-quality oaks dominate the wood charcoal assemblage, especially in the Toyah component, but other species such as mulberry and elm also are present. Botanical density is much greater in the Toyah component than in the site's older components, possibly due to increased plant-related activities, but more likely due to better preservation in younger deposits").

In such a situation, one could simply pick whichever scenario best fits one's preconceptions, which is always dangerous, but of the two scenarios (the site area being moister and more wooded vs. being drier and less wooded [either due to environmental change or human actions, or some combination of both]) during the Toyah phase, we tend to favor the latter one, for three reasons: (1) the scale of comparison with modern snail samples is more local; (2) as evident in the species descriptions above, there is a fair amount of disagreement in the literature about habitat preferences of particular species; and (3) it is doubtful that a species-by-species account will provide habitat data of the quality desired, as individual species are not "diagnostic" of particular environments; i.e., there is no one-to-one relationship between particular species and particular habitat types. Correspondence analysis and other ordination techniques compare entire assemblages, therefore accounting for spread across habitats regardless of what any individual species does. This approach has paid excellent dividends elsewhere (Peacock and Gerber 2008) and has the added attraction of increased discrimination with increased numbers of local samples. What this situation thus presents is an opportunity to emphasize that the "informal" habitat characterizations that tend to show up in archaeological reports simply cannot be taken at face value. What is badly needed are more (in fact, much more) systematic, modern surveys in which snails are recovered using very fine screens and high-quality habitat data (vegetation cover and density, soil chemistry, slope, aspect, etc.) are recorded (e.g., Peacock 2015), along with very careful recovery of large numbers of snails from archaeological contexts. This must include hand-sorting of the light fractions of flotation samples, as was done for 41HM61. While both the recovery process and analysis of microsnails are very time-consuming endeavors, the potential promise of high-quality environmental data, in areas where standard paleo-environmental data sources such as pollen may be lacking, makes the effort entirely worthwhile. 


\title{
Chapter 16
}

\section{Nutritional Value and Content for Some Common Archaic Foods}

\author{
Jon C. Lohse
}

\section{Introduction}

An important component of most definitions of the "Archaic" involves some emphasis on diversification of food resources that became integrated into local or regional diets in comparison with earlier periods. Willey and Phillips (1958) summarized some of the characteristics of this period from a continental perspective, and many of their traits refer in one way or another to food consumption or production, including changes in technologies utilized to procure or process food. In addition to changes in food preparation technology, it was recognized early on that many Archaic period subsistence economies were also decidedly regionalized. That is, they included a focus on locally available resources; consequently, archaeologists could distinguish with relative ease subsistence economies that were associated with, and even defined by, differing environmental zones. This regional signature was important enough that Willey (1966:60) later restricted his use of the term "Archaic" to refer to cultures of the eastern North American "woodland and river valleys in which subsistence was based on small-game hunting, fishing, and wild-plant collecting." This usage sets the "Archaic Tradition" apart from contemporary, but seemingly distinct traditions, such as Old Cordilleran or Desert. The present study area is included in this region, which extended from the Gulf of Mexico northward through the Plains and into eastern Canada.
The process of diet regionalization often involves constraints to settlement mobility, for example through population packing. Reduction of catchment sizes, the territory from which commonly consumed foodstuffs are obtained (Flannery 1976), may require that previously overlooked plants or animals become integrated into local or regional diets. Another outcome of these kinds of demographic conditions is that some previously utilized resources are no longer available. For example, stable carbon and nitrogen isotope data from the Texas coastal plain indicate that, while Early Archaic populations enjoyed diets of terrestrial as well as marine foods, by Late Archaic times consumption of foods from these two resource areas was restricted to populations living in those regions (Hard and Katzenberg 2011; Ricklis 2012). In the course of reconstructing prehistoric cultural adaptations and cultural patterns, analysts may wish to understand how dietary regionalization was influenced by the nutritional values of selected foodstuffs, and also what implications this fundamental change in the structure of prehistoric diets had for different groups. This may certainly be the case when low-value foodstuffs, i.e. those having poor or minimal energetic or nutritional qualities, appear in the record.

Across much of Archaic North America, freshwater shellfish (mussels), in particular, appear to fit this description. Meighan (1969) contended that mussels, generally, were low in food energy and Parmalee and 
Klippel (1974) corroborated this observation by reporting low overall nutritional composition (minerals and vitamins) of the pink heelsplitter (Proptera alata) and mucket (Actinonaiae carinata), two freshwater mussels common in eastern North America. The low nutritional value of freshwater mussels raises the question of why or under what circumstances they were targeted as a food resource by prehistoric hunter-gatherers (e.g., Casey 1986). This overview describes some nutritional aspects of food value as they may apply to, or inform, archaeological analyses. Emphasis is placed on foodstuffs that may have been commonly available to Archaic hunter-gatherers in and near the project area. This includes, in particular, freshwater mussels (class Pelecypoda; order Unionoidia), as remains of these have been reported at numerous sites in and near central Texas (Lintz 1996; Lintz et al. 1993; Lohse 2009; Mehalchick and Kibler 2008; see Randklev et al. 2009).

Due to their common occurrence in Archaic faunal assemblages in Texas (or in nearby regions of North America), foods considered here are freshwater mussels (pink heelsplitter [formerly Properta alata, now Potamilus alatus], mucket [Actinonias carinata], and blue mussel [Mytilus edulis $]^{1}$, none of which are native to Texas and, in the case of blue mussel, are marine species); bison (Bison bison); deer (Odocoileus sp.), rabbit (Sylvilagus floridanus)2; freshwater (channel) catfish (Ictalurus punctatus); pecan (Carya

$1 \quad$ Lintz (1996) submitted for nutritional analyses samples of Cyrtonaias sp. and Quadrula sp. collected from modern contexts along the west-central portion of the Colorado River and its tributaries of Elm Creek and the Concho River. Samples were intended to provide comparative data to understand and assess the nutritional values of archaeological samples excavated from sites 41TG307 and 41TG309. Samples were submitted to NDRC Laboratories, Inc., in Houston, Texas, which later became part of Intertek Testing Services Environmental Laboratories, Inc. (ITS). In 2000 , the U.S. Federal government indicted ITS for fraudulent business practices, including failure to perform analyses within prescribed quality assurance/quality control criteria required by the Environmental Protection Agency (EPA), and then sending and receiving information relating to monetary payment for these analyses through the U.S. Postal Service. The period during which these practices were reportedly carried out includes the date of Lintz's submission. Consequently, the results reported by Lintz (1996:Table 3), unfortunately comprising the only available nutritional data for freshwater mussels from Texas, are seen as unreliable.

Parmalee and Klippel (1974) list Sylvilagus floridanus; this is the only species specifically identified in this review. Nutritional data are available on the USDA nutritional database for "wild rabbit," but no scientific classification data are available. Many other species of "rabbit" exist and could be considered as well. illinoinensis); and sotol (Dasylirion texanum). Complete information of interest, including full nutritional profiles, are not available for all relevant food resources. For example, few data are available for freshwater mussels and none at all were found for sotol beyond general discussions of this food as a source of carbohydrates. In these instances, closely related resources will be identified and discussed for the purposes of building a general understanding of certain resources as they may have been important at different times in the study area. Dozens of different species have been identified for some resources (freshwater mussels in particular but to a lesser degree also including rabbits), but complete data regarding nutrition or frequency of prehistoric exploitation do not exist for most of these. Species selected for inclusion here are those that were important at some point in those regions surrounding central Texas. These include either eastern North America in inland terrestrial habitats defined by river systems or arid western North America.

\section{The Nature of Nutrients}

Maintaining a suitable level of appropriate nutrient intake is essential for growth and development and also for meeting the biological needs of the human body. An estimated 45 nutrients are needed in order to maintain what is considered to be a "healthy condition" (Sebrell and Haggerty 1971). These nutrients fall into five general categories: (1) amino acids (proteins) and a source of nonspecific nitrogen; (2) lipids (fats and oils), including triglycerides and linoleic acid; (3) carbohydrates, which occur largely in complex forms that convert to the simple sugar glucose; (4) 17 minerals; and (5) 13 vitamins (Wing and Brown 1979:2). The "nutritional value" of any particular food depends on its nutrient content, nutrient availability, quantity eaten, and its relationship to the composition of the total diet (Marchello et al. 1984). Anthropologists commonly treat energetic content, counted in calories, as a kind of shorthand indicator or proxy for food value. However, an unbalanced diet that is rich in some nutrients, for example proteins (a polymer of amino acids), but poor in others, leads inevitably to poor health and, potentially, to societal collapse. Consequently, developing some understanding of overall nutritional value in addition to calculating energetic value is necessary for detailed reconstructions of prehistoric foodways.

\section{What Matters and Why}

In addition to providing energy, different nutritional elements provide other benefits for human growth, development, and health. Carbohydrates, 
fats, and proteins are all sources of energy. However, while protein constitutes approximately 75 percent of the dry weight of soft bodily tissue, and thus certain limitations exist in terms of how much can be stored, fat can be stored in practically unlimited quantities (Wing and Brown 1979:47). Moreover, when sufficient caloric intake is obtained from fats and carbohydrates, proteins are instead converted to body tissue. Another critical function served by proteins is that when broken down they aid in metabolic processes. Because they supply the building material for body tissue, proteins are important during stages of growth or recuperation.

Lipids (fats and oils) offer a more concentrated form of energy than either carbohydrates or proteins (Wing and Brown 1979). These are easily stored by the human body, and can be available for conversion to energy long after consumption, as opposed to carbohydrates, which provide greater energy boosts soon after consumption. Beyond their importance as sources of reserve energy, many essential fats (those that cannot be produced by the body) also provide a source of fat-soluble vitamins (vitamins A, D, K, and E). Perhaps most importantly, essential fatty acids, including omega-3 fatty acid, are important for the neurological development of fetuses and nursing infants (DGAC 2010), and are closely associated with longer gestation time, improved visual acuity in infants, and increased overall fetal growth (McGrane et al. 2012). Of all aspects of nutritional health, the benefits for fetal and infant health derived from some essential fatty acids, primarily monounsaturated fats, are perhaps the only instance where simple increases in nutrient consumption alone (iron or calcium for example) may be inadequate for satisfying the requirements of different stages of human development and growth (e.g., Ladipo 2000). Generally, monounsaturated fats are considered "good" fats and have demonstrated positive effects on cognition, memory retention, and neurological development. Polyunsaturated fats have less of a beneficial effect, while saturated fats are associated with poor memory retention and overall neurological capactiy (Okereke et al. 2012). Monounsaturated fats are super abundant in nuts like pecans (see below), and have been identified as key food resources for mobile foragers across the world (Kelly 1995; see Arnn 2012:194-195 for discussion of the use of this resource by hunters and gatherers in Texas).

Carbohydrates, which occur in high quantities in foods like grains, fruits, and vegetables, provide greater amounts of caloric energy by percentage of diet than proteins. The increase in carbohydrate consumption (especially geophytes), termed the Carbohydrate Revolution and starting by around 9000 to 10,000 years ago (Thoms 2008, 2009), may represent a response to the disappearance of most large-bodied game animals (as potential sources of protein-based energy) following the end of the Pleistocene. Because plants migrate at a considerably slower rate than most animals, the increased reliance on plant-based carbohydrates may be at least as important as the demise of megafaunal resources in terms of diet regionalization, if not more so. Some carbohydrates (as well as some proteins and some fats) occur as complex, rather than simple, polymers. Many complex carbohydrates (and proteins and fats) cannot be digested by the human body without some form of modification, such as exposure to heat (Wandsnider 1997). Through the development of cooking technologies required to convert non-ingestible inulin into ingestible simple sugars, a wider range of plant foods, especially those that store most of their energy in subterranean elements, became available to prehistoric hunter-gatherers.

In relation to proteins, lipids, and carbohydrates, the human body's requirements of minerals and vitamins are relatively minor by proportion, most falling in the range of a gram or less. Additionally, understanding the role of vitamins and minerals in diet is complicated by issues of absorption, complex interrelationships between some nutrients, and of the potential for vitamin loss during food preparation. The primary minerals present in the human body, and required to sustain good health, include magnesium, sodium, chloride, potassium, sulfur, calcium, and phosphorous (these latter two are commonly considered together). Sulfur occurs commonly in many sources of protein, particularly animal-based protein. Sodium, potassium, and magnesium all occur widely in natural plant and animal foods (Wing and Brown 1979), and would have been readily available to prehistoric hunter-gatherers in and around the project area. Sodium works in combination with chloride and also with potassium for carbohydrate and protein metabolism. Animals are also a good source of magnesium, as are leafy greens. Calcium and phosphorous (also available in plants and animals) are known as primary mineral elements of skeletal composition. Iron, required for oxygen transport and cellular respiration (Wing and Brown 1979:56), is recommended in enhanced dosages for pregnant women versus the rest of the population because of the added burden placed on red blood cells, not to mention overall increase in blood supply. Vitamins, in contrast to minerals, are classified according to their solubility in either water or fat. This classification is important, as it helps determine efficiency 
of transport and storage in the body. Water-soluble vitamins include thiamine, riboflavin, niacin, pantothenic acid, vitamin $\mathrm{B}_{6}$ group, folic acid, vitamin $\mathrm{B}_{12}$, and vitamin $\mathrm{C}$. Fat-soluble vitamins include vitamins A, D, K, and E (Wing and Brown 1979:57-61).

\section{How Are Nutrients Measured?}

Reporting of data regarding nutritional content varies, with some cases or studies including much finer detail than others depending on target audience or intended use of such data. Typically, reported nutrient composition includes data on energy (in kilocalories), approximate composition (protein, fat, fiber, water or moisture [occasionally], and mineral ash), and minerals and vitamins for food products for which recommended daily allowances have been made. Additionally, other contents including sodium, potassium, and other nutrients may also be presented if analyses of these data are requested (Wing and Brown 1979). In order to compare units or foods or to quantify intake, nutritional data are commonly standardized, such as gram (g) or milligram (mg) per 100-gram edible food portion (e.g., mg/100 g) (McCarthy and Matthews 1984). Calories are often presented in kilocalories ( $\mathrm{kcal}$ ) per gram of edible food portion. A calorie is the amount of energy required to raise one gram of water by one degree Celcius. A kilocalorie is the amount of energy required to raise one kilogram of water by this same increase; a kcal is the equivalent of 1,000 calories.

Reporting nutritional data today is intended to help consumers balance diets and obtain nutritional intake corresponding with recommendations of various government agencies or fad diet programs. However, it can be difficult to know the reliability of the reported data (Stewart 1997). Methods commonly employed that would affect data reliability (for archaeological purposes) include: (1) using values from a different but similar food (i.e., using deer to estimate elk [Reidhead 1976:Table 7]), (2) calculating values from different forms of the same food (such as seasonal changes to animal health), (3), calculating values from other components of the same food, and/or (4) assuming a zero value (after Schakel et al. 1997). Additionally, nutritional values in pre-industrial contexts (as well as today) depend on factors such as manner of food preparation (raw, dry, dry roasted, oil roasted, toasted, conversion to flour, etc.; see Marchello et al. 1989); season of procurement (e.g., Reidhead 1976:Table 7); whether foods have been stored and if so for how long and under what conditions (Reidhead 1976; Wandsnider 1997); the age/sex profile, health stature, and feeding regime of prey animals (Marchello et al. 1989); what part of the plant/animal is being consumed; and others. As a result, nutritional data from any single specimen of food may not accurately or completely represent that type of food. Because of these kinds of issues, it can be important not only to understand what food is being considered, but also what portion of it was consumed and how (or whether) it was processed.

A number of commercial laboratories provide analytical services for researchers interested in understanding, in quantified detail, the nutritional and caloric content of food. For example, the website for American Analytical Chemistry Laboratories (http://www. aaclabs.com/), a commercial analytical chemistry company (and subsidiary of Intertek since 2011), lists herbal and natural compounds; vitamins; dietary nutrients; minerals and metals; amino acids, proteins, sugars and polysaccharides; phytosterols, pro-hormones and hormones; oils, fats, and phospholipids; enzymes; antioxidants and bioassays; and nutrition labeling as services they provide for customers wanting to understand the chemical composition of different foodstuffs or food products. The Nutrient Data Laboratory (NDL) (http://fnic.nal.usda.gov/food-composition/ usda-nutrient-data-laboratory) of the U.S. Department of Agriculture (USDA) (http://www.ars.usda.gov/ main/site_main.htm?modecode $=12-35-45-00)$ is responsible for developing and maintaining the National Nutrient Database for Standard Reference (http://ndb. nal.usda.gov/), an online searchable database listing the full nutritional value of over 8,000 foods. The current version of the database is Standard Reference 26; prior versions have gradually been updated, resulting in nutrient data for more foods but also in older values having been reported in various publications that may not correspond with subsequent studies. Not all foods that would have been consumed by prehistoric hunter-gatherers, such as sotol, are included, and the site does not list all scientifically classified taxons for each species (for example, only blue mussels, the marine Mytilus edulis, are listed for mollusks). Another possible shortcoming of this tool is that not all possible food preparation options are included. For example, data for blue mussels are only included for "raw" and "cooked, moist heat." Nevertheless, this online tool is useful for consumers and researchers alike who may want detailed information about different nutritional aspects or components of some important foodstuffs. Indeed, many consumer-oriented sources of information that present caloric, vitamin, mineral, or fat content are ultimately linked with the NDL database. While individual studies report nutrient data for foods like pecans (Duke 2001; Hall 2000), some mussels (Parmalee and Klippel 1974), and bison (Marchello et 
al. 1989), the NDL database is probably the most useful single starting point for any comparative study of food nutrient data.

\section{Nutritional Values of Archaic Foods}

Data are not evenly available for the foodstuffs listed above that would have been important to Archaic hunter-gatherers (freshwater mussels [pink heelsplitter and mucket], bison, white-tailed deer, rabbits, channel catfish, pecan, and sotol). For example, research conducted for this review identified no nutritional data whatsoever for sotol. Below, nutrient data are presented for different foods. Some explanation is provided regarding different sources and apparent discrepancies in the reported data. Constituents included are those listed in the NDL database concise report (the alternative option is a more detailed, lengthy report), standardized according to 100 -g portions unless otherwise noted. Not all nutrients listed are included here; omitted are those that are not consistently reported for each food included in this study (sugars; Folate, DFE; vitamin $\mathrm{B}_{12}$; vitamin $\mathrm{A}$, RAE, etc.), those consistently having no value (total dietary fiber), and cholesterol. Following convention, constituents are listed as proximates (water in $\mathrm{g}$ or moisture by percentage; protein, total lipids, and carbohydrates by difference), minerals (calcium, iron, magnesium, phosphorous, potassium, sodium, and zinc), vitamins (vitamin $\mathrm{C}$, total ascorbic acid; thiamin, riboflavin, vitamin $\mathrm{B}_{6}$, and vitamin $\mathrm{A}$, IU), and lipids (total saturated, total monounsaturated, and total polyunsaturated fatty acids). In some cases, such as the different fatty acids in farm-raised catfish, reported data are more detailed.

\section{Freshwater Mussels}

The only studies found reporting nutritional data for freshwater mussles are by Parmalee and Klippel (1974) (pink heelsplitter and mucket) and Lintz (1996) (Quadrula sp. and Cyrtonaias sp.) (Table 16-1). Reidhead (1976:Table 7) lists nutritional data for mussels, but derived these values by averaging those reported by Parmalee and Klippel. Data reported by Lintz are reproduced here, but readers are referred to footnote 1 for possible concerns regarding the reliability of these data. The NDL database lists blue mussels, but these are from intertidal, coastal habitats and may not be perfectly suitable as comparisons to freshwater mussels. Given the large number of freshwater mussels present in North America, including Texas ( $n=52$ species), their near-ubiquity in archaeological sites, and what can be considered their very poorly known nutrient values, more research on this food resource seems warranted.
Some of the discrepancies among these values are difficult to reconcile. For example, the mineral content varies by orders of magnitudes, with calcium and iron reported by Lintz (1996) being the most extreme. The elevated phosphorous values reported by Parmalee and Klippel (1974) are more than twice as high as raw blue mussels, and almost twice as high as cooked blue mussels. However, reported sodium values are as skewed in favor of blue mussels as other minerals are against this taxon. There seems to be general agreement among the proximates, except that Lintz (1996) reports no carbohydrate content whatsoever. The fact that blue mussels live in intertidal, coastal habitats, which have considerably different environmental inputs than the terrestrial river systems inhabited by other taxa, may at least partly explain these discrepancies.

Consuming mussels can carry some health risks, with symptoms ranging from diarrhea to vomiting, paralysis, and, in some cases, death. So-called "shellfish poisoning" is largely limited to saltwater (marine) species, and results from a group of microalgal toxins called azaspiracids (Tillmann et al. 2009). Freshwater mussels, in contrast, are not associated with algal toxins. Rather, since these are filter feeders, they can easily ingest high levels of pollutants, including ammonia, chloride, copper, and others. These pollutants, which are increasingly common in waterways of the United States, remain in mussel tissue, where they can pose a health risk if consumed (Augspurger et al. 2007). Although this process has led to approximately 70 of nearly 300 species that are native to the United States being federally listed as threatened or endangered (U.S. Fish and Wildlife 2007), it was not likely to have been a serious concern for prehistoric foragers.

\section{Rabbits}

Only two studies are identified for rabbit, the NDL database and data reproduced by Parmalee and Klippel (1974) from Watt and Merrill (1963) (Table 16-2). Parmalee and Klippel (1974:Table 4) list the species as Sylvilagus floridanus; no taxon is presented in the NDL database. However, this source provides data on raw game rabbit as well as cooked (stewed) game rabbit.

As with other foods, rabbit nutrient data are difficult to interpret because of their poor quality. Generally, these seem to have greater caloric value than mussels, although their overall mineral content is not quite as high. Lipid values are approximately equivalent. 
Table 16-1. Available Nutritional Data for Mussels.

\begin{tabular}{|c|c|c|c|c|c|c|c|}
\hline & Constituent (Unit) & 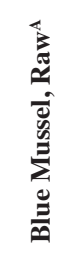 & 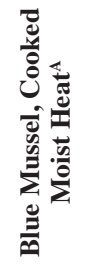 & 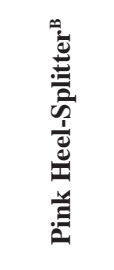 & 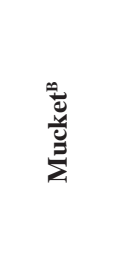 & 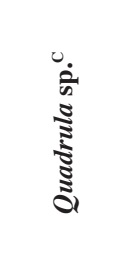 & 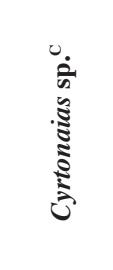 \\
\hline \multirow{5}{*}{ 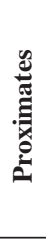 } & Water $(\mathrm{g})$ & 80.58 & 61.15 & $76.5(\%)$ & $82.2(\%)$ & $80.0(\%)$ & $82.8(\%)$ \\
\hline & Energy (kcal) & 86 & 172 & 77 & 58 & 80 & 70 \\
\hline & Protein $(\mathrm{g})$ & 11.9 & 23.8 & 9.5 & 7.8 & 12.3 & 12.1 \\
\hline & Total lipid (fat) (g) & 2.24 & 4.48 & .8 & .7 & 3.1 & 2.1 \\
\hline & Carbohydrate, by difference (g) & 3.69 & 7.39 & 7.8 & 4.5 & 0 & 0 \\
\hline \multirow{7}{*}{ 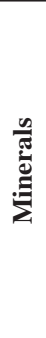 } & Calcium, $\mathrm{Ca}(\mathrm{mg})$ & 26 & 33 & 370 & 320 & 1020 & 670 \\
\hline & Iron, $\mathrm{Fe}(\mathrm{mg})$ & 3.95 & 6.72 & 12.5 & 12.2 & 67 & 28 \\
\hline & Magnesium, Mg (mg) & 34 & 37 & - & - & - & - \\
\hline & Phosphorous, $\mathrm{P}$ (mg) & 197 & 285 & 812 & 520 & - & - \\
\hline & Potassium, K (mg) & 320 & 268 & 41 & 26 & - & - \\
\hline & Sodium, $\mathrm{Na}(\mathrm{mg})$ & 286 & 369 & 23 & 7 & 84 & 54 \\
\hline & Zinc, Zn (mg) & 1.6 & 2.67 & - & - & - & - \\
\hline \multirow{6}{*}{ 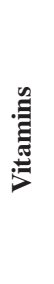 } & Vitamin C, total ascorbic acid (mg) & 8 & 13.6 & - & - & 4 & 4 \\
\hline & Thiamin (mg) & .16 & .3 & 0 & 0 & 0 & 0 \\
\hline & Riboflavin (mg) & .21 & .42 & .3 & .2 & .15 & .21 \\
\hline & Niacin (mg) & 1.6 & 3 & 2 & .9 & .43 & .57 \\
\hline & Vitamin B-6 (mg) & .05 & .1 & - & - & - & - \\
\hline & Vitamin A, IU (IU) & 160 & 304 & - & - & 80 & 65 \\
\hline \multirow{3}{*}{ :气 } & Fatty acids, total saturated (g) & .425 & .85 & - & - & - & - \\
\hline & Fatty acids, total monounsaturated $(\mathrm{g})$ & .507 & 1.014 & - & - & - & - \\
\hline & Fatty acids, total polyunsaturated (g) & .606 & 1.212 & - & - & - & - \\
\hline
\end{tabular}

Note: All values calculated per 100-g serving unless otherwise noted.

A NDL database

B Parmalee and Klippel (1974)

D Lintz (1996)

\section{Deer}

Multiple sources provide data for "deer" (Odocoileus sp.), yet not all deer nutritional data are consistent and some potentially wide variation can be seen. For example, Reidhead (1976:Table 7) provides nutritional data for "deer, dried" for each season (summer, fall, winter, spring). The source for these data is cited as Watt and Merrill (1963). Watt and Merrill (1963) are also cited for deer data in Parmalee and Klippel (1974:Table 4). The NDL database lists data for several variations of game deer, including raw; cooked, roasted; ground, raw; ground, cooked pan-broiled; loin, lean only 1-inch steak cooked, broiled; shoulder clod, lean only, cooked, braised; and others. Only ground, raw and ground, cooked (pan-broiled) are included here, as it is considered that "ground" effectively represents a homogenized value of different cuts (Table 16-3). 
Table 16-2. Available Nutritional Data for Rabbit.

\begin{tabular}{|c|c|c|c|c|}
\hline & Constituent (Unit) & 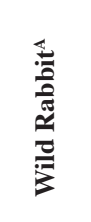 & 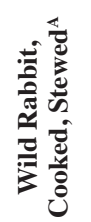 & 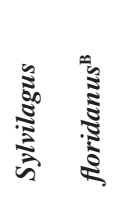 \\
\hline \multirow{5}{*}{ 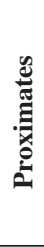 } & Water $(\mathrm{g})$ & 80.58 & 61.37 & $73.0(\%)$ \\
\hline & Energy (kcal) & 114 & 173 & 135 \\
\hline & Protein $(g)$ & 21.79 & 33.02 & 21 \\
\hline & Total lipid (fat) (g) & 2.32 & 3.51 & 5 \\
\hline & Carbohydrate, by difference (g) & 0 & 0 & 0 \\
\hline \multirow{6}{*}{ 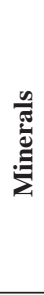 } & Calcium, Ca (mg) & 12 & 18 & - \\
\hline & Iron, $\mathrm{Fe}(\mathrm{mg})$ & 3.2 & 4.85 & - \\
\hline & Magnesium, Mg (mg) & 29 & 31 & - \\
\hline & Phosphorous, P (mg) & 226 & 240 & - \\
\hline & Potassium, K (mg) & 378 & 343 & - \\
\hline & Sodium, $\mathrm{Na}(\mathrm{mg})$ & 50 & 45 & - \\
\hline \multirow{5}{*}{ } & Vitamin C, total ascorbic acid (mg) & 0 & 0 & - \\
\hline & Thiamin (mg) & .03 & .02 & - \\
\hline & Riboflavin (mg) & .06 & .07 & - \\
\hline & Niacin (mg) & 6.5 & 6.4 & - \\
\hline & Vitamin A, IU (IU) & 0 & 0 & - \\
\hline \multirow{3}{*}{ 串 } & Fatty acids, total saturated (g) & .69 & 1.05 & - \\
\hline & Fatty acids, total monounsaturated (g) & .63 & .95 & - \\
\hline & Fatty acids, total polyunsaturated (g) & .45 & .68 & - \\
\hline
\end{tabular}

Note: All values calculated per 100-g serving unless otherwise noted.

A NDL database

B Parmalee and Klippel (1974)

These sources of data on deer are very difficult to compare because the NDL database presents so many additional data than what is reproduced in Reidhead (1976). Nonetheless, the seasonal data do indicate some important variation in the nutritional value of deer that is unavailable in other sources and that would have been of extreme relevance in prehistoric times. Clearly, deer taken during the fall are of poorer nutritional quality in every category (except, oddly, caloric content) than that of other seasons. Additional variation is also seen according to the manner of preparation. For instance, cooked deer contains much greater amounts of protein than "dried" fall season deer and also greater amounts of phosphorous and iron.

\section{Bison}

Bison bison (nutritional data for extinct forms of Bison sp., such as Bison antiquus and Bison occidentalis, are not available), while not as ubiquitous in archaeological assemblages as other artiodactyls such as deer, was nonetheless an important food resource for hunter-gatherers during periods when it was available (Lohse et al. 2014a, 2014b, 2014c). Moreover, 
Table 16-3. Available Nutritional Data for Deer.

\begin{tabular}{|c|c|c|c|c|c|c|c|}
\hline & Constituent (Unit) & 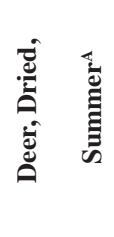 & 总 & 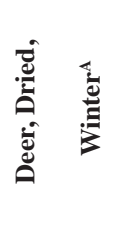 & 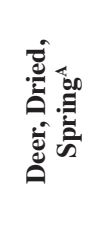 & 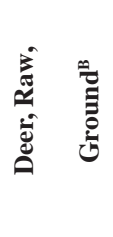 & 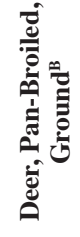 \\
\hline \multirow{5}{*}{ 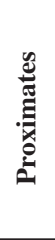 } & Water (g) & - & - & - & - & 71.15 & 64.23 \\
\hline & Energy (kcal) & 138.43 & 255.55 & 198.34 & 125.75 & 157 & 187 \\
\hline & Protein $(\mathrm{g})$ & 20.8 & 17.6 & 19.2 & 21 & 21.78 & 26.45 \\
\hline & Total lipid (fat) (g) & - & - & - & - & 7.13 & 8.22 \\
\hline & Carbohydrate, by difference (g) & - & - & - & - & 0 & 0 \\
\hline \multirow{7}{*}{ 尝 } & Calcium, $\mathrm{Ca}(\mathrm{mg})$ & - & - & - & - & 11 & 14 \\
\hline & Iron, $\mathrm{Fe}(\mathrm{mg})$ & 2.6 & 2.2 & 2.4 & 2.6 & 2.92 & 3.35 \\
\hline & Magnesium, $\mathrm{Mg}(\mathrm{mg})$ & - & - & - & - & 21 & 24 \\
\hline & Phosphorous, P (mg) & 152 & 130 & 141 & 154 & 201 & 228 \\
\hline & Potassium, K (mg) & - & - & - & - & 330 & 364 \\
\hline & Sodium, $\mathrm{Na}(\mathrm{mg})$ & - & - & - & - & 75 & 78 \\
\hline & Zinc, Zn (mg) & - & - & - & - & 4.2 & 5.2 \\
\hline \multirow{6}{*}{ 竭 } & Vitamin C, total ascorbic acid (mg) & - & - & - & - & 42 & 4 \\
\hline & Thiamin (mg) & .11 & .09 & .10 & .12 & 0 & 0 \\
\hline & Riboflavin (mg) & .26 & .22 & .24 & .26 & .287 & .327 \\
\hline & Niacin (mg) & 5.43 & 4.6 & 4.98 & 5.48 & 5.7 & 9.257 \\
\hline & Vitamin B-6 (mg) & - & - & - & - & .464 & .468 \\
\hline & Vitamin A, IU (IU) & 83 & 83 & 83 & 83 & 0 & 0 \\
\hline \multirow{3}{*}{$\frac{n}{3}$} & Fatty acids, total saturated (g) & - & - & - & - & 3.361 & 3.993 \\
\hline & Fatty acids, total monounsaturated (g) & - & - & - & - & 1.344 & 1.939 \\
\hline & Fatty acids, total polyunsaturated (g) & - & - & - & - & .394 & .444 \\
\hline
\end{tabular}

Note: All values calculated per 100-g serving unless otherwise noted.

A Reidhead (1976)

B NDL database

bison ranching has become increasingly popular in North America in recent years as an alternate to beef as a source of red meat. Over the course of this resurgence, some nutritional data have been compiled and presented for bison, primarily as a means of comparison against feedlot beef (e.g., Cox 1978). However, methodologies in early studies employed to calculate nutrient data for commercial purposes tended to be inconsistent and often focused only on a few nutritional components (Marchello et al. 1989).
At present, complete nutritional data for bison are available from the NDL database for several cuts and also from two industry sources. The NDL database lists cuts including ribeye, ground, top sirloin, shoulder, and others. Perhaps more important for the purposes of this overview, however, is that the site lists "game meat, bison" and also "bison, grass-fed." Comparing nutritional content for several of the game meat versus the two grass-fed options indicated that grass-fed bison tends to be far lower in fat content than game meat. On this basis, 
Table 16-4. Available Nutritional Data for Bison.

\begin{tabular}{|c|c|c|c|c|}
\hline & Constituent (Unit) & 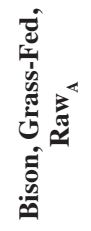 & 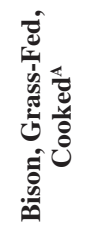 & 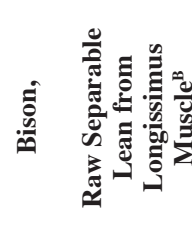 \\
\hline \multirow{5}{*}{ 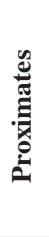 } & Water (g) & 71.59 & 65.09 & - \\
\hline & Energy (kcal) & 146 & 179 & 138 \\
\hline & Protein $(\mathrm{g})$ & 20.23 & 25.45 & $21.7(\%)$ \\
\hline & Total lipid (fat) (g) & 7.21 & 8.62 & $1.9(\%)$ \\
\hline & Carbohydrate, by difference (g) & 0 & 0 & - \\
\hline \multirow{7}{*}{ 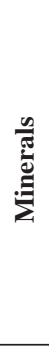 } & Calcium, $\mathrm{Ca}(\mathrm{mg})$ & 11 & 14 & 5.9 \\
\hline & Iron, $\mathrm{Fe}(\mathrm{mg})$ & 2.78 & 3.19 & 2.6 \\
\hline & Magnesium, Mg (mg) & 21 & 23 & 25 \\
\hline & Phosphorous, $\mathrm{P}$ (mg) & 194 & 213 & 187 \\
\hline & Potassium, K (mg) & 328 & 353 & 343 \\
\hline & Sodium, $\mathrm{Na}(\mathrm{mg})$ & 70 & 76 & 54 \\
\hline & Zinc, Zn (mg) & 4.59 & 5.34 & 2.8 \\
\hline \multirow{6}{*}{ 咅 } & Vitamin $\mathrm{C}$, total ascorbic acid (mg) & 0 & 0 & - \\
\hline & Thiamin (mg) & .141 & .139 & - \\
\hline & Riboflavin (mg) & .246 & .264 & - \\
\hline & Niacin (mg) & 5.322 & 5.966 & - \\
\hline & Vitamin B-6 (mg) & .383 & .401 & - \\
\hline & Vitamin A, IU (IU) & 0 & 0 & - \\
\hline \multirow{3}{*}{$\frac{n}{3}$} & Fatty acids, total saturated (g) & 2.917 & 3.489 & $43.3(\%)$ \\
\hline & Fatty acids, total monounsaturated $(\mathrm{g})$ & 2.753 & 3.293 & $45.1(\%)$ \\
\hline & Fatty acids, total polyunsaturated (g) & .336 & .402 & $11.7(\%)$ \\
\hline
\end{tabular}

Note: All values calculated per $100-\mathrm{g}$ serving unless otherwise noted.

A NDL database

B Marchello et al. (1989)

it was assumed that the grass-fed varieties would more closely represent the "free range" grass-fed nature of prehistoric bison. Therefore, both examples of grass-fed bison ("raw" and "cooked") are included in this overview. Additional data are from Marchello et al. (1989) who examined rib steaks from 30 bison selected from North Dakota, Wyoming, Iowa, New York, and Virgnia, as well as nine shoulder roasts and three round steaks. No feeding regime or age information is available for this sample. Nevertheless, the use of multiple samples should help even out resulting calculations and, in some cases, make them more useful as a general indicator of the nutrient quality of bison meat (Table 16-4).

\section{Catfish}

Catfish, perhaps more so than bison, has broad if regional appeal today as a preferred food. Consequently, some nutritional data are available for freshwater channel catfish (Ictalurus punctatus) that have been 
developed for commercial producers. Given the conditions under which these fish populations are raised and managed, they are unlikely to be directly comparable to non-farm-raised catfish for the purpose of understanding the kinds of nutritional benefits prehistoric hunter-gatherers may have derived from consuming catfish (e.g., Scott 2012). Still, as with bison, sample sizes used in commercial catfish studies are likely to be more robust than those developed for other databases.

Nutrition data for catfish included in this overview come from a study by the Mississippi Agricultural \& Forestry Experiment Station at Mississippi State University (Robinson and Li 2005). This study conducted nutritional analyses on three separate occasions (May, 1998; October, 1998; February, 1999); each analysis is based on a robust sample of 50 fish. Results are reported as mean data with standard deviations (SD). Additional data are taken from the NDL database. That website lists catfish, wild, raw; catfish, farmed, raw; catfish, breaded and fried; catfish, wild, cooked over dry heat; and catfish, farmed, cooked over dry heat. For this review, both forms of wild catfish are used (raw and cooked over dry heat) (Table 16-5).

These catfish studies may be as important for understanding how representative such studies can be, as they are for indicating what this food resource may have meant to prehistoric hunter-gatherer-fisher folk. The large sample size used by Robinson and Li (2005) indicates the potentially very wide range of values that can be measured for any particular nutrient. For instance, protein $($ mean $=16.3 \pm .4)$ shows a range of measured values of 13.7 to 18.7 (Robinson and $\mathrm{Li}$ 2005:Table 1). Fat values show an even wider spread, with a measured range of 1.9 to 10.9 in a single study. Clearly, there can be considerable variation (at least for proximate constituents) within a controlled sample. While this is potentially true for any animal food discussed in this overview, few data exist for other taxa that illustrate this point quite as clearly.

\section{Pecans}

Pecans (Carya illinoinensis) were widely utilized in prehistoric times where they occurred throughout eastern North America, primarily within the Mississippi River valley and its alluvial drainages in central and eastern North America, where deep, moist soils support large groves (Hall 2000; Hammett 1997). Spanish explorers recorded the intensive seasonal use of pecans from south Texas, along the lower Guadalupe River valley, through central Texas, and into the Caddo area of east Texas (Hall 2000:107). Pecans contain low levels of juglone, which may inhibit the growth potential of other plants. Additionally, aflatoxins have been reported in pecan nuts in cases where groves have been affected by certain fungi. Although aflatoxins are carcinogenic, most adult humans maintain a high tolerance and are rarely affected (Duke 2001:70). Otherwise, pecans are not thought to be toxic.

Multiple sources are available that indicate the nutritional value of pecans. These include the NDL database, a review specifically of nuts for food and herbal uses (Duke 2001), and a publication by the Human Nutrition Information Service of the USDA detailing the composition of nut and seed products (McCarthy and Matthews 1984). Nutrient data presented in Hall (2000:109-110) are reproduced from an earlier edition of Duke (2001), and are not included here. Hall (2000) also presents some proximate data for pecans that are taken from an ethnobotanical study of remains found at the Koster site in Illinois (Asch et al. 1972). Those data are superseded by studies included here, and are also not reproduced. Although some apparent duplication exists between some of the sources, data for dry roasting for example, the study by McCarthy and Matthews (1984) is of value for its listing of pecan flour, a manner of preparation not included elsewhere (Table 16-6). Another value of this source is that it specifically lists how many samples are included in each reported value, which represents the mean \pm SD. Numbers of samples are not included here.

At least a couple of observations are immediately obvious based on the data presented in Table 166. First, nutrition data by McCarthy and Matthews (1984) are strikingly lower in some minerals (calcium and potassium) than what is reported in other sources. This discrepancy is hard to reconcile, as it even appears for identical manners of pecan preparation (e.g., dry roasted). Assuming that such discrepancies do not identify McCarthy and Matthews as unreliable, the reported protein and carbohydrate content of pecan flour indicate that this form of preparation is likely to have had some important benefits over other kinds of preparation. However, converting pecans to flour seems to delete the overwhelming majority of their lipid values. Otherwise, this food would have been an outstanding source of lipids for prehistoric foragers who exploited pecans on at least a seasonal basis (Hall 2000). As such, its importance as a food item may have been highest for pregnant or post-natal females.

\section{Sotol (Agave)}

Sotol (Dasylirion texanum) is one of a number of geophytic plants, or perennial plants that bear their overwintering buds underground as bulbs, tubers, or 
Table 16-5. Available Nutritional Data for Catfish.

\begin{tabular}{|c|c|c|c|c|}
\hline & Constituent (Unit) & 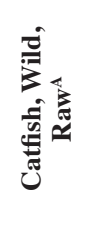 & 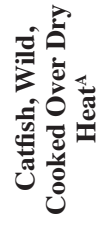 & 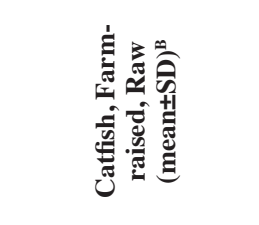 \\
\hline \multirow{5}{*}{ 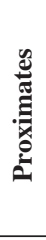 } & Water $(\mathrm{g})$ & 80.36 & 77.67 & - \\
\hline & Energy (kcal) & 95 & 105 & 118 \\
\hline & Protein $(\mathrm{g})$ & 16.38 & 18.47 & $16.3 \pm .4$ \\
\hline & Total lipid (fat) (g) & 2.82 & 2.85 & $5.4 \pm .3$ \\
\hline & Carbohydrate, by difference (g) & 0 & 0 & - \\
\hline \multirow{7}{*}{ 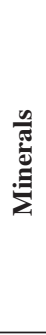 } & Calcium, $\mathrm{Ca}(\mathrm{mg})$ & 14 & 11 & $9.1 \pm .1$ \\
\hline & Iron, $\mathrm{Fe}(\mathrm{mg})$ & .3 & .35 & $.5 \pm .05$ \\
\hline & Magnesium, Mg (mg) & 23 & 28 & $22.4 \pm 2.1$ \\
\hline & Phosphorous, P (mg) & 209 & 304 & $179.9 \pm 10.1$ \\
\hline & Potassium, K (mg) & 358 & 419 & $353.6 \pm 16.3$ \\
\hline & Sodium, $\mathrm{Na}(\mathrm{mg})$ & 43 & 50 & $40.4 \pm 3$ \\
\hline & Zinc, Zn (mg) & .51 & .61 & $.59 \pm .06$ \\
\hline \multirow{6}{*}{ 咅 } & Vitamin C, total ascorbic acid (mg) & .7 & .8 & - \\
\hline & Thiamin (mg) & .21 & .227 & $.19 \pm .04$ \\
\hline & Riboflavin (mg) & .072 & .067 & $.14 \pm .02$ \\
\hline & Niacin (mg) & 1.907 & 2.385 & $1.35 \pm .21$ \\
\hline & Vitamin B-6 (mg) & .116 & .106 & - \\
\hline & Vitamin A, IU (IU) & 50 & 50 & - \\
\hline \multirow{3}{*}{$\stackrel{0}{0}$} & Fatty acids, total saturated (g) & .722 & .744 & $23.59(\% \text { of total fat })^{\mathrm{C}}$ \\
\hline & Fatty acids, total monounsaturated $(\mathrm{g})$ & .844 & 1.099 & $43.51(\% \text { of total fat })^{\mathrm{D}}$ \\
\hline & Fatty acids, total polyunsaturated (g) & .865 & .636 & $25.94(\% \text { of total fat })^{\mathrm{E}}$ \\
\hline
\end{tabular}

Note: All values calculated per 100-g serving unless otherwise noted.

A NDL database

B Robinson and $\mathrm{Li}(2005)$

C Includes fatty acids 14:0, 16:0, 18:0.

D Includes fatty acids $16: 1,18: 1,20: 1$.

E Includes fatty acids 18:2 n-6, 18:3 n-6, 18:3 n-3, 20:2 n-6, 20:3 n-9, 20:3 n-6, 20:4 n-6, 20:5 n-3, 20:5 n-6, 22:5 n-3, 22:5 n-6, $22: 6$ n-3.

rhizomes (Thoms 1989:1). The use of a large number of these kinds of plants as food resources has been documented across western and central North America (Thoms 2008, 2009), and several taxa have been reported from Texas and neighboring regions (Tull 1987). Sotol, along with agave, lechuguilla, and yucca, are all part of the Agavaceae family. As noted earlier, no sources consulted for this review contained detailed nutritional data for sotol. However, agave is listed in the NDL database, and may be considered as a suitable proxy for sotol.

Agaves, like other geophytes, provide an important source of carbohydrates and minerals (Thoms 1989). Agaves, however, can be dangerous to consume. Raw agave heart (Agave neomexicana, Agave havardiana, Agave gracilipes, and Agave parryi; Tull 1989) contains caustic juices, while lechuguil- 
Table 16-6. Available Nutritional Data for Pecans.

\begin{tabular}{|c|c|c|c|c|c|c|c|}
\hline & Constituent (unit) & 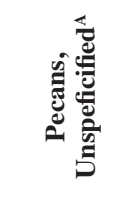 & 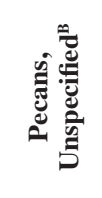 & 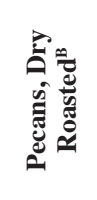 & 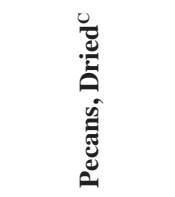 & 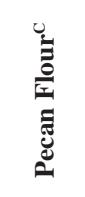 & 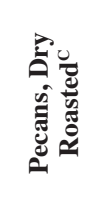 \\
\hline \multirow{5}{*}{ 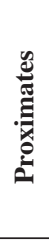 } & Water $(\mathrm{g})$ & - & 3.52 & 1.12 & $4.82 \pm .234$ & 10.7 & 1.1 \\
\hline & Energy (kcal) & $711-718$ & 691 & 710 & 667 & 329 & 659 \\
\hline & Protein $(\mathrm{g})$ & $9.5-9.7$ & 9.17 & 9.5 & $7.75 \pm .427$ & 31.87 & 7.97 \\
\hline & Total lipid (fat) (g) & $73.7-75.3$ & 71.97 & 74.27 & $67.64 \pm 1.268$ & 1.43 & 64.6 \\
\hline & Carbohydrate, by difference $(\mathrm{g})$ & $13.4-15.1$ & 13.86 & 13.55 & 18.24 & 50.73 & 22.33 \\
\hline \multirow{7}{*}{ 尝 } & Calcium, Ca (mg) & $75-76$ & 70 & 72 & $36 \pm 4.524$ & 32 & 35 \\
\hline & Iron, $\mathrm{Fe}(\mathrm{mg})$ & 2.5 & 2.53 & 2.8 & $2.13 \pm .062$ & 1.97 & 2.18 \\
\hline & Magnesium, Mg (mg) & - & 121 & 132 & $128 \pm 3.786$ & 120 & 133 \\
\hline & Phosphorous, P (mg) & 299-334 & 277 & 293 & $291 \pm 21.177$ & 274 & 304 \\
\hline & Potassium, K (mg) & $624-1499$ & 410 & 424 & $392 \pm 28.954$ & 334 & 370 \\
\hline & Sodium, $\mathrm{Na}(\mathrm{mg})$ & $0-3$ & 0 & 1 & $1 \pm .368$ & 1 & 1 \\
\hline & Zinc, Zn (mg) & - & 4.53 & 5.07 & $5.47 \pm .276$ & 5.13 & 5.68 \\
\hline \multirow{6}{*}{ 芸 } & Vitamin C, total ascorbic acid (mg) & 2.1 & 1.1 & .7 & 2 & - & - \\
\hline & Thiamin (mg) & $.74-.89$ & .66 & .45 & .848 & - & .317 \\
\hline & Riboflavin (mg) & $.11-.13$ & .13 & .107 & .128 & - & .106 \\
\hline & Niacin (mg) & .93 & 1.167 & 1.167 & .887 & - & - \\
\hline & Vitamin B-6 (mg) & - & .21 & .187 & .188 & - & - \\
\hline & Vitamin A, IU (IU) & - & 56 & 140 & 128 & - & - \\
\hline \multirow{3}{*}{$\frac{n}{3}$} & Fatty acids, total saturated (g) & - & 6.18 & 6.283 & 5.419 & .095 & 5.175 \\
\hline & Fatty acids, total monounsaturated (g) & - & 40.801 & 43.957 & 42.161 & .736 & 40.265 \\
\hline & Fatty acids, total polyunsaturated (g) & - & 21.614 & 20.572 & 16.746 & .292 & 15.993 \\
\hline
\end{tabular}

Note: All values calculated per 100-g serving unless otherwise noted.

$\begin{array}{ll}\text { A } & \text { Duke (2001) } \\ \text { B } & \text { NDL database } \\ \text { C } & \text { McCarthy and Matthews (1984) }\end{array}$

la hearts (Agave lecheguilla) are not safe to eat under any circumstances. These plants also contain high concentrations of a compound called saponin, which is used as soap and medicine, and was used to make poison for arrows in early historic times (Tull 1989:22). Saponin levels vary in terms of location and intensity among different agaves; for instance, yucca flowers and fruits are edible while leaves, roots, heart, and trunk are not (Tull 1989:27).
As noted, several species of agave exist, but perhaps the most common in the study area is Agave americana, also known as the century plant or maguey (Tull 1989). Several parts of the agave are edible, including flowers, leaves, stalks, root bulbs, and sap. Presumably, different preparation techniques may have existed for each part. Parsons and Parsons (1990) describe ethnographically documented processes of cooking leaves and the main body of the 
Table 16-7. Available Nutritional Data for Agave as a Proxy for Sotol.

\begin{tabular}{|c|c|c|c|c|}
\hline & Constituent (Unit) & 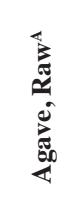 & 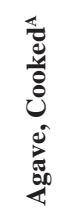 & 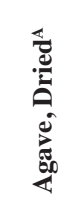 \\
\hline \multirow{5}{*}{ 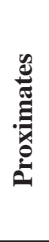 } & Water $(\mathrm{g})$ & 81.83 & 65.4 & 11.64 \\
\hline & Energy (kcal) & 68 & 135 & 341 \\
\hline & Protein $(g)$ & .52 & .99 & 1.71 \\
\hline & Total lipid (fat) (g) & .15 & .29 & .69 \\
\hline & Carbohydrate, by difference $(\mathrm{g})$ & 16.23 & 32 & 81.98 \\
\hline \multirow{7}{*}{ 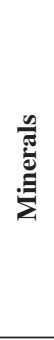 } & Calcium, $\mathrm{Ca}(\mathrm{mg})$ & 417 & 460 & 770 \\
\hline & Iron, Fe (mg) & 1.8 & 3.55 & 3.64 \\
\hline & Magnesium, $\mathrm{Mg}(\mathrm{mg})$ & 55 & 39 & 207 \\
\hline & Phosphorous, P (mg) & 7 & 9 & 37 \\
\hline & Potassium, K (mg) & 127 & 59 & 767 \\
\hline & Sodium, $\mathrm{Na}(\mathrm{mg})$ & 14 & 13 & 14 \\
\hline & Zinc, Zn (mg) & .15 & .25 & 12.1 \\
\hline \multirow{6}{*}{ 号 } & Vitamin C, total ascorbic acid (mg) & 4 & .3 & .3 \\
\hline & Thiamin (mg) & .029 & .012 & .021 \\
\hline & Riboflavin (mg) & .039 & .099 & .644 \\
\hline & Niacin (mg) & .162 & .162 & .87 \\
\hline & Vitamin B-6 (mg) & .055 & .087 & .216 \\
\hline & Vitamin A, IU (IU) & 37 & 113 & 18 \\
\hline \multirow{3}{*}{ : } & Fatty acids, total saturated (g) & - & - & - \\
\hline & Fatty acids, total monounsaturated $(\mathrm{g})$ & - & - & - \\
\hline & Fatty acids, total polyunsaturated (g) & - & - & - \\
\hline
\end{tabular}

Note: All values calculated per 100-g serving unless otherwise noted.

\section{A NDL database}

plant (heart) in roasting facilities in Mexico; Fish et al. (1986) describe similar practices in the American Southwest. This process is necessary to convert by hydrolysis nondigestible inulin to a form that people could digest (Yanovsky and Kingsbury 1931).

Three different forms of agave are listed in the Indian Foods section of the NDL database: raw, cooked, and dried. No specific detail is given on which part of the plant is included. Nonetheless, nutritional data for these three forms of agave may characterize the nutritional value of the plant in general, and may indicate the approximate nutritional value(s) of sotol (Table 16-7).

Agave data indicate that the food is a poor source of proteins, vitamins, and lipids when compared with other resources included in this review. However, agave is the best source for carbohydrates out of all the foods considered here, and is also high in some minerals. Because agave, like pecans, is comparatively low in many vitamins and some important proximates 
(e.g., protein), it is difficult to envision a prehistoric diet focused solely, or perhaps even primarily, on this resource. However, agave could easily have been an important complement to a diet that also featured suitable sources of protein, other vitamins, and lipids, even if these other resources were comparatively low in carbohydrates.

\section{Understanding the Nutritional Value of Mussels in Archaic Diets}

This review presents an array of nutrient data for a number of foods that were important to Archaic hunter-gatherers in Texas. Additionally, it identifies potentially serious issues regarding the usefulness of data available for reconstructing some aspects of dietary behavior. Chief among these is the fact that only one source, the NDL database, contains even some data for most food resources of interest. Where other sources of data are available, such as from studies performed for commercial (bison and catfish) or for academic (freshwater mussels) purposes, wide variations sometimes exist between the different datasets. Sources of variation can be attributable to issues of individual seasonality, animal health stature and feeding regimen, laboratory methodology for compiling nutrient data, sample size, internal laboratory protocols for ensuring reliability of scientific measurements, and probably others. With respect to freshwater mussels in particular, a number of factors influence the value of this resource as food.

Mussels live in sediment deposits in active streams and rivers; most species prefer stable gravels, sands, and mixed substrates covered by less than two meters of water, although some have been found in depths exceeding 4.5 meters (Howells et al. 1996). Deep deposits such as these can be difficult to reach without use of dredging or submersible gear, and may have been inaccessible to prehistoric foragers. Bedrock streambeds, unconsolidated deposits, and still pools where waterborne nutrients are unavailable and waste materials cannot be removed from the vicinity are all poor mussel habitats.

The reproductive processes for many species depend on the presence of fish, which act as a host for transporting fertilized larvae elsewhere in the alluvial system (see discussion by Lintz 1996:T3 ). As a result, resource patches that become depopulated through overharvesting or unfavorable environmental conditions can become replenished within a period of about eight years, and sometimes less time depending on external considerations like the behavior of fish populations, climate, and other factors.

Surveys of mussel density across the state record densities from greater than $1 / \mathrm{m}^{2}$ in select portions of the Guadalupe and Little Brazos rivers to approximately $0.4 / \mathrm{m}^{2}$ in parts of the Concho River (Howells 1994, cited in Lintz 1996:T-2). Others have estimated mussel densities that vary from $>10 / \mathrm{m}^{2}$ to $<0.001 / \mathrm{m}^{2}$ (Andy Blair, personal communication to Jim Abbott, 2015). Lintz (1996:T-2) suggests that these modern surveys are not likely to be indicative of prehistoric densities, since commercial licenses for collecting mussels averaged 188 licenses/year from 1978-1991. Contemporary commercial harvesting, environmental decline due to pollution, and habitat loss from dam construction and siltation have all combined to reduce and even threaten modern mussel populations. Consequently, estimations of prehistoric distribution or density are likely to be problematic and are probably unreliable. A better approach to predicting where mussels would have been targeted in the past would be simply documenting where they occur in archaeological deposits, and working with available contextual and environmental data to reconstruct extant conditions favorable to mussel predation in relation to other possible food sources.

Bivalves grow according to a number of factors including nutrient availability, oxygen supply, water levels, and water temperature. In regions with pronounced seasonal variation in temperature (e.g., northern latitudes, drainages strongly affected by snowmelt, etc.), mussels tend to "rest" (not grow) during cooler periods. Mild winters and summer droughts that occur in southerly latitudes, including Texas, are thought to confound the seasonal signatures in growth patterns for mussels generally (Lintz 1996) and for Amblema plicata from near Waco Lake in particular (Culleton 2008). Although several species are "seasonal" in that they reproduce during summer months, many Unionidae spawn continuously throughout the year. As mussel meat weight (measured in meat weight-to-shell weight ratios) is highest just prior to spawning, this adversely affects analysts' ability to predict which season(s) would have been ideal for consuming mussels based on returns of meat weight. Some bivalves would have yielded higher returns during summer months, whereas many other species would have yielded higher returns approximately randomly throughout the year. 
In the case of marine, and probably freshwater, mussels, variation in the ratio of meat weight to shell weight can be due to large intraspecies variation by individual specimen due to different habitat conditions, declining meat-to-shell ratio for older specimens, lower meat ratios in species inhabiting cooler waters, uneven seasonal nutrient availability, and uneven seasonal growth due to annual reproductive cycles (Koloseike 1969, cited in Lintz 1996:T-6). These factors can even apply to the same species depending on its distribution, and together make it likely that freshwater mussels, generally, were considered a year-round food resource. Lintz (1996:T-3) notes that the modern proscription against eating (saltwater) mussels in months lacking the letter " $R$ " (May, June, July, August) is probably due to the presence of gritty-textured larvae within the mussel soft tissue, and that this practice is likely to be a cultural perspective that should not be applied to prehistoric hunter-gatherers.

With these considerations in mind, below is a proposed protocol for guiding future investigation into the role of central Texas mussel species in prehistoric diets. This protocol is adapted from Lintz (1996), who addressed the nutrient and food value of mussels in the context of understanding Early Archaic occupation on alluvial terraces along the Concho River, near San Angelo (Quigg et al. 1996). Not all of Lintz's (1996) recommendations are included here, and certain additional considerations are added as deemed necessary. Once this proposed protocol has been carried out a few times, TxDOT may wish to consider whether sufficient quantified and reliable data exist for freshwater mussels that not all of these recommended steps, especially those involving collection of modern species for analysis, should be carried out for every future project for which reconstructing food nutritional value is a priority.

\section{Proposed Protocol}

1. Because the nutritional importance of food (i.e., its role in the prehistoric diet) depends on nutrient content, quantity eaten, and the food's relationship to the composition of the total diet (Marchello et al. 1984), it is recommended that several variables be defined in addition to the identification and analysis of mussels. Specifically, analysis of mussels (and other foodstuff remains) should be contextualized through the use of reconstructed temporal units within site deposits. Analyses of foodstuffs should follow phases of work focused on reconstructing site components and stratigraphy. Additionally, remains of other foodstuffs that are present in contexts also containing mussels should be expertly identified by taxon for the purposes of compiling a "Diet Content Inventory" (DCI) that generally characterizes the diet of a particular time period as represented by analyzable archaeological remains. The focus of the DCI should be on that part of the diet represented by the archaeological remains of a particular time-controlled assemblage. This is preferable to an analytical focus on any given "meal" that may be inferable from a particular context, since individual "meals," insofar as these can be meaningfully reconstructed, are likely to be too narrow in terms of a representative sample of overall diet. In cases where recovery strategies necessary and/or appropriate for recovering food remains (e.g., nested fine-screening, flotation, paleobotanical analyses) are not feasible or were not outlined in the research program, these omissions should be clearly stated at the outset so that subsequent analysts are aware that the DCI is partial and incomplete.

2. In cases where identifiable mussel remains are present, whether in temporally definable components or in primary context features, it is recommended that researchers perform appropriate taxonomic identifications, conducted by a knowledgeable expert, to identify which mussel species are present. Specimens subjected to such analyses should be recovered from verifiable archaeological contexts demonstrating actual exploitation as opposed to having been deposited on-site through natural (e.g., alluvial) processes. Furthermore, this taxonomic classification should serve as the basis for subsequent quantifications of overall meat yield from mussel assemblages. That is, the following calculations should be performed by taxonomic class, so that biases such as preservation or species-specific responses to climatic or environmental conditions that affect growth rates are limited or restricted to those classes rather than shared more broadly across the entire assemblage.

3. It is important to quantify total mussel food mass represented by an assemblage, according to taxa present therein, in order to calculate the contribution of that assemblage to the prehistoric diet. Mussel remains should be quantified by use of standard zooarchaeological techniques. These include Number of Individual Specimens (NISP) and Minimum Number of Individuals (MNI). These are basically equal to the Number of Specimens (NSP) and Number of Non-repetitive Elements (NRE) that were used in Chapter 14 of the present report). For freshwater mussels, NISP can be problematic in that this technique often results in biased (exaggerated) counts as a result of poor preservation and through the inclusion of fragments. 
MNI (i.e. NRE) may yield more realistic (conservative) numbers in cases where left and right umbos are separated from the general assemblage, and the MNI/ NRE figure is derived from the higher number of these two elements (see Casey 1986:56). Total shell weight is not considered a reliable indication of overall food mass because high degrees of variation may exist in the relationship between shell weight and meat weights for some species (Lintz 1996:T-8). Because of possible factors involving preservation or recovery bias, the method(s) for quantifying mussel frequency in analyzed components should be clearly explained, including discussion given to why other methods may not have been deemed suitable.

4. Mussel frequency should be converted to approximate meat weight as a means of quantifying total nutritional contribution to the DCI. The ultimate objective of this conversion is to understand nutrient data of identified mussel specimens according to some standardized value. Nutrient contribution (in $\mathrm{g}$ or $\mathrm{mg}$; see Tables 16-1 through 16-7, above) per $100 \mathrm{~g}$ of meat weight is the recommended standard, and deviations from this standard should be clearly explained.

Using modern samples, Lintz (1996:T-2) calculated the average meat weights of five mussel species: Anodonta, $23.5 \mathrm{~g}(n=1)$; Lampsilis teres, $26.83 \mathrm{~g} \pm$ $11.5 \mathrm{~g}(n=3) ;$ Cyrtonaias tampiconensis, $14.63 \mathrm{~g} \pm$ $6.63 \mathrm{~g}(n=34) ;$ Potamilus purporatus, $41.88 \mathrm{~g} \pm 26.07$ g (n=23); Quadrula sp., $18.26 \mathrm{~g} \pm 7.51 \mathrm{~g}(n=36)$; and Tritigonia verrucosa, $28.59 \mathrm{~g} \pm 7.33 \mathrm{~g}(n=17)$. Lintz (1996:T-7) found that, generally, meat weights parallel shell size, measured as length $\mathrm{x}$ width $\mathrm{x}$ thickness (larger shell size $=$ more meat weight), with only a couple of exceptions in the case of thin-shelled species. Shell weight, however, correlated much more poorly with meat weight and is not seen as an efficient means of calculating freshwater mussel meat weight (Lintz 1996:T-7 - T-8).

Lintz (1996:T-10) calculated an average weight of $23.8 \mathrm{~g}$ from 114 mussels from the Colorado River basin. Using data presented in Lintz's study (1996:T2), the average size of mussels in his study was 269.16 $\mathrm{cm}^{3}$; this results in an average of $1 \mathrm{~g}$ of mussel meat for each $11.3 \mathrm{~cm}^{3}$ of mussel size. Therefore, it is recommended that analysts calculate the average size of mussels in archaeological assemblages in $\mathrm{mm}$ and divide this number by 11.3 , the volume (in $\mathrm{cm}^{3}$ ) of shell size that is associated with approximately one $g$ of shell weight in the modern sample of 114 mussels compiled and analyzed by Lintz (1996). This formula is as follows:

$$
M W_{A V G}=(\mathrm{TS} \div \mathrm{N}) \div 11.3
$$

where $\mathrm{TS}=$ size in $\mathrm{mm}^{3}$ of all shells considered $(\mathrm{L} \mathrm{x}$ W $x$ Th), $\mathrm{N}=$ number of mussels in the component(s) being analyzed, and $\mathrm{MW}_{\mathrm{AVG}}=$ calculated average meat weight per bivalve.

It should be kept in mind that this formula, based as it is on a modern assemblage, approximates the average meat weight for mussels that might be found in an archaeological assemblage. Assemblages consisting solely of a single species are likely to yield greater or lesser quantities of meat weight. However, most reported assemblages (e.g., Lintz et al. 1993; Mehalchick and Kibler 2008; plus those from 41HM61, see Chapter 14) consist of multiple species mixed together rather than single species, suggesting that an approach that uses averages derived from representative populations is an appropriate means of estimating prehistoric meat yield. Archaeologists commonly note that prehistoric specimens are smaller on average than modern ones (e.g., Mehalchick and Kibler 2008). Calculating average meat yields by shell size also avoids this problem when working with prehistoric assemblages that are likely to be smaller on average than modern samples. This methodology for estimating the total yield of meat weight is recommending in the absence of species-specific meat weight data for each of the 52 species found in Texas.

5. In addition to reconstructing total meat weight, it is recommended that analysts compile data regarding the nutritional value of mussels represented in a given assemblage. This review finds that existing nutrient data for freshwater mussels are problematically few and that available data are likely to be unreliable. It is therefore recommended that nutrient data be compiled from appropriate modern analogs as a means of understanding prehistoric nutrient yield. If archaeologically identified species are not available for collecting, either because of conservation status or absence from the study area, then nutritional data from proxy species should be considered (following the common practice in contemporary food nutrient studies; see Schakel et al. [1997]).

Collection strategies should seek to compile data approximately representative of the habitat from which that assemblage was derived and not from the archaeological assemblage(s) in question. Specifically, collection activities should be conducted on a waterway as near to the project area as is feasible, regardless of whether the species present include those identified in the archaeological assemblage(s). This focus recog- 
nizes mussel beds rather than any particular species of mussels as the key resource patch (Jones 1991; Wolverton et al. 2010) targeted by prehistoric hunter-gatherer-foragers. Energetic and nutritional yields from that patch are likely to have been understood in advance at a general level but were probably not precisely anticipated because of unknown variables that included mollusk density, the range of individual sizes present, the specific species to be included, and others.

All collection activities should be conducted under the authority of a Scientific Permit for Research, issued by Texas Parks and Wildlife (http://www.tpwd. state.tx.us/business/permits/land/wildlife/research/). In order to ensure that listed species are not inadvertently taken, a malacologist or other personnel suitably familiar with mollusks of Texas should be included in the collection fieldwork. Specific details about sample size and target-species diversity within the collection should be informed by the nature, size, and diversity of the archaeological assemblage(s) in question. However, it should not be expected that collection plans will result in recreated assemblages that perfectly mirror those found in the archaeological record. Viable collection plans are likely to be affected by access to nearby waterways, protected status of different species that may be present, actual density of mussel populations in chosen study areas, and other factors.

Once a collection plan is successfully completed, collected mussel specimens should be submitted to an accredited analytical chemistry laboratory. In this instance, "accredited" refers to ISO 17025, the standard developed by the International Organization for Standardization that specifies the general requirements for the competence to carry out tests and/or calibrations, including sampling. This standard covers testing and calibration performed using standard methods, non-standard methods, and laboratory-developed methods. In the absence of this standardization certification, TxDOT may consider whether they will accept a performing laboratory's statement of protocols to ensure standardized results of analytical measurements.

Prior to submission, analysts should calculate the total meat weight of collected mussels. These data can be used to double-check, confirm, or correct meat weight calculations presented above.

Minimally, analyses of submitted mussel specimens should evaluate samples for proximates (water, energy, protein, total lipid [fat], and carbohydrate), minerals (calcium, iron, magnesium, phosphorous, potassium, sodium, and zinc), vitamins (Vitamin C [total ascorbic acid], thiamin, riboflavin, niacin, vita$\min \mathrm{B}_{6}$, and vitamin $\mathrm{A}[\mathrm{IU}]$ ), and lipids (total saturated fatty acids, total monounsaturated fatty acids, and total polyunsaturated fatty acids). These values are widely reported in the NDL database, and are therefore considered important for the purposes of comparing the nutrient value of multiple foods.

Using information produced by these analyses, the total nutritional yield of mussels in the archaeological assemblage(s) in question can be calculated as follows:

$$
M W_{A V G} x N=\mathrm{TNC}
$$

where TNC $=$ Total Nutrient Contribution of archaeological mussel assemblage.

With TNC calculated in this manner, the total contribution of freshwater mussels to component-scale food intake is known. This information is most useful, however, when considered alongside comparable data for other foodstuffs identified in the same component.

\section{Applicable Laws and Regulations}

Freshwater mussels in Texas can only be collected in accordance with rules and policies established by the Texas Parks and Wildlife Department (TPWD). Currently, daily limits for harvests are 25 pounds of whole mussels or 12 pounds of shell per person/day (these and other weight limits may not apply to scientific permits). A fishing license and freshwater fishing stamp are required. Hand collection is mandated, and some regions of the state are defined as no-collection sanctuaries. Collections for scientific study are to be carried out under a Scientific Permit for Research.

Many of the freshwater mussel species occurring in Texas ( $n=15$ of 49 extant species ${ }^{3}$; three others are extirpated or presumed extinct) are listed as Threatened or Endangered nongame species and therefore may not be taken or possessed (31 Texas Administrative Code $\$ 57.157)$. In addition to these legislated protec-

3
As of 2013, state-listed Threatened freshwater mussels in Texas include false spike (Quadrula mitchelli), golden orb (Quadrula aurea), Louisiana pigtoe (Pleurobema ridellii), Mexican fawnsfoot (Truncilla cognata), salina mucket (Potamilus metnecktayi), sandbank pocketbook (Lampsilis satura), smooth pimpleback (Quadrula houstonensis), southern hickorynut (Obovaria jacksoniana), Texas fatmucket (Lampsilis bracteata), Texas fawnsfoot (Truncilla macrodon), Texas heelsplitter (Potamilus amphichaenus), Texas hornshell (Popenaias popeii), Texas pigtoe (Fusconaia askewi), Texas pimpleback (Quadrula petrina), and triangle pigtoe (Fusconaia lananensis). 
tions, TPWD maintains a listing program that recognizes mussel species as critically imperiled, imperiled, vulnerable, apparently stable, and stable (designated by rating of S1 to S5, respectively). Twenty-one of 49 extant species, including those listed as Threatened or Endangered, are rated as S1 or S2 [TPWD Nongame and Rare Species Program]). Eleven others are rated as vulnerable (S3).

The status of freshwater mussels is related in part to the commercial exploitation of these animals for different uses. The primary contributing factors, however, relate to habitat loss from dam construction, sedimentation of streams and rivers, or over-use of water for commercial purposes; the accumulation of pollutants in freshwater systems; and to changes in climate that alter ecological balances that are important to reproductive cycles.
Although no specific prohibitions exist regarding the scientific collection of those species listed as imperiled or critically imperiled, excluding those listed by the state as Threatened or at the federal level as Endangered or a candidate for such listing, this overview recommends that consultants to TxDOT be mindful of the vulnerable nature of mussel populations generally, and focus proposed collection activities on those species that appear to exist in abundance. These include species listed as S4 or S5 (http://www.tpwd.state.tx.us/huntwild/wild/ wildlife_diversity/texas_rare_species/mussels/musselstatus.phtml). A compilation of state-listed Endangered and Threatened and federally-listed Endangered and Candidates-for-Endangered designation can be found at http://www.tpwd.state.tx.us/huntwild/wild/wildlife_ diversity/texas_rare_species/listed/texas_rare_species/ listed_species/invertebrates.phtml. 


\section{Chapter 17}

\section{SumMary AND RECOMMENDATIONS

\author{
Richard A. Weinstein \\ Jon C. Lohse
}

NRHP testing at site 41HM61 recovered abundant archaeological evidence of repeated visitation and occupation of the locale from at least the late Middle Archaic to Late Prehistoric (Toyah) times. Classes of archaeological data that were recovered from the site include features representing the exploitation of freshwater mussels as a food resource, light quantities of burned and fire-cracked rocks, zooarchaeological and paleobotanical remains from food procurement and related processing activities, and chipped stone artifacts from tool refurbishment and discard. Only limited evidence suggests tool manufacture or production occurred at the site, and our interpretations of the site's lithic tool remains is that visits to this locale were likely of short duration, and may have involved very small numbers of people. In addition to cultural remains, sediment samples from different time periods and contexts were processed by flotation, and terrestrial gastropods recovered from these samples were analyzed for taxa present for the purposes of characterizing habitat and environmental change at the site over time. The site does not contain abundant deposits from any one particular time period, but instead contains a low-density record of multiple time periods spanning at least 4,000 years of regional prehistory. Excavations failed to reach the bottom of alluvial deposits capable of containing cultural deposits, and the total extent of this site's sequence remains unknown.

Based on our findings, we conclude and recommend that site 41HM61 is eligible for inclusion in the National Register of Historic Places under eligibility
Criterion D (36 CFR 60; 36 CFR 800). Likewise, the site is considered eligible for status as a Texas State Antiquities Landmark (SAL) (Texas Natural Resources Code, Title 9, Chapter 191; Texas Administrative Code, Title 13, Chapter 26). The site contains intact archaeological deposits at least two meters deep, with distinct living surfaces and features representative of several prehistoric occupations. Minimally, the earliest of these occupations extend from the latter part of the Middle Archaic period (Temporal Interval G) to the early, middle, and late portions of the Late Archaic period (Temporal Intervals $\mathrm{H}$ and I; Late Archaic 2, 3, and 4), ca. 2460 B.C. to A.D. 850 (or A.D. 1050 if the tentative reservoir correction for mussel shells is correct). These are followed by the site's latest occupation, which includes a Toyah component dating to the latter part of the Late Prehistoric period (Temporal Interval K), ca. A.D. 1450 to 1650.

Although the best available radiocarbon data come from the Toyah component situated on the north side of the channelized Leon River, and suggest that the latest site occupations actually may have extended into what archaeologists describe as the early Historic period (as late as the late-1500s or early 1600s), that part of the site appears to have been heavily damaged during highway construction, leaving only a small remnant of intact deposits available for examination during the current project. Thus, the investigations carried out in that area are considered to have exhausted the limited information potential of the Toyah component. No further archaeological investigations are warranted north of the channelized river. 
In spite of the relatively low density of remains, perhaps the defining characteristics of the site are: (1) that its deposits are exceedingly well ordered with respect to time; (2) that most archaeological intervals that have been defined regionally are represented to some degree; (3) that minimal disturbances are found to have taken place within the southern part of the site that would disrupt or disturb the integrity of these deposits; and (4) that, given the proper approaches to sample selection and dating, precise chronologies of cultural events can be compiled that would allow archaeologists and the interested public to understand in detail the timing and nature of prehistoric cultural adaptation in response to numerous processes (e.g., social responses to exogenous cultural influences, adaptation to climate change, etc.) that can be proposed or recognized by archaeologists.

\section{Summary of Fieldwork}

Fieldwork at site 41HM61 entailed the reopening and recording of three of TxDOT's prior 14 backhoe trenches (BTs 4, 9, and 11, totaling 14 linear meters), the excavation and recording of eight new trenches (BTs 15 through 22, totaling 98 linear meters), ${ }^{1}$ and the controlled excavation of six (roughly 50-by-50-cm or ca. 1-by-1-m) witness columns (WCs 1 through 6) and five contiguous sets of 1-by-1-m units (Blocks 1 through 5). All told, $4.92 \mathrm{~m}^{3}$ of soil was hand excavated during the work on the witness columns, and another $14.05 \mathrm{~m}^{3}$ of soil was removed during the hand excavations of the blocks.

As noted, excavations on the north side of the present-day Leon River channel uncovered one primary occupation related to the Toyah phase of the Late Prehistoric period (Temporal Interval K). Within the ROW, this occupation covered a very restricted area around the location of Block 1, measuring roughly 11 $\mathrm{m}$ north-south by $12 \mathrm{~m}$ east-west for a total of ca. 127 $\mathrm{m}^{2}$. Given that Block 1 removed ca. $10.5 \mathrm{~m}^{2}$, only ca. $116.5 \mathrm{~m}^{2}$ are estimated to remain for future investigation, and an unknown but likely significant part of that area was destroyed by the ditch or gully encountered in the eastern third of Block 1.

Below the Toyah component, scattered evidence of earlier occupations were revealed on the north side

1 BT 23 is not included in this total, as it was dug only to provide a window into the deep stratigraphy in the southern part of the site. Save for its western wall, no walls were profiled and no field specimens were recorded. Thus the effort devoted to the excavation and recording of BT 23 was not comparable to the effort devoted to all other trenches. of the river. However, no diagnostic artifacts or radiocarbon samples were obtained to help date these earlier occupations. Given the presence of a wealth of Late Archaic occupations on the south side of the river, plus the highly disturbed nature of most of the deposits north of the river, it is questionable whether additional work on the north side would yield useful information. For those reasons, and as discussed above for the Toyah component, no further work is recommended for the Archaic occupations north of channelized Leon River.

In contrast to the minor occupation areas identified on the north side of the river, the south side produced a fairly large area of intact cultural remains, measuring roughly $61 \mathrm{~m}$ north-south by $76 \mathrm{~m}$ eastwest, for an area of ca. 4,200 $\mathrm{m}^{2}$. Excavations on the south side removed $13.3 \mathrm{~m}^{2}$, leaving approximately $4,187 \mathrm{~m}^{2}$ for future research. Besides covering a much larger area of cultural activity than the north side, the south side also revealed evidence of several distinct Archaic period occupations. The most obvious were within the Upper West Range's A horizon, and these were present in all trenches, WCs, and blocks. Several mussel shell and fire-cracked rock features, plus possibly three separate living surfaces were recognized. Diagnostic artifacts included several whole and partial Marcos and Ensor dart points, plus fragments of likely Marcos or Ensor points, all indicative of Late Archaic 2 and 3 period occupation(s) equivalent to Temporal Intervals $\mathrm{H}$ and I. Although no diagnostic artifacts of the Late Archaic 4 period (Temporal Interval I) were recovered, a radiocarbon date on the F. 16 shell deposit in WC 2 and Block 2 indicates that such an occupation likely also is present at the site.

Beneath the Upper West Range A horizon were uncovered several more occupation surfaces and scattered artifacts and faunal remains. Almost all of these appear to be situated within an A horizon related to the Lower West Range alluvium. Again, these mainly consisted of clusters of mussel shells and fire-cracked rocks. One such group, Features 19 and 20, potentially represents a single cooking episode wherein mussel shells were laid atop a layer of silt that covered a hot-rock oven. Radiocarbon dates from these two features indicated that they likely were contemporaneous and were laid down during the Late Archaic 2 period (Interval $\mathrm{H}$ of the Collins sequence), sometime between ca. 820 and 750 B.C. They also appear to be contemporaneous with a Lange dart point found at the same depth several meters to the north in BT 15 .

The deepest and earliest occupation on the south side of the river was represented by several 
mussel shell concentrations, two of which (Features 18 and 28) were exposed during the excavation of Block 5. Although no diagnostic artifacts were found associated with these features, radiocarbon dates on organic sediment and a mussel shell from F. 18 suggest an occupation between ca. 2460 and 2275 B.C. This date range falls within the late Middle Archaic period (Temporal Interval G of the Collins sequence), and represents the oldest dated component thus far recognized at the site.

As noted in Chapters 7 and 8 (see Tables 7-12 and 8-11), controlled hand excavations at 41HM61 removed $14.05 \mathrm{~m}^{3}$ of soil. If one disregards the numerous pieces of fire-cracked rock and the few unmodified pebbles recovered, then these excavations produced a total of 90 patterned tools/tool fragments or pieces of debitage (14 from the WCs and 76 from the blocks). This amounts to 6.4 lithic artifacts per cubic meter of excavation. Similarly, vertebrate faunal remains recovered from the hand excavations produced a total of 1,097 elements (371 from the WCs and 726 from the blocks) (see Chapter 13). This amounts to 78.1 elements per cubic meter of excavation. While this relatively small density of lithics and faunal remains has been noted throughout the report, and at other locales could be taken to mean that site potential is not particularly high, that is not the case at 41HM61. The relative paucity of recovered artifacts and bone is negated greatly by the fact that the site has numerous cultural components spanning thousands of years, with many of the components (or the components' features) stratigraphically and horizontally separable from each other.

Based on nature of the site and the results of the current CEI investigations, a number of topics of interest and importance to archaeological research in the region potentially can be addressed at 41HM61. For purposes of discussion, we have organized some obvious topics according to whether they contribute to our knowledge of the past, or whether work at the site helps improve archaeologists' methodological approaches to similar sites. Based on our findings, we conclude and recommend that data-recovery-level work be conducted at the site in the event that plans for bridge replacement or road improvement be further developed and scheduled for construction. Some of the topics addressed in our findings, and which could be further pursued in Phase III investigations, are summarized below.

\section{Contributions to Knowledge: Category of Site Type for the Middle Leon River Drainage}

Site 41HM61 is not unlike many other sites located along the banks or within the floodplain of the Leon River (see Chapters 3 and 4) and perhaps the upper reaches of similar rivers throughout central and north-central Texas. These sites represent thousands of years of occupation, minimally spanning the late Middle Archaic to late Toyah times in the present case. However, at 41HM61 each occupation is clearly separated and can be easily defined in spite of the fact that such events do not appear to have been long-lived or intense. It is significant that this pattern of site use remained constant for the documented periods of occupation. That is, each component seems to reflect a limited set of activities based on low artifact frequencies associated with each temporal period. This pattern raises questions about the role of 41HM61 in regional settlement patterns and cultural systems over time. From this perspective, it would be important to know how common in the region is this pattern of light but serial reoccupation, and how this site and others like it articulate with larger sites elsewhere that show evidence for more intensive habitation? With further work it may be possible to define such sites according to a particular type or category. In other words, the kinds of large-scale cultural aggregations (e.g., Conkey 1980, 1991) that characterize other high-density, multi-temporal archaeological deposits (Wilson-Leonard, Buckeye Knoll, Gault and other sites are good examples of aggregation sites in Texas) clearly did not take place at 41HM61. Rather, each restricted temporal span has its own occupation debris, many include cultural features relating to cooking or food processing, and the general volume of debris relating to tool manufacture and other economic activities is very light. This means that the site can be used as a sort of terrestrial "time capsule" of the prehistoric record, a phrase often used to describe historic shipwrecks and the data they can provide. Such low-density and stratigraphically separable deposits are generally understood to be free from the temporal mixing of deposits and remains that confound other, more intensively occupied sites. Although each temporal period as expressed at 41HM61 may not fully cover the length assigned to that period at the regional level, taken in aggregate these periods are capable of providing precisely dated information capable of addressing a number of possible research topics. 


\section{Improving Regional Chronologies}

The geoarchaeological character of this part of the Leon River Valley means that ancient surfaces were often buried rapidly, and that this process apparently occurred frequently in the past but under low-energy conditions where the erosion and loss of extant landforms and soils was minimal. From an archaeological perspective, this means that the record of human presence preserved at $41 \mathrm{HM} 61$ is fairly complete and continuous, even in spite of its low-density nature. As a consequence, several temporal intervals are well represented that are only poorly defined in regional models. We discussed three examples.

\section{Early Late Archaic 2: Lange}

One example is the time period associated with Lange-type dart points. This type was previously reported in abundance at the Loma Sandia cemetery site (41LK28) in Live Oak County (Taylor and Highley 1995). Reported radiocarbon dates from that component range from about 850-600 B.C., or about 2800$2550 \mathrm{cal}$ B.P. (see Turner et al. 2011:127). The Lange type is not as distinctive technologically as those that occur immediately before (e.g., Pedernales, Marshall) or after (Montell, Castroville) and this period is generally not well defined regionally. Lohse et al. (2014a) omitted this type and period in their revised radiocarbon-based chronology for central Texas, and Lange points, generally, are less commonly reported among central Texas Late Archaic assemblages than earlier and later types.

Based on reported data from Live Oak County, Lange points seemingly date to about $2800-2550$ cal B.P. This range fits into the early portion of the Late Archaic 2 period (3100-2150 cal B.P.). However, this dated interval would also be associated with bison in the regional model presented by Lohse et al (2014c). The second occurrence of Late Archaic bison, $\mathrm{LA}_{\mathrm{B}} 2$, is thought to have begun around $2700 \mathrm{cal} \mathrm{B.P.} \mathrm{and} \mathrm{ex-}$ tended until about $2150 \mathrm{cal}$ B.P. However, no bison remains were recovered from the Lange component at $41 \mathrm{HM} 61$, and it is uncertain whether this type was associated with bison hunters or whether it predates the appearance of bison in the region. Our findings, although imprecise, suggest that Lange dates to about 2770-2700 or so cal B.P. (based on the greatest probability distribution of sample Beta-315690 from Feature 19; see discussion in Chapter 10). Accordingly, we suggest that Lange is likely to be slightly older than the reported ages from 41LK28, and that the type also pre-dates the regional $\mathrm{LA}_{\mathrm{B}} 2$ bison event. If this con- clusion can be verified in the future, the ability to confidently rule out associations between Lange-period cultural practices with exploitation of bison would be of significant help to regional researchers interested in providing resolution for the Late Archaic 2 period. While based on a very small amount of data, we identify this issue as one that can be very meaningfully addressed in future work at sites with both well-defined Lange components and well preserved faunal remains.

\section{Late Archaic 2/3: Marcos, Ensor, and Bison}

A second example of how site deposits at 41HM61 can improve regional chronologies is in the transition from Marcos to Ensor, the timing between these periods, and what environmental or other factors may have been involved in this shift. According to the regional chronological model summarized in Chapter 3, Late Archaic 2 ends with the Marcos type and the following period, Late Archaic 3, starts with Ensor. This distinction is admittedly arbitrary to some degree and it is not well known when or why Marcos types declined in popularity among regional hunter-gatherers and Ensor points became more prevalent. Typologically, it can be very difficult to tell some Marcos points apart from some Ensors. This problem was particularly germane at 41HM61; of the Ensor and Marcos specimens recovered during these excavations, one analyst classified all points as Marcos, another classified them all as Ensors, and a third analyst split them evenly into the two types. Technologically, these two styles share much in common and are distinguished primarily by whether the stems are corner (Marcos) or side (Ensor) notched. However, determining the specific angle of notching is often subjective, and even lightly reworked specimens could easily be placed into either category.

Considerations of typological clarification between some Marcos and some Ensor points is relevant here, because this shift should be seen as one (of many) social or cultural changes that took place around 2150 cal B.P. (Lohse et al. 2014a:278). Clearly, these cultural changes took place over a somewhat longer span of time than implied by this precise date. Nonetheless, if the regional bison model presented in Chapter 3 (Lohse et al.2014c) is approximately correct, accurately dating the end of $\mathrm{LA}_{\mathrm{B}} 2$ event is critical to defining one of the major cultural patterns of the Late Archaic period. The Marcos-Ensor transition at 41HM61 apparently covers this period almost perfectly. Bison are associated at the site with Marcos specimens but not with Ensor points, and sites that can confidently demonstrate Ensor-bison associations are absolutely critical to resolving this issue. We suggest that 
41HM61 is an ideal site at which to resolve this issue, as future work seems likely to recover bison remains that can be reliably dated to the time period ascribed to the Ensor point style, at least the early portion of this type's use period. Considering the unreliable date derived from the split bison sample dated by ultrafiltration to $2090 \pm 30$ (Beta-370014; see Chapter 10), it would be extremely important that such remains be dated by use of the XAD pretreatment technique. This issue is an outstanding example of one where even a few decades of radiocarbon inaccuracy may obscure the very cultural patterns that are of interest for understanding. Such future research, whether carried out at 41HM61 or elsewhere, may find suitable evidence for establishing Late Archaic 2/3, rather than Late Archaic 2 or Late Archaic 3, as an important cultural period that includes the shift from Marcos to Ensor and that captures the end of the $\mathrm{LA}_{\mathrm{B}} 2$ subsistence pattern.

\section{Toyah Chronology}

The Toyah period of Texas prehistory has received a great deal of academic attention recently (e.g., Arnn 2012; Carpenter et al. 2012b; Collins 2004; Johnson 1994; Kenmotsu and Boyd 2014b). This period is arguably among the most important anthropologically and, perhaps, historically as it represents the final prehistoric cultural patterns that were in place at the time of European arrival. It thus offers an analytical opportunity to extend back into time archaeological models of cultural behavior that have some controls in terms of written historical accounts (e.g., Foster 2008; Wade 2003).

In spite of this recent spate of research, the period continues to be presented as an undifferentiated $\sim 400$-year-long period of generally unbroken or continuous cultural practices. Mauldin et al. (2013) suggest different dietary practices may have been pursued during this period based on stable isotope $(\mathrm{C}$ and $\mathrm{N})$ data from the Coleman cemetery (41BX568), but do not conclude whether such differences were temporal in nature as opposed to intra-group variation perhaps relating to age-sex differences.

Based on directly dated XAD-treated bison remains, Lohse et al. (2014c) suggest that a three-part chronology may be available for the Toyah period that is defined by an early period of bison exploitation, a period with a relative absence of bison, and a final period corresponding with the early Historic period when bison returned to the landscape. Weinstein et al. (2014) date these periods at approximately A.D. 13001420 (early Toyah), A.D. 1420-1565 (bison-free mid- dle Toyah), and ca. $1565-1750$ or so (late Toyah and afterwards). This sequence appears to correlate with fluctuations in solar energy output, called Grand Solar Minima that are associated with temperature fluctuations at the outset of the Little Ice Age (Weinstein et al. 2014). In an earlier climatic reconstruction using stable $\mathrm{C}$ and $\mathrm{N}$ data from regional bison samples, Lohse et al. (2014b) did not have enough samples from the early historic period to confidently verify this pattern. However, the three additional XADpurified AMS dates on early Historic bison from 41HM61 (UCIAMS-140842, UCIAMS-140840, and UCIAMS-140841; see Chapter 10) increase the number of reliable dates from the early Historic period from four to seven, more than enough for confident statistical treatment following the criteria set forth in Lohse et al. (2014b; also Hoppe et al. 2006). Moreover, and importantly for the present discussion, they help confirm the early Historic period as one when bison were present in the region and as distinct from the preceding period which seems to be defined by the absence of bison. We still present the early Historic facet of the Toyah horizon as provisional until more secure dates are available, but findings from the work at 41HM61 support the three-part Toyah chronology proposed earlier. If verified by future work at 41HM61 or elsewhere, this finding could prove enormously significant for our overall understanding of the Late Prehistoric period in central Texas and nearby regions, specifically, and the south-central portion of the Southern Plains in general.

\section{Methodological Advances: Importance of Backhoe Work in Alluvial Floodplains}

In addition to the potential to greatly improve aspects of the central Texas regional cultural chronology, CEI's work at 41HM61 reinforces, from a methodological perspective, the importance of backhoe trenching as a way to identify and understand sites in active alluvial settings. Initial work at the site by TxDOT archaeologists included the excavation of no fewer than 14 backhoe trenches in the project area right-of-way, including 11 in and around the site area. Largely as a result of the low frequency of cultural remains that were encountered, eight additional trenches were required (excavated during the test-level work reported here) in order to help demonstrate that the remains at the site are, in fact, present in primary context. One clear conclusion that can be reached from the understanding of how this site developed is that simple shovel testing or limited backhoe work may be insufficient for locating or fairly characterizing sites 
in similar settings. Hand excavations carried out in block manner, as well as witness columns that were excavated alongside some backhoe trenches were necessary in order to recover artifact data from appropriately fine contexts for demonstrating the intact nature of the site. Yet, without a heavy emphasis on backhoe work for site delineation and geological interpretation, it seems likely that 41HM61 would not have been recognized as having such widespread yet low-density remains that, we suggest, contribute in such a significant manner to its NRHP eligibility.

\section{Value of Fine-Grained Data for Environmental Reconstruction}

A substantial effort was expended to sort flotation samples from 41HM61 according to heavy and light fractions as well as by nested screen size. This effort resulted in robust datasets that are important for addressing different kinds of research questions at the site, and should be considered as applicable elsewhere as well. Perhaps the best example of the information to be gained as a result of this effort is the terrestrial gastropod analysis reported by Peacock et al. (Chapter 15). Many of the most environmentally sensitive taxa are represented among the smallest class of gastropod remains, and can only be recovered through such efforts as were expended here. As a result, those analysts are able to present views of environmental conditions for different time periods that directly contradict more straight-forward analyses of such remains based on limited samples. Those analyses, as Peacock et al. explain, are based on problematic non-representative samples that lack the degree of sensitivity that characterizes the 41HM61 assemblage. Additionally, use of representative sample lots by time period for polar ordination contextualized by experimental assemblages collected from different modern habitats, helps those analysts present environmental conditions during the Middle Archaic, Late Archaic, and Late Prehistoric periods in a more useful, meaningful way. Future application of these recovery and analytical approaches would be important in helping TxDOT and its consulting contractors reconstruct environmental data elsewhere in the state.

\section{New Approaches to Radiocarbon Sample Selection}

A variety of sample types were selected for dating at 41HM61, producing differing degrees of "reliability" in terms of accuracy and precision of the resulting dates (see Chapter 10). This approach to dating archaeological deposits is perhaps relatively new to
Texas archaeology, but places emphasis on closing the temporal gap between targeted and dated events. CEI recommends that this approach be considered for broader application as one way to achieve more finely grained models of prehistoric behavior and related environmental events and processes.

\section{Site Recommendations}

As reviewed above, the northern part of the site within the ROW has only a limited research potential, given its relatively small area of coverage and damage from past construction activities. More than likely, there are other, better preserved Toyah components in the region that likely would provide more useful data than that still potentially available in the northern part of 41HM61. Thus, as noted earlier, the excavations conducted north of the Leon River channel are considered to have exhausted the limited research potential in that area. Accordingly, no further work is recommended there.

The southern part of site 41HM61 is a completely different story, given the presence of intact and deeply stratified cultural deposits. Thus, that part of the site should be mitigated through either avoidance or data-recovery investigations. If avoidance is not an option, then data recovery should strive to acquire a reasonable amount of data on the Archaic components present in the area. Depending on the size of a site to be affected by construction, several previous data-recovery projects conducted by CEI have involved investigation of about 10 to 20 percent of the eligible site area within a project's ROW (Ryan 2004; Weinstein 1991, 1995, 2002, 2005, 2013; Weinstein et al. 1989). Since the south side contains ca. $4,187 \mathrm{~m}^{2}$ of remaining intact cultural deposits within the U.S. Hwy. 281 ROW, data recovery ideally should examine somewhere between ca. 420 and $840 \mathrm{~m}^{2}$ of that area. Furthermore, since most of the features and living surfaces found in the southern area were located around BTs 11,15 , and 16 , it is suggested the majority of the data-recovery investigations take place east of the U.S. Hwy. 281 bridge in the area of those trenches. Many of the burned-rock and mussel shell features exposed by those trenches should be relocated and examined through proper archaeological excavation.

\section{One Final Thought}

As a final thought, it should be reiterated that the current project only examined areas of site 41HM61 within the U.S. Hwy. 281 ROW. It is clear from the current investigations that intact portions of the site, 


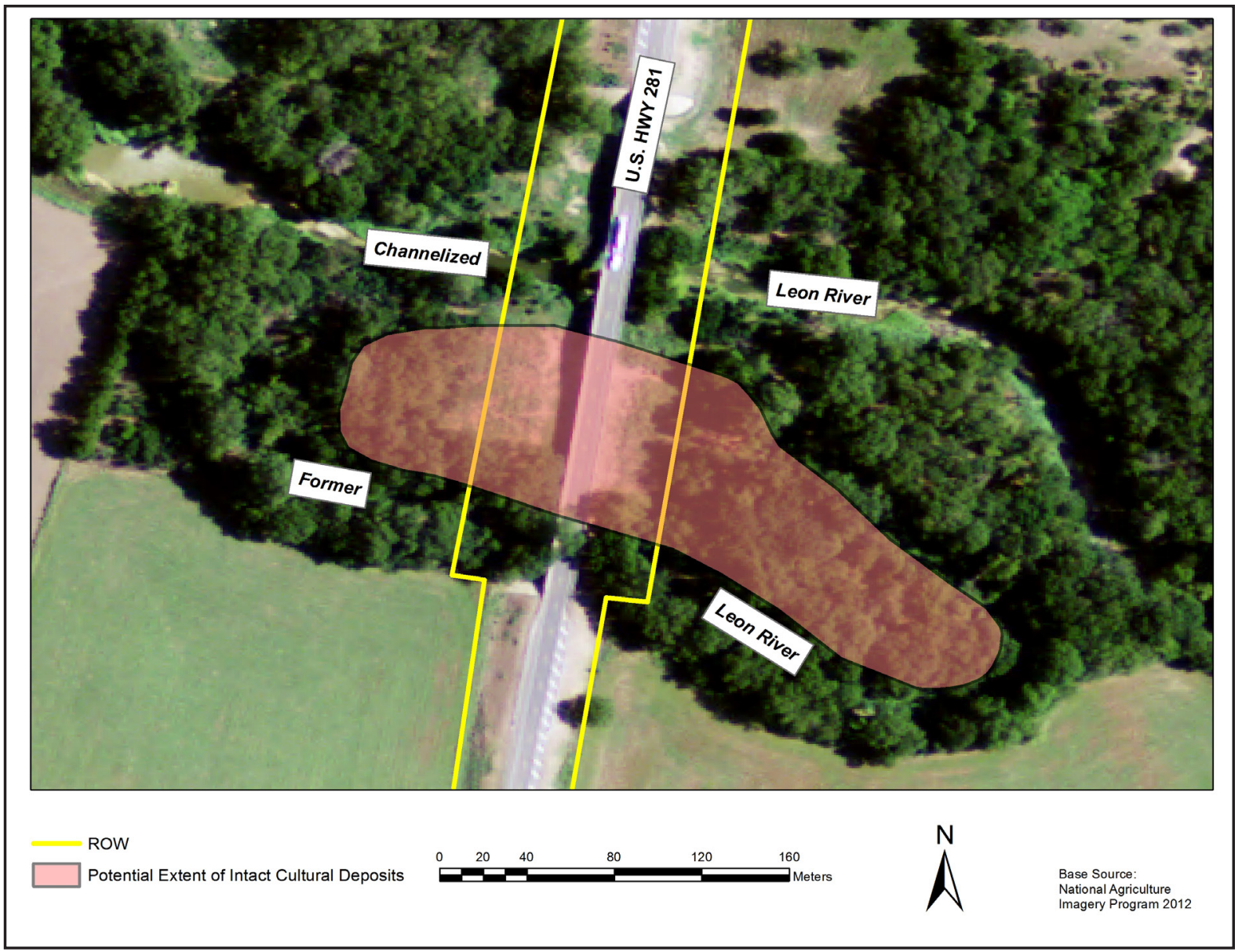

Figure 17-1. Aerial image showing the potential extent of intact cultural deposits south of the channelized Leon River at the U.S. Highway 281 bridge. Note that these deposits conceivably could occur throughout much of the area bounded by the former Leon River on the east, south, and west, and the channelized Leon River on the north.

both north and south of the channelized Leon River, extend beyond the limits of the ROW. In the case of the northern portion of the site, the "Toyah-like" occupation extends for some unknown distance to the east of the eastern ROW line (see discussion above and Figure 6-38). In the southern part of the site, the numerous Archaic deposits extend for unknown distances both to the east and west of the ROW (again, see discussion above and Figure 6-23). Given the fact that the original channel of the Leon River winds past the site to the east, west, and south, a case can be made that the Archaic occupations could extend across most of the terrain encapsulated by both the former and channelized versions of the river. This area today extends for a maximum distance of ca. $55 \mathrm{~m}$ to the west of the western ROW line and ca. $156 \mathrm{~m}$ to the southeast of the eastern ROW line (Figure 17-1). Thus, it is possible, though certainly not confirmed, that the southern part of the site may cover an area somewhat greater than what was examined within the highway ROW. If future replacement of the bridge entails rerouting the highway and acquiring new property either to the east or west of the existing ROW, then archaeological investigations similar to those conducted for the current project will need to occur within the newly acquired area. 


\section{REFERENCES}

Abbott, James T.

2011 Geoarcheological Observations Made in Conjunction with Mechanical Survey along US281 at the Leon River, Hamilton County, Texas (CSJ 0251-01-058). Environmental Affairs Division, Texas Department of Transportation, Austin.

Abbott, James T., and W. Nicholas Trierweiler (editors)

1995 NRHP Significance Testing of 57 Prehistoric Archeological Sites on Fort Hood, Texas. 2 vols. Archeological Resource Management Series, Research Report No. 34. United States Army, Fort Hood, Texas.

Adcock, Sarah, and Matt Hanks

2008 Exposing Refuse Creation and Disposal Activities at a Late-Prehistoric Campsite on the Leon River using ArcGIS Spatial Analyst. Paper presented at the 79th Annual Meeting of the Texas Archeological Society, Lubbock.

Allen, D. C., and E. P. Cheatum

1961 Ecological Implications of Fresh-Water and Land Gastropods in Texas Archeological Studies. Bulletin of the Texas Archeological Society 31:291-316.
Arakawa, Fumiyasu, Scott G. Ortman, M. Steven Shackley, and Andrew I. Duff

2011 Obsidian Evidence of Interaction and Migration from the Mesa Verde Region, Southwest Colorado. American Antiquity 76(4):773-795.

Aran, Luis, and Lindsey Estep

2007 How to Manage, Visualize and Analyze Intra-site Archaeological Data Using GIS. Paper presented at the 78th Annual Meeting of the Texas Archeological Society, San Antonio.

Arnn, John Wesley, III

2012 Land of the Tejas: Native American Identity and Interaction in Texas, A.D. 1300 to 1700. University of Texas Press, Austin.

Arnn, John W., III, Douglas K. Boyd, and Karl W. Kibler

2000 Archeological Testing and Reassessment of 41CV1423, Coryell County, Fort Hood, Texas. Archeological Resource Management Series, Research Report No. 40. United States Army, Fort Hood, Texas. 
Arnn, John, Rebecca Shelton, and Linda W. Ellis

2010 Prehistoric Ceramics in the North Central Texas, Prairie Savanna, and Central Texas Archeological Regions. In Regional Summaries of Prehistoric and Early Historic Ceramics in Texas for the Council of Texas Archeologists, assembled and edited by Linda W. Ellis and Timothy K. Perttula, pp. 58-75. CTA Ceramics Protocol Committee, Council of Texas Archeologists, Austin.

Archeological Staff

2008 Integrity Protocol (Draft), Assessing Site Integrity for TxDOT Projects: Guidelines, Practical Considerations, and Lines of Evidence. MS on file, Environmental Affairs Division, Texas Department of Transportation, Austin.

Arrington, Amanda Leigh, Kali James, and Jennifer Lauren Moon

2009 Creating a Visual Database of Wood Charcoal Samples of Five Common Trees from Central Texas. Poster presented at the 80th Annual Meeting of the Texas Archeological Society, Del Rio.

Asch, N. B., Richard I. Ford, and D. L. Asch

1972 Paleoethnobotany of the Koster Site: The Archaic Horizons. Report of Investigations No. 24. Illinois State Museum, Springfield.

Augspurger, Tom, F. James Dwyer, Christopher G. Ingersoll, and Cynthia M. Kane

2007 Advances and Opportunities in Assessing Contaminant Sensitivity of Freshwater Mussel (Unionidae) Early Life Stages. Environmental Toxicology and Chemistry 26:2025-2028.

Baerreis, David A.

1973 Gastropods and Archaeology. In Variation in Anthropology: Essays in Honor of John C. McGregor, edited by D. W. Lathrap and J. Douglas, pp. 43-54. Illinois Archaeological Survey, Urbana.

2005 Terrestrial Gastropods at the Carlston Annis Site, 15Bt5: Their Habitat and Climatic Implications. In Archaeology of the Middle Green River Region, Kentucky, edited by William H. Marquardt and Patty Jo Watson, pp. 243-255. Monograph No. 5.
Institute of Archaeology and Paleoenvironmental Studies, Florida Museum of Natural History, University of Florida, Gainesville.

Barnes, Virgil E.

1970 Geologic Atlas of Texas: Waco Sheet. Bureau of Economic Geology, University of Texas at Austin.

Barry, J. C.

2011 A Lithic Analysis Concerning the Technological Strategy in the Manufacture of Late Prehistoric Toyah Phase Scrapers at Site 41HY188, Hays County, Texas. Unpublished Master's thesis, School of Archaeology and Ancient History, University of Leicester, Leicester, England.

Barrett, Glynn, Lucie Dingwall, Vince Gaffney, Simon Fitch, Cheryl Huckerby, and Tony Maguire

2007 Heritage Management at Fort Hood, Texas: Experiments in Historic Landscape Characterisation. Archaeopress, Oxford, England.

Basch, Paul F., Philip Bainer, and Jerry Wilhm

1961 Some Ecological Characteristics of the Molluscan Fauna of a Typical Grassland Situation in East Central Kansas. The American Midland Naturalist 66(1):178-199.

Bement, Leland C.

1994 Hunter-Gatherer Mortuary Practices during the Central Texas Archaic. University of Texas Press, Austin.

Blair, W. Frank

1950 The Biotic Provinces of Texas. The Texas Journal of Science 2(1):93-117.

Bobrowsky, Peter T.

1984 The History and Science of Gastropods in Archaeology. American Antiquity 49:77-93.

Bradley, Bruce A., Michael B. Collins, and Andrew Hemmings

2010 Clovis Technology. Archaeological Series No. 17. International Monographs in Prehistory, University of Michagan, Ann Arbor. 
Branson, Branley A.

1960 The Recent Gastropods of Oklahoma III. Terrestrial Species: Pupillidae, Carychiidae, Strobilopsidae and Oligyridae. Proceedings of the Oklahoma Academy of Science for 1960:45-69. Norman, Oklahoma.

Broehm, Cory J., and Karl W. Kibler

2004 Interim Report on Data Recovery Excavations at 41HM51, Hamilton County, Texas. Prewitt and Associates, Inc., Austin. Submitted to Archeological Studies Program, Environmental Affairs Division, Texas Department of Transportation, Austin.

Broehm, Cory J., Karl W. Kibler, and E. Frances Gadus

2004 Interim Report on Survey and Test Excavations at 41HM46 and 41HM51, Hamilton County, Texas. Prewitt and Associates, Inc., Austin. Submitted to Archeological Studies Program, Environmental Affairs Division, Texas Department of Transportation, Austin.

Brown, Kenneth M.

2002 Snails From the Quarter-Inch and EighthInch Screens. In The Smith Creek Bridge Site (41 DW 270): A Terrace Site in De Witt County, Texas, by Dale Hudler, Keith Prilliman, and Thomas Gustavson, pp. 212-275. Studies in Archeology No. 35. Texas Archeological Research Laboratory, University of Texas at Austin. Archeology Studies Program. Report No. 17. Environmental Affairs Division, Texas Department of Transportation, Austin.

2006 The Bench Deposits at Berger Bluff: Early Holocene-Late Pleistocene Depositional and Climatic History. Unpublished Ph.D. dissertation, Department of Anthropology, University of Texas at Austin.

Brown, Kenneth M., and Sheila M. Hughes

2003 Snail Remains Associated with the Rice's Crossing Site (41 WM 815). In Archeological Investigations at 41 WM 815, A Blackland Prairie Site, Williamson County, Texas, by Russell K. Brown- low, pp. 121-137. Studies in Archeology No. 36. Texas Archeological Research Laboratory, University of Texas at Austin. Archeological Studies Program, Report No. 23. Environmental Affairs Division, Texas Department of Transportation, Austin.

Brown T. A., D. E. Nelson, J. S. Vogel, and J. R. Southon

1988 Improved Collagen Extraction by Modified Longin Method. Radiocarbon 30(2): 171-7.

Byrd, Abby

2010 Living on the Leon - A Comparative Study of Hunter-Gatherer Housing Structures. Poster presented at the 81st Annual Meeting of the Texas Archeological Society, Corpus Christi.

Campbell, Joshua S. and William C. Johnson 2004 Temporal Predictive Model for Fort Hood, Texas: A Pilot Study in the Cowhouse Creek Drainage. Archeological Resource Management Series, Research Report No. 54. United States Army, Fort Hood, Texas.

Carlson, David L. (editor)

1993a Archaeological Investigations in Bull Branch: Results of the 1990 Summer Archaeological Field School. Archaeological Resource Management Series, Research Report No. 19. United States Army, Fort Hood, Texas.

(editor)

1993b Archaeological Investigations in Spicewood Creek: Results of the 1991 Summer Archaeological Field School. Archaeological Resource Management Series, Research Report No. 22. United States Army, Fort Hood, Texas.

(editor)

1997 Archaeological Investigations along Owl Creek: Results of the 1992 Summer Archaeological Field School. Archaeological Resource Management Series, Research Report No. 29. United States Army, Fort Hood, Texas. 
Carpenter, Stephen M.

2012 Synthesis and a Revised Model of Toyah. In The Little Paint Site: A Classic Toyah Camp on the South Llano River, Kimble County, Texas, by Stephen M. Carpenter, Kevin A. Miller, Charles D. Frederick, Leslie G. Cecil, Mercedes C. Cody, and Abby Peyton, pp. 233262. SWCA Cultural Resources Report No. 12-429. SWCA, Inc., Austin. Archeological Studies Program. Report No. 148. Environmental Affairs Division, Texas Department of Transportation, Austin.

2013 Site Structure - The Order of Things. In The Siren Site: The Long Transition from Archaic to Late Prehistoric Lifeways on the Eastern Edwards Plateau of Central Texas, by Stephen M. Carpenter, Kevin A. Miller, Mary Jo Galindo, Brett A. Houk, Charles Frederick, Mercedes C. Cody, John Lowe, Ken Lawrence, Kevin Hanselka, and Abby Peyton, pp. 223-246. SWCA Cultural Resources Report No. 13-93. SWAC, Inc., Austin. Archeological Studies Program. Report No. 142. Environmental Affairs Division, Texas Department of Transportation, Austin.

Carpenter, Stephen M., Abby Peyton, Mercedes C. Cody, and Kevin A. Miller

2012a Overview of the Little Paint Site and Results of its Study. In The Little Paint Site: A Classic Toyah Camp on the South Llano River, Kimble County, Texas, by Stephen M. Carpenter, Kevin A. Miller, Charles D. Frederick, Leslie G. Cecil, Mercedes C. Cody, and Abby Peyton, pp. 53-80. SWCA Cultural Resources Report No. 12-429. SWAC, Inc., Austin. Archeological Studies Program. Report No. 148. Environmental Affairs Division, Texas Department of Transportation, Austin.

Carpenter, Steve, and Christian Hartnett

2011 Archaic Macroeconomic Spheres: A Case Study from Fort Hood, Central Texas. Bulletin of the Texas Archeological Society 82:223-249.
Carpenter, Steve, Christian T. Hartnett, J. D. Lowe, and Kevin A. Miller

2010 Data Recovery Investigations on the Cowdog Crossing Site: A Study of the End of the Archaic, Fort Hood, Coryell County, Texas. SWCA Cultural Resources Report No. 1-356. SWAC, Inc., Austin. Archeological Resource Management Series. Research Report No. 56. United States Army, Fort Hood, Texas.

Carpenter, Stephen M., Kevin A. Miller, Charles D. Frederick, Leslie G. Cecil, Mercedes C. Cody, and Abby Peyton

2012b The Little Paint Site: A Classic Toyah Camp on the South Llano River, Kimble County, Texas. SWCA Cultural Resources Report No. 12-429. SWAC, Inc., Austin. Archeological Studies Program. Report No. 148. Environmental Affairs Division, Texas Department of Transportation, Austin.

Casiano, Alexis

2010 Deer Hide Processing Activities at the Upper Sprague Site in Hamilton County, Texas. Paper presented at the 81st Annual Meeting of the Texas Archeological Society, Corpus Christi.

Casey, Joanna Louise

1986 The Prehistoric Exploitation of Unionacean Bivalve Molluscs in the Lower Tennessee-Cumberland-Ohio River Valleys in Western Kentucky. Unpublished Master's thesis, Department of Archaeology, Simon Fraser University, Vancouver.

Cheatum, Elmer P., and Richard W. Fullington

1973 The Recent and Pleistocene Members of the Pupillidae and Urocoptidae (Gastropoda) in Texas. In The Aquatic and Land Mollusca of Texas. Bulletin No. 1., Pt. 2 (whole volume). Dallas Museum of Natural History, Dallas.

Claassen, Cheryl

1998 Shells. Cambridge University Press, Cambridge.

2000 Quantifying Shell: Comments on Mason, Peterson, and Tiffany. American Antiquity 65(2):415-418. 
Clark, John W., Jr.

1973 The Problem of the Land Snail Genus Rabdotus in Texas Archeological Sites. The Nautilus 87(1):24.

1976 Álvar Nuñez and the Snail Rabdotus in Texas. The Nautilus 90(1):13-14.

Collins, Michael B.

1995 Forty Years of Archaeology in Central Texas. Bulletin of the Texas Archeological Society 66:361-400.

2004 Archeology in Central Texas. In The Prehistory of Texas, edited by Timothy $\mathrm{K}$. Perttula, pp. 101-126. Texas A\&M University Press, College Station.

Collins, Michael B., and Jon C. Lohse

2004 The Nature of Clovis Blades and Blade Cores. In Entering America: Northeast Asia and Beringia Before the Last Glacial Maximum, edited by David B. Madsen, pp. 159-183. University of Utah Press, Salt Lake City.

Collins, Michael B., D. M. Yelacic, and C. Britt Bousman 2011 "Realms," A Look at Paleoclimate and Projectile Points in Texas. Bulletin of the Texas Archeological Society 82:3-30.

Conkey, Margaret W.

1980 The Identification of Prehistoric Hunter-Gatherer Aggregation Sites: the Case of Altamira. Current Anthropology 21:609630.

1991 Contexts of Action, Contexts for Power: Material Culture and Gender in the Magdalenian. In Engendering Archaeology: Women and Prehistory, edited by Joan M. Gero and Margaret W. Conkey, pp. 57-92. Blackwell Publishers, Oxford, England.

Core, H. A., Wilfred A. Cote, and A. C. Day

1979 Wood Structure and Identification. 2nd ed. Syracuse University Press, Syracuse, New York.

Cox, B. L.

1978 Comparison of Meat Quality from Bison and Beef Cattle. Unpublished Batchelor of Science thesis, University of Saskatchewan, Saskatoon.
Creel, Darrell G.

1990 Excavations at 41TG91, Tom Green County, Texas 1978. Publications in Archaeology Report No. 38. Highway Design Division, Texas State Department of Highways and Public Transportation, Austin.

Culleton, Brendan J.

2008 Stable Isotope Seasonality Study of Mussel Shells. In Hunters and Gatherers of the North Bosque River Valley: Excavations at Baylor, Britton, McMillan, and Higginbotham Sites, Waco Lake, McLennan County, Texas, by Gemma Mehalchick and Karl W. Kibler, pp. 475-484. Reports of Investigations No. 156. Prewitt and Associates, Inc., Austin. Submitted to Fort Worth District, U.S. Army Corps of Engineers.

Creel, Darrell, Jeffrey R. Ferguson, and Nancy A. Kenmotsu

2013 A Compositional Analysis of Central Texas Hunter-Gatherer Ceramics and Its Implications for Mobility, Ethnic Group Territory, and Interaction. Bulletin of the Texas Archeological Society 84:29-83.

Davies, Paul

2008 Snails: Archaeology and Landscape Change. Oxbow Books, Oxford, England.

Davis, Linda W.

1993 Weed Seeds of the Great Plains: A Handbook for Identification. University Press of Kansas, Lawrence.

Dial, Susan W.

1998 Clear Fork Tools. In Wilson Leonard: An 11,000-Year Archeological Record of Hunter-Gatherers in Central Texas, Volume II: Chipped Stone Artifacts, assembled and edited by Michael B. Collins, pp. 507-535. Studies in Archeology No. 31. Texas Archeological Research Laboratory, The University of Texas at Austin. Archeology Studies Program. Archeological Report No. 10. Environmental Affairs Division, Texas Department of Transportation, Austin. 
Dietary Guidelines Advisory Committee

2010 Report of the Dietary Guidelines Advisory Committee on the Dietary Guidelines for Americans, 2010, to the Secretary of Agriculture and the Secretary of Health and Human Services. Agricultural Research Service, U.S. Department of Agriculture, Washington, D.C.

Diggs, George M., Jr., Barney L. Lipscomb, and Robert J. O'Kennon

1999 Shinner's \& Mahler's Illustrated Flora of North Central Texas. Botanical Miscellany No. 16. Botanical Research Institute Institute of Texas, Fort Worth.

DiPietro, Lyndsay

2008 The Case of the Lone Bison Scapula and Rib Bone, Area D, Upper Sprague Site, Hamilton County. Paper presented at the 79th Annual Meeting of the Texas Archeological Society, Lubbock.

Dreimanis, A.

1962 Quantitative Gasometric Determination of Calcite and Dolomite Using a Chittick Apparatus. Journal of Sedimentary Petrology 32(3):520-529.

Driver, Jonathan C.

1992 Identification, Classification and Zooarchaeology. Circaea 9(1):35-47.

2011 Identification, Classification and Zooarchaeology. Ethnobiology Letters 2:1939.

Duke, James A.

2001 Handbook of Nuts. 2nd ed. CRC Press, Boca Raton, Flordia.

Durham, Ashley

2010 Analysis of Lithic Artifacts Recovered from the Upper Sprague Site, Area D, Hamilton County, Texas. Poster presented at the 81st Annual Meeting of the Texas Archeological Society, Corpus Christi.

Evans, John G.

1972 Land Snails in Archaeology. Seminar Press, London.
Everett, Jenny, and Larry Kocian

2007 Descriptive, Nutritional and Contextual Analysis of Freshwater Mussels from Area D, Upper Sprague Site (41HM54), Hamilton County. Paper presented at the 78th Annual Meeting of the Texas Archeological Society, San Antonio.

Fish, S., P. Fish, C. Miksicek, and J. Madsen

1986 Prehistoric Agave cultivation in Southern Arizona. Desert Plants 7:107-112.

Flannery, Kent V. (editor)

1976 The Early Mesoamerican Village. Academic Press, New York.

Foster, William C.

2008 Historic Native Peoples of Texas. University of Texas Press, Austin.

Fritz, Gayle J., Virginia Drywater Whitekiller, and James W. McIntosh

2001 Ethnobotany of Ku-Nu-Che: Cherokee Hickory Nut Soup. Journal of Ethnobiology 21(2):1-27.

Fullington, Richard W., and William L. Pratt, Jr.

1974 The Helicinidae, Carychiidae, Achatinidae, Bradybaenidae, Bulimulidae, Cionellidae, Haplotrematidae, Helicidae, Oreohelicidae, Spiraxidae, Streptaxidae, Strobilopsidae, Thysanophoridae, Valloniidae (Gastropoda) in Texas. In The Aquatic and Land Mollusca of Texas. Bulletin No. 1., Pt. 3 (whole volume). Dallas Museum of Natural History, Dallas.

Gilmore, Melvin R.

1991 Uses of Plants by the Indians of the Missouri River Region. Reprinted. University of Nebraska Press, Lincoln. Originally published 1914, University of Nebraska Press, Lincoln.

Giovas, Christina M.

2009 The Shell Game: Analytic Problems in Archaeological Mollusc Quantification. Journal of Archaeological Science 36(7):1557-1564.

Glassow, Michael A.

2000 Weighing vs. Counting Shellfish Remains: A Comment on Mason, Peterson, and Tiffany. American Antiquity 65(2):407-414. 
Goetz, Jim R., and Allan D. Nelson

2009 First Records of 13 Mammalian Species within the Southwestern Cross Timbers Region of Texas. Occasional Papers No. 284. Museum of Texas Tech University, Lubbock.

Gould, Frank W.

1962 Texas Plants - A Checklist and Ecological Summary. Texas Agricultural Experiment Station, The Agricultural and Mechanical College of Texas, College Station, Texas.

Gould, Frank W., G. O. Hoffman, and C. A. Rechenthin 1960 Vegetational Areas of Texas. Leaflet No. 492. Agricultural Experiment Station, Texas A\&M University, College Station.

Grassbaugh, Emily

2010 Past and Present Fauna of the Leon River Riparian Zone and Surrounding Uplands in Hamilton County, Texas. Poster presented at the 81st Annual Meeting of the Texas Archeological Society, Corpus Christi.

Grayson, Donald K.

1984a Levels of Measurement. In Quantitative Zooarchaeology, edited by Donald K. Grayson, pp. 93-115. Academic Press, New York.

1984b The Basic Counting Units. In Quantitative Zooarchaeology, edited by Donald K. Grayson, pp. 16-92. Academic Press, New York.

Griffith, G. E., S. A. Bryce, J. M. Omernick, J. A. Comstock, A. C. Rogers, B. Harrison, S. L. Hatch, and D. Bezanson

2004 Ecoregions of Texas. Map at scale of $1: 2,500,000$. Bureau of Economic Geology, University of Texas at Austin.

2010 Ecoregions of Texas. Map at scale of 1:2,500,000. Bureau of Economic Geology, University of Texas at Austin. Originally published 2004, Bureau of Economic Geology, University of Texas at Austin. Electronic document, http://www.lib. utexas.edu/geo/pics/ecoregionsoftexas. jpg, accessed February 15, 2012.
Haley, Morgan, and Carol Macaulay

2008 Part 3: Pecans. A Look at Food Resource Exploitation at a Late-Prehistoric Campsite in Central Texas: Subsistence Activities at the Upper Sprague Site, Hamilton County, Texas (41HM54). Poster presented at the 79th Annual Meeting of the Texas Archeological Society, Lubbock.

Hall, Grant D.

2000 Pecan Food Potential in Prehistoric North America. Economic Botany 54(1):103-112.

Hames, Raymond B., and William T. Vickers

1982 Optimal Diet Breadth Theory as a Model to Explain Variability in Amazonian Hunting. American Ethnologist 9(2):358-378.

Hammett, Julia E.

1997 Interregional Patterns of Land Use and Plant Management in Native North America. In People, Plants, and Landscapes: Studies in Paleoethnobotany, edited by Kristen J. Gremillion, pp. 195216. University of Alabama Press, Tuscaloosa.

Hard, Robert J., and M. A. Katzenberg

2011 A Stable Isotope Study of Hunter-Gatherer-Fisher Diet, Mobility, and Intensification on the Texas Gulf Coast. American Antiquity 76:709-751.

Hayward, O. T., P. M. Allen, and D. L. Amsbury

1990 Lampasas Cut Plain-Evidence for Cyclic Evolution of a Regional Landscape, Central Texas. Guidebook No. 2. Geological Society of America, Dallas.

Henry, Donald O.

1995 Cultural and Paleoenvironmental Successions Revealed by the Hog Creek Archeological Investigation, Central Texas. In Advances in Texas Archeology: Contributions from Cultural Resource Management, Vol. 1, edited by James E. Bruseth and Timothy K. Perttula, pp. 51-79. Cultural Resource Management Report No. 5. Texas Historical Commission, Austin. 
Hester, Thomas R., and T. C. Hill, Jr.

1975 Eating Land Snails in Prehistoric Southern Texas: Ethnohistoric and Experimental Data. The Nautilus 89(2):37-78.

Hoadley, R. Bruce

1990 Identifying Wood: Accurate Results with Simple Tools. Taunton Press, Newtown, Connecticut.

Honea, Kenneth H.

1962 The Rammadyat of Northwest Africa and the Burned Rock Middens of Texas. Bulletin of the Texas Archeological Society 32:316-320.

Hoppe, Kathryn A., Adina Paytan, and Page Chamberlain

2006 Reconstructing Grassland Vegetation and Paleotemperatures Using Carbon Isotope Ratios of Bison Tooth Enamel. Geology 34:649-652.

Howells, Robert G.

1994 Preliminary Distributional Surveys of Freshwater Bivalves in Texas: Progress Report for 1992. Management Data Series No. 105. Texas Parks and Wildlife Department, Austin.

2013 Field Guide to Texas Freshwater Mussels. BioStudies, Kerrville, Texas.

Howells, Robert G., Raymond W Neck, and Harold D. Murray

1996 Freshwater Mussels of Texas. Texas Parks and Wildlife Department, Austin.

Hubricht, Leslie

1985 The Distributions of the Native Land Mollusks of the Eastern Unites States. Zoology (New Series) No. 24. The Field Museum of Natural History, Chicago.

Hudler, Dale

1997 Determining Clear Fork Tool Function Through Use-Wear Analysis: A Discussion of Use-Wear Methods and Clear Fork Tools. Studies in Archeology No. 25. Texas Archeological Research Laboratory, The University of Texas at Austin.
InsideWood

2004-onwards. InsideWood. North Carolina State University, Raleigh. Electronic document, http://insidewood.lib.ncsu. edu/search, accessed March 3, 2014.

Jameson, Bryan

2007 Excavation Activities at the Upper Sprague Site, 41HM54, Hamilton County, Texas. Paper presented at the 78th Annual Meeting of the Texas Archeological Society, San Antonio.

Jameson, Bryan, and Daniel R. Potter

1999 Test Excavations at the Sprague Site: A Multicomponent Site in Hamilton County. In The Steward: Collected Papers on Texas Archeology, Vol. 5, edited by Daniel R. Potter and Helen Simons, pp. 27-47. Texas Archeological Stewardship Network, Texas Historical Commission, Austin.

Johnson, LeRoy, Jr.

1994 Life and Times of Toyah-Culture Folk: Buckhollow Encampment, Site 41KM16, Kimble County, Texas. Report No. 38. Office of the State Archeologist, Texas Historical Commission, Austin, and Texas Department of Transportation, Austin.

Jones, Terry L.

1991 Marine-Resource Value and the Priority of Coastal Settlement: A California Perspective. American Antiquity 56:419443.

Kelly, Robert L.

1995 The Foraging Spectrum. Smithsonian Institution Press, Washington, D.C.

Kelly, Robert L., Todd A. Surovell, Bryan N. Shuman, and Geoffrey M. Smith

2013 A Continuous Climatic Impact on Holocene Human Population in the Rocky Mountains. Proceedings of the National Academy of Sciences 110:443-447. National Academy of Sciences, Washington, D. C.

Kenmotsu, Nancy A., and Douglas K. Boyd

2012a The Toyah Phase in Texas: An Introduction and Retrospective. In The Toyah 
Phase of Central Texas: Late Prehistoric Economic and Social Processes, edited by Nancy A. Kenmotsu and Douglas K. Boyd, pp. 1-18. Texas A\&M University Press, College Station.

Kenmotsu, Nancy A., and Douglas K. Boyd (editors)

2012b The Toyah Phase of Central Texas: Late Prehistoric Economic and Social Processes. Texas A\&M University Press, College Station.

Kerr, Jonathan P., and Paul D. Bundy

2010 Archaeological Investigations within the Proposed Argosy Lawrenceburg Casino Expansion Project Area in Dearborn County, Indiana, Vol.I: Prehistoric Sites. Contract Publication Series No. 07153.01. Cultural Resource Analysts, Inc., Lexington, Kentucky. Submitted to Penn National Gaming Company, Inc., Alton, Illinois.

Kibler, Karl W.

2012 The Role of Exotic Materials in Toyah Assemblages in a Late Prehistoric Economic and Social System. In The Toyah Phase of Central Texas: Late Prehistoric Economic and Social Processes, edited by Nancy A. Kenmotsu and Douglas K. Boyd, pp. 76-89. Texas A\&M University Press, College Station.

Kibler, Karl W., and Cory J. Broehm

2005 Data Recovery at Site 41HM51, Hamilton County, Texas. Current Archeology in Texas 7(1):18-22.

Koloseike, Alan

1969 On Calculating the Prehistoric Food Resource Value of Molluscs. Archaeological Survey Annual Report 11:143-160. Department of Anthropology, University of California, Los Angeles.

LBJ School of Public Affairs

1978 Texas Natural Regions and River Basins. Policy Research Project, Report No. 31. LBJ School of Public Affairs. Electronic document, http://texasaquaticscience. org/wp-content/uploads/2013/07/ C3_fig3.5-aquatic-science-texas.jpg, accessed January 19, 2015.
Leffler, John

2012 Hamilton County. In Handbook of Texas Online. Texas State Historical Association, Austin. Electronic document, http://www.tshaonline.org/handbook/ online/articles/hch03, accessed February 16, 2012.

Ladipo, Oladapo A.

2000 Nutrition in Pregnancy: Mineral and Vitamin Supplements. The American Journal of Clinical Nutrition 72:280290.

Lewand, R. L., Jr.

1969 The Geomorphic Evolution of the Leon River System. Bulletin No. 17. Baylor Geological Studies, Baylor University, Waco.

Lintz, Christopher

1996 Dietary Data of Mussel Shell Assemblage. In Early Archaic Use of the Concho River Terraces: Cultural Resource Investigations at $41 T G 307$ and 41TG309, Tom Green County, San Angelo, Texas. Technical Report No. 11058. TRC Mariah Associates, Inc., Austin. Submitted to Texas Water Development Board, Austin.

Lintz, Christopher, Abby C. Treece, Fred M. Oglesby, Karl Kibler, Patrick O’Neill, W. Nicholas Trierweiler, Charles Frederick, J. Michael Quigg, and A. J. Taylor 1993 Cultural Resource Investigations in the O. H. Ivie Reservoir, Concho, Coleman, and Runnels Counties, Texas. Vol. II: Test Excavations at Prehistoric Sites and Assessment of Rock Cairn Features. Technical Report No. 346-II. Mariah Associates, Inc., Austin. Submitted to Colorado River Municipal Water District, Big Spring, Texas.

Lohse, Jon C.

2009 Archaeological Investigations on the Herd Ranch in Western Menard County, Texas. Archaeological Studies Report No. 19. Center for Archaeological Studies, Texas State University-San Marcos.

Lohse, Jon C., and Laly M. Cholak

2011 Toward a Useful Radiocarbon Chronology for Central Texas. Paper presented at the 
82nd Annual Meeting of the Texas Archeological Society, Fort Worth.

Lohse, Jon C., Stephen L. Black, and Laly M. Cholak 2014a Toward an Improved Archaic Radiocarbon Chronology for Central Texas. Bulletin of the Texas Archeological Society 85:251-279.

Lohse, Jon C., David B. Madsen, Brendan J. Culleton, and Douglas J. Kennett

2014b Isotope Paleoecology of Episodic Midto-Late Holocene Bison Population Expansions in the Southern Plains, U.S.A. Quaternary Science Reviews 101:1-13.

Lohse, Jon C., Brendan J. Culleton, Stephen L. Black, and Douglas J. Kennett

2014c A Precise Chronology of Middle to Late Holocene Bison Exploitation on the Far Southern Plains. Journal of Texas Archeology and History 1: 94-126.

Longin, R.

1971 New Method of Collagen Extraction for Radiocarbon Dating. Nature 230:241242.

Lyman, R. Lee

1979 Available Meat from Faunal Remains: A Consideration of Techniques. American Antiquity 44(3):536-546.

1984 Bone Density and Differential Survivorship of Fossil Classes. Journal of Anthropological Archaeology 3(4):256299.

1994a Quantitative Units and Terminology in Zooarchaeology. American Antiquity 59(1):36-71.

1994b Vertebrate Taphonomy. Cambridge University Press, Cambridge, England

2008 Quantitative Paleozoology. Cambridge University Press, New York.

Lyman, R. Lee, and Kenneth M. Ames

2007 On the Use of Species-Area Curves to Detect the Effects of Sample Size. Journal of Archaeological Science 34(12):1985-1990.
McCarthy, Marie A., and Ruth H. Matthews

1984 Composition of Foods: Nut and Seed Products. Agriculture Handbook No. 8-12. U.S. Department of Agriculture, Washington, D.C.

McCune, B., and M. J. Mefford

2011 PC-ORD. Multivariate Analysis of Ecological Data. Version 6.08. MjM Software, Gleneden Beach, Oregon.

McEachern, George Ray, Larry A. Stein, and Julian W. Sauls

1977 Texas Pecan Orchards. Texas A\&M University, College Station. Electronic document, http://aggie-horticulture.tamu.edu/ extension/fruit/pecanorchard/pecanorchard. html, accessed August 31, 2010.

McGrane, Mary, Thomas V. Fungwe, Donna Blum-Kemelor, and Kellie O'Connell

2012 Maternal Intake of Seafood Omega-3 Fatty Acids and Infant Health: A Review of the Evidence. Nutrition Insight No. 46. Center for Nutrition Policy and Promotion, U.S. Department of Agriculture, Washington, D.C.

Machette, Michael N.

1985 Calcic soils of the Southwestern United States. In Soils and Quaternary Geology of the Southwestern United States, edited by D. L. Weide, pp. 1-21. Special Paper No. 203. Geological Society of America, Boulder, Colorado.

1986 Calcium and Magnesium Carbonates. In Field and Laboratory Procedures Used in Soil Chronosequence Studies, edited by Michael J. Singer and Peter Janitzky, pp. 3033. Bulletin No. 1648. Geological Survey, U.S. Department of the Interior. U.S. Government Printing Office, Washington, D.C.

Malof, Andrew F.

2014 Texas Snails in Archaeological Contexts. Electronic document, http:/www. dirtbrothers.org/editorial/malouf/html, accessed March 24, 2014.

Mann, Jesi, and Kassie Kemp

2007 A Toyah Campsite on the Leon River: Excavations at the Upper Sprague 
Site (41HM54), Hamilton County, Texas. Paper presented at the 78th Annual Meeting of the Texas Archeological Society, San Antonio.

Mann, M. E., Z. Zhang, S. Rutherford, R. S. Bradley, M. K. Hughes, D. Shindell, C. Ammann, G. Faluvegi, and $\mathrm{F}$. Ni

2009 Global Signatures and Dynamical Origins of the Little Ice Age and Medieval Climate Anomaly. Science 326:12561260.

Marchello, M. J., D. B. Milne, and W. D. Slanger 1984 Selected Macro and Micro Minerals in Ground Beef and Longissimus Muscle. Journal of Food Science 49:105-106.

Marchello, M. J., W. D. Slanger, D. B. Milne, A. G. Fischer, and P. T. Berg

1989 Nutrient Composition of Raw and Cooked Bison bison. Journal of Food Composition and Analysis 2:177-185.

Martin, Alexander C., and William D. Barkley 1961 Seed Identification Manual. University of California Press, Berkeley.

Mason, Roger D., Mark L. Peterson, and Joseph A. Tiffany

1998 Weighing vs. Counting: Measurement Reliability and the California School of Midden Analysis. American Antiquity 63(2):303-324.

Mauldin, Raymond P., Robert J. Hard, Cynthia M. Muñoz, Jennifer L. Z. Rice, Kirsten Verostick, Daniel R. Potter, and Nathanael Dollar

2013 Carbon and Nitrogen Stable Isotope Analysis of Hunter-Gatherers from the Coleman Site, a Late Prehistoric Cemetery in Central Texas. Journal of Archaeological Science 40:1369-1381.

Mead, Jim I.

1991 Late Pleistocene and Holocene Molluscan Faunas and Environmental Changes in Southeastern Arizona. In Beamers, Bobwhites, and Blue-Points: Tributes to the Career of Paul W. Parmalee, edited by James R. Purdue, Walter E. Klippel, and Bonnie W. Styles, pp. 215-
226. Scientific Papers Vol. 23. Illinois State Museum, Springfield; and Report of Investigations No. 52. Department of Anthropology, University of Tennessee, Knoxville.

Mehalchick, Gemma., and Karl W. Kibler

2005 National Register Testing of Nine Prehistoric Sites on Fort Hood, Texas: The 2001-2002 Season. Archeological Resource Management Series, Research Report No. 50. United States Army, Fort Hood, Texas.

Mehalchick, Gemma, and Karl W. Kibler

2008 Hunters and Gatherers of the North Bosque River Valley: Excavations at the Baylor, Britton, McMillan, and Higginbotham Sites, Waco Lake, McLennan County, Texas. Reports of Investigations No. 156. Prewitt and Associates, Inc., Austin. Submitted to Fort Worth District, U.S. Army Corps of Engineers.

Mehalchick, Gemma, Karl Kleinbach, Douglas K. Boyd, and Karl W. Kibler

2000 Geoarcheological Investigations and National Register Testing of 52 Prehistoric Archeological Sites on Fort Hood, Texas: The 1997 Season. Archeological Resource Management Series, Research Report No. 39. United States Army, Fort Hood, Texas.

Mehalchick, Gemma, K. Killian, Karl W. Kibler, and Douglas K. Boyd

2002 Geoarcheological Investigations at the Clear Creek Golf Course Site (41CV413), Fort Hood, Texas. Archeological Resource Management Series, Research Report No. 46. United States Army, Fort Hood, Texas.

Mehalchick, Gemma, K. Killian, S. Christopher Caran, and Karl W. Kibler

2003a Geoarcheological Investigations and National Register Testing of 57 Prehistoric Archeological Sites on Fort Hood, Texas: The 1999 Season. Archeological Resource Management Series, Research Report No. 44. United States Army, Fort Hood, Texas. 
Mehalchick, Gemma, Karl W. Kibler, A. M. Holmes, Christopher W. Ringstaff, and Douglas K. Boyd 2003b National Register Testing of 19 Prehistoric Sites on Fort Hood, Texas: The 2000-2001 Season. Archeological Resource Management Series, Research Report No. 47. United States Army, Fort Hood, Texas.

Mehalchick, Gemma, Douglas K. Boyd, Karl W. Kibler, and Christopher W. Ringstaff

2004 Shifting Sands and Geophytes: Geoarcheological Investigations at Paluxy Sites on Fort Hood, Texas. Archeological Resource Management Series, Research Report No. 48. United States Army, Fort Hood, Texas.

Meighan, Clement E.

1969 Molluscs as Food Remains in Archaeological Sites. In Science in Archaeology, 2nd ed, edited by Don Brothwell and Eric Higgs, pp. 415-422. Praeger, New York.

Millard, Alex, and Carol Macaulay

2008 Part 1: Freshwater Mussel. A Look at Food Resource Exploitation at a Late-Prehistoric Campsite in Central Texas: Subsistence Activities at the Upper Sprague Site, Hamilton County, Texas (41HM54). Poster presented at the 79th Annual Meeting of the Texas Archeological Society, Lubbock.

Millard, Alex, Shamara Sneed, Morgan Haley, and Carol Macaulay

2008 A Look at Food Resource Exploitation at a Late Prehistoric Campsite in Central Texas: Subsistence Activities at the Upper Sprague Site, Hamilton County, Texas (41HM54) - Part 1: Freshwater Mussel; Part 2: Faunal Bone; and Part 3: Pecans. Paper presented at the 79th Annual Meeting of the Texas Archeological Society, Lubbock.

Miller, Myles R., III

1996 The Chronometric and Relative Chronology Project. Section 1: Background of the Chronometric and Relative Chronology Project. Archaeological Technical Report No 5. Anthropology Research Center, Department of Sociology and Anthropology, University of Texas at El Paso.
Moerman, Daniel E.

1998 Native American Ethnobotany. Timber Press, Portland, Oregon.

Morey, Darcy F., and George M. Crothers

1998 Clearing Up Clouded Waters: Paleoenvironmental Analysis of Freshwater Mussel Assemblages from the Green River Shell Middens, Western Kentucky. Journal of Archaeological Science 25:907-928.

Neck, Raymond W.

1994 Interpretations of Molluscan Remains from the Mustang Branch Site (41HY209). In Archaic and Late Prehistoric Human Ecology in the Middle Onion Creek Valley, Hays County, Texas, by Robert A. Ricklis and Michael B. Collins, pp. 491-497. Studies in Archaeology No. 19. Texas Archeological Research Laboratory, University of Texas at Austin.

Nekola, Jeffrey C.

2004 Terrestrial Gastropod Fauna of Northeastern Wisconsin and the Southern Upper Peninsula of Michigan. American Malacological Bulletin 18:21-44.

Nekola, Jeffrey C., and Brian F. Coles

2010 Pupillid Land Snails of Eastern North America. American Malacological Bulletin 28:29-57.

Nordt, Lee C.

1992 Archaeological Geology of the Fort Hood Military Reservation, Ft. Hood, Texas. Archeological Resource Management Series, Research Report No. 25. United States Army, Fort Hood, Texas.

1993 Additional Geoarchaeological Investigations at the Fort Hood Military Reservation, Ft. Hood, Texas. Archaeological Resource Management Series, Research Report No. 28 (Addendum to Report No. 25). United States Army, Fort Hood, Texas.

Okereke, Olivia I., Bernard A. Rosner, Dae H. Kim, Jae H. Kang, Nancy R. Cook, JoAnn E. Manson, Julie E. Buring, Walter C. Willett, and Francine Grodstein

2012 Dietary Fat Types and 4-Year Cognitive Change in Community-Dwelling Older Women. Annals of Neurology 72:124-134. 
Panshin, Alexis J., and Carol de Zeeuw

1980 Textbook of Wood Technology: Structure, Identification, Properties, and Uses of the Commercial Woods of the United States and Canada. 4th ed. McGraw-Hill Book Company, New York.

Parmalee, Paul W., and Walter E. Klippel

1974 Freshwater Mussels as a Prehistoric Food Resource. American Antiquity 39:421-434.

Parsons, Jeffery R., and Mary H. Parsons

1990 Maguey Utilization in Highland Central Mexico: An Archaeological Ethnography. Anthropological Papers No. 82. Museum of Anthropology, University of Michigan, Ann Arbor.

Peacock, Evan

2015 Prehistoric Molluscan Faunas of the Mississippi Black Prairie. In Southeastern Grasslands: Natural History, Conservation, and Management, edited by JoVonn Hill and John Barone. University of Alabama Press, Tuscaloosa, in press.

Peacock, Evan, and Shawn Chapman

2001 Taphonomic and Biogeographic Data from a Plaquemine Shell Midden on the Ouachita River, Lousiana. Southeastern Archaeology 20(1):44.

Peacock, Evan, and Jochen Gerber

2008 Using Land Snails and Freshwater Mussels to Chart Human Transformation of the Landscape: An Example from North Mississippi, U.S.A. In Case Studies in Environmental Archaeology, edited by Elizabeth Reitz, C. Margaret Scarry, and Sylvia J. Scudder, pp. 123-141. 2nd ed. Springer Science and Business Media, New York.

Peacock, Evan, and Rebecca Melsheimer

2003 Terrestrial Gastropods from Archaeological Contexts in the Black Belt Province of Mississippi. In Blackland Prairies of the Gulf Coastal Plain: Nature, Culture, and Sustainability, edited by Evan Peacock and Timothy J. Schauwecker, pp. 27-47. University of Alabama Press, Tuscaloosa.
Peacock, Evan, Janet Rafferty, and S. Homes Hogue 2005 Land Snails, Artifacts and Faunal Remains: Understanding Site Formation Processes at Prehistoric/Protohistoric Sites in the Southeastern United States. In Archaeomalacology: Molluscs in Former Environments of Human Behavior, edited by Daniella E. Bar-Yosef Mayer, pp. 6-17. Oxbow Books, England.

Peacock, Evan, Charles R. Randklev, Steve Wolverton, Ronald A. Palmer, and Sarah Zaleski

2012 The "Cultural Filter," Human Transport of Mussel Shell, and the Applied Potential of Zooarchaeological Data. Ecological Applications 22(5):14461459.

Pearsall, Deborah M.

2000 Paleoethnobotany: A Handbook of Procedures. 2nd ed. Academic Press, San Diego.

Perttula, Timothy K., Sergio A. Iruegas, and Hector Neff

2003 Caddoan Pottery in Central Texas: Geochemical Analyses of Ceramics from Fort Hood and Vicinity. Archeological Resource Management Series, Research Report No. 51. United States Army, Fort Hood, Texas.

Pilsbry, Henry A.

1940 Land Mollusca of North America (North of Mexico), Vol. I, Pt. 2. Monograph No. 3. The Academy of Natural Sciences of Philadelphia, Philadelphia.

1946 Land Mollusca of North America (North of Mexico), Vol. II, Pt. 1. Monograph No. 3. The Academy of Natural Sciences of Philadelphia, Philadelphia.

1948 Land Mollusca of North America (North of Mexico), Vol. II, Pt. 2. Monograph No. 3. The Academy of Natural Sciences of Philadelphia, Philadelphia.

Pratt, William L., Jr.

1981 A Revision of the Land Snail Genus Polygyra in Texas. Unpublished Ph.D. dissertation, Department of Biology, University of Arizona, Tucson. 
Prewitt, Elton R.

1981 Cultural Chronology in Central Texas. Bulletin of the Texas Archeological Society 52:65-89.

Quigg, J. Michael, Jay Peck, Christopher Lintz, Abby C. Treece, Charles D. Frederick, Roman Clem, G. Lain Ellis, Paul Schuchert, and James T. Abbott

1996 Early Archaic Use of the Concho River Terraces: Cultural Resource Investigations at 41YG307 and 41TG309, Tom Green County, San Angelo, Texas. Technical Report No. 11058. TRC Mariah Associates, Inc., Austin. Submitted to City of Angelo, Texas.

Randklev, Charles R., and Benjamin J. Lundeen

2012 Prehistoric Biogeography and Conservation Status of Threatened Freshwater Mussels (Mollusca: Unionidae) in the Upper Trinity River Drainage, Texas. In Conservation Biology and Applied Zooarcheology, edited by Steve Wolverton and R. Lee Lyman, pp. 68-91. University of Arizona Press, Tuscon.

Randklev, Charles R., Matthew S. Johnson, Eric T. Tsakiris, Julie Groce, and Neal Wilkins

2013 Status of the Freshwater Mussel (Unionidae) Communities of the Mainstem of the Leon River, Texas. Aquatic Conservation: Marine and Freshwater Ecosystems 23(3):390-404.

Randklev, Charles R., Steve Wolverton, Benjamin Lundeen, and James H. Kennedy

2010 A Paleozoological Perspective on Unionid (Mollusca: Unionidae) Zoogeography in the Upper Trinity River Basin, Texas. Ecological Applications: A Publication of the Ecological Society of America 20(8):23592368.

Randklev, Charles R., Steve Wolverton, and James H. Kennedy

2009 A Biometric Technique for Assessing Prehistoric Freshwater Mussel Population Dynamics (Family: Unionidae) in North Texas. Journal of Archaeological Science 36:205-213.

Rangel, Nikki, and Laurel Witt

2010 Hammerstones, Broken Bones, and Metatarsal Soup: Replicating Lipid Extraction from Bones. Paper presented at the 81st
Annual Meeting of the Texas Archeological Society, Corpus Christi.

Reed, Arizona, and Kris Beach

2009 From the Upper Sprague Site and Beyond: A Look at the Uniformity and Variability of Archaeological Thermal Fractures at Late Prehistoric Sites in Central Texas. Poster presented at the 80th Annual Meeting of the Texas Archeological Society, Del Rio.

Reimer, P. J., M. G. L. Baillie, E. Bard, A. Bayliss, J. W. Beck, P. G. Blackwell, C. Bronk Ramsey, C. E. Buck, G. S. Burr, R. L. Edwards, M. Friedrich, P. M. Grootes, T. P. Guilderson, I. Hajdas, T. J. Heaton, A. G. Hogg, K. A. Hughen, K. F. Kaiser, B. Kromer, S. W. Manning, R. W. Reimer, D. A. Richards, J. R. Southon, S. Talamo, C. S. M. Turney, J. van der Plicht, and C. E. Weyhenmeyer

2009 IntCal09 and Marine09 Radiocarbon Age Calibration Curves, 0-50,000 Years cal BP. Radiocarbon 51:1111-1150.

Ricklis, Robert A.

2012 Cultural and Ecological Change. In Archeology and Bioarcheology of the Buckeye Knoll Site (41VT98), Victoria County, Texas, edited by Robert A. Ricklis, Richard A. Weinstein, and Douglas C. Wells, pp. 679-700. 3 vols. Coastal Environments, Inc., Corpus Christi. Submitted to Galveston District, U.S. Army Corps of Enigneers.

Riskind, David H., and David D. Diamond

1988 An Introduction to Environments and Vegetation. In Edwards Plateau Vegetation: Plant Ecological Studies in Central Texas, edited by Bonnie B. Amos and Frederick R. Gehlbach, pp. 1-15. Baylor University Press, Waco.

Robinson, Edwin, and Menghe Li

2005 A Summary of Catfish Nutrition Research Conducted Under a Cooperative Agreement Between MAFES and Delta Western Research Center. Bulletin No. 1144. Mississippi Agricultural and Forestry Experiment Station, Mississippi State University, Starkville.

Ryan, Joanne

2004 Data-Recovery Excavations at the Hedgeland Site (16CT19), Catahoula Parish, Louisiana. Coastal Environments, Inc., 
Baton Rouge. Submitted to Vicksburg District, U.S. Army Corps of Engineers.

Saenz, Sarah, and Becki Shallenberger

2009 An Analysis of Fractured Longbones Recovered at the Upper Sprague Site (41HM54), Hamilton County, Texas. Poster presented at the 80th Annual Meeting of the Texas Archeological Society, Del Rio.

Schakel, Sally F., I. Marilyn Buzzard, and Susan E. Gebhardt

1997 Procedures for Estimating Nutrient Values for Food Composition Databases. Journal of Food Composition and Analysis 10:102114.

Schambach, Frank F.

2003 Osage Orange Bows, Indian Horses, and the Blackland Prairies of Northeastern Texas. In Blackland Prairies of the Gulf Coastal Plain: Nature, Culture, and Sustainability, edited by Evan Peacock and Timothy Schauwecker, pp. 212-236. University of Alabama Press, Tuscaloosa.

Schoeneberger, P. J., D. A. Wysocki, E. C. Benham, and W, D. Broderson (editors)

2002 Field Bookfor Describing and Sampling Soils. Version 2.0. National Soil Survey Center, Natural Resources Conservation Service, U.S. Department of Agriculture, Lincoln, Nebraska.

Schoener, Thomas W.

1971 Theory of Feeding Strategies. Annual Review of Ecology and Systematics 2:369-404.

Schoeninger, Margaret J., and Christopher S. Peebles

1981 Effect of Mollusc Eating on Human Bone Strontium Levels. Journal of Archaeological Science 8:391-397.

Schulte, E. E., and B. G. Hopkins

1996 Estimation of Soil Organic Matter by Weight Loss-On-Ignition. In Soil Organic Matter: Analysis and Interpretation, edited by F. R. Magdoff, M. A. Tabatabai and E. A.Hanlon, Jr., pp. 2132. Special Publication No. 46. Soil Science Society of America, Madison, Wisconsin.
Scott, Susan L.

2012 Vertebrate Faunal Bone. In Archaeology and Bioarchaeology of the Buckeye Knoll Site (41VT98), Victoria County, Texas, edited by Robert A. Ricklis, Richard A. Weinstein, and Douglas C. Wells, pp. 255-293. Coastal Environments, Inc., Corpus Christi. Submitted to Galveston District, U.S. Army Corps of Enigneers.

Sebrell, William H., and James J. Haggerty

1971 Food and Nutrition. Time-Life Books, New York.

Seltzer, Jennifer Lee

2007 Determining the Presence of Cultural Bias in Wood Charcoal from Lyon's Bluff (22OK520), a Mound Center in Oktibbeha County, Mississippi. Unpublished Master's thesis, Department of Anthropology, Mississippi State University, Starkville.

Shafer, Harry J., and Thomas R. Hester

2013 Projectile Points and Other Lithics. In Underwater Archaeology at 41HY147, the Terrace Locality at Spring Lake, edited by Jon C. Lohse, pp. 17-51. Archaeological Studies Report No. 28. Center for Archaeological Studies, Texas State University-San Marcos.

Shaw, Leslie C., Raymond W. Neck, James L. Theler, and Michael B. Collins

1998 The Molluscan Paleoassemblage. In Wilson-Leonard: An 11,000-Year Archeological Record of Hunter-Gatherers in Central Texas: Vol. 5. Special Studies, edited and assembled by Michael B. Collins, pp. 1555-1600. Studies in Archeology No. 31. Texas Archeological Research Laboratory, University of Texas at Austin. Archeological Studies Program. Report No. 10. Environmental Affairs Division, Texas Department of Transportation, Austin.

Simmons, Frank

1956 Snails of the Burnt Rock Middens. In Central Texas Archeologist No. 7, edited by Frank Watt, pp. 48-51. Central Texas Archeologist, Waco. 
Simpson, Duane

2008 Using Near-Surface Geophysical Survey, Excavation, and Soil Coring to Investigate Prehistoric Rockshelter Sites and Historic Cemeteries at Fort Hood, Texas. Bulletin of the Texas Archeological Society 79:107-124.

2011 National Register Testing of 24 Prehistoric Archaeological Rockshelter Sites on Fort Hood, Texas. Archeological Resource Management, Series Research Report No. 57. United States Army, Fort Hood, Texas.

Simpson, Duane, and Ryan Peterson

2004 Non-Invasive Burial Determination Using Near-Surface Geophysical Survey and Soil Chemical Testing at Fort Hood, Texas and Camp LeJeune, North Carolina. Archeological Resource Management Series, Research Report No. 55. United States Army, Fort Hood, Texas.

Sneed, Shamara, and Carol Macaulay

2008 Part 2: Faunal Bone. A Look at Food Resource Exploitation at a Late-Prehistoric Campsite in Central Texas: Subsistence Activities at the Upper Sprague Site, Hamilton County, Texas (41HM54). Poster presented at the 79th Annual Meeting of the Texas Archeological Society, Lubbock.

Snyder, Christine L. C.

2012 The Analysis of Terrestrial Snails to Infer Hunter-Gatherer Environmental Impacts in the Middle Savannah River Valley, Georgia and South Carolina. Unpublished Ph.D. dissertation, Department of Anthropology, University of Florida, Gainesville.

Stafford, T. W., Jr, K. Brendel, and R. C. Duhamel

1988 Radiocarbon, 13C and 15N Analysis of Fossil Bone: Removal of Humates with XAD-2 Resin. Geochimica et Cosmochimica Acta 52:2257-2267.

Stewart, Kent K.

1997 What are the Variances of Food Composition Data? Journal of Food Composition and Analysis 10:87.
Talalay, Laurie, Donald R. Keller, and Patrick J. Munson 1984 Hickory Nuts, Walnuts, Butternuts, and Hazelnuts: Observations and Experiments Relevant to Their Aboriginal Exploitation in Eastern North America. In Experiments and Observations on $A b$ original Wild Plant Food Utilization in Eastern North America, edited by Patrick J. Munson, pp. 338-359. Prehistory Research Series Vol. 6, No. 2. Indiana Historical Society, Indianapolis.

Taylor, Anna J., and Cheryl L. Highley

1995 Archaeological Investigations at the Loma Sandia Site (41LK28): A Prehistoric Cemetery and Campsite in Live Oak County, Texas. Studies in Archeology No. 20. Texas Archeological Research Laboratory, The University of Texas at Austin.

Taylor, R. E., and Ofer Bar-Yosef

2014 Radiocarbon Dating: An Archaeological Perspective. 2nd ed. Left Coast Press, Walnut Creek, California.

Texas Department of Transportation

2011 Contract No. 57-1XXSA004, Work Authorization No. 57-102SA004, Contract for Scientific Services. Texas Department of Transportation, Austin.

Texas Forest Service

2008a Texas Eco-Regions. In Trees of Texas. Texas Forest Service, Texas A\&M University, College Station. Electronic document, http://texastreeid tamu.edu/ content/texasEcoRegions/GrandPrairiePlains/, accessed February 17, 2012.

2008b How to ID. In Trees of Texas. Texas Forest Service, Texas A\&M University, College Station. Electronic document, http://texastreeid.tamu.edu/content/ howToID/, accessed February 17, 2012.

Texas Parks and Wildlife Department

2014 Nongame and Rare Species Program: Freshwater Mussels of Texas. Electronic document, http://www.tpwd.state. tx.us/huntwild/wild/wildlife_diversity/ texas_rare_species/mussels/mussel-status.phtml, accessed February 6, 2014. 
Theler, James L., Don G. Wyckoff, and Brian J. Carter 2004 The Southern Plains Gastropod Survey: The Distribution of Land Snail Populations in an American Grassland Environment. American Malacological Bulletin 18:1-20.

Thoms, Alston V.

1989 The Northern Roots of Hunter-Gatherer Intensification: Camas and the Pacific Northwest. Unpublished Ph.D. dissertation, Department of Anthropology, Washington State University, Pullman.

2008 Ancient Savannah Roots of the Carbohydrate Revolution in South-Central North America. Plains Anthropologist 53(205):121-136.

2009 Rocks of Ages: Propogation of HotRock Cookery in Western North America. Journal of Archaeological Science 36:573-591.

Tillmann, Urban, Malte Elbrächter, Bernd Krock, Uwe John, and Allan Cembella

2009 Azadinium spinosum gen. et sp. nov. (Dinophyceae) Identified as a Primary Producer of Azaspiracid toxins. European Journal of Phycology 44:63-79.

Trierweiler, W. Nicholas (editor)

1994 Archeological Investigations on 571 Prehistoric Sites at Fort Hood, Bell and Coryell Counties, Texas. Archeological Resource Management Series, Research Report No. 31. United States Army, Fort Hood, Texas. (editor)

1996 Archeological Testing at Fort Hood: 1994-1995. 2 vols. Archeological Resource Management Series, Research Report No. 35. United States Army, Fort Hood, Texas.

Truitt, Ashley N.

2010 An Analysis of Gastropods Recovered in Area D of the Upper Sprague Site, Hamilton County, Texas. Poster presented at the 81st Annual Meeting of the Texas Archeological Society, Corpus Christi.
Tryon, Tabatha

2010 Revealing Microscopic Signatures of Fire-Cracked Rock. Paper presented at the 81st Annual Meeting of the Texas Archeological Society, Corpus Christi.

Tull, Delena

1987 Edible and Useful Plants of Texas and the Southwest. Texas Monthly Press, Austin.

Tuttle, Grace

2010 Feast or Famine: Mussel Exploitation at a Late Prehistoric Site in Hamilton County, Texas. Paper presented at the 81st Annual Meeting of the Texas Archeological Society, Corpus Christi.

Turgeon, Donna D., James F. Quinn, Jr., Arthur E. Bogan, Eugene V. Coan, Frederick G. Hochberg, William G. Lyons, Paula M. Mikkelsen, Richard J. Neves, Clyde F. E. Roper, Gary Rosenberg, Barry Roth, Amelie Scheltema, Fred G. Thompson, Michael Vecchione, and James D. Williams

1998 Common and Scientific Names of Aquatic Invertebrates from the United States and Canada: Mollusks. 2nd ed. Special Publication No. 26. American Fisheries Society, Bethesda.

Turner, Ellen Sue, Thomas R. Hester, and R. L. McReynolds

2011 Stone Artifacts of Texas Indians. Taylor Trade Publishing, New York.

U.S. Department of Agriculture, Agricultural Research Service (USDA, ARS)

2013 USDA National Nutrient Database for Standard Reference. Release No. 26. Electronic document, http://www.ars.usda. gov/ba/bhnrc/ndl, accessed March 18, 2014.

U.S. Department of Agriculture, Natural Resources Conservation Service (USDA, NRCS)

2014 The PLANTS Database. National Plant Data Team, Natural Resources Conservation Service, U.S. Department of Agriculture, Greensboro, North Carolina. Electronic document, http://plants.usda.gov, accessed March 19, 2014.

U.S. Department of Agriculture

2015 National Agriculture Imagery Program, Hamilton County, Texas. naip12_nc- 
cir_1m_3198_16_3. Electronic document, http://tnris.org/data-download/\#/county/ Hamilton, accessed January 5, 2015.

U.S. Fish and Wildlife Service

2014 Endangered and Threatened Wildlife and Plants; Review of Native Species that are Candidates for Listing as Endangered or Threatened; Annual Notice of Findings on Resubmitted Petitions; Annual Description of Progress on Listing Actions. U.S. Federal Register 79(234):72450-72497.

2007 Conserving the Nature of America: New Publications Advance Understanding of Freshwater Mussel Sensitivity to Pollutants. Electronic document, http://molluskconservation.org/Library/pdf/FWS_briefing_Mussel Series.pdf, accessed February 4, 2014.

\section{U.S. Geological Survey}

1956 Eidson Lake. 7.5-Minute Topographic Quadrangle Map, 1:24,000. U.S. Topographic and Historical Topographic Map Collection. Electronic document, http://geonames.usgs.gov/ apex/f?p=262:18:0::NO:RP:P18_ STATE\%2CP18_SCALE\%2CP18_ MAP_NAME\%2CP18_MAP TYPE:TX\%2CALL\%2C\% 5Ceidson+lake $\% 5 \mathrm{C} \% 2 \mathrm{Call}$, accessed January $15,2015$.

1956 Gentrys Mill. 7.5-Minute Topographic Quadrangle Map, 1:24,000. U.S. Topographic and Historical Topographic Map Collection. Electronic document, http:/geonames.usgs.gov/ apex/f?p=262:18:0::NO:RP:P18_ STATE\%2CP18_SCALE\%2CP18_ MAP_NAME\%2CP18_M A TYPE:TX\%2CALL\%2C\%5Cgentrys+mill\%5C\%2Call, accessed January 15, 2015.

Van Geel, Bas, Johannes Van Der Plicht, M. R. Kilian, E. R. Klaver, J. H. M. Kouwenberg, H. Renssen, I. Reynaud-Farrera, and H. T. Waterbolk

1998 The Sharp Rise of $\Delta^{14} \mathrm{C}$ ca. 800 cal BC: Possible Causes, Related Climatic Teleconnections and the Impact on Human Environments. Radiocarbon 40:535-550.
Wade, Mariah

2003 Native Americans of the Edwards Plateau, 1582-1799. University of Texas Press, Austin.

Wandsnider, LuAnn

1997 The Roasted and the Boiled: Food Composition and Heat Treatment with Special Emphasis on Pit-Hearth Cooking. Journal of Anthropological Archaeology 16:1-48.

Wang, Yang, Ronald Amundson, and Susan Trumbore 1996 Radiocarbon Dating of Soil Organic Matter. Quaternary Research 45:282288.

Wang, Yang, A. Hope Jahren, and Ronald Amundson 1997 Potential for 14C Dating of Biogenic Carbonate in Hackberry (Celtis) Endocarps. Quaternary Research 47:337343.

Warren, Robert E

1991 Freshwater Mussels as Paleoenvironmental Indicators: A Quantitative Approach to Assemblage Analysis. In Beamers, Bobwhites, and Blue-Points: Tributes to the Career of Paul W. Parmalee, edited by James R. Purdue, Walter E. Klippel, Bonnie W. Styles, and Paul W. Parmalee, pp. 23-66. Scientific Papers Vol. 23. Illinois State Museum, Springfield; and Report of Investigations No. 52. Department of Anthropology, University of Tennessee, Knoxville.

Wasson, Chelsey, and Melissa Windham

2010 Inventory of the Edible and Medicinal Plant Species of Hamilton County, Texas. Poster presented at the 81st Annual Meeting of the Texas Archeological Society, Corpus Christi.

Waters, Michael R., and Thomas W. Stafford, Jr.

2007 Redefining the Age of Clovis: Implications for the Peopling of the Americas. Science 315:1122-1126.

Watt, Bernice K., and Anabel I. Merrill

1963 Composition of Foods: Raw, Processed, Prepared. Agriculture Handbook No. 8. U.S. Department of Agriculture, Washington, D.C. 
Weinstein, Richard A.

1991 Lido Harbor (41 GV 82): A Late Prehistoric Campsite and Extraction Locale, Galveston County, Texas. Coastal Environments, Inc., Baton Rouge. Submitted to Galveston District, U.S. Army Corps of Engineers.

1995 Data-Recovery Plan for Site 41 CL 59, Channel to Victoria, Calhoun County, Texas. Coastal Environments, Inc., Baton Rouge. Submitted to Galveston District, U.S. Army Corps of Engineers. (editor)

2002 Archaeological Investigations at the Guadalupe Bay Site (41 CL 2): Late Archaic through Historic Occupation along the Channel to Victoria, Calhoun County, Texas. 2 vols. Coastal Environments, Inc., Baton Rouge. Submitted to Galveston District, U.S. Army Corps of Engineers.

(editor)

2005 Lake Providence: A Terminal Coles Creek Culture Mound Center, East Carroll Parish, Louisiana. 2 vols. Coastal Environments, Inc., Baton Rouge. Submitted to Vicksburg District, U.S. Army Corps of Engineers.

(editor)

2013 Early Archaic through Late Prehistoric Settlement along the Lower Lavaca River: Archaeological Data-Recovery Investigations at the Possum Bluff and Kendrick's Hill Sites, Jackson County, Texas. 3 vols. Coastal Environments, Inc., Baton Rouge. Submitted to Galveston District, U.S. Army Corps of Engineers.

Weinstein, Richard A., Charles D. Frederick, Timothy K. Perttula, Brittney Gregory, and Jennifer A. Kelly

2012 Archaeological and Geological Investigations at Site 41HM61, Hamilton County, Texas: Interim Report. Coastal Environments, Inc., Corpus Christi. Submitted to Archeological Studies Branch, Environmental Affairs Division, Texas Department of Transportation, Austin.
Weinstein, Richard A., Thurston H. Hahn III, Margaret Swett Henson, David B. Kelley, and James P. Whelan, Jr.

1989 Archaeological Testing and Mitigation at Cedar Hill Park, Wallisville Lake Project, Chambers County, Texas. Coastal Environments, Inc., Baton Rouge. Submitted to Galveston District, U.S. Army Corps of Engineers.

Weinstein, Richard A., Jon C. Lohse, Brendan J. Culleton, and Douglas J. Kennett

2014 Toyah Bison, Chronology, and Climate. Paper presented at the 85th Annual Meeting of the Texas Archeological Society, San Marcos.

Wheeler, Elizabeth A.

2011 InsideWood - A Web Resource for Hardwood Anatomy. IAWA Journal 32(2):199-211.

Willey, Gordon R.

1966 An Introduction to American Archaeology. Vol. 1: North and Middle America. Prentice-Hall, Englewood Cliffs, California.

Willey, Gordon R., and Philip Phillips

1958 Method and Theory in American Archaeology. The University of Chicago Press, Chicago.

Williams, Alan N.

2012 The Use of Summed Radiocarbon Probability Distributions in Archaeology: A Review of Methods. Journal of Archaeological Science 39:578-589.

Williams, James D., Arthur E. Bogan, and Jeffrey T. Garner

2008 Freshwater Mussels of Alabama and the Mobile Basin in Geogria, Mississippi, and Tenessee. University of Alabama Press, Tuscaloosa.

Wing, Elizabeth S., and Antoinette B. Brown

1979 Paleonutrition: Method and Theory in Prehistoric Foodways. Academic Press, New York.

Wolverton, Steve

2008 Characteristics of Late Holocene American Black Bears in Missouri: Evidence from Two Natural Traps. Ursus 19(2):177-184. 
2013 Data Quality in Zooarchaeological Faunal Identification. Journal of Archaeological Method and Theory 20(3):381-396.

Wolverton, Steve, Jonathan Dombrosky, and R. Lee Lyman

2014 Practical Significance: Ordinal Scale Data and Effect Size in Zooarchaeology. International Journal of Osteoarchaeology (April).

Wolverton, Steve, Charles R. Randklev, and James H. Kennedy

2010 A Conceptual Model for Freshwater Mussel (Family: Unionidae) Remains Preservation in Zooarchaeological Assemblages. Journal of Archaeological Science 37(1):164-173.
Yanovksy, E., and R. M. Kingsbury

1931 New Sources of Inulin. Journal of the American Chemical Society 53:15971601.

Zeidler, J. A. (compiler and editor)

2004 Military Impacts and Archaeological Site Mitigation Methods at the Firebreak Site (41CV595), Fort Hood, Texas. Archeological Resource Management Series, Research Report No. 53. United States Army, Fort Hood, Texas. 